\title{
SYNTHESIS OF SMALL MOLECULE INHIBITORS FOR THE TREATMENT OF DISEASE
}

\author{
by \\ Hilary Mary Corkran
}

A thesis

submitted to the Victoria University of Wellington in fulfilment of the requirements for the degree of Doctor of Philosophy

Victoria University of Wellington

2014 


\begin{abstract}
Three aspects of the protecting-group-free (PGF) synthesis of small molecules have been described in this thesis. In the first part, the PGF azasugar synthesis methodology was applied to 2-deoxy-D-glucose with the intention of selectively forming the six-membered azasugar 5-epi-fagomine. Surprisingly, four products were formed in the key $\mathrm{I}_{2}$-mediated carbamate annulation step, with a pyrrolidine being the major product after optimisation. This was formed in $15 \%$ yield. A mechanism that explains the formation of the four carbamates was proposed, which was supported by an investigation into related halocyclisation reactions.
\end{abstract}

The next part of this thesis describes the development of a new PGF methodology for the synthesis of conduramines, another class of biologically interesting molecules. Conduramines are amino polyhydroxy cyclohexenes and some conduramines have glycosidase inhibitory activity. These molecules are also useful precursors to a variety of biologically useful molecules including aminocyclitols and azasugars. The key steps in the PGF synthesis of conduramines are a Vasella-Barbier amination, a reaction that forms new $\mathrm{C}-\mathrm{C}$ and $\mathrm{C}-\mathrm{N}$ bonds concomitantly, and a ring closing metathesis in the presence of free hydroxyl and amine groups. To this end, a 4-deoxy 3 -conduramine was prepared in just four steps and in $27 \%$ yield.

Finally, the preparation of an amine library and its biological testing for the identification of a new anti-tuberculosis drug is described. Two short syntheses were used to prepare alkenylamines and amines from the corresponding sugar, with various lipophilic groups attached to the amine. A 20-member amine library was prepared, and the compounds were tested for anti-mycobacterial activity in a mycobacterial growth inhibition assay. The most active compounds were subjected to further biological testing to determine their general cytotoxic properties. Two amines, arabinohexadecylamine and arabinohexadecylmethylamine, were identified as having the best potential for use as anti-tuberculosis drugs, and have been sent to Colorado State University for subsequent in vivo testing in a mouse model of tuberculosis. 


\section{Acknowledgements}

During my PhD I have been fortunate to have had the support and encouragement of many people. Firstly, I would like to thank my supervisors, Drs Bridget Stocker and Mattie Timmer. Thank you for your support, for always finding time for me, and for the various pep-talks along the way. I really admire your enthusiasm for chemistry and I have learnt a lot under your guidance, from chemistry to writing and more.

I would like to acknowledge Alex, Amy, Ben, Janice, Jessie, Kris, Kristel, Rhia and Stefan as well as the past members of the Immunoglycomics group. Thanks for making the lab such a fun place to be, I really appreciate all the great discussions and laughs that we have had along the way. I would like to acknowledge Dr. Emma Dangerfield whose research was the foundation for my $\mathrm{PhD}$. Thank you for all of your advice, and for being such an inspirational role model. I acknowledge the help of James Baty (MIMR) for carrying out the cytotoxicity assays, and also Fenella Rich (MIMR) who helped with the BCG assay. I appreciate the help of the various support staff in SCPS, particularly Grant, and Sally, and especially Ian for all of the hours he put in helping me to tune the NMR for $\mathrm{D}_{2} \mathrm{O}$ samples. I would also like to acknowledge the people at the Malaghan Institute for sharing their space with us chemists in the first years of my $\mathrm{PhD}$, and allowing me to carry out my BCG screening in the immunology labs.

Finally I would like to acknowledge my friends for their support over the last few years, especially Hanna, Saz, and Rach for always being there, even via distance. Thank you to my dancing friends at Full Swing, for all the great dances, and lots of fun times. I have also had a great bunch of flatmates, and would particularly like to thank Kerry, Sam, Sarah, Jane and Lance for being so supportive in the final stage of my $\mathrm{PhD}$.

Thank you to my family for all of their love and support. Special thanks to my sisters, Jen and Ali. Finally I would like to thank my Mum and Dad for encouraging me to do what I love, believing in me even when I doubted myself, and supporting me in so many other ways leading up to and during this $\mathrm{PhD}$. 
"It's not easy being green."

- Kermit the Frog 


\section{Table of Contents}

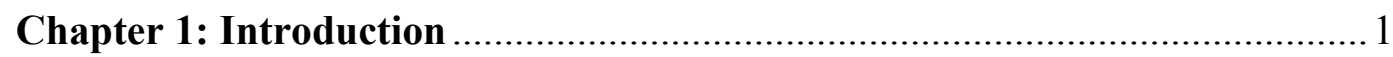

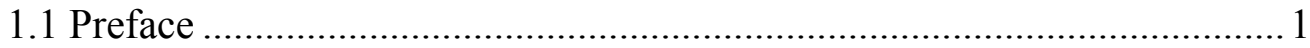

1.2 Green Chemistry and Protecting-Group-Free Synthesis .............................. 3

1.3 Azasugars as Glycosidase Inhibitors and Molecular Chaperones .............. 17

1.4 C-C Bond Forming Reactions for the Synthesis of Conduramines...........22

1.5 Small Molecules as Tuberculosis Drugs ................................................2.

1.6 The Process of Drug Discovery ....................................................................

1.7 Thesis Overview …………………………………………....................... 41

\section{Chapter 2: Applications and Limitations of the $\mathbf{I}_{\mathbf{2}}$-mediated Carbamate} Annulation for the Synthesis of Piperidines.......................................53

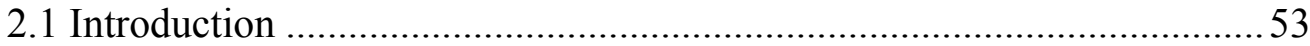

2.2 Application of the PGF Azasugar Methodology to 2-Deoxy Glucose ..... 60

2.3 Proposed Models to Explain the Formation of Pyrrolidines and Piperidines via the $\mathrm{I}_{2}$-mediated Carbamate Annulation ............................72

2.4 Comparison of the outcome of the 2-Deoxy Glucose and

2 Deoxy Galactose derived Alkenylamine Cyclisations using

Transition State Models........................................................................ 75

2.5 Proposed Explanation of the Multiple Products formed in the

2 Deoxy Glucose PGF Azasugar Synthesis............................................. 78

2.6 Wider Relevance: Related 6- $N$-Cyclisations ................................................ 84

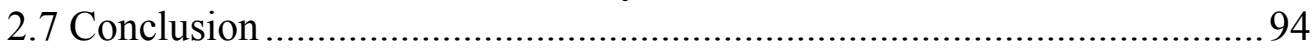

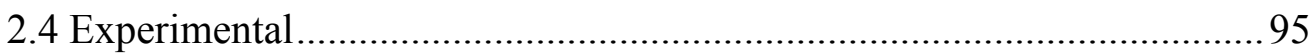

Chapter 3: Development of a C-C Bond Forming Reaction for the

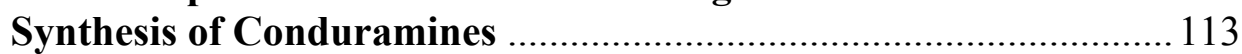

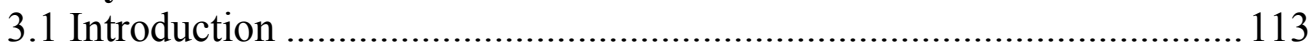

3.2 Development of a PGF C-C bond Forming Reaction..............................116

3.3 RCM for the Synthesis of a Conduramine Analogue .............................. 132

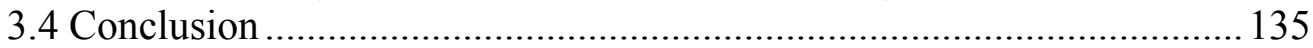

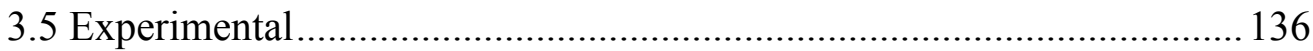


Chapter 4: Lipophilic Amines as Potential TB Drugs.

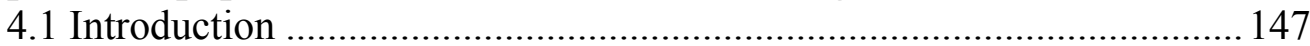

4.2 Second Generation Amine Library Synthesis ..................................... 150

4.3 Biological Testing: Results and Discussion ........................................ 161

4.4 Optimised Syntheses of Lead Compounds ............................................ 181

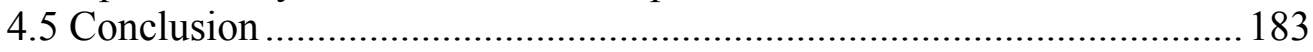

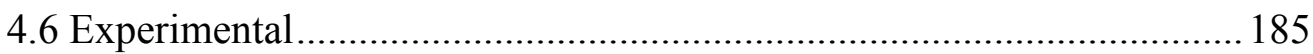

Chapter 6: Global Conclusion and Future Prospects ..................................207

6.1 The PGF Synthesis of Azasugars ......................................................207

6.2 The PGF Synthesis of Conduramines...............................................212

6.3 The Synthesis and Testing of Lipophilic Amines as Anti-TB Drugs.....216

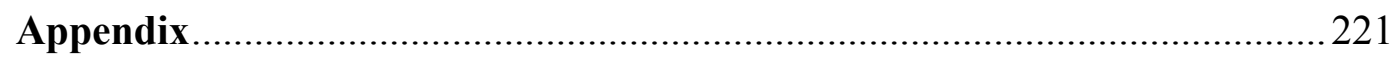

Chapter 2: NMR Spectra ............................................................ 221

Chapter 3: NMR Spectra ................................................................ 253

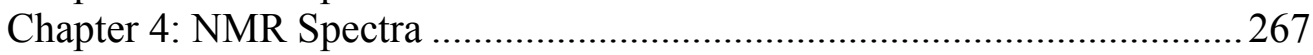

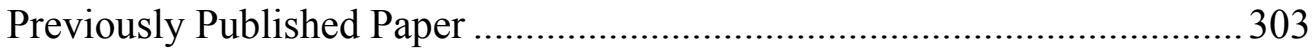




\section{List of Abbreviations}

\begin{tabular}{|c|c|c|c|}
\hline Ac & acetvl & EQ & environmental quotient \\
\hline $\mathrm{AcOH}$ & acetic acid & $\begin{array}{l}\text { equiv. } \\
\text { ER }\end{array}$ & endoplasmic reticulum \\
\hline \multirow[t]{3}{*}{ ADMET } & adsorption, distribution, & ESI & electron spray ionisation \\
\hline & metabolism, and excretion & Et & ethyl \\
\hline & - toxicity & FDA & Food and Drug \\
\hline \multirow[t]{2}{*}{ AD-mix } & asymmetric & & Administration \\
\hline & dihydroxylation mix & $\mathrm{h}$ & $\operatorname{hour}(\mathrm{s})$ \\
\hline$a q$. & aqueous & HL60 & human leukaemia cell line \\
\hline $\mathrm{Ar}$ & aryl & $\mathrm{HMBC}$ & heteronuclear multiple \\
\hline AraT & arabinosyltransferase & & bond correlation \\
\hline $\mathrm{atm}$ & atmosphere & HRMS & high resolution mass \\
\hline ATP & adenosine triphosphate & & spectrometry \\
\hline \multirow[t]{2}{*}{ BCG } & $\begin{array}{l}\text { Bacillus Calmette-Guérin, } \\
\text { weakened strain of } M \text {. }\end{array}$ & HSQC & $\begin{array}{l}\text { heteronuclear single } \\
\text { quantum coherence }\end{array}$ \\
\hline & bovis & $\mathrm{Hz}$ & hertz \\
\hline $\mathrm{Bn}$ & Benzyl & $\mathrm{IC}_{50}$ & half maximal inhibitory \\
\hline Boc & tert-butyloxycarbonyl & & concentration \\
\hline br & broad & Imid. & imidazole \\
\hline Calcd. & calculated & IND & investigational new drug \\
\hline $\mathrm{Cbz}$ & carboxybenzyl & $i \operatorname{Pr}$ & isopropyl \\
\hline COSY & correlated NMR spectrum & IR & infrared spectroscopy \\
\hline cpd & compound & $J$ & coupling constant \\
\hline d & doublet & LAM & lipoarabinonmannan \\
\hline d & $\operatorname{day}(\mathrm{s})$ & LHMDS & lithium \\
\hline DBU & $\begin{array}{l}\text { 1,8-Diazabicycloundec-7- } \\
\text { ene }\end{array}$ & Lit. & $\begin{array}{l}\text { hexamethyldisilazide } \\
\text { literature }\end{array}$ \\
\hline DCM & dichloromethane & $\log P$ & octanol/water partition \\
\hline & diastereomeric exces & LSD & lysosomal storage \\
\hline DGJ & $\begin{array}{l}\text { 1-deoxygalactonojiri- } \\
\text { mycin }\end{array}$ & $\mathrm{m}$ & $\begin{array}{l}\text { disorder } \\
\text { multiplet }\end{array}$ \\
\hline DIBAL-H & $\begin{array}{l}\text { diisobutylaluminium } \\
\text { hydride }\end{array}$ & MDR-TB & $\begin{array}{l}\text { multi-drug-resistant } \\
\text { tuberculosis }\end{array}$ \\
\hline DiPEA & $\begin{array}{l}N, N \text {-diisopropylethyl- } \\
\text { amine }\end{array}$ & $\begin{array}{l}\mathrm{Me} \\
\mathrm{MHz}\end{array}$ & $\begin{array}{l}\text { methyl } \\
\text { mega hertz }\end{array}$ \\
\hline DMAP & 4-dimethylaminopyridine & MIC & minimum inhibitory \\
\hline DME & dimethoxyethane & & concentration \\
\hline DMF & dimethylformamide & MIMR & Malaghan Institute of \\
\hline DMSO & dimethyl sulfoxide & & Medical Research \\
\hline DNA & deoxyribonucleic acid & $\min$ & minutes \\
\hline DOX & doxorubicin & mRNA & messenger ribonucleic \\
\hline $\mathrm{E}$ & electrophile & & acid \\
\hline E. coli & Escherichia coli & MS & mass spectrometry \\
\hline E-factor & environmental factor & $M t b$ & Mycobacterium \\
\hline EMB & ethambutol & & tuberculosis \\
\hline
\end{tabular}




\begin{tabular}{|c|c|c|c|}
\hline MTT & $\begin{array}{l}\text { 3-(4,5-Dimethylthiazol-2- } \\
\text { yl)-2,5-diphenyltetra- } \\
\text { zoliumbromide }\end{array}$ & PyBroP & $\begin{array}{l}\text { Bromotripyrrolidino- } \\
\text { phosphonium } \\
\text { hexafluorophosphate }\end{array}$ \\
\hline M. bovis & Mycobacterium bovis & PZA & pyrazinamide \\
\hline \multirow[t]{3}{*}{ M. smegmatis } & & quant. & quantitative \\
\hline & Mycobacterium & $\mathrm{RCM}$ & ring closing metathesis \\
\hline & smegmatis & Red-Al & reducing aluminium, \\
\hline$m / z$ & mass to charge ratio & & sodium bis(2- \\
\hline \multirow[t]{2}{*}{$\mathrm{NAD}^{+} / \mathrm{NADH}$} & & & methoxyethoxy)aluminum \\
\hline & $\begin{array}{l}\text { Nicotinamide adenine } \\
\text { dinucleotide redox pair }\end{array}$ & ref. & $\begin{array}{l}\text { hydride } \\
\text { reference }\end{array}$ \\
\hline \multirow[t]{4}{*}{$\mathrm{NADP}^{+} / \mathrm{NADH}$} & & $R_{\mathrm{f}}$ & retention factor \\
\hline & Nicotinamide adenine & $\mathrm{rt}$ & room temperature \\
\hline & dinucleotide phosphate & s & singlet \\
\hline & redox pair & SAR & structure activity \\
\hline NBS & $N$-bromosuccinimide & & relationship \\
\hline NDA & new drug approval & sat. & saturated \\
\hline NIS & $N$-iodosuccinimide & SDS & sodium dodecyl sulfate \\
\hline NMO & $N$-methylmorpholine $N$ - & SI & Selectivity Index \\
\hline \multirow[t]{2}{*}{ NMR } & $\begin{array}{l}\text { oxide } \\
\text { nuclear magnetic }\end{array}$ & $\mathrm{S}_{\mathrm{N}} 2$ & $\begin{array}{l}\text { bimolecular nucleophilic } \\
\text { substitution }\end{array}$ \\
\hline & resonance & $\mathrm{t}$ & triplet \\
\hline \multirow[t]{2}{*}{ OADC } & oleic albumin dextrose & TAB & Tween albumin broth \\
\hline & catalase & TB & tuberculosis \\
\hline Obsd. & observed & $\mathrm{Tf}$ & trifluoromethanesulfonate \\
\hline${ }^{1} \mathrm{O}_{2}$ & singlet oxygen & TFA & trifluoroacetic acid \\
\hline$p$ & para & THF & tetrahydrofuran \\
\hline PBS & phosphate-buffered saline & TLC & thin layer chromatography \\
\hline PG & protecting group & TMS & trimethylsilyl \\
\hline PGF & protecting-group-free & tRNA & transfer ribonucleic acid \\
\hline $\mathrm{Ph}$ & phenyl & $\mathrm{TS}$ & transition state \\
\hline ppm & parts per million & $\mathrm{Ts}_{2} \mathrm{O}$ & para-toluenesulfonyl \\
\hline PSA & polar surface area & & anhydride \\
\hline$p \mathrm{TsOH}$ & para-toluene sulfonic acid & & version \\
\hline & & XDR-TB & $\begin{array}{l}\text { extensively drug-resistant } \\
\text { tuberculosis }\end{array}$ \\
\hline
\end{tabular}




\section{Chapter 1: Introduction}

\subsection{Preface}

Many small molecules are effective drugs. Some are common in every household, such as aspirin, (1) (Figure 1.1), which is an analgesic, antipyretic, and antiinflammatory medication that works by inhibiting the production of thromboxane, thereby thinning the blood. ${ }^{1}$ Another example, Prozac ${ }^{\circledR}$ (2), is a selective serotonin re-uptake inhibitor for the treatment of major depression and other psychiatric disorders, ${ }^{2}$ while cisplatin (3) is a chemotherapeutic used to treat various cancers and works by binding to and cross-linking DNA, which ultimately leads to cell death by apoptosis. ${ }^{3,4}$ While all three drugs contain vastly different chemical skeletons, each can be prepared in remarkably few steps.<smiles>CC(=O)Oc1ccccc1C(=O)O</smiles>

1<smiles>CNCC[C@@H](Oc1ccc(C(F)(F)F)cc1)c1ccccc1</smiles>

2<smiles>N[Pb](N)(Cl)Cl</smiles>

3

Figure 1.1: Small molecule drugs: aspirin (1), $\operatorname{Prozac}^{\circledR}(2)$, and cisplatin (3).

An attraction of pursuing small molecules as potential drugs is their ease of synthesis, which allows for more rapid screening and therefore faster establishment of lead compounds for the treatment of disease. In contrast, the total syntheses of larger and more complex molecules can be difficult and time 
consuming. These complex total syntheses often require protecting group manipulations that increase the number of steps and ultimately lead to lower yields and increased costs.

This thesis outlines research on the protecting-group-free (PGF) synthesis of small molecules as potential drug candidates. To this end, a number of different molecular scaffolds were prepared. First, azasugars were synthesised using an adaptation of the Vasella-reductive amination and $\mathrm{I}_{2}$-mediated carbamate annulation methodology developed within the Stocker-Timmer group. ${ }^{5}$ Azasugars are notable glycosidase inhibitors, ${ }^{6}$ and can therefore be used in the treatment of a variety of diseases. The next class of molecules targeted was the conduramines, a scaffold that provides access to many biologically useful molecules. The preparation of conduramines required the development of a new $\mathrm{C}-\mathrm{C}$ bond forming methodology, which was based on a Vasella-Barbier amination reaction. Finally, the development of a small molecule amine library for the treatment of tuberculosis was undertaken. Here, novel amines and alkenylamines with different sugar and lipophilic amine components were prepared without the use of protecting groups and were subsequently screened for tuberculostatic and cytotoxic activities. From this work, a lead lipophilic amine was identified. Thus, with the development of a new PGF synthesis, the extension of an existing PGF methodology, and the application of PGF synthesis to the treatment of disease, a variety of factors relating to the efficient synthesis of small molecule drugs were explored. 


\subsection{Green Chemistry and Protecting-Group-Free Synthesis}

\subsubsection{Green Chemistry}

Green chemistry is defined as "the design, development and implementation of chemical processes and products to reduce or eliminate substances hazardous to human health and the environment."7 This theme has been further developed into the twelve principles of green chemistry, which include objectives such as maximising reaction efficiency (with respect to atom economy as well as yield), the use of safe, renewable, and environmentally benign chemicals (including solvents), energy efficiency (e.g. reactions performed at ambient temperature and pressure where possible), and waste prevention at the source rather than 'end-ofpipe' waste remediation. ${ }^{7,8}$ There are several ways to determine the 'greenness' of a chemical process. These include atom economy, environmental factor (Efactor), and environmental quotient (EQ). ${ }^{8,9}$ Atom economy, initially conceived by Trost in the 1980s, is a measure of how many of the reactant's atoms end up in the product, but does not take yield, spent catalysts or solvents into account. ${ }^{9 \mathrm{~b}}$ To take the additional waste into account, the concept of E-factor, defined as mass of waste per mass of product, was developed by Sheldon. ${ }^{8,9 a}$ The E-factor, however, fails to take into account the nature of the waste produced and for that reason, the concept of the EQ has been defined, which is the product of the E-factor and an arbitrary quotient describing the nature of the waste, Q. Here Q is dependent on the recycling or ease of disposal of the waste. ${ }^{8}$ As society becomes more concerned with the overall efficiency of any given process and its effects on the environment, the challenge for today's organic chemist is to prepare complex molecules as efficiently as possible and generate minimal waste in the process. ${ }^{10}$

One way to improve the overall efficiency of a synthesis is to avoid the use of protecting groups (PGs). The use of PGs has undoubtedly led to an explosive growth in the complexity and successful synthesis of targeted compounds, however the use of PGs also introduces higher costs in terms of extra reagents and 
solvents, and increased number of steps, which often results in a reduction of the overall yield. PGF chemistry addresses these challenges via the design of new synthetic schemes to simplify chemical production (the invention of novel reactions) and allowing for the use of solvents that are environmentally and ecologically benign. ${ }^{11,12}$ Key in this approach is the avoidance of separate chemical transformations to temporarily block other potentially reactive functional groups. This can be achieved by the careful design of synthetic routes to generate a product chemoselectively. ${ }^{13}$

Several methods have been employed by chemists to avoid protecting groups. These include in situ protection and deprotection, the mimicking of biological pathways used in nature, skeleton-building reactions that are functional-group tolerant, changes to the sequence of functional group introduction, and the development of new methodology in order to avoid protecting groups. ${ }^{12,14}$ These approaches are briefly discussed below.

\subsubsection{In situ Protection}

In situ protection is the avoidance of a side reaction through the in situ transformation into a less reactive group, and is preferred when only one transformation is required. The approach includes protonation/deprotonation strategies, as in the case of the synthesis of $\left( \pm\right.$ )-fawcettimine (10) (Scheme 1.1). ${ }^{15}$ The alkaloid fawcettimine was originally extracted from Lycopodium fawcettii, a plant material collected from the Blue Mountain Range in Jamaica in $1959 .{ }^{16}$ The synthesis of fawcettimine was not PGF by design, but by necessity due to the incorporation of protecting groups negatively affecting the reactivity of the protected intermediates. First enone 4 and bis(trimethylsilyl)alkene 5 were combined in the presence of a Lewis acid in a Hosomi-Sakurai reaction to give allylic alcohol $6 .{ }^{17}$ Although trimethylsilyl (TMS) groups are traditionally used as protecting groups, here the carbon-bonded TMS group is required for the allylation reaction and the TMS ether is simultaneously removed during the course of the reaction, and therefore is not used as a PG. Allylic alcohol $\mathbf{6}$ was 
transformed into amine 7 in seven steps, which included an intramolecular Michael addition and an Arndt-Eistert homologation. ${ }^{18}$ Treatment of amine 7 with $p$-toluenesulfonic anhydride $\left(\mathrm{Ts}_{2} \mathrm{O}\right)$ gave tosylated adduct 8 due to failure to selectively tosylate the primary alcohol group of intermediate 7 . Thus formation of the nine-membered ring under basic conditions, followed by detosylation gave tricyclic intermediate 9 in $65 \%$ yield (two-steps). It was necessary to remove the tosyl group at this stage, due to difficulty removing the $N$-tosyl group at a later stage in the synthesis; therefore, the $N$-tosyl group was not technically employed as a protecting group in this synthesis. Oxidation of the alcohol in tricycle 9 was followed by in situ protection by protonation of the amine with perchloric acid and ozonolysis of the double bond. Finally, deprotonation with sodium bicarbonate gave $( \pm$ )-fawcettimine (10) in an overall yield of $17 \%$ over 13 steps, an improvement on an earlier synthesis, which yielded only $0.1 \%$ product after 26 steps. ${ }^{19}$ More recently, in 2007, Toste and co-workers reported the first asymmetric total synthesis of $(+)$-fawcettimine, ${ }^{20}$ with the use of protecting groups, in a 13-step reaction sequence with an overall yield of 14\%. There have subsequently been other reports of this synthesis, ${ }^{21,22}$ however the synthetic strategy used in the paper by Heathcock et al. has remained a key strategy, and one of the most efficient to date. ${ }^{23}$ 
$\overbrace{\mathrm{CN}}^{+1}$

4

5<smiles>C=C1C[C@H]2C[C@@H](C)C[C@H](O)[C@]2(CC[13CH3])[C@H]1CCCO[AsH3]</smiles>

8

1) $n-\mathrm{Bu}_{4} \mathrm{NOH}$ benzene $69 \%$

2) Naphthalene $\mathrm{Na}$, DME $94 \%$<smiles>C=C1CC2C[C@@H](C)C[C@H](O)C23CCNCCC13</smiles>

9

1) $\mathrm{CrO}_{3}, \mathrm{AcOH}, 87 \%$

2) $\mathrm{HClO}_{4}$

3) $\mathrm{O}_{3}$

4) $\mathrm{NaHCO}_{3}, 95 \%$<smiles>C=C(CC)COC(C)C(=O)OC</smiles>

7

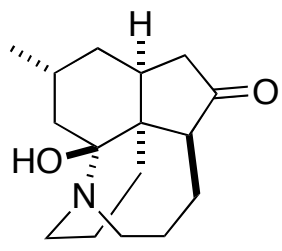

( \pm )-fawcettimine (10)

Scheme 1.1: PGF synthesis of $( \pm)$-fawcettimine. ${ }^{15}$

Other in situ protection PGF syntheses include the eight-step synthesis of welwitindolinone A (14, Scheme 1.2), ${ }^{24}$ a natural product that was originally extracted from blue-green algae in $1994 .{ }^{25}$ The first step of the synthesis involved the opening of an epoxide $\mathbf{1 1}$ by a Grignard reagent in the presence of a ketone group, which was made possible by the in situ formation of enolate 12, before addition of the Grignard reagent to give 13. Seven subsequent PGF steps allowed for the first total synthesis of welwitindolinone A (14). 
<smiles>C=C(C)C1CC(=O)C(C)C2CCCCC12</smiles>

11

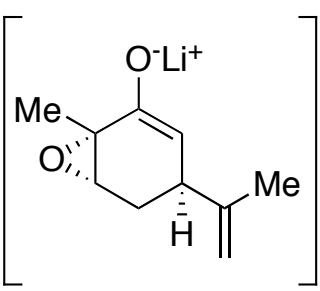

12<smiles>C=C[C@]1(C)C(=O)C[C@@H](C(=C)C)C[C@H]1O</smiles>

13

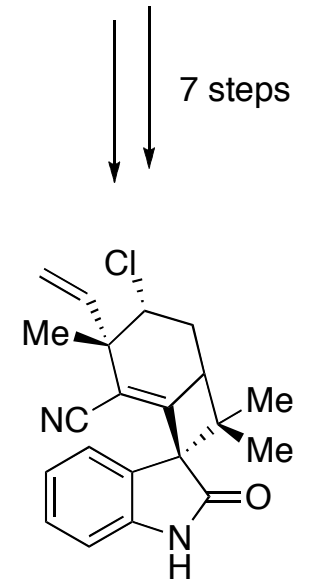

(+)-welwitindolinone A (14)

Scheme 1.2: In situ protection step towards PGF synthesis of (+)-welwitindolinone A. ${ }^{24}$

\subsubsection{Synthesis of Compounds with Few Competing Reactivities}

Some molecules contain few reactive groups that are likely to undergo side reactions, which readily allows for the avoidance of PGs. The presence of few competing reactivities in $( \pm)$-subincanadine $F(\mathbf{2 2})$ allowed for the synthesis of this compound in a $33 \%$ yield over seven steps (Scheme 1.3$)$. ${ }^{26}$ Subincanadine F was originally isolated from a Brazilian medicinal plant Aspidosperma subincanum Mart, and early biological screening revealed that it had in vitro cytotoxic activity towards murine lymphoma L1210 cells $\left(\mathrm{IC}_{50}=2.4 \mu \mathrm{g} / \mathrm{mL}\right)$ and human epidermoid carcinoma $\mathrm{KB}$ cells $\left(\mathrm{IC}_{50}=4.8 \mu \mathrm{g} / \mathrm{mL}\right) .{ }^{27}$ The synthesis of $( \pm)$ subincanadine F (22) began with the Pictet-Spengler ${ }^{28}$ condensation of tryptamine 
15 with methyl bromopyruvate to form 16, which led to olefinic indoloazepine 17 after skeletal rearrangement in the presence of base. Reduction of the alkene in $\mathbf{1 7}$ with $\mathrm{NaCNBH}_{3}$ afforded amine 18, which was subjected to a Michael addition using methyl acrylate to give diester 19 in good yield. A Dieckmann condensation followed, ${ }^{29}$ which was achieved in the presence of 2 equiv. of $t$-BuOK in THF at room temperature to give the subincanadine core $\mathbf{2 0}$ in $82 \%$ yield. Hydrolysis and decarboxylation gave ketone 21, which underwent an aldol reaction with acetaldehyde, followed by dehydration, to afford ( \pm )-subincanadine $F(\mathbf{2 2})$. 
<smiles>NCCc1c[nH]c2ccccc12</smiles>

15<smiles>COC(=O)CBr</smiles>

16<smiles>CC(=O)C1=CNCCc2c1[nH]c1ccccc21</smiles>

17

$\mathrm{NaCNBH}_{3}$ $99 \%$<smiles>COC(=O)C1CC2C(=O)N(CCc3c2[nH]c2ccccc32)C1</smiles>

20

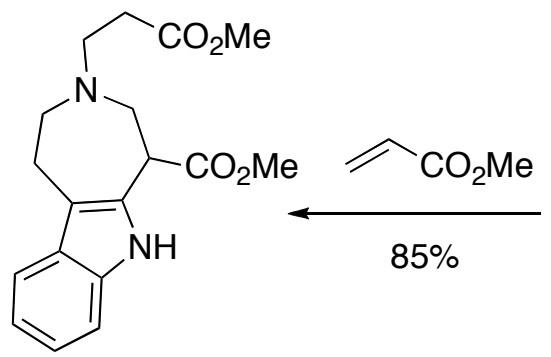

19<smiles>CC(=O)C1CNCCc2c1[nH]c1ccccc21</smiles>

18<smiles>C[C@H](O)[C@@H](O)C=O</smiles>

21

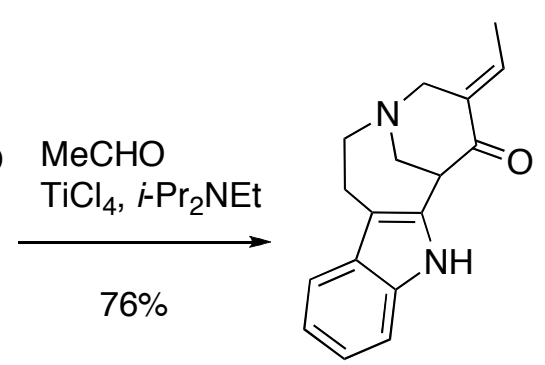

( \pm )-subincanadine $\mathrm{F}(\mathbf{2 2})$

Scheme 1.3: PGF synthesis of ( \pm -subincanadine $F^{26}$

Another example of a synthesis involving few competing reactivities is the total synthesis of ( \pm )-patchouli alcohol (28) by Danishefsky and Dumas (Scheme 4). ${ }^{30}$ The synthesis began with a Diels-Alder reaction of diene $\mathbf{2 3}$ and methyl vinyl ketone (24) to establish the carbon framework in bicyclic ketone 25. Hydrogenolysis of the alkene and base-mediated equilibration of the acetyl group to the equatorial position were undertaken before treatment with an organolithium reagent and conversion to the allylic chloride 26. Substitution of the chloride, 
followed by hydrogenation gave alcohol 27 , which was converted to $( \pm)$-patchouli alcohol (28) through treatment with $\mathrm{PBr}_{3}$ and cyclisation with $\mathrm{Na}$ in THF.<smiles>CC1=CC=CC(C)(C)C1=O</smiles><smiles>C=CC(C)=O</smiles>

24

23
$93 \%$

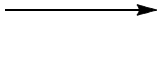

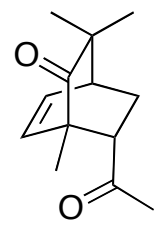

25
1) $\mathrm{H}_{2}, \mathrm{Pd} / \mathrm{C}$

$$
\text { quant. }
$$

2) $\mathrm{NaOMe}, 65 \%$

3) $\mathrm{Li}, \mathrm{THF}$

4) $\mathrm{HCl}-\mathrm{CHCl}_{3}$

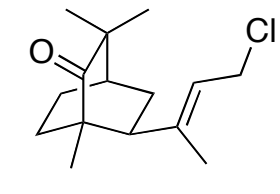

26

1) $\mathrm{H}_{2} \mathrm{O}$, dioxane $85 \%$

2) $\mathrm{H}_{2}, \mathrm{Pd} / \mathrm{C}$

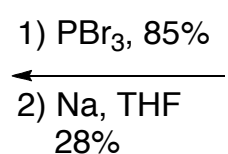
$28 \%$

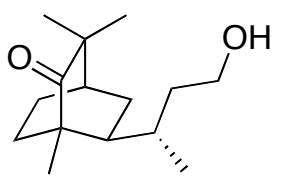

27

( \pm )-patchouli alcohol (28)

Scheme 1.4: PGF synthesis of $( \pm)$-patchouli alcohol (28).$^{30}$ 


\subsubsection{Biomimetic synthesis}

Biomimetic synthesis is defined as the laboratory design of intermediates or reaction sequences inspired by the natural enzymatic pathway without using the enzyme. $^{12}$ A biomimetic synthesis of ( \pm )-elysiapyrone A (37), which was originally isolated by Cueto et al. from the sea slug Elysia diomedea, ${ }^{31}$ took advantage of a cascade of $6 \pi$ and $8 \pi$ electrocyclic reactions that mimics the biosynthetic pathway used in nature (Scheme 1.5). ${ }^{32}$ The synthesis began with the conversion of ester $\mathbf{2 9}$ into aldehyde 30, before enolate addition and Dess-Martin oxidation $^{33}$ formed diketone $\mathbf{3 1}$ as a mixture of stereoisomers. Base-mediated cyclocondensation, followed by regioselective methylation gave pyrone 32, which underwent Stille coupling with a vinyl-tin reagent to form intermediate tetraene 33. In situ $8 \pi$ electrocyclisation of $\mathbf{3 3}$ to $\mathbf{3 4}$, followed by a $6 \pi$ electrocyclisation completed the cascade with the formation of the bicyclo[4.2.0]octadiene 35, and its epimer, as the major and minor products, respectively. The formation of epimers can be explained by the formation of cis or trans products in the $6 \pi$ electrocyclisation. Singlet oxygen was used in a [4+2] cycloaddition to form peroxide 36, which was isomerised to ( \pm )-elysiapyrone A (37) in the presence of a $\mathrm{Ru}(\mathrm{II})$ catalyst. $^{14,32}$ 

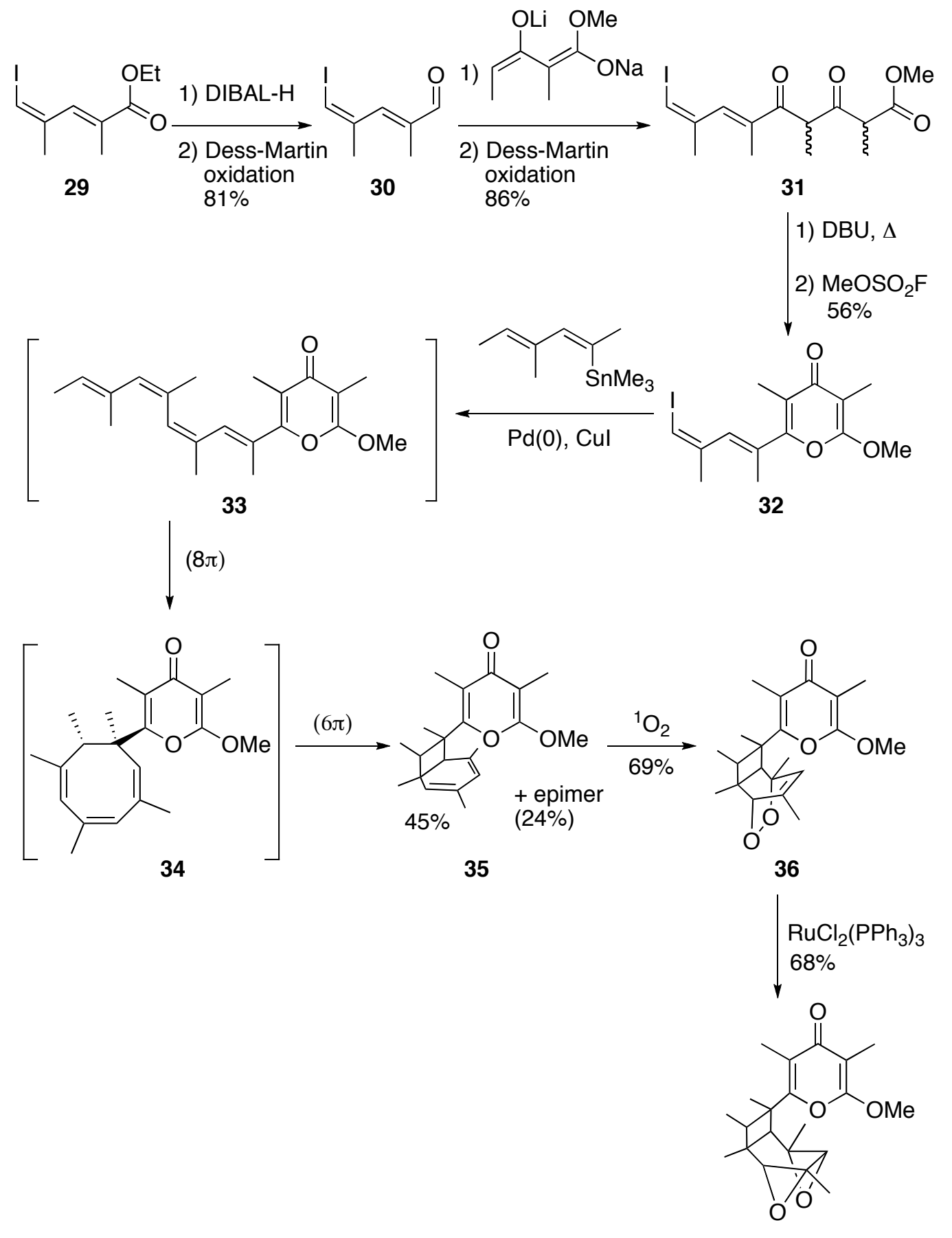

( \pm )-elysiapyrone A (37)

Scheme 1.5: Biomimetic PGF synthesis of ( \pm )-elysiapyrone A (37). ${ }^{32}$

Another example of a biomimetic synthesis was the preparation of $( \pm)$-allamcin (40) by Trost and co-workers (Scheme 1.6). ${ }^{34}$ Here, diol formation across the least hindered double bond of intermediate (38) was followed by periodate 
cleavage to form hemi-acetal intermediate 39. The intermediate was directly treated with $\mathrm{NaOAc}$ causing a cascade that selectively formed $( \pm)$-allamcin (40).

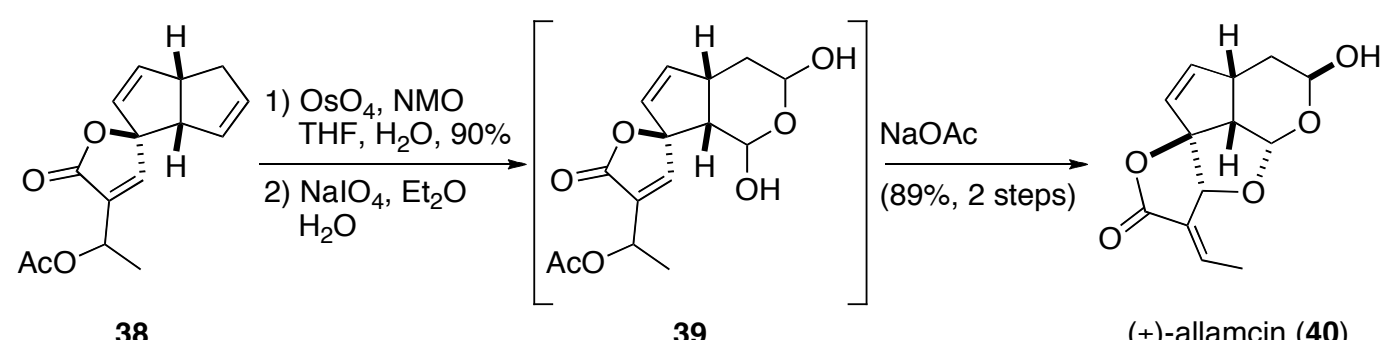

Scheme 1.6: Biomimetic synthesis of $( \pm)$-allamcin $(\mathbf{4 0}) .^{34}$

\subsubsection{Invention oriented synthesis}

Invention oriented synthesis is the term given to PGF methodology whereby the development of new methodology is required to reach a synthetic target. ${ }^{12}$ An elegant example of an invention oriented synthesis of a natural product is that developed by Newhouse and Baran for the synthesis of ( \pm )-psychotrimine (45, Scheme 1.7). ${ }^{35}$ Psychotrimine (45) is a trimeric tryptamine alkaloid that was originally isolated from the leaves of the shrub Psychotria rostrata. ${ }^{36}$ The invention of new methodology for the formation of the uncommon N1-C3 bond was required in the synthesis. Here, $o$-iodoaniline and $N$-iodosuccinimide (NIS) were used in combination with tryptophan derivative $\mathbf{4 1}$ to form pyrroloindoline 42 in the novel C-N bond-forming step. In the past, C-C tryptophan dimers and N1-C2 reactions have been observed under similar reaction conditions, and the N1-C3 bond formation was unprecedented. Detailed mechanistic analysis suggests the reaction proceeds via initial halogenation of $o$-iodoaniline, followed by nucleophilic attack of the corresponding tryptophan enamine and subsequent ring closure. ${ }^{37}$ Pyrroloindoline $\mathbf{4 2}$ was then subjected to an iodide-selective Larock annulation and desilylation $(\mathbf{4 2} \rightarrow \mathbf{4 3}),{ }^{38}$ followed by a Buchwald-Goldberg-Ullmann reaction to give trimeric species $44 .{ }^{39}$ Finally, reduction with Red-Al gave ( \pm )-psychotrimine $\mathbf{4 5}$ in a five-step sequence that was preferable to the previously reported 16-step synthesis. ${ }^{40}$ 


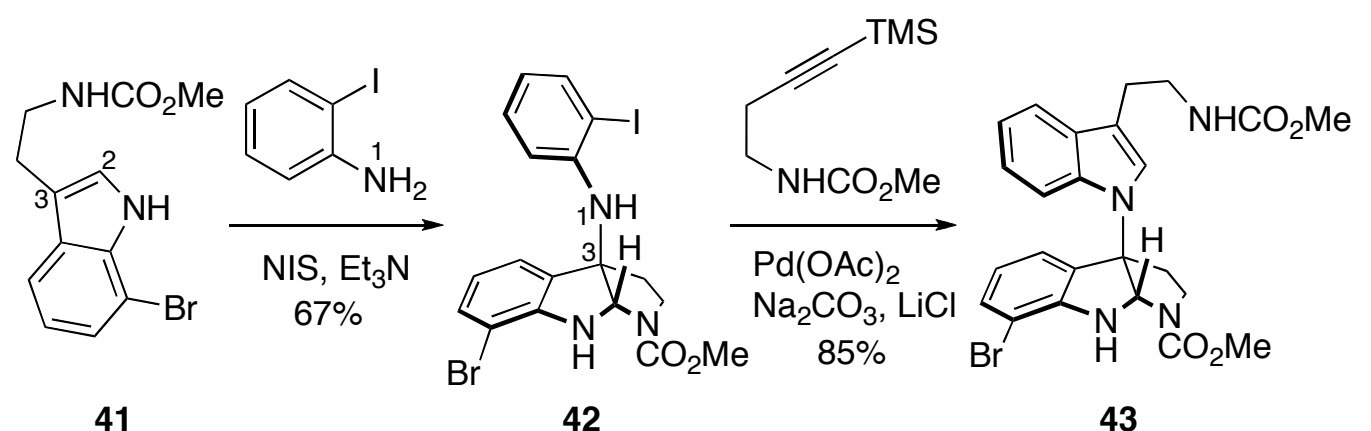

42<smiles>COC(=O)NCCc1c[nH]c2ccccc12</smiles>

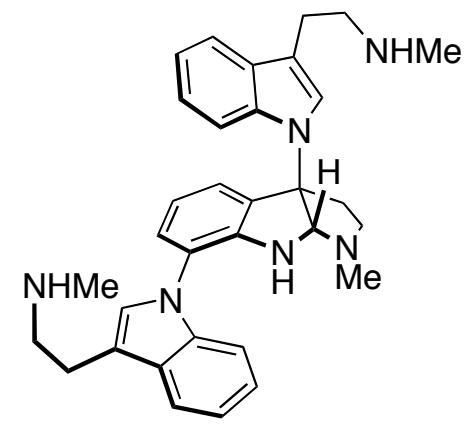

( \pm )-psychotrimine (45)

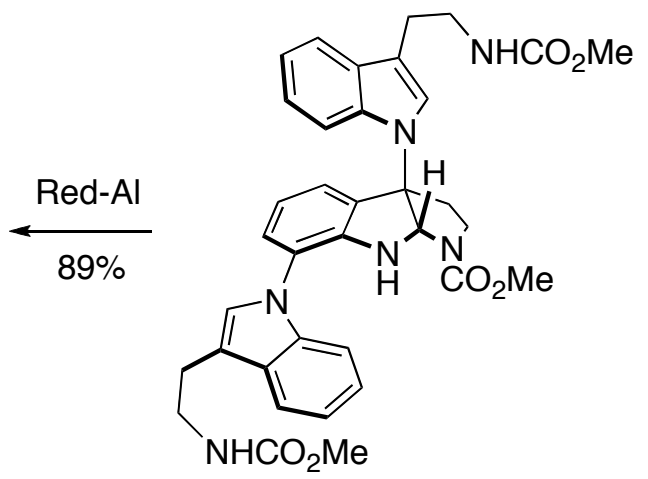

44

Scheme 1.7: PGF synthesis of ( \pm -psychotrimine $(45){ }^{35}$

Other invention oriented PGF syntheses whereby new chemical methodologies were developed includes the single-step synthesis of 6-arylpurine ribonucleosides (46, Scheme 1.8A) from inosine 47, which involved a modified Suzuki-Miyaura coupling. ${ }^{41}$ An improved synthesis of (+)-welwitindolinone A (14) by the Baran group employs a novel synthetic step that involves an oxidative ring contraction of (-)-fischerindole I (48, Scheme 1.8B), itself prepared in a seven-step synthesis from a readily available terpenoid, using xenon difluoride to modify the $\mathrm{C} 2-\mathrm{C} 3$ indole double bond without affecting the remaining alkenes. ${ }^{42}$ 
A.

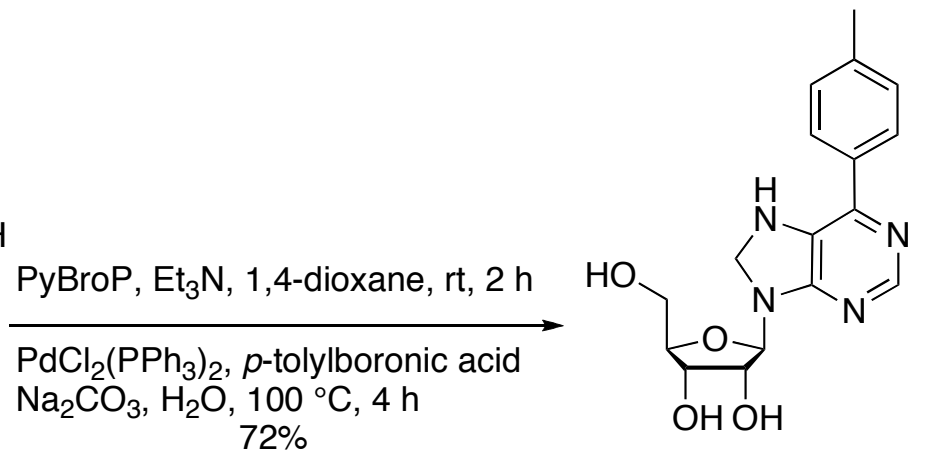

47

46

B.

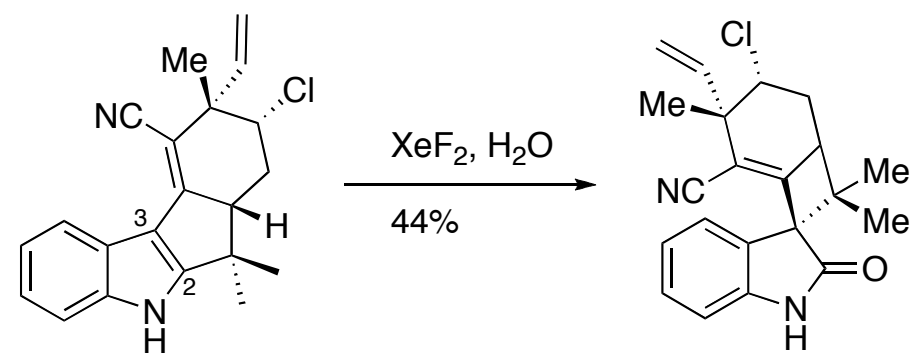

(-)-fischerindole I (48)

(+)-welwitindolinone A (14)

Scheme 1.8: Arylpurine nucleoside 46 and (+)-welwitindolinone A (14), made with newly developed PGF methodologies. ${ }^{41,42}$

The PGF azasugar methodology is an example of invention oriented synthesis with particular relevance to this thesis. The development of two new reactions allowed five-membered azasugars to be prepared from readily available furanoses in a five-step synthesis (Scheme 1.9). ${ }^{5,43,44}$ The synthesis of 1,4-dideoxy-1,4imino-L-lyxitol $(\mathbf{5 5})^{5 \mathrm{a}}$ began with a Fischer glycosylation of D-ribose 49 to give methyl furanoside 50, which was iodinated at the primary hydroxyl to form methyl iodoriboside $\mathbf{5 1}$ in moderate yield. The first novel reaction, a modified Vasella-reductive amination, gave primary amine $\mathbf{5 2}$ in excellent yield and chemoselectivity. In this reaction a methyl iodoglycoside is submitted to a zincmediated Vasella reaction followed by a reductive amination with ammonia in situ. Key in this reaction was the use of excess ammonia and ammonium acetate to yield the primary amine $\mathbf{5 2}$ rather than the secondary amine (53), with the latter being formed under normal reductive amination conditions. ${ }^{5 b, 45,46}$ Alkenylamine 52 was subjected to a novel carbamate annulation procedure where the 
3,4-cis carbamate 54 was formed stereoselectively and in excellent yield. The reaction is suggested to proceed via initial halocyclisation, followed by attack of carbon dioxide (formed in situ from $\mathrm{NaHCO}_{3}$ ) to give the desired carbamate. ${ }^{47,48}$ Hydrolysis using $\mathrm{NaOH}$ completed the synthesis to provide pyrrolidine $\mathbf{5 5}$ in five steps from D-ribose and in 55\% overall yield, which is the best yield reported for the pyrrolidine. ${ }^{5 a}$ This novel methodology has been applied to the synthesis of five- and six-membered azasugars, where stereoselective 3,4- or 4,5-cis azasugars were formed preferentially over the trans diastereomers. ${ }^{5 \mathrm{a}, \mathrm{c}, 43,44}$<smiles>OCC1O[C@H](O)[C@@H](O)[C@@H]1O</smiles>

49

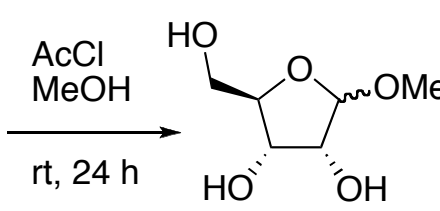

50

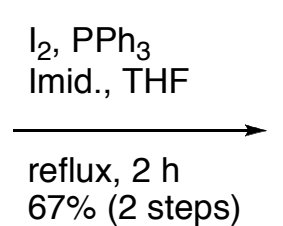<smiles>CO[C@H]1O[C@H](CI)[C@@H](O)[C@H]1O</smiles>

51 $\mathrm{Zn}, \mathrm{NaCNBH}_{3}$ $\mathrm{NH}_{3}, \mathrm{NH}_{4} \mathrm{OAc}$ $\mathrm{EtOH}$, reflux $18 \mathrm{~h}, 91 \%$<smiles>[R][C@@H]1N[C@H](CO)[C@H](O)[C@H]1O</smiles>
55

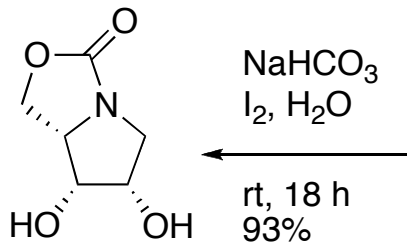

54<smiles>C=C[C@H](O)[C@@H](O)CN</smiles>

52<smiles>O[C@@H](C=CI)[C@H](O)CNC[C@@H](O)[C@H](O)C=CI</smiles>

Scheme 1.9: Total synthesis of 1,4-dideoxy-1,4-imino-L-lyxitol (55). ${ }^{5}$ 


\subsection{Azasugars as Glycosidase Inhibitors and Molecular Chaperones}

\subsubsection{Azasugars}

Azasugars are carbohydrates with nitrogen replacing the ring oxygen. Due to their similarities to furanoses and pyranoses, azasugars can bind to glycosidases and other sugar binding enzymes, and thus have potential in the treatment of a range of diseases including Type 2 diabetes, viral and bacterial infections, lysosomal storage disorders (LSDs), cancer, and cystic fibrosis. ${ }^{49,50}$ There are several classes of azasugars (Figure 1.2) including the pyrrolidines (five membered azasugars), piperidines (six membered azasugars), pyrrolizidines (1-azabicyclo [3.3.0] octanes, fused five-five bicyclic rings), indolizidines (1-azabicyclo [4.3.0] nonanes, fused five-six bicyclic rings), and notropanes (8-azabicyclo [3.2.1] octanes, fused five-six bicyclic rings). ${ }^{51}$ Members of each class have been found in a variety of plants and microorganisms. ${ }^{50}$<smiles>OC1(O)CCCNC1</smiles>
pyrrolidines<smiles>OC1CCCNC1</smiles>

piperidines<smiles>OC1CC2CCCN2CC1O</smiles>

pyrrolizidines<smiles>OC1CCN2CCCCC12O</smiles>

indolizidines<smiles>OC1CC2CC(O)CC(C1)N2</smiles>

nortropanes

Figure 1.2: Different classes of azasugars.

\subsubsection{Glycosidases as Potential Drug Targets}

Glycosidases are enzymes that catalyse the hydrolysis of glycosidic linkages and are involved in numerous fundamental biological processes including the break down of polysaccharides driving intestinal digestion, cellular function such as post-translational processing of glycoproteins, and lysosomal catabolism of glycoconjugates. ${ }^{50}$ Glycosidases play an important and varied role in a number of diseases. For example, cancerous tumours present unusual carbohydrate structures due to changes in the $\mathrm{N}$ - and $\mathrm{O}$-glycan biosynthesis and the inhibition of key enzymes involved in glycosidase reactions, ${ }^{52}$ while LSDs (see Section 1.3.3), such 
as Gaucher's disease, Fabry's disease and Tay-Sachs disease, result from various mutated glycosidase enzymes involved in the catabolic pathway for glycosphingolipids. ${ }^{53}$ A number of bacteria and viruses target carbohydrates on mammalian cell surfaces and utilise glycosidases in their internalisation and/or pathogenesis mechanisms. ${ }^{54}$ The neuraminidase (carbohydrate binding receptor) in influenza viruses cleaves the sialic acids from the glycoproteins on the surface of an infected cell, releasing the pathogen. ${ }^{55}$ Inhibition of the neuraminidase effectively traps the virus on the cell surface, and therefore stops the virus from reproducing.

The enzymatic hydrolysis of glycosidic bonds occurs through one of two mechanisms, with either the retention or inversion of stereochemistry at the newly formed anomeric centre. ${ }^{56}$ In an inverting mechanism the oligosaccharide binds to the enzyme active site along with a water molecule, and the glycosidic linkage is hydrolysed via an $\mathrm{S}_{\mathrm{N}} 2$-like transition state that has some oxocarbenium character (Figure 1.3A). The retaining glycosidase mechanism occurs through a two-step process. The oligosaccharide undergoes nucleophilic substitution by a residue in the enzyme active site, and the glycosidic linkage is hydrolysed via an $\mathrm{S}_{\mathrm{N}}$ 2-like transition state, leaving the glycoside covalently bound to the enzyme (Figure 1.3B) ${ }^{57}$ Nucleophilic attack on the anomeric centre by a water molecule occurs from the unhindered side of the sugar. The new bond is formed through a second inverting transition state, effecting retention of stereochemistry at the anomeric centre. An azasugar, which will be protonated at physiological $\mathrm{pH}$, can potentially bind to the glycosidase active site by mimicking the charge density of the native glycoside transition state, inhibiting the enzyme (Figure 1.3C). ${ }^{57}$ 
A.

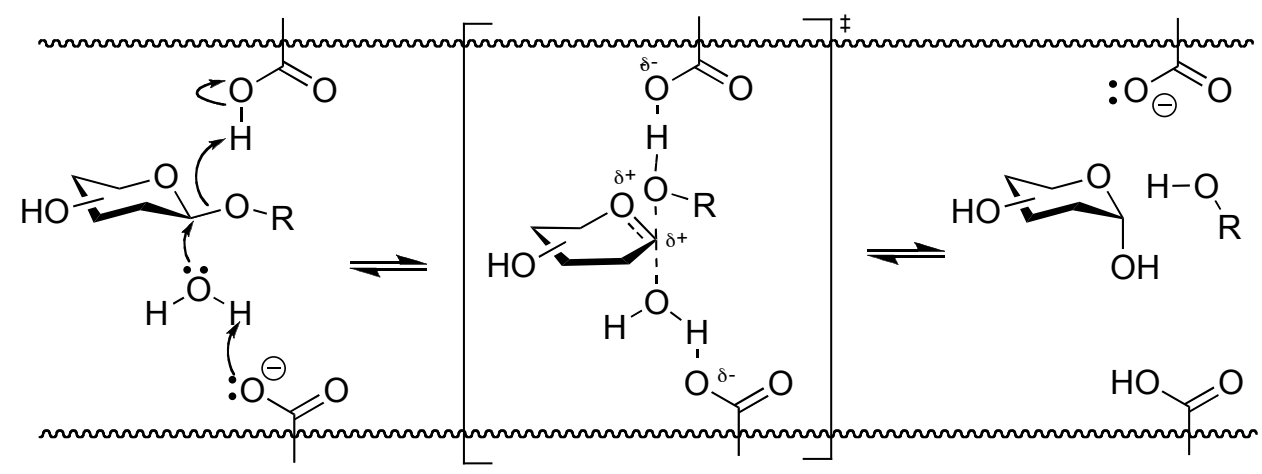

B.
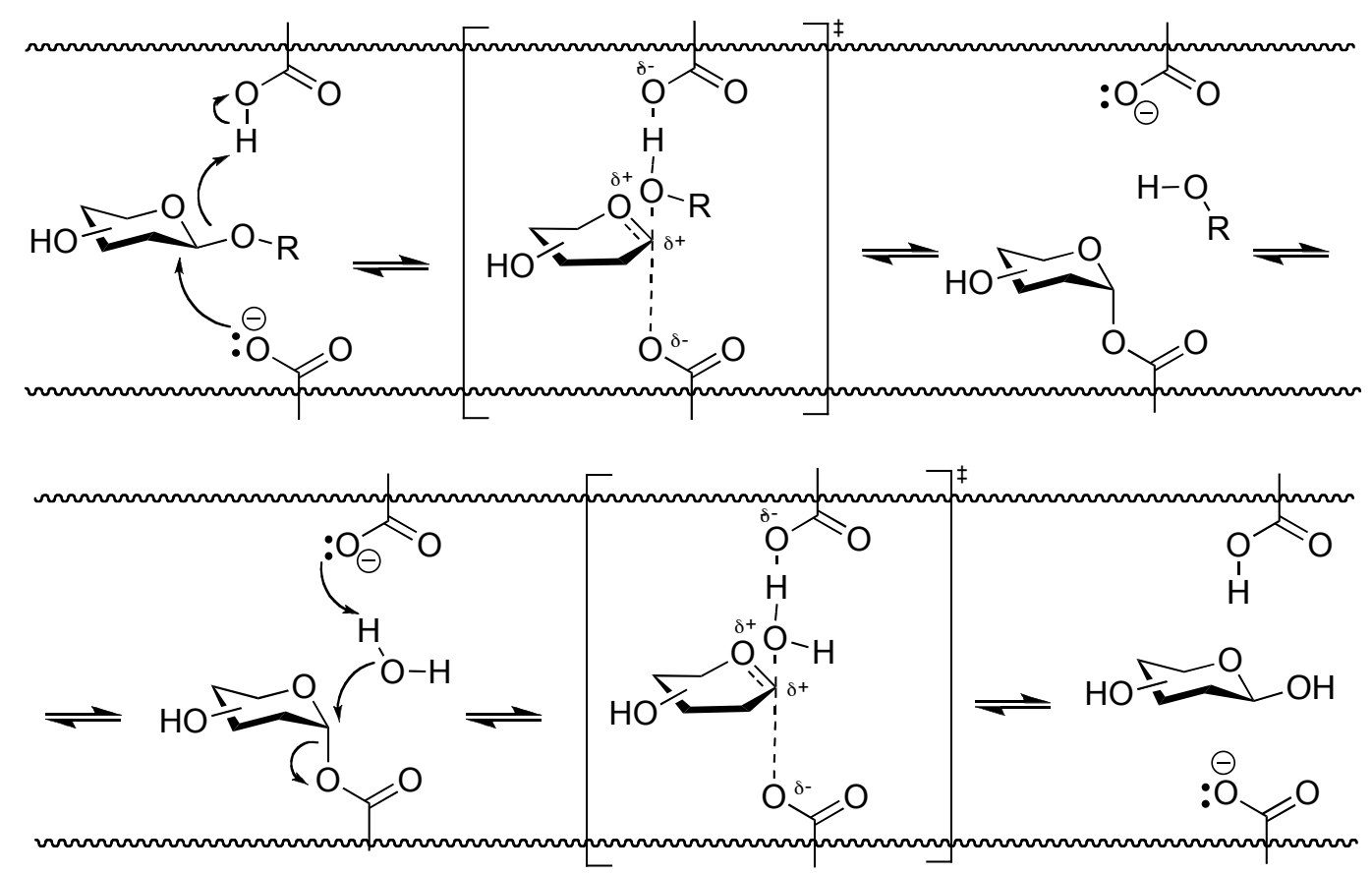

C.

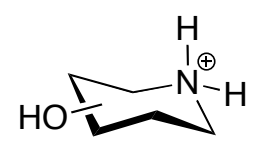

Figure 1.3: Proposed mechanisms of glycosidase enzyme catalysis, the enzyme active site, including residues involved in the catalysis, is shown. A: Inverting glycosidase mechanism of action. B: Retaining glycosidase mechanism of action. C: Protonated azasugar transition state mimic. ${ }^{56}$ 
$\begin{array}{llll}\text { 1.3.3 P } & \text { F } & \text { P } & \text { C }\end{array}$

For an enzyme or protein to function properly, the primary sequence(s) of amino acids must correctly fold to form the tertiary or quaternary structure of the functional protein. Under normal cellular conditions this may be aided by the presence of a molecular chaperone - a separate protein that guides the peptide folding to give a functional protein, without being involved in the final protein function or activity. ${ }^{58}$ Certain genetically inherited diseases result from the misfolding and/or aggregation of proteins, causing reduction in enzymatic function and hence the build up of intermediate substrates in an enzymatic pathway. Such diseases include cystic fibrosis, LSDs, Alzheimer's disease, and cataracts. ${ }^{59,60}$

LSDs are a collection of more than 50 inherited diseases characterised by defective lysosomal function, which results from the failure to transport or metabolise lipids, proteins and carbohydrates causing a build up of these substrates within the cell. ${ }^{61}$ These rare metabolic diseases cause a variety of physical and neurological symptoms including skeletal deformities, heart problems, enlarged liver and spleen, eyesight problems, and brain degeneration. ${ }^{62}$

Often the genetic mutation resulting in protein misfolding is a simple point mutation resulting from a single amino acid substitution in the primary sequence. This may only slightly reduce the folded protein's activity, but often hinders the folding and thus quality control mechanisms stop the protein from exiting the endoplasmic reticulum (ER) for its cellular target. Pharmacological chaperones are molecules that have been developed to encourage protein folding in the treatment of protein misfolding disorders. ${ }^{60}$ The pharmacological chaperone binds to the active site at an early stage in protein folding, thereby stabilising the protein and encouraging a conformation close to that of the native protein. This allows the protein to pass internal quality control mechanisms and exit the ER for its biological target within the cell. ${ }^{63}$ For example, Fabry disease is a lysosomal storage disorder caused by lack of lysosomal $\alpha$-galactosidase A; the misfolding of 
this enzyme causes some forms of the disease. The azasugar 1-deoxy galactonojirimycin, DGJ 56, is currently in clinical trials for use as a pharmacological chaperone in the treatment of Fabry disesase (Figure 1.4). ${ }^{64,65}$ For an effective LSD drug, a molecule must support protein folding by binding to the enzyme active site, while not binding preferentially to the native substrate. DGJ is a nanomolar inhibitor of $\alpha$-galactosidase $A$ in vitro, and at sub-inhibitory concentrations in vivo, is an effective pharmacological chaperone. ${ }^{64}$<smiles>OC[C@H]1NC[C@@H](O)[C@H](O)[C@@H]1O</smiles>

DGJ (56)<smiles>CCCCN1C[C@H](O)[C@@H](O)[C@H](O)[C@H]1O</smiles>

Miglustat (57)

Figure 1.4: Azasugars of clinical significance for the treatment of lysosomal storage disorders.

Azasugars may also be used as glycosidase inhibitors in the treatment of misfolded protein disorders by way of substrate reduction therapy. An example of this is in the use of Miglustat (57) for the treatment of Gaucher's disease. ${ }^{66}$ Gaucher's disease is a lysosomal storage disorder caused by a build up of glucosylceramide in cells due to poor activity of the glucocerebrosidase enzyme. ${ }^{67}$ Rather than repairing the function of the faulty enzyme, Miglustat inhibits the synthesis of glucosylceramide, reducing the amount of substrate produced so that there is no glycolipid build up within the cells. 


\subsection{C-C Bond Forming Reactions for the Synthesis of Conduramines}

\subsubsection{Conduramines}

For PGF chemistry to be more widely incorporated into the design of synthetic strategies, new chemoselective methodologies need to be developed. Invention oriented synthesis has enabled the preparation of a number of interesting compounds by a PGF and therefore 'greener' approach, ${ }^{35,41,42}$ as illustrated by the development of the modified Vasella-reductive amination and carbamate methodologies for synthesis of azasugars. ${ }^{5,43}$ A natural extension of this work is the development of chemoselective $\mathrm{C}-\mathrm{C}$ bond forming reactions, which will allow access to a variety of molecules, including conduramines.

Conduramines such as conduramine A-1 (58, Figure 1.5) are derivatives of the natural products conduritols, ${ }^{68}$ of which conduritol A (59) was isolated from the bark of the vine Marsdema condurango.$^{69,70}$ Some conduramines have activity as glycosidase inhibitors, ${ }^{71}$ and these molecules provide access to many other biologically useful compounds including azasugars ${ }^{72}$ and aminocyclitols. ${ }^{73,74}$ Two examples of conduramine derivatives with medical relevance are Tamiflu ${ }^{\circledR}(\mathbf{6 0})$ and $N$-octyl valienamine (61). Tamiflu (60) is a well-known aminocyclitol that is used for the treatment of influenza. It is a glycosidase inhibitor that acts on the neuraminidase enzyme of the influenza virus. ${ }^{75} \mathrm{~N}$-Octyl valienamine (61), on the other hand, is being investigated for use as a chemical chaperone for the treatment of Gaucher's disease. ${ }^{76,77}$ Although protected conduramine analogues have been prepared earlier, ${ }^{78}$ the fully deprotected amines have not been reported. The development of PGF methodology to synthesise conduramines therefore provides access to an array of biologically significant molecules. 
<smiles>N[C@H]1C=C[C@@H](O)[C@H](O)C1O</smiles>

58<smiles>CCOC(=O)C1=C[C@@H](OC(CC)CC)[C@H](NC(C)=O)[C@H](N)C1</smiles>

60<smiles>O[C@H]1C=C[C@@H](O)[C@H](O)[C@@H]1O</smiles>

59<smiles>CCCCCCCCN[C@H]1C=C(CO)[C@@H](O)[C@H](O)[C@H]1O</smiles>

61

Figure 1.5: Conduramine A-1 (58) and conduritol A (59) and conduramine derivatives Tamiflu ${ }^{\circledR}(\mathbf{6 0})$ and $N$-octyl valienamine (61).

\subsubsection{The Barbier Reaction for C-C bond Formation}

The PGF preparation of conduramines requires the development of new methodology for the $\mathrm{C}-\mathrm{C}$ bond forming reaction, a PGF Barbier-type reaction was proposed for this key step. A Barbier reaction is the reaction of an aldehyde or ketone with an alkyl halide and a metal (e.g., $\mathrm{Zn}, \mathrm{Mg}$, In) in situ to form a substituted alcohol. ${ }^{79}$ The Barbier reaction has been combined with other reactions to perform multiple steps in one pot. Madsen and coworkers prepared a tandem Vasella-Barbier reaction on methyl iodoriboside 62, using allyl bromide 63 as the nucleophile, to give triol 64 in quantitative yield and moderate selectivity (Scheme 1.10). ${ }^{80} \mathrm{Key}$ in the reaction was the use of $\mathrm{Zn}$ in the Vasella reductive elimination and as the activating agent for the Barbier reaction. The reaction required sonication, presumably to ensure the $\mathrm{Zn}$ was well dispersed and the reaction mixture was homogeneous, but dry conditions were not necessary. Indium was also used in the Vasella-Barbier reaction, which led to slightly reduced yields and the opposite diastereoselectivity. ${ }^{81}$ 
<smiles>CO[C@H]1OC(CI)[C@@H](O)[C@H]1O</smiles>

62

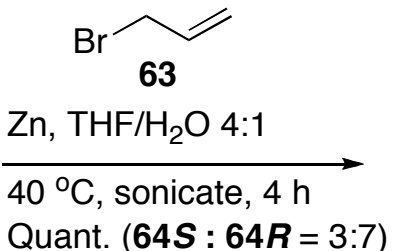

Quant. (64S : 64R = 3:7)<smiles>C=CC[C@H](O)C(O)[C@@H](O)CC=C</smiles>

$64 R$

Scheme 1.10: Vasella-Barbier reaction of methyl iodoriboside. ${ }^{80}$

The addition of benzylamine (65) to the Vasella-Barbier reaction was an extension of the methodology, which was undertaken in the presence of an isopropylidine protected methyl iodoriboside 66 (Scheme 1.11). ${ }^{81}$ Here the Vasella reaction leads to the generation of an aldehyde, which is subject to nucleophilic attack by benzylamine (68) to give an imine. The carbon nucleophile formed from the $\mathrm{Zn}$ insertion in the $\mathrm{C}-\mathrm{Br}$ bond of allyl bromide (66), attacks the imine to form diene 67 in high yield and selectivity. The use of sonication was required. Dry conditions were employed, however an earlier paper by the same group reported a similar yield when the reaction was carried out in the presence of water. $^{80}$

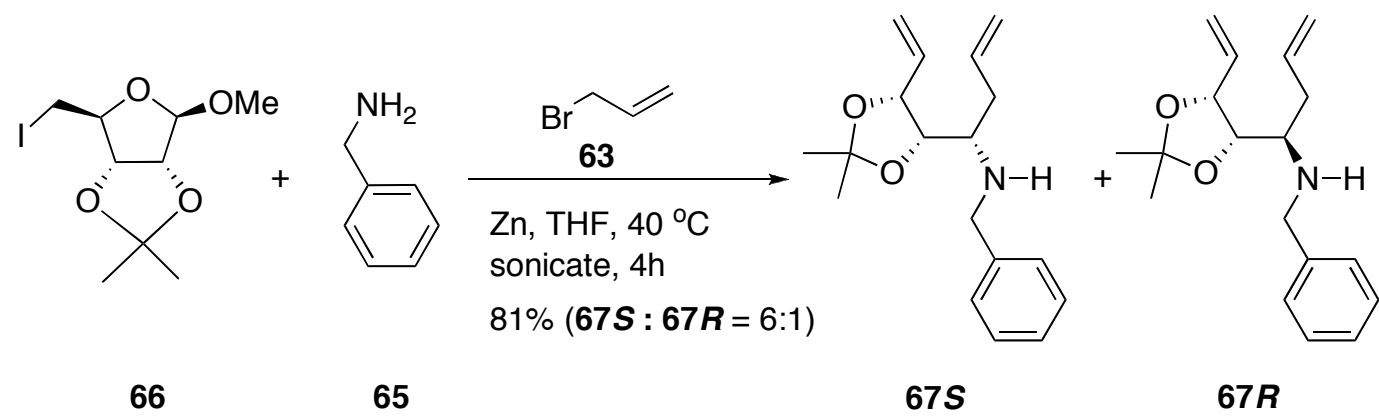

Scheme 1.11: Vasella-Barbier-amination reaction of a protected methyl iodoriboside. $^{81}$

Finally, Behr et al. subjected D-xylose (68) to benzylamine (68) to quantitatively form glycosylamine 69 (Scheme 1.12). ${ }^{82}$ The hemiaminal ether 72 was treated with indium and allyl bromide (66) at $\mathrm{rt}$ in $\mathrm{MeOH}$ to achieve a Barbier reaction producing alkene $\mathbf{7 0}$ in good yield (72\%) and excellent diastereoselectivity 
$(>95 \%)$. The reaction sequence could also be performed in a single pot with no reduction in yield or selectivity. Key to the reaction was the use of indium powder; the use of either $\mathrm{Sn}$ or $\mathrm{Zn}$ in place of In was unsuccessful.

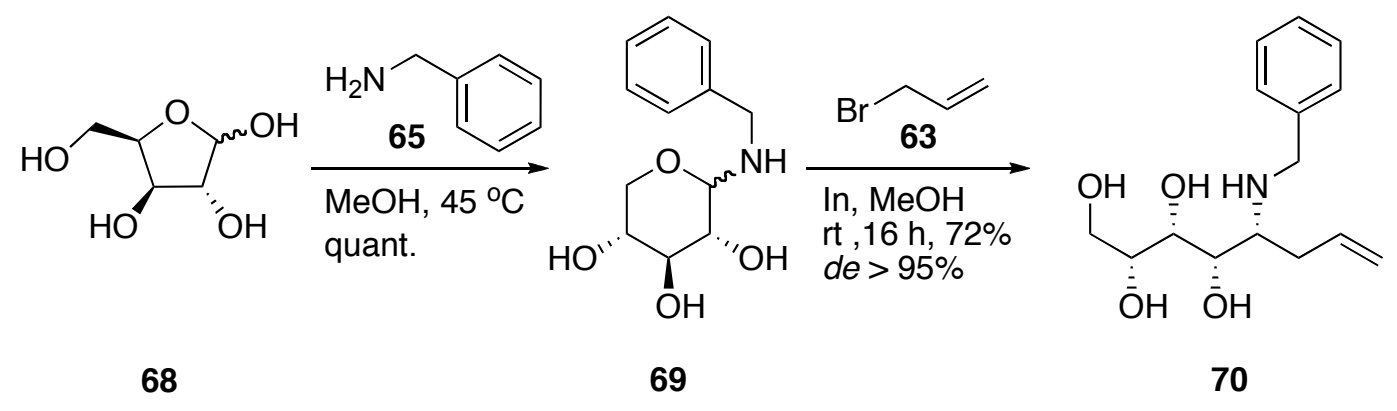

Scheme 1.12: Barbier amination reaction on D-xylose. ${ }^{82}$

The Vasella-Barbier amination reaction is amenable to the development of a PGF protocol. This is supported by the facts that a Vasella-Barbier reaction has been reported in the absence of $\mathrm{PGs},{ }^{80}$ a Vasella-Barbier amination reaction has been described with protected amine and alcohol groups, ${ }^{81}$ and a Barbier amination has been achieved with unprotected hydroxyl groups. ${ }^{82}$ When considered as a whole, these results suggest that a PGF Vasella-Barbier amination with a primary amine such as benzylamine is plausible. An extension of this methodology would be the use of ammonia as the amine source, utilizing an 'unprotected amine' in the reaction.

\subsubsection{Ring Closing Metathesis}

Ring closing metathesis (RCM) is the cyclisation of a dialkene aided by an organometallic catalyst (Scheme 1.13A). The reaction is entropically driven through the generation of two products, the desired cyclic alkene and a small alkene by-product that is often volatile, hence the reaction usually goes to completion. ${ }^{83}$ The four main catalysts: Grubbs I and II, and Hoveyda-Grubbs I and II, are shown in Scheme 1.13B. The catalysts vary in substrate scope and specificity, functional group tolerance, and activity. 
A:

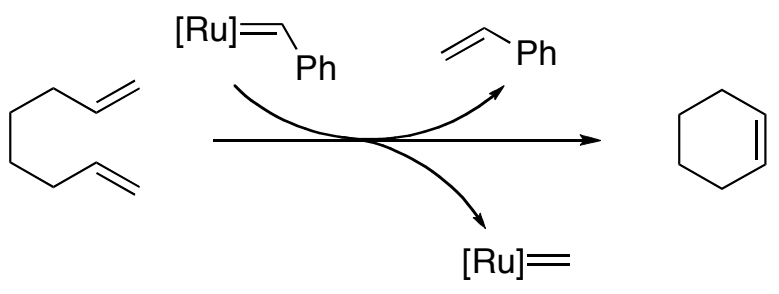

B:

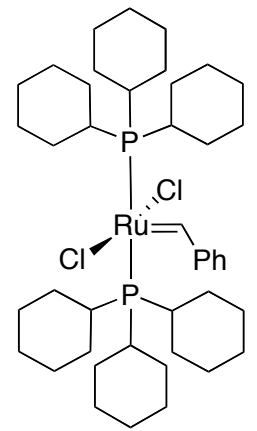

Grubbs I

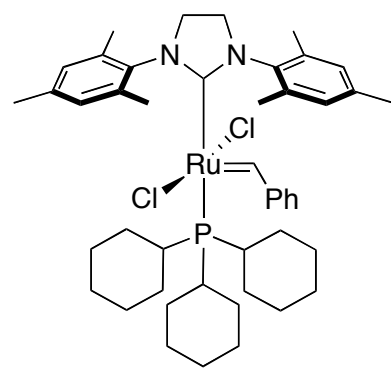

Grubbs II

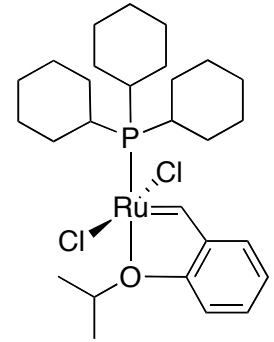

Hoveyda-Grubbs I

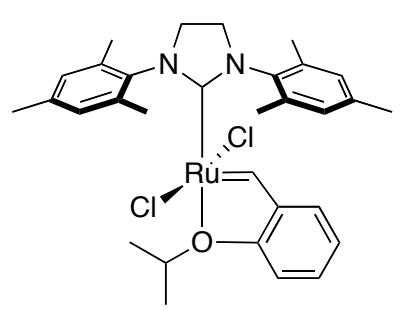

Hoveyda-Grubbs II

Scheme 1.13: A: Example of ring closing metathesis. B: The four main RCM catalysts.

RCM with Grubbs' catalyst I was shown to tolerate a range of functional groups including acids, alcohols and aldehydes. ${ }^{84}$ For example, RCM of triol 71 with Grubbs' $1^{\text {st }}$ generation catalyst afforded the anticipated cyclohexene triol $\mathbf{7 2}$ in excellent yield (Scheme 1.14A). ${ }^{80,81}$ Poor conversion was noted in the presence of secondary amine 73, even with a higher catalyst loading (10 mol\%), and acetylation of the amine was required to achieve cyclisation to cyclohexene $\mathbf{7 4}$ in good yield (Scheme 1.14B). The incompatibility of amines with RCM catalysts has been attributed to amine-mediated degradation of a catalyst that contains a phosphine ligand (e.g., Grubbs I, Grubbs II, Hoveyda-Grubbs I) ${ }^{85}$ in the presence of a primary or secondary amine. Degradation occurs via ligand exchange between the amine and the phosphine on the catalyst. Here, the benzylidene precatalyst undergoes one cycle of RCM to form the methylidene catalyst, the amine group binds to the metal, substituting the phosphine ligand, which is free to attack the methylidene moiety, thereby degrading the catalyst (Scheme 1.15). Strategies to avoid this problem include protection of the amine functionality with 
bulky or electron withdrawing groups, ${ }^{86,87}$ in situ protection by protonation to form the corresponding ammonium salt, ${ }^{84,88}$ or utilisation of a catalyst without a phosphine ligand, such as Hoveyda-Grubbs II. ${ }^{83,89,90}$

A:

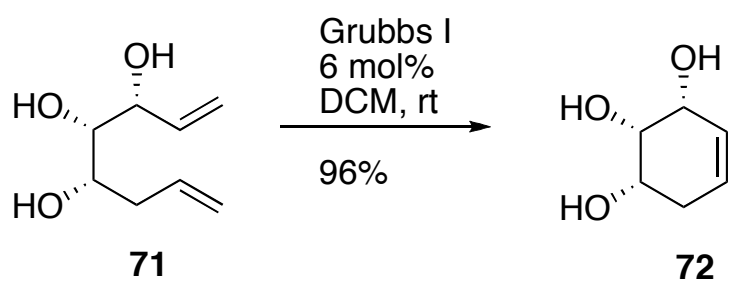

B:
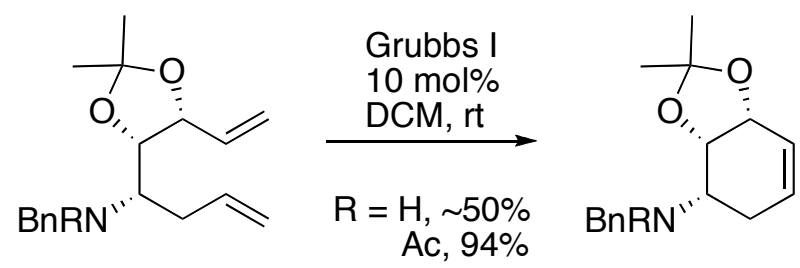

73

74

Scheme 1.14: Functional group tolerance of RCM.

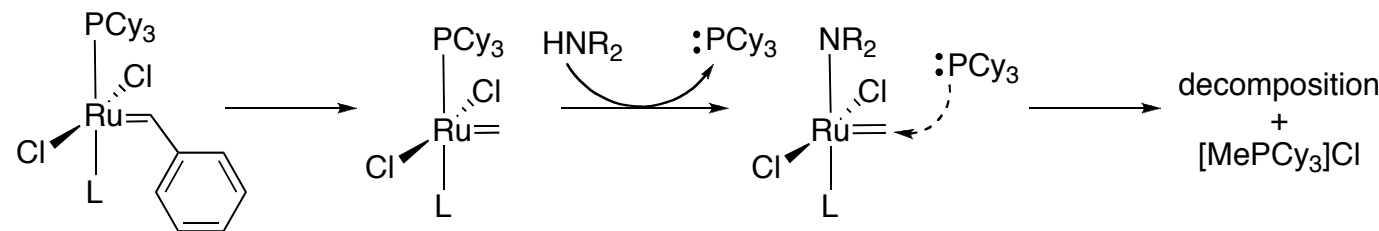

Scheme 1.15: Amine-mediated catalyst degradation pathway, $L=$ ligand $^{85}$

Metathesis catalysts were originally used under oxygen free and dry conditions, ${ }^{84}$ however, catalyst design has improved to the extent that examples of olefin metathesis reactions carried out in aqueous or protic solvents have recently been reported. ${ }^{83,91} \mathrm{RCM}$ reactions have been carried out in dimethoxyethane/water and acetone/water mixtures using the Hoveyda-Grubbs II catalyst as a heterogeneous catalyst. $^{89}$ Additionally, homogeneous catalysts based on the Grubbs and Hoveyda-Grubbs catalysts depicted in Scheme 1.13B have been developed with polyethylene glycol (PEG), or quaternary amine salts attached to a ligand (Figure 1.6), to increase water solubility and therefore improve activity. ${ }^{92,93}$ 

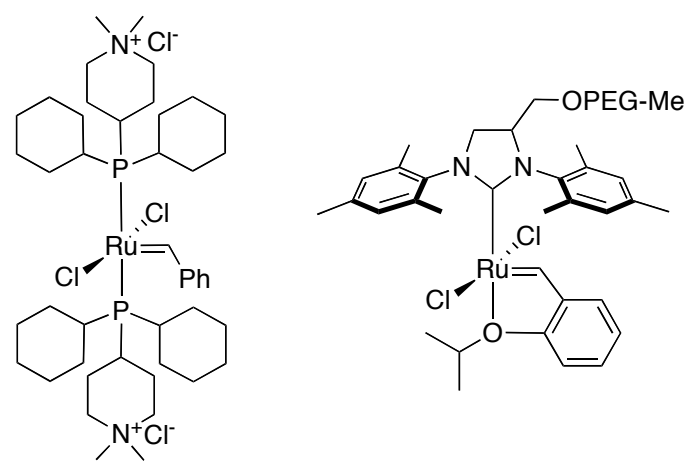

Figure 1.6: Water soluble RCM catalysts.

In 2011, Robinson and coworkers reported the successful olefin metathesis of primary amines (Scheme 1.16). ${ }^{94}$ Diene $\mathbf{7 5}$ was cyclised to cyclopentene $\mathbf{7 6}$ in $>95 \%$ yield, as determined by ${ }^{1} \mathrm{H}$ NMR. This was the first example of a primary amine being successfully cyclised by RCM in such a high yield, and took advantage of both the quaternary amine protection strategy, and the use of the Hoveyda-Grubbs II catalyst that has no labile phosphine ligands. The metathesis reactions were also tested on the free amine, as well as the chloride, triflate, and tetrafluoroborate ammonium salts. The free amine metathesis reaction was unsuccessful, while the reaction with the ammonium chloride salt resulted in a significantly reduced yield ( $38 \%$ yield). The triflate and tetrafluroborate salts proceeded to give conversions comparable to the tosylate $(83-91 \%$ yield $)$. This is the strategy that will be applied to the synthesis of conduramines, due to the simple 'protection' strategy for the amine, and the use of a readily available catalyst.

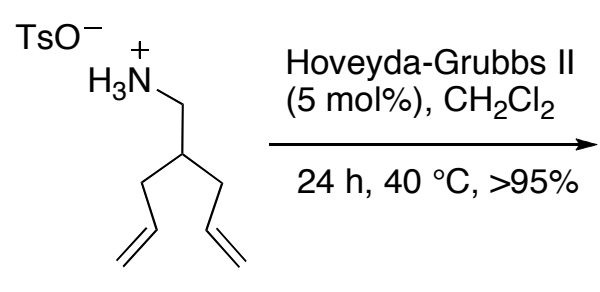

75

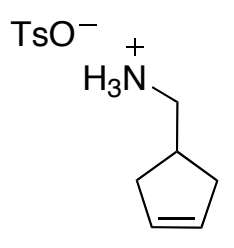

76

Scheme 1.16: RCM of tosylate salt of a primary amine. 


\subsection{Small Molecules as Tuberculosis Drugs}

\subsubsection{Tuberculosis}

Tuberculosis (TB), the disease caused by infection with Mycobacterium tuberculosis (Mtb), is a worldwide problem. Each year TB kills around 1.3 million people, with millions more infected with the bacteria. ${ }^{95}$ In New Zealand, on average one person a day is diagnosed with TB. The rate of infection for Māori and Pacific Island people is also significantly higher than for European ethnic groups. ${ }^{96}$ With the increased mobility of individuals worldwide, and increasing disparity between the classes, TB is a problem in both developed, and developing nations.

\subsubsection{Pathogenesis of Tuberculosis}

The most common form of tuberculosis is pulmonary TB (infection of the lungs), which is caused by the inhalation of the $M t b$ bacilli that are dispersed when an infected individual coughs or sneezes. ${ }^{97}$ The infection may spread from the lungs to cause extrapulmonary $\mathrm{TB}$, which can infect almost any organ in the body. Symptoms of TB include a cough, fever, weight loss, fatigue, chest pain and blood in the sputum. ${ }^{97,98} \mathrm{~TB}$ is diagnosed by culturing the sputum for identification of the bacteria, and by a chest x-ray for the identification of lung infections. $^{98}$

Once the bacteria reach the lungs they are phagocytosed by the alveolar macrophages. The bacteria are either immediately killed through the activation of the immune system, or the bacilli are able to avoid the innate immune response by preventing the phagosome from fusing with a lysosome, stalling the killing process. ${ }^{99}$ The bacteria multiply until they eventually burst the macrophage, expelling bacilli into the lungs, before being phagocytosed once again by the surrounding macrophages, and the process is repeated. Additionally, the 
engulfment of bacilli by macrophages marks the beginning of granuloma formation. A granuloma is a collection of immune cells surrounding the living and lysed macrophages that contain the mycobacterial infection. ${ }^{100,101}$ Often the formation of a granuloma does not kill the bacteria but instead keeps the infection controlled and contained. The granuloma contains a variety of immune cells that work to stabilise bacterial growth, causing the bacilli to enter a non-replicating state known as latent tuberculosis. ${ }^{101}$ Latent $\mathrm{TB}$ does not give the patient symptoms of active TB, however it may become active at some later stage, potentially years after the initial infection, as a result of a weakened immune system. ${ }^{102}$ If the granuloma fails to contain the disease, or latent TB is reactivated, then the bacteria will replicate unchecked in the lungs causing active TB that may be spread throughout the body (causing extrapulmonary TB) or transmitted by coughing. ${ }^{101}$

Mycobacteria have a complicated cell wall structure that protects the bacterium from its environment (Figure 1.7). At the base of the cell wall is the peptidoglycan, a cross-linked polymer of peptides and amino sugars. The peptidoglycan forms a backbone, to which the arabinogalactan is linked via a rhamnose- $N$-acetyl-glucosamine-phosphate linker unit. ${ }^{103}$ Arabinogalactans are polymers of arabinose and galactose and are essential for the structural integrity of the mycobacterial cell wall. ${ }^{104}$ At the reducing end of the arabinogalactan, mycolic acids are covalently bound. The lipophilic mycolic acids represent the outmost layer of the bacterial cell wall, and are attached to either the arabinogalactan, or to a trehalose unit in the form of trehalose dimycolates (TDMs) and trehalose monomycolates (TMMs), which are present on the cell surface. The mycolic acids consist of alkyl chains of up to $C_{90}$ in length, ${ }^{104}$ and therefore reduce the permeability of the cell wall, providing a physical barrier that protects the bacteria from antibiotics and the host's immune response. ${ }^{102}$ Also present in the cell wall are the lipoarabinomannans (LAMs) that are anchored to the plasma membrane by a phosphoryl-inositol-mannose (PIM) linker. ${ }^{104}$ The LAMs are involved in the virulence of $M t b$ by modulating the host's immune system. ${ }^{105}$ 

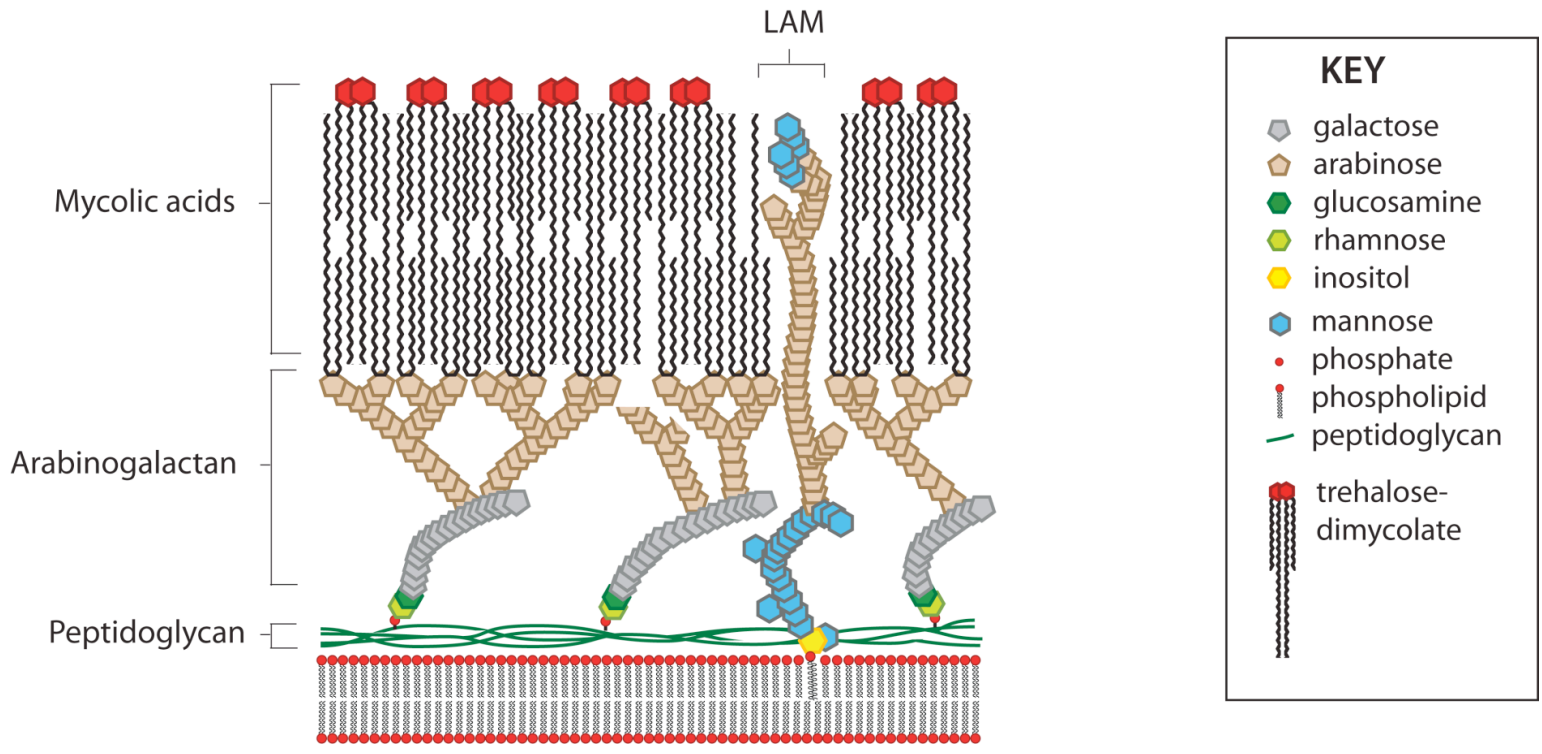

Figure 1.7: Cartoon of the structure of the Mycobacterial cell wall. ${ }^{106}$

\subsubsection{Treatment of Tuberculosis}

\subsubsection{Vaccination}

The ideal treatment of $M t b$ would be prevention by vaccination. The current TB vaccine, Bacillus Calmette-Gerin (BCG), which contains a weakened strain of bovine tuberculosis M. bovis, ${ }^{107}$ protects against severe childhood TB but has varied efficacy against adult pulmonary TB. ${ }^{108}$ Research into a new, more effective TB vaccination is underway, ${ }^{109,110}$ however, a recent phase two clinical trial of a booster vaccine candidate demonstrated insignificant protection against TB. ${ }^{111}$ There is only a limited understanding of the memory immune response required for protection against $M t b$ infection $^{112}$ and no good animal model to accurately represent the human disease. ${ }^{110}$ These factors explain why no new TB vaccinations have been developed since BCG. Furthermore, as a significant proportion of the world's population is already infected with the disease, treatment of $\mathrm{TB}$ in the future will still require both vaccination and medication strategies. 


\subsubsection{Anti-TB Drugs}

Tuberculosis is a difficult disease to treat because the causative agent, $M t b$, has several defense mechanisms. The ability of the bacteria to prevent phagosomelysosome fusion, to form granulomas to evade the immune system, the presence of persistent, latent $\mathrm{TB}$, and the protective lipophilic cell wall have all been discussed in Section 1.5.2. As a result of the difficulty in treating tuberculosis, the treatment involves the use of a selection of first and second line drugs. First line drugs are generally the more effective and specific antimycobacterial drugs, and usually have fewer side effects than the second line drugs. The second line drugs are broad spectrum antibacterials, most of which are injectable rather than orally available, and accordingly, are more expensive than the first line drugs. ${ }^{106,113}$ Normal treatment of drug-sensitive TB begins with an intensive two month course of all first line drugs: isoniazid, rifampin, pyrazinamide, and ethambutol (EMB), followed by a further four months of treatment with just rifampin and isoniazid (Figure 1.8). ${ }^{114}$ Following the six months of treatment the patient is considered cured, however recurrence of the disease occurs in $2-3 \%$ of all new TB cases. ${ }^{114}$ 


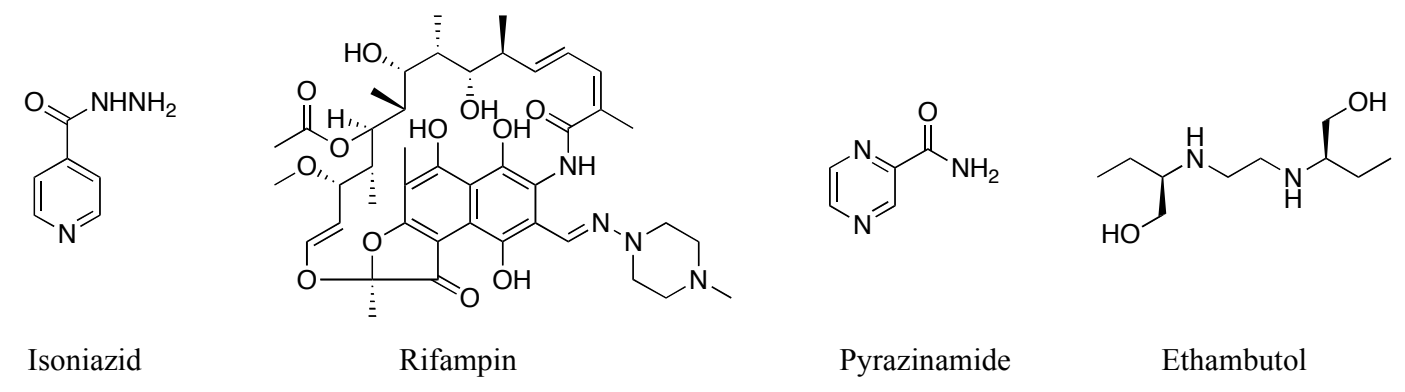

Second Line Drugs<smiles>COc1c(N2C[C@H]3CCCN[C@H]3C2)c(F)cc2c(=O)c(C(=O)O)cn(C3CC3)c12</smiles>

Moxifloxacin (Fluoroquinolone)

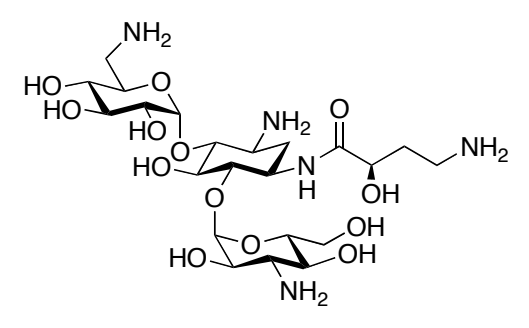

Amikacin

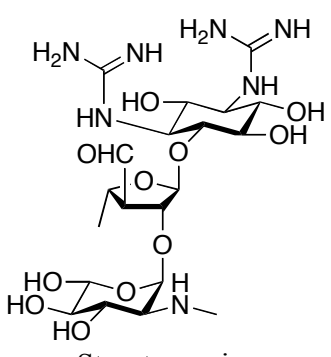

Streptomycin

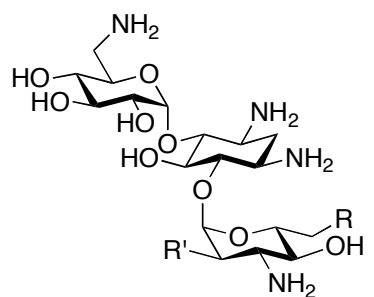

Kanamycin $\mathrm{A}: \mathrm{R}=\mathrm{NH}_{2}, \mathrm{R}^{\prime}=\mathrm{OH}$ $\mathrm{B}: \mathrm{R}=\mathrm{NH}_{2}, \mathrm{R}^{\prime}=\mathrm{NH}_{2}$ $\mathrm{C}: \mathrm{R}=\mathrm{OH}, \mathrm{R}^{\prime}=\mathrm{NH}_{2}$

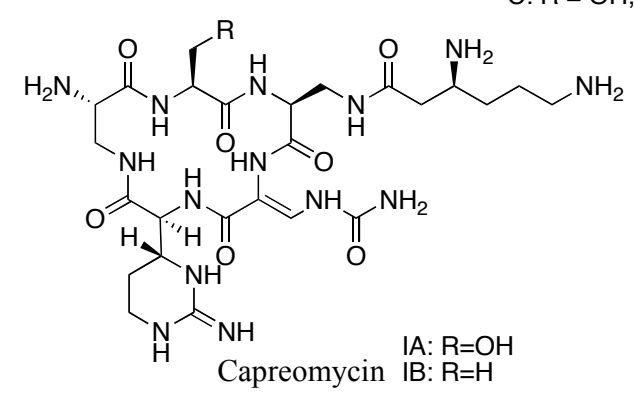

Figure 1.8: First line TB drugs and commonly used second line drugs. ${ }^{106}$

Drug resistant tuberculosis arises from infected individuals not complying to the lengthy drug regimens required for treatment. Patients become non-infectious after a few weeks but must finish the drug course to remove the non-replicating bacteria and achieve a clinical cure. Side effects of the drugs, including hepatotoxicity (liver damage), can force termination of treatment and facilitate drug resistance. ${ }^{115}$ Multi-drug resistant TB (MDR-TB) is defined as resistance to both isoniazid and rifampin, while extensively drug restistant TB (XDR-TB) occurs when a $M t b$ strain is resistant to isoniazid, rifampin, a fluoroquinolone, and at least one of kanamycin, capreomycin, or amikacin. ${ }^{15,116}$ There have also been reported cases of drug resistance beyond XDR-TB, where the bacteria may be 
resistant to all known anti-TB medications. This is termed totally drug resistant TB (TDR-TB). ${ }^{117}$ Treatment of the drug resistant forms of TB varies depending on what drugs the patient is resistant to, but usually involves administration of more of the fluoroquinolone and injectable second line drugs (streptomycin, capreomycin, amikacin and kanamycin). ${ }^{14,118}$ The increasing presence of drug resistant TB underlies the need for new anti-TB medications.

The current TB drugs have a variety of different modes of action. Isoniazid is a prodrug that is oxidised in vivo to the active species, which inhibits mycolic acid synthesis, thereby compromising the integrity of the bacterial cell wall. ${ }^{106,115,119}$ EMB also inhibits cell wall biosynthesis by targeting the arabinosyl transferase enzymes involved in the synthesis of the arabinogalactan. ${ }^{106,115,119}$ Pyrazinamide is a prodrug that is converted to its active form, pyrazinoic acid, in vivo. Pyrazinoic acid inhibits trans-translation, a process that manages non-functioning proteins and rescues stalled ribosomes in RNA translation. ${ }^{120}$ Rifampin, another drug that inhibits RNA translation, works by binding to RNA polymerase and blocking RNA synthesis. ${ }^{106,115,119}$ Of the second line drugs, the fluoroquinolones inhibit enzymes involved in DNA replication, while streptomycin, kanamycin, amikacin, capreomycin are all inhibitors of protein synthesis. ${ }^{106,115,119}$ Kanamycin and capreomycin both contain mixtures of components (as depicted in Figure 1.5), all of which are active against $M t b .{ }^{121,122}$ There are many validated targets that anti-TB drugs act on and any new antituberculosis drug that acts with a novel mechanism may provide the best chance of success against drug resistant TB.

\subsubsection{New Drugs in the Pipeline}

In recent years many potential new antituberculosis drugs have entered clinical trials. ${ }^{123}$ Fluoroquinolones moxifloxacin (Figure 1.8) and gatifloxacin (Figure 1.9) are broad spectrum antibiotics and are already approved as second line anti-TB drugs for MDR-TB. Moxifloxacin and gatifloxacin are in phase III clinical trials for their use as first line TB drugs in the treatment of drug sensitive tuberculosis, with the objective of reducing the combination drug therapy treatment time from 
six months to four months. ${ }^{118}$ Fluoroquinolones inhibit DNA gyrase and/or topoisomerase IV - enzymes that are involved in the supercoiling of DNA necessary for replication. ${ }^{119}$<smiles>COc1c(N2CCNC(C)C2)c(F)cc2c(=O)c(C(=O)O)cn(C3CC3)c12</smiles>

Gatifloxacin (Fluoroquinolone)<smiles>COc1nc2ccc(Br)cc2cc1C(c1ccccc1)[C@H](CCN(C)C)c1cccc2ccccc12</smiles>

Bedaquiline<smiles>CC(C)=CCC/C(C)=C/CNCCNC1C2CC3CC(C2)CC1C3</smiles>

SQ109<smiles>C[C@]1(COc2ccc(N3CCC(Oc4ccc(OC(F)(F)F)cc4)CC3)cc2)Cn2cc([N+](=O)[O-])nc2O1</smiles>

Delamanid

Figure 1.9: Emerging tuberculosis drugs.

Diarylquinoline bedaquiline (Figure 1.9) is the first new approved drug for the treatment of tuberculosis in over 40 years, and was granted advanced approval for the treatment of MDR- and XDR-TB. ${ }^{124}$ It is currently in Phase II trials for the treatment of MDR-TB and also for the treatment of drug sensitive tuberculosis. ${ }^{125,126}$ Bedaquiline inhibits a proton pump involved in ATP synthesis, and is also active against non-replicating (dormant) TB. ${ }^{127,128}$ That said, the drug 
may cause heart arrhythmias, ${ }^{129}$ and the drug's early approval is controversial as the successful clinical trial outcome was based on the clearance of the bacteria as measured by sputum cultures rather than the number of patient deaths. ${ }^{130}$

Nitroimidazoles are pro-drugs that are reduced by bacterial nitroreductases to form the active drugs in vivo. The nitroimidazole drugs PA-824 and delamanid (Figure 1.9) are in phase II and phase III clinical trials, respectively. Both drugs inhibit mycolic acid biosynthesis under aerobic conditions and thereby inhibit actively replicating bacteria, while they kill non-replicating bacteria in anaerobic conditions through the release of nitric oxide within the cell. ${ }^{131,132}$ Delamanid is the second new anti-TB drug recently approved for the treatment of MDR-TB, although it is also still in clinical trials. ${ }^{133}$

Ethylenediamine SQ109, an analogue of EMB, was identified from a 63000 compound library, and is now in phase II trials. ${ }^{134}$ SQ109 inhibits mycolic acid biogenesis by targeting a membrane transporter of trehalose monomycolate (TMM). ${ }^{135}$ This is a different target to that of EMB, thus SQ109 is also active against EMB resistant TB. ${ }^{119}$

There are several drugs currently in phase II and III clinical trials for the treatment of tuberculosis, some of which have been discussed. While there are drug candidates in pre-clinical trials, there are currently no drugs in phase I trials. Accordingly, there is a need to fill this gap in the TB drug development pipeline, as some of the later stage drug candidates will inevitably fail phase II or III clinical trials. $^{123,119}$ 


\subsection{The Process of Drug Discovery}

Drug discovery and development is a long and challenging process. In recent years the process has become even more demanding as stricter health and safety regulations and increasing economic pressures develop. ${ }^{136,137}$ An overview of the drug discovery process is given in Figure 1.10.

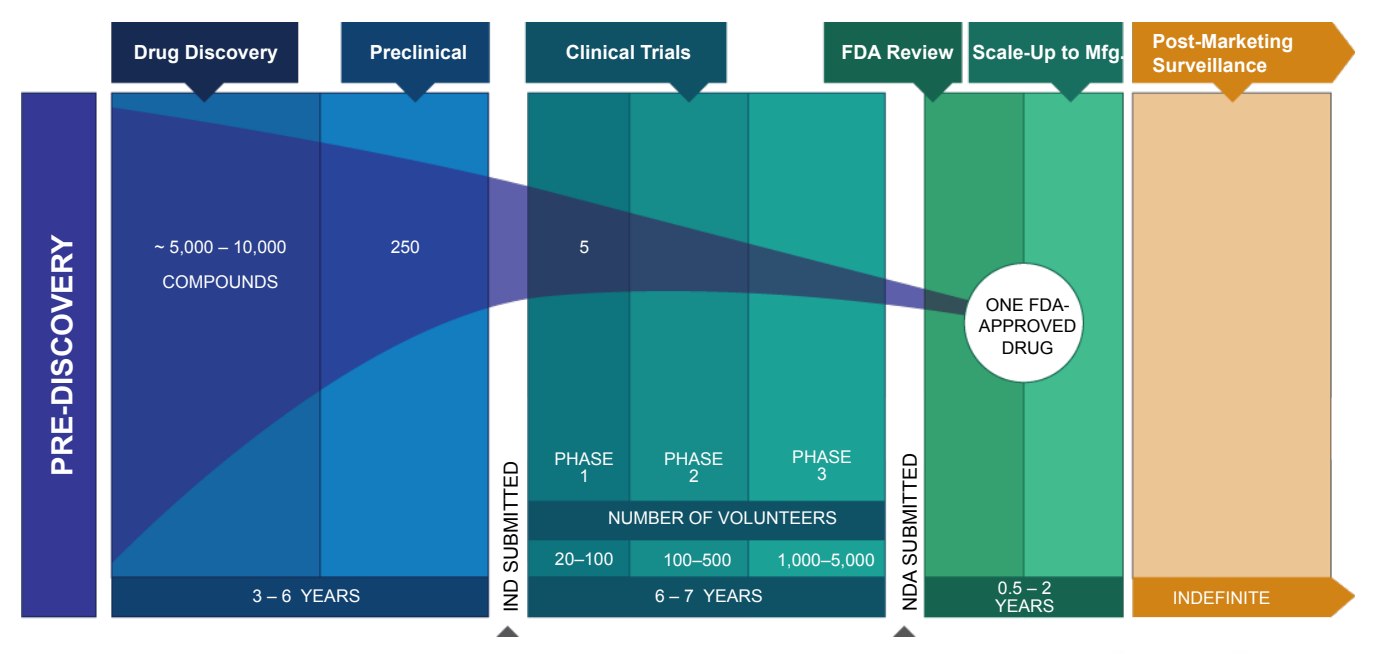

Figure 1.10: The drug discovery process, IND = investigational new drug, NDA $=$ new drug approval. Reproduced from Pharmaceutical Research and Manufacturers of America with permission. ${ }^{138}$

\subsubsection{Screening Methods}

Either whole cell or enzyme based screening methods are used to screen for active compounds. A biological target (e.g., an enzyme) that can bind a drug molecule causing growth inhibition or toxicity needs to be identified and validated to ensure that the target is effective and accessible in vitro and in vivo. ${ }^{139}$ Alternatively, for whole cell screening the cell model needs to be validated as a representative model of the disease (e.g., the use of BCG as a model for Mtb infection). ${ }^{140}$ There is much debate about the utility of whole cell versus target based drug screening strategies and there is no consensus about which model is best. ${ }^{141,142}$ 


\subsubsection{Screening and Lead Identification}

Drug screening is used to determine which compounds are the best inhibitors. There are many ways in which the inhibitory concentration of a drug candidate is determined from an assay. ${ }^{143,144} \mathrm{~A}$ common assay readout is fluorescence, whereby a fluorescent protein or dye displays a measurable change in fluorescence intensity at the inhibitory concentration for a given compound. In this way, the high throughput screening of large compound libraries $(>10,000$ compounds) can be automated.

Compounds may be obtained through synthesis, extraction of natural product sources, or purchasing of a compound library, and there are two general strategies for the identification of leads. The first is a randomised screening approach, which is compatible with high throughput screening methods for large compound libraries, while a structure-based molecular design approach focuses on the design of specific molecules to inhibit an enzymatic target. ${ }^{145}$

The screening process is designed to provide lead compounds that inhibit the target or cell at low concentrations. Optimisation of the lead compounds through the systematic structural variation of the molecular scaffold gives a second generation compound library and provides a better understanding of the structure activity relationship (SAR) of the class of molecules. The optimisation process may be repeated several times until a drug candidate with the desired activity (often nanomolar inhibition) has been discovered.

\subsubsection{Pharmacokinetic and other Biological Testing}

A newly identified lead compound needs to be tested in a variety of models to validate its efficacy and safety. If the optimised drug lead was originally screened in an isolated target enzyme then in vitro whole cell screening is the next logical step. By comparison, if the compound was initially tested in a whole cell model, 
then the drug mechanism of action, and enzyme target still needs to be identified at some stage. However, often in vivo studies precede studies for identification of the mechanism of action. Absorption, distribution, metabolism, excretion, and toxicity (ADMET) studies should also be carried out at the earliest possible stage and, if possible, in parallel with target screening. ${ }^{146}$ Without the appropriate pharmacokinetic properties, a potential drug will not reach its biological target in the human body and will therefore fail to treat the disease. Lipinski's rule of five has been developed as a useful predictor of the absorption properties of a compound. By adhering to these guidelines for bioavailability (i.e. molecular weight $\leq 500 \mathrm{~g} / \mathrm{mol}$, no more than five hydrogen-bond donors, the octanol/water partition coefficient $\mathrm{cLogP} \leq 5$, and no more than 10 hydrogen bond acceptors) orally available compounds with good absorption properties are favoured. ${ }^{147}$ That said, Lipinski's rule of five only applies to compounds that are absorbed by passive diffusion through the cell membrane, and compounds that act on, or are transported by biological transporter proteins are therefore exempt.

There are numerous other pharmacokinetic properties and physiological targets to be screened. ${ }^{139,148}$ In particular, cytotoxicity testing in vitro (e.g., anti-proliferation assays on human $\mathrm{T}$ cells) to confirm that the lead compound is not toxic is important. Next, the lead compound is subjected to an animal model to confirm efficacy of the drug against the disease in vivo and to further explore the compound's safety and pharmacological profile. ${ }^{149}$ If at any stage a compound fails, then it may be sent back for further optimisation through repetition of the previous stages. A successful lead compound will progress to an investigational new drug (IND) and be submitted for clinical trials. ${ }^{139}$

\subsubsection{Clinical Trials of the Investigational New Drug}

With proven efficacy in an animal model and promising pharmacokinetic data, the IND will enter clinical trials, as highlighted herein. In phase I clinical trials, the drug is tested on a small group ( $\sim 20-80$ people) of healthy adults to determine its safety, maximum dose, dose treatment range, and potential side effects. ${ }^{150,151}$ The 
main goal of phase II clinical trails is to explore whether a drug works in adult volunteers ( $\sim 100-500$ people) who are affected by the disease or illness. ${ }^{138,150,151}$ Phase III clinical trials are carried out on thousands of volunteer patients and the objective of the trial is to confirm the efficacy of the drug on a statistically and clinically relevant sample size. ${ }^{150,151}$

The drug discovery and development process often takes more than 10 years, from library screening to new drug on the market. The monitoring of efficacy, safety and side effects once the drug is on the market (phase IV) continues for many years to identify long-term effects, unexpected side effects, and optimal methods of use. This is essential as the larger sample size when in clinical use provides evidence for rare side effects or uncommon drug interactions that may have been missed in the clinical trials. ${ }^{150,151}$ 


\subsection{Thesis Overview}

This thesis describes the use of PGF methodologies for the synthesis of biologically significant molecules.

Chapter 2 describes the application of the PGF methodology to the synthesis of six-membered azasugars, first by providing an overview of work performed in this research field, and then by exploring how different chiral scaffolds affect the PGF carbamate annulation reaction. It then elaborates on the use of halocyclisations in the synthesis of piperidines, and provides mechanistic insight and an explanation of why different products are formed from different chiral starting materials.<smiles>[R]C1C(O)OC(CO)C(O)C1O</smiles>

$\mathrm{R}=\mathrm{OH}, \mathrm{H}$<smiles>OCC1NC[C@@H](O)[C@H](O)[C@@H]1O</smiles><smiles>OCC1NCCC(O)[C@@H]1O</smiles><smiles>OC[C@H]1NCC[C@@H](O)[C@@H]1O</smiles><smiles>NCC1O[C@H](CI)[C@@H](O)C1O</smiles><smiles>OC[C@@H](O)[C@H]1NCC[C@@H]1O</smiles>

The second part of the thesis, described in Chapter 3, explores development of a new C-C bond forming methodology to enable the PGF synthesis of conduramines. A PGF Vasella-Barbier amination was developed, and then a PGF RCM undertaken to afford a 4-deoxy-3-conduramine in few steps.<smiles>C=CC[C@H](N)[C@@H](O)[C@H](C=C)O[C@H](C)C(C)C</smiles> 
Finally, the development of a potential new anti-TB drug using a PGF approach is discussed (Chapter 4). This involved the preparation of a 20-member lipophilic amine library and the in vitro antimycobacterial screening of these compounds. Additional cytotoxicity testing was also undertaken within the group of Prof. Michael Berridge at the Malaghan Institute of Medical Research. ${ }^{152}$ From this work, arabino hexadecylmethylamine was identified as the lead compound, and its single step synthesis was optimised allowing for its preparation in $90 \%$ yield.<smiles>CN(CC1CC1(C)C)C[C@H](O)[C@@H](O)[C@H](O)CO</smiles>

Chapter 5 provides a brief summary of the work, along with future directions for these projects. 


\subsection{References}

1. Hersh, E. V.; Moore, P. A.; Ross, G. L. Clin. Ther. 2000, 22, 500-548.

2. Wong, D. T.; Bymaster, F. P.; Engleman, E. A. Life Sci. 1995, 57, 411441.

3. Rosenberg, B.; Van Camp, L.; Krigas, T. Nature 1965, 205, 698-699.

4. Munchausen, L. L. Proc. Natl. Acad. Sci. U.S.A. 1974, 71, 4519-4522.

5. a) Dangerfield, E. M.; Timmer, M. S. M.; Stocker, B. L. Org. Lett. 2009, 11, 535-538; b) Dangerfield, E. M.; Plunkett, C. H.; Win-Mason, A. L.; Stocker, B. L.; Timmer, M. S. M. J. Org. Chem. 2010, 75, 5470-5477; c) Dangerfield, E. M.; Gulab, S. A.; Plunkett, C. H.; Timmer, M. S. M.; Stocker, B. L. Carbohydr. Res. 2010, 345, 1360-1365.

6. Asano, N.; Nash, R. J.; Molyneux, R. J.; Fleet, G. W. J. TetrahedronAsymmetr. 2000, 11, 1645-1680.

7. Anastas, P. T.; Warner, J. C. Green Chemistry: Theory and Practice; Oxford University Press: Oxford, 1998.

8. Sheldon, R. A. Chem. Commun. 2008, 3352-3365.

9. a) Sheldon, R. A. Pure and Appl. Chem. 2000, 72, 1233-1246; b) Trost, B. Science 1991, 254, 1471-1477.

10. Gaich, T.; Baran, P. S. J. Org. Chem. 2010, 75, 4657-4673.

11. Li, C.-J.; Trost, B. M. Proc. Natl. Acad. Sci. U.S.A. 2008, 105, 1319713202.

12. Young, I. S.; Baran, P. S. Nat. Chem. 2009, 1, 193-205.

13. Shenvi, R. A.; O'Malley, D. P.; Baran, P. S. Acc. Chem. Res. 2009, 42, 530-541.

14. Hoffmann, R. W. Synthesis 2006, 3531,3541.

15. Heathcock, C. H.; Blumenkopf, T. A.; Smith, K. M. J. Org. Chem. 1989, 54, 1548-1562.

16. Burnell, R. H. J. Chem. Soc. 1959, 3091-3093.

17. Hosomi, A.; Sakurai, H. Tetrahedron Lett. 1976, 17, 1295-1298.

18. Arndt, F.; Eistert, B. Chem. Ber. 1935, 68, 200-208. 
19. Harayama, T.; Takatani, M.; Inubushi, Y. Chem. Pharm. Bull. 1980, 28, 2394-2402.

20. Linghu, X.; Kennedy-Smith, J. J.; Toste, F. D. Angew. Chem. Int. Ed. 2007, 46, 7671-7673.

21. Yang, Y.-R.; Shen, L.; Huang, J.-Z.; Xu, T.; Wei, K. J. Org. Chem. 2011, 76, 3684-3690.

22. Jung, M. E.; Chang, J. J. Org. Lett. 2010, 12, 2962-2965.

23. Murphy, R. A.; Sarpong, R. Chem. Eur. J. 2014, 20, 42-56.

24. Baran, P. S.; Richter, J. M. J. Am. Chem. Soc. 2005, 127, 15394-15396.

25. Stratmann, K.; Moore, R. E.; Bonjouklian, R.; Deeter, J. B.; Patterson, G. M. L.; Shaffer, S.; Smith, C. D.; Smitka, T. A. J. Am. Chem. Soc. 1994, 116, 9935-9942.

26. Chen, P.; Cao, L.; Li, C. J. Org. Chem. 2009, 74, 7533-7535.

27. Kobayashi, J. i.; Sekiguchi, M.; Shimamoto, S.; Shigemori, H.; Ishiyama, H.; Ohsaki, A. J. Org. Chem. 2002, 67, 6449-6455.

28. Pictet, A.; Spengler, T. Chem. Ber. 1911, 44, 2030-2036.

29. Dieckmann, W. Chem. Ber. 1894, 27, 102 \& 965.

30. Danishefsky, S.; Dumas, D. Chem. Commun. 1968, 1287-1288.

31. Cueto, M.; D'Croz, L.; Matè, J. L.; San-Martín, A.; Darias, J. Org. Lett. 2005, 7, 415-418.

32. Barbarow, J. E.; Miller, A. K.; Trauner, D. Org. Lett. 2005, 7, 2901-2903.

33. Dess, D. B.; Martin, J. C. J. Org. Chem. 1983, 48, 4155-4156.

34. Trost, B. M.; Balkovec, J. M.; Mao, M. K.-T. J. Am. Chem. Soc. 1986, 108, 4974-4983.

35. Newhouse, T.; Baran, P. S. J. Am. Chem. Soc. 2008, 130, 10886-10887.

36. Takayama, H.; Mori, I.; Kitajima, M.; Aimi, N.; Lajis, N. H. Org. Lett. 2004, 6, 2945-2948.

37. Newhouse, T.; Lewis, C. A.; Eastman, K. J.; Baran, P. S. J. Am. Chem. Soc. 2010, 132, 7119-7137.

38. Larock, R. C.; Yum, E. K.; Refvik, M. D. J. Org. Chem. 1998, 63, 76527662. 
39. Antilla, J. C.; Klapars, A.; Buchwald, S. L. J. Am. Chem. Soc. 2002, 124, 11684-11688.

40. Matsuda, Y.; Kitajima, M.; Takayama, H. Org. Lett. 2008, 10, 125-128.

41. Kang, F.-A.; Sui, Z.; Murray, W. V. J. Am. Chem. Soc. 2008, 130, 1130011302.

42. Baran, P. S.; Maimone, T. J.; Richter, J. M. Nature 2007, 446, 404-408.

43. Dangerfield, E. M.; Plunkett, C. H.; Stocker, B. L.; Timmer, M. S. M. Molecules 2009, 14, 5298-5307.

44. Timmer, M. S. M.; Dangerfield, E. M.; Cheng, J. M. H.; Gulab, S. A.; Stocker, B. L. Tetrahedron Lett. 2011, 52, 4803-4805.

45. Gomez, S.; Peters, J. A.; Maschmeyer, T. Adv. Synth. Catal. 2002, 344, 1037-1057.

46. Bódis, J.; Lefferts, L.; Müller, T.; Pestman, R.; Lercher, J. Catal. Lett. 2005, 104, 23-28.

47. Win-Mason, A. L.; Dangerfield, E. M.; Tyler, P. C.; Stocker, B. L.; Timmer, M. S. M. Eur. J. Org. Chem. 2011, 4008-4014.

48. Stocker, B. L.; Win-Mason, A. L.; Timmer, M. S. M. Carbohydr. Res. 2012, 356, 163-171.

49. a) Kumari, N.; Reddy, B. G.; Vankar, Y. D. Eur. J. Org. Chem. 2009, 160169; b) Ciliberti, E.; Galvani, R.; Gramazio, F.; Haddas, S.; Leonelli, F.; Passacantilli, P.; Piancatelli, G. Eur. J. Org. Chem. 2007, 1463-1473; c) Wardrop, D. J.; Waidyarachchi, S. L. Nat. Prod. Rep. 2010, 27, 14311468; d) Davis, B. G. Tetrahedron-Asymmetr. 2009, 20, 652-671; e) Dwek, R. A.; Butters, T. D.; Platt, F. M.; Zitzmann, N. Nat. Rev. Drug Discov. 2002, 1, 65-74.

50. Asano, N.; Kato, A.; Watson, A. A. Mini-Rev. Med. Chem. 2001, 1, 145154.

51. Afarinkia, K.; Bahar, A. Tetrahedron-Asymmetr. 2005, 16, 1239-1287.

52. Stocker, B. L.; Dangerfield, E. M.; Win-Mason, A. L.; Haslett, G. W.; Timmer, M. S. M. Eur. J. Org. Chem. 2010, 1603-1603.

53. Butters, T. D.; Dwek, R. A.; Platt, F. M. Chem. Rev. 2000, 100, 46834696.

54. Karlsson, K.-A. Curr. Opin. Struct. Biol. 1995, 5, 622-635. 
55. Matrosovich, M. N.; Matrosovich, T. Y.; Gray, T.; Roberts, N. A.; Klenk, H.-D. J. Virol. 2004, 78, 12665-12667.

56. Rye, C. S.; Withers, S. G. Curr. Opin. Chem. Biol. 2000, 4, 573-580.

57. Gloster, T. M.; Meloncelli, P.; Stick, R. V.; Zechel, D.; Vasella, A.;

Davies, G. J. J. Am. Chem. Soc. 2007, 129, 2345-2354

58. Ellis, R. J.; Hemmingsen, S. M. Trends Biochem. Sci. 1989, 14, 339-342.

59. a) Thomas, P. J.; Qu, B.-H.; Pedersen, P. L. Trends Biochem. Sci. 1995, 20, 456-459; b) Welch, W. J.; Brown, C. R. Cell Stress Chaperon. 1996, 1 , 109-115.

60. Chaudhuri, T. K.; Paul, S. FEBS J. 2006, 273, 1331-1349.

61. Schulze, H.; Sandhoff, K. Biochim Biophys Acta 2014, 1841, 799-810.

62. Futerman, A. H.; van Meer, G. Nat. Rev. Mol. Cell Biol. 2004, 5, 554-565.

63. Loo, T. W.; Clarke, D. M. J. Biol. Chem. 1997, 272, 709-712.

64. Fan, J.-Q.; Ishii, S.; Asano, N.; Suzuki, Y. Nat. Med. 1999, 5, 112-115.

65. Germain, D. P. Orphanet J. Rare Dis. 2010, 5:30.

66. Giraldo, P.; Alfonso, P.; Atutxa, K.; Fernandez-Galan, M. A.; Barez, A.; Franco, R.; Alonso, D.; Martin, A.; Latre, P.; Pocovi, M. Haematologica 2009, 94, 1771-5.

67. Brady, R. O.; Kanfer, J. N.; Shapiro, D. Biochem. Biophys. Res. Commun. 1965, 18, 221-225.

68. Hudlicky, T.; Luna, H.; Olivo, H. F.; Andersen, C.; Nugent, T.; Price, J. D. Perkin Trans. 1 1991, 2907-2917.

69. Kübler, K. Arch. Pharm. 1908, 346.

70. Dangschat, G.; Fischer, H. O. L. Naturwissenschaften 1939, 27.

71. Paul, B. J.; Willis, J.; Martinot, T. A.; Ghiviriga, I.; Abboud, K. A.; Hudlicky, T. J. Am. Chem. Soc. 2002, 124, 10416-10426.

72. Hudlicky, T.; Rouden, J.; Luna, H. J. Org. Chem. 1993, 58, 985-987.

73. Braun, H.; Burger, W.; Kresze, G.; Schmidtchen, F. P.; Vaerman, J. L.; Viehe, H. G. Tetrahedron-Asymmetr. 1990, 1, 403-415.

74. Nakajima, M.; Hasegawa, A.; Kurokawa, T. Liebigs Ann. Chem. 1965, 689. 
75. Harrington, P. J.; Brown, J. D.; Foderaro, T.; Hughes, R. C. Org. Process Res. Dev. 2004, 8, 86-91.

76. Yu, Z.; Sawkar, A. R.; Kelly, J. W. FEBS J. 2007, 274, 4944-4950.

77. Suzuki, Y. Brain Dev. 2013, 35, 515-523.

78. Alegret, C.; Benet-Buchholz, J.; Riera, A. Org. Lett. 2006, 8, 3069-3072.

79. Barbier, P. Compt. Rend., 1899, 128, 110.

80. Hyldtoft, L.; Poulsen, C. S.; Madsen, R. Chem. Commun. 1999, 21012102.

81. Hyldtoft, L.; Madsen, R. J. Am. Chem. Soc. 2000, 122, 8444-8452.

82. Behr, J.-B.; Hottin, A.; Ndoye, A. Org. Lett. 2012, 14, 1536-1539.

83. Vougioukalakis, G. C.; Grubbs, R. H. Chem. Rev. 2010, 110, 1746-1787.

84. Fu, G. C.; Nguyen, S. T.; Grubbs, R. H. J. Am. Chem. Soc. 1993, 115, 9856-9857.

85. Lummiss, J. A. M.; Ireland, B. J.; Sommers, J. M.; Fogg, D. E. ChemCatChem 2014, 6, 459-463.

86. Felpin, F.-X.; Lebreton, J. Eur. J. Org. Chem. 2003, 3693-3712.

87. Philips, A. J.; Abell, A. D. Aldrichim. Acta 1999, 32, 75-89.

88. Fürstner, A.; Grabowski, J.; Lehmann, C. W. J. Org. Chem. 1999, 64, 8275-8280.

89. Binder, J. B.; Blank, J. J.; Raines, R. T. Org. Lett. 2007, 9, 4885-4888.

90. Compain, P. Adv. Synth. Catal. 2007, 349, 1829-1846.

91. Kirkland, T. A.; Lynn, D. M.; Grubbs, R. H. J. Org. Chem. 1998, 63, 9904-9909.

92. Jordan, J. P.; Grubbs, R. H. Angew. Chem. Int. Ed. 2007, 46, 5152-5155.

93. Hong, S. H.; Grubbs, R. H. J. Am. Chem. Soc. 2006, 128, 3508-3509.

94. Woodward, C. P.; Spiccia, N. D.; Jackson, W. R.; Robinson, A. J. Chem. Commun. 2011, 47, 779-781. 
95. World Health Organization (WHO) Global Tuberculosis Report 2013; WHO: Geneva; 23 Oct 2013. Available from: http://apps.who.int/iris/bitstream/10665/91355/1/9789241564656_eng.pdf (accessed January 18, 2014).

96. Das, D.; Baker, M.; Calder, L. N. Z. Med. J. 2006, 119, U2249.

97. Smith, I. Clin. Microbiol. Rev. 2003, 16, 463-496.

98. Lawn, S. D.; Zumla, A. I. Lancet 2011, 378, 57-72.

99. Mueller, P.; Pieters, J. Immunobiology 2006, 211, 549-556.

100. Saunders, B. M.; Cooper, A. M. Immunol. Cell. Biol. 2000, 78, 334-341.

101. Russell, D. G.; Cardona, P.-J.; Kim, M.-J.; Allain, S.; Altare, F. Nat. Immunol. 2009, 10, 943-948.

102. Bhowruth, V.; Alderwick, L. J.; Brown, A. K.; Bhatt, A.; Besra, G. S. Biochem. Soc. Trans. 2008, 36, 555-565.

103. McNeil, M.; Daffe, M.; Brennan, P. J. J. Biol. Chem. 1990, 265, 1820018206.

104. Chatterjee, D. Curr. Opin. Chem. Biol. 1997, 1, 579-588.

105. Maiti, D.; Bhattacharyya, A.; Basu, J. J. Biol. Chem. 2001, 276, 329-33.

106. Dangerfield, E. M.; Win-Mason, A. L.; Timmer, M. S. M.; Stocker, B. L. ChemEd. NZ 2009, 116, 2-9.

107. Kaufmann, S. H. E.; McMichael, A. J. Nat. Med. 2005, 11, S33-S44.

108. Andersen, P.; Doherty, T. M. Nature Reviews Microbiol. 2005, 3, 656662.

109. Verreck, F. A. W.; Vervenne, R. A. W.; Kondova, I.; van Kralingen, K. W.; Remarque, E. J.; Braskamp, G.; van der Werff, N. M.; Kersbergen, A.; Ottenhoff, T. H. M.; Heidt, P. J.; Gilbert, S. C.; Gicquel, B.; Hill, A. V. S.; Martin, C.; McShane, H.; Thomas, A. W. PLoS ONE 2009, 4, e5264.

110. Hussey, G.; Hawkridge, T.; Hanekom, W. Paediatr. Respir. Rev. 2007, 8, $148-154$.

111. Tameris, M. D.; Hatherill, M.; Landry, B. S.; Scriba, T. J.; Snowden, M. A.; Lockhart, S.; Shea, J. E.; McClain, J. B.; Hussey, G. D.; Hanekom, W. A.; Mahomed, H.; McShane, H. Lancet, 2013, 381, 1021-1028.

112. Goldsack, L.; Kirman, J. R. Tuberculosis 2007, 87, 465-473. 
113. Jasmer, R. M.; Snyder, D. C.; Saukkonen, J. J.; Hopewell, P. C.; Bernardo, J.; King, M. D.; Kawamura, L. M.; Daley, C. L. Clin. Infect. Dis. 2004, 38, 363-369.

114. Treatment of Tuberculosis: Guidelines; 4th ed.; WHO: Geneva, 2010.

115. Janin, Y. L. Bioorg. Med. Chem. 2007, 15, 2479-2513.

116. Centers for Disease Control and Prevention. Morb. Mortal. Wkly Rep. 2006, 55, 301-308.

117. a) Udwadia, Z. F.; Amale, R. A.; Ajbani, K. K.; Rodrigues, C. Clin. Infect. Dis. 2012, 54, 579-581; b) Migliori, G., De Iaco, G., Besozzi, G., Centis, R.; Cirillo, D. Euro Surveill. 2007, 12, E070517.1; c) Velayati, A. A.; Masjedi, M. R.; Farnia, P.; Tabarsi, P.; Ghanavi, J.; Ziazarifi, A. H.; Hoffner, S. E. Chest 2009, 136, 420-5.

118. Yew, W. W.; Cynamon, M.; Zhang, Y. Expert Opin. Emerg. Drugs 2011, $16,1-21$.

119. Zumla, A.; Nahid, P.; Cole, S. T. Nat. Rev. Drug Discov. 2013, 12, 388404.

120. Shi, W.; Zhang, X.; Jiang, X.; Yuan, H.; Lee, J. S.; Barry 3rd, C. E.; Wang, H.; Zhang, W.; Zhang, Y. Science 2011, 333, 1630-1632.

121. Herr, E. B.; Redstone, M. O. Ann. NY Acad. Sci. 1966, 135, 940-946.

122. National Center for Biotechnology Information. PubChem Compound Database; $\mathrm{CID}=6032$, http://pubchem.ncbi.nlm.nih.gov/summary/summary.cgi?cid=6032 (accessed June 26, 2014).

123. Working Group on New TB Drugs. Drug Pipeline; http://www.newtbdrugs.org/pipeline.php (Accessed March 10, 2014).

124. McNeil, M.; Daffe, M.; Brennan, P. J. J. Biol. Chem. 1990, 265, 1820018206.

125. Mikušová, K.; Yagi, T.; Stern, R.; McNeil, M. R.; Besra, G. S.; Crick, D. C.; Brennan, P. J. J. Biol. Chem. 2000, 275, 33890-33897.

126. Diacon, A. H.; Pym, A.; Grobusch, M.; Patientia, R.; Rustomjee, R.; PageShipp, L.; Pistorius, C.; Krause, R.; Bogoshi, M.; Churchyard, G.; Venter, A.; Allen, J.; Palomino, J. C.; De Marez, T.; van Heeswijk, R. P. G.; Lounis, N.; Meyvisch, P.; Verbeeck, J.; Parys, W.; de Beule, K.; Andries, K.; Neeley, D. F. M. N. Engl. J. Med. 2009, 360, 2397-405. 
127. Andries, K.; Verhasselt, P.; Guillemont, J.; Göhlmann, H. W. H.; Neefs, J.-M.; Winkler, H.; Van Gestel, J.; Timmerman, P.; Zhu, M.; Lee, E.; Williams, P.; de Chaffoy, D.; Huitric, E.; Hoffner, S.; Cambau, E.; Truffot-Pernot, C.; Lounis, N.; Jarlier, V. Science 2005, 307, 223-227.

128. Koul, A.; Vranckx, L.; Dendouga, N.; Balemans, W.; Van den Wyngaert, I.; Vergauwen, K.; Göhlmann, H. W.; Willebrords, R.; Poncelet, A.; Guillemont, J.; Bald, D.; Andries, K. J. Biol. Chem. 2008, 283, 25273-80.

129. Janssen Therapeutics, Sirturo bedaquiline; http://www.sirturo.com/ (accessed 24/03/2014).

130. Avorn, J. JAMA 2013, 309, 1349-1350.

131. Singh, R.; Manjunatha, U.; Boshoff, H. I. M.; Ha, Y. H.; Niyomrattanakit, P.; Ledwidge, R.; Dowd, C. S.; Lee, I. Y.; Kim, P.; Zhang, L.; Kang, S.; Keller, T. H.; Jiricek, J.; Barry 3rd, C. E. Science 2008, 322, 1392-1395.

132. Stover, C. K.; Warrener, P.; VanDevanter, D. R.; Sherman, D. R.; Arain, T. M.; Langhorne, M. H.; Anderson, S. W.; Towell, J. A.; Yuan, Y.; McMurray, D. N.; Kreiswirth, B. N.; Barry 3rd, C. E.; Baker, W. R. Nature 2000, 405, 962-966.

133. European Medicines Agency, European Medicines Agency recommends two new treatment options for tuberculosis; http://www.ema.europa.eu/ema/index.jsp?curl=pages/news_and_events/ne ws/2013/11/news_detail_001972.jsp\&mid=WC0b01ac058004d5c1 (accessed 24/03/2014).

134. Protopopova, M.; Hanrahan, C.; Nikonenko, B.; Samala, R.; Chen, P.; Gearhart, J.; Einck, L.; Nacy, C. A. J. Antimicrob. Chemother. 2005, 56, 968-974.

135. Tahlan, K.; Wilson, R.; Kastrinsky, D. B.; Arora, K.; Nair, V.; Fischer, E.; Barnes, S. W.; Walker, J. R.; Alland, D.; Barry 3rd, C. E.; Boshoff, H. I. Antimicrob. Agents Chemother. 2012, 56, 1797-809.

136. Paul, S. M.; Mytelka, D. S.; Dunwiddie, C. T.; Persinger, C.. C.; Munos, B. H.; Lindborg, S. R.; Schacht, A. L. Nat. Rev. Drug Discov. 2010, 9, 203-214.

137. Jeffrey, S. H., Drug Discovery in the Modern Age. In Industrialization of Drug Discovery, CRC Press: Boca Raton, 2005; pp 1-12.

138. Pharmaceutical Research and Manufacturers of America, Biopharmaceuticals in Perspective, Facts and Figures 2012, Washington, DC: PhRMA, March 2012. http://www.innovation.org/index.cfm/ToolsandResources/Charts (accessed 13/03/14). 
139. Hughes, J. P.; Rees, S.; Kalindjian, S. B.; Philpott, K. L. Br. J. Pharmacol. 2011, 162, 1239-49.

140. Altaf, M.; Miller, C. H.; Bellows, D. S.; O'Toole, R. Tuberculosis 2010, 90, 333-337.

141. Moore, K.; Rees, S. J. Biomol. Screen 2001, 6, 69-74.

142. Miller, C. H.; O'Toole, R. F. Expert Opin. Drug Discov. 2011, 6, 839-854.

143. Beggs, M.; Emerick, V.; Archer, R., Hight-Throughput Screening. In Industrialization of Drug Discovery, Jeffrey, S. H., Ed. CRC Press: Boca Raton, 2005; pp 103-136.

144. Stoeckli, K.; Haag, H., High-throughput Screening. In Drug Discovery and Development: Technology in Transition, 1st ed.; Rang, H. P., Ed. Churchill Livingstone / Elsevier: Edinburgh, 2006; pp 99-120.

145. Walpole, C. S. J., The role of chemistry in the drug discovery process. In Drug Discovery and Development: Technology in Transition, 1st ed.; Rang, H. P., Ed. Churchill Livingstone / Elsevier: Edinburgh, 2006; pp 121-139.

146. Wess, G.; Urmann, M.; Sickenberger, B. Angew. Chem. Int. Ed. 2001, 40, 3341-3350.

147. Lipinski, C. A.; Lombardo, F.; Dominy, B. W.; Feeney, P. J. Adv. Drug Delivery Rev. 1997, 23, 3-25.

148. Ducharme, J.; Dudley, A. J.; Thompson, R. A., Pharmacokinetic Issues in Drug Discovery. In Drug Discovery and Development: Technology in Transition, 1st ed.; Rang, H. P., Ed. Churchill Livingstone / Elsevier: Edinburgh, 2006; pp 141-162.

149. Rang, H. P., Pharmacology: Its Role in Drug Discovery. In Drug Discovery and Development: Technology in Transition, 1st ed.; Rang, $\mathrm{H}$. P., Ed. Churchill Livingstone / Elsevier: Edinburgh, 2006; pp 163-176.

150. Easdale, C.; Vose, C. W., Clinical Development. In Drug Discovery and Development: Technology in Transition, 1st ed.; Rang, H. P., Ed. Churchill Livingstone / Elsevier: Edinburgh, 2006; pp 255-272.

151. Lee, C.-J.; Lee, L. H.; Wu, C. L.; Lee, B. R.; Chen, M.-L., Clinical Trials of Drugs and Biopharmaceuticals. CRC Press: Boca Raton, 2006.

152. Baty, J. W.; Berridge, M. V. Unpublished work, Malaghan Institute of Medical Research: Wellington, 2012. 


\section{Chapter 2: Applications and}

\section{Limitations of the $\mathbf{I}_{2}$-mediated}

\section{Carbamate Annulation for the}

\section{Synthesis of Piperidines}

\subsection{Introduction}

\subsubsection{Six-membered Ring Iminosugars and the Treatment of Disease}

Iminosugars have enormous therapeutic potential in the treatment of a number of diseases such as cancer, diabetes, and lysosomal storage disorders. ${ }^{1}$ Notable members of the piperidine iminosuguar family include $N$-hydroxyethyl-DNJ (Miglitol 77), which is approved for the treatment of non-insulin-dependent diabetes, ${ }^{2}$ and 1-deoxygalactonojirimycin (DGJ, 56), recently used in a Phase 2 clinical trial for the treatment of Fabry's disease (Figure 2.1). ${ }^{3}$ The corresponding 2-deoxy piperidines, fagomine (78), and the unnatural 4-epi-fagomine 79 also exhibit promising biological activities. Fagomine isomer 79 selectively inhibits coffee bean $\alpha$-galactosidase activity with a $50 \%$ inhibition concentration $\left(\mathrm{IC}_{50}\right)$ of $8 \mu \mathrm{M}^{4}{ }^{4}$ Fagomine (78) was found to lower peak blood glucose levels in a rat model when fed with glucose or starch, without causing insulin release. ${ }^{5}$ A 
clinical trial on the effects of fagomine (78) on glycaemic responses to sucrose has also recently been completed. ${ }^{6}$<smiles>OCCN1C[C@H](O)[C@@H](O)[C@H](O)[C@H]1CO</smiles>

77<smiles>OC[C@H]1NC[C@@H](O)[C@H](O)[C@@H]1O</smiles>

56<smiles>OC[C@H]1NCC[C@@H](O)[C@@H]1O</smiles><smiles>OC[C@H]1NCC[C@@H](O)[C@@H]1O</smiles>

78

79

Figure 2.1: Piperidines.

\subsubsection{Retrosynthesis}

Given the biological activities of piperidines, the application of the PGF

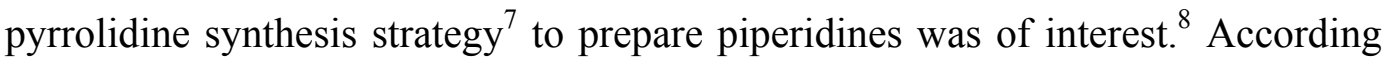
to this strategy, the target piperidines $\mathbf{8 0}$ could be attained following the hydrolysis of the intermediate cyclic carbamates 81, themselves prepared via the $\mathrm{I}_{2}$-mediated cyclisation of alkenylamine precursors 82 (Scheme 2.1). Alkenylamines 82 would in turn be prepared from methyl iodoglycosides 83 via the recently reported protecting-group-free Vasella-reductive amination methodology. ${ }^{9}$ This approach was based on the assumption that when $\mathrm{R}^{1}=\mathrm{OH}$, alkenylamine 82 should cyclise to form the desired piperidine ( $N$-cyclisation) rather than undergoing $O$-cyclisation, which would lead to the undesired aminomethyl furan. ${ }^{10}$ 
<smiles>CC=CC1CNC(CO)C(O)C1O</smiles>

80

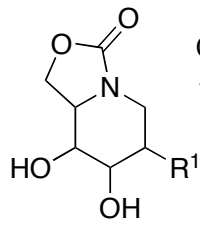

81<smiles>[R]C(CN)C(O)C(O)C=C</smiles>

82
Vasella Reductive Amination<smiles>COC1OC(CI)C(O)C(O)C1[Tl]</smiles>

83

Scheme 2.1: Retrosynthetic analysis for the synthesis of piperidines.

\subsubsection{Previous Cyclisations from Hexose Scaffolds}

1-Deoxygalactonojirimycin (DGJ, 56) was the first piperidine prepared via the PGF azasugar synthesis methodology (Scheme 2.2). ${ }^{11,12}$ Beginning with the methyl galactoside 84, iodination of the primary hydroxyl gave $\mathbf{8 5}$ in only $49 \%$ yield due to the formation of 3,6-anhydro- $\alpha$-D-galactopyranoside 86 by competing intramolecular cyclisation. Following this, subjection of iodide $\mathbf{8 5}$ to the Vasella-reductive amination conditions provided alkenylamine 87 in good (85\%) yield. Next, the carbamate annulation gave a 3:1:1 ratio of cis-piperidine 88a, trans-piperidine $\mathbf{8 8 b}$, and furanose $\mathbf{8 8 c}$, respectively. Cyclisation to the piperidine framework was much slower and resulted in lower stereoselectivity compared to the previously reported pyrrolidine annulation methodology. ${ }^{7}$ Hydrolysis of the carbamate and purification by silica gel flash column chromatography allowed for DGJ (56) to be prepared in a respectable 17\% yield (from 84). 


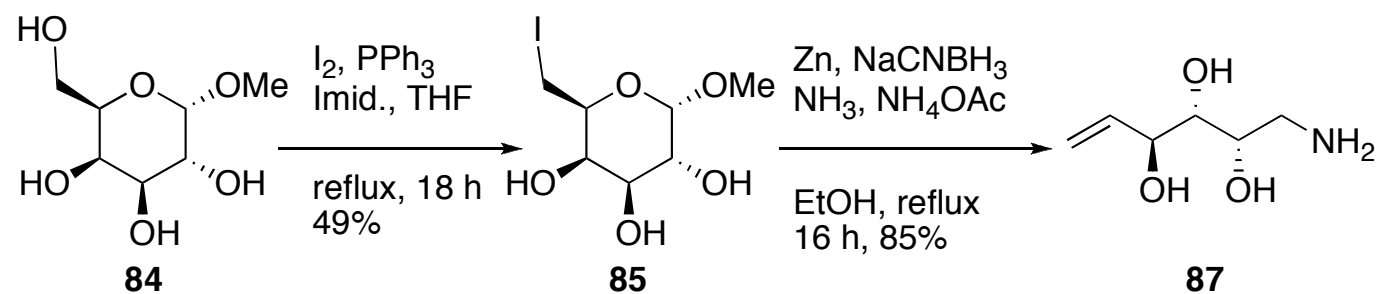<smiles>OC[C@H]1NC[C@@H](O)[C@@H](O)[C@@H]1O</smiles>

DGJ (56)<smiles>O=C1OC[C@H]2[C@@H](O)[C@H](O)[C@@H](O)CN12</smiles>

$88 a$<smiles>O=C1OC[C@H]2[C@@H](O)[C@H](O)[C@@H](O)CN12</smiles>

$88 b$<smiles>O=C1NCC2OC(CO1)C(O)C2O</smiles>

$88 c$

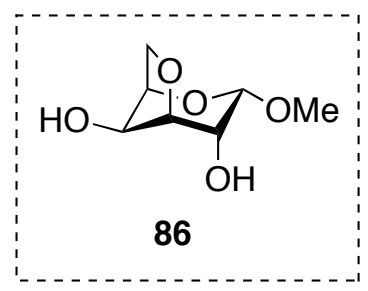

Scheme 2.2: Synthesis of DGJ (56). ${ }^{11,12}$

Following on from the successful synthesis of DGJ (56) from galactose, the preparation of a glucose-derived azasugar, 1,5-dideoxy-1,5-imino-L-iditol (89), was attempted (Scheme 2.3). ${ }^{10,12}$ To this end, methyl glucopyranoside 90 was subjected to triphenylphosphine, imidazole and iodine to give the corresponding iodosugar 91 in 98\% yield. ${ }^{9}$ Next, a Vasella-reductive amination led to the smooth formation of alkenylamine 92, again in excellent (93\%) yield and with only minor $(<5 \%)$ traces of the secondary amine. ${ }^{13}$ Alkenylamine 92 was then treated with $\mathrm{I}_{2}$ and $\mathrm{NaHCO}_{3}$ in attempted formation of carbamate 93, however characterisation suggested formation of either the aminomethyl furan 94 or piperidine 95 . Acetylation of the crude reaction mixture revealed furan 96, and hence the 
product from the $\mathrm{I}_{2}$-mediated annulation reaction was assigned as aminomethyl furan 94. While piperidine 95 could have been hydrolysed to give the desired piperidine 89, furan 94 indicated a dead-end in the PGF synthesis from glucose. Attempted optimisation to encourage attack of the nitrogen atom during the annulation reaction was unsuccessful with no observable formation of the desired carbamate 93. The inherent problem of controlling chemoselectivity during protecting-group-free syntheses is well known and explains why the use of protecting groups, though undesirable in terms of atom economy, is still required for many syntheses.<smiles>CO[C@H]1O[C@H](CO)[C@@H](O)[C@H](O)[C@H]1O</smiles>

90

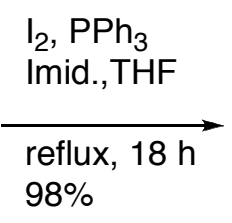

$98 \%$<smiles>CO[C@H]1OC(CI)[C@@H](O)[C@H](O)[C@H]1O</smiles>

91

$$
\mid \begin{aligned}
& \mathrm{Zn}, \mathrm{NaCNBH}_{3} \\
& \mathrm{NH}_{3}, \mathrm{NH}_{4} \mathrm{OAC} \\
& \mathrm{EtOH}, \text { reflux } \\
& 18 \mathrm{~h}, 93 \%
\end{aligned}
$$<smiles>CCCCCCNCC1O[C@@H](CI)C(OC(C)=O)C1OC(C)=O</smiles>

96
1) $I_{2}, \mathrm{NaHCO}_{3}$

$\mathrm{H}_{2} \mathrm{O}, \mathrm{rt}, 7 \mathrm{~d}$

2) Pyridine, $\mathrm{Ac}_{2} \mathrm{O}$ rt, $18 \mathrm{~h}$<smiles>C=CC(O)C(O)C(O)CN</smiles>

92
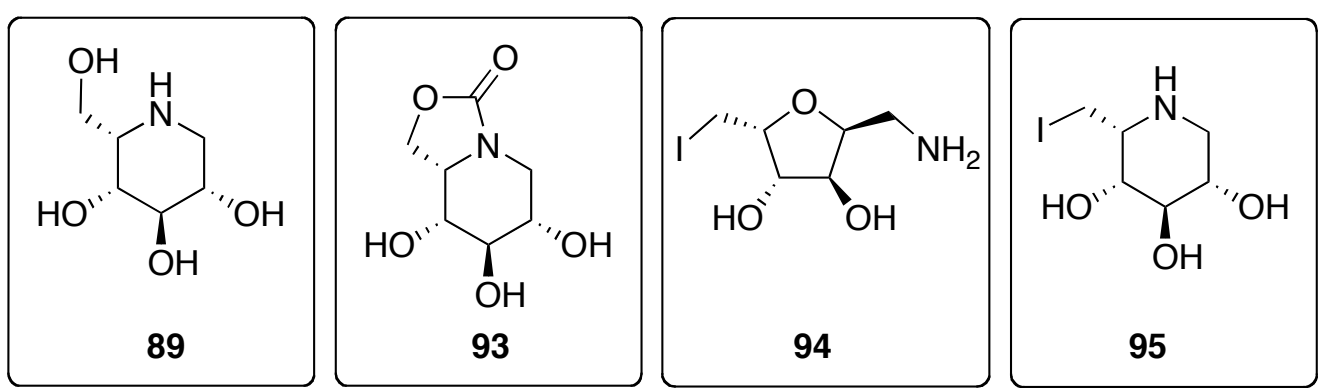

Scheme 2.3: Formation of undesired iodo-furanoside by $\mathrm{I}_{2}$-mediated annulation. ${ }^{12}$ 
2-O-cyclisation was observed when the glucose and galactose scaffolds were subjected to the carbamate annulation conditions. As 2-deoxy-D-glucose and 2deoxy-D-galactose scaffolds are devoid of a hydroxyl functionality at C-2, it was purported that 6-N cyclisation would prevail when the corresponding alkenylamines were subjected to the PGF annulation methodology. This would provide access to the fagomine family, six-membered azasugars that retain interesting biological properties without a $\mathrm{C}-2$ hydroxyl group $\left(\mathrm{R}^{1}=\mathrm{H}\right.$, Scheme 2.1). The synthesis of 4-epi-fagomine 79 began with Fischer glycosidation of 2deoxy-D-galactose (97) to give the corresponding methyl glycoside 98 in modest (40\%) yield (Scheme 2.4), ${ }^{10,14}$ with the kinetically favoured furan formed as a byproduct. Iodination of methyl glycoside 98 gave only bicyclic pyranoside $99,{ }^{15}$ due to intramolecular cyclisation similar to that observed en route to DGJ. ${ }^{11}$ To avoid this, the installation an isopropylidine protecting group was required, and concomitant installation of the methyl group gave galactoside 100. Iodination yielded primary iodide 101, and removal of the isopropylidine group produced the desired methyl iodoglycoside $\mathbf{1 0 2}$ in $94 \%$ yield. Subjection of $\mathbf{1 0 2}$ the Vasellareductive amination conditions yielded alkenylamine $\mathbf{1 0 3}$ in excellent (99\%) yield. Alkenylamine 103 was then subjected to a carbamate annulation reaction. Again, cyclisation to the six-membered ring proved sluggish with no appreciable product formation after seven days at room temperature. Optimisation of the reaction conditions revealed carbamates $\mathbf{1 0 4 a}$ and $\mathbf{1 0 4 b}$ formed in a 3:1 ratio when the reaction was carried out at $50{ }^{\circ} \mathrm{C}$ over three days. This was improved to give a diastereoselectivity of $>95: 5$ (i.e. solely cis isomer 104a by NMR) when the reaction was performed at $35^{\circ} \mathrm{C}$ over five days, with the improved diastereoselectivity suggesting kinetic control of the reaction. Under these conditions carbamate 104a was isolated in $86 \%$ yield. To complete the synthesis, carbamate 104a was then hydrolysed via treatment with $\mathrm{NaOH}$ in $\mathrm{EtOH}$ at reflux. This resulted in the formation of 4-epi-fagomine (79) in 92\% yield, completing this remarkably efficient six-step synthesis with an overall yield of 52\%. The need for a protecting group could not be avoided in this synthesis, because of the inherent reactivity of the galacto configuration. The protecting group manipulations added one additional step to the synthesis; however, an expedient 
synthesis of 4-epi-fagomine (79) was still achieved with the best overall yield to date. $^{16}$<smiles>OCC1O[C@H](O)C[C@@H](O)[C@@H]1O</smiles>

97<smiles>CO[C@H]1C[C@@H](O)[C@@H](O)[C@@H]1CO</smiles>

98

$\mathrm{MeOH}$, Acetone dimethoxypropane $3 \% \mathrm{AcCl}, \mathrm{rt}, 42 \mathrm{~h}$<smiles>CO[C@@H]1C[C@H]2OC(C)(C)O[C@@H]2[C@H](CO)O1</smiles>

100

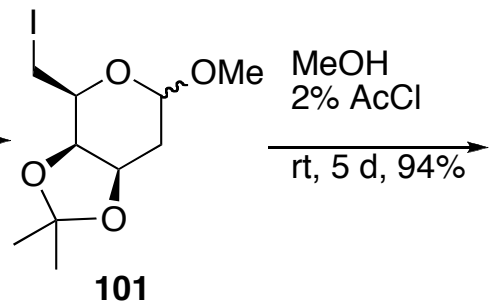

101<smiles>CO[C@H]1C[C@@H](O)[C@H](O)[C@H](CI)O1</smiles>

$\mathrm{Zn}, \mathrm{NaCNBH}_{3}$ $\mathrm{NH}_{3}, \mathrm{NH}_{4} \mathrm{OAC}$ EtOH, reflux $18 \mathrm{~h}, 99 \%$

$\mathrm{I}_{2}, \mathrm{NaHCO}_{3}$

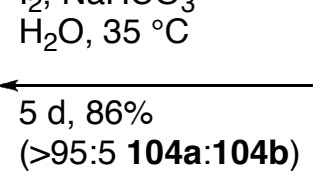<smiles>C=CC(O)C(O)CCN</smiles>

103

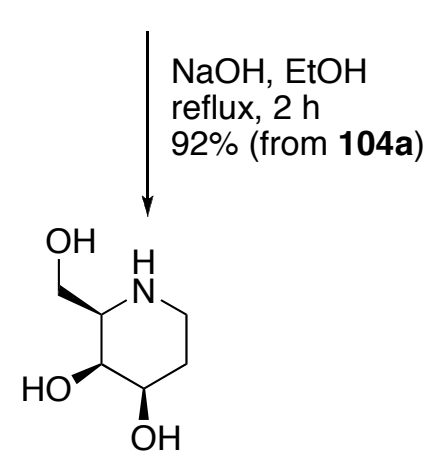

79

Scheme 2.4: Synthesis of 4-epi-fagomine (79). ${ }^{14}$ 


\subsection{Application of the PGF Azasugar Methodology to 2-Deoxy Glucose}

The PGF strategy for the synthesis of fagomine analogues was applied to 2-deoxy-D-glucose (105) for the synthesis of 5-epi-fagomine (108) (Scheme 2.5). To begin, 2-deoxy-D-glucose (105) was converted to methyl glycoside 106 under Fischer glycosidation conditions and then treated with iodine, triphenylphosphine and imidazole at $75^{\circ} \mathrm{C}$ for $1.5 \mathrm{~h}$ to give primary iodide $\mathbf{1 0 7}$ in good overall yield (64\%, 2 steps). ${ }^{17,18}$ Reaction times and temperatures were important to avoid overiodination or incomplete consumption of starting material. Doubly iodinated glucoside 109 was a key by-product that was observed by TLC. This was further evidenced by high resolution mass spectrometry $\left([\mathrm{M}+\mathrm{Na}]^{+}=420.8773\right)$ in combination with NMR characterisation, where a downfield shift of the H-3 (from $\delta 3.97 \mathrm{ppm}$ in $\mathbf{1 0 7}$ to $\delta 4.62$ in 109), and a carbon shift of C-3 from $\delta 69.1$ to $\delta$ $33.1 \mathrm{ppm}$, indicated a different substituent on the 3-position. Over-iodination of 2deoxy glucose has been observed previously, ${ }^{17}$ and as the $3-\mathrm{OH}$ is less sterically hindered than the 4-OH, this is anticipated to be the more reactive centre. While the galacto-sugars were seen to undergo intramolecular ring closure under iodination conditions, this was not observed for the gluco analogues. This demonstrates how differences in stereochemistry can affect reactivity. 


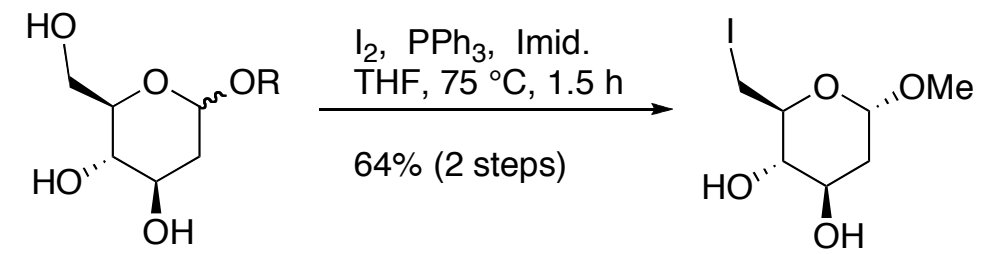

$$
\begin{aligned}
& \text { 105: } \mathrm{R}=\mathrm{H} \\
& \text { 106: } \mathrm{R}=\mathrm{Me}
\end{aligned} \begin{aligned}
& \mathrm{AcCl} \\
& \mathrm{MeOH} \\
& \mathrm{rt}, 22 \mathrm{~h}
\end{aligned}
$$

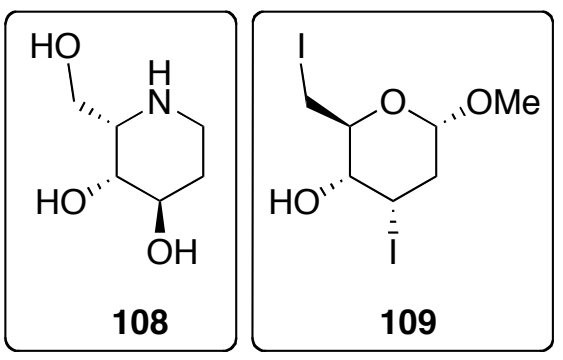

107

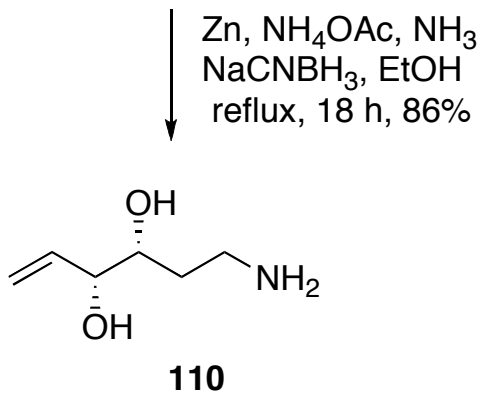

$\mathrm{Zn}, \mathrm{NH}_{4} \mathrm{OAc}, \mathrm{NH}_{3}$ $\mathrm{NaCNBH}, \mathrm{EtOH}$ reflux, $18 \mathrm{~h}, 86 \%$

110

Scheme 2.5: Synthesis of alkenylamine 110 derived from 2-deoxy-D-glucose (105).

Iodide 107 was then treated with $\mathrm{Zn}, \mathrm{NaCNBH}_{3}, \mathrm{NH}_{3}$ and $\mathrm{NH}_{4} \mathrm{OAc}$ according to the Vasella-reductive amination protocol to effect smooth transformation into alkenylamine 110 in good (86\%) yield. The mechanism of the Vasella-reductive amination is shown in Scheme 2.6, whereby zinc insertion in the C-I bond then an electron cascade ejecting the methoxide group forms the corresponding aldehyde. The aldehyde then undergoes a reductive amination with ammonia to form the desired primary alkenylamine 110. The normal method of alkenylamine purification (elution from Dowex- $\mathrm{H}^{+}$cation exchange resin using $35 \%$ aqueous ammonia) was unsuccessful here due to the strong affinity of alkenylamine $\mathbf{1 1 0}$ for the resin leading to low product recovery. Purification by reverse phase chromatography and dialysis techniques were attempted before a 'salting out' work up procedure was developed. This involved transformation of the initial saturated $\mathrm{NH}_{4} \mathrm{OAc}$ solution into $\mathrm{NaCl}$ through the addition of acid and then base, allowing for removal of large quantities of salt before column purification. Briefly, the crude alkenylamine reaction mixture was concentrated to remove excess ammonia and solvent, then 1.2 equiv. $\mathrm{HCl}_{(\text {aq) }}$ was added to the remaining salt mixture converting $\mathrm{NH}_{4} \mathrm{OAc}$ into $\mathrm{NH}_{4} \mathrm{Cl}$ and $\mathrm{AcOH}$. Concentration of the 
$\mathrm{AcOH}$ and excess $\mathrm{HCl}$, followed by addition of 1.0 equiv. of aqueous $\mathrm{NaOH}$ allowed conversion of $\mathrm{NH}_{4} \mathrm{Cl}$ into $\mathrm{NaCl}_{(\mathrm{s})}$ and $\mathrm{NH}_{3}(\mathrm{aq})$, which could also be removed in vacuo. Due to differences in solubility, alkenylamine $\mathbf{1 1 0}$ could be dissolved in $\mathrm{EtOH}$, while the $\mathrm{NaCl}$ was only minimally soluble, hence filtration could be used to remove much of the salt. The remainder of the $\mathrm{NaCl}$ could be removed with a short $\mathrm{SiO}_{2}$ column (eluting in DCM/EtOH/MeOH/35\% aqueous $\left.\mathrm{NH}_{3}, 25 / 2 / 2 / 1, \mathrm{v} / \mathrm{v} / \mathrm{v} / \mathrm{v}\right)$, to provide clean alkenylamine 110, as a white solid.<smiles>C=C[C@H](O)[C@@H](O)CC(C)(CC)C(=O)N=C</smiles>

107<smiles>C=C[C@H](O)[C@@H](O)CCN</smiles>

Scheme 2.6: Mechanism of the Vasella-reductive amination of iodide $\mathbf{1 0 7}$

After the successful purification of alkenylamine 110, this was then subjected to a variety of annulation conditions (Table 2.1). As previously highlighted, slightly warmer temperatures were required for the annulation of alkenylamine 103, and because of this, alkenylamine $\mathbf{1 1 0}$ was first treated with $\mathrm{I}_{2}$ and $\mathrm{NaHCO}_{3}$ (sat. aq.) at $40{ }^{\circ} \mathrm{C}$ (entry 1 , Table 2.1 ). These conditions led to a complex mixture of four carbamate products later identified as pyrrolidine 111, the two piperidine diastereomers 112a and 112b, and iodide 113, with iodide 113 being the major product in this instance. In an attempt to limit the formation of so many carbamate products, the reaction temperature was lowered and the number of equivalents of $\mathrm{NaHCO}_{3}$ reduced (entry 2). After stirring the reaction mixture at room 
temperature for nine days, however, no product formation was observed. Next, iodine was added in portions over the course of the reaction and this was stirred at room temperature until all starting material was consumed, as gauged by TLC analysis (entry 3). While these conditions invoked annulation reactions, and a slight improvement in the ratio of the piperidine carbamate 112a was observed, iodide $\mathbf{1 1 3}$ was once again the major product and all four carbamates were still formed. The reaction was then attempted at room temperature again using a saturated solution of $\mathrm{NaHCO}_{3}$ and $\mathrm{I}_{2}$ (5 equiv.) added in one portion at the start of the reaction (entry 4). Under these conditions, formation of iodide 113 was reduced and pyrrolidine 111 was formed with modest selectivity in a ratio of 4:2:2:3 (111:112a:112b:113). The role of the halide in influencing the ratio of products was then investigated through the use of $\mathrm{Br}_{2}$ (entry 5), however this proved futile with degradation being observed. Further changes were then made to the number of equivalents of reagents and the temperature at which the reaction was performed, however, in all instances, complex mixtures of products were observed and the best yield of any single product, apart from iodide 113, was still found to be that of pyrrolidine 111 (as highlighted in entry 4). Though disappointing, pyrrolidine 111 could nevertheless be isolated as a pure compound in 10-30\% yield following flash silica gel column chromatography (eluting in $2 \%$ $\mathrm{MeOH}$ in EtOAc) and reverse phase column chromatography $\left(\mathrm{C} 8, \mathrm{H}_{2} \mathrm{O}\right)$. The range of yield reflects the difficulty of this chromatographic separation. The piperidines 112a and 112b could not be separated from one another and were isolated in a poor (ca. 20\%) combined yield. 
Table 2.1: Carbamate annulation reaction for alkenylamine 110

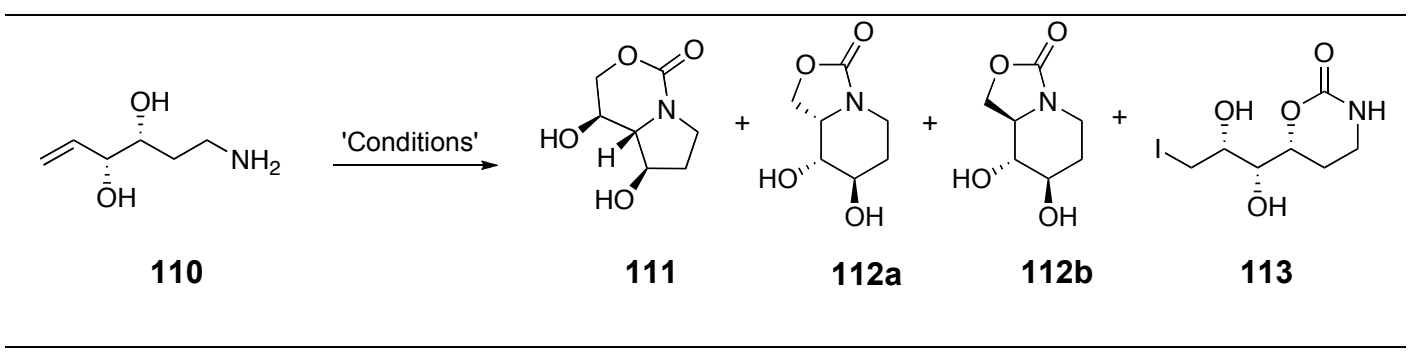

Entry Conditions $\quad$ Products

$(111: 112 a: 112 b: 113)^{a}$

\begin{tabular}{|c|c|c|}
\hline 1 & $\mathrm{I}_{2}$ (5 equiv.), $\mathrm{NaHCO}_{3}$ (sat.), $40^{\circ} \mathrm{C}, 18 \mathrm{~h}$ & $3: 2: 2: 8$ \\
\hline 2 & $\mathrm{I}_{2}$ (5 equiv.), $\mathrm{NaHCO}_{3}(1.5$ equiv.), r.t., $9 \mathrm{~d}$ & Starting material 110 \\
\hline \multirow[t]{2}{*}{3} & $\mathrm{I}_{2}(3 \mathrm{x} 1.5$ equiv. added over $22 \mathrm{~d})$, & $3: 2: 1: 7$ \\
\hline & $\mathrm{NaHCO}_{3}$ (sat.), r.t. & \\
\hline 4 & $\mathrm{I}_{2}$ (5 equiv.), $\mathrm{NaHCO}_{3}$ (sat.), r.t., $5 \mathrm{~d}$ & $4^{b}: 2: 2: 3$ \\
\hline 5 & $\mathrm{Br}_{2}$ (5 equiv.), $\mathrm{NaHCO}_{3}$ (sat.), r.t., $3 \mathrm{~d}$ & Decomposition \\
\hline
\end{tabular}

${ }^{a}$ As determined by ${ }^{1} \mathrm{H}$ NMR analysis of the crude reaction mixture.

${ }^{\mathrm{b}} \mathbf{1 1 1}$ was isolated as a pure compound in 10-30\% yield following column chromatography.

To confirm the structure of pyrrolidine 111 and alkyl iodide 113, extensive 1D and 2D NMR spectral analysis was undertaken. For pyrrolidine 111, a correlation was observed in the HMBC spectrum between $\mathrm{H}-4$ and $\mathrm{C}-1$ that allowed the central 5-membered ring system of $\mathbf{1 1 1}$ to be established. High resolution mass spectrometry gave a mass the same as that of carbamates 112a and 112b $([\mathrm{M}+$ $\left.\mathrm{Na}]^{+}=196.0579\right)$, and a characteristic carbon shift of $\delta\left({ }^{13} \mathrm{C}\right) 154.4 \mathrm{ppm}$ confirmed the formation of a carbamate. An HMBC cross-peak was observed 
between the carbamate carbonyl and $\mathrm{H}-1$ of pyrrolidine 111, but overlapping ${ }^{1} \mathrm{H}$ NMR signals for H-3 and H-6a ( $\delta 4.24$ ppm) meant that the observed correlation between $\mathrm{H}-6 \mathrm{a}$ and $\mathrm{C}=\mathrm{O}$ could not be confirmed. NMR analysis of the acetylated derivative 114 was more beneficial. Analysis of the ${ }^{1} \mathrm{H}$ NMR spectrum for azasugar 114 (see appendix) reveals baseline impurities, which can be assigned as small amounts of acetylated piperidines 112a and 112b or iodide 113. As the product was of sufficient purity to enable the required characterisation, further purification was unnecessary. In pyrrolidine 114, downfield shifts of the H-3 and $\mathrm{H}-5$ protons (to $\delta 5.19 \mathrm{ppm}$ and $\delta 5.12 \mathrm{ppm}$ respectively) separated these signals from the H-6 proton signals, which did not move significantly. The observed proton shifts indicated that the 3- and 5-positions were acetylated and this was confirmed by the corresponding correlations in the HMBC spectrum. An HMBC cross-peak between the carbamate carbonyl and H-6a in the acetylated adduct 114 supported establishment of the 5/6 ring system of carbamates 111 and 114. The overlapping proton signals in the NMR for pyrrolidine 111 meant that the configuration of the stereocentres could not be determined unequivocally, however the acetylated derivative 114 allowed determination of the relative configurations of the H-5, H-4 and H-6b stereocentres. Indeed, in pyrrolidine 114, two large $\left(J_{4,5}=J_{5,6 \mathrm{~b}}=9 \mathrm{~Hz}\right)$ trans-diaxial couplings, and the smaller coupling constant between $\mathrm{H}-5$ and $\mathrm{H}-6 \mathrm{a}\left(J_{5,6 \mathrm{a}}=4.7 \mathrm{~Hz}\right)$, indicated an axial/equatorial relationship between these two protons. As the stereochemistry at C-3 is known from the starting material 110, NOE correlations were then used to solve the stereochemistry of the remaining centres. NOE correlations were observed between H-5 and H-3, H-3 and H-2a, H-2a and H-1a, and H-6a and H-5 (Figure 2.2), indicating these protons to be on the bottom face of the molecule, while NOE correlations between $\mathrm{H}-2 \mathrm{~b}$ and $\mathrm{H}-4$, and $\mathrm{H}-4$ and $\mathrm{H}-6 \mathrm{~b}$ identified these protons to be on the opposite face thereby allowing for the assignment of the Lallo-stereochemistry. Pyrrolidine 111 was then treated with $\mathrm{NaOH}$ in EtOH, which resulted in the smooth hydrolysis of the carbamate providing previously undisclosed trihydroxylated pyrrolidine 115 in 5-15\% yield over five steps (Scheme 2.7). The group of Stephen Pyne previously prepared the enantiomer of 115. ${ }^{19}$ Comparison of NMR data showed only minor differences in chemical 
shifts, which can be explained by the use of a different NMR solvent, and differences in $\mathrm{pH}$ (in our hands, 115 was treated with conc. $\mathrm{DCl}$ to ensure the amine was fully protonated). Optical rotation of 115 was measured as $[\alpha]_{\mathrm{D}}{ }^{26}=-$ $1.8(c=0.41, \mathrm{MeOH})$, while the optical rotation of the enantiomer was of the opposite sign, and a slightly larger magnitude, reported as $[\alpha]_{\mathrm{D}}^{22}=+4.7(c=4.0$, $\mathrm{MeOH}$ ), which can again be explained by difference in concentration, and protonation state of the two compounds.

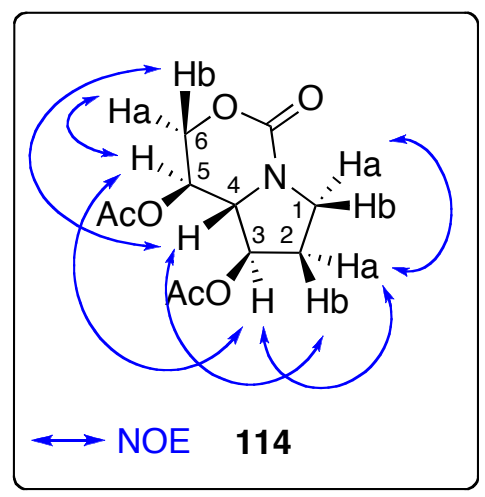

Figure 2.2: NOE correlations for acetylated carbamate 114 .<smiles>O=C1OC[C@@H](O)[C@H]2C(O)CCN12</smiles>

111

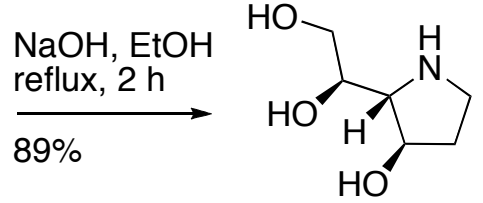

115

Scheme 2.7: NOE correlations for acetylated carbamate 114 and synthesis of trihydroxylated pyrrolidine 115. 
At this stage, the piperidine carbamates $112 \mathrm{a}$ and $\mathbf{1 1 2 b}$ were also hydrolysed to give 5-epi-fagomine (108) and fagomine (78), which were separated by flash silica gel column chromatography (Scheme 2.8). Spectral data was similar to that previously reported, ${ }^{16 \mathrm{~d}, 20}$ again with some variation due to slight differences in $\mathrm{pH}^{21}$<smiles>O=C1OC[C@@H]2[C@H](O)[C@@H](O)CCN12</smiles>

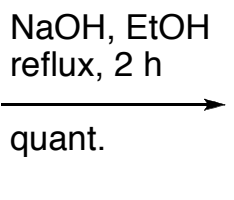

$112 b$<smiles>OCC1NCC[C@@H](O)[C@@H]1O</smiles>

108<smiles>OC[C@@H]1NCCC(O)[C@@H]1O</smiles>

78

Scheme 2.8: Hydrolysis of piperidine carbamates to give fagomine (78) and 5epi-fagomine (108).

Confirmation of the structure of iodide 113 was more challenging. Mass spectrometric analysis $\left.\left(m / z[\mathrm{M}+\mathrm{H}]^{+}=301.9888\right]\right)$ indicated the presence of an iodide in the molecule, and a characteristic ${ }^{13} \mathrm{C}$ NMR chemical shift at $\delta 6.2 \mathrm{ppm}$ suggested that this belonged to a primary iodide group, and therefore was most likely at the C-6 position. The characteristic ${ }^{13} \mathrm{C}$ NMR peak at $\delta 154.7 \mathrm{ppm}$ suggested the presence of a carbamate group. No HMBC cross-peak was observed between the carbonyl and $\mathrm{H}-3$, and the correlation between the carbamate and $\mathrm{H}-1$ was difficult to confirm due to overlap in the proton signals of $\mathrm{H}-1$ and $\mathrm{H}-6 \mathrm{~b}$. The acetylated adduct 116 (Figure 2.3, Scheme 2.9) was thus prepared to aid structural elucidation. Upon acetylation, downfield shifts of protons $\mathrm{H}-4$ and H-5 were observed (from overlapping at $\delta 3.76 \mathrm{ppm}$, to $\delta 5.34$ and $5.14 \mathrm{ppm}$, respectively), indicating acetylation of the 4- and 5-OH groups, and confirming the product to be linear rather than cyclic. Proton H-3, which was already at a relatively low field ( $\delta 4.50 \mathrm{ppm}$ ), did not move significantly upon acetylation indicating that 
there was no free hydroxyl on C-3 that could be acetylated. There was an $\mathrm{NH}$ peak in the proton NMR of 116, predicting that the amine was not acetylated. An HMBC cross-peak observed between the carbamate carbonyl and H-1 explained why the amine group was not acetylated, and confirmed the iodo methylene group to be at the C-6 position. Again no correlation in the HMBC spectrum was observed between the carbamate and H-3, but a weak HMBC cross-peak was observed between the carbamate and $\mathrm{H}-4$, presumably a long-range correlation. When looked at as a whole, this leads to the characterisation of acetylated carbamate 116 and hence iodide $\mathbf{1 1 3 .}$ 


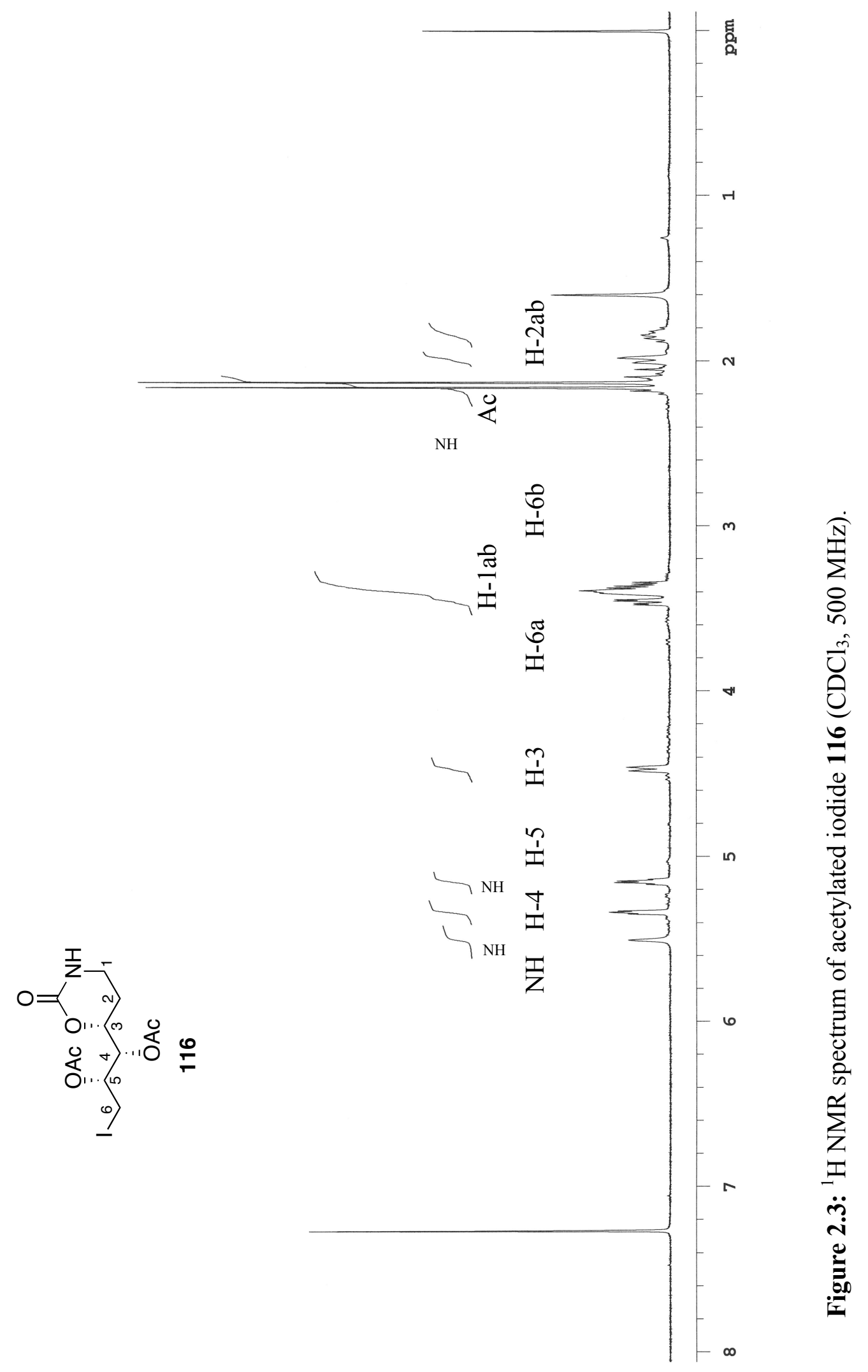



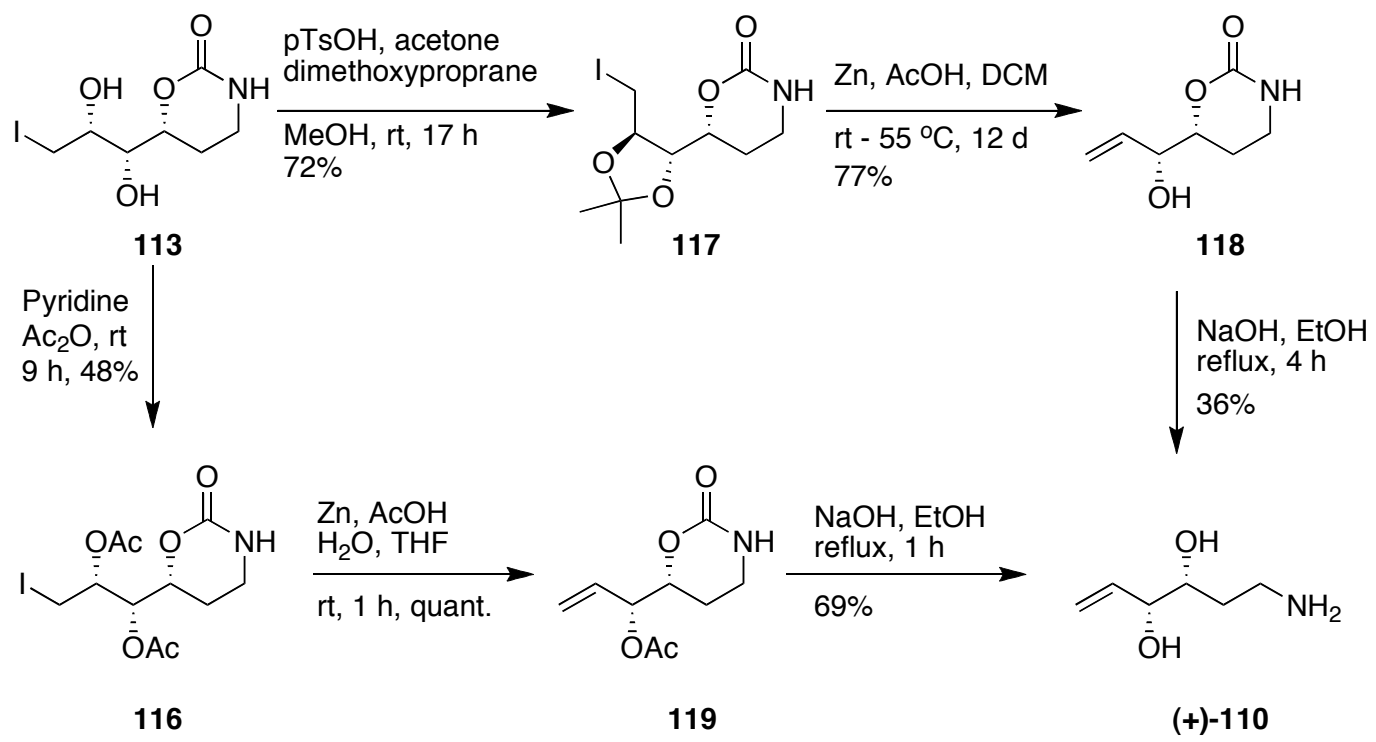

Scheme 2.9: Determination of structure of iodo-carbamate 113 via transformation into alkenylamine $(+)-\mathbf{1 1 0}$.

As the stereochemistry of compound $\mathbf{1 1 3}$ also needed to be confirmed, it was proposed that the synthesis of the corresponding alkenylamine (Scheme 2.9) would allow for confirmation of the structure of $\mathbf{1 1 3}$, including the chirality of all stereogenic centres. To this end, iodide $\mathbf{1 1 3}$ was converted to the corresponding acetonide 117. On the basis of a slightly smaller $\Delta \delta$ for the acetonide methyl group proton signals $\left(\Delta \delta{ }^{1} \mathrm{H}=0.039 \mathrm{ppm}\right),{ }^{22}$ and diagnostic $\delta{ }^{13} \mathrm{C} \approx 27 \mathrm{ppm}$ for both methyl groups $\left(\delta{ }^{13} \mathrm{C}=27.0\right.$ and $\left.\delta{ }^{13} \mathrm{C}=27.6 \mathrm{ppm}\right),{ }^{23}$ the relative stereochemistries of the 4- and 5-substituents was determined as trans in the acetonide 5-membered ring. There is less difference in the chemical environment of the acetonide methyl groups when in the trans configuration compared with those in the cis configuration (Figure 2.4). Therefore in iodide 113, as drawn in the zig-zag conformation in Scheme 2.9, a syn relationship would be expected between the 4- and 5-OHs. Opening of the acetonide, via the oxidative addition of zinc and subsequent reductive ring opening then provided the truncated carbamate 118 in good yield. Finally, hydrolysis of the carbamate in 118 via treatment with $\mathrm{NaOH}$ under reflux for $4 \mathrm{~h}$ gave the desired alkenylamine 110. To confirm the methodology, alkenylamine (+)-110 was also synthesised from the acetylated 
adduct 116, by way of reductive elimination of 5-OAc $(\rightarrow \mathbf{1 1 9})$ and subsequent carbamate hydrolysis. Comparison of the ${ }^{1} \mathrm{H}$ NMR and ${ }^{13} \mathrm{C}$ NMR spectra of the synthesised alkenylamine with $(+)-110$ revealed identical spectra, and the optical rotation was of the same sign and comparable magnitude $\left([\alpha]_{\mathrm{D}}{ }^{27}=+37.5(c=1.0\right.$, $\mathrm{MeOH})$ and $\left.[\alpha]_{\mathrm{D}}{ }^{27}=+31.8(c=0.2, \mathrm{MeOH})\right)$, thus establishing the structure of the synthesised alkenylamine to be that of the starting material, $(+)-\mathbf{1 1 0}$. Using this information and the previously deduced trans relationship in acetonide 117 the starting iodo-carbamate 113 was thus determined to be $3(R), 4(R), 5(R)$, as depicted in Scheme 2.9.<smiles>[R]C1OC(C)(C)OC1[R]</smiles>

Expected values (trans):

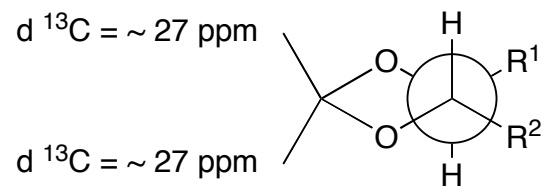

Dd ${ }^{1} \mathrm{H}(\mathrm{Me})<0.04 \mathrm{ppm}$

Expected values (cis):<smiles>[R][C-]1OC(C)(C)OC1[R]</smiles>

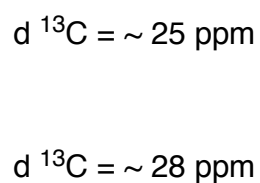<smiles>[R7]C1C2CC3C1OC2OC3(C)C</smiles>

Dd ${ }^{1} \mathrm{H}(\mathrm{Me})>0.04 \mathrm{ppm}$<smiles>CC1(C)O[C@@H](CI)[C@@H]([C@H]2CCNC(=O)O2)O1</smiles>

117-trans

Observed values (trans):

$\mathrm{d}^{13} \mathrm{C}=27.0 \mathrm{ppm}$

$\mathrm{d}^{13} \mathrm{C}=27.6 \mathrm{ppm}$

$\mathrm{Dd}{ }^{1} \mathrm{H}(\mathrm{Me})=0.039 \mathrm{ppm}$

Figure 2.4: Characteristic cis and trans acetonide 117 NMR shifts ${ }^{22,23}$ for the determination of relative stereochemistry of iodide $\mathbf{1 1 3}$. 


\subsection{Proposed Models to Explain the Formation of Pyrrolidines and Piperidines via the $\mathbf{I}_{2}$-mediated Carbamate Annulation}

Four carbamates were formed in the $\mathrm{I}_{2}$-mediated cyclisation of the 2-deoxyglucose derived amine 110, ${ }^{10}$ while only one carbamate was formed when 2deoxy-galacto alkenylamine $\mathbf{1 0 3}$ was subjected to the optimised carbamate annulation conditions. ${ }^{14}$ It is important to propose an explanation for the formation of the different products in the $\mathrm{I}_{2}$-mediated carbamate annulation of hexenylamines. For clarity of understanding, it is necessary to first explain the mechanism of the $\mathrm{I}_{2}$-mediated cyclisation in the formation of pyrrolidines, as a similar transition state model has been proposed for the 6- $\mathrm{N}$-cyclisations to form piperidines.

The formation of pyrrolidines via the $\mathrm{I}_{2}$-mediated carabamate annulation has been shown to be highly stereoselective in favour of the 3,4-cis pyrrolidine. ${ }^{7}$ Here, the stereochemistry of the new chiral centre is established during the formation of the intermediate iodide $\mathbf{1 2 1}$ from alkenylamine $\mathbf{1 2 0}$ (Figure 2.5A), ${ }^{24}$ and the preference for the 3,4-cis configuration can be explained by considering transition state models proposed by Chamberlin ${ }^{25}$ and Gouverneur, ${ }^{26}$ where the selective formation of the 3,4-cis pyrrolidine $\mathbf{1 2 2}$ relies on stereodirecting effects of the allylic hydroxyl (Figure 2.5B). ${ }^{7 b}$ Assuming the transition state adopts an envelope structure, with the amine nucleophile attacking the alkene-iodine complex through a Bürgi-Dunitz trajectory, then there are two transition states (TSs) that can be adopted: the $\mathrm{OH}$-in-plane transition state (I), and the H-in-plane transition state (II), whereby the alignment of the allylic $\mathrm{OH}$ or $\mathrm{H}$ with the plane of the double bond is considered. In the H-in-plane TS (II), where the allylic $\mathrm{H}$ is in the plane of the double bond, the $\mathrm{C}-\mathrm{O}$ antibonding $\left(\sigma^{*}\right)$ and the $\mathrm{C}=\mathrm{C} \pi$ orbitals are aligned and electron density is therefore withdrawn from the alkene-iodine complex. This destabilises the H-in-plane TS, and disfavours the formation of the 3,4-trans pyrrolidine. Conversely, in the $\mathrm{OH}-$ in-plane TS (I), the unfavourable C-O $\sigma^{*}$ to $\mathrm{C}=\mathrm{C} \pi$ orbital overlap is minimised, hence this TS, which leads to the cis pyrrolidine, is favoured. ${ }^{7 b, 24}$ 
A.<smiles>C=C[C@H](O)[C@@H](O)CN</smiles>

B.

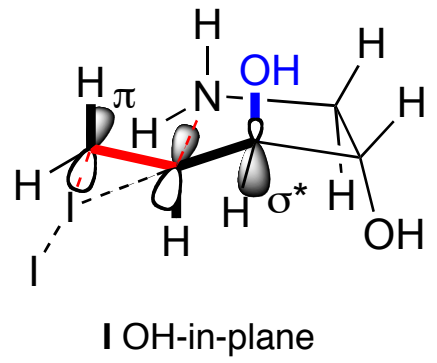

Only product

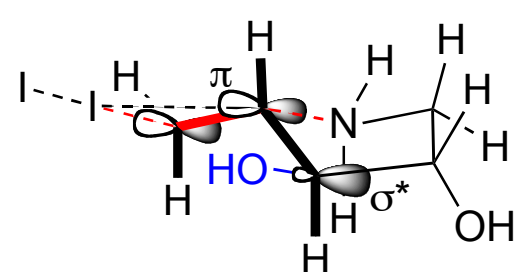

II H-in-plane

Not observed

Figure 2.5: Formation of pyrrolidines via the $\mathrm{I}_{2}$-mediated carabamate annulation. $^{7 \mathrm{c}, 24}$ A. The stereoselectivity of the reaction is determined by the formation of the intermediate iodo-amine 121. B. Two possible transition states en route to the formation of the diastereomeric pyrrolidines: the $\mathrm{OH}$-in-plane TS I, which leads to the 3,4-cis product, and the H-in-plane TS II, which would give the 3,4-trans product.

For the formation of piperidines via the $\mathrm{I}_{2}$-mediated carbamate annulation, similar $\mathrm{OH}$-in-plane and H-in-plane TS models can be used (Figure 2.6). ${ }^{12}$ When applying this model to the formation of six-membered rings, the relative orientation of the $\mathrm{I}_{2}$-alkene complex (i.e. either pseudo equatorial or pseudo axial) also needs to be considered. Here, it is assumed that the pseudo-axial alkene conformation is less stable due to steric interactions. Thus, for the $\mathrm{I}_{2}$-mediated carbamate annulation reaction in the synthesis of piperidines there are four chairlike transition states that need to be considered (III-VI, Figure 2.6). Of the two transition states (III and IV) that lead to the preferred cis piperidine (formed during the synthesis of DGJ ${ }^{11}$ and 4-epi-fagomine, ${ }^{10}$ see Section 2.1.3), the $\mathrm{OH}$ - 
in-plane, pseudo-equatorial alkene conformer III is likely to be more favourable than the H-in-plane, pseudo-axial alkene conformer IV. Similarly, the two trans TSs ( V and VI) are likely to be less stable than III, with the OH-in-plane TS V having a pseudo-axial alkene group, while the H-in-plane conformer VI would have unfavourable $\mathrm{C}-\mathrm{O} \sigma^{*}$ to $\mathrm{C}=\mathrm{C} \pi$ orbital overlap. It should also be mentioned that when comparing the $5 \mathrm{~N}$ and $6 \mathrm{~N}$ cyclisation transition states there is greater overlap between the $\mathrm{C}-\mathrm{O} \sigma^{*}$ to $\mathrm{C}=\mathrm{C} \pi$ orbitals in the $\mathrm{H}$-in-plane conformers of the five-membered rings. Thus the cis directing effect of the allylic $\mathrm{OH}$ has less influence during $6 \mathrm{~N}$ cyclisations compared to $5 \mathrm{~N}$ cyclisations. In addition to the above effects, the ring substituents (e.g. hydroxyl groups) of the six-membered rings are also expected to influence the selectivity of the cyclisation if the orientation of these substituents results in unfavourable 1,3-diaxial interactions.

$\mathrm{OH}$-in-plane

cis

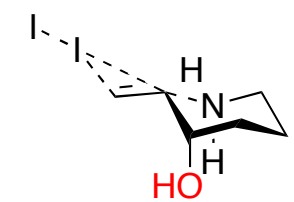

III

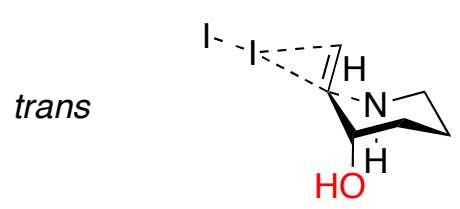

V
$\mathrm{H}$-in-plane

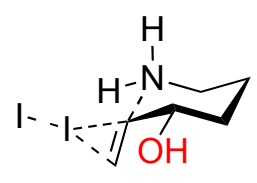

IV

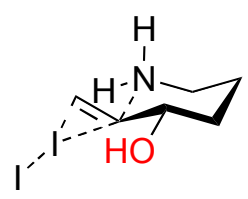

VI

Figure 2.6: Six-membered transition states for the $I_{2}$-mediated halocyclisation of amino hexenols in the formation of piperidines. 


\subsection{Comparison of the Outcome of the 2-Deoxy-Glucose and 2-Deoxy-Galactose derived Alkenylamine Cyclisations using Proposed Transition State Models}

As described in Sections 2.1 and 2.2, the use of the $\mathrm{I}_{2}$-mediated carbamate annulation for the PGF synthesis of piperidines led to a range of outcomes. The PGF synthesis of pyrrolidines proceeds smoothly and with excellent cisselectivity for the carbamate annulation, ${ }^{24}$ however, this methodology does not always translate readily to the synthesis of piperidines. DGJ (56) and 4-epifagomine (79) were formed with good chemo- and stereoselectivity, while attempts at forming other piperidines (e.g. 1,5-dideoxy-1,5-imino-L-iditol and 5epi-fagomine) were less successful.

The first factor to consider when applying the carbamate annulation methodology to the synthesis of piperidines is $O$ - versus $N$-cyclisation. As illustrated en route to the synthesis of DGJ, ${ }^{11}$ when using D-galactose as a starting material, it was possible to favour formation of the desired piperidine, which is remarkable given the general preference for 5 - versus 6-membered ring formation. ${ }^{27,28}$ Conversely, when using D-glucose as a starting material, ${ }^{12}$ only the furan was observed.

To prevent formation of the furan as a competing reaction product, the synthesis of piperidines devoid of the hydroxyl functionality at C-2 was undertaken. As illustrated, the chirality of the alkenylamine plays a crucial role in determining the number of products formed during the annulation reaction. The alkenylamine derived from 2-deoxy-D-galactose (103) was transformed into cis carbamate 104a with excellent chemo- and diastereoselectivity ( $>95: 5$, cis:trans). However, subjecting the corresponding 2-deoxy-D-glucose alkenylamine (110) to the $I_{2^{-}}$ mediated carbamate annulation conditions resulted in the formation of four products: pyrroldine 111, cis and trans piperidines 112a and 112b, and iodide 113 despite efforts to optimise the reaction. 
To explain why the two seemingly similar alkenylamines $\mathbf{1 0 3}$ and $\mathbf{1 1 0}$ led to such different reaction outcomes, the corresponding six-membered iodocyclisation transition states need to be considered (Figures 3.3 and 3.4). For the 2-deoxy-Dgalactose series, the four transition states VII to $\mathbf{X}$ are possible (Figure 2.7). Transition state VII for the 2-deoxy-D-galactose series depicts the lowest energy conformer that leads to the cis product, due to a favourable pseudo-equatorial $\mathrm{I}_{2}$ alkene configuration and more stable allylic OH-in-plane conformation. In contrast, TS VIII could also lead to the major cis product, however, this conformation has an unfavourable pseudo-axial $\mathrm{I}_{2}$-alkene orientation and $\mathrm{H}$-inplane conformation that increases the energy of TS VIII relative to TS VII. Of the transition states that lead to the minor trans carbamate, it is unclear whether TS IX, with an unfavourable pseudo-axial alkene, or TS X, with an unfavourable Hin-plane conformation, would have the lower energy TS and hence be responsible for formation of the minor product.

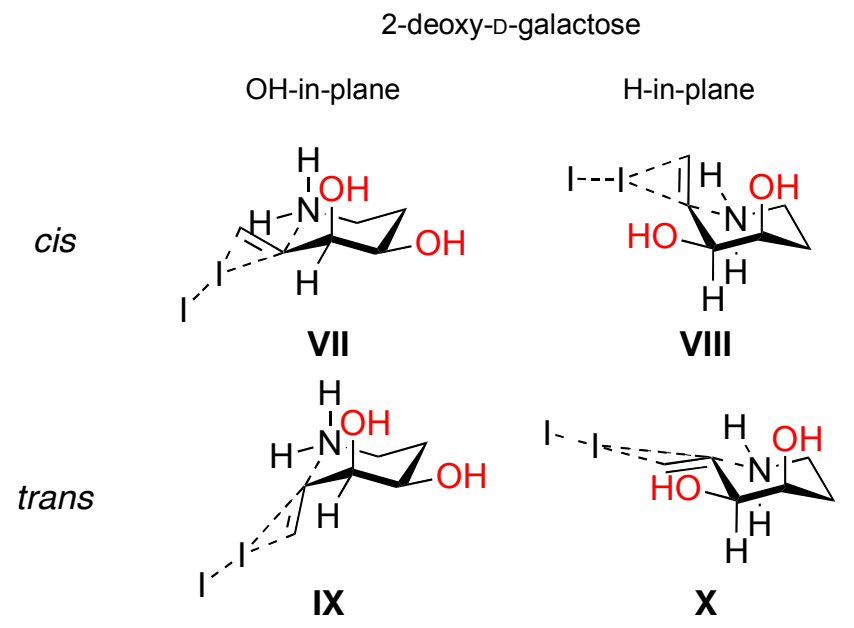

Figure 2.7: Six-membered iodocyclisation transition states for 2-deoxy-Dgalactose.

For the 2-deoxy-D-glucose series, the relative axial or equatorial orientation of the hydroxyl substituents also need to be considered. The transition states for the 2deoxy-D-glucose series XI to XIV are given in Figure 2.8. In this case, all four transition states involve a combination of favourable and unfavourable 
interactions. For the two transition states that lead to the major cis carbamate, $\mathrm{OH}-$ in-plane TS XI has a favourable pseudo-equatorial alkene configuration, but ring hydroxyl substituents in an unfavourable axial orientation, while TS XII has a pseudo-axial alkene and H-in-plane conformation, both of which are unfavourable, but equatorial ring hydroxyls. The minor trans carbamate could be formed from $\mathrm{OH}-\mathrm{in}-$ plane $\mathrm{TS}$ XIII, with three unfavourable axial ring susbstituents, or the H-in-plane TS XIV, which has all equatorial substituents. The presence of fewer unfavourable interactions in TSs XI and XIV suggest that these are the lower energy transition states for the major and minor products, respectively. The unfavourable axial ring OHs of TS XI would increase the overall energy of this transition state making it closer in energy to TS XIV.

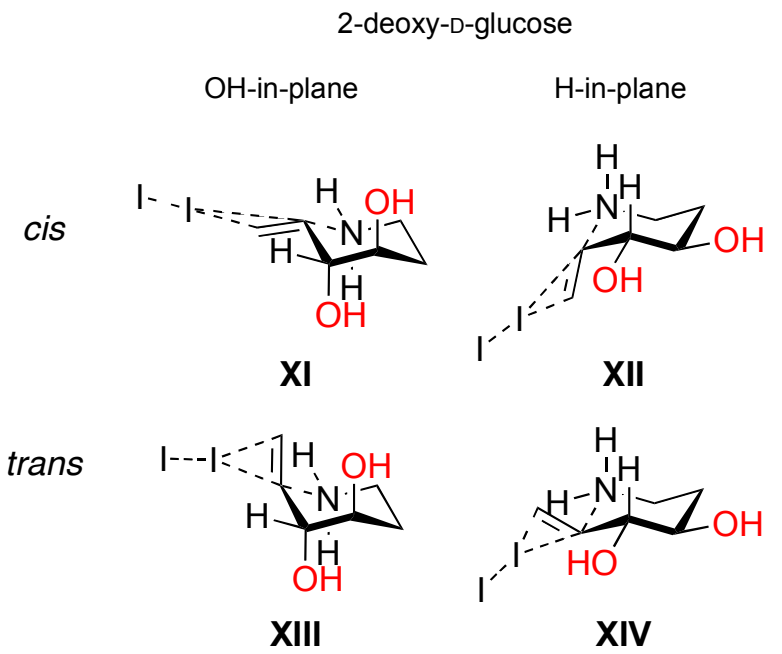

Figure 2.8: Six-membered iodocyclisation transition states for 2-deoxy-Dglucose.

In summary, for the 2-deoxy-D-galactose series there is one favoured transition state (TS VII), which leads to the preferential formation of the cis-piperidine carbamate 104a. For the 2-deoxy-D-glucose series, however, there does not appear to be one iodo-cyclisation transition state of substantially lower energy. Thus a significant yield of numerous products were observed in the carbamate annulation, where products pyrrolidine 110, cis and trans piperidines 112a and $\mathbf{1 1 2 b}$, and iodide 113 were formed in a 4:2:2:3 ratio, respectively. 


\subsection{Proposed Explanation of the Multiple Products formed in the 2-Deoxy-Glucose PGF Azasugar Synthesis}

To explain the formation of multiple products from the treatment of alkenylamine 110 with $\mathrm{I}_{2}$ and $\mathrm{NaHCO}_{3}$, the following reaction mechanisms were proposed (Scheme 2.10). First, attack of iodine from the top face of the alkenylamine 110 (via XV) leads to an intermediate that can be transformed into piperidine 112a, iodide 113 and pyrrolidine 111. Here, pathway ' $A$ ' involves amine attack on the iodine complex at $\mathrm{C}-5$, followed by the addition of $\mathrm{CO}_{2}$ (formed via the dissociation of carbonic acid) to give the cis carbamate 112a in accordance with the previously published annulation methodology. ${ }^{24}$ Iodocarbamate 113, contains a chiral backbone including a new C-5 stereocenter that was not present in parent alkenylamine 110. The synthesis of iodocarbamate 113, is thought to occur via $\mathrm{S}_{\mathrm{N}} 2$ attack of water on the $\mathrm{I}_{2}$-alkene complex (pathway 'B'), followed by the addition of $\mathrm{CO}_{2}$ to the linear iodoamine. The carbamate formation in iodide 113 is thought to occur via carbamic acid formation with the addition of a proton from the aqueous solvent. Following this, the nucleophilic attack of the $3-\mathrm{OH}$ is expected to lead to carbamate 113. There are examples in the literature for the formation of similar carbamic acids, ${ }^{12}$ however the formation of a carbamate between an alcohol and amine under comparable conditions is unreported. There is literature precedent for carbamate formation from $\mathrm{CO}_{2}$ under high pressure and temperature, ${ }^{29}$ or in the presence of a catalyst, ${ }^{30}$ however none of these reactions were carried out in water. $\mathrm{NaHCO}_{3}$ is more soluble in water than in other solvents, hence $\mathrm{CO}_{2}$ would be more readily available for carbamate formation under these conditions. Additionally, iodine may act as a catalyst in this carbamate annulation. The regioselectivity observed in the attack on the $\mathrm{I}_{2}$-alkene complex follows Markovnikov's rule, while the stereoselectivity is more difficult to rationalise. The observation of only one iodocarbamate diastereomer, however, suggests that $\mathbf{X V}$ is lower in energy than XVI and hence the intermolecular nucleophilic attack of $\mathrm{H}_{2} \mathrm{O}$ on $\mathbf{X V}$ (pathway B) is more energetically favourable than the equivalent pathway on XVI. 


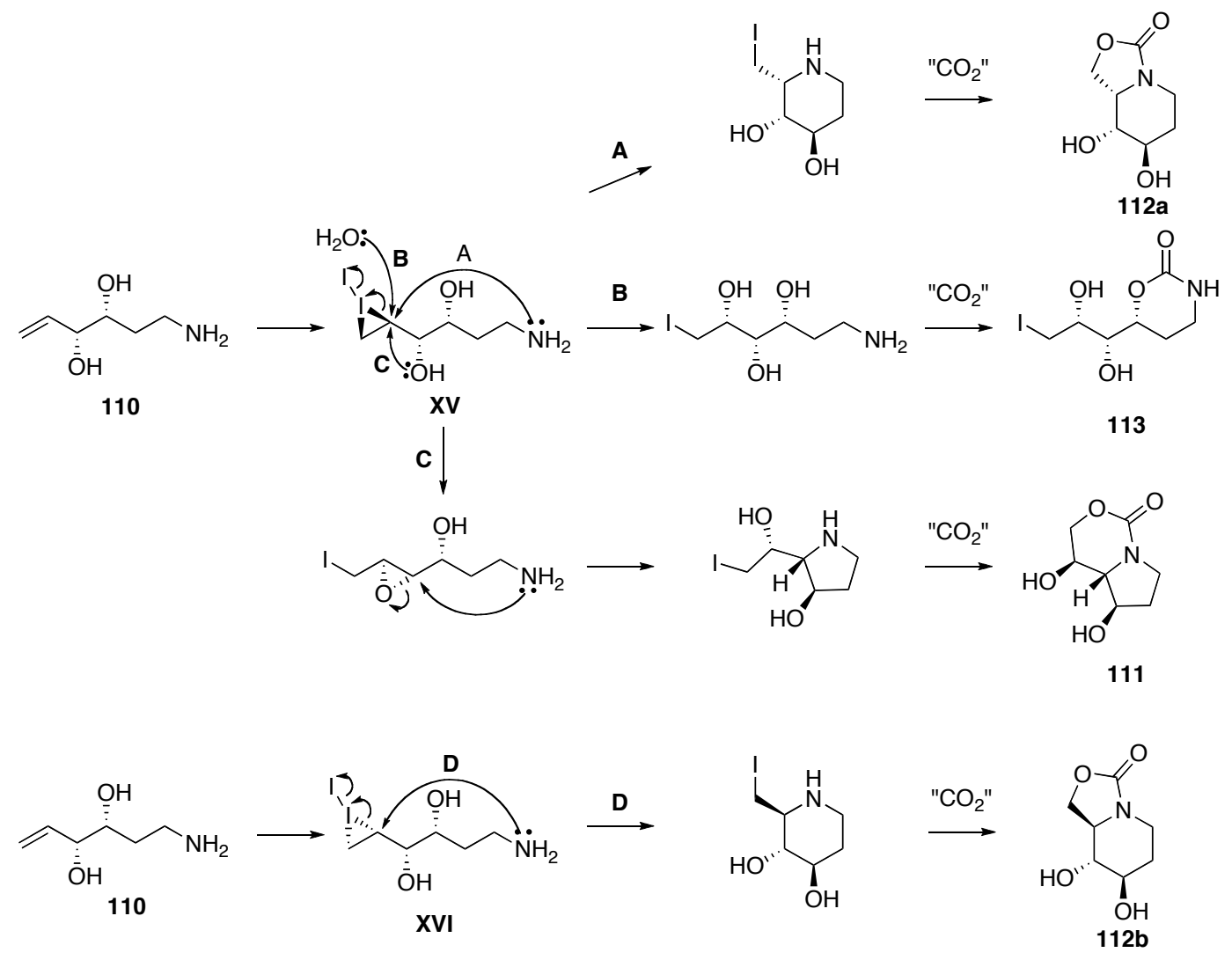

Scheme 2.10: Proposed mechanism for the formation of pyrrolidine 111, piperidines 112a and 112b, and iodide 113 following the subjection of alkenylamine $\mathbf{1 1 0}$ to iodine and aqueous $\mathrm{NaHCO}_{3}$.

While there is no literature precedent for the selective formation of a linear terminal iodide similar to iodocarbamate $\mathbf{1 1 3}$ through the reaction of iodine with an unsubstituted allylic alcohol, a number of halohydrin reactions have been reported for similar substrates. In these reactions, both the substitution pattern and accessibility of the halide-alkene complex influenced regio- ${ }^{31,32}$ and stereochemical $^{33,34}$ outcomes. In the most closely related system involving halohydrin formation, an allylic alcohol 123 was subjected to iodic acid in acetone and a mixture of the terminal alcohol 124 and terminal iodide 125 were observed as the major and minor products, respectively (Scheme 2.11). ${ }^{31}$ Unfortunately, no stereochemical data was reported for this reaction. In the $\mathrm{I}_{2}$-mediated carbamate annulation of alkenylamine 110, however, there was no indication of products 
formed due to the opening of the iodine complex by water at the terminal carbon or from water attack on the diastereomeric iodine complex. It should also be noted that the possibility of $\mathbf{1 1 3}$ being formed via a Payne rearrangement ${ }^{35}$ of the intermediate epoxide (pathway $\mathrm{C}$ ) is unlikely as this reaction typically requires strongly basic conditions, ${ }^{36}$ as illustrated by the conversion of allylic alcohol 126 to allylic epoxide 127 under the mediation of $\mathrm{NaOH}$ (Scheme 2.12). ${ }^{37}$ It is also conceivable that formation of a cyclic carbamate at the 3-position, or the formation of a carbamic acid that 'protects' the amine, ${ }^{38}$ takes place prior to halohydrin formation and this provides an alternative route to 113. Such a cyclic carbamate intermediate, however, does not add to a conceivable mechanism for the formation of either pyrrolidine $\mathbf{1 1 1}$ or piperidine 112a.

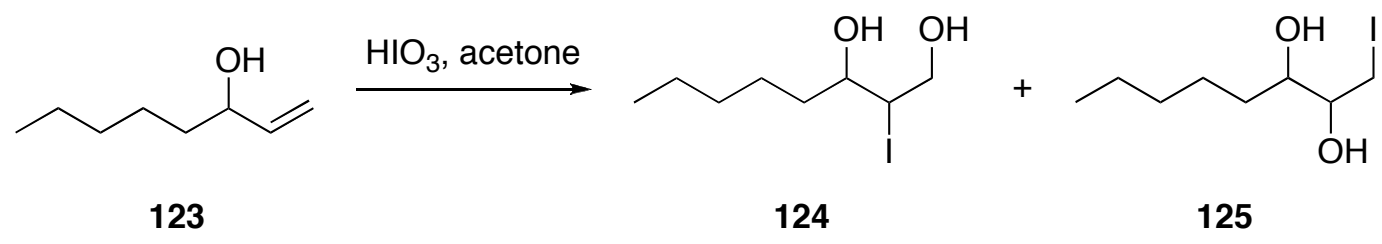

$124: 125=77 \%: 7.4 \%$

Scheme 2.11: Halohydrin reaction of a termination alkene (stereochemistry not given in the literature). ${ }^{31}$

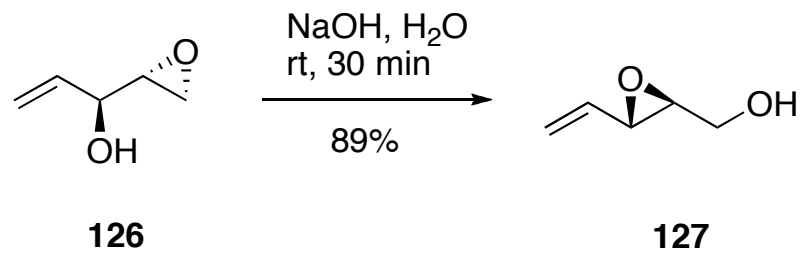

Scheme 2.12: Payne rearrangement under strongly basic conditions. ${ }^{37}$

To explain the formation of pyrrolidine 111, a mechanism that supports the inversion of stereochemistry at $\mathrm{C}-4$, and formation of a chiral centre at $\mathrm{C} 5$ is required. Accordingly, an iodo-epoxide (pathway 'C', Scheme 2.10) is proposed 
as a key intermediate. ${ }^{39,40}$ Here, nucleophilic 5-exo-tet ring opening ${ }^{41}$ of the epoxide, followed by the addition of $\mathrm{CO}_{2}$ forms carbamate 111. Finally, the formation of trans-piperidine $\mathbf{1 1 2 b}$ can be envisioned to occur via the $\mathrm{S}_{\mathrm{N}} 2$ attack of the diastereomeric iodine complex (pathway D), whereby XVI leads to the conformation of the iodine-alkene complex. Subsequent addition of $\mathrm{CO}_{2}$ to the intermediate cyclic iodoamine would then give piperidine $\mathbf{1 1 2 b}$. Finally, it should be noted that attack at the 5-position of the intermediate epoxide discussed in pathway $\mathrm{C}$ could also lead to trans piperidine $\mathbf{1 1 2 b}$ through a 6-endo-trig cyclisation. According to Baldwin's rules, this is less favored than the corresponding 5-exo-trig cyclisation $(\rightarrow \mathbf{1 1 2 b}),{ }^{41}$ especially in the absence of a bulky group $\alpha$ - to the nitrogen. ${ }^{42}$

When comparing the proposed mechanism for the formation of carbamates $\mathbf{1 1 1}$ to 113 in Scheme 2.10, with the results obtained from the reaction optimisation (Table 2.1), it is important to note that the mechanism was proposed to explain the products formed under optimal conditions (i.e. entry 4, Table 2.1). As a result of this, there is some disconnect between the variation in reaction conditions, and the proposed mechanism. When a reduced amount (1.5 equiv.) of $\mathrm{NaHCO}_{3}$ was used in the reaction, no product formation was observed, which could suggest that $\mathrm{NaHCO}_{3}$ (as a source of $\mathrm{CO}_{2}$ ) was the limiting reagent. A similar result was observed in the galactose derived carbamate formation, where minimal $\mathrm{NaHCO}_{3}$ resulted in an incomplete reaction after $7 \mathrm{~d} .^{12}$ It is surprising that no iodide intermediates (or degradation products as a result of unstable intermediates) were observed under these conditions, given that proposed first step in the mechanism in Scheme 2.10 does not involve $\mathrm{CO}_{2}$. There are several possible explanations for this observation. As well as being a source of $\mathrm{CO}_{2}$ in the reaction, $\mathrm{NaHCO}_{3}$ could also influence the $\mathrm{pH}$ of the solution, which could be important in deprotonating alkenylamine 110, which was added as the $\mathrm{HCl}$ salt. It could also be that the ionic strength is important in the reaction, or that the excess $\mathrm{NaHCO}_{3}$ aids the solubility of the iodine, which is involved in the rate determining step of the carbamate annulation. Another possibility is that the carbamate annulation occurs though an alternative mechanism where $\mathrm{CO}_{2}$ is involved in the first step. A possible 
mechanism for the formation of iodide $\mathbf{1 1 3}$ is displayed in Scheme 2.13. Iodine association with the top face of amine 110, is followed by the attack of the 3-OH on $\mathrm{CO}_{2}$ to form a carbonate ester. The subsequent attack of this species at $\mathrm{C} 5$ could lead to the formation of a cyclic six-membered carbonate, which is then proposed to undergo amine attack on the carbonyl group leading to the formation of iodo carbamate 113. However this mechanism is unlikely, as carbonates have never been made by the reaction of alcohols with aqueous $\mathrm{NaHCO}_{3}$. Carbonates can be prepared from allylic alcohols using $\mathrm{CO}_{2}$ and a strong base (e.g. BuLi) $)^{43,44}$ however these reactions would not be possible under aqueous conditions. Additionally Venturello et al. described the formation of cyclic carbonates from halohydrins and a $\mathrm{Me}_{4} \mathrm{NHCO}_{3} / \mathrm{CO}_{2}$ solution in $\mathrm{MeCN}$. ${ }^{45}$ If the PGF carbamate annulation of amine $\mathbf{1 1 0}$ were occurring by this mechanism, the isolation of halohydrin 113 would not be observed. Alternatively, the formation of a piperidine carbonate was recently reported with evidence of aziridine formation, rather than carbonate substitution, as the key cyclisation step, ${ }^{46}$ however the presence of an aziridine intermediate has been ruled out under the conditions used in this study. ${ }^{24}$<smiles>C=C[C@H](O)[C@H](O)CCN</smiles>

113

Scheme 2.13: Alternative mechanism for the formation of iodo carbamate 113. 
By proposing reaction mechanisms to account for the formation of products $\mathbf{1 1 1}$, 112a, 112b, and 113, it may be possible to tailor the starting materials to favour one particular product over the others, and further support the proposed mechanism. Indeed the preparation of a protected version of the hypothesised iodo epoxide intermediate, and successful carbamate annulation from this would support the mechanism. This will be further discussed in Chapter 5 (Future Prospects). 


\subsection{Wider Relevance: Related 6- $N$-Cyclisations}

To control the regioselectivity of cyclisation reactions in the preparation of piperidines, most synthetic strategies involve the use of protected scaffolds, such as amine 128, to avoid the formation of smaller (e.g. five-membered) rings, and rely on the preference for six- over seven-membered rings (i.e. 129 vs. 130) to favour the piperidine scaffold (Scheme 2.14). The control of stereochemistry, however, can be more challenging. While the $\mathrm{OH}$-in-plane vs. H-in-plane transition state model has some success in predicting the stereochemical outcome of the cyclisations, other factors such as across-the-ring trans directing effects, choice of the cyclisation mediator, and thermodynamic $v s$. kinetic reaction control can also influence product formation. These will be highlighted in the following examples.<smiles>C=CC([O+])C(OCCO)C(CNP)C(=O)OCc1ccccc1</smiles>

128

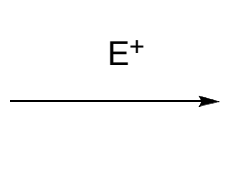

$P G=$ protecting group $\mathrm{E}=$ Electrophile

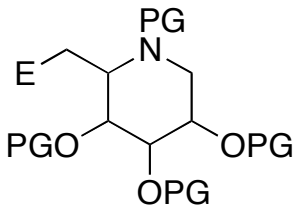

129 vs.

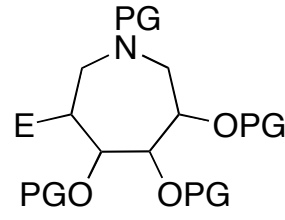

130

Scheme 2.14: Protecting group controlled regiochemistry during halocyclisations.

In addition to the successful PGF-synthesis of DGJ and 4-epi-fagomine via an $\mathrm{I}_{2}$ mediated carbamate annulation, there are also a number of other halocyclisations involving the use of PGs whereby the 4,5- (or 5,6-) cis product was the major isomer formed (Table 2.2). As summarised in the PGF-synthesis of 4-epifagomine (Section 2.1.3), 2-deoxy-galactose 103 underwent iodocyclisation and carbamate annulation to selectively give cis carbamate 104a under kinetic conditions (entry 1). The PGF synthesis of cis carbamate 88a en route to DGJ was also discussed earlier. Although this iodocyclisation of galacto alkenylamine $\mathbf{8 7}$ 
was less selective, with trans piperidine $\mathbf{8 8 b}$ and amino furan $88 \mathrm{c}$ also observed, the reaction conditions could be optimised so that the cis carbamate 88a was the major product formed (entry 2). NIS has been used to induce cyclisations of protected amino heptenols with high stereocontrol, as illustrated by the 5,6-cis selective cyclisation of $\mathbf{1 3 1}, \mathbf{1 3 3}$ and 135 to give the corresponding iodoamines 132, 134, and 136, respectively (entries 3-5). Of particular note is that cyclisation of 133 forms 134 stereoselectively (entry 4) despite the unfavourable 2,6-cis relationship across the ring, which, in other instances, has been shown to adversely effect the stereochemical outcome (see Scheme 2.15 and the nearby discussion). 
Table 2.2: $C i s$ selective 6- $N$-cyclisations

\begin{tabular}{|c|c|c|c|c|c|c|}
\hline Entry & Alkenylamine & $\begin{array}{l}\text { Reaction } \\
\text { conditions }\end{array}$ & Cyclic Product & $\begin{array}{l}\text { Ratio: } \\
\text { cis:trans }\end{array}$ & Yield & Ref. \\
\hline 1 & $\underbrace{\mathrm{OH}}_{\substack{\mathrm{OH} \\
103}} \mathrm{NH}_{2}$ & $\begin{array}{l}\mathrm{I}_{2}, \\
\mathrm{NaHCO}_{3}, \\
35 \quad{ }^{\circ} \mathrm{C}, \\
\mathrm{H}_{2} \mathrm{O}, 5 \mathrm{~d}\end{array}$ & 104a & $>95: 5$ & $86 \%$ & 10 \\
\hline 2 & $\underbrace{\mathrm{OH}}_{\mathrm{OH}}$ & $\begin{array}{l}\mathrm{I}_{2}, \\
\mathrm{NaHCO}_{3}, \\
50 \quad{ }^{\circ} \mathrm{C}, \\
\mathrm{H}_{2} \mathrm{O}, 2 \mathrm{~d}\end{array}$ & 88a & $3: 1: 1^{\mathrm{a}}$ & $60 \%{ }^{\mathrm{a}}$ & 11 \\
\hline 3 & $\underbrace{\mathrm{OBn}}_{\substack{\mathrm{OBn} \\
\mathbf{O B n}}}$ & $\begin{array}{l}\text { NIS, } \\
\text { DCM, rt, } \\
3 \mathrm{~h}\end{array}$ & $\underbrace{\mathrm{N}_{\mathrm{OBn}}}_{\substack{\mathrm{OBn} \\
\mathbf{1 3 2}}}$ & $>95: 5$ & $80 \%$ & 47 \\
\hline 4 & 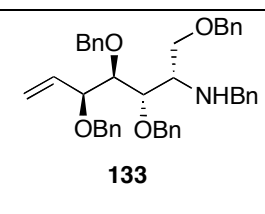 & $\begin{array}{l}\text { NIS, } \\
\text { DCM, rt, } \\
3 \mathrm{~h}\end{array}$ & 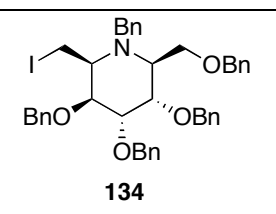 & $>95: 5$ & $90 \%$ & 47 \\
\hline 5 & $\overbrace{\substack{\mathrm{OBn} \mathrm{O} B n \\
135}}^{\mathrm{BnO}} \int_{\mathrm{NHBn}}^{\mathrm{OBn}}$ & $\begin{array}{l}\text { NIS, } \\
\text { DCM, rt, } \\
3 \mathrm{~h}\end{array}$ & 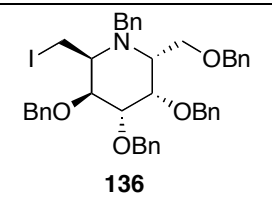 & $>95: 5$ & $69 \%$ & 47 \\
\hline
\end{tabular}




\begin{tabular}{|c|c|c|c|c|c|c|}
\hline Entry & Alkenylamine & $\begin{array}{l}\text { Reaction } \\
\text { conditions }\end{array}$ & Cyclic Product & $\begin{array}{l}\text { Ratio: } \\
\text { cis/trans }\end{array}$ & Yield & Ref. \\
\hline 6 & 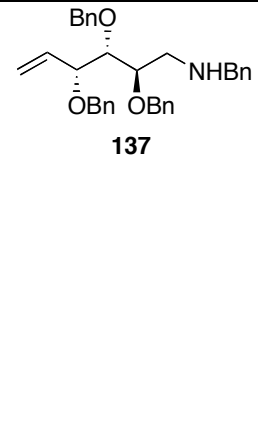 & $\begin{array}{l}\text { i) } \\
\mathrm{Hg}(\mathrm{TFA})_{2} \text {, } \\
\mathrm{THF} \\
\text { ii) } \\
\mathrm{NaBH}_{4}, \\
\mathrm{DMF}_{2} \mathrm{O}_{2}\end{array}$ & (3) & $7: 1$ & quant. & 48 \\
\hline 7 & $\underbrace{\mathrm{BnO}}_{\substack{\mathrm{OBn} \overline{\mathrm{O} B n} \\
140}} \mathrm{NHBn}$ & $\operatorname{Hg}(\mathrm{TFA})_{2}$ & (4) & 7.5:1 & $85 \%$ & 49 \\
\hline 8 & $\underbrace{\mathrm{BnO}}_{\substack{\mathrm{OBn} \mathrm{O} B n \\
143}} \int_{\mathrm{NHCbz}}^{\mathrm{OBn}}$ & $\mathrm{Hg}(\mathrm{TFA})_{2}$ & 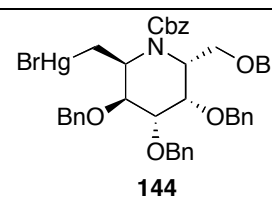 & $>95: 5$ & $76 \%$ & 50 \\
\hline 9 & $\sum_{\mathrm{OBn}}^{\mathrm{OBn}} \int_{145}^{\mathrm{OBn}}$ & $\mathrm{Hg}(\mathrm{OAc})_{2}$ & $\underbrace{\mathrm{OBn}}_{\substack{\mathrm{O} B n \\
146}}$ & $>95: 5$ & $71 \%$ & 51 \\
\hline
\end{tabular}

a Carbamate products 88a:88b:88c observed in a $3: 1: 1$ ratio by ${ }^{1} \mathrm{H}$ NMR spectroscopy. Yield of $\mathbf{8 8 a}$ was estimated based on ratios observed by ${ }^{1} \mathrm{H}$ NMR spectroscopy.

$\mathrm{Hg}$ (II) salts have also been shown to give good cis-selectivity in the 6- $\mathrm{N}$ cyclisation reactions (entries 6-9, Table 2.2). $\mathrm{Hg}(\mathrm{TFA})_{2}$ was reported to provide the corresponding cis-piperidines in high yields and good to excellent selectivity. Manno derivative 137 displayed good selectivity, and quantitative yield, when subjected to $\operatorname{Hg}(\mathrm{TFA})_{2}$ followed by oxidative demercuration, giving a 7:1 ratio of cis 138 : trans 139 isomers (entry 6). A notable improvement in selectivity was 
observed for the cyclisation of galacto alkenylamine 140 in entry 7 when kinetic conditions were used instead of thermodynamic conditions (see Scheme 2.19), providing a good selectivity for cis piperidine $\mathbf{1 4 1}$ over the trans isomer $\mathbf{1 4 2}$. A $\mathrm{CH}_{2} \mathrm{OBn}$ group $\alpha$ to the amine in alkenylamines 143 and 145 , encouraged the selective formation of cis piperidines 144 and 146 (entries 8 and 9), respectively. Here the 2,6 trans directing effect (due to across-the-ring steric interactions) and the 5,6 cis preferences are in agreement, giving excellent selectivity. Comparison of the PGF iodo-cyclisation of galacto alkenylamine 87 (entry 2) and the Hgmediated cyclisation of the corresponding benzyl-protected alkenylamine $\mathbf{1 4 0}$ (entry 7) suggests that the protected derivative is more cis selective. The cis selectivity of the protected alkenylamine may be due to the steric interactions of the bulky protecting groups increasing the energy of the less favoured (trans) transition state. However, it is also possible that the differing cyclisation conditions are responsible for the observed differences in selectivity.

While the above examples illustrate a preference for the 4,5- (or 5,6-) cis products during aminocyclisation reactions, there are also examples where mixtures of $c i s$ and trans products are formed. Both the ring substitutents and the annulation conditions used have been shown to influence the regio- and stereochemical outcome of annulation reactions. The use of PGs allows for better control of the regiochemistry of the annulation, yet even with PGs, the stereochemical outcome of the reaction is not easy to predict.

An example of a PG synthesis of piperidines leading to the 5,6-trans product is the iodocyclisation for the preparation of aza- $C$-glycosides displayed in Scheme 2.15. ${ }^{47}$ Here, benzyl protected aminoheptenols 131 and 147 were submitted to NIS (1 equiv.) in DCM at rt effecting cyclisation to the corresponding aza-Cglycosides 132 and 148, respectively, in excellent yield and stereoselectivity. When amine 131 was submitted to the cyclisation conditions, the 5,6-cis, 2,6trans piperidine 132 was formed (see entry 2, Table 2.2), however, cyclisation of amine 147 gave the 2,6-trans, 5,6-trans piperidine 148. The difference in the stereochemical preference of the two reactions can be explained by the reduction 
in 1,3-diaxial interactions when the groups at the 2- and 6-postions adopt a trans relationship. The configuration at the 2-position appears to be the major contributing factor when explaining which of the stereoisomers at the 6-position will be preferred. The across-the-ring trans directing effect has also been observed during the formation of pyrrolidines with substituents at the 2- and 5positions, ${ }^{52}$, although in these examples, often mixtures of diastereomers were obtained.<smiles>C=CC(OCc1ccccc1)C(O)C(OCc1ccccc1)C(COc1ccccc1)Nc1ccccc1</smiles>

131<smiles>C=C[C@@H](OCc1ccccc1)C(Br)C(O)C(COc1ccccc1)NCc1ccccc1</smiles>

147
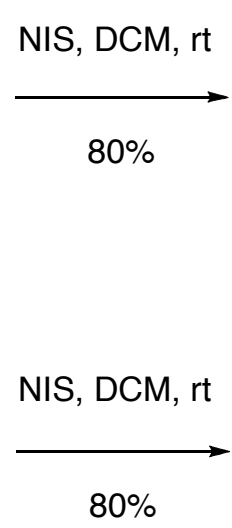

Scheme 2.15: Benzyl protected iodocyclisation giving the 5,6-trans product as the major diastereomer. ${ }^{47}$

Examples of gluco alkenylamines that were seen to favour the formation of the 4,5-trans piperidines have been given in Scheme 2.16. Benzylated alkenylamine 149 was subjected to $I_{2}$-mediated annulation conditions to give cis and trans piperidine iodides $\mathbf{1 5 0}$ and $\mathbf{1 5 1}$, in a ratio of 35:59, respectively. ${ }^{53}$ Similarly, $\mathrm{Hg}-$ mediated cyclisation of alkenylamine 149 gave cis and trans bromomercurials 152 and 153, respectively, ${ }^{48}$ also in ca. 1:1.6 ratio. The same ratio of cis:trans piperidines 155 and 156 was observed in the $\mathrm{Hg}$ mediated annulation of benzyl protected hydroxyethyl amine $154{ }^{54}$ Transition state models similar to those discussed earlier for the cyclisation of the 2-deoxy-D-glucose alkenylamine 110 
(Figure 2.8) can explain the poor selectivity. The position of the electron withdrawing allylic OBn group, and steric interactions of the alkene and OBn ring substituents have similar effects on the transition state energies, thus a mixture of diastereomers results.

A:

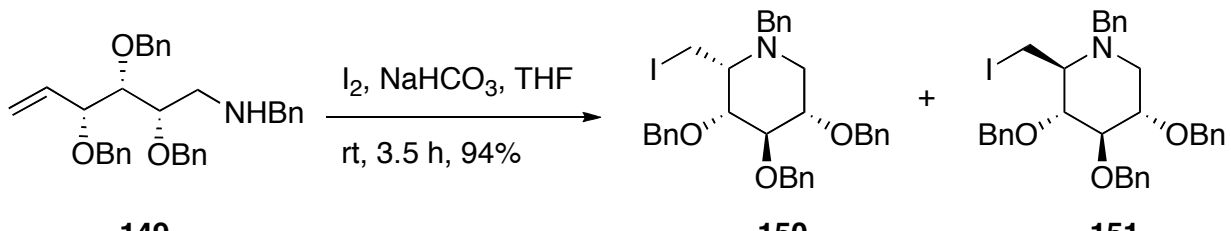

$150: 151=35: 59$

B:

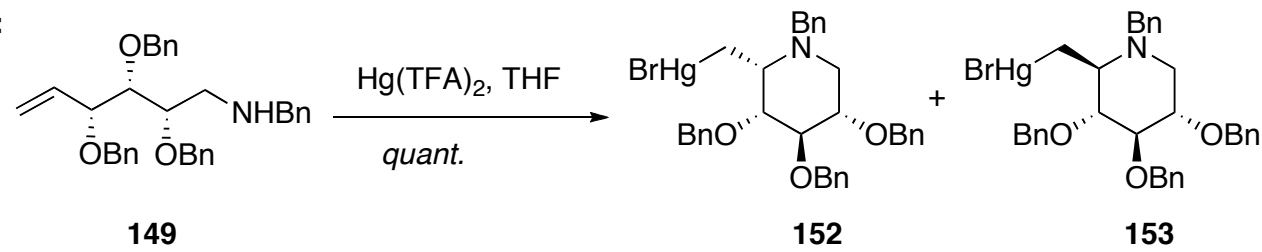

$152: 153=39: 61$

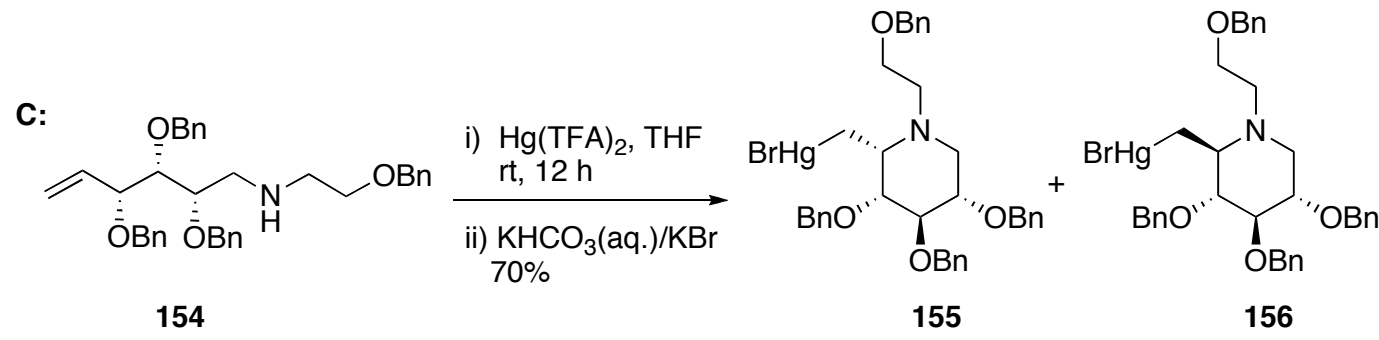

$155: 156=1: 1.6$

Scheme 2.16: Halocyclisations of gluco amines that favour trans piperidine formation. ${ }^{48,53,54}$

Another example where the stereochemical outcome of the amino-cyclisation reaction changes depending on the substrate used is the $\mathrm{Pd}(\mathrm{II})$ mediated chlorocyclisation of alkenylamines. ${ }^{55}$ Here, the Pd(II) catalysed chlorocyclisation from D-gluco amine 157 was remarkably selective, with the 4,5-cis azasugar 158 formed as the major product, and only minor amounts of the corresponding diastereomer 159 observed (Scheme 2.17A). ${ }^{55}$ Given the poor selectivity observed for the cyclisation of the gluco alkenylamines in Scheme 2.16, the excellent cis 
selectivity observed here was unforeseen. In contrast, three products were observed in the $\mathrm{Pd}(\mathrm{II})$ catalysed cyclisation of galactose-derived alkenylamine 160 (Scheme 2.17B). ${ }^{55}$ The inversion of stereochemistry at $\mathrm{C} 4$ enabled the formation of bicycle $\mathbf{1 6 1}$ in addition to the anticipated cis- and trans-piperidines 162 and 163, respectively. A variety of reaction conditions were studied in the $\mathrm{Pd}(\mathrm{II})$ catalysed cyclisation. Here, $\mathrm{AcOH}$ as solvent favoured formation of bicycle 161 (conditions A), while DMF gave the best selectivity for the trans piperidine 163 (conditions B). A ${ }^{1} \mathrm{C}_{4}$ chair of the transition state and coordination of $\mathrm{Pd}$ to the 3-O-Bn play predominant roles in the formation of the products. In particular, the formation of bicycle $\mathbf{1 6 1}$ has been proposed to occur via the bis-coordination of the alkene and the C-3 benzyl ether to the metal, followed by nucleophilic attack of the amine on the alkene/ $\pi$-complex (TS XVII, Scheme 2.17C). Reductive elimination in the presence of $\mathrm{CuCl}_{2}$ then gives bicycle 161 .

A:

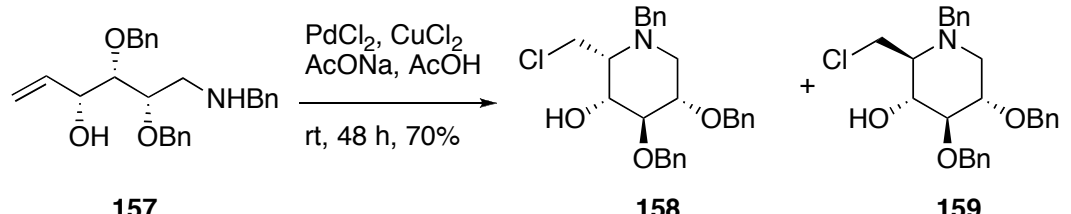

157

158

$158: 159=19: 1$

B:

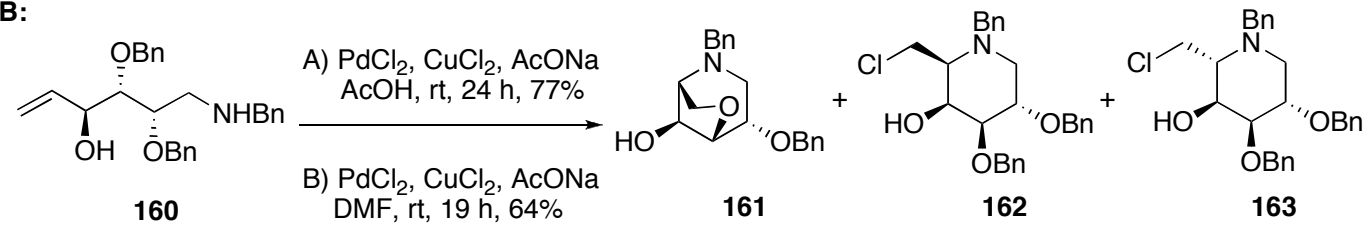

A) $161: 162: 163=49: 1: 27$

B) $161: 162: 163=4: 1: 16$

C:

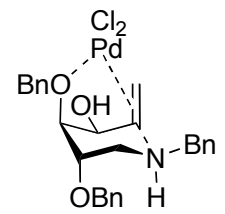

XVII

Scheme 2.17: $\operatorname{Pd}(\mathrm{II})$ catalysed cyclisations. A: Cyclisation of the glucose derivative. B: Cyclisation of the galactose derivative. C: Transition state involved in the formation of bicycle $161 .^{55}$ 
When performing a $\mathrm{Pd}(\mathrm{II})$ catalysed aminocarbonylation reaction using protected gluco alkenylamine 157, the selectivity under each set of conditions (A or B, Scheme 2.18) differed. ${ }^{56,57}$ Cis bicycle $\mathbf{1 6 5}$ was favoured when $\mathrm{CuCl}_{2}$ was used as the co-oxidant (conditions A), while trans piperidine 164 was favoured when $\mathrm{LiCl}$ and $p$-benzoquinone were used in place of $\mathrm{CuCl}_{2}$ (conditions $\mathrm{B}$ ). A variety of other reaction conditions were tested, however none improved on the yields and selectivities noted for conditions A and B. In all instances a mixture of the cis and trans bicyclic lactones 164 and 165 were observed, and when $\mathrm{CuCl}_{2}$ was used as the co-oxidant, cis-piperidine $\mathbf{1 5 8}$ was a major by-product. These results are in contrast to the previously mentioned Pd(II) catalysed chlorocyclisation from gluco amine 157 (Scheme 2.17A), where only the 5,6-cis product was formed. It is unclear why conditions $\mathrm{A}$ and $\mathrm{B}$ favour different diastereomers, or why the conditions are less selective than the chlorocyclisation in the previous scheme, but this may be related to a change in the mechanism of the reaction when carried out under each set of conditions.
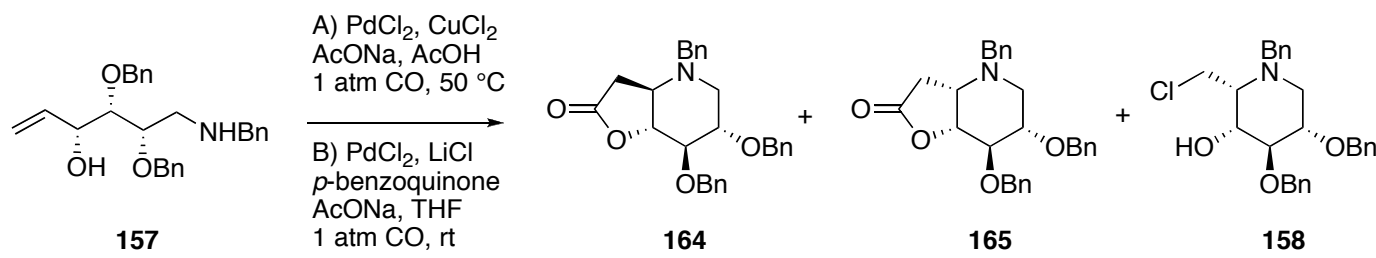

A) $164: 165: 158=1: 5: 1,55 \%$

B) $164: 165: 158=4: 1: 0,66 \%$

Scheme 2.18: Aminocarbonylation of gluco alkenylamine $157 .^{56,57}$

Finally, it should also be noted that thermodynamic or kinetic reaction control can sometimes be used to influence the stereoselectivity of an amino cyclisation. For example, Ganem and co-workers observed thermodynamic and kinetic control gave different stereoselectivity of amino mercuration cyclisations (Scheme 2.19). ${ }^{49}$ Galacto-configured amine $\mathbf{1 4 0}$ was subjected to mercury-mediated cyclisation under thermodynamic (conditions A) and kinetic control (conditions B). A mixture of products containing 4,5-cis-azasugar 141, the 4,5-trans-azasugar 
142, and an unidentified by-product were obtained under both sets of conditions, however the kinetic conditions provided cis-piperidine 141 preferentially in $75 \%$ yield. Amine $\mathbf{1 4 1}$ is likely to be formed through an OBn-in-plane transition state, which is anticipated to be the lower energy transition state, and hence gives rise to the kinetic product. Under thermodynamic conditions, a 1:1 ratio of the cis:trans isomers 141:142 is observed, indicating that the energies of the products are similar.

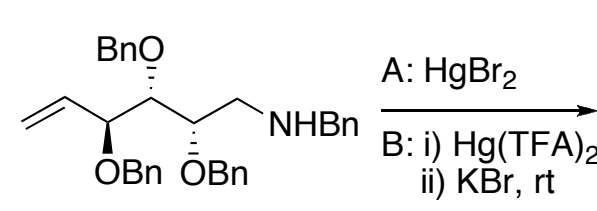

140<smiles>BrCC[C@H]1NC[C@@H](Br)[C@H](OCc2ccccc2)[C@@H]1OBr</smiles>

141

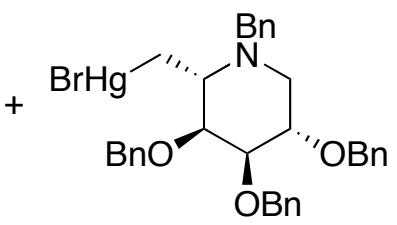

142

A: 141:142:unknown $=45 \%: 45 \%: 10 \%$

B: 141:142:unknown $=75 \%: 10 \%: 15 \%$

Scheme 2.19: Thermodynamic (A) vs. kinetic (B) control in Hg-mediated cyclisations. $^{49}$

These literature examples of 6-N-halocyclisations show that the selectivity of these reactions varies depending on the reaction conditions used and the stereochemistry of the starting material. This indicates that it is difficult to predict the selectivity of such a reaction, and helps to explain the formation of multiple products in the PGF halocyclisations. The observation of consistently poor selectivity in gluco derived alkenylamines further supports the observation of reduced selectivity (i.e. the formation of four carbamate products) in the carbamate annulation of the 2-deoxy-glucose analogue. 


\subsection{Conclusion}

The PGF azasugar methodology has been applied to the 2-deoxyglucose scaffold. The key cyclisation step, the $\mathrm{I}_{2}$-mediated carbamate annulation, resulted in a series of competing intramolecular reactions that produced four carbamates. A variety of synthetic and spectroscopic techniques were used to identify the carbamates as: the anticipated cis piperidine 112a, the corresponding trans isomer 112b, pyrrolidine 111, and iodide 113. To this end, previously undisclosed enantiomer of trihydroxypyrrolidine $\mathbf{1 1 5}$ was prepared in five steps and modest (up to $15 \%$ ) overall yield, using a completely PGF strategy. These studies highlight the limitations of using the carbamate annulation for the preparation of piperidines in protecting-group-free syntheses, although the work also points to the potential of this methodology for the synthesis of interesting chiral scaffolds when using either protected or suitably functionalised alkenylamines as starting materials. 


\subsection{Experimental}

\section{General Experimental}

Unless otherwise stated, all reactions were performed under atmospheric air. THF (Lab-Scan) was distilled from $\mathrm{LiAlH}_{4}$ prior to use. Pyridine was distilled over $\mathrm{KOH}$ prior to use. $\mathrm{H}_{2} \mathrm{O}, \mathrm{MeOH}$ (Pure Science), and EtOH (absolute, Pure Science), were distilled prior to use. EtOAc (Pure Science), and petroleum ether (Pure Science), HCl (PanReac), AcOH (Ajax Finechem), DCM (LabServ), 35\% aqueous $\mathrm{NH}_{3}$ (J. T. Baker Chemical Co.), $\mathrm{NaHCO}_{3}$ (PureScience), 2-deoxy-Dglucose (Sigma-Aldrich), $\mathrm{AcCl}$ (B\&M), $\mathrm{PPh}_{3}$ (Merck), imidazole (Aldrich), $\mathrm{I}_{2}$ (BDH), $\mathrm{NaCNBH}_{3}$ (Aldrich), $\mathrm{NaOH}$ (Pure Science), and $\mathrm{NH}_{4} \mathrm{OAc}$ (AnalaR), $\mathrm{Ac}_{2} \mathrm{O}$ (Acros) were used as received. All chemicals obtained from commercial suppliers were used without further purification. $\mathrm{Zn}$ dust was activated by the careful addition of concentrated $\mathrm{H}_{2} \mathrm{SO}_{4}$, followed by decantation and washing with EtOH $(3 \times)$ and hexanes $(3 \times)$ and storage under dry hexanes. All solvents were removed by evaporation under reduced pressure. Reactions were monitored by TLC analysis on Macherey-Nagel silica gel coated plastic sheets with detection by coating with $20 \% \mathrm{H}_{2} \mathrm{SO}_{4}$ in EtOH followed by charring at $c a .150{ }^{\circ} \mathrm{C}$, by coating with a solution of ninhydrin in EtOH followed by charring at $c a .150{ }^{\circ} \mathrm{C}$, or by coating with a solution of $5 \% \mathrm{KMnO}_{4}$ and $1 \% \mathrm{NaIO}_{4}$ in $\mathrm{H}_{2} \mathrm{O}$ followed by heating. Column chromatography was performed on Pure Science silica gel (4063 micron). Dowex ${ }^{\circledR}$ W50-X8 acidic resin (Sigma) and Dowex ${ }^{\circledR} 1$ 1X4-50 basic resin (Sigma) were used for ion exchange chromatography and HP-20 (Supelco) for reverse phase chromatography. High-resolution mass spectra were recorded on a Waters Q-TOF Premier ${ }^{\mathrm{TM}}$ Tandem Mass Spectrometer using positive electrospray ionisation. Optical rotations were recorded using an Autopol II (Rudolf Research Analytical) at $589 \mathrm{~nm}$ (sodium D-line). Infrared spectra were recorded as thin films using a Bruker Tensor 27 FTIR spectrometer, equipped with an Attenuated Total Reflectance (ATR) sampling accessory, and are reported in wave numbers $\left(\mathrm{cm}^{-1}\right)$. Nuclear magnetic resonance spectra were recorded at $20{ }^{\circ} \mathrm{C}$ in $\mathrm{D}_{2} \mathrm{O}, \mathrm{CD}_{3} \mathrm{OD}$, or $\mathrm{CDCl}_{3}$ using either a Varian Unity-INOVA operating at 300 
MHz or a Varian Unity operating at $500 \mathrm{MHz}$. Chemical shifts are given in ppm ( $\delta)$ and were internally referenced to the residual solvent peak. NMR peak assignments are based on 2D NMR experiments (COSY, HSQC, and HMBC).<smiles>CO[C@H]1C[C@@H](O)[C@@H](O)[C@H](CO)O1</smiles>

Methyl 2-deoxy- $\alpha / \beta$-D-glucopyranoside (106): To a solution of $\mathrm{AcCl}(240 \mu \mathrm{L})$ in $\mathrm{MeOH}(240 \mathrm{~mL})$, was added 2-deoxy-D-glucose (105) (1200 $\mathrm{mg}, 7.3 \mathrm{mmol}$ ) and the reaction was stirred at room temperature for $18 \mathrm{~h}$. The reaction was neutralised by the addition of Dowex- $\mathrm{OH}^{-}$, filtered and concentrated. The resulting oil was used without further purification. The methyl 2 -deoxy- $\alpha / \beta$ D-glucopyranoside (106) was obtained as a colourless oil in an 8:1 $\alpha: \beta$ ratio. $\alpha$ isomer: $\mathrm{R}_{f}=0.27\left(10 \% \mathrm{MeOH}\right.$ in EtOAc); ${ }^{1} \mathrm{H} \mathrm{NMR}\left(600 \mathrm{MHz}, \mathrm{D}_{2} \mathrm{O}\right) \delta 4.86(\mathrm{~d}$, $\left.J_{1,2 \mathrm{~b}}=3.5 \mathrm{~Hz}, 1 \mathrm{H}, \mathrm{H}-1\right), 3.83\left(\mathrm{dd}, J_{5,6 \mathrm{a}}=2.1, J_{6 \mathrm{a}, 6 \mathrm{~b}}=12.0 \mathrm{~Hz}, 1 \mathrm{H}, \mathrm{H}-6 \mathrm{a}\right), 3.79-$ $3.87(\mathrm{~m}, 1 \mathrm{H}, \mathrm{H}-3), 3.73\left(\mathrm{dd}, J_{5,6 \mathrm{~b}}=5.5, J_{6 \mathrm{a}, 6 \mathrm{~b}}=12.0 \mathrm{~Hz}, 1 \mathrm{H}, \mathrm{H}-6 \mathrm{~b}\right), 3.56$ (ddd, $\left.J_{5,6 \mathrm{a}}=2.1, J_{5,6 \mathrm{~b}}=5.5, J_{4,5}=9.6 \mathrm{~Hz}, 1 \mathrm{H}, \mathrm{H}-5\right), 3.32(\mathrm{~s}, 3 \mathrm{H}, \mathrm{OMe}), 3.31(\mathrm{~m}, 1 \mathrm{H}, \mathrm{H}-$ 4), $2.10\left(\mathrm{dd}, J_{2 \mathrm{a}, 3}=5.3, J_{2 \mathrm{a}, 2 \mathrm{~b}}=13.5 \mathrm{~Hz}, 1 \mathrm{H}, \mathrm{H}-2 \mathrm{a}\right), 1.67\left(\mathrm{ddd}, J_{1,2 \mathrm{~b}}=3.5, J_{2 \mathrm{~b}, 3}=\right.$ 12.0, $\left.J_{2 \mathrm{a}, 2 \mathrm{~b}}=13.5 \mathrm{~Hz}, 1 \mathrm{H}, \mathrm{H}-2 \mathrm{~b}\right) ;{ }^{13} \mathrm{C} \mathrm{NMR}\left(150 \mathrm{MHz}, \mathrm{D}_{2} \mathrm{O}\right) \delta 98.1(\mathrm{C} 1), 71.9$ (C5), 70.8 (C4), 68.0 (C3), 60.5 (C6), 54.2 (OMe), 36.4 (C2); HRMS(ESI) m/z calcd. for $\left[\mathrm{C}_{7} \mathrm{H}_{14} \mathrm{O}_{5}+\mathrm{Na}\right]^{+}: 201.0733$, obsd,: 201.0735. $\beta$ isomer: $\mathrm{R}_{f}=0.27(10 \%$ $\mathrm{MeOH}$ in EtOAc); ${ }^{1} \mathrm{H}$ NMR $\left(600 \mathrm{MHz}, \mathrm{D}_{2} \mathrm{O}\right) \delta 4.59\left(\mathrm{dd}, J_{1,2 \mathrm{a}}=1.8, J_{1,2 \mathrm{~b}}=9.9\right.$ $\mathrm{Hz}, 1 \mathrm{H}, \mathrm{H}-1), 3.89$ (dd, $\left.J_{5,6 \mathrm{a}}=2.0, J_{6 \mathrm{a}, 6 \mathrm{~b}}=12.0 \mathrm{~Hz}, 1 \mathrm{H}, \mathrm{H}-6 \mathrm{a}\right), 3.65-3.72(\mathrm{~m}, 2 \mathrm{H}$, $\mathrm{H} 3$ and $\mathrm{H}-6 \mathrm{~b}), 3.48$ (s, 3H, OMe), $3.32(\mathrm{~m}, 1 \mathrm{H}, \mathrm{H}-5), 3.21$ (t, $J_{3,4}=J_{4,5}=9.6 \mathrm{~Hz}$, $1 \mathrm{H}, \mathrm{H}-4), 2.21\left(\mathrm{ddd}, J_{1,2 \mathrm{a}}=1.8, J_{2 \mathrm{a}, 3}=5.1, J_{2 \mathrm{a}, 2 \mathrm{~b}}=12.9 \mathrm{~Hz}, 1 \mathrm{H}, \mathrm{H}-2 \mathrm{a}\right), 1.43$ (ddd, $\left.J_{1,2 \mathrm{~b}}=9.9, J_{2 \mathrm{~b}, 3}=12.0, J_{2 \mathrm{a}, 2 \mathrm{~b}}=12.9 \mathrm{~Hz}, 1 \mathrm{H}, \mathrm{H}-2 \mathrm{~b}\right) ;{ }^{13} \mathrm{C} \mathrm{NMR}\left(150 \mathrm{MHz}, \mathrm{D}_{2} \mathrm{O}\right) \delta$ 100.6 (C1), 75.9 (C5), 70.9 (C4), 70.2 (C3), 60.8 (C6), 56.4 (OMe), 38.0 (C2); HRMS(ESI) $m / z$ calcd. for $\left[\mathrm{C}_{7} \mathrm{H}_{14} \mathrm{O}_{5}+\mathrm{Na}\right]^{+}:$201.0733, obsd,: 201.0735 . 
<smiles>CO[C@H]1C[C@@H](O)[C@@H](O)C[C@H]1CI</smiles>

Methyl 2,6-dideoxy-6-iodo- $\alpha$-D-glucoside (107): To a solution of methyl 2-deoxy-D-glucoside $(70.1 \mathrm{mg}, 0.4 \mathrm{mmol})$ in dry THF $(4 \mathrm{~mL})$ under an atmosphere of argon, was added imidazole (81.6 mg, $1.2 \mathrm{mmol}), \mathrm{PPh}_{3}(157 \mathrm{mg}$, $0.6 \mathrm{mmol})$, and $\mathrm{I}_{2}(152 \mathrm{mg}, 0.6 \mathrm{mmol})$. The reaction was heated to $75^{\circ} \mathrm{C}$ for $1.5 \mathrm{~h}$, then cooled and concentrated. The product was purified by silica gradient flash column chromatography (Petroleum Ether/EtOAc, 2/1, v/v), then reverse phase HP20 chromatography $(\mathrm{MeOH} /$ water, 1/5, v/v) to give the methyl 2,6-dideoxy-6iodo- $\alpha$-D-glucopyranoside (107) as a colourless oil $(74.1 \mathrm{mg}, 0.26 \mathrm{mmol}, 64 \%$ over 2 steps from 2-deoxy glucose 105). $\mathrm{R}_{f}=0.42(1 \% \mathrm{MeOH}$ in EtOAc); $[\alpha]_{\mathrm{D}}^{23}=+84.0\left(c=1.0, \mathrm{CHCl}_{3}\right)\left(\right.$ lit $=[\alpha]_{\mathrm{D}}{ }^{27}=+97, \mathrm{c}=0.9$ in chloroform $\left.{ }^{58}\right)$; IR (film) 3387, 2934, 1442, 1377, 1211, 1128, 1044, 966, $938 \mathrm{~cm}^{-1} ;{ }^{1} \mathrm{H}$ NMR (500 $\left.\mathrm{MHz} \mathrm{CDCl}_{3}\right) \delta 4.83\left(\mathrm{~d}, J_{1,2 \mathrm{~b}}=3.4 \mathrm{~Hz}, 1 \mathrm{H}, \mathrm{H}-1\right), 3.97\left(\mathrm{ddd}, J_{2 \mathrm{a}, 3}=5.1, J_{3,4}=8.7\right.$, $\left.J_{2 \mathrm{~b}, 3}=11.7 \mathrm{~Hz}, 1 \mathrm{H}, \mathrm{H}-3\right), 3.57-3.62$ (m, 1H, H-6a), 3.40 (s, 3H, OMe), 3.35-3.41 (m, 2H, H-5 and H-6b), 3.24-3.30 (m, 1H, H-4), $2.16\left(\mathrm{ddd}, J_{1,2 \mathrm{a}}=1.0, J_{2 \mathrm{a}, 3}=5.1\right.$, $\left.J_{2 \mathrm{a}, 2 \mathrm{~b}}=12.9 \mathrm{~Hz}, 1 \mathrm{H}, \mathrm{H}-2 \mathrm{a}\right), 1.71\left(\mathrm{ddd}, J_{1,2 \mathrm{~b}}=3.2, J_{2 \mathrm{~b}, 3}=11.7, J_{2 \mathrm{a}, 2 \mathrm{~b}}=12.9 \mathrm{~Hz}\right.$, 1H, H-2b); ${ }^{13} \mathrm{C}$ NMR (125 MHz, $\mathrm{CDCl}_{3}$ ) $\delta 98.7$ (C1), 77.6 (C4), 70.4 (C5), 69.1 (C3), 55.3 (OMe), 37.8 (C2), 7.9 (C6); HRMS(ESI) $\mathrm{m} / z$ calcd. for $\left[\mathrm{C}_{7} \mathrm{H}_{13} \mathrm{O}_{4} \mathrm{I}+\mathrm{Na}\right]^{+}:$310.9751, obsd.: 310.9751 .<smiles>CO[C@H]1C[C@@H](I)[C@@H](O)C(CI)O1</smiles>

$0.76\left(10 \% \mathrm{MeOH}\right.$ in EtOAc); ${ }^{1} \mathrm{H}$ NMR $\left(500 \mathrm{MHz}, \mathrm{CDCl}_{3}\right) \delta 4.87(\mathrm{~d}, J=4.1 \mathrm{~Hz}$, $1 \mathrm{H}, \mathrm{H}-1), 4.62$ (dd, $J=4.0, J=8.0 \mathrm{~Hz}, 1 \mathrm{H}, \mathrm{H}-3), 3.66-3.51$ (m, 2H, H-5 and H6a), 3.44-3.34 (m, 4H, H-6b and OMe), 2.66-2.41 (m, 3H, H-2a, H-2b, and H-4); ${ }^{13} \mathrm{C}$ NMR (125 MHz, $\mathrm{CDCl}_{3}$ ) $\delta 97.6$ (C1), 70.8 (C4), 70.3 (C5), 55.4 (OMe), 37.4 (C2), 33.1 (C3) 7.2 (C6); HRMS(ESI) $m / z$ calcd. for $\left[\mathrm{C}_{7} \mathrm{H}_{12} \mathrm{O}_{3} \mathrm{I}_{2}+\mathrm{Na}\right]^{+}$: 420.8768 , obsd.: 420.8773 . 
<smiles>C=CC(O)C(O)CCN</smiles>

(3R,4R)-1-Amino-hex-5-ene-3,4-diol hydrochloride (110):

To a solution of methyl 2,6-dideoxy-6-iodo- $\alpha$-D-glucoside (107) (111 mg, 0.39 mmol) in a saturated solution of $\mathrm{NH}_{4} \mathrm{OAc}$ in $\mathrm{EtOH}(7.3 \mathrm{~mL})$ was added activated $\mathrm{Zn}(450 \mathrm{mg}, 6.9 \mathrm{mmol}), \mathrm{NaCNBH}_{3}(85 \mathrm{mg}, 1.3 \mathrm{mmol})$ and $30 \%$ aqueous $\mathrm{NH}_{3}(2.9$ $\mathrm{mL}$ ). The mixture was stirred at reflux for $4.5 \mathrm{~h}$, cooled to room temperature, filtered through celite and concentrated under reduced pressure. $30 \mathrm{~mL} \mathrm{HCl}(2 \mathrm{M})$ was added and $\mathrm{AcOH}$ was removed by evaporation. Coevaporation with water/EtOH was performed to remove traces of $\mathrm{AcOH}$, before an aqueous solution of $\mathrm{NaOH}(40 \mathrm{~mL}, 1.25 \mathrm{M})$ was added and the $\mathrm{NH}_{3}$ was evaporated. The resulting solid was filtered and washed with $\mathrm{EtOH}$, to remove the bulk of the insoluble $\mathrm{NaCl}$ salt, and the filtrate and combined washings were concentrated before dry loading on silica for column chromatography (DCM/EtOH/MeOH/35\% aqueous $\mathrm{NH}_{3}, \quad 55 / 2 / 2 / 1$ to $5 / 2 / 2 / 1, \mathrm{v} / \mathrm{v} / \mathrm{v} / \mathrm{v}$ ). Alkenylamine 110, was obtained as the $\mathrm{HCl}$ salt after the addition of $\mathrm{HCl}(1.2 \mathrm{M}$, aq) and concentration to obtain a white solid (55.5 $\mathrm{mg}, 0.33 \mathrm{mmol}, 86 \%) . \mathrm{R}_{f}=$ $0.16\left(\mathrm{DCM} / \mathrm{EtOH} / \mathrm{MeOH} / 35 \%\right.$ aqueous $\left.\mathrm{NH}_{3}, 5 / 2 / 2 / 1, \mathrm{v} / \mathrm{v} / \mathrm{v} / \mathrm{v}\right) ;[\alpha]_{\mathrm{D}}{ }^{27}=+37.5(c$ = 1.0, MeOH); IR (film) 3336, 2924, 1621, 1505, 1468, 1396, 1312, 1255, 1122, 1020, 997, 931, $854 \mathrm{~cm}^{-1} ;{ }^{1} \mathrm{H} \mathrm{NMR}\left(500 \mathrm{MHz}, \mathrm{D}_{2} \mathrm{O}\right) \delta 5.87\left(\mathrm{ddd}, J_{4,5}=6.7, J_{5,6 \text {-cis }}\right.$ $\left.=10.5, J_{5,6 \text {-trans }}=17.3 \mathrm{~Hz}, 1 \mathrm{H}, \mathrm{H}-5\right), 5.34\left(\mathrm{~d}, J_{5,6 \text {-trans }}=17.3 \mathrm{~Hz}, 1 \mathrm{H}, \mathrm{H}-6\right.$-trans $)$, $5.28\left(\mathrm{~d}, J_{5,6-c i s}=10.5 \mathrm{~Hz}, 1 \mathrm{H}, \mathrm{H}-6-c i s\right), 4.03\left(\mathrm{dd}, J_{4,5}=6.7, J_{3,4}=6.8 \mathrm{~Hz}, 1 \mathrm{H}, \mathrm{H}-\right.$ 4), $3.70\left(\mathrm{ddd}, J_{2 \mathrm{a}, 3}=2.9, J_{2 \mathrm{~b}, 3}=5.4, J_{3,4}=6.8 \mathrm{~Hz}, 1 \mathrm{H}, \mathrm{H}-3\right), 3.13(\mathrm{~m}, 2 \mathrm{H}, \mathrm{H}-1)$, 1.89 (m, 1H, H-2a), 1.77 (m, 1H, H-2b); ${ }^{13} \mathrm{C}$ NMR (125 MHz, D $\left.2 \mathrm{O}\right) \delta 136.1$ (C5), 118.1 (C6), 75.4 (C4), 71.7 (C3), 37.2 (C1), 29.4 (C2); HRMS(ESI) m/z calcd. for $\left[\mathrm{C}_{6} \mathrm{H}_{13} \mathrm{O}_{2} \mathrm{~N}+\mathrm{H}\right]^{+}:$132.1019, obsd.: 132.1031 .

Iodo-cyclisation/carbamate annulation: To a solution of alkenylamine hydrochloride $110(240 \mathrm{mg}, 1.4 \mathrm{mmol})$ in saturated aqueous $\mathrm{NaHCO}_{3}(7.2 \mathrm{~mL})$ (made fresh immediately prior to use) was added $I_{2}(1900 \mathrm{mg}, 7.5 \mathrm{mmol})$ and $\mathrm{NaHCO}_{3}(1400 \mathrm{mg}, 17 \mathrm{mmol})$. The solution was stirred at room temperature for 5 days, filtered, and concentrated under reduced pressure. The products were 
separated by repeated silica plug $(0-10 \% \mathrm{MeOH}$ in EtOAc, v/v), and reverse phase columns (octyl bonded endcapped silica beads) eluting in $\mathrm{H}_{2} \mathrm{O}$ (for carbamates 111, 112a and 112b) and $\mathrm{MeOH}$ (for iodide 113)), all as white solids. Yield of $\mathbf{1 1 1}=10-30 \%$.

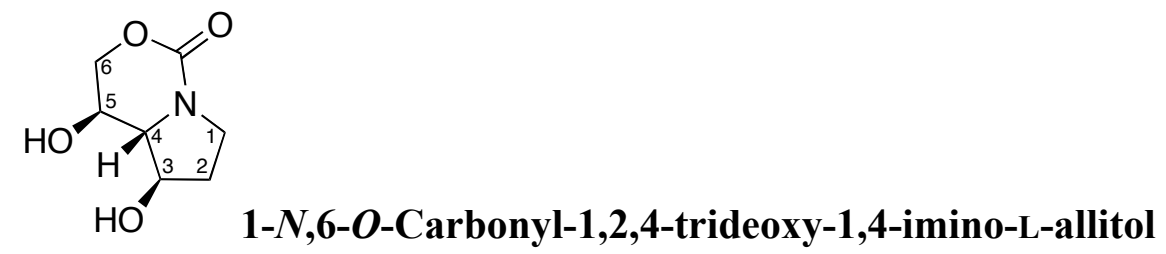

(111): $[\alpha]_{\mathrm{D}}^{25}=-0.5(c=0.4, \mathrm{MeOH})$; IR (film) 3390, 3331, 2965, 2914, 1719, 1634, 1517, 1477, 1455, 1133, 1110, $1070 \mathrm{~cm}^{-1}$; ${ }^{1} \mathrm{H}$ NMR (500 MHz, D $\left.2 \mathrm{O}\right) \delta$ 4.19-4.27 (m, 2H, H-3, H-6a), 3.94-4.03 (m, 2H, H-5, H-6b), 3.47 (dd, $J_{1,2 \mathrm{a}}=6.1, J_{1,2 \mathrm{~b}}=9.0$ $\mathrm{Hz}, 2 \mathrm{H}, \mathrm{H}-1), 3.28$ (t, $\left.J_{4,5}=J_{3,4}=7.7 \mathrm{~Hz}, 1 \mathrm{H}, \mathrm{H}-4\right), 2.24\left(\mathrm{dq}, J_{1,2 \mathrm{a}}=J_{2 \mathrm{a}, 3}=6.1\right.$, $\left.J_{2 \mathrm{a}, 2 \mathrm{~b}}=12.6 \mathrm{~Hz}, 1 \mathrm{H}, \mathrm{H}-2 \mathrm{a}\right), 1.80\left(\mathrm{dq}, J_{1,2 \mathrm{~b}}=J_{2 \mathrm{~b}, 3}=9.0, J_{2 \mathrm{a}, 2 \mathrm{~b}}=12.6 \mathrm{~Hz}, 1 \mathrm{H}, \mathrm{H}-\right.$ 2b); ${ }^{13} \mathrm{C}$ NMR (150 MHz, $\left.\mathrm{D}_{2} \mathrm{O}\right) \delta 154.4(\mathrm{C}=\mathrm{O}), 74.0$ (C3), 69.2 (C6), 64.8 (C4), 64.2 (C5), 44.2 (C1), 30.2 (C2); HRMS(ESI) $\mathrm{m} / \mathrm{z}$ calcd. for $\left[\mathrm{C}_{7} \mathrm{H}_{11} \mathrm{O}_{4} \mathrm{~N}+\mathrm{Na}\right]^{+}$: 196.0580, obsd.: 196.0579 .<smiles></smiles><smiles>O=C1OC[C@@H]2[C@@H](O)C(O)CCN12</smiles>
$\mathrm{OH}$ 1-N,6-O-Carbonyl-5-epi-fagomine (112a) and 1-N,6-O-

Carbonyl-fagomine (112b): IR (film) 3409, 2948, 2840, 1632, 1462, 1403, 1092 , $1010 \mathrm{~cm}^{-1}$. Major isomer (112a): ${ }^{1} \mathrm{H}$ NMR $\left(500 \mathrm{MHz}, \mathrm{D}_{2} \mathrm{O}\right) \delta 4.53\left(\mathrm{t}, J_{5,6 \mathrm{a}}=\right.$ $\left.J_{6 \mathrm{a}, 6 \mathrm{~b}}=9.0 \mathrm{~Hz}, 1 \mathrm{H}, \mathrm{H}-6 \mathrm{a}\right), 4.34\left(\mathrm{dd}, J_{5,6 \mathrm{~b}}=6.0, J_{6 \mathrm{a}, 6 \mathrm{~b}}=9.0 \mathrm{~Hz}, 1 \mathrm{H}, \mathrm{H}-6 \mathrm{~b}\right), 4.23$ $\left(\mathrm{ddd}, J_{4,5}=2.5, J_{5,6 \mathrm{~b}}=6.0, J_{5,6 \mathrm{a}}=9.0 \mathrm{~Hz}, 1 \mathrm{H}, \mathrm{H}-5\right), 4.06\left(\mathrm{dd}, J_{3,4}=3.2, J_{2 \mathrm{a}, 3}=6.3\right.$ $\mathrm{Hz}, 1 \mathrm{H}, \mathrm{H}-3), 3.73(\mathrm{~m}, 1 \mathrm{H}, \mathrm{H}-4), 3.56\left(\mathrm{dd}, J_{1 \mathrm{a}, 2 \mathrm{a}}=6.3, J_{1 \mathrm{a}, 1 \mathrm{~b}}=13.5 \mathrm{~Hz}, 1 \mathrm{H}, \mathrm{H}-1 \mathrm{a}\right)$, $3.23\left(\mathrm{td}, J_{1 \mathrm{~b}, 2 \mathrm{a}}=3.7, J_{1 \mathrm{a}, 1 \mathrm{~b}}=J_{1 \mathrm{~b}, 2 \mathrm{~b}}=13.5 \mathrm{~Hz}, 1 \mathrm{H}, \mathrm{H}-1 \mathrm{~b}\right), 1.95-2.02(\mathrm{~m}, 1 \mathrm{H}, \mathrm{H}-2 \mathrm{a})$, $1.64\left(\mathrm{~d}, J_{2 \mathrm{a}, 2 \mathrm{~b}}=15.0 \mathrm{~Hz}, 1 \mathrm{H}, \mathrm{H}-2 \mathrm{~b}\right) ;{ }^{13} \mathrm{C} \mathrm{NMR}\left(125 \mathrm{MHz}, \mathrm{D}_{2} \mathrm{O}\right) \delta 159.2(\mathrm{C}=\mathrm{O})$, 66.5 (C3), 66.5 (C4), 64.1 (C6), 53.2 (C5), 35.2 (C1), 24.4 (C2); HRMS(ESI) m/z calcd. for $\left[\mathrm{C}_{7} \mathrm{H}_{11} \mathrm{O}_{4} \mathrm{~N}+\mathrm{Na}\right]^{+}:$196.0586, obsd.: 196.0587. Minor isomer (112b): ${ }^{1} \mathrm{H}$ NMR $\left(500 \mathrm{MHz}, \mathrm{D}_{2} \mathrm{O}\right) \delta 4.53\left(\mathrm{t}, J_{5,6 \mathrm{a}}=J_{6 \mathrm{a}, 6 \mathrm{~b}}=9.0 \mathrm{~Hz}, 1 \mathrm{H}, \mathrm{H}-6 \mathrm{a}\right), 4.31(\mathrm{dd}$, 
$\left.J_{5,6 \mathrm{~b}}=5.0, J_{6 \mathrm{a}, 6 \mathrm{~b}}=9.0 \mathrm{~Hz}, 1 \mathrm{H}, \mathrm{H}-6 \mathrm{~b}\right), 3.68-3.71(\mathrm{~m}, 1 \mathrm{H}, \mathrm{H}-1 \mathrm{a}), 3.67\left(\mathrm{ddd}, J_{5,6 \mathrm{~b}}=\right.$ $\left.5.0, J_{5,6 \mathrm{a}}=9.0, J_{4,5}=9.5 \mathrm{~Hz}, 1 \mathrm{H}, \mathrm{H}-5\right), 3.62\left(\mathrm{ddd}, J_{2 \mathrm{~b}, 3}=5.0, J_{3,4}=9.5, J_{2 \mathrm{a}, 3}=11.5\right.$ $\mathrm{Hz}, 1 \mathrm{H}, \mathrm{H}-3), 3.34\left(\mathrm{t}, J_{3,4}=J_{4,5}=9.4 \mathrm{~Hz}, 1 \mathrm{H}, \mathrm{H}-4\right), 3.03\left(\mathrm{td}, J_{1 \mathrm{~b}, 2 \mathrm{a}}=3.2, J_{1 \mathrm{a}, 1 \mathrm{~b}}=\right.$ $\left.J_{1 \mathrm{~b}, 2 \mathrm{~b}}=13.0 \mathrm{~Hz}, 1 \mathrm{H}, \mathrm{H}-1 \mathrm{~b}\right), 1.92-1.98(\mathrm{~m}, 1 \mathrm{H}, \mathrm{H}-2 \mathrm{a}), 1.51\left(\mathrm{ddt}, J_{2 \mathrm{~b}, 3}=5.0, J_{1 \mathrm{a}, 2 \mathrm{~b}}=\right.$ $\left.11.7, J_{1 \mathrm{~b}, 2 \mathrm{~b}}=J_{2 \mathrm{a}, 2 \mathrm{~b}}=13.0 \mathrm{~Hz}, 1 \mathrm{H}, \mathrm{H}-2 \mathrm{~b}\right) ;{ }^{13} \mathrm{C} \mathrm{NMR}\left(125 \mathrm{MHz}, \mathrm{D}_{2} \mathrm{O}\right) \delta 158.7$ (C=O), 74.5 (C4), 71.4 (C3), 66.5 (C6), 57.6 (C5), 38.7 (C1), 30.8 (C2); HRMS(ESI) $m / z$ calcd. for $\left[\mathrm{C}_{7} \mathrm{H}_{11} \mathrm{O}_{4} \mathrm{~N}+\mathrm{Na}\right]^{+}:$196.0580, obsd.: 196.0587.<smiles>O=C1NCC[C@H](C(O)C(O)CI)O1</smiles>

(113): $\mathrm{R}_{f}=0.26(10 \% \mathrm{MeOH}$ in EtOAc $) ;[\alpha]_{\mathrm{D}}{ }^{26}=-8.9(c=0.67, \mathrm{MeOH}) ; \mathrm{IR}$ (film) 3367, 2928, 1680, 1488, 1457, 1300, 1223, 1108, 1021, $523 \mathrm{~cm}^{-1}$; ${ }^{1} \mathrm{H}$ NMR $\left(500 \mathrm{MHz}, \mathrm{D}_{2} \mathrm{O}\right) \delta 4.50$ (dt, $\left.J=3.3, J=9.9 \mathrm{~Hz}, 1 \mathrm{H}, \mathrm{H}-3\right), 3.72-3.81$ (m, 2H, H-4 and H-5), 3.44 (dd, $J=3.9, J=10.5 \mathrm{~Hz}, 1 \mathrm{H}, \mathrm{H}-6 \mathrm{a}), 3.29-3.37$ (m, 3H, H-1ab and H-6b), 1.90-2.01 (m, 2H, H-2ab); ${ }^{13} \mathrm{C}$ NMR (125 MHz, $\left.\mathrm{D}_{2} \mathrm{O}\right) \delta 154.7$ (C=O), 76.1 (C3), 71.8, 68.1 (C4, C5), 35.8 (C1), 19.6 (C2), 6.2 (C6); HRMS(ESI) m/z calcd. for $\left[\mathrm{C}_{7} \mathrm{H}_{12} \mathrm{O}_{4} \mathrm{NI}+\mathrm{H}\right]^{+}:$301.9884, obsd.: 301.9888 .

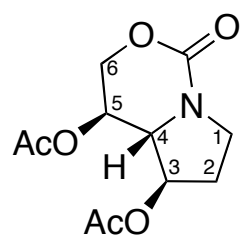

\section{3,5-Di-O-acetyl-1- $N, 6-O$-carbonyl-1,2,4-trideoxy-1,4-imino-L-}

allitol (114): Carbamate 111 (124.7 mg, $0.7 \mathrm{mmol})$ was subjected to dry pyridine $(1.0 \mathrm{~mL})$ and acetic anhydride $(1.0 \mathrm{~mL})$ at $\mathrm{rt}$, under an argon atmosphere, overnight $(14 \mathrm{~h})$. After concentration, the crude compound was dry-loaded on silica before gradient column chromatography (Petroleum Ether to Petroleum Ether/EtOAc, 1/1, v/v). Acetylated carbamate $\mathbf{1 1 4}$ was recovered as a white solid. $\mathrm{R}_{f}=0.44\left(5 \% \mathrm{MeOH}\right.$ in EtOAc); $[\alpha]_{\mathrm{D}}{ }^{27}=+19.9(c=0.1, \mathrm{MeOH})$; IR (film) 2957, $2925,1741,1711,1430,1367,1238,1070,754 \mathrm{~cm}^{-1} ;{ }^{1} \mathrm{H}$ NMR $\left(500 \mathrm{MHz}, \mathrm{CDCl}_{3}\right)$ $\delta 5.16\left(\mathrm{dt}, J_{3,4}=6.5, J_{2 \mathrm{a}, 3}=J_{2 \mathrm{~b}, 3}=7.5 \mathrm{~Hz}, 1 \mathrm{H}, \mathrm{H}-3\right), 5.06\left(\mathrm{td}, J_{5,6 \mathrm{a}}=4.9, J_{4,5}=J_{5,6 \mathrm{~b}}\right.$ 
$=9.0 \mathrm{~Hz}, 1 \mathrm{H}, \mathrm{H}-5), 4.32\left(\mathrm{dd}, J_{5,6 \mathrm{a}}=4.9, J_{6 \mathrm{a}, 6 \mathrm{~b}}=11.0 \mathrm{~Hz}, 1 \mathrm{H}, \mathrm{H}-6 \mathrm{a}\right), 4.05\left(\mathrm{dd}, J_{5,6 \mathrm{~b}}\right.$ $\left.=9.0, J_{6 \mathrm{a}, 6 \mathrm{~b}}=11.0 \mathrm{~Hz}, 1 \mathrm{H}, \mathrm{H}-6 \mathrm{~b}\right), 3.79\left(\mathrm{dt}, J_{1 \mathrm{a}, 2 \mathrm{a}}=J_{1 \mathrm{a}, 2 \mathrm{~b}}=7.5, J_{1 \mathrm{a}, 1 \mathrm{~b}}=11.0 \mathrm{~Hz}\right.$, $1 \mathrm{H}, \mathrm{H}-1 \mathrm{a}), 3.50-3.57$ (m, 2H, H-1b and H-4), $2.32\left(\mathrm{dt}, J_{1 \mathrm{a}, 2 \mathrm{a}}=J_{1 \mathrm{~b}, 2 \mathrm{a}}=J_{2 \mathrm{a}, 3}=7.5\right.$, $\left.J_{2 \mathrm{a}, 2 \mathrm{~b}}=14.5 \mathrm{~Hz}, 1 \mathrm{H}, \mathrm{H}-2 \mathrm{a}\right), 2.11(\mathrm{~s}, 3 \mathrm{H}, \mathrm{Me}), 2.08(\mathrm{~s}, 3 \mathrm{H}, \mathrm{Me}), 1.88$ (dt, $J_{1 \mathrm{a}, 2 \mathrm{~b}}=$ $\left.J_{1 \mathrm{~b}, 2 \mathrm{~b}}=J_{2 \mathrm{~b}, 3}=7.5, J_{2 \mathrm{a}, 2 \mathrm{~b}}=14.5 \mathrm{~Hz}, 1 \mathrm{H}, \mathrm{H}-2 \mathrm{~b}\right) ;{ }^{1} \mathrm{H} \mathrm{NMR}\left(300 \mathrm{MHz}, \mathrm{CD}_{3} \mathrm{OD}\right) \delta$ $5.19\left(\mathrm{dd}, J_{3,4}=7.2, J_{2 \mathrm{~b}, 3}=7.9 \mathrm{~Hz}, 1 \mathrm{H}, \mathrm{H}-3\right), 5.12\left(\mathrm{dd}, J_{5,6 \mathrm{a}}=4.7, J_{4,5}=J_{5,6 \mathrm{~b}}=8.7\right.$ $\mathrm{Hz}, 1 \mathrm{H}, \mathrm{H}-5), 4.32\left(\mathrm{dd}, J_{5,6 \mathrm{a}}=4.7, J_{6 \mathrm{a}, 6 \mathrm{~b}}=10.8 \mathrm{~Hz}, 1 \mathrm{H}, \mathrm{H}-6 \mathrm{a}\right), 4.11\left(\mathrm{dd}, J_{5,6 \mathrm{~b}}=\right.$ $\left.8.7, J_{6 \mathrm{a}, 6 \mathrm{~b}}=10.8 \mathrm{~Hz}, 1 \mathrm{H}, \mathrm{H}-6 \mathrm{~b}\right), 3.66\left(\mathrm{dt}, J_{1 \mathrm{a}, 2 \mathrm{a}}=J_{1 \mathrm{a}, 2 \mathrm{~b}}=8.0, J_{1 \mathrm{a}, 1 \mathrm{~b}}=11.1 \mathrm{~Hz}, 1 \mathrm{H}\right.$, $\mathrm{H}-1 \mathrm{a}), 3.62\left(\mathrm{dd}, J_{3,4}=7.2, J_{4,5}=8.7 \mathrm{~Hz}, 1 \mathrm{H}, \mathrm{H}-4\right), 3.49\left(\mathrm{ddd}, J_{1 \mathrm{~b}, 2 \mathrm{~b}}=4.7, J_{1 \mathrm{~b}, 2 \mathrm{a}}=\right.$ 9.1, $\left.J_{1 \mathrm{a}, 1 \mathrm{~b}}=11.1 \mathrm{~Hz}, 1 \mathrm{H}, \mathrm{H}-1 \mathrm{~b}\right), 2.34\left(\mathrm{dddd}, J_{1 \mathrm{~b}, 2 \mathrm{~b}}=4.7, J_{2 \mathrm{~b}, 3}=7.9, J_{1 \mathrm{a}, 2 \mathrm{~b}}=8.0\right.$, $\left.J_{2 \mathrm{a}, 2 \mathrm{~b}}=12.9 \mathrm{~Hz}, 1 \mathrm{H}, \mathrm{H}-2 \mathrm{a}\right), 2.07$ (s, 3H, Me), 2.05 (s, 3H, Me), 1.88 (ddt, $J_{1 \mathrm{a}, 2 \mathrm{~b}}=$ $\left.J_{2 \mathrm{~b}, 3}=7.9, J_{1 \mathrm{~b}, 2 \mathrm{~b}}=9.1, J_{2 \mathrm{a}, 2 \mathrm{~b}}=12.9 \mathrm{~Hz}, 1 \mathrm{H}, \mathrm{H}-2 \mathrm{~b}\right) ;{ }^{13} \mathrm{C} \mathrm{NMR}\left(125 \mathrm{MHz}, \mathrm{CDCl}_{3}\right) \delta$ $170.1(\mathrm{C}=\mathrm{O}, \mathrm{Ac}), 169.9(\mathrm{C}=\mathrm{O}, \mathrm{Ac}), 151.6(\mathrm{C}=\mathrm{O}), 75.2(\mathrm{C} 3), 66.7(\mathrm{C} 6), 65.7(\mathrm{C} 5)$, 63.2 (C4), 44.9 (C1), 28.8 (C2), $20.9\left(\mathrm{CH}_{3}, \mathrm{Ac}\right), 20.8\left(\mathrm{CH}_{3}, \mathrm{Ac}\right)$; HRMS(ESI) $\mathrm{m} / z$ calcd. for $\left[\mathrm{C}_{11} \mathrm{H}_{15} \mathrm{O}_{6} \mathrm{~N}+\mathrm{Na}\right]^{+}: 280.0792$, obsd.: 280.0791 .

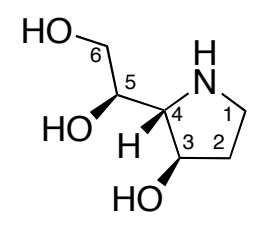

1,2,4-Trideoxy-1,4-imino-L-allitol (115): Carbamate 111 (10.6 $\mathrm{mg}, 0.061 \mathrm{mmol})$ was dissolved in $\mathrm{EtOH}(1 \mathrm{~mL})$ and $\mathrm{NaOH}(26 \mathrm{mg}, 0.6 \mathrm{mmol})$ was added. The solution was refluxed for $2 \mathrm{~h}$, then neutralised with aqueous $\mathrm{HCl}$ (1 M) before loading on silica for chromatography (DCM/EtOH/MeOH/35\% aqueous $\mathrm{NH}_{3}, 55 / 2 / 2 / 1$ to $\left.15 / 2 / 2 / 1, \mathrm{v} / \mathrm{v} / \mathrm{v} / \mathrm{v}\right)$. The product 115 was obtained as a white solid (8.0 mg, $0.054 \mathrm{mmol}, 89 \%) . \mathrm{R}_{f}=0.19$ (DCM/EtOH/MeOH/35\% aqueous $\left.\mathrm{NH}_{3}, 5 / 2 / 2 / 1, \mathrm{v} / \mathrm{v} / \mathrm{v} / \mathrm{v}\right) ;[\alpha]_{\mathrm{D}}{ }^{26}=-1.8(c=0.41, \mathrm{MeOH})$ (lit (115enantiomer) $=[\alpha]_{\mathrm{D}}^{22}=+4.7, \mathrm{c}=4.0, \mathrm{MeOH}^{19}$ ); IR (film) 3309, 2956, 2927, 1629, 1420, 1089, $1041 \mathrm{~cm}^{-1} ;{ }^{1} \mathrm{H}$ NMR $\left(500 \mathrm{MHz}, \mathrm{D}_{2} \mathrm{O}\right) \delta 4.33\left(\mathrm{dt}, J_{2 \mathrm{~b}, 3}=J_{3,4}=\right.$ 4.3, $\left.J_{2 \mathrm{a}, 3}=6.2 \mathrm{~Hz}, 1 \mathrm{H}, \mathrm{H}-3\right), 3.78\left(\mathrm{dd}, J_{4,5}=4.3, J_{5,6}=10.3 \mathrm{~Hz}, 1 \mathrm{H}, \mathrm{H}-5\right), 3.44-$ $3.52(\mathrm{~m}, 2 \mathrm{H}, \mathrm{H}-6), 3.35$ (t, $\left.J_{3,4}=J_{4,5}=4.3 \mathrm{~Hz}, 1 \mathrm{H}, \mathrm{H}-4\right), 3.21\left(\mathrm{dd}, J_{1,2 \mathrm{~b}}=6.3, J_{1,2 \mathrm{a}}\right.$ $=8.1 \mathrm{~Hz}, 2 \mathrm{H}, \mathrm{H}-1), 2.02\left(\mathrm{ddd}, J_{2 \mathrm{a}, 3}=6.2, J_{1,2 \mathrm{a}}=8.1, J_{2 \mathrm{a}, 2 \mathrm{~b}}=14.2 \mathrm{~Hz}, 1 \mathrm{H}, \mathrm{H}-2 \mathrm{a}\right)$, $1.78\left(\mathrm{ddd}, J_{2 \mathrm{~b}, 3}=4.3, J_{1,2 \mathrm{~b}}=6.3, J_{2 \mathrm{a}, 2 \mathrm{~b}}=14.2 \mathrm{~Hz}, 1 \mathrm{H}, \mathrm{H}-2 \mathrm{~b}\right) ;{ }^{13} \mathrm{C} \mathrm{NMR}(125 \mathrm{MHz}$, 
$\left.\mathrm{D}_{2} \mathrm{O}\right) \quad \delta \quad 69.4(\mathrm{C} 3), 68.4(\mathrm{C} 5), 67.1$ (C4), 62.5 (C6), 44.1 (C1), 32.6 (C2); HRMS(ESI) $m / z$ calcd. for $\left[\mathrm{C}_{6} \mathrm{H}_{13} \mathrm{O}_{3} \mathrm{~N}+\mathrm{H}\right]^{+}: 148.0968$, obsd.: 148.0978 .

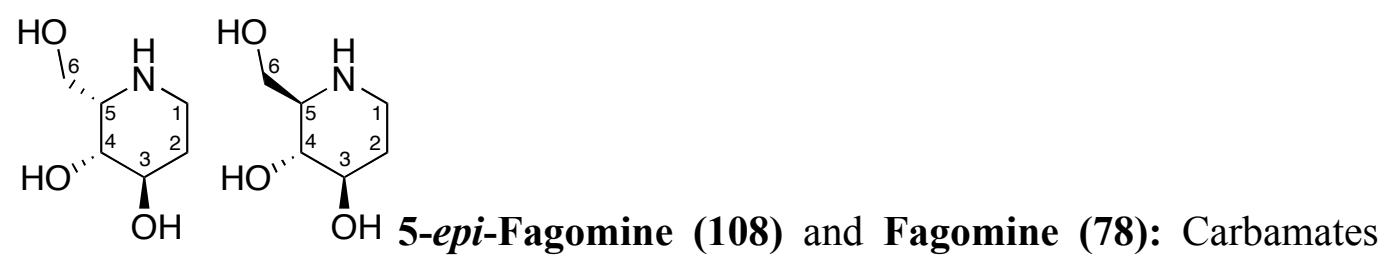

112a and 112b (11.7 mg, $0.07 \mathrm{mmol})$ were dissolved in EtOH $(1 \mathrm{~mL})$ and $\mathrm{NaOH}$ (80 mg, $2 \mathrm{mmol}$ ) was added. The solution was refluxed for $2 \mathrm{~h}$, then neutralised with aqueous $\mathrm{HCl}(1 \mathrm{M})$, followed by concentration in vacuo. Purification by gradient silica column chromatography (DCM/EtOH/MeOH/35\% aqueous $\mathrm{NH}_{3}$, $45 / 2 / 2 / 1$ to $15 / 2 / 2 / 1, \mathrm{v} / \mathrm{v} / \mathrm{v} / \mathrm{v}$ ) gave the products $\mathbf{7 8}$ and $\mathbf{1 0 8}$ as a white solid and a mixture of diastereomers (12.4 mg, $0.07 \mathrm{mmol}$, quant.). 5-epi-Fagomine (108): $\mathrm{R}_{\mathrm{f}}$ $=0.24\left(\mathrm{DCM} / \mathrm{EtOH} / \mathrm{MeOH} / 35 \%\right.$ aqueous $\left.\mathrm{NH}_{3}, 5 / 2 / 2 / 1, \mathrm{v} / \mathrm{v} / \mathrm{v} / \mathrm{v}\right) ;[\alpha]_{\mathrm{D}}{ }^{29}=-8.9(c$ $=0.63, \mathrm{MeOH})\left(\mathrm{lit}=[\alpha]_{\mathrm{D}}=-11.6, \mathrm{c}=0.94, \mathrm{H}_{2} \mathrm{O}^{16 \mathrm{~d}}\right) ; \mathrm{IR}($ film) 3364, 2970, 1425, 1366, 1217, $1079 \mathrm{~cm}^{-1}$; ${ }^{1} \mathrm{H}$ NMR (500 MHz, D $\left.2 \mathrm{O}\right) \delta 4.02$ (m, 1H, H-3), 3.93 (m, $1 \mathrm{H}, \mathrm{H}-4), 3.85\left(\mathrm{dd}, J_{5,6 \mathrm{a}}=4.9, J_{6 \mathrm{a}, 6 \mathrm{~b}}=12.0 \mathrm{~Hz}, 1 \mathrm{H}, \mathrm{H}-6 \mathrm{a}\right), 3.80\left(\mathrm{dd}, J_{5,6 \mathrm{~b}}=8.5\right.$, $\left.J_{6 \mathrm{a}, 6 \mathrm{~b}}=12.0 \mathrm{~Hz}, 1 \mathrm{H}, \mathrm{H}-6 \mathrm{~b}\right), 3.54\left(\mathrm{dd}, J_{5,6 \mathrm{a}}=4.9, J_{5,6 \mathrm{~b}}=8.5 \mathrm{~Hz}, 1 \mathrm{H}, \mathrm{H}-5\right), 3.20-$ 3.31 (m, 2H, H-1ab), 2.16-2.24 (m, 1H, H-2a), 1.84 (d, $J_{2 \mathrm{a}, 2 \mathrm{~b}}=14.5 \mathrm{~Hz}, 1 \mathrm{H}, \mathrm{H}-$ 2b); ${ }^{13} \mathrm{C}$ NMR (125 MHz, $\left.\mathrm{D}_{2} \mathrm{O}\right) \delta 65.8$ (C4), 64.8 (C3), 59.5 (C6), 55.8 (C5), 38.9 (C1), 23.6 (C2); HRMS(ESI) $\mathrm{m} / z$ calcd. for $\left[\mathrm{C}_{6} \mathrm{H}_{13} \mathrm{O}_{3} \mathrm{~N}+\mathrm{H}\right]^{+}$: 148.0974, obsd.: 148.0968. Fagomine (78): $\mathrm{R}_{f}=0.33\left(\mathrm{DCM} / \mathrm{EtOH} / \mathrm{MeOH} / 35 \%\right.$ aqueous $\mathrm{NH}_{3}$, $5 / 2 / 2 / 1, \mathrm{v} / \mathrm{v} / \mathrm{v} / \mathrm{v}) ;[\alpha]_{\mathrm{D}}{ }^{29}=+8.4(c=0.27, \mathrm{MeOH})\left(\right.$ lit $=[\alpha]_{\mathrm{D}}=+12.2, \mathrm{c}=0.33$, $\mathrm{MeOH}^{16 \mathrm{~d}}$ ); IR (film) 3367, 2930, 1461, 1271, $1073 \mathrm{~cm}^{-1} ;{ }^{1} \mathrm{H}$ NMR (500 MHz, $\left.\mathrm{D}_{2} \mathrm{O}\right) \delta 3.93\left(\mathrm{dd}, J_{5,6 \mathrm{a}}=3.2, J_{6 \mathrm{a}, 6 \mathrm{~b}}=12.5 \mathrm{~Hz}, 1 \mathrm{H}, \mathrm{H}-6 \mathrm{a}\right), 3.88\left(\mathrm{dd}, J_{5,6 \mathrm{~b}}=5.5, J_{6 \mathrm{a}, 6 \mathrm{~b}}\right.$ $=12.5 \mathrm{~Hz}, 1 \mathrm{H}, \mathrm{H}-6 \mathrm{~b}), 3.71\left(\mathrm{ddd}, J_{2 \mathrm{a}, 3}=4.9, J_{3,4}=9.0, J_{2 \mathrm{~b}, 3}=11.7 \mathrm{~Hz}, 1 \mathrm{H}, \mathrm{H}-3\right)$, $3.52\left(\mathrm{t}, J_{3,4}=J_{4,5}=9.0 \mathrm{~Hz}, 1 \mathrm{H}, \mathrm{H}-4\right), 3.44\left(\mathrm{ddd}, J_{1 \mathrm{a}, 2 \mathrm{a}}=2.5, J_{1 \mathrm{a}, 2 \mathrm{~b}}=4.1, J_{1 \mathrm{a}, 1 \mathrm{~b}}=\right.$ $13.5 \mathrm{~Hz}, 1 \mathrm{H}, \mathrm{H}-1 \mathrm{a}), 3.12-3.16(\mathrm{~m}, 1 \mathrm{H}, \mathrm{H}-5), 3.10\left(\mathrm{dd}, J_{1 \mathrm{~b}, 2 \mathrm{a}}=2.5, J_{1 \mathrm{~b}, 2 \mathrm{~b}}=J_{1 \mathrm{a}, 1 \mathrm{~b}}=\right.$ $13.5 \mathrm{~Hz}, 1 \mathrm{H}, \mathrm{H}-1 \mathrm{~b}), 2.21\left(\mathrm{ddd}, J=2.5, J_{2 \mathrm{a}, 3}=4.9, J_{2 \mathrm{a}, 2 \mathrm{~b}}=13.5 \mathrm{~Hz}, 1 \mathrm{H}, \mathrm{H}-2 \mathrm{a}\right)$, $1.72\left(\mathrm{ddt}, J_{1 \mathrm{a}, 2 \mathrm{~b}}=4.1, J_{2 \mathrm{~b}, 3}=11.7, J_{1 \mathrm{a}, 2 \mathrm{~b}}=J_{2 \mathrm{a}, 2 \mathrm{~b}}=13.5 \mathrm{~Hz}, 1 \mathrm{H}, \mathrm{H}-2 \mathrm{~b}\right) ;{ }^{13} \mathrm{C} \mathrm{NMR}$

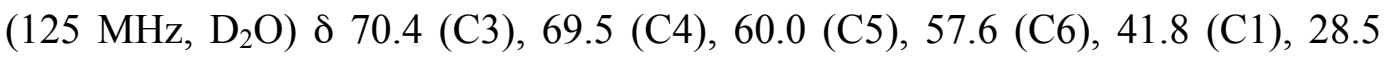
(C2); HRMS(ESI) $m / z$ calcd. for $\left[\mathrm{C}_{6} \mathrm{H}_{13} \mathrm{O}_{3} \mathrm{~N}+\mathrm{H}\right]^{+}: 148.0968$, obsd.: 148.0968. 


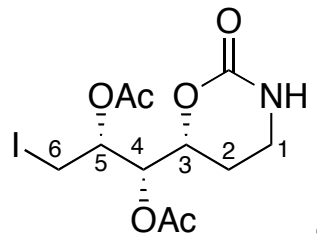

4,5-Di-O-acetyl-1-amino-1- $N, 3-O$-carbonyl-1,2,6-trideoxy-6iodo-L-gulitol (116): Iodide 113 (20.4 mg, $0.07 \mathrm{mmol}$ ) was subjected to dry pyridine $(0.5 \mathrm{~mL})$ and acetic anhydride $(0.5 \mathrm{~mL})$ at room temperature under an argon atmosphere overnight $(9 \mathrm{~h})$. After concentration and repeated coevaporation with toluene to remove pyridine, the crude compound was dry-loaded on silica before gradient column chromatography (Petroleum Ether to Petroleum Ether/EtOAc, 1/1, v/v). Acetylated iodide 116 was recovered as a white solid in $48 \%$ yield $(12.5 \mathrm{mg}, 0.03 \mathrm{mmol}) . \mathrm{R}_{f}=0.44(10 \% \mathrm{MeOH}$ in EtOAc $) ;[\alpha]_{\mathrm{D}}{ }^{25}=+6.6$ $\left(c=0.23, \mathrm{CHCl}_{3}\right)$; IR (film) 3266, 3056, 2927, 1742, 1716, 1373, 1266, 1219, $1117,1059,1024,598.7 \mathrm{~cm}^{-1} ;{ }^{1} \mathrm{H}$ NMR (500 MHz, $\left.\mathrm{CDCl}_{3}\right) \delta 5.51$ (br s, $\left.1 \mathrm{H}, \mathrm{NH}\right)$, $5.34\left(\mathrm{dd}, J_{3,4}=3.7, J_{4,5}=5.5 \mathrm{~Hz}, 1 \mathrm{H}, \mathrm{H}-4\right), 5.14\left(\mathrm{dd}, J_{5,6 \mathrm{a}}=4.5, J_{4,5}=J_{5,6 \mathrm{~b}}=5.5\right.$ $\mathrm{Hz}, 1 \mathrm{H}, \mathrm{H}-5), 4.47$ (d, $\left.J_{2 \mathrm{~b}, 3}=10.8 \mathrm{~Hz}, 1 \mathrm{H}, \mathrm{H}-3\right), 3.46\left(\mathrm{dd}, J_{5,6 \mathrm{a}}=4.5, J_{6 \mathrm{a}, 6 \mathrm{~b}}=11.4\right.$ $\mathrm{Hz}, 1 \mathrm{H}, \mathrm{H}-6 \mathrm{a}), 3.37-4.43(\mathrm{~m}, 2 \mathrm{H}, \mathrm{H}-1 \mathrm{ab}), 3.36\left(\mathrm{dd}, J_{5,6 \mathrm{~b}}=5.5, J_{6 \mathrm{a}, 6 \mathrm{~b}}=11.4 \mathrm{~Hz}\right.$, $1 \mathrm{H}, \mathrm{H}-6 \mathrm{~b}), 2.16$ (s, 3H, 4-OAc), 2.13 (s, 3H, 5-OAc), 2.00 (d, $J_{2 \mathrm{a}, 2 \mathrm{~b}}=14.2 \mathrm{~Hz}$, 1H, H-2a), 1.79-1.89 (m, 1H, H-2b); ${ }^{13} \mathrm{C}$ NMR (125 MHz, $\left.\mathrm{CDCl}_{3}\right) \delta 170.2(\mathrm{C}=\mathrm{O}$, 4-Ac), $169.9(\mathrm{C}=\mathrm{O}, 5-\mathrm{Ac}), 152.9(\mathrm{C}=\mathrm{O}), 75.0$ (C3), 73.4 (C4), 70.4 (C5), 38.9 (C1), 22.8 (C2), $20.9\left(\mathrm{CH}_{3}, \mathrm{Ac}\right), 20.6\left(\mathrm{CH}_{3}, \mathrm{Ac}\right), 3.3$ (C6); HRMS(ESI) $\mathrm{m} / z$ calcd. for $\left[\mathrm{C}_{11} \mathrm{H}_{16} \mathrm{O}_{6} \mathrm{NI}+\mathrm{H}\right]^{+}: 386.0095$, obsd.: 386.0094 .<smiles>CC1(C)O[C@H](CI)[C@H](CCI)O1</smiles>

\section{1-Amino-1- $\mathrm{N,3-O}$-carbonyl-1,2,6-trideoxy-6-iodo-4,5-O-}

isopropylidene-L-gulitol (117): Iodide 113 (8.8 $\mathrm{mg}, 0.3 \mathrm{mmol})$ was dissolved in acetone $(0.45 \mathrm{~mL})$, dimethoxypropane $(0.45 \mathrm{~mL})$, and $\mathrm{MeOH}(0.25 \mathrm{~mL}) .100 \mu \mathrm{L}$ $p$ TsOH. $\mathrm{H}_{2} \mathrm{O}$ in acetone $(2.85 \mathrm{mg} / \mathrm{mL})$ was added and the reaction was stirred at room temperature overnight $(17 \mathrm{~h})$. The reaction was neutralised with Dowex- $\mathrm{OH}^{-}$ 
, filtered and concentrated to give a white solid 117 (7.2 $\mathrm{mg}, 0.02 \mathrm{mmol}, 72 \%)$ that was used without further purification. $\mathrm{R}_{f}=0.49(10 \% \mathrm{MeOH}$ in EtOAc); $[\alpha]_{\mathrm{D}}^{23}=-23.0\left(c=0.48, \mathrm{CHCl}_{3}\right)$; IR (film) 3282, 2985, 2930, 1700, 1487, 1456, 1421, 1372, 1294, 1239, 1214, 1107, 1069, $554 \mathrm{~cm}^{-1} ;{ }^{1} \mathrm{H}$ NMR (500 MHz, $\left.\mathrm{CDCl}_{3} / \mathrm{CD}_{3} \mathrm{OD} 95 / 5\right) \delta 4.40$ (app dt, $\left.J_{3,4}=2.2, J_{2 \mathrm{a}, 3}=10.0 \mathrm{~Hz}, 1 \mathrm{H}, \mathrm{H}-3\right), 4.20(\mathrm{dt}$, $\left.J_{5,6 \mathrm{a}}=J_{5,6 \mathrm{~b}}=4.7, J_{4,5}=7.5 \mathrm{~Hz}, 1 \mathrm{H}, \mathrm{H}-5\right), 3.83\left(\mathrm{dd}, J_{3,4}=2.2, J_{4,5}=7.5 \mathrm{~Hz}, 1 \mathrm{H}, \mathrm{H}-\right.$ 4), $3.41\left(\mathrm{ddd}, J_{1 \mathrm{a}, 2 \mathrm{~b}}=3.7, J_{1 \mathrm{a}, 2 \mathrm{a}}=5.8, J_{1 \mathrm{a}, 1 \mathrm{~b}}=11.0 \mathrm{~Hz}, 1 \mathrm{H}, \mathrm{H}-1 \mathrm{a}\right), 3.36(\mathrm{~m}, 1 \mathrm{H}$, $\mathrm{NH}), 3.31-3.35$ (m, 1H, H-1b), 3.31 (dd, $\left.J_{5,6 \mathrm{a}}=4.7, J_{6 \mathrm{a}, 6 \mathrm{~b}}=10.8 \mathrm{~Hz}, 1 \mathrm{H}, \mathrm{H}-6 \mathrm{a}\right)$, $3.28\left(\mathrm{dd}, J_{5,6 \mathrm{~b}}=4.7, J_{6 \mathrm{a}, 6 \mathrm{~b}}=10.8 \mathrm{~Hz}, 1 \mathrm{H}, \mathrm{H}-6 \mathrm{~b}\right), 2.06\left(\mathrm{dt}, J_{1 \mathrm{a}, 2 \mathrm{a}}=5.8, J_{1 \mathrm{~b}, 2 \mathrm{a}}=J_{2 \mathrm{a}, 3}\right.$ $\left.=10.0, J_{2 \mathrm{a}, 2 \mathrm{~b}}=14.0 \mathrm{~Hz}, 1 \mathrm{H}, \mathrm{H}-2 \mathrm{a}\right), 1.98(\mathrm{~m}, 1 \mathrm{H}, \mathrm{H}-2 \mathrm{~b}), 1.43(\mathrm{~s}, 3 \mathrm{H}, \mathrm{Me}), 1.40(\mathrm{~s}$, $3 \mathrm{H}, \mathrm{Me}) ;{ }^{13} \mathrm{C} \mathrm{NMR}\left(125 \mathrm{MHz}, \mathrm{CDCl}_{3} / \mathrm{CD}_{3} \mathrm{OD}\right.$ 95/5) $\delta 154.4(\mathrm{C}=\mathrm{O}), 110.7$ (iPr$\left.\underline{\mathrm{C}}\left(\mathrm{CH}_{3}\right)_{2}\right), 82.4(\mathrm{C} 4), 75.1(\mathrm{C} 3), 74.6(\mathrm{C} 5), 38.7(\mathrm{C} 1), 27.6,27.0\left(\mathrm{iPr}-\mathrm{C}\left(\underline{\mathrm{CH}}_{3}\right)_{2}\right)$, 23.3 (C2), 6.1 (C6); HRMS(ESI) $\mathrm{m} / z$ calcd. for $\left[\mathrm{C}_{10} \mathrm{H}_{16} \mathrm{O}_{4} \mathrm{NI}+\mathrm{H}\right]^{+}:$342.0197, obsd.: 342.0201 .

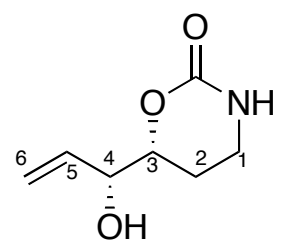

D-threo-1-Amino-1-O,3- $N$-carbonyl-1,2,5,6-tetradeoxy-hex-5enose (118): Iodo-acetonide (117) $(6.8 \mathrm{mg}, 0.02 \mathrm{mmol})$ was subjected to DCM $(0.3 \mathrm{~mL}), \mathrm{AcOH}(0.1 \mathrm{~mL})$ and zinc $(27.6 \mathrm{mg}, 0.2 \mathrm{mmol})$, and stirred at $40-55^{\circ} \mathrm{C}$ for $12 \mathrm{~d}$. The reaction mixture was filtered through silica, and concentrated, to remove zinc. Crude product was purified by silica column chromatography (Petroleum Ether to Petroleum Ether/EtOAc, 1/3, v/v) yielding 118 as a white solid (2.4 mg, $0.015 \mathrm{mmol}, 77 \%) . \mathrm{R}_{f}=0.22\left(10 \% \mathrm{MeOH}\right.$ in EtOAc); $[\alpha]_{\mathrm{D}}{ }^{29}=$ 12.8 ( $c=0.16, \mathrm{MeOH}$ ); IR (film) 3373, 2926, 2856, 1682, 1489, 1459, 1294, 1108, 1071, 1028, $946 \mathrm{~cm}^{-1} ;{ }^{1} \mathrm{H}$ NMR $\left(500 \mathrm{MHz}, \mathrm{D}_{2} \mathrm{O}\right) \delta 5.92\left(\mathrm{ddd}, J_{4,5}=6.6\right.$, $\left.J_{5,6 \text {-cis }}=10.5, J_{5,6 \text {-trans }}=17.3 \mathrm{~Hz}, 1 \mathrm{H}, \mathrm{H}-5\right), 5.40\left(\mathrm{app} \mathrm{dt}, J_{4,6 \text {-trans }}=1.2, J_{5,6 \text {-trans }}=\right.$ $17.3 \mathrm{~Hz}, 1 \mathrm{H}, \mathrm{H}-6$-trans), 5.32 (app dt, $J_{4,6 \text {-cis }}=1.2, J_{5,6-c i s}=10.5 \mathrm{~Hz}, 1 \mathrm{H}, \mathrm{H}-6$-cis), $4.35\left(\mathrm{ddd}, J_{2 \mathrm{a}, 3}=3.0, J_{3,4}=5.7, J_{2 \mathrm{~b}, 3}=10.5 \mathrm{~Hz}, 1 \mathrm{H}, \mathrm{H}-3\right), 4.24\left(\mathrm{ddt}, J_{4,6 \text {-trans }}=J_{4,6-}\right.$ $\left.{ }_{c i s}=1.2, J_{3,4}=5.7, J_{4,5}=6.6 \mathrm{~Hz}, 1 \mathrm{H}, \mathrm{H}-4\right), 3.33\left(\mathrm{ddd}, J_{1 \mathrm{a}, 2 \mathrm{a}}=3.0, J_{1 \mathrm{a}, 2 \mathrm{~b}}=6.9, J_{1 \mathrm{a}, 1 \mathrm{~b}}\right.$ 
$=12.0 \mathrm{~Hz}, 1 \mathrm{H}, \mathrm{H}-1 \mathrm{a}), 3.32\left(\mathrm{ddd}, J_{1 \mathrm{~b}, 2 \mathrm{a}}=4.5, J_{1 \mathrm{~b}, 2 \mathrm{~b}}=10.5, J_{1 \mathrm{a}, 1 \mathrm{~b}}=12.0 \mathrm{~Hz}, 1 \mathrm{H}, \mathrm{H}-\right.$ 1b), $1.99\left(\mathrm{ddt}, J_{2 \mathrm{a}, 3}=J_{1 \mathrm{a}, 2 \mathrm{a}}=3.0, J_{1 \mathrm{~b}, 2 \mathrm{a}}=4.5, J_{2 \mathrm{a}, 2 \mathrm{~b}}=14.1 \mathrm{~Hz}, 1 \mathrm{H}, \mathrm{H}-2 \mathrm{a}\right), 1.84(\mathrm{dtd}$, $\left.J_{1 \mathrm{a}, 2 \mathrm{~b}}=6.9, J_{1 \mathrm{~b}, 2 \mathrm{~b}}=J_{2 \mathrm{~b}, 3}=10.5, J_{2 \mathrm{a}, 2 \mathrm{~b}}=14.1 \mathrm{~Hz}, 1 \mathrm{H}, \mathrm{H}-2 \mathrm{~b}\right) ;{ }^{13} \mathrm{C} \mathrm{NMR}(150 \mathrm{MHz}$, $\left.\mathrm{D}_{2} \mathrm{O}\right) \delta 156.8(\mathrm{C}=\mathrm{O}), 134.9(\mathrm{C} 5), 118.4(\mathrm{C} 6), 80.2$ (C3), 73.5 (C4), $37.8(\mathrm{C} 1)$, 21.7 (C2); HRMS(ESI) $\mathrm{m} / z$ calcd. for $\left[\mathrm{C}_{7} \mathrm{H}_{11} \mathrm{O}_{3} \mathrm{~N}+\mathrm{H}\right]^{+}:$158.0812, obsd.: 158.0805 .<smiles>C=C[C@H](OC(C)=O)[C@H]1CCNC(=O)O1</smiles>

D-threo-4-O-Acetyl-1-amino-1-O,3- $\mathrm{N}$-carbonyl-1,2,5,6-

tetradeoxy-hex-5-enose (119): Iodide 116 (10.7 $\mathrm{mg}, 0.03 \mathrm{mmol})$ was dissolved in THF $(0.3 \mathrm{~mL})$ and $\mathrm{H}_{2} \mathrm{O}(0.06 \mathrm{~mL}), \mathrm{AcOH}(0.06 \mathrm{~mL})$ and zinc $(62 \mathrm{mg}, 0.6$ mmol) were added. The resulting mixture was then stirred at room temperature for $1 \mathrm{~h}$. The reaction mixture was filtered through celite, washed with DCM and $\mathrm{EtOH}$, and concentrated before coevaporation with $\mathrm{H}_{2} \mathrm{O}$ and toluene to remove traces of $\mathrm{AcOH}$. The crude product was purified by silica column chromatography (Petroleum Ether to Petroleum Ether/EtOAc, 1/3, v/v) to give 119 as a white solid (5.5 mg, 0.03 mmol, quant.). $\mathrm{R}_{f}=0.38\left(10 \% \mathrm{MeOH}\right.$ in EtOAc); $[\alpha]_{\mathrm{D}}{ }^{25}=-11.0(c$ $=0.13, \mathrm{CHCl}_{3}$ ); IR (film) 3278, 2925, 2854, 1703, 1489, 1459, 1424, 1372, 1294, 1227, 1104, 1023, 950, $763 \mathrm{~cm}^{-1} ;{ }^{1} \mathrm{H}$ NMR $\left(500 \mathrm{MHz}, \mathrm{CDCl}_{3}\right) \delta 5.88\left(\mathrm{ddd}, J_{4,5}=\right.$ $\left.6.5, J_{5,6-\text { cis }}=10.5, J_{5,6-\text { trans }}=17.0 \mathrm{~Hz}, 1 \mathrm{H}, \mathrm{H}-5\right), 5.51$ (br s, $\left.1 \mathrm{H}, \mathrm{NH}\right), 5.44\left(\mathrm{~d}, J_{4,5}=\right.$ $6.5 \mathrm{~Hz}, 1 \mathrm{H}, \mathrm{H}-4), 5.43$ (d, J5,6-trans $=17.0 \mathrm{~Hz}, 1 \mathrm{H}, \mathrm{H}-6$-trans), 5.37 (d, $J_{5,6-\text {-cis }}=$ $10.5 \mathrm{~Hz}, 1 \mathrm{H}, \mathrm{H}-6-c i s), 4.39$ (ddd, $J=2.5, J=5.5, J_{2 \mathrm{~b}, 3}=10.5 \mathrm{~Hz}, 1 \mathrm{H}, \mathrm{H}-3$ ), 3.353.45 (m, 2H, H-1ab), 2.13 (s, 3H, Me), 1.94-2.01 (m, 1H, H-2a), 1.86 (dtd, $J=$ $\left.6.5, J=J_{2 \mathrm{~b}, 3}=10.5, J_{2 \mathrm{a}, 2 \mathrm{~b}}=14.0 \mathrm{~Hz}, 1 \mathrm{H}, \mathrm{H}-2 \mathrm{~b}\right) ;{ }^{13} \mathrm{C} \mathrm{NMR}\left(125 \mathrm{MHz}, \mathrm{CDCl}_{3}\right) \delta$ $170.0(\mathrm{C}=\mathrm{O}, \mathrm{Ac}), 153.8(\mathrm{C}=\mathrm{O}), 131.5$ (C5), 120.4 (C6), 77.5 (C3), 74.5 (C4), 39.0 (C1), 22.5 (C2), $21.2\left(\mathrm{CH}_{3}, \mathrm{Ac}\right)$; HRMS(ESI) $\mathrm{m} / \mathrm{z}$ calcd. for $\left[\mathrm{C}_{9} \mathrm{H}_{13} \mathrm{O}_{4} \mathrm{~N}+\mathrm{H}\right]^{+}$: 200.0917, obsd.: 200.0918. 
<smiles>C=CC(O)C(O)CCN</smiles>

(3R,4R)-6-Amino-hex-1-ene-3,4-diol hydrochloride (110): Acetylated alkene carbamate (119) $(5.7 \mathrm{mg}, 0.03 \mathrm{mmol})$ was dissolved in EtOH (1 $\mathrm{mL}$ ) and $\mathrm{NaOH}(80 \mathrm{mg}, 2 \mathrm{mmol}$ ) was added. The solution was refluxed for $1 \mathrm{~h}$, neutralised with aqueous $\mathrm{HCl}(1.2 \mathrm{M})$, then concentrated in vacuo. Purification by gradient silica column chromatography (DCM/EtOH/MeOH/35\% aqueous $\mathrm{NH}_{3}$, $65 / 2 / 2 / 1$ to $5 / 2 / 2 / 1, \mathrm{v} / \mathrm{v} / \mathrm{v} / \mathrm{v}$ ) gave the alkenylamine, which was converted into the $\mathrm{HCl}$ salt (110) by the addition of $\mathrm{HCl}(1.2 \mathrm{M}$, aq) and concentration to obtain a white solid (3.3 mg, $0.02 \mathrm{mmol}, 69 \%) . \mathrm{R}_{f}=0.16(\mathrm{DCM} / \mathrm{EtOH} / \mathrm{MeOH} / 35 \%$ aqueous $\left.\mathrm{NH}_{3}, 5 / 2 / 2 / 1, \mathrm{v} / \mathrm{v} / \mathrm{v} / \mathrm{v}\right) ;[\alpha]_{\mathrm{D}}{ }^{27}=+31.8(c=0.2, \mathrm{MeOH})$. 


\subsection{References:}

1. For some recent reviews outlining the biological activity of azasugars, see: a) Asano, N.; Nash, R. J.; Molyneux, R. J.; Fleet, G. W. J. TetrahedronAsymmetr. 2000, 11, 1645-1680; b) Butters, T. D.; Dwek, R. A.; Platt, F. M. Curr. Top. Med. Chem. 2003, 3, 561-574; c) Greimel, P.; Spreitz, J.; Stütz, A. E.; Wrodnigg, T. M. Curr. Top. Med. Chem. 2003, 3, 513-523; d) Borges de Melo, E.; da Silveira Gomes, A.; Carvalho, I. Tetrahedron 2006, 62, 10277-10302; e) Merino, P.; Delso, I.; Marca, E.; Tejero, T.; Matute, R. Curr. Chem. Biol. 2009, 3, 253-271; f) Nash, R. J.; Kato, A.; Yu, C.-Y.; Fleet, G. W. J. Future Med. Chem. 2011, 3, 1513-1521; g) Lopez, O.; Merino-Montiel, P.; Martos, S.; Gonzalez-Benjumea, A. In Carbohydrate Chemistry, Rauter, A. P.; Lindhorst, T., Eds. The Royal Society of Chemistry: Cambridge, 2012; Vol. 38, pp 215-262. h) Alonzi, D. S.; Butters, T. D. Chimia 2011, 65, 35-39. i) Iminosugars: From Synthesis to Therapeutic Applications; Compain, P., Martin, O. R. Eds.; John Wiley \& Sons: Chichester, 2007.

2. Segal, P.; Feig, P. U.; Schernthaner, G.; Ratzmann, K. P.; Rybka, J.; Petzinna, D.; Berlin, C. Diabetes Care, 1997, 20, 687-91.

3. See: http://www.clinicaltrials.gov/ct/gui/show/NCT00231036 (accessed 07/07/13), A Study of AT1001 in Patients With Fabry Disease.

4. Kato, A.; Miyauchi, S.; Kato, N.; Nash, R. J.; Yoshimura, Y.; Nakagome, I.; Hirono, S.; Takahata, H.; Adachi, I. Bioorg. Med. Chem. 2011, 19, 3558-3568.

5. Gómez, L.; Molinar-Toribio, E.; Calvo-Torras, M. Á.; Adelantado, C.; Juan, M. E.; Planas, J. M.; Cañas, X.; Lozano, C.; Pumarola, S.; Clapés, P.; Torres, J. L. Br. J. Nutr. 2012, 107, 1739-1746.

6. See: http://clinicaltrials.gov/ct2/show/study/NCT01811303 (accessed 12/01/14), Effects of Added D-fagomine on Glycaemic Responses to Sucrose.

7. a) Dangerfield, E. M.; Timmer, M. S. M.; Stocker, B. L. Org. Lett. 2009, 11, 535-538; b) Dangerfield, E. M.; Gulab, S. A.; Plunkett, C. H.; Timmer, M. S. M.; Stocker, B. L. Carbohydr. Res. 2010, 345, 1360-1365; c)

Dangerfield, E. M.; Plunkett, C. H.; Stocker, B. L.; Timmer, M. S. M. Molecules 2009, 14, 5298-5307. 
8. For recent reviews concerning the synthesis of azasugars, see: a) Pearson, M. S. M.; Mathé-Allainmat, M.; Fargeas, V.; Lebreton, J. Eur. J. Org. Chem. 2005, 2159-2191; b) Afarinkia, K.; Bahar, A. TetrahedroAsymmetr. 2005, 16, 1239-1287; c) Davis, B. G. Tetrahedron-Asymmetr. 2009, 20, 652-671; d) Stocker, B. L.; Dangerfield, E. M.; Win-Mason, A. L.; Haslett, G. W.; Timmer, M. S. M. Eur. J. Org. Chem. 2010, 16151637; e) Wijdeven, M. A.; Willemsen, J.; Rutjes, F. P. J. T. Eur. J. Org. Chem. 2010, 2831-2844.

9. $\quad$ Dangerfield, E. M.; Plunkett, C. H.; Win-Mason, A. L.; Stocker, B. L.; Timmer, M. S. M. J. Org. Chem. 2010, 75, 5470-5477.

10. Corkran, H. M.; Munneke, S.; Dangerfield, E. M.; Timmer, M. S. M.; Stocker, B. L. J. Org. Chem., 2013, 78, 9791-9802.

11. Timmer, M. S. M.; Dangerfield, E. M.; Cheng, J. M. H.; Gulab, S. A.; Stocker, B. L. Tetrahedron Lett. 2011, 52, 4803-4805.

12. Dangerfield, E. M. The Synthesis of Carbohydrates for the Treatment of Disease. PhD Thesis, Victoria University of Wellington, Wellington, 2011.

13. For a full discussion of the factors influencing the protecting-group-free reductive amination methodology: a) Miriyala, B.; Bhattacharyya, S.; Williamson, J. S. Tetrahedron 2004, 60, 1463-1471; b) Pelter, A.; Rosser, R. M.; Mills, S. J. Chem. Soc., Perkin Trans. 1 1984, 717-720; c) Borch, R. F.; Bernstein, M. D.; Durst, H. D. J. Am. Chem. Soc. 1971, 93, $2897-$ 2904; d) Gomez, S.; Peters, J. A.; van der Waal, J. C.; van den Brink, P. J.; Maschmeyer, T. Appl. Catal., A 2004, 261, 119-125; e) Gomez, S.; Peters, J. A.; Maschmeyer, T. Adv. Synth. Catal. 2002, 344, 1037-1057; f) Baxter, E.; Reitz, A. In Organic Reactions; Overman, L.E., Ed.; John Wiley \& Sons: New York, 2002; Vol. 59, pp 1-714.

14. Munneke, S. Protecting Group Free Synthesis of Pyrrolidine and Piperidine Imino-sugars. Masters Report, Victoria University of Wellington, Wellington, 2011.

15. Foster, A. B.; Overend, W. G.; Stacey, M.; Vaughan, G. J. Chem. Soc. 1954, 3367-3377. 
16. Previous syntheses of 4-epi-fagomine have been reported: a) Asano, N.; Oseki, K.; Kizu, H.; Matsui, K. J. Med. Chem. 1994, 37, 3701-3706; b) Heiker, F.-R.; Schueller, A. M. Carbohydr. Res. 1990, 203, 314-318; c) Takahata, H.; Banba, Y.; Ouchi, H.; Nemoto, H.; Kato, A.; Adachi, I. J. Org. Chem. 2003, 68, 3603-3607; d) van den Berg, R. J. B. H. N.;

Wennekes, T.; Ghisaidoobe, A.; Donker-Koopman, W. E.; Strijland, A.; Boot, R. G.; van der Marel, G. A.; Aerts, J. M. F. G.; Overkleeft, H. S. ACS Med. Chem. Lett. 2011, 2, 519-522; e) Kumari, N.; Reddy, B. G.; Vankar, Y. D. Eur. J. Org. Chem. 2009, 160-169.

17. Yorimitsu, H.; Murakami, Y.; Takamatsu, H.; Nishimura, S.; Nakamura, E. Chem. Asian. J. 2007, 2, 57-65

18. Skaanderup, P. R.; Poulsen, C. S.; Hyldtoft, L.; Jorgensen, M. R.; Madsen, R., Synthesis 2002, 1721-1727.

19. Swamy, N. K.; Pyne, S. G. Synth. Commun. 2011, 41, 2435-2445.

20. Bates, R. W.; Shuyi Ng, P. Tetrahedron Lett. 2011, 52, 2969-2971.

21. Jiangseubchatveera, N.; Bouillon, M. E.; Liawruangrath, B.; Liawruangrath, S.; Nash, R. J.; Pyne, S. G. Org. Biomol. Chem. 2013, 11, 3826-3833.

22. Lombardo, M.; Morganti, S.; Trombini, C. J. Org. Chem. 2003, 68, 9971006.

23. a) Dana, G.; Danechpajouh, H. Bull. Soc. Chim. Fr. 1980, 395-399; b) Bock, M.; Buntin, K.; Müller, R.; Kirschning, A. Angew. Chem. Int. Ed. 2008, 47, 2308-2311.

24. Stocker, B. L.; Win-Mason, A. L.; Timmer, M. S. M. Carbohydr. Res. 2012, 356, 163-171.

25. Chamberlin, A. R.; Mulholland, R. L., Jr.; Kahn, S. D.; Hehre, W. J. J. Am. Chem. Soc. 1987, 109, 672-677.

26. Tredwell, M.; Luft, J. A. R.; Schuler, M.; Tenza, K.; Houk, K. N.; Gouverneur, V. Angew. Chem. Int. Ed. 2008, 47, 357-360.

27. Casadei, M. A.; Galli, C.; Mandolini, L. J. Am. Chem. Soc. 1984, 106, 1051-1056.

28. Galli, C.; Mandolini, L. Eur. J. Org. Chem. 2000, 3117-3125.

29. Bhanage, B. M.; Fujita, S.-i.; Ikushima, Y.; Arai, M. Green Chem. 2003, 5, 340-342. 
30. Tamura, M.; Honda, M.; Noro, K.; Nakagawa, Y.; Tomishige, K. J. Catal. 2013, 305, 191-203.

31. Song, W.-J.; Suh, D.-Y.; Kang, Y.-H.; No, K.; Han, B. H. Bull. Korean Chem. Soc. 1998, 19, 593-595.

32. a) Ohta, H.; Sakata, Y.; Takeuchi, T.; Ishii, Y. Chem. Lett. 1990, 733-736;

b) Masuda, H.; Takase, K.; Nishio, M.; Hasegawa, A.; Nishiyama, Y.; Ishii, Y. J. Org. Chem. 1994, 59, 5550-5555; c) Chamberlin, A. R.; Mulholland, R. L., Jr. Tetrahedron 1984, 40, 2297-2302.

33. Giese, B.; Bartmann, D. Tetrahedron Lett. 1985, 26, 1197-1200.

34. Chamberlin, A. R.; Dezube, M.; Dussault, P.; McMills, M. C. J. Am. Chem. Soc. 1983, 105, 5819-5825.

35. Payne, G. B. J. Org. Chem. 1962, 27, 3819-3822.

36. Hanson, R. M. In Organic Reactions; Overman, L.E., Ed.; John Wiley \& Sons: New Jersey, 2002; Vol. 60, pp 1-156.

37. Jäger, V.; Schröter, D.; Koppenhöfer, B. Tetrahedron 1991, 47, $2195-$ 2210 .

38. a) Hampe, E. M.; Rudkevich, D. M. Tetrahedron 2003, 59, 9619-9625; b) McGhee, W.; Riley, D.; Christ, K.; Pan, Y.; Parnas, B. J. Org. Chem. 1995, 60, 2820-2830; c) Dell'Amico, D. B.; Calderazzo, F.; Labella, L.; Marchetti, F.; Pampaloni, G. Chem. Rev. 2003, 103, 3857-3898; d) Peeters, A.; Ameloot, R.; De Vos, D. E. Green Chem. 2013, 15, 15501557.

39. Midland, M. M.; Halterman, R. L. J. Org. Chem. 1981, 46, 1227-1229.

40. For literature precedent for the formation of iodo-expoxides; see: a) Winstein, S.; Goodman, L. J. Am. Chem. Soc. 1954, 76, 4373-4378; b) Lindgren, B. O.; Svahn, C. M. Acta Chem. Scand. 1970, 24, 2699-2704; c) Ganem, B. J. Am. Chem. Soc. 1976, 98, 858-859; d) Santelli, M.; Viala, J. Tetrahedron Lett. 1977, 18, 4397-4400; e) Evans, R. D.; Magee, J. W.; Schauble, J. H. Synthesis 1988, 862-868; f) Brunel, Y.; Roussseau, G. Synlett 1995, 323-324.

41. Baldwin, J. E. J. Chem. Soc., Chem. Commun. 1976, 734-736.

42. Wipf, P.; Stephenson, C. R. J.; Walczak, M. A. A. Org. Lett. 2004, 6, 3009-3012.

43. Cardillo, G.; Orena, M.; Porzi, G.; Sandri, S. J. Chem. Soc., Chem. Commun. 1981, 465-6. 
44. Bongini, A.; Cardillo, G.; Orena, M.; Porzi, G.; Sandri, S. J. Org. Chem. 1982, 47, 4626-33.

45. Venturello, C.; D'Aloisio, R. Synthesis 1985, 33-4.

46. Davies, S. G.; Figuccia, A. L. A.; Fletcher, A. M.; Roberts, P. M.; Thomson, J. E. Org. Lett. 2013, 15, 2042-2045.

47. Martin, O. R.; Liu, L.; Yang, F. Tetrahedron Lett. 1996, 37, 1991-1994.

48. Bernotas, R. C.; Ganem, B. Tetrahedron Lett. 1985, 26, 1123-1126.

49. Bernotas, R. C.; Pezzone, M. A.; Ganem, B. Carbohydr. Res. 1987, 167, 305-311.

50. Martin, O. R.; Saavedra, O. M.; Xie, F.; Liu, L.; Picasso, S.; Vogel, P.; Kizu, H.; Asano, N. Bioorg. Med. Chem. 2001, 9, 1269-1278.

51. Liu, P. S. J. Org. Chem. 1987, 52, 4717-4721.

52. a) Chorghade, M. S.; Cseke, C. T.; Liu, P. S. Tetrahedron-Asymmetr. 1994, 5, 2251-2254; b) Bouix, C.; Bisseret, P.; Eustache, J. Tetrahedron Lett. 1998, 39, 825-828; c) Win-Mason, A. L.; Jongkees, S. A. K.; Withers, S. G.; Tyler, P. C.; Timmer, M. S. M.; Stocker, B. L. J. Org. Chem. 2011, 76, 9611-9621; d) Win-Mason, A. L.; Dangerfield, E. M.; Tyler, P. C.; Stocker, B. L.; Timmer, M. S. M. Eur. J. Org. Chem. 2011, 4008-4014.

53. Hügel, H. M.; Hughes, A. B.; Khalil, K. Aust. J. Chem. 1998, 51, 11491155 .

54. Fouace, S.; Therisod, M. Tetrahedron Lett. 2000, 41, 7313-7315.

55. Szolcsányi, P.; Gracza, T. Tetrahedron 2006, 62, 8498-8502.

56. Szolcsányi, P.; Gracza, T.; Koman, M.; Prónayová, N.; Liptaj, T. Chem. Commun. 2000, 471-472.

57. Szolcsányi, P.; Gracza, T.; Koman, M.; Prónayová, N.; Liptaj, T. Tetrahedron-Asymmetr. 2000, 11, 2579-2597.

58. Durette, P. L. Synthesis 1980, 1037-1038. 


\section{Chapter 3: Development of a}

\section{C-C Bond Forming Reaction for}

\section{the Synthesis of Conduramines}

\subsection{Introduction}

A variety of biologically significant molecules contain conduramine motifs, some of which have been depicted in Figure 3.1. Aminoshikimic acid 166 was recently identified as a competitive inhibitor of the $M t b$ shikimate kinase enzyme, ${ }^{1}$ an enzyme that is essential to many pathogenic bacteria including $M t b$, which is also absent from human cells. ${ }^{2}$ The shikimate kinase enzyme is responsible for the phosphorylation of shikimic acid (167), hence the conduramine containing analogue, aminoshikimic acid $\mathbf{1 6 6}$ has potential as an anti-tuberculosis drug. Another conduramine containing motif is that of narciclasine (168), a natural product that was extracted from daffodil bulbs. ${ }^{3}$ Narciclasine (168) exhibits promising anti-cancer activity, including cytotoxicity against the HeLa (cervical cancer) cell line down to $0.1 \mu \mathrm{g} / \mathrm{mL}^{3}$ The validamycin (169) and acarbose (170) scaffolds both contain the same conduramine motif, however each molecule has a different biological target. ${ }^{4}$ Validamycin (169) is a potent trehalase inhibitor and is used as a fungicide in the treatment of sheath blight disease in rice plants. ${ }^{4}$ Acarbose, on the other hand, is a drug used to treat of type 2 diabetes. The conduramine moiety in acarbose is the active pharmacophore responsible for the observed $\alpha$-glucosidase inhibition in the intestine. ${ }^{4}$ Additionally, the second line 
anti-tuberculosis drugs streptomycin, kanamycin and amikacin (Chapter 1, Figure 1.8) contain related aminoglycoside scaffolds that could also be prepared from conduramines.<smiles>N[C@H]1C=C(C(=O)O)C[C@H](O)[C@H]1O</smiles>

Aminoshikimic acid (166)<smiles>O=C(O)C1=C[C@H](O)[C@H](O)C(O)C1</smiles>

Shikimic acid (167)<smiles>O=C1NC2C(=C[C@H](O)[C@@H](O)[C@H]2O)c2cc3c(c(O)c21)OCO3</smiles>

Narciclasine (168)<smiles>OCC1=C[C@@H](N[C@H]2C[C@H](CO)[C@@H](O[C@H]3O[C@H](CO)[C@@H](O)[C@H](O)[C@H]3O)[C@H](O)[C@H]2O)[C@H](O)[C@@H](O)[C@@H]1O</smiles>

Validamycin (169)

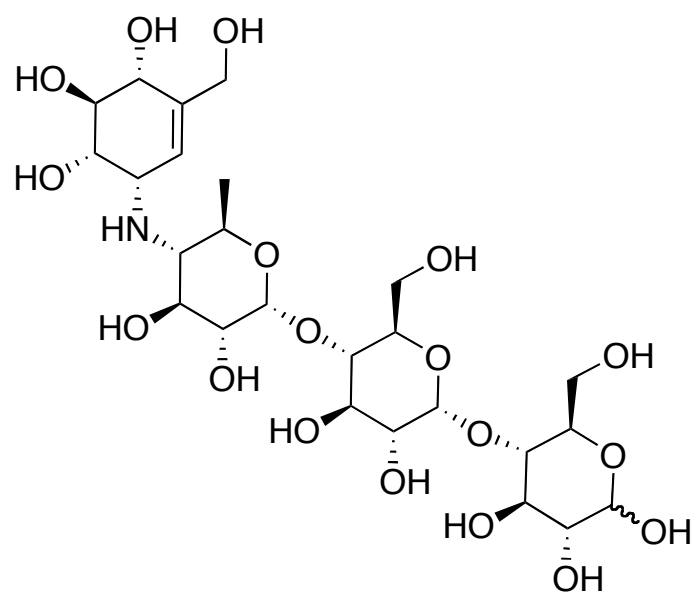

Acarbose (170)

Figure 3.1: Biologically relevant structures containing a conduramine motif.

To gain access to the conduramine family, an efficient PGF method for their preparation was sought and hence the 4-deoxy-3-conduramines were pursued. Retrosynthetic analysis suggested that 4-deoxy-3-conduramine $\mathbf{1 7 1}$ could be made from diene 172 via a PGF ring closing metathesis (RCM) reaction (Scheme 3.1). The preparation of diene $\mathbf{1 7 2}$ required a new PGF C-C and C-N bond forming reaction to install the allyl and amine functional groups simultaneously, which was envisioned through the development of a PGF Vasella-Barbier amination on methyl iodoxylofuranoside 173. The 4,5-anti stereochemistry in $\mathbf{1 7 2}$ was anticipated to result from chelation control during the Barbier reaction. The iodide 173 could be prepared in two steps from D-xylose (174) using literature 
procedures. $^{5}$ A similar method for the synthesis of 4-deoxy-3-conduramines was employed by Verhelst et al., to produce the protected conduramines in three steps and $59 \%$ overall yield from the protected furanoses, ${ }^{6,7}$ however, the final deprotection steps were not reported.<smiles>N[C@H]1CC=C[C@@H](O)[C@@H]1O</smiles>

171<smiles>OCC1O[C@@H](O)[C@@H](O)[C@@H]1O</smiles>

174<smiles>CCOc1ccccc1</smiles><smiles>C=C</smiles>

173

Scheme 3.1: Retrosynthesis of 4-deoxy-3-conduramine 171. 


\subsection{Development of a PGF C-C bond Forming Reaction}

The development of a PGF Vasella-Barbier amination began with the preparation of the corresponding methyl iodoxylofuranoside 173 from D-xylose (174) (Scheme 3.2). This was achieved in 78\% yield over two steps using literature procedures. ${ }^{5}$ Next, a PGF Vasella-Barbier amination was attempted through the reaction of iodide 173 with indium powder, $\mathrm{AcOH}, 35 \% \mathrm{NH}_{3 \text { (aq.), and allyl }}$ bromide in refluxing THF. The proposed mechanism for the Vasella-Barbier amination is depicted in Scheme 3.3. Indium inserts in the C-I bond of iodide $\mathbf{1 7 3}$ and an electron cascade to form the aldehyde follows. The aldehyde is then attacked by the amine to give the corresponding imine. Indium insertion in the CBr bond of allyl bromide leads to nucleophilic attack on the imine to give the desired diene 172. Unfortunately, under the conditions shown in Scheme 3.2, although diene 172 could be identified by mass spectrometry, no product was isolated. Purification of the reaction mixture by silica column chromatography revealed a product that appeared to be triol $\mathbf{1 7 5}$ on the basis of a downfield shift in ${ }^{13} \mathrm{C}$ NMR signal for the C5 ( $\left.\delta 75.3 \mathrm{ppm}\right)$, where the corresponding amine C5 would be expected close to $\delta 50 \mathrm{ppm}$. To confirm the formation of this product,

triol diastereomers $175 S$ and $175 R$ were prepared according to a literature procedure (Scheme 3.4), ${ }^{8}$ and indeed, the ${ }^{1} \mathrm{H}$ NMR spectrum of triols $\mathbf{1 7 5 S}$ and $175 R$ was found to be identical to the spectrum obtained from the attempted Vasella-Barbier amination reaction of methyl iodoxylofuranoside 173. Although full conversion of the iodide starting material 173 was observed, triol 175 was the only product isolated, hence the low yield suggests that degradation was also occurring. 
<smiles>OCC1O[C@H](O)[C@@H](O)[C@@H]1O</smiles>

174 i) $0.3 \% \mathrm{AcCl}, \mathrm{MeOH}$

ii) Imid. $\mathrm{PPh}_{3}, \mathrm{I}_{2}$

THF, reflux, $1.5 \mathrm{~h}$

$78 \%$ (2 steps)<smiles>CO[C@@H]1O[C@H](CI)[C@@H](O)[C@H]1O</smiles>

173

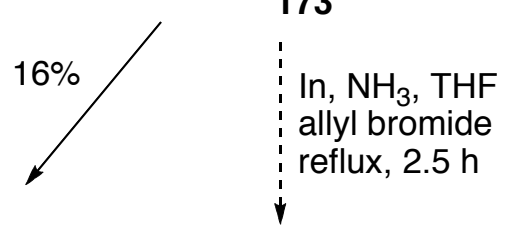<smiles>C=CC[C@H](O)[C@@H](O)C(O)C=C</smiles>

175<smiles>C=CC[C@H](N)[C@@H](O)[C@H](O)C=C</smiles>

172

Scheme 3.2: Attempted synthesis of diene 172 and resultant product triol 175.
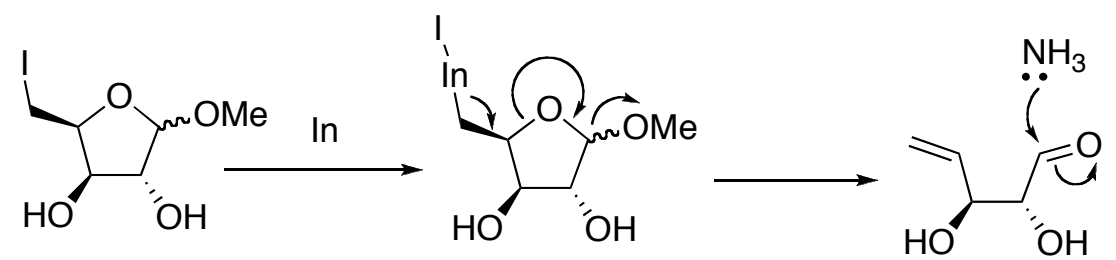

173

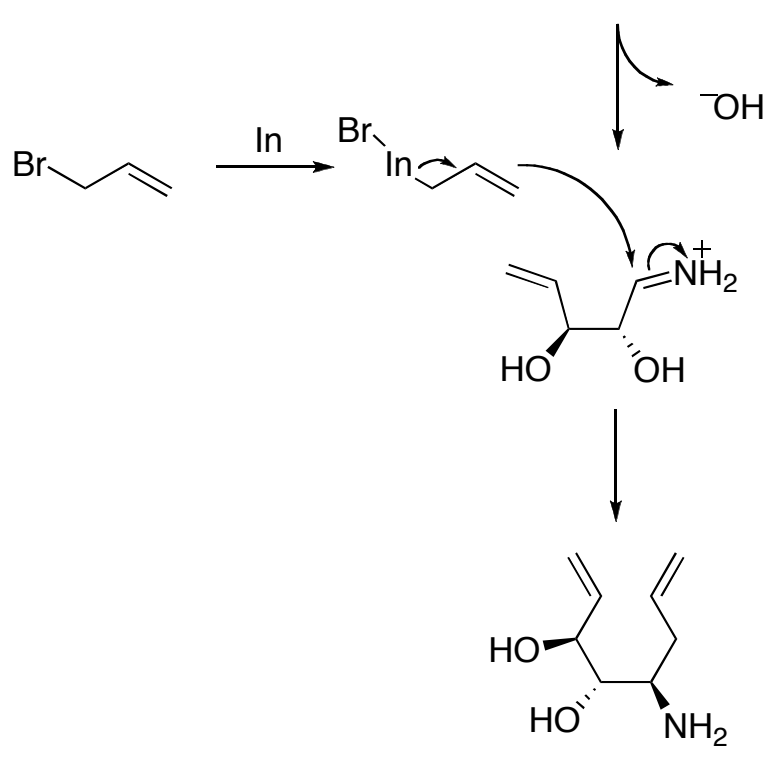

172

Scheme 3.3: Proposed mechanism of the PGF Vasella-Barbier amination. 


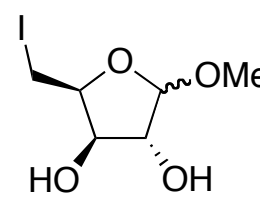

173

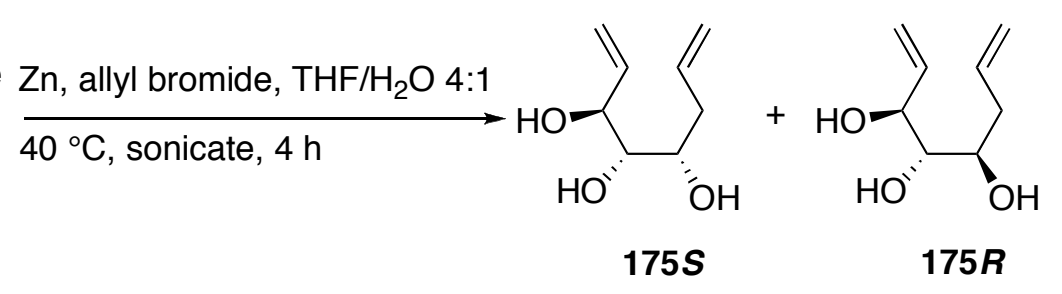

$(175 S: 175 R=3: 7)$

Scheme 3.4: A Vasella-Barbier reaction to form triols 175.

As triol 175 was the major product formed from the initial Vasella-Barbier amination conditions, a number of other reaction conditions for the PGF C-C bond forming reaction were trialled. During the course of these studies, it was determined that the presence of water in the reaction mixture encouraged the formation of triol 175. The use of both excess $\mathrm{NH}_{3}$, and allyl bromide was necessary to promote product formation, as degradation was also observed, however when iodide $\mathbf{1 7 3}$ was subjected to excess reagents a number of byproducts were observed by mass spectrometry. These were identified as products from the nucleophilic attack of ammonia on allyl bromide (176 to 179, Figure 3.2 ), as well as the secondary and tertiary amine dienes, $\mathbf{1 8 0}$ and $\mathbf{1 8 1}$, which were most likely formed from mono- or di-allylamines 176 and 177 (which are more nucleophilic than ammonia) reacting with iodide $\mathbf{1 7 3}$ in the Vasella-Barbier amination. While these findings provide an idea of how to reduce the formation of triol 175, and what was responsible for the formation of the over-allylated products, it was still difficult to determine how to best optimise for the formation of the desired product 172. Accordingly, the preparation of a benzylamine diene 182 was proposed as an intermediate target (Scheme 3.5). The preparation of diene 182 would allow for the development of the C-C bond forming methodology with the use of a primary amine source (instead of $\mathrm{NH}_{3}$ ) and it was predicted that this would limit the by-products formed from the reaction of the amine with allyl bromide. Ultimately, the choice of amine could be revisited, with the intention of attempting the synthesis of diene $\mathbf{1 7 2}$ again when the successful PGF preparation of benzylamine diene $\mathbf{1 8 2}$ was established. 
<smiles>C=CC[NH3+]</smiles>

176

$\left[\mathrm{C}_{3} \mathrm{H}_{7} \mathrm{~N}+\mathrm{H}\right]^{+}$

calcd.: 58.0651

obsd.: 58.0663<smiles>C=CC[N+](CC=C)(CC=C)CC=C</smiles>

179

$\left[\mathrm{C}_{12} \mathrm{H}_{20} \mathrm{~N}\right]^{+}$

calcd.: 178.1590

obsd.: 178.1597<smiles>C=CC[NH2+]CC=C</smiles>

177

$$
\begin{aligned}
& {\left[\mathrm{C}_{6} \mathrm{H}_{11} \mathrm{~N}+\mathrm{H}\right]^{+}} \\
& \text {calcd.: } 98.0964 \\
& \text { obsd.: } 98.0971
\end{aligned}
$$

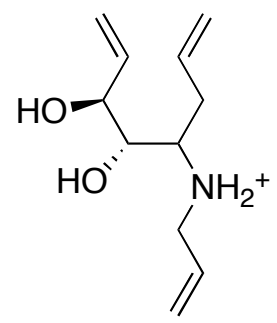

180

$\left[\mathrm{C}_{11} \mathrm{H}_{19} \mathrm{NO}_{2}+\mathrm{H}\right]^{+}$ calcd.: 198.1489 obsd.: 198.1497

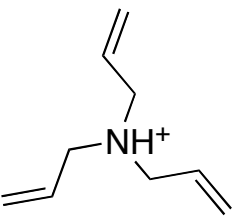

178

$\left[\mathrm{C}_{9} \mathrm{H}_{15} \mathrm{~N}+\mathrm{H}\right]^{+}$

calcd.: 138.1277

obsd.: 138.1282

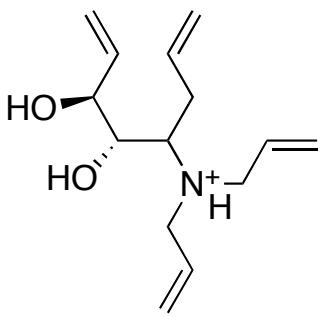

181

$\left[\mathrm{C}_{14} \mathrm{H}_{23} \mathrm{NO}_{2}+\mathrm{H}\right]^{+}$

calcd.: 238.1802

obsd.: 238.1813

Figure 3.2: Allylamine by-products observed by mass spectrometry.<smiles>CO[C@H]1O[C@H](CI)[C@@H](O)[C@H]1O</smiles>

173

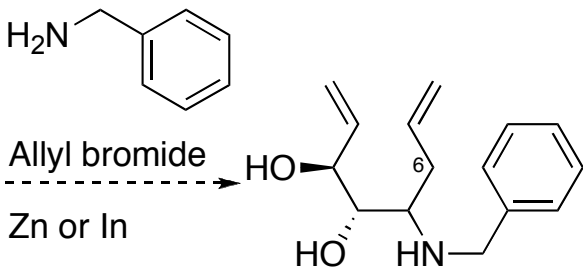

182

Scheme 3.5: Proposed reaction to target benzylamine diene $\mathbf{1 8 2}$.

Before the PGF synthesis of the new target, benzylamine $x y$ lo diene 182 (Scheme 3.5), was attempted, the preparation of an analogous ribo diene $\mathbf{1 8 3}$ via a literature protection/deprotection methodology was undertaken (Scheme 3.6), with two goals in mind: Firstly, returning to a literature method would confirm that the reported synthetic procedure was reliable, and that a protected VasellaBarbier amination was possible. More importantly, the preparation of ribo diene 
183 would provide a TLC reference for use in the development of the VasellaBarbier amination for the synthesis of the xylo diene 182. Similarly, the ${ }^{1} \mathrm{H}$ NMR and ${ }^{13} \mathrm{C}$ NMR spectra of diene isomer $\mathbf{1 8 3}$, although not identical, could also be used for comparison purposes. To this end, D-ribose (62) was subjected to Fischer methylation with concomitant isopropylidine protection of the syn diol and the primary hydroxyl was subsequently iodinated to provide protected iodide $\mathbf{6 6}$ in excellent yield (Scheme 3.6). Next, the Vasella-Barbier amination was undertaken according to the procedure developed by Madsen and coworkers ${ }^{8}$ which involved the sonication of iodide 66, benzylamine 184, and $\mathrm{Zn}$ in THF under dry conditions, followed by the portion-wise addition of allyl bromide. The reaction was complete after $4 \mathrm{~h}$, at which stage workup and purification by silica gel column chromatography provided protected benzylamine diene $67 \mathrm{~S}$ as a single isomer in a modest $32 \%$ yield. Comparison the ${ }^{1} \mathrm{H}$ NMR couplings with those reported previously ${ }^{8}$ confirmed that diene 675 was the syn diastereomer. Finally, to complete the synthesis, diene $\mathbf{6 7 S}$ was deprotected under aqueous acidic conditions, providing diol $\mathbf{1 8 3}$ in $94 \%$ yield. Thus the synthesis was successfully completed, providing ribo diene $\mathbf{1 8 3}$ in a modest (unoptimised) yield of $24 \%$. As the main goal of this synthesis was to provide ribo diene $\mathbf{1 8 3}$ for use as a reference standard, optimisation of the protected Vasella-Barbier amination reaction was not undertaken, and the modest yield could be attributed to the isolation of a single diastereomer, as well as the formation of some alcohol $\mathbf{1 8 5}$ as a by-product. 


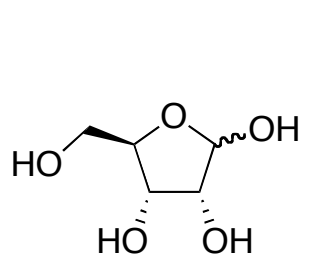

62 i) $0.5 \% \mathrm{HCl}$,

Acetone/MeOH

$1 / 1,91 \%$

ii) Toluene/MeCN 5/1, Imid., $\mathrm{PPh}_{3}$ $\mathrm{I}_{2}$, reflux, $30 \mathrm{~min}$ $88 \%$<smiles>CO[C@H]1O[C@H](CI)[C@H]2OC(C)(C)O[C@H]12</smiles>

66 $\mathrm{H}_{2} \mathrm{~N}$
184

$\mathrm{Zn}$, THF, allyl bromide sonicate, $4 \mathrm{~h}, 32 \%$<smiles>C=CC[C@H](NCc1ccccc1)[C@@H](O)[C@H](O)C=C</smiles>

183

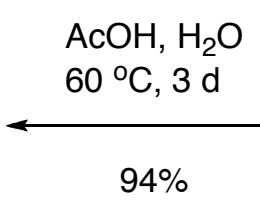

675

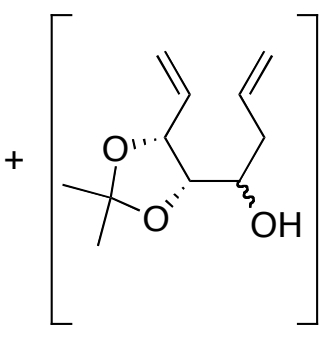

185

Scheme 3.6: Acetonide protected Vasella-Barbier amination reaction.

With the successful preparation of reference ribo diene 183 completed, the Vassella-Barbier amination on iodo methylxyloside 173 without the use of protecting groups, to give benzylamine xylo diene 182, was then pursued (Scheme 3.5). Here, iodo methylxyloside 173 was subjected to the same Vasella-Barbier amination conditions as iodo riboside 66 ( $\mathrm{Zn}$, THF, sonication, allyl bromide added portion-wise), however no product formation was observed. The VasellaBarbier reaction was then subjected to variations in the reaction time, solvent (EtOH or THF), heat $v s$. sonication, and the addition of $\mathrm{AcOH}$ (to favour imine formation), however in all attempted reactions, no product was observed. Monitoring the formation of xylo diene $\mathbf{1 8 2}$ by TLC revealed multiple product spots, including allylbenzylamine 186 (Figure 3.3). This by-product 186 had the same retention factor as the reference ribo diene $\mathbf{1 8 3}$ (and xylo diene 182) hence, the use of benzylamine diene $\mathbf{1 8 3}$ as a TLC reference was not very useful in monitoring reaction progress. However, it was noted from the disappearance of 
the starting material by TLC, that the Vasella component of the reaction required either sonication or reflux for the metal insertion and reductive elimination to proceed. Additionally, the stepwise addition of reagents to pre-form the aldehyde or imine led to degradation, as has been noted previously for hydroxyaldehydes. ${ }^{9}$ As the use of $\mathrm{Zn}$ in the Vasella-Barbier amination did not yield much success, the reagent was then substituted with indium powder. ${ }^{10}$ First, a Vasella-reductive amination with benzylamine 184 and $\mathrm{NaCNBH}_{3}$ was undertaken to confirm that indium could also be used for the Vasella component (Scheme 3.7), and indeed alkenylamine $\mathbf{1 8 7}$ was successfully formed in $71 \%$ yield. A variety of VasellaBarbier amination conditions were then explored using indium as the metal and eventually the formation of diene $\mathbf{1 8 2}$ was achieved when using 10 equiv. of both indium and benzylamine 184 and 2 equiv. of both allyl bromide and $\mathrm{AcOH}$ in THF ( $5 \mathrm{~mL} / \mathrm{mmol}$ ) at reflux overnight. Xylo diene 182 was initially identified by ${ }^{1} \mathrm{H}$ NMR spectroscopy of the crude reaction mixture whereby ${ }^{1} \mathrm{H}$ resonances at 2.4 ppm, corresponding to H-6ab could be identified. The formation of product was further supported by high resolution mass spectrometry. Purification of the reaction mixture by silica gel column chromatography then led to the isolation of benzylamine diene 182, albeit in a modest (ca. 5\%) yield.

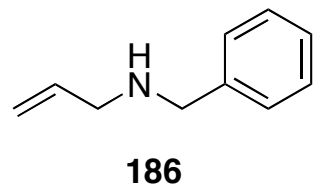

Figure 3.3: Allylbenzylamine by-product 186.

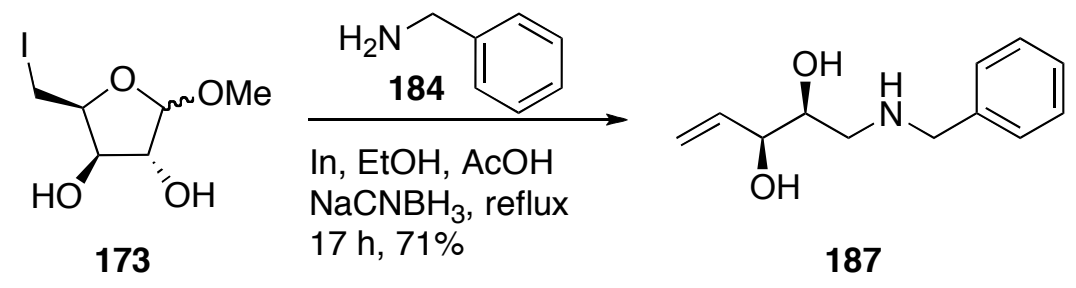

Scheme 3.7: Vasella reductive amination of iodide $\mathbf{1 7 3}$ to give benzylalkenylamine $187 .^{11}$ 
In order to optimise the synthesis of diene 182, a rapid method to estimate the yield of this product was required. Ideally, such methodology would allow for the quantification of the product yield directly from the crude reaction mixture, as ${ }^{1} \mathrm{H}$ NMR analysis of the crude reaction mixture was also ineffective due to the number of products formed, and similarly, isolation and purification of the product was difficult and time consuming. Accordingly, a high resolution mass spectrometry quantification method was attempted. To this end, an internal standard, tertiary amine $\mathbf{1 8 8}$ (Figure 3.4 ), was added to the mass spectrometry samples to compare the relative amount of product formed under a given set of reaction conditions. To estimate the quantity of diene $\mathbf{1 8 2}$ that was produced in a given reaction, one drop $(\sim 20 \mu \mathrm{L})$ of the reaction mixture was triturated and decanted from a methanolic solution of the internal standard $(10 \mathrm{~mL})$ and submitted for direct injection high resolution mass spectrometry. The peak height ratio for the protonated internal standard amine $188\left(\mathrm{~m} / \mathrm{z}:\left[\mathrm{C}_{15} \mathrm{H}_{27} \mathrm{NO}_{3}+\mathrm{H}\right]^{+}=\right.$ 270.2064) versus the diene $182\left(\mathrm{~m} / z:\left[\mathrm{C}_{15} \mathrm{H}_{21} \mathrm{NO}_{2}+\mathrm{H}\right]^{+}=248.1645\right)$ then gave an indication of the amount of product formed in the reaction. In a similar vein, the mass spectrometry method could also be used to identify relative ratios of amine by-product, allylbenzylamine $186\left(m / z:\left[\mathrm{C}_{10} \mathrm{H}_{13} \mathrm{~N}+\mathrm{H}\right]^{+}=148.1121\right)$.<smiles>C=C[C@@H](O)CCN(CC[C@H](O)C=C)CC[C@@H](O)C=C</smiles>

188

Figure 3.4: Mass spectrometry internal standard, tertiary amine $\mathbf{1 8 8 .}$ 
Using the MS method, optimal reaction conditions (10 equiv. AcOH, 6 equiv. In, 10 equiv. $\mathrm{BnNH}_{2}$, and 4 x 2 equiv. allyl bromide, refluxed in $5 \mathrm{~mL} / \mathrm{mmol} \mathrm{THF}$ for 6 h) were identified (Scheme 3.8), however, unfortunately the isolated yield of diene 182 was only $16 \%$, which was significantly lower than the anticipated yield based on MS quantification. The disparity between the expected and isolated yields indicates a limitation of the MS quantification methodology with variations in drop size, reaction concentration due to solvent evaporation over the course of the reaction, and the formation of insoluble products in the reaction mixture, limiting the accuracy of the MS method. Moreover, the difficulty in separating product 182 from the by-product allylbenzylamine 186 by silica column chromatography may have led to the degradation of diene $\mathbf{1 8 2}$ on the silica column and contributed to the low isolated yield. Accordingly, while the MS technique did provide an indication of whether an alteration to the reaction conditions was beneficial to product formation, the technique was not an accurate method to quantify the amount of diene $\mathbf{1 8 2}$ formed, and thus, for the subsequent PGF Vasella-Barbier optimisation studies, the MS technique was not employed.<smiles>CO[C@H]1O[C@H](CI)[C@@H](O)[C@H]1O</smiles>

173

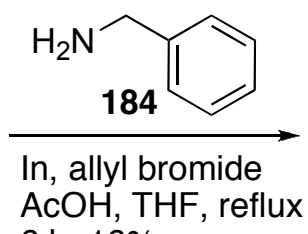

$6 \mathrm{~h}, 16 \%$

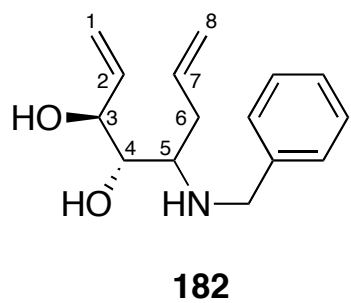

Scheme 3.8: PGF Vasella-Barbier benzylamination.

Having achieved the successful Vasella-Barbier amination with benzylamine $\mathbf{1 8 4}$ to form diene 182, albeit in modest yield, the development of a PGF VasellaBarbier amination to form primary amine $\mathbf{1 7 2}$ was resumed with the confidence that unprotected diol 173 was amenable to the reaction conditions. To avoid overallylation of the amine, an amine source that was less nucleophilic towards allyl bromide was sought. To this end, a literature search revealed that $\mathrm{NH}_{4} \mathrm{OAc}$ had been previously used in a Barbier-Mannich reaction to form secondary amine 'dimers', ${ }^{12}$ and hence the PGF Vasella-Barbier amination was attempted using 
$\mathrm{NH}_{4} \mathrm{OAc}$ rather than $\mathrm{NH}_{3}$ as the amine source (Scheme 3.9). Analysis of the crude reaction mixture by ${ }^{1} \mathrm{H}$ NMR spectroscopy provided evidence that amino diene 172 was formed, whereby a spectrum similar, but not identical to that of triol 175 was observed. Indeed, purification by Dowex $-\mathrm{H}^{+}$ion exchange chromatography, and subsequent silica gel column chromatography enabled the successful isolation of diene $\mathbf{1 7 2}$ in ca. 5\% yield. The ${ }^{1} \mathrm{H}$ NMR spectrum of this compound is given in Figure 3.5, where full ${ }^{1} \mathrm{H}$ assignments are made.

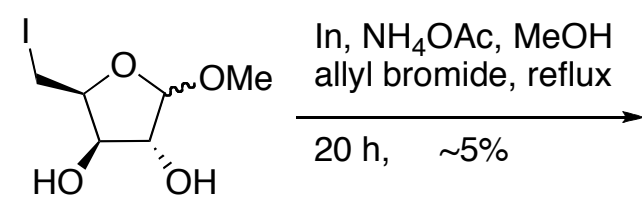

173

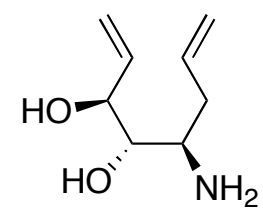

172

Scheme 3.9: Vasella-Barbier reaction with unprotected amine. 


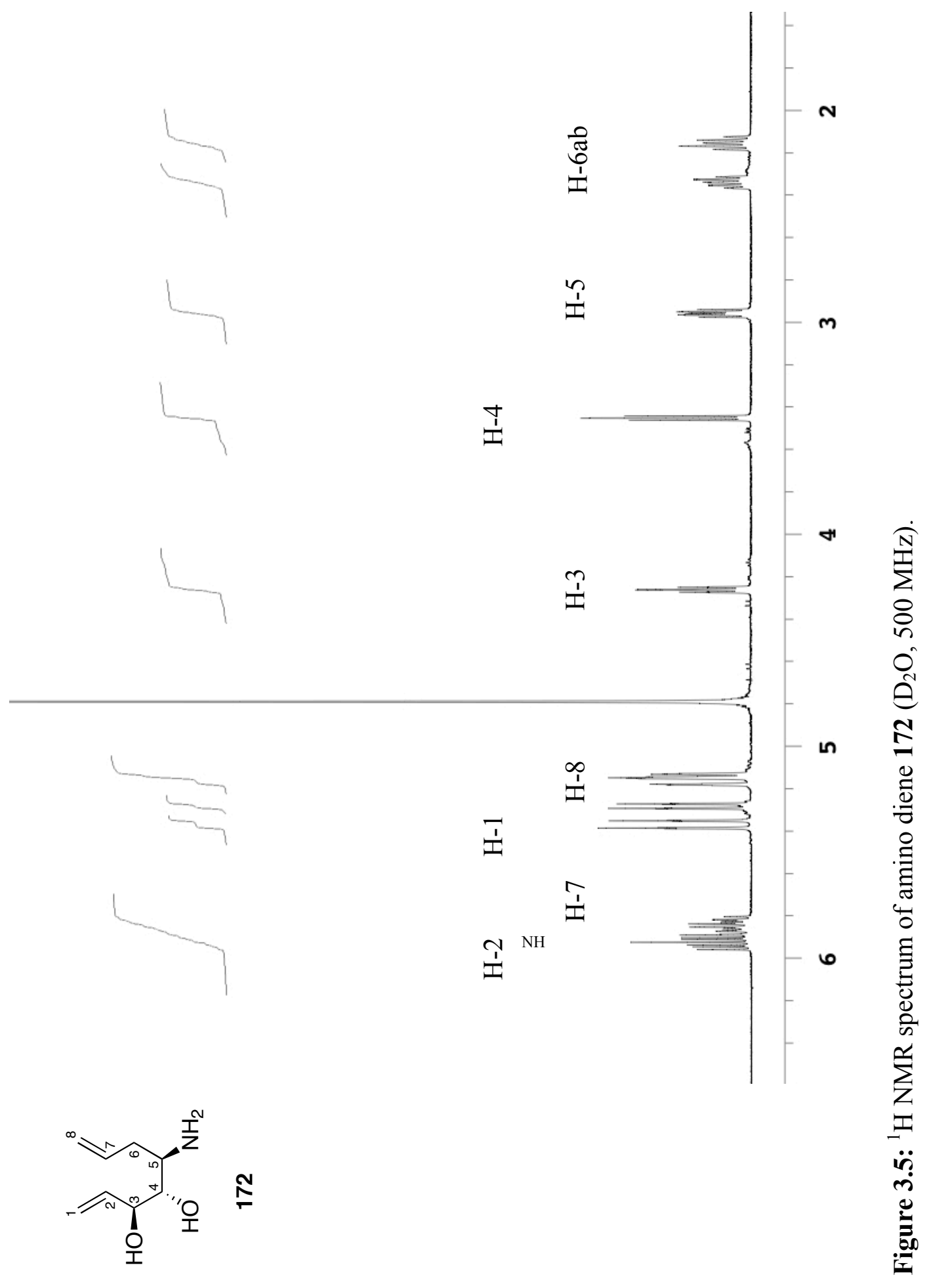


Having determined a methodology that allowed for the synthesis of diene 172, optimisation of the reaction conditions was undertaken (Table 3.1). All reactions were performed in dry conditions, under Ar, with the dropwise addition of allyl bromide to the refluxing reaction mixture over $10 \mathrm{~min}$. From the initial conditions of 6 equiv. of indium powder, 2 equiv. of each $\mathrm{NH}_{4} \mathrm{OAc}$ and allyl bromide, refluxed in $\mathrm{MeOH}$ ( $5 \mathrm{~mL} / \mathrm{mmol}$ of xyloside 173) overnight (entry 1), a larger excess (6 equiv.) of both ammonium acetate and allyl bromide gave a small improvement in yield ( $8 \%$, entry 2$)$. A dilution of the reaction mixture to $10 \mathrm{~mL} / \mathrm{mmol}$, with the use of additional $\mathrm{NH}_{4} \mathrm{OAc}$ (24 equiv., entry 3) also resulted in an improved $(20 \%)$ yield. Next, the concentration of $\mathrm{NH}_{4} \mathrm{OAc}$ was further increased to a nearly saturated solution (48 equiv., entry 4), however, no improvement in yield was observed in this case (18\% yield). To test the necessity of the dropwise addition of the allyl bromide, a reaction under the same conditions as entry 3 was performed, with the only difference being the addition of allyl bromide in one portion at the beginning of the reaction (entry 5). Very little product was obtained under these conditions, with an insoluble solid (presumably a polymer) being observed. Changes to the solvent were then made, with EtOH and THF replacing $\mathrm{MeOH}$ (entries 6 and 7, respectively), though both reactions provided insubstantial amounts of product. In the case of entry 6 , the EtOH was not dry and hence triol 175 was predominantly formed, however, freshly distilled dry THF was used in entry 7 and this reaction was also very poor yielding. That said, the reaction in THF was notably slower, with incomplete reaction after $2 \mathrm{~d}$ refluxing, which suggests poor solubility of one of the starting materials. 
Table 3.1: Reaction conditions for the Vasella-Barbier amination

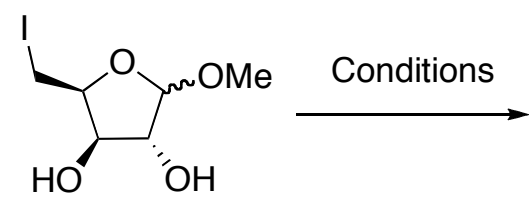

173

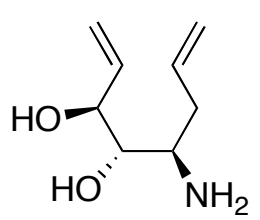

172

\begin{tabular}{|c|c|c|}
\hline Entry & Conditions & Yield of 172 \\
\hline 1 & $\begin{array}{l}\text { In (6 equiv.), } \mathrm{NH}_{4} \mathrm{OAc} \text { ( } 2 \text { equiv.), allyl bromide dropwise } \\
\text { ( } 2 \text { equiv.), } \mathrm{MeOH}(5 \mathrm{~mL} / \mathrm{mmol}) \text {, reflux, } 24 \mathrm{~h}\end{array}$ & $\sim 5 \%$ \\
\hline 2 & $\begin{array}{l}\text { In (6 equiv.), } \mathrm{NH}_{4} \mathrm{OAc} \text { (6 equiv.), allyl bromide dropwise } \\
\text { ( } 6 \text { equiv.), } \mathrm{MeOH}(5 \mathrm{~mL} / \mathrm{mmol}) \text {, reflux, } 16 \mathrm{~h}\end{array}$ & $8 \%$ \\
\hline 3 & $\begin{array}{l}\text { In }(6 \text { equiv. }), \mathrm{NH}_{4} \mathrm{OAc} \text { (24 equiv.), allyl bromide } \\
\text { dropwise (6 equiv.), } \mathrm{MeOH}(10 \mathrm{~mL} / \mathrm{mmol}), \text { reflux, } 20 \mathrm{~h}\end{array}$ & $20 \%$ \\
\hline 4 & $\begin{array}{l}\text { In }(6 \text { equiv. }), \mathrm{NH}_{4} \mathrm{OAc} \text { (48 equiv.), allyl bromide } \\
\text { dropwise (6 equiv.), } \mathrm{MeOH}(10 \mathrm{~mL} / \mathrm{mmol}), \text { reflux, } 20 \mathrm{~h}\end{array}$ & $18 \%$ \\
\hline 5 & $\begin{array}{l}\left.\text { In }(6 \text { equiv. }), \mathrm{NH}_{4} \mathrm{OAc} \text { ( } 24 \text { equiv. }\right) \text {, allyl bromide } 1 \\
\text { portion (6 equiv.), } \mathrm{MeOH}(10 \mathrm{~mL} / \mathrm{mmol}), \text { reflux, } 21 \mathrm{~h}\end{array}$ & $<5 \%$ \\
\hline 6 & $\begin{array}{l}\text { In }(6 \text { equiv. }), \mathrm{NH}_{4} \mathrm{OAc}(24 \text { equiv. }) \text {, allyl bromide } \\
\text { dropwise (6 equiv.), EtOH }(10 \mathrm{~mL} / \mathrm{mmol}) \text {, reflux, } 17 \mathrm{~h}\end{array}$ & $<5 \%$ \\
\hline 7 & $\begin{array}{l}\left.\text { In }(6 \text { equiv. }), \mathrm{NH}_{4} \mathrm{OAc} \text { ( } 24 \text { equiv. }\right) \text {, allyl bromide } \\
\text { dropwise (6 equiv.), THF }(10 \mathrm{~mL} / \mathrm{mmol}) \text {, reflux, } 44 \mathrm{~h}\end{array}$ & $\begin{array}{l}\text { Incomplete } \\
<<5 \%\end{array}$ \\
\hline 8 & $\begin{array}{l}\text { In }(6 \text { equiv. }), \mathrm{NH}_{4} \mathrm{OAc}(24 \text { equiv. }), \text { allyl bromide } \\
\text { dropwise }(6 \text { equiv. }), \mathrm{MeOH}(10 \mathrm{~mL} / \mathrm{mmol}) \text {, sonicate } 11 \mathrm{~h}\end{array}$ & Alcohol only \\
\hline 9 & $\begin{array}{l}\text { In }(6 \text { equiv. }), \mathrm{NH}_{4} \mathrm{OAc} \text { (24 equiv.), allyl bromide } \\
\text { dropwise (6 equiv.), } \mathrm{MeOH}(20 \mathrm{~mL} / \mathrm{mmol}) \text {, reflux, } 15 \mathrm{~h}\end{array}$ & $7 \%$ \\
\hline
\end{tabular}




\begin{tabular}{|c|c|c|}
\hline Entry & Conditions & Yield of $\mathbf{1 7 2}$ \\
\hline 10 & $\begin{array}{l}\text { In }(6 \text { equiv. }), \mathrm{NH}_{4} \mathrm{OAc}(24 \text { equiv. }), \text { allyl bromide } \\
\text { dropwise (6 equiv.), } \mathrm{MeOH}(10 \mathrm{~mL} / \mathrm{mmol}), 28 \% \\
\mathrm{NH}_{3} / \mathrm{MeOH} \text { (6 equiv.) reflux, } 15 \mathrm{~h}\end{array}$ & $9 \%$ \\
\hline 11 & $\begin{array}{l}\text { In (6 equiv.), } \mathrm{NH}_{4} \mathrm{OAc}(24 \text { equiv. }) \text {, allyl bromide } \\
\text { dropwise (6 equiv.), } \mathrm{MeOH}(10 \mathrm{~mL} / \mathrm{mmol}), \mathrm{AcOH}(6 \\
\text { equiv.), reflux, } 21 \mathrm{~h}\end{array}$ & $9 \%$ \\
\hline $12^{\mathrm{a}}$ & $\begin{array}{l}\text { In }(6 \text { equiv. }), \mathrm{NH}_{4} \mathrm{OAc}(24 \text { equiv. }) \text {, allyl bromide } \\
\text { dropwise ( } 6 \text { equiv. }), \mathrm{MeOH}(10 \mathrm{~mL} / \mathrm{mmol}), \text { reflux, } 20 \mathrm{~h}\end{array}$ & $35 \%$ \\
\hline
\end{tabular}

a Performed on a 2 mmol scale, when all other reactions were performed on a $0.5 \mathrm{mmol}$ scale.

As many literature procedures for Barbier reactions use sonication, ${ }^{10,13}$ this technique was used in entry 8 , however, disappointingly, only alcohol $\mathbf{1 7 5}$, was observed. Next, a more dilute solution of $20 \mathrm{~mL} / \mathrm{mmol}$ of furanoside 173 was used with the aim of reducing the formation of the dimer 189 as well as reducing polymerisation (entry 9). Although never isolated, dimer 189 was observed by high resolution mass spectrometry $\left(\mathrm{m} / \mathrm{z}\right.$ : $\left[\mathrm{C}_{16} \mathrm{H}_{27} \mathrm{NO}_{4}+\mathrm{H}\right]^{+}$calcd. $=298.2013$, obsd. $=298.2025)$. This could be formed from the reaction of aldehyde $\mathbf{1 9 0}$ and product amine 172, and the subsequent Barbier reaction of the resulting imine (Scheme 3.10). Unfortunately, the lowered concentration of entry 9 resulted in a low yield of $7 \%$, which may occur as a result of degradation of the corresponding aldehyde or imine. ${ }^{11}$ Upon further assessment of the literature, it was noted that the $\mathrm{pH}$ of the reaction mixture was important to favour primary amine formation in the development of the PGF Vasella-reductive amination. ${ }^{11}$ Thus, the reaction conditions were adjusted through the addition of small amounts (6 equiv.) of either $\mathrm{AcOH}$ ( $\mathrm{pH} 7$, entry 10), or $\mathrm{NH}_{3}$ (28\% methanolic, $\mathrm{pH} 8$, entry 11). Surprisingly, although the $\mathrm{pH}$ of the reaction mixtures varied only slightly $(c f . \mathrm{pH}$ 7.5 observed in entry 3 ), both reactions resulted in a lowered yield of amine $\mathbf{1 7 2}$. Because of the presence of electrophilic allyl bromide in the $\mathrm{C}-\mathrm{C}$ bond forming 
reaction, the use of even a small excess of ammonia to increase the $\mathrm{pH}$ appeared undesirable, presumably due to the formation of over-allylated products. Therefore, with a variety of conditions attempted and only a low yield achieved, the reaction was scaled up in order to produce enough diene $\mathbf{1 7 2}$ to continue to the RCM step. Surprisingly, when the reaction was scaled four times to a $600 \mathrm{mg}$ ( 2.2 mmol) scale reaction (entry 12 ), the yield was also improved to $35 \%$. This result may be attributed to the dryness of the reaction, as large scale reactions are less sensitive to the small amounts of water present.
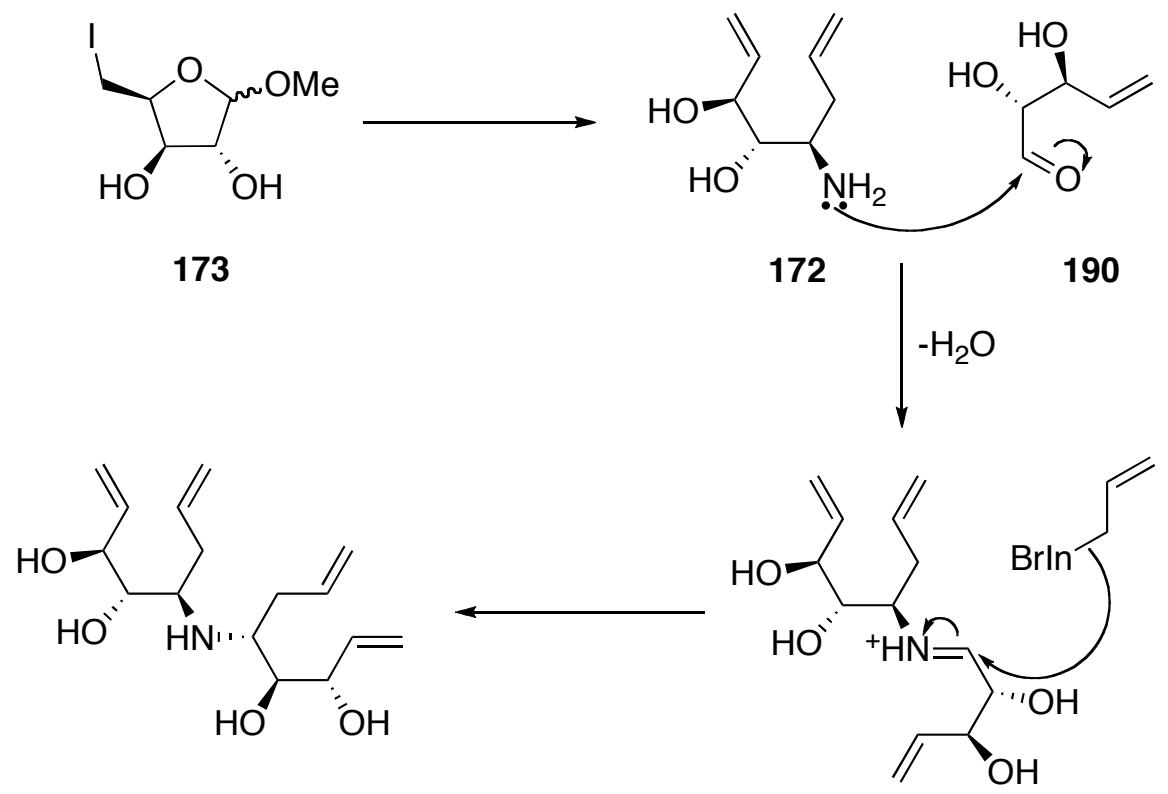

189

Scheme 3.10: Mechanistic explanation of dimer 189 formation.

Purification of amino diene $\mathbf{1 7 2}$ by Dowex- $\mathrm{H}^{+}$and then silica column chromatography provided the product as a single isomer (the 4,5-anti isomer). The 4,5-anti relationship was established from the conformationally locked cyclohexene 171 following the RCM of the linear diene 172 (see Section 3.3). Accordingly, a Cram-chelate model can be used to explain the 4,5-anti selectivity of the $\mathrm{C}-\mathrm{C}$ bond forming reaction (Figure 3.6), whereby after imine formation 
indium chelates between the $5-\mathrm{NH}$ and the 4-OH groups, ${ }^{14}$ locking the conformation of the molecule. With a bulky allyl alcohol group (R) blocking one side of the molecule, the nucleophilic Barbier reagent can only attack from the $R e$ face, leading to the anti relationship between C-4 and C-5 substituents. Here, it should be noted that baseline impurities in the ${ }^{1} \mathrm{H}$ NMR spectra were occasionally noted, which may indicate the presence of tiny amounts of the syn $\mathbf{1 7 2}$ isomer or the dimer 189.
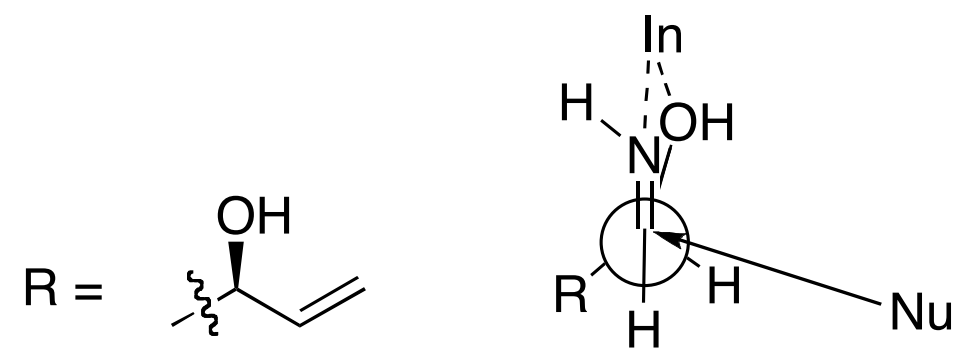

Figure 3.6: Cram-chelate model for the stereoselectivity of the Vasella-Barbier amination to form diene $\mathbf{1 7 2 .}$ 


\subsection{RCM for the Synthesis of a Conduramine Analogue}

Having successfully prepared amino diene $\mathbf{1 7 2}$ via a PGF route, the RCM reaction to form conduramine derivative $\mathbf{1 7 1}$ was then explored (Scheme 3.11). RCM on a molecule containing a primary amine has only been reported once in the literature, ${ }^{15}$ and this utilised a protection by protonation strategy and the HoveydaGrubbs $2^{\text {nd }}$ generation catalyst. Using this approach, amine 172 was thus transformed into the ammonium triflate salt and subjected to $5 \mathrm{~mol} \%$ of the Hoveyda-Grubbs II catalyst in dry THF. TLC analysis revealed that the reaction was complete after $1 \mathrm{~h}$, and following purification by flash silica column chromatography (DCM:MeOH:EtOH:35\% $\quad \mathrm{NH}_{3 \text { (aq.) }} \quad$ 55:2:2:1), the target conduramine $\mathbf{1 7 1}$ was obtained in a quantitative yield. To test the scope of this reaction, and confirm the necessity of the ammonium triflate salt, the reaction was also attempted on the free amine 172. No reaction was observed by TLC after several hours stirring at $\mathrm{rt}$, and gentle heating and then refluxing of the reaction mixture with the addition of more catalyst also failed to induce the desired reaction. In contrast, when the ammonium chloride salt of diene $\mathbf{1 7 2}$ was used in the RCM, conduramine 171 was successfully isolated in $72 \%$ yield. The RCM reaction of the $\mathrm{HCl}$ salt required an $8 \mathrm{~mol} \%$ catalyst loading and heating, thus the quantitative reaction of the triflate salt was still preferred. 
<smiles>C=CC[C@H](N)[C@@H](O)C(O)C=C</smiles>

172 i) $\mathrm{TfOH}, \mathrm{H}_{2} \mathrm{O}$

ii) Hoveyda-Grubbs II THF, rt, $1 \mathrm{~h}$

quant.

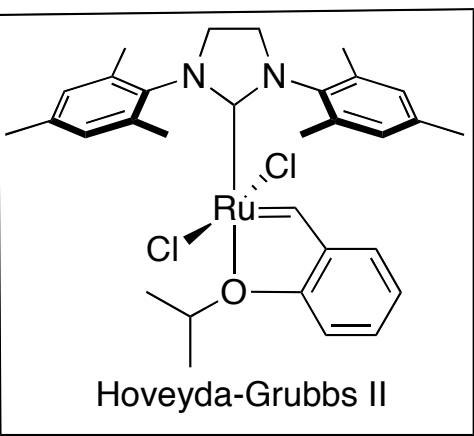<smiles>N[C@H]1CC=C[C@@H](O)[C@]1(O)[In]</smiles>

171

Scheme 3.11: PGF conduramine synthesis.

Confirmation of the structure of conduramine 171 by NMR spectroscopy involved the identification of ${ }^{1} \mathrm{H}$ couplings between the $\mathrm{CH}_{2}$ group at $\mathrm{C}-6$ and the alkene $\mathrm{CH}$ at $\mathrm{C}-1$. The disappearance of the terminal alkene peaks in the ${ }^{1} \mathrm{H}$ NMR spectrum, as well as reduced integration of the alkene signals supported this assignment (Figure 3.8), as did high resolution mass spectrometry, where an ion at the mass of the protonated amine was clearly visible $\left(m / z\right.$ : $\left[\mathrm{C}_{6} \mathrm{H}_{11} \mathrm{NO}_{2}+\mathrm{H}\right]^{+}$calcd. $=130.0863$, obsd. $=130.0865)$. Having confirmed the formation of a substituted cyclohexene, the stereochemistry at C-5 could thus be determined as anti to C-4 hydroxyl based on large couplings between H-4 and H-5 and also between H-5 and H-6b $\left(J_{4,5}=J_{5,6 \mathrm{~b}}=10.5 \mathrm{~Hz}\right)$ suggesting a diaxial relationship between these protons (Figure 3.7).

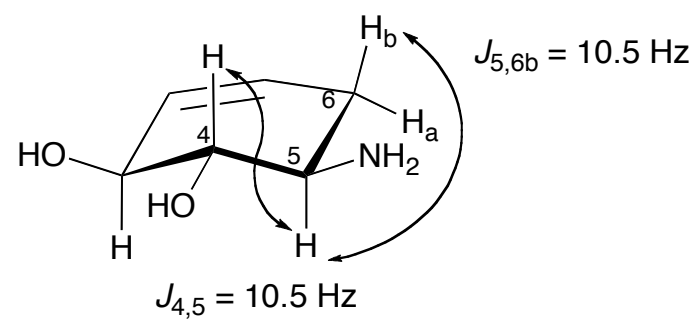

Figure 3.7: Coupling constants for the determination of the 4,5-anti relationship in conduramine $\mathbf{1 7 1}$. 


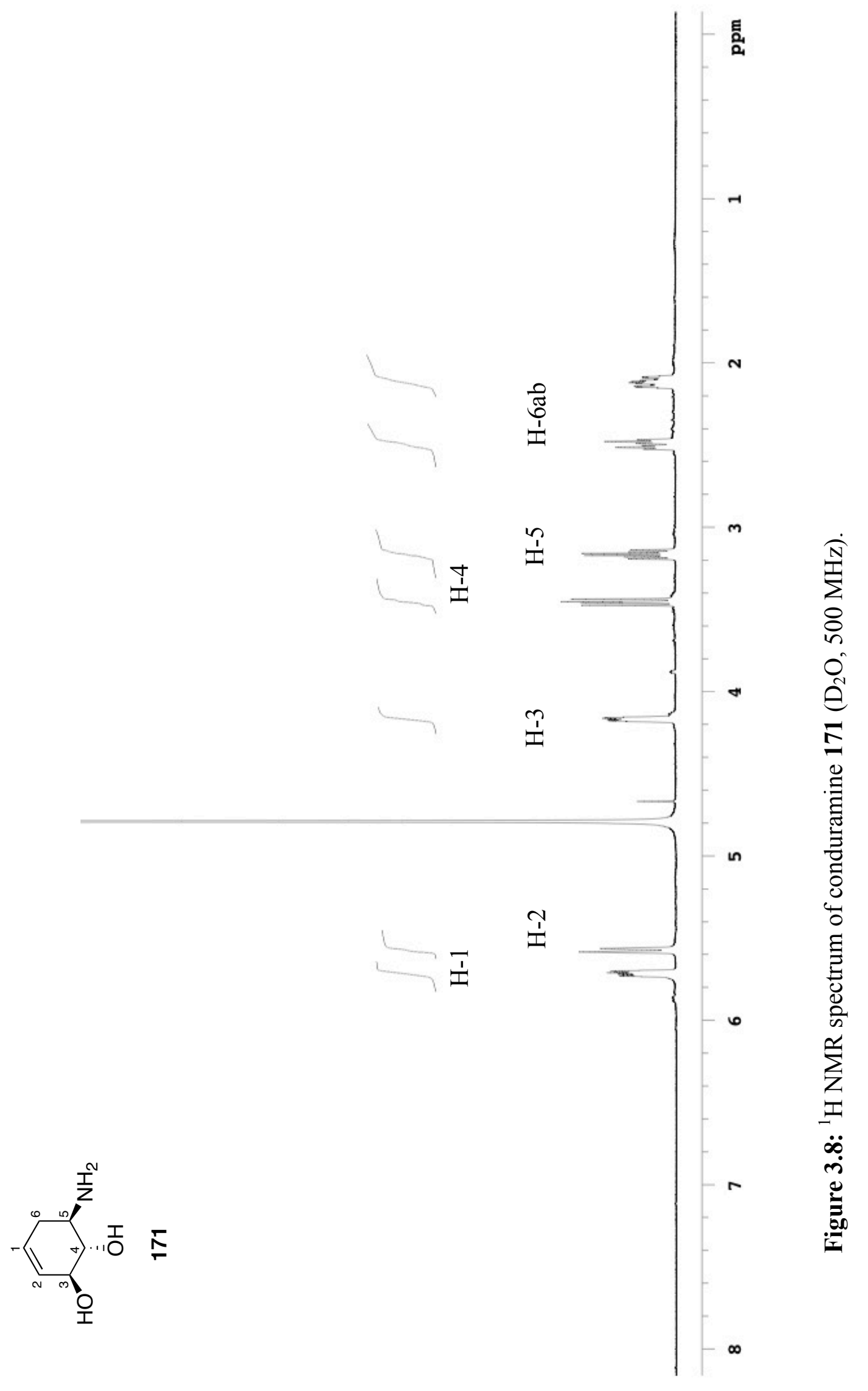




\subsection{Conclusion}

In summary, a short, stereoselective PGF synthesis of 4-deoxy-3-conduramines has been presented, as illustrated by the preparation of conduramine 171 which was synthesised in four steps and in an overall yield of $27 \%$. The synthesis of conduramine $\mathbf{1 7 1}$ required the installation of both a $\mathrm{C}-\mathrm{C}$ and a $\mathrm{C}-\mathrm{N}$ bond and hence the PGF Vasella-Barbier amination was developed. A Cram chelate model could be used to explain the 4,5-anti selectivity of the novel C-C bond forming methodology. In the final step, an in situ protection strategy was utilised to allow the quantitative RCM of diene 172, and the formation of the desired 4-deoxy-3conduramine 171. Taken as a whole, this methodology provides the first step towards a useful synthetic route that has potential to be extended for the development of a variety of products, as will be elaborated on in Chapter 5 . 


\subsection{Experimental}

\section{General Experimental}

Unless otherwise stated, all reactions were performed under atmospheric air. allyl bromide (Merck), EtOH (absolute, Pure Science), $\mathrm{H}_{2} \mathrm{O}, \mathrm{MeOH}$ (Pure Science), and TfOH (Sigma) were distilled prior to use. EtOAc (Pure Science), petroleum ether (Pure Science), AcOH (Ajax Finechem), AcCl (B\&M), Acetone (Fischer), benzylamine (Sigma-Aldrich), DCM (LabServ), $\mathrm{HCl}$ (PanReac), Hoveyda Grubbs II Catalyst (Aldrich), Indium powder (AlfaAesar), $\mathrm{MgSO}_{4}$ (PureScience), 35\% aqueous $\mathrm{NH}_{3}$ (LabServ), $\mathrm{NaCNBH}_{3}$ (Aldrich), $\mathrm{NaHCO}_{3}$ (PureScience), $\mathrm{NH}_{4} \mathrm{OAc}$ (AnalaR), D-ribose (Sigma-Aldrich), and D-xylose (Sigma) were used as received. All chemicals obtained from commercial suppliers were used without further purification. $\mathrm{Zn}$ dust was activated by the careful addition of concentrated $\mathrm{H}_{2} \mathrm{SO}_{4}$, followed by decantation and washing with $\mathrm{EtOH}(3 \times)$ and hexanes $(3 \times)$ and storage under dry hexanes. All solvents were removed by evaporation under reduced pressure. Reactions were monitored by TLC analysis on Macherey-Nagel silica gel coated plastic sheets with detection by coating with $20 \% \mathrm{H}_{2} \mathrm{SO}_{4}$ in EtOH followed by charring at $c a .150{ }^{\circ} \mathrm{C}$, by coating with a solution of ninhydrin in EtOH followed by charring at $c a .150{ }^{\circ} \mathrm{C}$, or by coating with a solution of $5 \%$ $\mathrm{KMnO}_{4}$ and $1 \% \mathrm{NaIO}_{4}$ in $\mathrm{H}_{2} \mathrm{O}$ followed by heating. Column chromatography was performed on Pure Science silica gel (40-63 micron). Dowex ${ }^{\circledR}$ W50-X8 acidic resin (Sigma) and Dowex ${ }^{\circledR}$ 1X4-50 basic resin (Sigma) were used for ion exchange chromatography and HP-20 (Supelco) for reverse phase chromatography. High-resolution mass spectra were recorded on a Waters Q-TOF Premier $^{\mathrm{TM}}$ Tandem Mass Spectrometer using positive electro-spray ionisation. Optical rotations were recorded using an Autopol II (Rudolf Research Analytical) at $589 \mathrm{~nm}$ (sodium D-line). Infrared spectra were recorded as thin films using a Bruker Tensor 27 FTIR spectrometer, equipped with an Attenuated Total Reflectance (ATR) sampling accessory, and are reported in wave numbers $\left(\mathrm{cm}^{-1}\right)$. Nuclear magnetic resonance spectra were recorded at $20{ }^{\circ} \mathrm{C}$ in $\mathrm{D}_{2} \mathrm{O}$ or $\mathrm{CDCl}_{3}$ using either a Varian Unity-INOVA operating at $300 \mathrm{MHz}$ or a Varian Unity 
operating at $500 \mathrm{MHz}$. Chemical shifts are given in ppm ( $\delta)$ and were internally referenced to the residual solvent peak. NMR peak assignments are based on 2D NMR experiments (COSY, HSQC, and HMBC).<smiles>CO[C@@H]1O[C@H](CI)[C@@H](O)[C@H]1O</smiles>

Methyl 5-deoxy-5-iodo- $\boldsymbol{\alpha} / \boldsymbol{\beta}$-D-xyloside (173): ${ }^{5}$ To a solution of D-xylose (10.04 g, $67 \mathrm{mmol})$ in $\mathrm{MeOH}(330 \mathrm{~mL}), \mathrm{AcCl}(1 \mathrm{~mL})$ was added and the reaction stirred at room temperature for $22 \mathrm{~h}$. The reaction was neutralised by the addition of Dowex $\left(\mathrm{OH}^{-}\right)$, filtered and concentrated to give the methyl xyloside. The resulting oil was used in the next step without further purification. To a solution of methyl xyloside $(11.0 \mathrm{~g}, 67 \mathrm{mmol})$ in dry THF $(300 \mathrm{~mL})$, imidazole (9.0 g, $132 \mathrm{mmol}), \mathrm{PPh}_{3}(26.0 \mathrm{~g}, 99 \mathrm{mmol})$, and $\mathrm{I}_{2}(25 \mathrm{~g}, 99 \mathrm{mmol})$ were added under an atmosphere of argon. The reaction was refluxed for $1.5 \mathrm{~h}$, then cooled and concentrated under reduced pressure. The product was taken up in petroleum ether/EtOAc, 2/1, v/v, and filtered through a silica plug to remove excess iodine. The product was further purified by reverse phase HP20 beads $(10 \%$ to $40 \% \mathrm{MeOH} /$ water, $\mathrm{v} / \mathrm{v})$ to give xyloside 173 as colourless oil in a 1:1 ratio of $\alpha$ - and $\beta$-anomers $(78 \%, 14.27 \mathrm{~g}, 52.1 \mathrm{mmol})$. Characterisation data are in full agreement with that reported. ${ }^{16}$

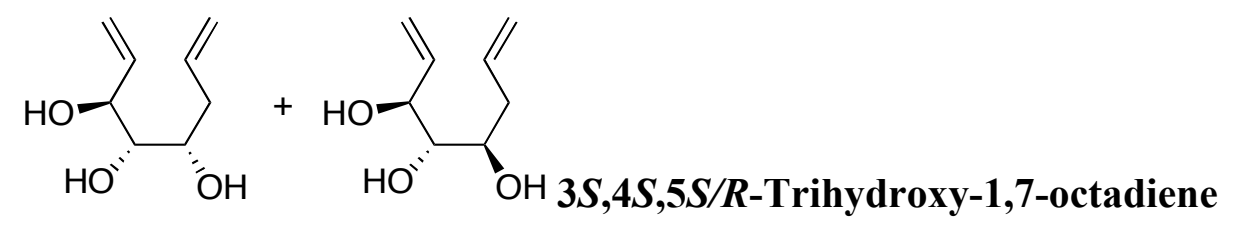

(175S/R): ${ }^{8}$ To a solution of methyl 5-deoxy-5-iodo- $\alpha / \beta$-D-xyloside (173) (100 $\mathrm{mg}, 0.36 \mathrm{mmol})$ in $\mathrm{THF} / \mathrm{H}_{2} \mathrm{O}(1.1 \mathrm{~mL}, 4 / 1$, v/v) was added $\mathrm{Zn}(234 \mathrm{mg}, 3.6$ mmol) and allyl bromide (95 $\mu \mathrm{L}, 1.1 \mathrm{mmol})$. The solution was sonicated for $4 \mathrm{~h}$, before filtration through celite provided the crude product $\mathbf{1 7 5}$ as a 3:7 mixture of $S: R$ diastereomers. Characterisation data are in agreement with that reported in the literature. $^{8}$ 


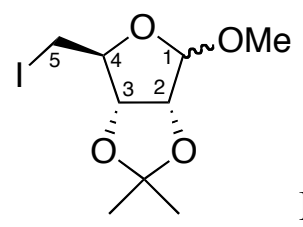

\section{Methyl 5-deoxy-5-iodo-2,3- $O$-isopropylidine- $\alpha / \beta$-D-riboside}

(66): To a solution of D-ribose (62) $(5.04 \mathrm{~g}, 33.6 \mathrm{mmol})$ in acetone/MeOH (68 $\mathrm{mL}, 1 / 1, \mathrm{v} / \mathrm{v})$ was added conc. $\mathrm{HCl}(350 \mu \mathrm{L})$ dropwise, and the reaction refluxed

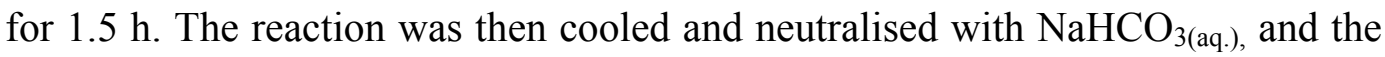
acetone $/ \mathrm{MeOH}$ solvent removed under reduced pressure. The aqueous layer was then extracted with EtOAc (3x), washed with $\mathrm{NaCl}_{(\mathrm{aq} .)}$, dried over $\mathrm{MgSO}_{4}$, filtered and concentrated to provide methyl 2,3-O-isopropylidine- $\alpha / \beta$-D-riboside as a colourless oil which was used in the next step without further purification $(6.25 \mathrm{~g}$, 31, mmol, 91\%). To a solution of methyl riboside (2.02 g, $9.9 \mathrm{mmol})$ in dry toluene/MeCN (36 mL, 5/1, v/v) was added $\mathrm{I}_{2}(3.03 \mathrm{~g}, 11.9 \mathrm{mmol}), \mathrm{PPh}_{3}(3.02 \mathrm{~g}$, $11.5 \mathrm{mmol})$, and imidazole $(1.09 \mathrm{~g}, 16.0 \mathrm{mmol})$ and the reaction refluxed under Ar for $30 \mathrm{~min}$. Upon cooling, $100 \mathrm{~mL} \mathrm{Et}_{2} \mathrm{O}$ was added and the organic layer was washed with $\mathrm{Na}_{2} \mathrm{~S}_{2} \mathrm{O}_{3 \text { (aq.) }}, \mathrm{H}_{2} \mathrm{O}$, then $\mathrm{NaCl}_{\text {(aq.), }}$ dried over $\mathrm{MgSO}_{4}$, filtered and concentrated under reduced pressure. Purification by silica gel flash column chromatography (petroleum ether/EtOAc, 19/1, v/v) provided methyl 5-deoxy-5iodo-2,3-O-isopropylidine- $\alpha / \beta$-D-riboside (66) as a pale yellow oil (2.72 g, 8.6 mmol, 88\%). $\mathrm{R}_{f}=0.71$ (petroleum ether/EtOAc, $\left.1 / 1, \mathrm{v} / \mathrm{v}\right) ;[\alpha]_{\mathrm{D}}{ }^{26}=-64.5(c=1.0$, $\left.\mathrm{CHCl}_{3}\right)$, lit. $^{17}[\alpha]_{\mathrm{D}}{ }^{25}=-65.7\left(c=1.0, \mathrm{CHCl}_{3}\right)$; IR (film) 2989, 2936, 1374, 1103, 1066, 868, $515 \mathrm{~cm}^{-1} .{ }^{1} \mathrm{H}$ NMR $\left(500 \mathrm{MHz}, \mathrm{CDCl}_{3}\right) \delta 5.03(\mathrm{~s}, 1 \mathrm{H}, \mathrm{H}-1), 4.75\left(\mathrm{~d}, J_{2,3}\right.$ $=5.9 \mathrm{~Hz}, 1 \mathrm{H}, \mathrm{H}-3), 4.61\left(\mathrm{~d}, J_{2,3}=5.9 \mathrm{~Hz}, 1 \mathrm{H}, \mathrm{H}-2\right), 4.42\left(\mathrm{dd}, J_{4,5 \mathrm{a}}=6.0, J_{4,5 \mathrm{~b}}=\right.$ $10.0 \mathrm{~Hz}, 1 \mathrm{H}, \mathrm{H}-4), 3.35(\mathrm{~s}, 3 \mathrm{H}, \mathrm{OMe}), 3.27\left(\mathrm{dd}, J_{4,5 \mathrm{a}}=6.0, J_{5 \mathrm{a}, 5 \mathrm{~b}}=10.0 \mathrm{~Hz}, 1 \mathrm{H}\right.$, $\mathrm{H}-5 \mathrm{a}), 3.14\left(\mathrm{t}, J_{4,5 \mathrm{~b}}=J_{5 \mathrm{a}, 5 \mathrm{~b}}=10.0 \mathrm{~Hz}, 1 \mathrm{H}, \mathrm{H}-5 \mathrm{a}\right), 1.46(\mathrm{~s}, 3 \mathrm{H}, \mathrm{PP}), 1.31(\mathrm{~s}, 3 \mathrm{H}$, iPr); ${ }^{13} \mathrm{C}$ NMR $\left(75 \mathrm{MHz}, \mathrm{CDCl}_{3}\right) 112.6\left(\mathrm{iPr}-\mathrm{C}\left(\mathrm{CH}_{3}\right)_{2}\right), 109.6(\mathrm{C} 1), 87.4(\mathrm{C} 4), 85.3$ (C2), $83.0(\mathrm{C} 3), 55.2(\mathrm{OMe}), 26.4\left(\mathrm{iPr}-\mathrm{C}\left(\mathrm{CH}_{3}\right)_{2}\right), 25.0\left(\mathrm{iPr}-\mathrm{C}\left(\underline{\mathrm{CH}}_{3}\right)_{2}\right), 6.7(\mathrm{C} 5)$; HRMS(ESI) $m / z$ calcd. for $\left[\mathrm{C}_{9} \mathrm{H}_{15} \mathrm{O}_{4} \mathrm{I}+\mathrm{H}\right]^{+}: 315.0088$, obsd.: 315.0120 . 


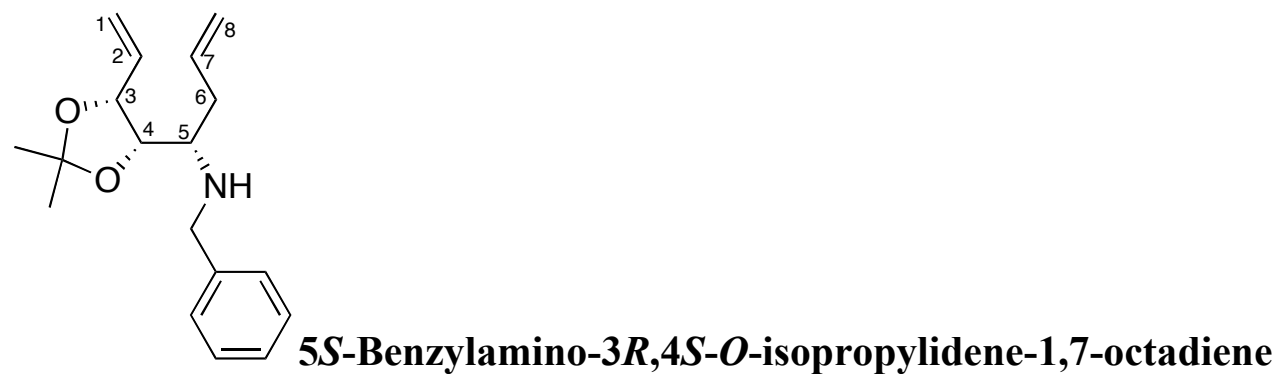

(67S): ${ }^{8}$ To a solution of methyl 5-deoxy-5-iodo-2,3- $O$-isopropylidine- $\alpha / \beta$-Driboside (66) (2.09 g, $6.7 \mathrm{mmol})$ in dry THF (4.3 mL) was added Zn (540 mg, 8.3 mmol) and benzylamine $(157 \mu \mathrm{L}, 1.4 \mathrm{mmol})$ and the reaction was sonicated under Ar for $30 \mathrm{~min}$. allyl bromide $(137 \mu \mathrm{L}, 1.6 \mathrm{mmol})$ was added dropwise to the sonicating reaction mixture in portions over $2.5 \mathrm{~h}$, and then sonication was continued for another $1 \mathrm{~h}$. The reaction mixture was then filtered through celite and washed with EtOAc, petroleum ether, and DCM before concentration under reduced pressure. Purification by silica gel flash column chromatography (petroleum ether/EtOAc, 19/1, v/v) provided 5S-benzylamino-3R,4S-Oisopropylidene-1,7-octadiene $(67 \mathrm{~S})(60.7 \mathrm{mg}, 0.21 \mathrm{mmol}, 32 \%) . \mathrm{R}_{f}=0.56$ (petroleum ether/EtOAc, 1/1, v/v). Characterisation data are in full agreement with that reported in the literature. ${ }^{8}$

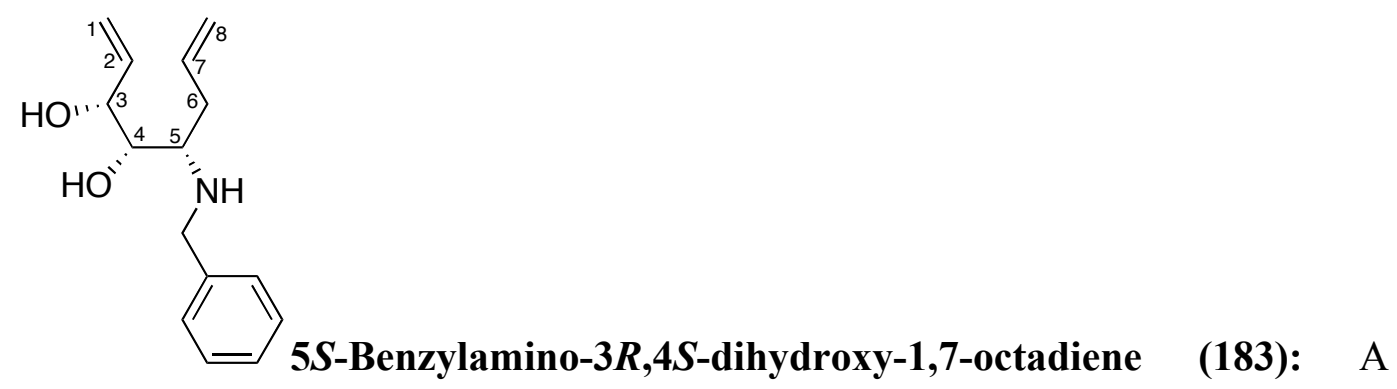

solution of $5 S$-benzylamino-3R,4S-O-isopropylidene-1,7-octadiene (67S) $(53.4$ $\mathrm{mg}, 0.19 \mathrm{mmol}), \mathrm{AcOH}(1 \mathrm{~mL})$ and $\mathrm{H}_{2} \mathrm{O}(0.2 \mathrm{~mL})$ was stirred at $60{ }^{\circ} \mathrm{C}$ for $3 \mathrm{~d}$. Concentration followed by purification by silica gel flash column chromatography (petroleum ether/EtOAc, 1/1, v/v) afforded 5S-Benzylamino-3R,4S-dihydroxy1,7-octadiene (183) as a pale oil (43.3 $\mathrm{mg}, 0.18 \mathrm{mmol}, 94 \%) . \mathrm{R}_{f}=0.53$ (DCM/EtOH/MeOH/30\% $\left.\mathrm{NH}_{3 \text { (aq.) }}, 105 / 2 / 2 / 1, \mathrm{v} / \mathrm{v} / \mathrm{v} / \mathrm{v}\right) ;[\alpha]_{\mathrm{D}}{ }^{26}=27.4$ (c=0.6, $\mathrm{MeOH}$ ); IR (film) 3363, 3031, 2957, 2925, 2857, 1639, 1494, 1454, 1079, 920, $748,698 \mathrm{~cm}^{-1} .{ }^{1} \mathrm{H}$ NMR $\left(500 \mathrm{MHz}, \mathrm{CDCl}_{3}\right) \delta$ 7.37-7.24 (m, 5H, $\left.\mathrm{H}_{\text {arom }}\right), 5.91(\mathrm{~J}=$ 
$\left.1.7, J_{2,3}=7.2, J_{1 \text { cis }, 2}=10.3, J_{1 \text { trans }, 2}=17.3 \mathrm{~Hz}, 1 \mathrm{H}, \mathrm{H}-2\right), 5.82\left(J_{7,8 c i s}=9.0, J_{7,8 \text { trans }}\right.$ $=16.9 \mathrm{~Hz}, 1 \mathrm{H}, \mathrm{H}-7), 5.37$ (d, $J_{1 \text { trans }, 2}=17.3 \mathrm{~Hz}, 1 \mathrm{H}, \mathrm{H}-1$ trans $), 5.29\left(\mathrm{~d}, J_{1 \text { cis }, 2}=\right.$ $10.3 \mathrm{~Hz}, 1 \mathrm{H}, \mathrm{H}-1$ cis $), 5.20$ (d, $\left.J_{7,8 c i s}=9.0 \mathrm{~Hz}, 1 \mathrm{H}, \mathrm{H}-8 c i s\right), 5.17$ (d, $J_{7,8 \text { trans }}=16.9$ $\mathrm{Hz}, 1 \mathrm{H}, \mathrm{H}-8$ trans), 4.10 (app. t, $J_{2,3}=J_{3,4}=7.5 \mathrm{~Hz}, 1 \mathrm{H}, \mathrm{H}-3$ ), 3.87 (d, $J_{\mathrm{Ha}, \mathrm{Hb}}=$ $12.4 \mathrm{~Hz}, 1 \mathrm{H}, \underline{\mathrm{C}}_{\underline{a}} \mathrm{H}_{\mathrm{b}} \mathrm{Bn}$ ), $3.75\left(\mathrm{~d}, J_{\mathrm{Ha}, \mathrm{Hb}}=12.4 \mathrm{~Hz}, 1 \mathrm{H}, \mathrm{CH}_{\mathrm{a}} \underline{\mathrm{H}}_{\underline{b}} \mathrm{Bn}\right.$ ), 3.27 (app. t, $\left.J_{3,4}=J_{4,5}=8.0 \mathrm{~Hz}, 1 \mathrm{H}, \mathrm{H}-4\right), 2.84\left(\mathrm{ddd}, J=4.2, J=6.1, J_{4,5}=7.6 \mathrm{~Hz}, 1 \mathrm{H}, \mathrm{H}-5\right)$, 2.58-2.45 (m, 2H, H-6); ${ }^{13} \mathrm{C}$ NMR (125 MHz, $\left.\mathrm{CDCl}_{3}\right) \delta 139.0$ (C-i, Bn), 138.5 (C2), 134.0 (C7), 128.8, 128.5, 127.6 (CH-Bn), 119.4 (C8), 118.3 (C1), 77.8 (C3), 71.6 (C4), 60.6 (C5), $51.6\left(\underline{\mathrm{CH}}_{2} \mathrm{Bn}\right), 33.6$ (C6); HRMS(ESI) $\mathrm{m} / z$ calcd. for $\left[\mathrm{C}_{15} \mathrm{H}_{21} \mathrm{O}_{2} \mathrm{~N}+\mathrm{H}\right]^{+}: 248.1645$, obsd.: 248.1654.<smiles>C=C[C@H](O)[C@H](O)CNCc1ccccc1</smiles>

1-Benzylamino-2S,3S-dihydroxy-pent-4-ene (187): To a solution of methyl 5-deoxy-5-iodo- $\alpha / \beta$-D-xyloside (173) (45 mg, $0.16 \mathrm{mmol}$ ) in EtOH $(3.3 \mathrm{~mL})$, was added benzylamine $(36 \mu \mathrm{L}, 0.33 \mathrm{mmol})$, indium (94 mg, $0.83 \mathrm{mmol}), \mathrm{NaCNBH}_{3}(31 \mathrm{mg}, 0.5 \mathrm{mmol})$, water $(100 \mu \mathrm{L})$, and $\mathrm{AcOH}(50 \mu \mathrm{L})$. The reaction was stirred under reflux for $17 \mathrm{~h}$, cooled, filtered through celite and the solvent was removed under reduced pressure. The reaction mixture was dry loaded onto silica gel and purified by gradient flash column chromatography (DCM/EtOH/MeOH/35\% $\mathrm{NH}_{3 \text { (aq.), }} 205 / 2 / 2 / 1$ to $155 / 2 / 2 / 1, \mathrm{v} / \mathrm{v} / \mathrm{v} / \mathrm{v}$ ) to give benzylalkenylamine $\mathbf{1 8 7}(24 \mathrm{mg}, \quad 0.12 \mathrm{mmol}, \quad 71 \%) . \quad \mathrm{R}_{f}=0.63$ $\left(\mathrm{DCM} / \mathrm{EtOH} / \mathrm{MeOH} / 35 \% \mathrm{NH}_{3 \text { (aq.) }}, 35 / 2 / 2 / 1, \mathrm{v} / \mathrm{v} / \mathrm{v} / \mathrm{v}\right) ;[\alpha]_{\mathrm{D}}{ }^{26}=-36.9(\mathrm{c}=0.9$, $\mathrm{MeOH}$ ); IR (film) 3381, 3086, 2902, 2844, 1646, 1454, 1106, 1045, $994 \mathrm{~cm}^{-1} .{ }^{1} \mathrm{H}$ $\operatorname{NMR}\left(500 \mathrm{MHz}, \mathrm{D}_{2} \mathrm{O}\right) \delta 7.41-7.30\left(\mathrm{~m}, 5 \mathrm{H}, \mathrm{H}_{\text {arom }}\right), 5.81\left(\mathrm{ddd}, J_{3,4}=6.6, J_{4,5 c i s}=\right.$ $\left.10.5, J_{4,5 \text { trans }}=17.2 \mathrm{~Hz}, 1 \mathrm{H}, \mathrm{H}-4\right), 5.29\left(\mathrm{~d}, J_{4,5 \text {-trans }}=17.2 \mathrm{~Hz}, 1 \mathrm{H}, \mathrm{H}-5\right.$ trans $), 5.22$ (d, $\left.J_{4,5-c i s}=10.5 \mathrm{~Hz}, 1 \mathrm{H}, \mathrm{H}-5 c i s\right), 3.99$ (app t, $J_{2,3}=J_{3,4}=6.1 \mathrm{~Hz}, 1 \mathrm{H}, \mathrm{H}-3$ ), 3.76 $\left(\mathrm{d}, J_{\mathrm{Ha}, \mathrm{Hb}}=13.3 \mathrm{~Hz}, 1 \mathrm{H}, \underline{\mathrm{C}}_{\underline{a}} \mathrm{H}_{\mathrm{b}} \mathrm{Bn}\right), 3.70\left(\mathrm{~d}, J_{\mathrm{Ha}, \mathrm{Hb}}=13.3 \mathrm{~Hz}, 1 \mathrm{H}, \mathrm{CH}_{\mathrm{a}} \underline{\mathrm{H}}_{\underline{b}} \mathrm{Bn}\right)$, $3.67\left(\mathrm{ddd}, J_{1 \mathrm{a}, 2}=3.4, J_{2,3}=5.6, J_{1 \mathrm{~b}, 2}=9.0 \mathrm{~Hz}, 1 \mathrm{H}, \mathrm{H}-2\right), 2.67\left(\mathrm{dd}, J_{1 \mathrm{a}, 2}=3.4, J_{1 \mathrm{a}, 1 \mathrm{~b}}\right.$ $=12.7 \mathrm{~Hz}, 1 \mathrm{H}, \mathrm{H}-1 \mathrm{a}), 2.57\left(\mathrm{dd}, J_{1 \mathrm{~b} .2}=9.0, J_{1 \mathrm{a}, 1 \mathrm{~b}}=12.7 \mathrm{~Hz}, 1 \mathrm{H}, \mathrm{H}-1 \mathrm{~b}\right) ;{ }^{13} \mathrm{C} \mathrm{NMR}$ (125 MHz, $\left.\mathrm{D}_{2} \mathrm{O}\right) \delta 138.7$ (C-i, Bn), 136.1 (C5), 128.6, 128.5, 127.4 (CH-Bn), 
117.7 (C5), 74.6 (C3), 72.2 (C2), $52.2\left(\underline{\mathrm{CH}}_{2} \mathrm{Bn}\right), 49.6$ (C1); HRMS(ESI) m/z calcd. for $\left[\mathrm{C}_{12} \mathrm{H}_{17} \mathrm{O}_{2} \mathrm{~N}+\mathrm{H}\right]^{+}:$208.1332, obsd.: 208.1338 .

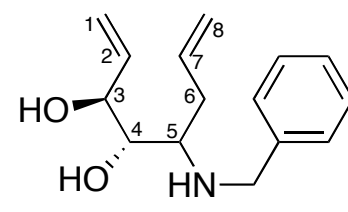

5-Benzylamino-3S,4S-dihydroxy-1,7-octadiene (182): To a solution of methyl iodoxyloside $173(138 \mathrm{mg}, 0.5 \mathrm{mmol})$ in THF (2.4 mL), was added indium powder (380 mg, $3.3 \mathrm{mmol}), \mathrm{AcOH}(300 \mu \mathrm{L}, 5.2 \mathrm{mmol})$, benzylamine (600 $\mu \mathrm{L}, 5.5 \mathrm{mmol})$, and allyl bromide $(100 \mu \mathrm{L}, 1.2 \mathrm{mmol})$. The reaction mixture was refluxed, with additional allyl bromide $(100 \mu \mathrm{L})$ added after $1 \mathrm{~h}, 2 \mathrm{~h}$, and $3 \mathrm{~h}$. After $6 \mathrm{~h}$ of refluxing, the reaction was cooled and $5 \mathrm{~mL}$ of aqueous $1.2 \mathrm{M} \mathrm{HCl}$ added. The reaction mixture was then stirred at room temperature for $5 \mathrm{~min}$ before being filtered through celite and concentrated in vacuo. The crude reaction mixture was dry loaded on silica gel for gradient flash chromatography (DCM/EtOH/MeOH/35\% $\mathrm{NH}_{3 \text { (aq.), }} 705 / 2 / 2 / 1$ to $305 / 2 / 2 / 1$, $\mathrm{v} / \mathrm{v} / \mathrm{v} / \mathrm{v})$. Repeated silica column chromatography was required to separate allyl benzylamine 186 from the desired diene (182), which was isolated as a white solid (20 mg, $0.08 \mathrm{mmol}, 16 \%) . \mathrm{R}_{f}=0.53\left(\mathrm{DCM} / \mathrm{EtOH} / \mathrm{MeOH} / 30 \% \mathrm{NH}_{3 \text { (aq.) }}\right.$, $105 / 2 / 2 / 1, \mathrm{v} / \mathrm{v} / \mathrm{v} / \mathrm{v}) ;[\alpha]_{\mathrm{D}}^{23}=-49.5(\mathrm{c}=1.0, \mathrm{MeOH}) ;$ IR (film) 3321, 3075, 3028, 2978, 2916, 2852, 1659, 1496, 1453, 1071, 1028, 993, 919, 741, $699 \mathrm{~cm}^{-1} .{ }^{1} \mathrm{H}$ NMR (500 MHz, $\left.\mathrm{CDCl}_{3}\right) \delta$ 7.40-7.26 (m, 5H, aromatics), 5.96-5.76 (m, 2H, H-2 and H-7), $5.42\left(\mathrm{dd}, J_{\text {lcis,1trans }}=1.6, J_{1 \text { trans }, 2}=17.1 \mathrm{~Hz}, 1 \mathrm{H}, \mathrm{H}-1\right.$ trans $), 5.26(\mathrm{dd}$, $\left.J_{\text {lcis,1trans }}=1.6, J_{1 c i s, 2}=10.5 \mathrm{~Hz}, 1 \mathrm{H}, \mathrm{H}-1 c i s\right), 5.19\left(\mathrm{~d}, J_{7,8 c i s}=11.1 \mathrm{~Hz}, 1 \mathrm{H}, \mathrm{H}-\right.$ $8 c i s), 5.16-5.13$ (m, 1H, H-8trans), 4.29-4.23 (m, 1H, H-3), 3.98 (d, $J_{\mathrm{Ha}, \mathrm{Hb}}=12.3$ $\left.\mathrm{Hz}, 1 \mathrm{H}, \underline{\mathrm{C}}_{\underline{a}} \mathrm{H}_{\mathrm{b}} \mathrm{Bn}\right), 3.76\left(\mathrm{~d}, J_{\mathrm{Ha}, \mathrm{Hb}}=12.3 \mathrm{~Hz}, 1 \mathrm{H}, \mathrm{CH}_{\mathrm{a}} \underline{\mathrm{H}}_{\underline{b}} \mathrm{Bn}\right), 3.49$ (br t, $J_{3,4}=$ $\left.J_{4,5}=2.4 \mathrm{~Hz}, 1 \mathrm{H}, \mathrm{H}-4\right), 2.84$ (ddd, $\left.J=3.3, J=5.1, J=7.5 \mathrm{~Hz}, 1 \mathrm{H}, \mathrm{H}-5\right), 2.57-$ 2.37 (m, 2H, H-6); ${ }^{13} \mathrm{C}$ NMR (125 MHz, $\left.\mathrm{CDCl}_{3}\right) \delta 139.2$ (C-i, Bn), 137.9, 134.8 (C2 and C7), 128.8, 128.5, 127.6 (CH-Bn), 118.4 (C8), 116.3 (C1), 75.1 (C3), 71.8 (C4), 59.9 (C5), $51.5\left(\underline{\mathrm{CH}}_{2} \mathrm{Bn}\right), 35.8$ (C6); HRMS(ESI) m/z calcd. for $\left[\mathrm{C}_{15} \mathrm{H}_{21} \mathrm{O}_{2} \mathrm{~N}+\mathrm{H}\right]^{+}:$248.1645, obsd.: 248.1654. 


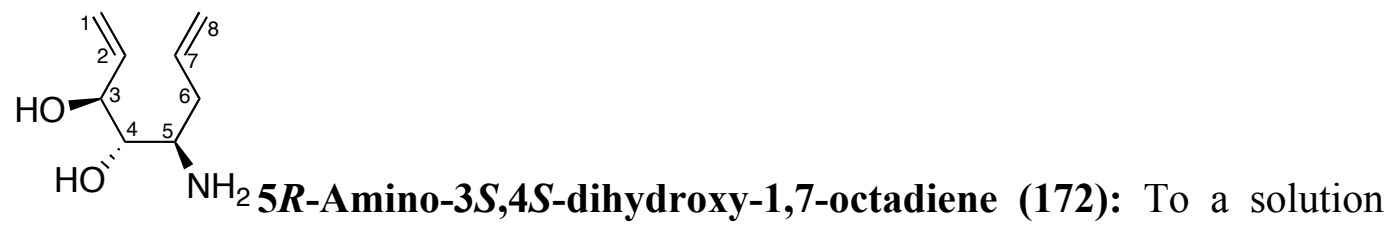
of methyl iodoxyloside 173 (602 mg, $2.2 \mathrm{mmol})$ in dry distilled MeOH (21.6 mL), was added indium powder $(1.49 \mathrm{~g}, 13 \mathrm{mmol})$, and $\mathrm{NH}_{4} \mathrm{OAc}(4.0 \mathrm{~g}, 51 \mathrm{mmol})$ and the reaction mixture was heated to reflux. allyl bromide $(1.2 \mathrm{~mL}, 13.9 \mathrm{mmol})$ was then added drop-wise over $10 \mathrm{~min}$ and the reaction mixture was refluxed under Ar for $20 \mathrm{~h}$ before being cooled to rt. $20 \mathrm{~mL}$ of aqueous $1.2 \mathrm{M} \mathrm{HCl}$ was added and the solution stirred at room temperature for $5 \mathrm{~min}$ before being filtered through celite, and concentrated in vacuo. The residue was loaded onto Dowex $-\mathrm{H}^{+}$cation exchange resin and eluted with $5-35 \% \mathrm{NH}_{3 \text { (aq.) }}$. Further purification by gradient silica gel flash column chromatography (DCM/EtOH/MeOH/35\% $\mathrm{NH}_{3 \text { (aq.), }}$, $205 / 2 / 2 / 1$ to $125 / 2 / 2 / 1, \mathrm{v} / \mathrm{v} / \mathrm{v} / \mathrm{v})$ provided amino diene (172) as a yellow oil (122 $\mathrm{mg}, 0.78 \mathrm{mmol}, 35 \%) . \mathrm{R}_{f}=0.53$ (DCM/EtOH$/ \mathrm{MeOH} / 30 \% \mathrm{NH}_{3 \text { (aq.) }}, 15 / 2 / 2 / 1$, $\mathrm{v} / \mathrm{v} / \mathrm{v} / \mathrm{v}) ;[\alpha]_{\mathrm{D}}^{23}=-17.6(\mathrm{c}=1.2, \mathrm{MeOH}) ;$ IR (film) 3355, 3076, 2978, 2906, 1640, 1581, 1437, 1047, 993, $918 \mathrm{~cm}^{-1} .{ }^{1} \mathrm{H}$ NMR $\left(500 \mathrm{MHz}, \mathrm{D}_{2} \mathrm{O}\right) \delta 5.93$ (ddd, $J_{2,3}=$ $\left.6.4, J_{1 \text { cis }, 2}=10.5, J_{1 \text { trans }, 2}=17.2 \mathrm{~Hz}, 1 \mathrm{H}, \mathrm{H}-2\right), 5.85\left(\mathrm{dddd}, J_{6 \mathrm{a}, 7}=6.8, J_{6 \mathrm{~b}, 7}=7.6\right.$, $\left.J_{7,8 \text { cis }}=10.2, J_{7,8 \text { trans }}=17.1 \mathrm{~Hz}, 1 \mathrm{H}, \mathrm{H}-7\right), 5.37\left(\mathrm{dt}, J_{1,3}=J_{1 \text { cis, }, \text { trans }}=1.2, J_{1 \text { trans }, 2}=\right.$ $17.2 \mathrm{~Hz}, 1 \mathrm{H}, \mathrm{H}-1$ trans), $5.28\left(\mathrm{dt}, J_{1,3}=J_{1 \text { cis, }, \text { trans }}=1.2, J_{1 \mathrm{cis}, 2}=10.5 \mathrm{~Hz}, 1 \mathrm{H}, \mathrm{H}-\right.$ 1 cis), $5.17\left(\mathrm{dd}, J_{6,8 \text { trans }}=1.9, J_{7,8 \text { trans }}=17.1 \mathrm{~Hz}, 1 \mathrm{H}, \mathrm{H}-8\right.$ trans $), 5.14\left(\mathrm{dd}, J_{6,8 c i s}=\right.$ $\left.1.1, J_{7,8 c i s}=10.2 \mathrm{~Hz}, 1 \mathrm{H}, \mathrm{H}-8 c i s\right), 4.26\left(\mathrm{ddd}, J_{1,3}=1.2, J_{3,4}=5.3, J_{2,3}=6.4 \mathrm{~Hz}\right.$, $1 \mathrm{H}, \mathrm{H}-3), 3.45\left(\mathrm{t}, J_{3,4}=J_{4,5}=5.3 \mathrm{~Hz}, 1 \mathrm{H}, \mathrm{H}-4\right), 2.96\left(\mathrm{dt}, J_{4,5}=J_{5,6 \mathrm{a}}=5.3, J_{5,6 \mathrm{~b}}=\right.$ $7.6 \mathrm{~Hz}, 1 \mathrm{H}, \mathrm{H}-5), 2.34$ (dddd, $J_{6 \mathrm{a}, 8}=1.2, J_{5,6 \mathrm{a}}=5.3, J_{6 \mathrm{a}, 7}=6.8, J_{6 \mathrm{a}, 6 \mathrm{~b}}=14.0 \mathrm{~Hz}$, $1 \mathrm{H}, \mathrm{H}-6 \mathrm{a}), 2.15$ (dt, $\left.J_{5,6 \mathrm{~b}}=J_{6 \mathrm{~b}, 7}=7.6, J_{6 \mathrm{a}, 6 \mathrm{~b}}=14.0 \mathrm{~Hz}, 1 \mathrm{H}, \mathrm{H}-6 \mathrm{~b}\right) ;{ }^{13} \mathrm{C}$ NMR $(125$ MHz, $\left.\mathrm{D}_{2} \mathrm{O}\right) \delta 136.9$ (C2), 134.8 (C7), 117.9 (C8), 117.1 (C1), 74.8 (C4), 73.4 (C3), 51.2 (C5), 37.4 (C6); HRMS(ESI) $m / z$ calcd. for $\left[\mathrm{C}_{8} \mathrm{H}_{15} \mathrm{O}_{2} \mathrm{~N}+\mathrm{H}\right]^{+}:$158.1176, obsd.: 158.1178 . 
<smiles>N[C@@H]1CC=C[C@@H](O)[C@H]1O</smiles>

5R-Amino-3S,4S-dihydroxy-cyclohex-1-ene (171): To a solution of amino diene $172(29.8 \mathrm{mg}, 0.2 \mathrm{mmol})$ in $\mathrm{H}_{2} \mathrm{O}(3 \mathrm{~mL})$ was added $20 \mu \mathrm{L}$ of distilled $\mathrm{TfOH}$. The solution was then concentrated under reduced pressure to give the ammonium triflate salt of diene 172, and the triflate salt co-evaporated with dry toluene before being subjected to dry THF $(1.9 \mathrm{~mL})$ and the HoveydaGrubbs $2^{\text {nd }}$ generation catalyst $(6.0 \mathrm{mg}, 0.01 \mathrm{mmol})$ under Ar at $\mathrm{rt}$ for $1 \mathrm{~h}$. The reaction mixture was then concentrated in vacuo before purification by gradient silica gel flash column chromatography (DCM/EtOH/MeOH/35\% $\mathrm{NH}_{3 \text { (aq.), }}$ $105 / 2 / 2 / 1$ to $55 / 2 / 2 / 1, \mathrm{v} / \mathrm{v} / \mathrm{v} / \mathrm{v})$ provided cyclohexene (171) as a pale oil $(24.5 \mathrm{mg}$, $0.2 \mathrm{mmol}$, quant.). $\mathrm{R}_{f}=0.16$ (DCM/EtOH/MeOH/30\% $\left.\mathrm{NH}_{3 \text { (aq.) }}, 15 / 2 / 2 / 1, \mathrm{v} / \mathrm{v} / \mathrm{v} / \mathrm{v}\right)$; $[\alpha]_{\mathrm{D}}^{23}=+24.5(\mathrm{c}=0.61, \mathrm{MeOH})$; IR (film) 3357, 3040, 2916, 1621, 1519, 1441 , 1242, 1225, 1168, 1071, 1026, 949, 692, $638 \mathrm{~cm}^{-1}$. ${ }^{1} \mathrm{H}$ NMR $\left(500 \mathrm{MHz}, \mathrm{D}_{2} \mathrm{O}\right) \delta$ $5.71\left(\mathrm{ddd}, J_{1,6 \mathrm{~b}}=2.4, J_{1,6 \mathrm{a}}=5.4, J_{1,2}=10.2 \mathrm{~Hz}, 1 \mathrm{H}, \mathrm{H}-1\right), 5.57\left(\mathrm{~d}, J_{1,2}=10.2 \mathrm{~Hz}\right.$, $1 \mathrm{H}, \mathrm{H}-2), 4.17\left(\mathrm{ddd}, J_{2,3}=1.8, J=3.6, J_{3,4}=7.8 \mathrm{~Hz}, 1 \mathrm{H}, \mathrm{H}-3\right), 4.46\left(\mathrm{dd}, J_{3,4}=\right.$ $\left.7.8, J_{4,5}=10.5 \mathrm{~Hz}, 1 \mathrm{H}, \mathrm{H}-4\right), 3.17\left(\mathrm{dt}, J_{5,6 \mathrm{a}}=5.4, J_{4,5}=J_{5,6 \mathrm{~b}}=10.5 \mathrm{~Hz}, 1 \mathrm{H}, \mathrm{H}-5\right)$, $2.50\left(\mathrm{dt}, J_{1,6 \mathrm{a}}=J_{5,6 \mathrm{a}}=5.4, J_{6 \mathrm{a}, 6 \mathrm{~b}}=17.5 \mathrm{~Hz}, 1 \mathrm{H}, \mathrm{H}-6 \mathrm{a}\right), 2.12\left(\mathrm{dddd}, J_{1,6 \mathrm{~b}}=2.4, J_{5,6 \mathrm{~b}}\right.$ $\left.=10.5, J=6.9, J_{6 \mathrm{a}, 6 \mathrm{~b}}=17.5 \mathrm{~Hz}, 1 \mathrm{H}, \mathrm{H}-6 \mathrm{~b}\right) ;{ }^{13} \mathrm{C} \mathrm{NMR}\left(125 \mathrm{MHz}, \mathrm{D}_{2} \mathrm{O}\right) \delta 128.2$ (C2), 125.6 (C1), 75.3 (C4), 72.0 (C3), 50.2 (C5), 30.5 (C6); HRMS(ESI) m/z calcd. for $\left[\mathrm{C}_{6} \mathrm{H}_{11} \mathrm{O}_{2} \mathrm{~N}+\mathrm{H}\right]^{+}: 130.0863$, obsd.: 130.0865 . 


\subsection{References}

1. Blanco, B.; Prado, V.; Lence, E.; Otero, J. M.; Garcia-Doval, C.; van Raaij, M. J.; Llamas-Saiz, A. L.; Lamb, H.; Hawkins, A. R.; GonzálezBello, C. J. Am. Chem. Soc. 2013, 135, 12366-12376.

2. Herrmann, K. M.; Weaver, L. M. Annu. Rev. Plant Biol. 1999, 50, 473503.

3. Kornienko, A.; Evidente, A. Chem. Rev. 2008, 108, 1982-2014.

4. Mahmud, T.; Lee, S.; Floss, H. G. Chem. Rec. 2001, 1, 300-310.

5. Skaanderup, P. R.; Poulsen, C. S.; Hyldtoft, L.; Jørgensen, M. R.; Madsen, R. Synthesis 2002, 1721-1727.

6. Verhelst, S. H. L.; Wiedenhof, W.; Ovaa, H.; van der Marel, G. A.; Overkleeft, H. S.; van Boeckel, C. A. A.; van Boom, J. H. Tetrahedron Lett. 2002, 43, 6451-6455.

7. Verhelst, S. H. L.; Wennekes, T.; van der Marel, G. A.; Overkleeft, H. S.; van Boeckel, C. A. A.; van Boom, J. H. Tetrahedron 2004, 60, 2813-2822.

8. Hyldtoft, L.; Madsen, R. J. Am. Chem. Soc. 2000, 122, 8444-8452.

9. Levene, P. A.; Walti, A. J. Biol. Chem. 1931, 94, 353-360.

10. a) Li, C.-J. Tetrahedron 1996, 52, 5643-5668; b) Podlech, J.; Maier, T. C. Synthesis 2003, 0633-0655; c) Behr, J.-B.; Hottin, A.; Ndoye, A. Org. Lett. 2012, 14, 1536-1539.

11. Dangerfield, E. M.; Plunkett, C. H.; Win-Mason, A. L.; Stocker, B. L.; Timmer, M. S. M. J. Org. Chem. 2010, 75, 5470-5477.

12. Bridger, G. J.; McEachern, E. J.; Skerlj, R.; Schols, D. Chemokine Receptor Binding Heterocyclic Compounds with Enhanced Efficacy. WO 2004/093817 A2, November 4, 2004.

13. de Souza-Barboza, J. C.; Pétrier, C.; Luche, J. L. J. Org. Chem. 1988, 53, 1212-1218.

14. Paquette, L. A.; Mitzel, T. M. J. Am. Chem. Soc. 1996, 118, 1931-1937.

15. Woodward, C. P.; Spiccia, N. D.; Jackson, W. R.; Robinson, A. J. Chem. Commun. 2011, 47, 779-781. 
16. Dangerfield, E. M. The Synthesis of Carbohydrates for the Treatment of Disease. PhD Thesis, Victoria University of Wellington, Wellington, 2011.

17. Calder, E. D. D.; Zaed, A. M.; Sutherland, A. J. Org. Chem 2013, 78, 7 223-7233. 


\section{Chapter 4: Lipophilic Amines as Potential TB Drugs}

\subsection{Introduction}

\subsubsection{Tuberculosis and the need for New Anti-TB Drugs}

Tuberculosis (TB) is a global health problem. According to the WHO Global TB report $^{1}$ there were an estimated 8.6 million new cases of TB worldwide in 2012. Of the 1.3 million TB deaths in 2012, approximately a quarter of these were from HIV positive TB sufferers. It was also estimated that approximately one third of the multi drug resistant (MDR) cases of TB were fatal. If left untreated, approximately $70 \%$ of infected (HIV negative) individuals will die within ten years of contracting the disease. ${ }^{2}$

The increasing drug resistance of $M t b$ and the inherent difficulty in killing the bacteria makes the continued development of TB drugs a pressing goal. Most drugs for TB currently in use were developed more than forty years ago and it is only in the last two years that any new anti-TB drugs have come onto the market. ${ }^{1,3}$ The development of new anti-TB drugs with unique modes of action are required to prevent further drug resistance arising. To this end, a protectinggroup-free (PGF) approach amenable to the efficient synthesis of potential TB drugs will be described. 


\subsubsection{Alkenylamines as Potential TB drugs}

The anti-TB drug ethambutol (EMB) and drug candidate SQ109 (Figure 4.1) are both inhibitors of cell wall biosynthesis, although they act on different enzymatic pathways. ${ }^{4,5}$ Key features of EMB and SQ109 are the secondary amine groups and the amphiphilic nature of the molecules, both of which are presumed to be important for penetration through the lipophilic cell wall, and anti-TB activity. Following on from this, it was proposed that alkenylamines 191 (Scheme 4.1), as structural analogues of EMB and SQ109, would also possess anti-TB activity.<smiles>CC(C)=CCC/C(C)=C/CNCCNC1C2CC3CC(C2)CC1C3</smiles>

SQ109<smiles>CC[C@H](CO)NCCN[C@H](CC)CO</smiles>

Ethambutol (EMB)

Figure 4.1: Emerging tuberculosis drug SQ109, and current first line TB drug EMB.

Previously within the Stocker-Timmer group, a first generation amine library was prepared and screened in a tuberculostatic Alamar Blue ${ }^{\circledR}$ BCG assay (Scheme 4.1). ${ }^{6}$ A colour change in the Alamar Blue ${ }^{\circledR}$ dye indicated the ability of a compound to inhibit the growth of the mycobacteria BCG (see Section 4.3). ${ }^{7,8}$ From this initial screening, alkenylamine 191a was identified as having modest growth inhibition ( $\mathrm{MIC}=500 \mu \mathrm{g} / \mathrm{mL}$ ) against BCG. ${ }^{6}$ This compound was readily prepared in three steps without the use of protecting groups and provided a molecular scaffold around which to base the synthesis of other potential TB drugs. To this end, a variety of alkenylamines $\mathbf{1 9 1 b}$-i were prepared via a PGF synthesis that involved few competing reactivities. ${ }^{6}$ Here the alkenylamines 191 were made via a modified Vasella-reductive amination of iodoglycosides 192 with a primary amine as the amine source. Iodoglycosides 192 were in turn prepared from the corresponding sugars 193 by Fischer glycosidation followed by iodination of the primary hydroxyl. ${ }^{9}$ 
Initial trends for compounds 191a-i indicated the arabinose derived alkenylamines to be slightly more active than the xylose or ribose derived compounds, and that long straight chain amines gave slightly better activity than the aromatic alkenylamines. The latter finding may be because mycobacteria have very thick cell walls consisting of mycolic acids, ${ }^{10}$ suggesting that the alkenylamines containing more lipophilic amine groups are better able to penetrate the lipophilic cell wall.

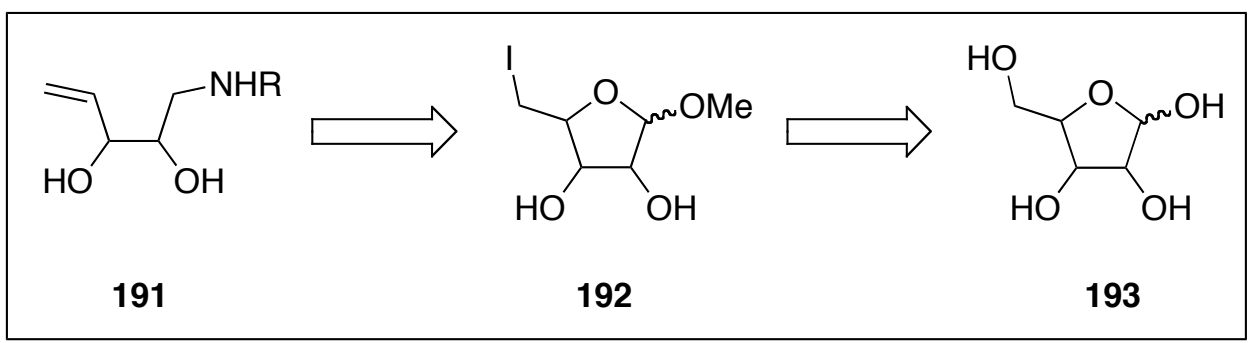

xylo<smiles>C=CC(O)C(O)CNC(c1ccccc1)c1ccccc1</smiles><smiles>C=C[C@H](O)[C@H](O)CNCc1ccccc1</smiles><smiles>C=C[C@H](O)[C@H](O)CNCCC</smiles>

$500 \mu \mathrm{g} / \mathrm{mL}$ $>500 \mu \mathrm{g} / \mathrm{mL}$

$250 \mu \mathrm{g} / \mathrm{mL}$

ribo<smiles>C=C[C@H](O)C(O)CNC(c1ccccc1)c1ccccc1</smiles><smiles>C=C[C@H](O)[C@H](O)CNCc1ccccc1</smiles>

$\mathrm{NI}$<smiles>C=C[C@H](O)C(O)CNCCC</smiles>

$500 \mu \mathrm{g} / \mathrm{mL}$

arabino<smiles>C=C[C@H](O)[C@H](O)CNC(c1ccccc1)c1ccccc1</smiles><smiles>C=C[C@H](O)[C@H](O)CNCc1ccccc1</smiles>

$500 \mu \mathrm{g} / \mathrm{mL}$

$>500 \mu \mathrm{g} / \mathrm{mL}$<smiles>C=C[C@H](O)[C@H](O)CNCCC</smiles>

$105 \mu \mathrm{g} / \mathrm{mL}$

Scheme 4.1: First generation amine library, with the minimum inhibitory concentration (MIC) for growth inhibition against $\mathrm{BCG},{ }^{6} \mathrm{NI}=$ no inhibition at or below $500 \mu \mathrm{g} / \mathrm{mL}$. 


\subsection{Second Generation Amine Library Synthesis}

To further explore the structure activity relationship (SAR) of the lipophilic amines, a second generation amine library was prepared. The BCG Alamar Blue ${ }^{\circledR}$ Growth Inhibition Assay ${ }^{7,8}$ was used as a model for the growth inhibition of tuberculosis and, for the most promising compounds, cytotoxicity studies were also undertaken. The molecular scaffold 194 around which the second generation amine library was based is shown in Figure 4.2. Variations in antimycobacterial activity induced by changes in the structure at $\mathrm{C} 4$ and $\mathrm{C} 5$ were investigated. Here, $\mathrm{C} 4 / 5$ alkene or dihydroxylated analogues were prepared using Vasella-reductive amination and reductive amination conditions, respectively. The use of arabinose, fucose and rhamnose derivatives in the reductive aminations provided variation in the stereochemistry of the hydroxyls, while the presence of an additional methyl group at $\mathrm{R}^{1}$ occurred in the fucose and rhamnose analogues. The use of different amines in the reductive aminations provided access to a range of alkyl groups. Linear and cyclic amines of sizes ranging from C6 to C16 were prepared. The variety of amine and sugar scaffolds used in the reactions aimed to provide a better understanding of how molecular size, three-dimensional shape, hydrophobicity, and sugar configuration affect antimycobacterial activity.

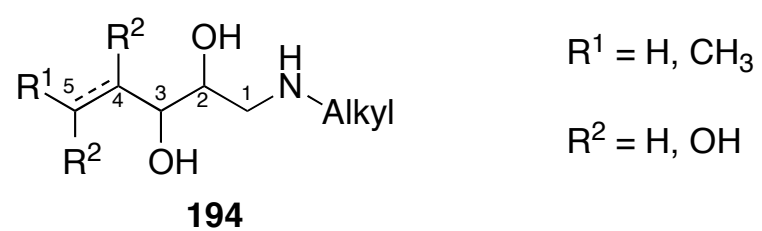

Figure 4.2: Molecular scaffold for the second generation amine library. 
The purpose of these syntheses was to prepare a large library of compounds, hence the optimisation of the reaction conditions would only be undertaken for the most active compounds. Initial reaction yields varied considerably due to variations in solubility and reactivity of the sugar and amine components and difficulty in separating the product from the unreacted amine during purification. A variety of conditions were used to encourage product formation for specific reductive amination reactions. Early literature precedent on the formation of related (unreduced) glycosylamines with long $\left(\mathrm{C}_{12}-\mathrm{C}_{18}\right)$ lipid amines reported stirring mixtures of amine and sugar in $i \mathrm{PrOH} / \mathrm{H}_{2} \mathrm{O}$ or $\mathrm{EtOH} / \mathrm{H}_{2} \mathrm{O}$ at $\mathrm{rt}$ for 2-15 days, ${ }^{11}$ while up to $\mathrm{C}_{12}$ glucosylamines (195) were reported by stirring a suspension of sugar 196 and amine $197 \mathrm{in} \mathrm{MeOH}$ at rt overnight (Scheme 4.2). ${ }^{12}$ To form the corresponding reduced amines, changes in solvent (DMSO/AcOH ${ }^{13,14}$ to $\left.\mathrm{MeOH} / \mathrm{H}_{2} \mathrm{O}\right)$; reducing agent $\left(\mathrm{NaCNBH}_{3}, \mathrm{NaBH}(\mathrm{OAc})_{3},{ }^{15} \mathrm{NaBH}_{4},{ }^{16} \mathrm{ZnCl}_{2}{ }^{17}\right.$ ) or hydrogenation; ${ }^{12,18,19}$ time of addition (one-pot or two-steps-one-pot); temperature (rt to reflux); and means of heating (conventional or microwave irradiation $^{14}$ ) have all been reported. A variety of these literature procedures were trialled accordingly.<smiles>OCC1O[C@H](O)[C@@H](O)[C@H](O)[C@H]1O</smiles>

196<smiles>CCCCCC(C)(C)C(C)CN</smiles>

197

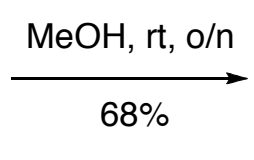<smiles>OC[C@H]1O[C@@H](NCC2CC2)[C@H](O)[C@H](O)[C@H]1O</smiles>

195

Scheme 4.2: Example amination reaction to form $N$-dodecylglucosylamine (195). ${ }^{12}$

To begin preparation of the second generation amine library, a series of reductive aminations of D-arabinose (198) using several different amines was undertaken (Table 4.1). In this way the amine products could be compared with the alkenylamines (made via Vasella-reductive aminations) to test the importance of 
the double bond on biological activity. A wide variety of amines were used to study the influence of the size and shape of the amine on anti-mycobacterial activity. To explore whether cyclic amines also inhibit mycobacterial growth, a variety of cyclic amines were used in reductive aminations with arabinose. To this end cyclohexylamine 199, cyclooctylamine 200, adamantylamine 201, and cyclododecylamine $\mathbf{2 0 2}$ were subjected to the reductive amination conditions yielding amines 203, 204, 205, and 206, respectively, in low (14-45\%) yields (entries 1-4). Key to the reaction was the use of EtOH as the solvent for optimal solubility of all reagents, whileß $\mathrm{AcOH}$ was also important to aid the solubility of the larger amines by protonation. The use of the amine as the limiting reagent avoided difficulties in separating unreacted amine and product amine during purification. 
Table 4.1: Reductive amination reactions

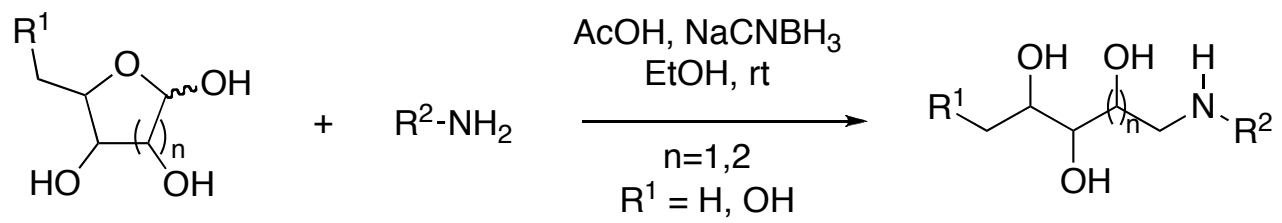

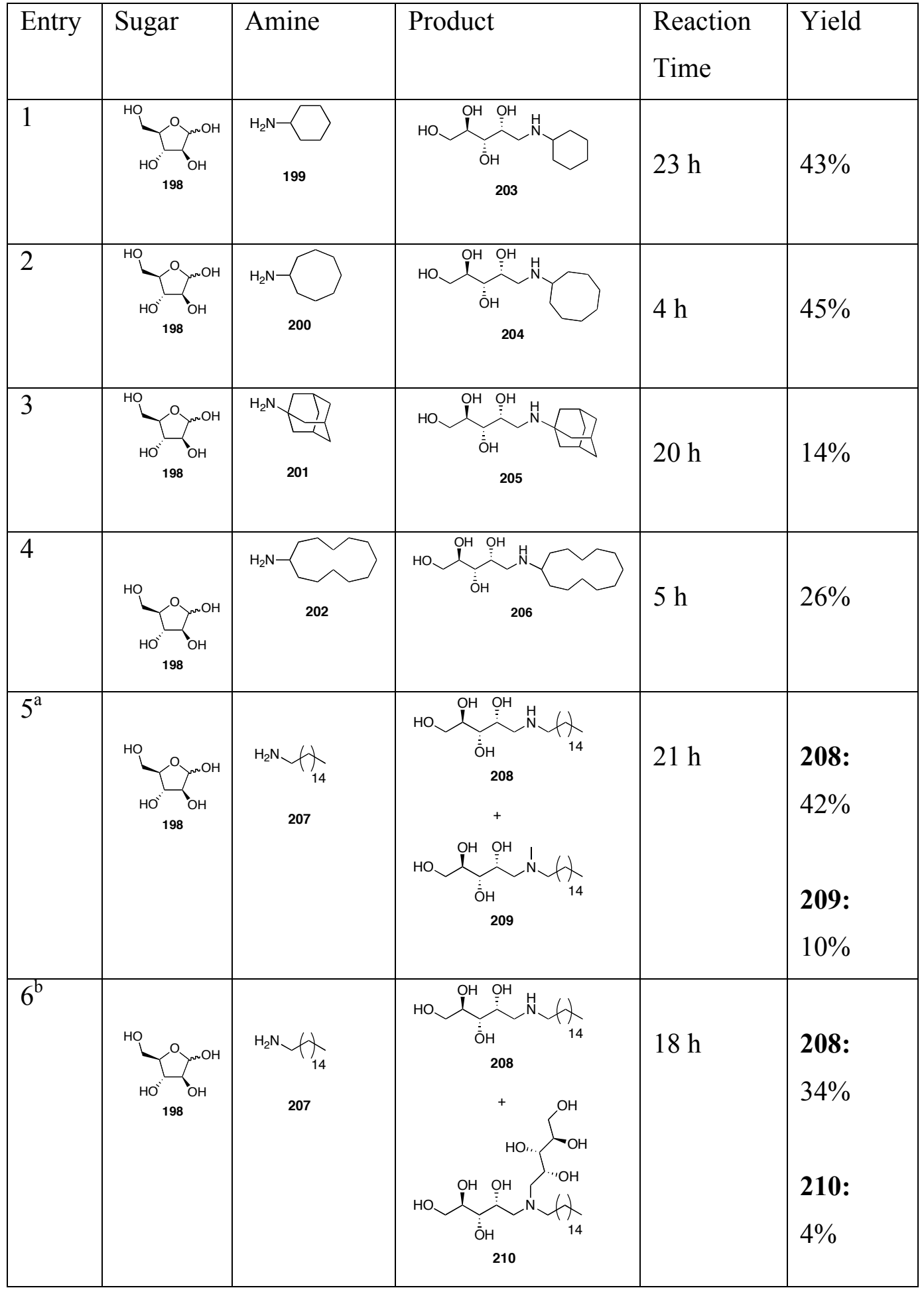




\begin{tabular}{|c|c|c|c|c|c|}
\hline Entry & Sugar & Amine & Product & $\begin{array}{l}\text { Reaction } \\
\text { Time }\end{array}$ & Yield \\
\hline 7 & $\underset{\mathrm{HOH}}{\mathrm{OO}}$ & ${ }_{199}^{\mathrm{H}_{2} \mathrm{~N}-C}$ & $\underbrace{\mathrm{OH}}_{\mathrm{OH}}$ & $3 d$ & $30 \%$ \\
\hline 8 & $\widehat{\mathrm{HOOH}} \underset{17}{\mathrm{O}} \mathrm{Z}^{\mathrm{NOH}}$ & 200 & $\mathrm{OH}$ & $22 \mathrm{~h}$ & $12 \%$ \\
\hline 9 & $\widehat{\mathrm{HOOH}}$ & $\mathrm{H}_{2} \mathrm{~N}-$ & $\mathrm{OH}$ & $7 \mathrm{~d}$ & $18 \%$ \\
\hline 10 & $\begin{array}{c}\mathrm{HO} \underset{\mathrm{HO}}{\mathrm{TO}} 7^{\mathrm{moH}} \\
21\end{array}$ & $\mathrm{H}_{2} \mathrm{~N}-$ & $\overbrace{\mathrm{OH}}^{\mathrm{OH}}$ & $19 \mathrm{~h}$ & $10 \%$ \\
\hline
\end{tabular}

${ }^{\text {a }}$ Reaction carried out in $\mathrm{MeOH}$ at $45{ }^{\circ} \mathrm{C}$, some formaldehyde was present in the reagent grade solvent. ${ }^{\mathrm{b}}$ Reaction carried out in $\mathrm{EtOH}$ at $50^{\circ} \mathrm{C}$.

To study the effect of lipophilicity on biological activity, the reductive amination of D-arabinose (198) with hexadecylamine (207) was carried out (to give 208), providing a larger linear amine for anti-mycobacterial testing (entries 5 and 6). Because of difficulties in solubilising the amine and sugar simultaneously, a variety of solvents (EtOH, DCM, PE, EtOH/DCM, DMSO/AcOH, $\mathrm{DMSO} / \mathrm{EtOH} / \mathrm{H}_{2} \mathrm{O}, \mathrm{MeOH}$ ) and reaction temperatures (ranging from rt to reflux) were trialled. Step-wise synthesis through imine formation followed by reduction was then attempted in refluxing methanol and $\mathrm{AcOH}$, however this led to a rapid degradation of the sugar. Gratifyingly, it was discovered that both the amine and the sugar were soluble in $\mathrm{MeOH}(7 \mathrm{~mL} / \mathrm{mmol}$ amine $)$ with $\mathrm{AcOH}(0.4 \mathrm{~mL} / \mathrm{mmol}$ amine) at $c a .45{ }^{\circ} \mathrm{C}$ (entry 5); the additional $\mathrm{AcOH}$ and the more dilute conditions helped to protonate and solubilise the amine. The reaction mixture was stirred overnight with $\mathrm{NaCNBH}_{3}$, achieving the synthesis of amine 208 in $42 \%$ yield. In addition to the successful synthesis of the desired arabinohexadecylamine $\mathbf{2 0 8}$, methylated by-product $\mathbf{2 0 9}$ was also formed as a result of further reductive amination of formaldehyde (impurity from the reagent grade $\mathrm{MeOH}$ ) with amine 
208. The solvent was subsequently changed to EtOH (entry 6), and in the absence of formaldehyde, the formation of methylamine $\mathbf{2 0 9}$ was not observed. Potentially as a result of the improved solubility of the D-arabinose (198) relative to amine 207 in $\mathrm{EtOH}$, diarabinoamine $\mathbf{2 1 0}$ was made via subsequent reductive amination of arabinohexadecylamine $\mathbf{2 0 8}$ with another molecule of D-arabinose (198). Although unexpected, methylamine $\mathbf{2 0 9}$ and diarabinoamine $\mathbf{2 1 0}$ were successfully isolated in sufficient quantities, which expanded the scope of the reaction and thus provided additional amines for anti-mycobacterial testing.

In the workup of amine 208, removal of the borane reducing agent was required to stop the additional reductions that led to by-product formation. A variety of workup techniques that were tested (lyophilisation, Dowex $-\mathrm{H}^{+}$chromatography, reversed phase chromatography) led to either insolubility of the amine, or excessive foaming on the rotary evaporator, due to the amphiphilic amine $\mathbf{2 0 8}$ having soap-like properties in water. Fortunately removal of the boranes using methanolic $\mathrm{HCl}(5 \%, \mathrm{v} / \mathrm{v})$ was successful and the resulting crude material could be purified by silica column chromatography. Separation of the amines was achievable with careful purification via normal phase chromatography and the amphiphilic arabinohexadecylamine $\mathbf{2 0 8}$ was successfully purified by taking advantage of the amine's marginal solubility in the DCM:EtOH:MeOH:35\% $\mathrm{NH}_{3(\mathrm{aq})}$ solvent mixture (as amine 208 was insoluble in many solvents). Hexadecylamine 208 eluted slowly from the column, over a gradient from 25:2:2:1 to 5:2:2:1 DCM:EtOH:MeOH:35\% $\mathrm{NH}_{3(\mathrm{aq})}$, which led to a slightly reduced yield when the synthesis of $\mathbf{2 0 8}$ was later optimised (see Section 5.4).

Characterisation of the amines was straight-forward, with a correlation in the HMBC spectrum observed between the $\mathrm{C} 1$ of the sugar and $\mathrm{C}^{\prime}{ }^{\prime}$ of the amine lipid for almost all amines prepared. Arabinocyclododecylamine 206 and diarabinohexyadecylamine $\mathbf{2 1 0}$ had no observable correlation, however the connectivity of these amines was supported by the downfield shift of the $\mathrm{Cl}^{\prime}$ of the amine upon binding to the sugar. The amine with two sugars coupled (210) was evidenced by a much lower running spot on TLC compared to 
arabinohexadecylamine $208\left(\mathrm{R}_{f}=0.17\right.$ for $\mathbf{2 1 0} c f$. $\mathrm{R}_{f}=0.40$ for $\mathbf{2 0 8}$ in $\left.\mathrm{DCM} / \mathrm{EtOH} / \mathrm{MeOH} / 35 \% \mathrm{NH}_{3(\mathrm{aq})}, 5 / 2 / 2 / 1, \mathrm{v} / \mathrm{v} / \mathrm{v} / \mathrm{v}\right)$, as well as a change in the peak integrations in the ${ }^{1} \mathrm{H}$ NMR spectrum, and a much larger molecular mass $(\mathrm{m} / \mathrm{z}$ : $\left[\mathrm{C}_{26} \mathrm{H}_{55} \mathrm{O}_{8} \mathrm{~N}+\mathrm{H}\right]^{+}$calcd. $=510.4004$, obsd. = 510.4004). Methylamine 209 could be identified by a higher running spot on TLC $\left(\mathrm{R}_{f}=0.57\right.$ in $\mathrm{DCM} / \mathrm{EtOH} / \mathrm{MeOH} / 35 \%$ aqueous $\left.\mathrm{NH}_{3}, 5 / 2 / 2 / 1, \mathrm{v} / \mathrm{v} / \mathrm{v} / \mathrm{v}\right)$, as well as the appearance of a singlet in the ${ }^{1} \mathrm{H}$ NMR spectrum $(\delta 2.93)$ that had HMBCs to both $\mathrm{H} 5 \mathrm{ab}$ and $\mathrm{H}^{\prime}$ ' confirming the presence of the methyl substituent. The mass spectrum $\left(m / z:\left[\mathrm{C}_{22} \mathrm{H}_{47} \mathrm{O}_{4} \mathrm{~N}+\mathrm{H}\right]^{+}\right.$calcd. $=390.3578$, obsd. $\left.=390.3594\right)$ further supports the identification of amine 209.

To investigate how the polyhydroxylated backbone of the compounds affect anti-mycobacterial activity, the reductive amination products of L-fucose (211) and cyclohexylamine (199), cyclooctylamine (200), and cyclododecylamine (202) were also prepared to give amines $212, \mathbf{2 1 3}$, and 214, respectively (entries 7-9, Table 4.1). L-Fucose has the same stereochemistry as D-arabinose at C2-4, and has $S$-stereochemistry defined at C5 due to the additional (C6) methyl group present. Comparison of the L-fucosylamines and D-arabinosylamines gives an indication of how the additional methyl group and $5 S$ stereochemistry affects activity. The L-rhamnose (215) scaffold, with very different stereochemistry to both L-fucose and D-arabinose was also used for the preparation of L-rhamnocyclooctylamine 216 to further expand the amine library (entry 10).

To complete the second generation amine library, alkenylamines were prepared using Vasella-reductive amination conditions (Table 4.2). The arabino configuration was retained, as this was observed to be more active in the first generation alkenylamines, and amines of varying size and configuration were prepared. To this end, methyl iodoarabinoside (217) was treated with $\mathrm{Zn}, \mathrm{AcOH}$, adamantylamine (201), and $\mathrm{NaCNBH}_{3}$ in refluxing $\mathrm{EtOH}$, to give adamantyl alkenylamine 218 in 49\% yield (entry 1). Cyclododecylamine 202 was next used to prepare alkenylamine 219 in modest $37 \%$ yield (entry 2), while the use of 
dibutylamine 220, allowed for the preparation of tri-substituted alkenylamine 221 (entry 3), which could be used to assess the effect of a tertiary amine with two shorter $\left(\mathrm{C}_{4}\right)$ alkyl groups in comparison to secondary amines with longer linear or cyclic amine groups attached. Two longer linear amines, tetradecylamine 222 and hexadecylamine 207, were then used in the Vasella-reductive amination to prepare alkenylamines $\mathbf{2 2 3}$ and 224, respectively (entries 4 and 5), to aid the understanding of how lipid length influences anti-mycobacterial activity (also see Figure 4.3). Fortunately, the alkenylamines were readily soluble in a variety of solvents. Isolation of the alkenylamines was challenging due to the similar polarities of the uncoupled amines and the product alkenylamines. The successful isolation of the alkenylamines was achieved with careful purification via silica column chromatography using a long column and eluting slowly (ca. DCM/MeOH/EtOH/35\% $\mathrm{NH}_{3 \text { (aq.) }}$; 205:2:2:1 v/v/v/v), providing clean compounds ready for biological testing. The ${ }^{1} \mathrm{H}$ NMR spectrum of alkenylamine 223 is presented in Figure 4.3 and the others are available in the appendices. 
Table 4.2: Products from the Vasella-reductive amination reaction of methyl iodoarabinoside 217 with various amines

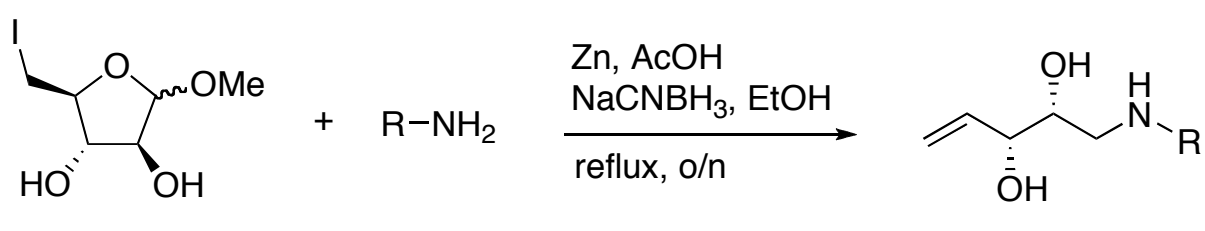

217

\begin{tabular}{|c|c|c|c|}
\hline Entry & Amine & Product & Yield \\
\hline 1 & ${ }^{\mathrm{H}_{2} \mathrm{~N}} \square$ & $\overbrace{{ }_{\text {OH }}}^{\mathrm{OH}_{218}^{H}}$ & $49 \%$ \\
\hline 2 & 202 & & $37 \%$ \\
\hline 3 & 220 & ÖH & $22 \%$ \\
\hline 4 & $\begin{array}{c}\mathrm{H}_{2} \mathrm{~N} \\
{ }_{222}\end{array}$ & ठิH & $44 \%$ \\
\hline 5 & $\begin{array}{c}\mathrm{H}_{2} \mathrm{~N} \backslash \mathrm{X} \\
{ }_{14} \\
207\end{array}$ & ${ }_{\bar{\partial}}$ & $69 \%$ \\
\hline
\end{tabular}




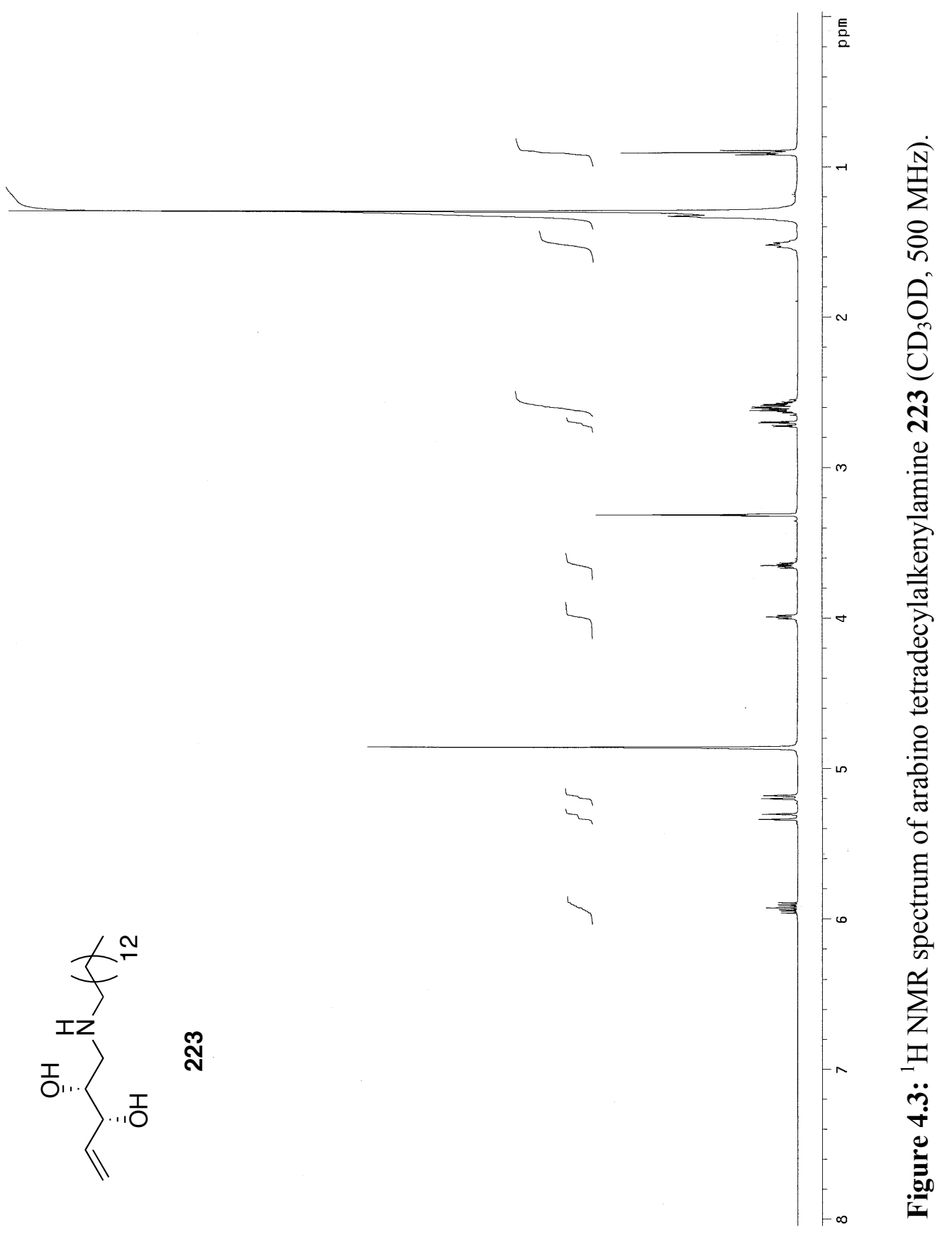


Finally, to explore the effect of $N$-methylation of an alkenylamine, a reductive amination of formaldehyde and hexadecylalkenylamine $\mathbf{2 2 4}$ was performed to give methylalkenylamine $\mathbf{2 2 5}$ in $73 \%$ yield (Scheme 4.3). Preparation of alkenylamine 225 allows for activity comparisons between the alkene and the 'dihydroxylated' analogue methylamine 209, and also between the series of methylated (tertiary) and unmethylated (secondary) amines. Having prepared a variety of different amines and alkenylamines with varied stereochemistry, size, shape, and hydrophobicity, this completed the second generation library. The amines were thus submitted for biological testing and analysis.<smiles>[Y4]C(C)(C)CNC[C@@H](O)[C@H](O)C=C</smiles>

224

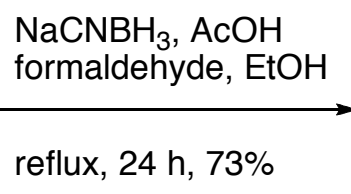

reflux, $24 \mathrm{~h}, 73 \%$

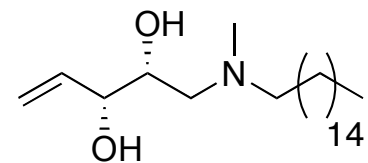

225

Scheme 4.3: Reductive methylation to give alkenylamine $\mathbf{2 2 5}$. 


\subsection{Biological Testing: Results and Discussion}

\subsubsection{Tuberculostatic Activity: BCG Alamar Blue ${ }^{\circledR}$ Growth Inhibition Screening}

With the second generation amine library in hand, biological testing commenced with a whole cell BCG model for the screening of anti-tuberculosis activity. Named after its developers, Bacillus Calmette-Guérin (BCG) is a strain of Mycobacterium bovis that has been weakened by culturing on artificial medium for many years, and is therefore no longer virulent to humans. ${ }^{20}$ As a species of mycobacteria, BCG is related to $M t b$ and hence displays very similar drug susceptibilities making it a good initial screen for anti-TB compounds. ${ }^{21}$ The BCG Alamar Blue ${ }^{\circledR}$ growth inhibition assay measures the smallest concentration of a compound that can effect growth inhibition of the bacteria (the minimum inhibitory concentration, MIC), providing an indication of the compound's tuberculostatic properties. ${ }^{22,23}$ In this work, the MIC is defined as the concentration of compound required to induce $100 \%$ growth inhibition, a fact worthy of mention as MIC values are sometimes reported as $50 \%$ or $90 \%$ inhibition. ${ }^{24}$ The Alamar Blue ${ }^{\circledR}$ dye contains resazurin, a blue coloured, nonfluorescent, redox active dye (Figure 4.4). The dye is reduced to the pink, fluorescent resorufin, in the presence of NADH/NADPH (produced by cell respiration). Accordingly, while the bacteria are growing the dye will turn pink, but when treated with a compound that kills the bacteria or inhibits their growth, the dye will remain blue. The assay is safe, sensitive, and inexpensive. 


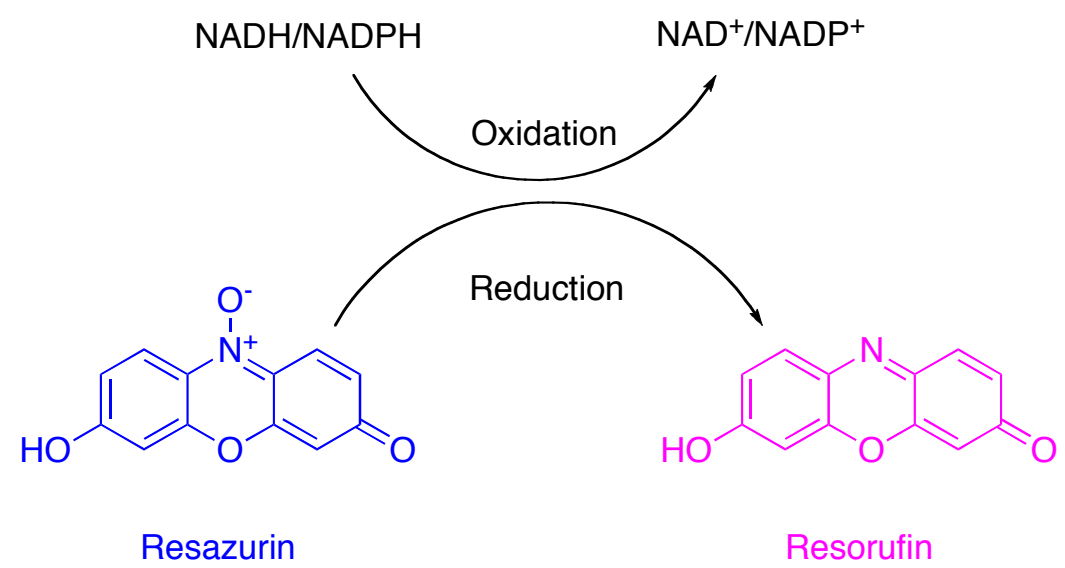

Figure 4.4: Alamar Blue ${ }^{\circledR}$ dye redox activity.

Two methods were used to screen the second generation amine library. Initially, to identify any active compounds, four amines were tested on a 96-well plate over three serial dilutions, with each compound tested in triplicate for reproducibility. From this, any compound displaying activity was retested over a range of six serial dilutions (with two compounds to a plate) to get a more accurate measure of a compound's MIC (see Section 5.6.2 for details of the assay protocol). The significantly active compounds were screened twice more to confirm the MIC value; where these values differed, an MIC range was given. Ethambutol (EMB, entry 1, Table 4.3) was used as a positive control on each plate. EMB has an MIC of $39 \mu \mathrm{M}$ in this assay, which is comparable to (if not slightly larger than) the measured MIC in vitro for $M t b(\mathrm{H} 37 \mathrm{Rv}, \mathrm{MIC}=2.4 \mu \mathrm{M})^{25}$ and $\mathrm{BCG}(\mathrm{MIC}=9.8$ $\mu \mathrm{M}) .{ }^{26}$ Arabinooctylalkenylamine (191i, entry 2$)$ the lead compound from the first generation library, with an MIC of $105 \mu \mathrm{g} / \mathrm{mL}$ or $1400 \mu \mathrm{M}$, is also reported in Table 4.3 for activity comparisons. The starting material amines cyclododecylamine 202, hexadecylamine 207, and tetradecylamine 222 were also tested to identify how the sugar backbone altered the anti-TB activity of the amines. These also display activity in the BCG model (entries 10, 14, and 19, respectively); however the product amines and alkenylamines derived from these generally displayed improved activity. 
Table 4.3: BCG Alamar Blue ${ }^{\circledR}$ growth inhibtion assay

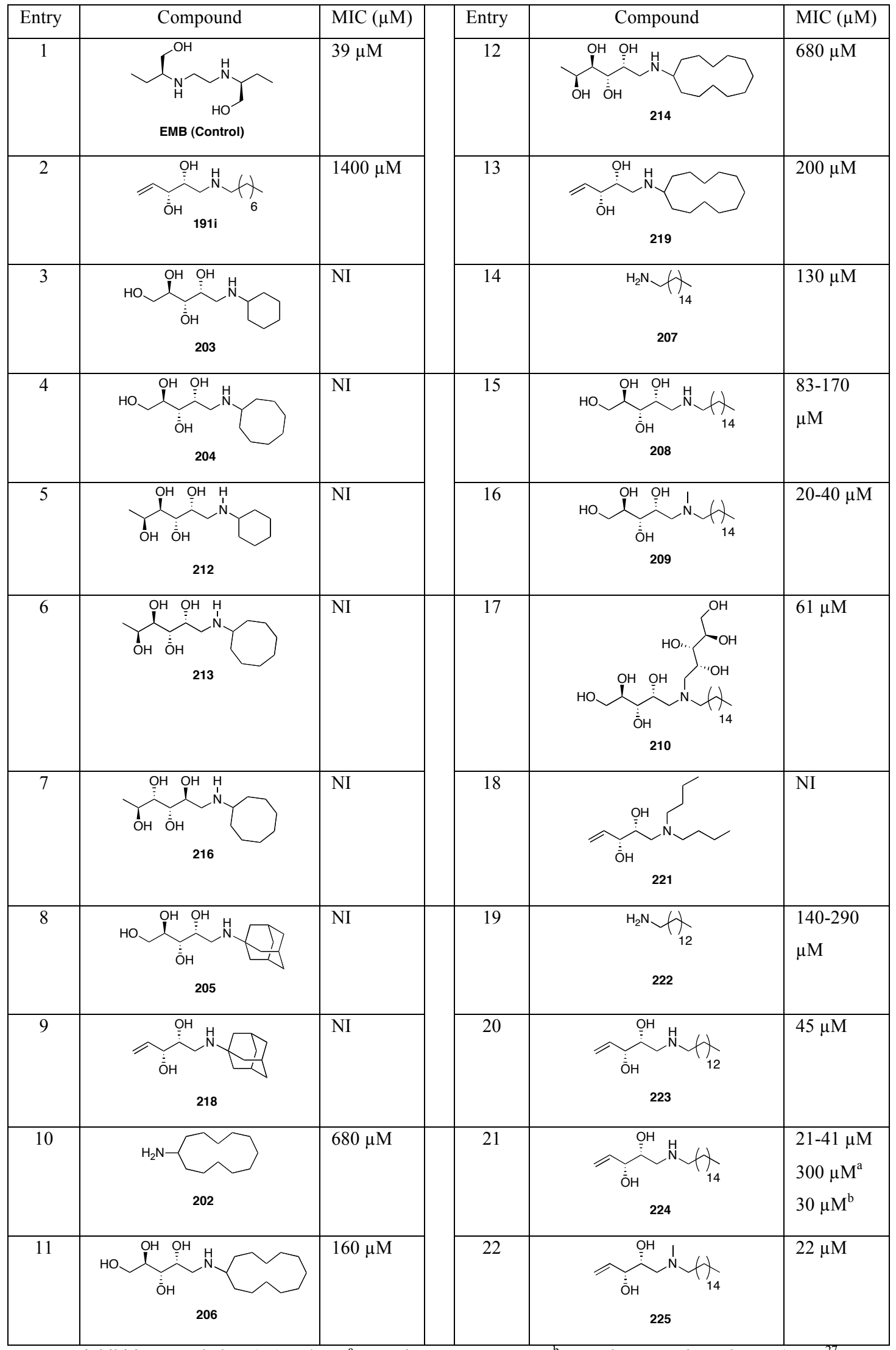

$\mathrm{NI}=$ no inhibition at or below $250 \mu \mathrm{g} / \mathrm{mL} .{ }^{\mathrm{a}}$ Tested on M. smegmatis. ${ }^{\mathrm{b}}$ Tested on M. tuberculosis H37Ra. ${ }^{27}$ 
For the reductive amination products it was seen that cyclohexylamines and cyclooctylamines, when coupled to arabinose (to give amines 203 and 204, entries 3 and 4, respectively), fucose (to give 212 and 213, entries 5 and 6, respectively) or rhamnose (216, entry 7) were inactive in the assay. This suggests that with the smaller cyclohexyl- or cyclooctylamines attached, the amines may not be lipophilic enough to pass through the hydrophobic bacterial cell wall. It is notable that the linear arabinooctylalkenylamine 191i (entry 2) was more active than the cyclooctylamines tested. This may be due to reduced hydrophobicity, or reduced flexibility of the cyclic amines, which affects their ability to penetrate the cell wall. The idea that more conformationally restrained amines are less active is supported by the observation that both adamantyl amine 205 and adamantyl alkenylamine 218 (entries 8 and 9) were also inactive, even though adamantylamine has two additional carbons compared with octylamine lead 191i.

The larger cyclic amines, arabinocyclododecylamine 206, fucocyclododecylamine 214, and arabinocyclododecylalkenylamine 219 (entries 11-13) showed more promising anti-mycobacterial activity. Both arabino configured amines 206 (160 $\mu \mathrm{M})$ and $219(200 \mu \mathrm{M})$ were more active than the fucose derived cyclododecylamine $214(680 \mu \mathrm{M})$, which had activity comparable to that of uncoupled cyclododecylamine 202 (entry 10). It was also observed that the presence or absence of the double bond in the molecules did not significantly affect activity (compare entry 11 with entry 13). Alternatively, this could be viewed as an indication that the addition of the two terminal hydroxyls in the reductive amination series also does not affect anti-mycobacterial activity.

The linear amines 208, 209, and 210 (entries 15-17) had improved activity compared with the cyclododecylamines. Methylamine $209(20-40 \mu \mathrm{M})$ was the most active, with activity comparable to that of first line TB drug EMB $(39 \mu \mathrm{M})$. 
The amine with two sugars attached (210) had slightly reduced activity $(61 \mu \mathrm{M})$, and arabinohexadecylamine $208(83-170 \mu \mathrm{M})$ was $c a$. half as active as methylamine 209. The reduced activity of hexadecylamine 208 may be due to insolubility, a result of the amphiphilic nature of the compound. As the amphiphilic amine was only soluble in DMSO at $c a 80^{\circ} \mathrm{C}$, or partially soluble in $\mathrm{MeOH}$ at $50{ }^{\circ} \mathrm{C}$, the delivery the amine to the bacteria in the assay was possibly affected.

Dibutylalkenylamine 221 was inactive at or below $250 \mu \mathrm{g} / \mathrm{mL}$ (entry 18), while its linear isomer, octylalkenylamine 191i, had some activity $(1400 \mu \mathrm{M}, 105$ $\mu \mathrm{g} / \mathrm{mL})$. This supports that suggestion that spatial arrangement and lipophilicity are important for activity. To determine how lipid length affects activity tetradecylalkenylamine $223(45 \mu \mathrm{M})$ and hexadecylalkenylamine $224(21-41 \mu \mathrm{M})$ were found to have comparable activity (entries 20-21). The addition of two more carbons to the amine group does not significantly improve the activity of hexadecylalkenylamine $\mathbf{2 2 4}$ compared to that of tetradecylalkenylamine $\mathbf{2 2 3}$. These alkenylamines also have similar activity to methylamine 209.

Finally, methylated alkenylamine $\mathbf{2 2 5}$ was tested for comparisons with alkenylamine 224 and methylamine 209. Methylated alkene 225 had an MIC of $22 \mu \mathrm{M}$ (entry 22) which is comparable to the dihydroxylated analogue 209 (20$40 \mu \mathrm{M})$ again indicating that the alkene functionality does not confer improved anti-mycobacterial activity. By comparison of alkenes 224 and 225 it appears that $\mathrm{N}$-methylation does not significantly improve activity, except in cases where it aids solubility (as observed in hexadecylamine $\mathbf{2 0 8}$ and the methylated counterpart 209).

To further test the scope and selectivity of the amines, one of the alkenylamine leads, hexadecylalkenylamine 224, was also tested for growth inhibition against 
other mycobacteria - Mycobacterium smegmatis (M. smegmatis) and an avirulent Mtb strain, H37Ra, by collaborators from the O'Toole group in the School of Biological Sciences (VUW). ${ }^{27}$ Although M. smegmatis is known to be more resistant than $\mathrm{TB},{ }^{21}$ it is often used as a compound screening model as it is a faster growing bacterium than BCG, and hence gives more rapid feedback in drug screening. Alkenylamine 224 was found to have an MIC of $300 \mu \mathrm{M}$ against $M$. smegmatis, which is less active than against BCG $(21-41 \mu \mathrm{M})$. When tested against H37Ra bacteria, hexadecylalkenylamine $\mathbf{2 2 4}$ was shown to have improved activity ( $\mathrm{MIC}=30 \mu \mathrm{M}$ ), which is promising for the class of compounds, as $\mathrm{H} 37 \mathrm{Ra}$ is a strain of $M t b$, and thus a more accurate predictor of activity than either BCG or M. smegmatis.

In terms of the ability of the amines to inhibit $M t b$ growth, there are a few general observations that can be made. First, the lipid size and shape appear to be important for anti-mycobacterial activity. This is evidenced by the reduced activity of the smaller and more conformationally restrained cyclic and adamantyl amines compared with the linear tetradecyl- and hexadecylamines. This may be due to the linear amines being more hydrophobic and therefore more able to pass through the waxy cell wall of $M t b$ to inhibit cell growth. The preferred linear structure may also make the amines more flexible and improve their ability to get inside the cell. Here, it should be noted that related compounds with various sugar and alkylamine components have been previously noted for both their surfactant properties and anti-fungal and anti-microbial activity. ${ }^{12,16,28}$ As for the chirality and number of hydroxyl groups on the hydrophilic portion of the compounds and how these influence activity, the initial studies from the first generation library suggest that the arabinose configuration is more active than the xylose or ribose configured alkenylamines. In the second generation amine library, it is unclear whether the arabinose configuration is preferred over rhamnose, as both cyclooctylamine derivatives (204 and 216) were inactive in the assay. The cyclododecylamine fucose derivative $\mathbf{2 1 4}$ was significantly less active than arabinocyclododecylamine $\mathbf{2 0 6}$, suggesting that the arabinose scaffold was 
preferred over the fucose scaffold. To gain a better understanding of the SAR with respect to sugar configurations, further chiral scaffolds of the most active amines (e.g. tetradecyl- or hexadecylamines) and a larger variety of sugars could be prepared and screened for anti-mycobacterial activity. It was also noted that an alkene group is not necessary for activity, as illustrated by alkenes 219 and 225 , which have similar activities to those of the corresponding dihydroxylated amines 206 and 209. This finding is important because the dihydroxy amines can be prepared from sugars in a single-step synthesis, an improvement on the three steps required to make alkenylamines using the Vasella-reductive amination conditions. 


\subsubsection{Anti-proliferative Activity and Selectivity}

Compounds that showed promising anti-mycobacterial activity in the BCG assay were screened for cytotoxicity using anti-proliferative HL60 and human T cell MTT assays. These give an indication of the selectivity of the compounds by measuring toxicity against a cancer cell line (HL60) and a healthy human blood cell line ( $\mathrm{T}$ cells). The choice of cell model for cytotoxicity screening varies depending on the aims of the research and the drug target. Generally immortalised cell lines or primary cell lines are used as human cytotoxicity models. ${ }^{29}$ The human leukaemia cell line HL60 is an immortalised cell line that is non adherant, inexpensive, easy to grow, and reproducible. A downside of immortalised cell lines is that they are not always representative of native cell types. ${ }^{30}$ Primary cells lines (such as the T cells), on the other hand, are very similar to their native cells, but have a short culture lifespan, and are more difficult to grow. ${ }^{29}$ For a potential anti-TB drug a low MIC against BCG is required as well as a high 50\% inhibition concentration $\left(\mathrm{IC}_{50}\right)$ for the human $\mathrm{T}$ cells. The $\mathrm{IC}_{50}$ for the HL60 cell line gives a further indication of the selectivity of the drug, and a low $\mathrm{IC}_{50}$ against the HL60 cell line, coupled with a high $\mathrm{IC}_{50}$ for $\mathrm{T}$ cells may indicate a promising anti-cancer drug. To quantify the selectivities for comparison of the properties of different amines, the selectivity index (SI) was calculated, whereby a larger SI indicates a better selectivity for the diseased cells over the normal human cells. For antimycobacterial selectivity:

$$
S I=\frac{I C_{50}(\text { Tcells })}{M I C(B C G)}
$$

And for anti-cancer selectivity:

$$
S I=\frac{I C_{50}(\text { Tcells })}{I C_{50}(H L 60)}
$$

As a comparison for the anti-mycobacterial activity, cytotoxicities and selectivities, first line TB drug EMB and Doxorubicin (DOX), a clinically used anti-cancer drug, were included in Table 4.4 (entries 1 and 2). 
Table 4.4: Second generation amine library - biological testing overview

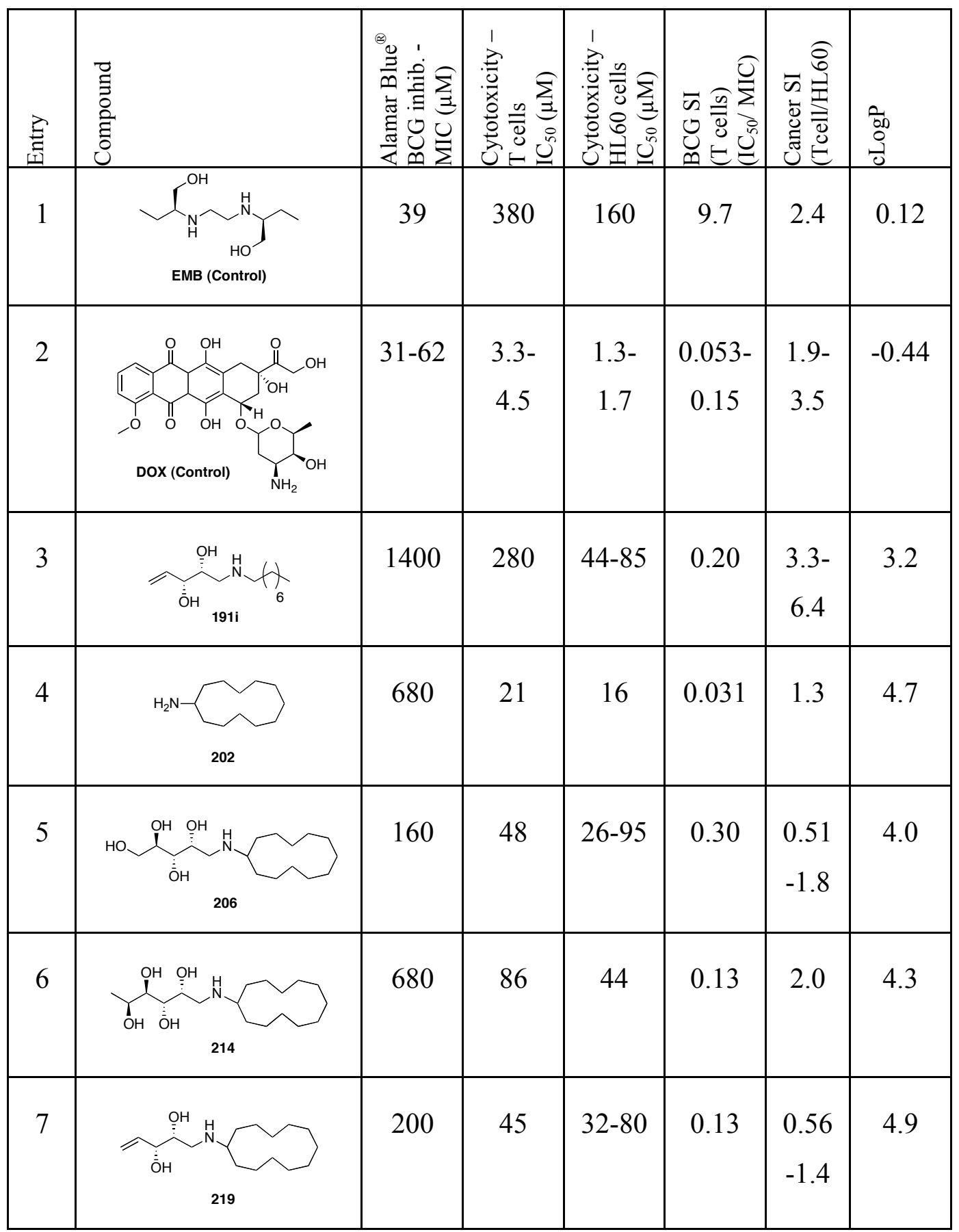




\begin{tabular}{|c|c|c|c|c|c|c|c|}
\hline 氞 & 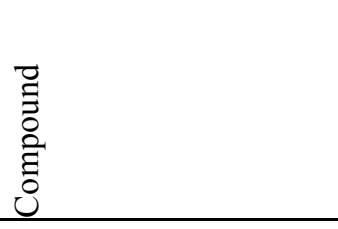 & 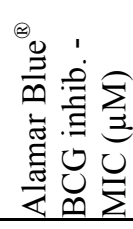 & 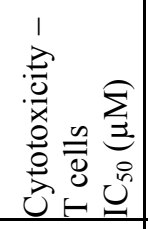 & 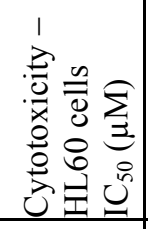 & 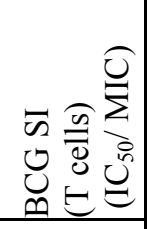 & 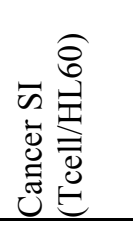 & $\begin{array}{l}\text { कo } \\
0 \\
0 \\
0\end{array}$ \\
\hline 8 & $\begin{array}{c}\mathrm{H}_{2} \mathrm{~N}-\mathrm{Cl}_{14} \\
207\end{array}$ & 130 & $47-82$ & $19-20$ & $\begin{array}{c}0.36- \\
0.63\end{array}$ & $\begin{array}{l}2.4- \\
4.3\end{array}$ & 7.3 \\
\hline 9 & $\underbrace{O H}_{\substack{0 .+208}}{ }_{14}^{O H}$ & $\begin{array}{l}83- \\
170\end{array}$ & $11-20$ & $\begin{array}{l}7.1- \\
9.2\end{array}$ & $\begin{array}{c}0.065- \\
0.24\end{array}$ & $\begin{array}{l}1.2- \\
2.8\end{array}$ & 6.9 \\
\hline 10 & 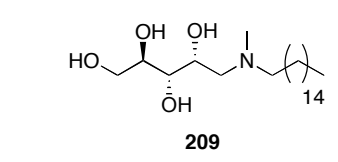 & $20-40$ & $\begin{array}{l}7.7- \\
9.5\end{array}$ & $\begin{array}{l}3.3- \\
4.1\end{array}$ & $\begin{array}{c}0.19- \\
0.48\end{array}$ & $\begin{array}{l}1.9- \\
2.9\end{array}$ & 7.2 \\
\hline 11 & $\underbrace{\mathrm{OH10}}_{\text {OH }}$ & 61 & 24-31 & 2.5 & $\begin{array}{c}0.39- \\
0.51\end{array}$ & $9.6-12$ & 5.1 \\
\hline 12 & $\begin{array}{c}\mathrm{H}_{2} \mathrm{~N}-\mathrm{H}_{12} \\
{ }_{222}\end{array}$ & $\begin{array}{l}140- \\
290\end{array}$ & 27 & $11-78$ & $\begin{array}{c}0.093- \\
0.19\end{array}$ & $\begin{array}{c}0.35- \\
2.5\end{array}$ & 6.2 \\
\hline 13 & 223 & 45 & 12 & $6.4-13$ & 0.27 & $\begin{array}{c}0.92- \\
1.9\end{array}$ & 6.4 \\
\hline 14 & 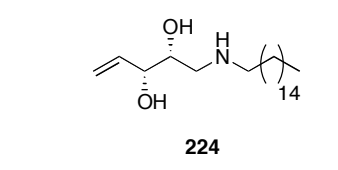 & $21-41$ & $\begin{array}{l}6.0- \\
9.7\end{array}$ & $\begin{array}{l}3.4- \\
4.3\end{array}$ & $\begin{array}{l}0.15- \\
0.46\end{array}$ & $\begin{array}{l}1.4- \\
2.9\end{array}$ & 7.4 \\
\hline 15 & 225 & 22 & $9.4-11$ & $\begin{array}{l}4.2- \\
4.9\end{array}$ & $\begin{array}{c}0.43- \\
0.50\end{array}$ & $\begin{array}{l}1.9- \\
2.6\end{array}$ & 8.1 \\
\hline
\end{tabular}

SI $=$ selectivity index, calculated as described in Section 5.3.2. cLogP $=$ computational octanol/water partition coefficient, as calculated by ChemDrawStd v.11.0 ${ }^{\circledR}$. 
A correlation between anti-mycobacterial activity and cytotoxicity (HL60 and T cells) was observed for the amines and alkenylamines in Table 4.4. The large linear amines and alkenylamines showed greater inhibition towards the human and bacterial cells compared to the smaller and/or cyclic amines. Comparison of the biological properties of the first generation lead octylalkenylamine 191i showed minimal cytotoxicity against HL60 cancer cells or human T cells, which corresponds to the limited growth inhibition observed for this compound against mycobacteria. The cyclododecylamine series (entries 5-7), regardless of the sugar attached, were less cytotoxic, displaying moderate anti-proliferative activity against HL60 $\left(\mathrm{IC}_{50}=26-95 \mu \mathrm{M}\right)$ and $\mathrm{T}$ cells $\left(\mathrm{IC}_{50}=45-86 \mu \mathrm{M}\right)$, in line with the moderate anti-mycobacterial activity noted earlier for these compounds. It is noteworthy that uncoupled cyclododecylamine 202 (entry 4) is more cytotoxic towards both cell lines than all corresponding reductive amination products. Poorer selectivity for bacterial cells $(\mathrm{SI}=0.031)$ was also observed for cyclododecylamine 202 compared to amines 206, 214, and $219(\mathrm{SI}=0.13-0.30)$.

The trend of increasing cytotoxicity or growth inhibition towards all cell lines was seen across the second generation amine library. The hexadecylamine reductive amination products 208 to 210 (entries 9-11), while having improved antimycobacterial activity, also had increased anti-proliferative activity against both HL60 cells $\left(\mathrm{IC}_{50}=2.5-9.2 \mu \mathrm{M}\right)$ and $\mathrm{T}$ cells $\left(\mathrm{IC}_{50}=7.7-31 \mu \mathrm{M}\right)$. The uncoupled hexadecylamine 207 (entry 8) also followed the trend with moderate toxicities observed across the anti-mycobacterial and anti-proliferative assays. The selectivity of amines $\mathbf{2 0 7}$ to $\mathbf{2 1 0}$ for the bacteria over the human T cells was significantly reduced when compared to EMB (SI < $0.65 c f$. EMB SI =9.7). Linear alkenylamines tetradecylalkenylamine 223, hexadecylalkenylamine 224, and hexadecylmethylalkenylamine 225 (entries 13-15) also continued the toxicity trend with the amines showing promising anti-mycobacterial activity ( $\mathrm{MIC}=21$ $45 \mu \mathrm{M})$, but also cytotoxicity that may limit therapeutic application (HL60 $\mathrm{IC}_{50}=$ 3.4-13 $\mu \mathrm{M}$, T cell $\left.\mathrm{IC}_{50}=6.0-12 \mu \mathrm{M}\right)$ resulting in poor selectivities for $\mathrm{BCG}(\mathrm{SI}<$ $0.50)$. 
The biological profile for cancer drug Doxorubicin (DOX) is also useful to frame the parameters important in cancer drug selectivity (entry 2). Doxorubicin is active against $\mathrm{BCG}(\mathrm{MIC}=31-62 \mu \mathrm{M})$, however as it is also toxic to human $\mathrm{T}$ cells, the selectivity for the bacteria is poor $(\mathrm{SI}=0.053-0.15)$. The cancer drug is highly toxic to HL60 cells and the selectivity for cancer cells (Cancer SI $=1.9$ 3.5) suggests some preference for the fast growing HL60 cells over the T cells. Although some selectivity is observed, doxorubicin is known to have poor selectivity for tumour tissues, and has noted side effects as a result of this narrow therapeutic window. ${ }^{31}$

Most compounds in the second generation library display anti-cancer selectivity similar to that of doxorubicin. In particular, hexadecylalkenylamines $\mathbf{2 2 4}$ and $\mathbf{2 2 5}$ had reasonable anti-proliferative activity against HL60 cells $\left(\mathrm{IC}_{50}=3.4-4.9 \mu \mathrm{M}\right)$. However, as this cytotoxicity is still approximately three times that of doxorubicin $\left(\mathrm{IC}_{50}=1.3-1.7 \mu \mathrm{M}\right)$ it is unlikely that these amines are active enough to be successful anti-cancer drugs.

The best anti-cancer selectivity observed was for diarabinohexadecylamine $\mathbf{2 1 0}$ $(\mathrm{SI}(\mathrm{T}$ cell/HL60) $=9.6-12$, entry 11), with a selectivity index that was significantly improved compared to that of anti-cancer drug doxorubicin (SI = 1.9-3.5), which is quite remarkable. There could be potential for this compound as an anti-cancer rather than anti-TB drug, and further biological testing of amine $\mathbf{2 1 0}$ is needed to establish its anti-cancer properties. 


\subsubsection{Lipinski's Rule of Five and cLogP}

Lipinski's rule of five for oral bioavailability outlines four requirements for druglikeness. It states that compounds with molecular weight $<500 \mathrm{~g} / \mathrm{mol}$, no more than five hydrogen bond donors, ten or less hydrogen bond acceptors, and cLogP $\leq 5$ are likely to be better absorbed into target cells within the body. ${ }^{32}$ These rules were derived from observations of already known drugs and therefore are not absolute. Lipinski's rule of five is only applicable to compounds that are delivered orally and pass through the cell membrane by passive diffusion.

The $\log \mathrm{P}$ value gives an indication of the lipophilicity of a compound and therefore its ability to reach the desired target within the cell. ${ }^{32,33}$ The octanol/water partition coefficient, $\mathrm{P}$, is the ratio of compound that would be partitioned in the octanol layer vs. the water layer, so a $\log \mathrm{P}$ value between 1 and 5 indicates that a compound is 10 to 100000 times more soluble in octanol than water, thus $\log \mathrm{P}>5$ indicates an extremely lipophilic compound, that will generally have poor solubility in the blood, and not be freely available for passive transport across membranes in the body. $\log \mathrm{P}<1$ implies a more hydrophilic compound that may be too soluble in water, and therefore fail to displace water from binding pockets. $\operatorname{LogP}$ values are rarely determined experimentally due to the large amount of compound needed, and the computational octanol/water partition coefficient (cLogP) is therefore used instead. cLogP is a computational prediction for LogP, which combines atomic contributions from smaller fragments of the compound with measured $\log P$ values to predict the $\operatorname{LogP}$ for a given molecule. A variety of different algorithms have been used to calculate computational $\log \mathrm{P}$ values, using different parameters and molecular contribution libraries. The accuracy of these cLogP values vary, ${ }^{34,35}$ however cLogP can still be qualitatively applied to a series of molecules to predict trends, and give an estimation of a compound's bioavailability. For compounds of the second generation amine library, cLogP was calculated using ChemDrawStd v.11.0 (Table 4.4). 
Interestingly, across the second generation amine library increasing antimycobacterial activity corresponds with increasing cLogP values. The most active compounds were observed to have $c \log P>5$. This indicates that the amines are highly lipophilic, and therefore likely to have reduced oral bioavailability. The trend in improved anti-mycobacterial activity corresponding with increased lipophilicity of the amines was noted earlier and is presumably due to the improved ability of the amines to penetrate the waxy mycobacterial cell wall. In this case, the lipophilicity that conveys activity of the amines is also responsible for the high $\operatorname{cLog} \mathrm{P}$ values. Although the $\operatorname{cLogP}$ values for the active second generation amines are disappointing, these values are only an estimation, and as with the rest of Lipinski's rules, there are exceptions. Therefore the in vivo testing of the most active compounds should be pursued and will provide a better indication of oral bioavailability. It is also worth considering an alternative method of drug delivery, ${ }^{36}$ other than an oral route, that could be applied to help the amine drug candidate reach its target in the body. For example, when applying Lipinski's rule of five to the anti-cancer drug Doxorubicin, the cLogP is -0.44 and DOX has too many H-bond donors and acceptors, thus it would not be expected to bioavailable as an oral drug. Indeed, DOX is not orally bioavailable and is therefore administered intravenously. ${ }^{37}$

From the second generation amine library, the only other exception to Lipinski's rule of five is the potential anti-cancer drug, diarabinohexadecylamine 210, which has a molecular weight of $509 \mathrm{~g} / \mathrm{mol}$, and eight hydrogen bond donor atoms. Given that the mechanism of action of these compounds is currently unknown, it could be that these lipophilic amines are membrane disruptors (indeed other amphiphilic molecules have been found to act as membrane disruptors) ${ }^{38}$ and therefore Lipinski's rule of five would not apply. Thus determination of the mechanism of action of potential anti-cancer candidate amine $\mathbf{2 1 0}$ should be a priority. 


\subsubsection{Alternative Measures of Drug-likeness}

As discussed in the previous section, Lipinski's rule of five suggested that the lead compounds from the second generation amine library are too lipophilic for oral bioavailability: however due to exceptions to Lipinski's rules, and it has been suggested that molecules that pass on three of the four the rules should not be discounted from drug discovery efforts. ${ }^{39}$ Additionally, since the development of Lipinski's rules, there has been many other selection criteria suggested for identifying drug-like molecules. Some of the alternative drug-likeness predictors have been described in this section.

Polar surface area (PSA) is the sum of the surface area of the polar atoms within a molecule. Kelder et al. have linked PSA to the bioavailabililty of a drug-like molecule. ${ }^{40}$ For drugs that are not active in the central nervous system (i.e. drugs that do not cross the blood-brain barrier) a PSA below $120 \AA^{2}$ is preferred, while central nervous system active drugs require a PSA less than 60-70 $\AA^{2}$.

Another set of rules for determining drug-likeness was established by Ghose et $a l^{41}$ After quantitative analysis of a different molecular library, a cLogP between -0.4 and 5.6, and molecular weight in the range $160-480 \mathrm{~g} / \mathrm{mol}$ were identified. In addition the total number of atoms (20 to 70 ) and the property of molar refractivity (the polarizability of a bulk substance, between 40 and 130) were also included. The total number of atoms in a molecule is important, as it relates to molecular weight, while the molar refractivity relates to the size and polarity of the bulk compound, hence relating to its solubility and absorption properties.

Oprea identified other properties important to predicting drug-likeness. ${ }^{42}$ In addition to the properties identified in Lipinski's rule of five, the number of rotatable bonds, and the number of rings in a molecule were considered important as they reflect the complexity of a molecule with respect to its flexibility and rigidity. It was established that 8 or fewer rotatable bonds, and 4 or fewer rings were necessary to maintain drug-like propeties in a molecule. 
A simplified model for drug-likeness was established by measurements of over 1100 drug candidates at GlaxoSmithKline, ${ }^{43}$ wherein Veber et al. suggested that molecular flexibility and polarity are key properties in predicting oral bioavailability. From this it was proposed that compounds that contain 10 or fewer rotatable bonds, and a PSA less than $140 \AA^{2}$ (or fewer than $13 \mathrm{H}$-bond donors and acceptors) were likely to have good oral bioavailability.

Consideration of these alternative measures of bioavailability with respect to the second generation amine library could be used to provide further insight on the drug-likeness of the lead compounds. The PSA for amine leads 208, 209, 223, 224, and 225 ranged from 44 to $93 \AA^{2}$ according to the programme Daylight. ${ }^{44}$ However, diarabinohexadecylamine $\mathbf{2 1 0}$ had a PSA of $165 \AA^{2}$, which exceeds the guideline of PSA $<140 \AA^{2}$. The molar refractivity of the amines is also anticipated to be large, due to the amphiphilic nature of the molecules. Furthermore, the lead amines would be very flexible due to the presence of more than eight rotatable bonds. Overall, there is a mixture of positive and negative factors influencing the bioavailability of the amines. Ultimately, the best predictor of bioavailability is success in an animal model for the disease. Future biological testing of the second generation amine leads will be discussed in the following section.

\subsubsection{Future Biological Testing}

Amine 209, and alkenylamines 223, 224, and 225 were identified as having the best anti-mycobacterial activity from the second generation amine library (MIC = 20-45 $\mu \mathrm{M}$ ). This activity is comparable to that of first line TB drug EMB (MIC = $39 \mu \mathrm{M})$ in the BCG Alamar Blue ${ }^{\circledR}$ assay, and up to a 70-fold improvement in the activity of the first generation lead octylalkenylamine $191 \mathrm{i}(\mathrm{MIC}=1400 \mu \mathrm{M})$ was achieved. Methylamine 209 was identified as the most promising target for further biological testing due to its simple, one-step synthesis with comparable activity to 
the alkenylamines (which require a three-step preparation), making it a more attractive target.

The unmethylated analogue of methylamine 209, arabinohexadecylamine 208 was slightly less active in the BCG growth inhibition assay $(\mathrm{MIC}=83-170 \mu \mathrm{M})$. This may be due to solubility, as the amphiphilic nature of amine $\mathbf{2 0 8}$ makes delivery to the bacterial cells more challenging. Despite its reduced anti-mycobacterial activity, the pursuit of hexadecylamine $\mathbf{2 0 8}$ as an anti-TB drug candidate was also of interest, to determine any marked difference between the in vitro and in vivo activity, and for SAR comparisons with methylamine 209. The pharmacokinetics of a compound can greatly influence its potential as a drug, and although amines 208 and 209 have promising anti-TB activity, cytotoxicity may limit therapeutic potential of these amines. That said, although in vitro screening gives a good starting point for lead optimisation in drug discovery, as it is a model, in vivo work is a better predictor of anti-TB activity and cytotoxicity. An example of this was the discovery of first line TB drug pyrazinamide, which is inactive in vitro, however in vivo activity studies were undertaken regardless, and the compound was found to be highly active. ${ }^{45}$ Both arabinohexadecylamine 208 and methylamine 209 can be made remarkably quickly and efficiently as the syntheses have been optimised to provide amines 208 and 209 on a $250 \mathrm{mg}$ scale (see Section 5.4). These amines have recently been sent to the group of Assoc. Prof. Anne Lenaerts at Colorado State University for in vivo testing in a mouse model of tuberculosis.

Diarabinohexadecylamine $\mathbf{2 1 0}$, is of interest for its impressive anti-cancer selectivity (SI = 9.6-12). As it does not obey Lipinski's rule of five, it may not be orally bioavailable, or it may indeed be a membrane disruptor hence determination of the mechanism of action of amine 210, and indeed this $\beta$ entire class of amines is of interest. An investigation into the in vivo anti-cancer activity of diarabinohexadecylamine $\mathbf{2 1 0}$ would also be beneficial. 


\subsubsection{Related Amphiphilic Amines}

A number of amphiphilic amines with relevant biological activity related to lead compounds 208, 209, and $\mathbf{2 1 0}$ have been reported (Figure 4.5). The surfactant properties of these amphiphilic molecules (e.g. their ability to form micelles) were also frequently reported. Glucose derived dodecylamine 226 was shown to suppress protein adsorption, and therefore reduce platelet adhesion when this molecule was used as a surfactant on polypropylene nonwoven fabrics. Amphiphilicity at the fabric surface is unfavourable for protein accumulation, and this property can have biomedical applications. ${ }^{46}$ Analogues of methylamine 208 and diarabinohexadecylamine $\mathbf{2 1 0}$, were also shown to have biological activity, with methylated 2-hydroxy-dodecylamine 227 and glucose dimer 228 being patented for use in formulation as surfactants for plant growth regulators, herbicides or pesticides. ${ }^{47}$ The molecules were shown to improve activity of the agrichemicals in formulation. Another related molecule with biological activity is lactose derived amine 229, which was identified as having antibacterial and

antifungal activity. ${ }^{16 \mathrm{a}, 28 \mathrm{~b}}$ Although this molecule has a slightly different structure, the amphiphilic nature and biological activity of the molecule is maintained. Gemini surfactant $\mathbf{2 3 0}$ maintains the same components as amphiphilic amines $\mathbf{2 0 8}$ to $\mathbf{2 1 0}$ but in a different structural arrangement. Due to their charged, amphiphilic nature, gemini surfactants have lower critical micelle concentrations compared to the corresponding monomeric amines such as $\mathbf{2 2 6}$. The surfactant $\mathbf{2 3 0}$ was also shown to have promising antimicrobial and antifungal activity, ${ }^{48}$ and such molecules are thought to convey biocidal activity through adsorption of the alkylamonium cation to the cell surface followed by diffusion into the cell and disruption of the cytoplasmic membrane ultimately leading to cell death. ${ }^{49} 3$ Deoxy-3-dodecylamino-allose $\mathbf{2 3 1}$ was identified as an inhibitor or promoter of plant growth, depending on the concentration of amine used. ${ }^{50}$ At a concentration of $2 \mathrm{mM}$, plant growth was inhibited, while at a much lower concentration of $0.1 \mathrm{mM}$, the plant growth rate was increased by approximately $40 \%$ compared to an untreated control. It is interesting to note that despite the use of a ring closed sugar of a different stereochemistry attached to the amine at a different position, 
biological activity in the form of plant growth inhibition was still observed. This may suggest that the bioactivity of these amines, and second generation leads $\mathbf{2 0 8}$ to $\mathbf{2 1 0}$, is not structure specific or due to favourable binding interactions, but rather general activity across the class of molecules due to the lipophilic/surfactant properties of these molecules.<smiles>OC[C@H](O)[C@@H](O)[C@H](O)[C@H](O)CNCC1CC1CC1CC1</smiles>

226

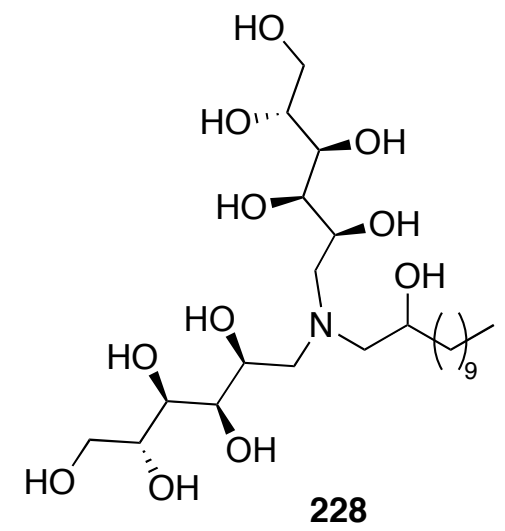<smiles>CN(C[C@H](O)[C@H](O)[C@H](O)[C@H](O)CO)CC(C)(O)C(C)(C)C</smiles>

227<smiles>OCC(O)[C@H](O[C@@H]1OC(CO)[C@H](O)[C@H](O)[C@H]1O)[C@@H](O)[C@H](O)CNCC1CC1</smiles>

229

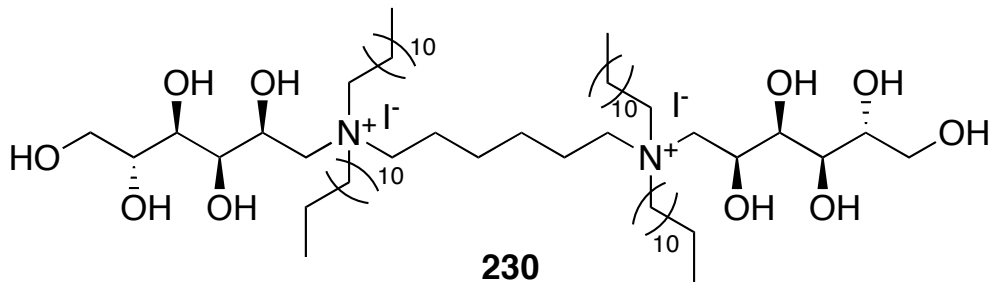

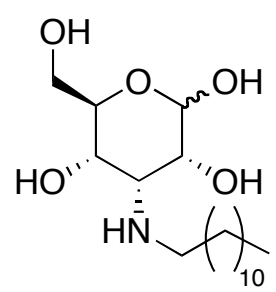

231<smiles>CC(N)C(O)CC(C)(C)CC1CC1</smiles>

232

Figure 4.5: Biologically active lipophilic amines. 
Finally, another amphiphilic amine, 1-deoxysphingoid 232, was recently extracted from a marine alga. ${ }^{51}$ This amine differs from the amine leads $\mathbf{2 0 8}$ to $\mathbf{2 1 0}$ however it maintains a hydrophilic part, an amine group, and a lipid portion. Amine 232 was identified as having activity against $M t b \mathrm{H} 37 \mathrm{Ra}\left(\mathrm{IC}_{50}=19.4 \mu \mathrm{M}\right)$ and HL60 cells $\left(\mathrm{IC}_{50}=8.8 \mu \mathrm{M}\right)$ suggesting a general cytotoxicity of the compound, similar to that observed in the second generation amine library. Indeed, 1deoxysphingosines have been previously identified as having a broad range of antimicrobial and cytotoxic activity. ${ }^{52}$ To inform on the mode of action of sphingosine 232, the compound was screened in a yeast knock out assay, against a library of 4800 nonessential gene deletion mutants of the yeast Saccharomyces cerevisiae. ${ }^{51}$ Genes involved in lipid metabolism and actin cytoskeleton organisation were identified as possible targets for amine 232. This could potentially inform on the mode of action of the amphiphilic amines in general, however both lipid metabolism and actin cytoskeleton organization pathways had been previously implicated in sphingolipid activity and therefore may be targets specific to the class of molecules.

A variety of amphiphilic amines have been discussed in this section. Some amines, such as $\mathbf{2 2 6}$ to $\mathbf{2 2 8}$, are close analogues to the amine leads $\mathbf{2 0 8}$ to $\mathbf{2 1 0}$, while others a more varied, while maintaining the key sugar and lipophilic amine portions that define the class of molecules. Growth inhibition or cytotoxicity of the amines was observed in a variety of different organisms including bacteria, fungi, yeast and plants suggesting that this class of amphiphilic amines displays non-specific inhibitory activity. This is in agreement with the activity observed in the testing of the second generation amine library (Section 5.3.2). These observations support the suggestion that the molecules may be acting nonspecifically as membrane disruptors. While some drugs work through membrane disruption pathways, specificity in a drug is essential, and the general bioactivity observed for this class of molecules against a range of different organisms suggests a lack of specificity. Confirmation of the mechanism of action of these molecules would therefore be beneficial. 


\subsection{Optimised Syntheses of Lead Compounds}

The synthesis of arabinohexadecylamine $\mathbf{2 0 8}$ was optimised by the addition of excess hexadecylamine 207 (10 equiv.) with $\mathrm{EtOH}$ (that did not contain the formaldehyde impurity) as the solvent to give amine $\mathbf{2 0 8}$ in $\mathbf{7 8 \%}$ yield (Scheme 4.4). As the imine formation step is in equilibrium, it follows that the large excess of amine $\mathbf{2 0 7}$ pushes the equilibrium in favour of imine formation. By favouring the imine formation, the D-arabinose (198) is rapidly used up in the reaction, reducing the likelihood of the product amine $\mathbf{2 0 8}$ forming and then attacking remaining sugar 198, to form the diarabinohexadecylamine 210 by-product. The difference in polarities of the reacting amine 207 and the amphiphilic arabinohexadecylamine $\mathbf{2 0 8}$ was significant hence chromatographic separation of these was straightforward.

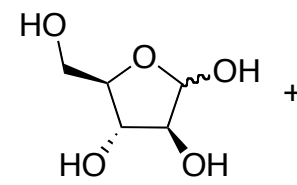

195

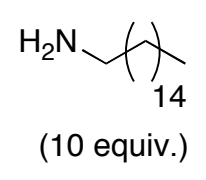

207

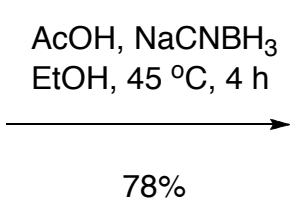

$78 \%$

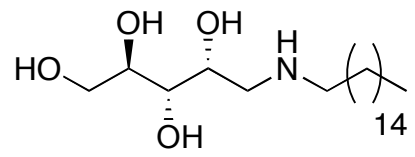

208

Scheme 4.4: Optimised synthesis of arabinohexadecylamine 208.

The optimised synthesis of methylamine $\mathbf{2 0 9}$ also required a large excess of amine 207. To this effect, 10 equiv. of hexadecylamine 207 in methanol was reacted with D-arabinose (198) and a small amount of $\mathrm{NaCNBH}_{3}$ first to form amine 208 in situ before the addition of 20 equiv. formaldehyde (as a 37\% aqueous solution), and then additional reducing agent, portion-wise to form methylamine 209 (Scheme 4.5). This could be isolated in an excellent $90 \%$ yield, and also was easily separable from the excess amine. 


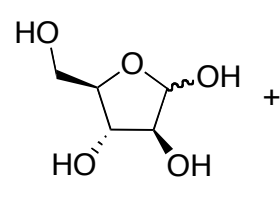

195

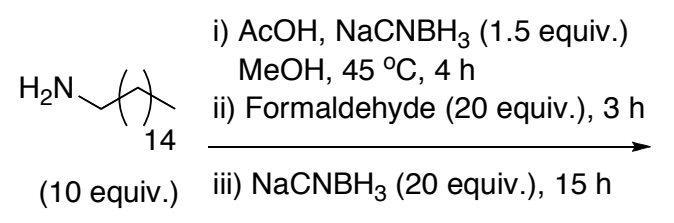

207
$90 \%$

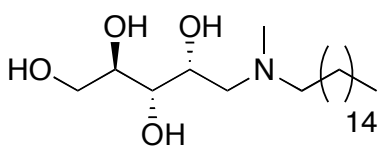

209

Scheme 4.5: Optimised synthesis of arabinohexadecyl(methyl)amine 209. 


\subsection{Conclusion}

A variety of different amines have been successfully synthesised and isolated using Vasella-reductive amination and reductive amination conditions. The amine yields vary considerably, due to challenges in solubility of the amine and sugar components and difficulty in purification of the product amines. In the interest of rapidly finding a new lead compound for drug discovery, only the syntheses of lead amines hexadecylamine $\mathbf{2 0 8}$ and methylamine 209 were optimised. The optimisation provided clean compounds 208 and 209 in excellent yields of $78 \%$ and $90 \%$, respectively.

Biological activity and bioavailability data was reported for the second generation library. The compounds were tested for anti-mycobacterial activity in the BCG Alamar Blue ${ }^{\circledR}$ growth inhibition assay. Longer, linear alkylamines were observed to be more active than shorter or more conformationally restricted alkylamines (e.g. cyclic or adamantylamines), and the alkene functionality present in the alkenylamines did not significantly affect activity. Methylation of the secondary amine only appeared to aid activity when this also improved solubility. Lead amine 209, and alkenylamines 223 to $\mathbf{2 2 5}$ were identified as the most active compounds, and when compared with the first generation lead compound 191i, up to a 70 -fold improvement in activity was achieved, giving the amines activity comparable to that of first line TB drug ethambutol. Additionally, alkenylamine 224 exhibited good $(30 \mu \mathrm{M})$ inhibition against an avirulent $M t b$ strain, H37Ra, and this is a promising result for the class of compounds as a whole.

Further biological testing and bioavailability studies revealed a trend in toxicities where increased cytotoxicity was observed with increased anti-mycobacterial activity. This implies the amines are generally toxic, rather than selective for mycobacteria, and this was supported by a review of related bioactive amphiphilic amines in the literature. Bioavailability studies revealed that the more active amines and alkenylamines fail Lipinski's rule of five based on $\operatorname{cLogP}>5$. Amine 
210 also failed based on molecular weight $>500 \mathrm{~g} / \mathrm{mol}$, and the presence of greater than five hydrogen bond donors.

The second generation compound library has shown varied toxicity towards both cancer cells and human $\mathrm{T}$ cells, thus there is scope for tuning these compounds to improve their activity towards HL60 cancer cells. Diarabinohexadecylamine 210 is a promising example of this; with remarkable selectivity for cancer cells over $\mathrm{T}$ cells $(\mathrm{SI}=9.6-12)$ and investigations into possible collaborations for the in vivo testing of the amine in a cancer model are underway.

Finally, arabinohexadecylamine $\mathbf{2 0 8}$ and arabinohexadecylmethylamine 209 were identified as promising anti-mycobacterial leads, and the single-step syntheses of these compounds were optimised. The in vivo testing of these amines in a mouse model of $M t b$ is underway at Colorado State University and results will be reported in due course. 


\subsection{Experimental}

\section{General Methods}

Unless otherwise stated, all reactions were performed under atmospheric air. $\mathrm{H}_{2} \mathrm{O}$, $\mathrm{MeOH}$ (Pure Science), and EtOH (absolute, Pure Science), were distilled prior to use. EtOAc (Pure Science), and petroleum ether (Pure Science), HCl (PanReac), $\mathrm{AcOH}$ (Ajax Finechem), DCM (LabServ), 35\% aqueous $\mathrm{NH}_{3}$ (LabServ), $\mathrm{AcCl}$ (B\&M), $\mathrm{NaCNBH}_{3}$ (Aldrich), $\mathrm{NH}_{4} \mathrm{OAc}$ (AnalaR), D-arabinose (Sigma-Aldrich), L-fucose (Sigma-Aldrich), L-rhamnose (Sigma-Aldrich), cyclohexylamine (Riedel), cyclooctylamine (Aldrich), 1-adamantylamine (Sigma), cyclododecylamine (Aldrich), hexadexylamine (Aldrich), formaldehyde (SigmaAldrich), di-n-butylamine (Sigma), and tetradecylamine (Aldrich) were used as received. All chemicals obtained from commercial suppliers were used without further purification. $\mathrm{Zn}$ dust was activated by the careful addition of concentrated $\mathrm{H}_{2} \mathrm{SO}_{4}$, followed by decantation and washing with EtOH $(3 \times)$ and hexanes $(3 \times)$ and storage under dry hexanes. All solvents were removed by evaporation under reduced pressure. Reactions were monitored by TLC analysis on Macherey-Nagel silica gel coated plastic sheets with detection by coating with $20 \% \mathrm{H}_{2} \mathrm{SO}_{4}$ in EtOH followed by charring at $c a .150{ }^{\circ} \mathrm{C}$, by coating with a solution of ninhydrin in EtOH followed by charring at $c a .150{ }^{\circ} \mathrm{C}$, or by coating with a solution of $5 \%$ $\mathrm{KMnO}_{4}$ and $1 \% \mathrm{NaIO}_{4}$ in $\mathrm{H}_{2} \mathrm{O}$ followed by heating. Column chromatography was performed on Pure Science silica gel (40-63 micron). Dowex ${ }^{\circledR}$ W50-X8 acidic resin (Sigma) and Dowex ${ }^{\circledR}$ 1X4-50 basic resin (Sigma) were used for ion exchange chromatography and HP-20 (Supelco) for reverse phase chromatography. High-resolution mass spectra were recorded on a Waters Q-TOF Premier $^{\mathrm{TM}}$ Tandem Mass Spectrometer using positive electro-spray ionisation. Optical rotations were recorded using an Autopol II (Rudolf Research Analytical) at $589 \mathrm{~nm}$ (sodium D-line). Infrared spectra were recorded as thin films using a Bruker Tensor 27 FTIR spectrometer, equipped with an Attenuated Total Reflectance (ATR) sampling accessory, and are reported in wave numbers $\left(\mathrm{cm}^{-1}\right)$. Nuclear magnetic resonance spectra were recorded at $20{ }^{\circ} \mathrm{C}$ in $\mathrm{D}_{2} \mathrm{O}, \mathrm{CD}_{3} \mathrm{OD}$, 
pyridine- $\mathrm{d}_{5}, \mathrm{CDCl}_{3}$, or DMSO- $\mathrm{d}_{6}$ at $\left(80{ }^{\circ} \mathrm{C}\right)$ using either a Varian Unity-INOVA operating at $300 \mathrm{MHz}$ or a Varian Unity operating at $500 \mathrm{MHz}$. Chemical shifts are given in ppm $(\delta)$ and were internally referenced to the residual solvent peak. NMR peak assignments are based on 2D NMR experiments (COSY, HSQC, and HMBC).

\subsubsection{Synthetic Experimental}

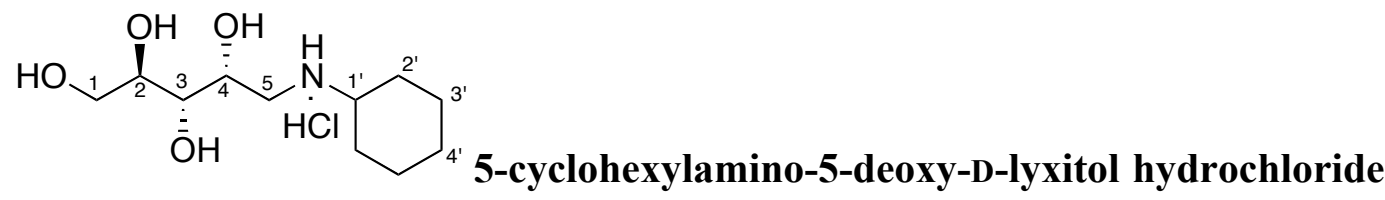

(203): To a solution of D-arabinose $(156 \mathrm{mg}, 1.0 \mathrm{mmol})$ in EtOH $(20 \mathrm{~mL})$, was added cyclohexylamine ( $89 \mathrm{mg}, 0.9 \mathrm{mmol}$ ), $\mathrm{NaCNBH}_{3}$ (194 mg, $3 \mathrm{mmol}$ ), water $(0.5 \mathrm{~mL})$, and $\mathrm{AcOH}(0.07 \mathrm{~mL})$. The reaction was stirred at room temperature for $23 \mathrm{~h}$. The solvent was then removed under reduced pressure, the residue redissolved in $\mathrm{H}_{2} \mathrm{O}$ and loaded onto Dowex $-\mathrm{H}^{+}$cation exchange resin. The product was eluted with $25 \%$ aqueous $\mathrm{NH}_{3}$, to give a white solid (90 mg, 0.39 mmol, 43\%) which was then acidified with $1 \mathrm{M} \mathrm{HCl}$ and concentrated to afford 5cyclohexylamino-5-deoxy-D-lyxitol hydrochloride (203). $\quad \mathrm{R}_{f}=0.16$ (DCM/EtOH/MeOH/30\% NH $\left.\mathrm{N}_{3 \text { (aq.) }}, 15 / 2 / 2 / 1, \mathrm{v} / \mathrm{v} / \mathrm{v} / \mathrm{v}\right) ;[\alpha]_{\mathrm{D}}^{25}=+12.8(\mathrm{c}=1.0$, EtOH); IR (film) 3324, 2935, 2858, 1636, 1455, 1032, $896 \mathrm{~cm}^{-1} .{ }^{1} \mathrm{H}$ NMR (500 $\left.\mathrm{MHz}, \mathrm{D}_{2} \mathrm{O}\right) \delta 4.17\left(\mathrm{dd}, J_{4,5}=3.2, J_{3,4}=8.8 \mathrm{~Hz}, 1 \mathrm{H}, \mathrm{H}-4\right), 3.80\left(\mathrm{dd}, J_{1 \mathrm{a}, 2}=2.6 \mathrm{~Hz}\right.$, $\left.J_{1 \mathrm{a}, 1 \mathrm{~b}}=11.7 \mathrm{~Hz}, 1 \mathrm{H}, \mathrm{H}-1 \mathrm{a}\right), 3.70\left(\mathrm{ddd}, J_{1 \mathrm{a}, 2}=2.6, J_{1 \mathrm{~b}, 2}=5.8, J_{2,3}=8.7 \mathrm{~Hz}, 1 \mathrm{H}, \mathrm{H}-\right.$ 2), $3.63\left(\mathrm{dd}, J_{1 \mathrm{~b}, 2}=5.8, J_{1 \mathrm{a}, 1 \mathrm{~b}}=11.7 \mathrm{~Hz}, 1 \mathrm{H}, \mathrm{H}-1 \mathrm{~b}\right), 3.48\left(\mathrm{~d}, J_{3,4}=8.8 \mathrm{~Hz}, 1 \mathrm{H}, \mathrm{H}-\right.$ 3), 3.25-3.19 (m, 2H, H-5), 3.18-3.11 (m, 1H, H-1'), 2.10-2.04 (m, 2H, H-2'a), 1.82 (d, $\left.J=12.5 \mathrm{~Hz}, 2 \mathrm{H}, \mathrm{H}-3{ }^{\prime} \mathrm{a}\right), 1.64$ (d, $\left.J=13.2 \mathrm{~Hz}, 2 \mathrm{H}, \mathrm{H}-4^{\prime} \mathrm{a}\right), 1.42-1.25$ (m, $4 \mathrm{H}, \mathrm{H}-2$ 'b, H-3'b) 1.18-1.11 (m, 2H, H-4'b); ${ }^{13} \mathrm{C}$ NMR (125 MHz, $\left.\mathrm{D}_{2} \mathrm{O}\right) \delta 71.0$ (C3), 70.4 (C2), 65.9 (C4), 62.7 (C1), 57.5 (C1'), 47.3 (C5), 28.9, 28.5 (C2'), 24.4 (C4'), 23.9, $23.9\left(\mathrm{C}^{\prime}\right)$; HRMS(ESI) $m / z$ calcd. for $\left[\mathrm{C}_{11} \mathrm{H}_{23} \mathrm{O}_{4} \mathrm{~N}+\mathrm{H}\right]^{+}:$234.1700, obsd.: 234.1705 . 
<smiles>OC[C@@H](O)[C@@H](O)CN[C]1[CH][14CH2][14CH2][14CH2][14CH2][14CH2][14CH2]1</smiles>

5-cyclooctylamino-5-deoxy-D-lyxitol (204): To a solution of D-arabinose $(100 \mathrm{mg}, 0.67 \mathrm{mmol})$ in EtOH $(13.3 \mathrm{~mL})$, was added cyclooctylamine (77 mg, $0.60 \mathrm{mmol}), \mathrm{NaCNBH}_{3}(126 \mathrm{mg}, 2 \mathrm{mmol})$, and water $(0.4 \mathrm{~mL})$. The reaction was stirred at room temperature for $4 \mathrm{~h}$. The solvent was then removed under reduced pressure, and the residue loaded onto Dowex- $\mathrm{H}^{+}$ cation exchange resin and eluted with $5-35 \% \mathrm{NH}_{3}$ in $\mathrm{EtOH} / \mathrm{H}_{2} \mathrm{O}$ to give 5-deoxy5-cyclooctylamino-5-deoxy-D-lyxitol (204) as a white solid (70 $\mathrm{mg}, 0.27 \mathrm{mmol}$, $45 \%) . \mathrm{R}_{f}=0.18\left(\mathrm{DCM} / \mathrm{EtOH} / \mathrm{MeOH} / 30 \% \mathrm{NH}_{3(\text { aq. })}, 15 / 2 / 2 / 1, \mathrm{v} / \mathrm{v} / \mathrm{v} / \mathrm{v}\right) ;[\alpha]_{\mathrm{D}}{ }^{25}=$ +4.9 (c = 1.0, EtOH); IR (film) 3348, 2925, 2857, 1642, 1469, 1446, 1054, 879 $\mathrm{cm}^{-1} .{ }^{1} \mathrm{H}$ NMR (500 MHz, CD $\left.{ }_{3} \mathrm{OD}\right) \delta 3.97\left(\mathrm{td}, J_{3,4}=2.1, J_{4,5}=6.2 \mathrm{~Hz}, 1 \mathrm{H}, \mathrm{H}-4\right)$, $3.79\left(\mathrm{dd}, J_{1 \mathrm{a}, 2}=3.2, J_{1 \mathrm{a}, 1 \mathrm{~b}}=10.9 \mathrm{~Hz}, 1 \mathrm{H}, \mathrm{H}-1 \mathrm{a}\right), 3.66\left(\mathrm{ddd}, J_{1 \mathrm{a}, 2}=3.2, J_{1 \mathrm{~b}, 2}=5.8\right.$, $\left.J_{2,3}=8.0 \mathrm{~Hz}, 1 \mathrm{H}, \mathrm{H}-2\right), 3.62\left(\mathrm{dd}, J_{1 \mathrm{~b}, 2}=5.8, J_{1 \mathrm{a}, 1 \mathrm{~b}}=10.9 \mathrm{~Hz}, 1 \mathrm{H}, \mathrm{H}-1 \mathrm{~b}\right), 3.42(\mathrm{dd}$, $\left.J_{3,4}=2.1, J_{2,3}=8.0 \mathrm{~Hz}, 1 \mathrm{H}, \mathrm{H}-3\right), 2.83\left(\mathrm{~d}, J_{4,5}=6.2 \mathrm{~Hz}, 2 \mathrm{H}, \mathrm{H}-5\right), 2.83-2.79(\mathrm{~m}$, 1H, H-1'), 1.87-1.73 (m, 4H, H-2'-5'), 1.61-1.59 (m, 4H, H-2'-5'), 1.59-1.46 (m, 6H, H-2'-5'); ${ }^{13} \mathrm{C}$ NMR (125 MHz, CD $\left.\mathrm{CD}_{3} \mathrm{OD}\right) \delta 74.3$ (C3), 73.0 (C2), 69.7 (C4), 64.9 (C1), 59.2 (C1'), 51.0 (C5), 33.0, 28.1, 26.9, 25.3 (C2'-5'); HRMS(ESI) m/z calcd. for $\left[\mathrm{C}_{13} \mathrm{H}_{27} \mathrm{O}_{4} \mathrm{~N}+\mathrm{H}\right]^{+}:$262.2013, obsd.: 262.2016.

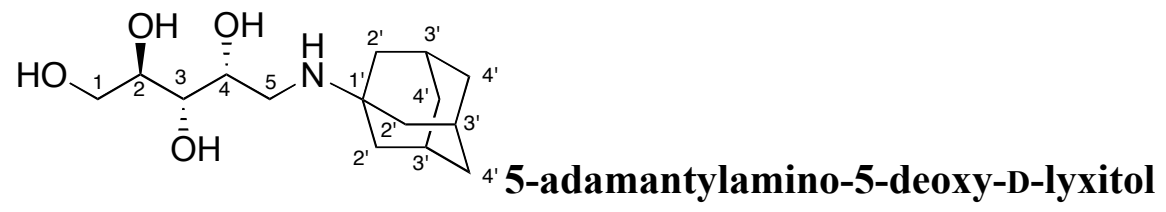

hydrochloride (205): To a solution of D-arabinose (100 mg, $0.67 \mathrm{mmol})$ in EtOH (3.4 mL), was added 1-adamantanamine (121 mg, $0.80 \mathrm{mmol}), \mathrm{NaCNBH}_{3}(126$ $\mathrm{mg}, 2 \mathrm{mmol})$, water $(0.34 \mathrm{~mL})$, and $\mathrm{AcOH}(0.05 \mathrm{~mL})$. The reaction was stirred at room temperature for $20 \mathrm{~h}$. The solvent was then removed under reduced pressure, and the residue loaded onto Dowex $-\mathrm{H}^{+}$cation exchange resin and eluted with $5-35 \% \quad \mathrm{NH}_{3}$ in $\mathrm{EtOH} / \mathrm{H}_{2} \mathrm{O}$. Further purification by $\mathrm{C}_{8}$ reverse phase chromatography $\left(\mathrm{H}_{2} \mathrm{O}\right.$ to $\left.\mathrm{H}_{2} \mathrm{O} / \mathrm{MeOH}, 1 / 1, \mathrm{v} / \mathrm{v}\right)$ and then gradient flash chromatography (DCM/EtOH/MeOH/35\% $\mathrm{NH}_{3 \text { (aq.) }}, 75 / 2 / 2 / 1$ to $35 / 2 / 2 / 1$, v/v/v/v), followed by acidification with $1 \mathrm{M} \mathrm{HCl}$ and then concentration afforded 5- 
adamantylamino-5-deoxy-D-lyxitol hydrochloride (205) as a white solid (30 $\mathrm{mg}$, $0.09 \mathrm{mmol}, 14 \%) . \mathrm{R}_{f}=0.09$ (DCM/EtOH/MeOH/30\% $\left.\mathrm{NH}_{3 \text { (aq.) }}, 15 / 2 / 2 / 1, \mathrm{v} / \mathrm{v} / \mathrm{v} / \mathrm{v}\right)$; $[\alpha]_{\mathrm{D}}^{25}=+6.6(\mathrm{c}=0.27, \mathrm{EtOH})$; IR (film) 3365, 2916, 2854, 1645, 1455, 1365, $1310,1071,1020 \mathrm{~cm}^{-1} .{ }^{1} \mathrm{H}$ NMR $\left(500 \mathrm{MHz}, \mathrm{D}_{2} \mathrm{O}\right) \delta 4.13\left(\mathrm{td}, J_{3,4}=1.7, J_{4,5}=6.4\right.$ $\mathrm{Hz}, 1 \mathrm{H}, \mathrm{H}-4), 3.82\left(\mathrm{dd}, J_{1 \mathrm{a}, 2}=2.8, J_{1 \mathrm{a}, 1 \mathrm{~b}}=11.7 \mathrm{~Hz}, 1 \mathrm{H}, \mathrm{H}-1 \mathrm{a}\right), 3.71\left(\mathrm{ddd}, J_{1 \mathrm{a}, 2}=\right.$ $\left.2.8, J_{1 \mathrm{~b}, 2}=5.9, J_{2,3}=8.9 \mathrm{~Hz}, 1 \mathrm{H}, \mathrm{H}-2\right), 3.65\left(\mathrm{dd}, J_{1 \mathrm{~b}, 2}=5.9, J_{1 \mathrm{a}, 1 \mathrm{~b}}=11.7 \mathrm{~Hz}, 1 \mathrm{H}\right.$, $\mathrm{H}-1 \mathrm{~b}), 3.50$ (dd, $\left.J_{3,4}=1.7, J_{2,3}=8.9 \mathrm{~Hz}, 1 \mathrm{H}, \mathrm{H}-3\right), 3.18$ (d, $J_{4,5}=6.4 \mathrm{~Hz}, 1 \mathrm{H}, \mathrm{H}-$ 5), 2.19 (br s, 3H, H-3'), 1.95-1.87 (m, 6H, H-2'), 1.74 (d, $J_{4^{\prime} \mathrm{a}, 4^{\prime} \mathrm{b}}=12.2 \mathrm{~Hz}, 3 \mathrm{H}$, H-4'a), 1.65 (d, $\left.J_{4^{\prime} \mathrm{a}, 4^{\prime} \mathrm{b}}=12.2 \mathrm{~Hz}, 3 \mathrm{H}, \mathrm{H}-4{ }^{\prime} \mathrm{b}\right) ;{ }^{13} \mathrm{C} \mathrm{NMR}\left(125 \mathrm{MHz}, \mathrm{D}_{2} \mathrm{O}\right) \delta 71.1$ (C3), 70.4 (C2), 66.2 (C4), 62.7 (C1), 57.8 (C1'), 42.7 (C5), 37.8 (C2'), 34.8 (C4'), 28.7 (C3'); HRMS(ESI) $m / z$ calcd. for $\left[\mathrm{C}_{15} \mathrm{H}_{27} \mathrm{O}_{4} \mathrm{~N}+\mathrm{H}\right]^{+}$: 286.2013, obsd.: 286.2022 .

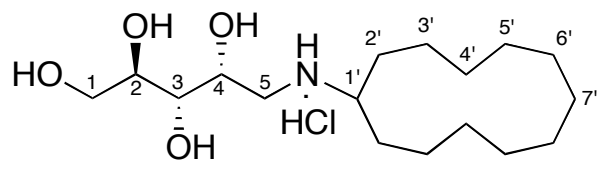

\section{5-cyclododecylamino-5-deoxy-D-lyxitol}

hydrochloride (206): To a solution of D-arabinose (100 mg, $0.67 \mathrm{mmol})$ in EtOH (13.3 mL), was added cyclododecylamine (243 mg, $1.33 \mathrm{mmol}), \mathrm{NaCNBH}_{3}(126$ $\mathrm{mg}, 2 \mathrm{mmol})$, and water $(0.4 \mathrm{~mL})$. The reaction was stirred at room temperature for $5 \mathrm{~h}$ then solvent removed under reduced pressure. The product was purified first by gradient flash chromatography (DCM/EtOH/MeOH/35\% $\mathrm{NH}_{3 \text { (aq.) }}$, $305 / 2 / 2 / 1$ to $5 / 2 / 2 / 1, \mathrm{v} / \mathrm{v} / \mathrm{v} / \mathrm{v})$, followed Dowex- $\mathrm{H}^{+}$cation exchange $\left(5-35 \% \mathrm{NH}_{3}\right.$ in $\mathrm{EtOH} / \mathrm{H}_{2} \mathrm{O}$ ) to give a white solid, 206, as the $\mathrm{HCl}$ salt upon acidification and subsequent concentration $(61 \mathrm{mg}, \quad 0.17 \mathrm{mmol}, \quad 26 \%) . \quad \mathrm{R}_{f}=0.24$ (DCM/EtOH/MeOH/30\% $\left.\mathrm{NH}_{3 \text { (aq.) }}, 15 / 2 / 2 / 1, \mathrm{v} / \mathrm{v} / \mathrm{v} / \mathrm{v}\right) ;[\alpha]_{\mathrm{D}}{ }^{25}=+8.1(\mathrm{c}=0.93$, EtOH); IR (film) 3330, 2929, 2862, 1576, 1471, 1446, $1074 \mathrm{~cm}^{-1} .{ }^{1} \mathrm{H}$ NMR (500 $\left.\mathrm{MHz}, \mathrm{CD}_{3} \mathrm{OD}\right) \delta$ 4.20-4.17 (m, $\left.1 \mathrm{H}, \mathrm{H}-4\right), 3.80\left(\mathrm{dd}, J_{1 \mathrm{a}, 2}=2.8, J_{1 \mathrm{a}, 1 \mathrm{~b}}=10.5 \mathrm{~Hz}\right.$, $1 \mathrm{H}, \mathrm{H}-1 \mathrm{a}), 3.68\left(\mathrm{ddd}, J_{1 \mathrm{a}, 2}=2.8, J_{1 \mathrm{~b}, 2}=5.4, J_{2,3}=8.1 \mathrm{~Hz}, 1 \mathrm{H}, \mathrm{H}-2\right), 3.65\left(\mathrm{dd}, J_{1 \mathrm{~b}, 2}\right.$ $\left.=5.4, J_{1 \mathrm{a}, 1 \mathrm{~b}}=10.5 \mathrm{~Hz}, 1 \mathrm{H}, \mathrm{H}-1 \mathrm{~b}\right), 3.47\left(\mathrm{dd}, J_{3,4}=1.7, J_{2,3}=8.1 \mathrm{~Hz}, 1 \mathrm{H}, \mathrm{H}-3\right)$, $3.31\left(\mathrm{dt}, J_{1^{\prime}, 2^{\prime} \mathrm{a}}=1.6, J_{1^{\prime}, 2^{\prime} \mathrm{b}}=3.2 \mathrm{~Hz}, 1 \mathrm{H}, \mathrm{H}-1^{\prime}\right), 3.21\left(\mathrm{dd}, J_{4,5 \mathrm{a}}=8.4, J_{5 \mathrm{a}, 5 \mathrm{~b}}=12.8\right.$ $\mathrm{Hz}, 1 \mathrm{H}, \mathrm{H}-5 \mathrm{a}), 3.18$ (dd, $\left.J_{4,5 \mathrm{~b}}=4.4, J_{5 \mathrm{a}, 5 \mathrm{~b}}=12.8 \mathrm{~Hz}, 1 \mathrm{H}, \mathrm{H}-5 \mathrm{~b}\right), 1.91-1.78$ (m, 2H, H-2'a), 1.74-1.66 (m, 2H, H-2'b), 1.57-1.35 (m, 18H, H-3'-H-7'); ${ }^{13} \mathrm{C}$ NMR (125 
$\left.\mathrm{MHz}, \mathrm{CD}_{3} \mathrm{OD}\right) \delta 73.3(\mathrm{C} 3), 72.7$ (C2), $67.4(\mathrm{C} 4), 64.6(\mathrm{C} 1), 57.9$ (C1'), 49.7 (C5), 27.3, 26.7 (C2') , 25.7, 25.6, 25.4, 24.1, 24.0, 23.9, 21.6, 21.3 (C3'-C7'); HRMS(ESI) $m / z$ calcd. for $\left[\mathrm{C}_{17} \mathrm{H}_{35} \mathrm{O}_{4} \mathrm{~N}+\mathrm{H}\right]^{+}: 318.2639$, obsd.: 318.2648 .<smiles>OC[C@H](O)[C@@H](O)[C@H](O)CN[C@H](Cl)[C@@H](O)CO</smiles>

hexadecylamino-D-lyxitol

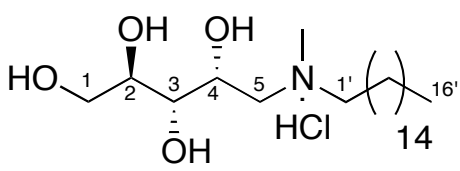

5-deoxy-5hexadecylmethylamino-D-lyxitol hydrochloride (209): To a solution of Darabinose $(200 \mathrm{mg}, 1.3 \mathrm{mmol})$ in $\mathrm{MeOH}(16.8 \mathrm{~mL})$, was added hexadecylamine (574 mg, $2.4 \mathrm{mmol}), \mathrm{NaCNBH}_{3}(126 \mathrm{mg}, 2 \mathrm{mmol})$, and AcOH $(0.96 \mathrm{~mL})$. The reaction was stirred at $45{ }^{\circ} \mathrm{C}$ for $21 \mathrm{~h}$ then the solvent was removed under reduced pressure to give 208, and 209 as a by-product. These could be separated by silica column chromatography (DCM/EtOH/MeOH/35\% $\mathrm{NH}_{3 \text { (aq.) }}, 105 / 2 / 2 / 1$ to 35/2/2/1, $\mathrm{v} / \mathrm{v} / \mathrm{v} / \mathrm{v})$ to give 208 as a white solid (211.2 $\mathrm{mg}, 0.56 \mathrm{mmol}, 42 \%$,) and 209, also as a white solid that was converted into the $\mathrm{HCl}$ salt by addition of $\mathrm{HCl}(1.2 \mathrm{M}$, aq.) and concentration (50 $\mathrm{mg}, 0.13 \mathrm{mmol}, 10 \%$ ).

5-deoxy-5-hexadecylamino-D-lyxitol hydrochloride (208): $\quad \mathrm{R}_{f}=0.40$

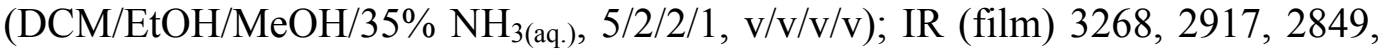
$1467,1093,1040,878 \mathrm{~cm}^{-1} .{ }^{1} \mathrm{H}$ NMR $\left(300 \mathrm{MHz}\right.$, DMSO-d $\left.6,80{ }^{\circ} \mathrm{C}\right) \delta 3.78-3.71$ $(\mathrm{m}, 1 \mathrm{H}, \mathrm{H}-4), 3.60\left(\mathrm{dd}, J_{1 \mathrm{a}, 2}=3.7, J_{1 \mathrm{a}, 1 \mathrm{~b}}=10.4 \mathrm{~Hz}, 1 \mathrm{H}, \mathrm{H}-1 \mathrm{a}\right), 3.50\left(\mathrm{ddd}, J_{1 \mathrm{a}, 2}=\right.$ $\left.3.7, J_{1 \mathrm{~b}, 2}=5.7, J_{2,3}=7.5 \mathrm{~Hz}, 1 \mathrm{H}, \mathrm{H}-2\right), 3.42\left(\mathrm{dd}, J_{1 \mathrm{~b}, 2}=5.7, J_{1 \mathrm{a}, 1 \mathrm{~b}}=10.4 \mathrm{~Hz}, 1 \mathrm{H}\right.$, H-1b), 3.31 (dd, $\left.J_{3,4}=2.5, J_{2,3}=7.5 \mathrm{~Hz}, 1 \mathrm{H}, \mathrm{H}-3\right), 2.71-2.62$ (m, 2H, H-5), 2.592.52 (m, 2H, H-1'), 1.47-1.36 (m, 2H, H-2'), 1.36-1.21 (m, 26H, H-3'-H-15'), $0.87\left(\mathrm{t}, J_{15^{\prime}, 16^{\prime}}=6.8 \mathrm{~Hz}, 3 \mathrm{H}, \mathrm{H}-16^{\prime}\right) ;{ }^{13} \mathrm{C}$ NMR $\left(75 \mathrm{MHz}, \mathrm{DMSO}-\mathrm{d}_{6}, 80{ }^{\circ} \mathrm{C}\right) \delta 72.9$ (C3), 71.7 (C2), 68.5 (C4), 63.5 (C1), 52.4 (C5), 48.9 (C5), 30.9, 28.6 (br. s), 26.4, $21.6\left(\mathrm{C}^{\prime}-\mathrm{C}^{\prime} 5^{\prime}\right), 13.5\left(\mathrm{C} 16^{\prime}\right)$; HRMS(ESI) $m / z$ calcd. for $\left[\mathrm{C}_{21} \mathrm{H}_{45} \mathrm{O}_{4} \mathrm{~N}+\mathrm{H}\right]^{+}$: 376.3421, obsd.: 376.3421 .

5-deoxy-5-hexadecylmethylamino-D-lyxitol hydrochloride (209): $\mathrm{R}_{f}=0.57$ $\left(\mathrm{DCM} / \mathrm{EtOH} / \mathrm{MeOH} / 35 \% \mathrm{NH}_{3 \text { (aq.) }}, 5 / 2 / 2 / 1, \mathrm{v} / \mathrm{v} / \mathrm{v} / \mathrm{v}\right) ;[\alpha]_{\mathrm{D}}{ }^{28}=+8.0 \quad(\mathrm{c}=1.0$, $\mathrm{MeOH}$ ); IR (film) 3333, 2953, 2918, 2850, 1467, 1081, 1033, $736 \mathrm{~cm}^{-1} .{ }^{1} \mathrm{H}$ NMR (300 MHz, $\left.\mathrm{CD}_{3} \mathrm{OD}\right) \delta 4.29$ (d, $J=9.3 \mathrm{~Hz}, 1 \mathrm{H}, \mathrm{H}-4$ ), 3.80 (app. d, $J=8.0 \mathrm{~Hz}, 1 \mathrm{H}$, 
H-1a), 3.72-3.60 (m, 2H, H-1b and H-2), 3.48-3.34 (m, 2H, H-3 and H-5a), 3.263.10 (m, 3H, H-1' and H-5b), 2.93 (s, 3H, N-Me), 1.84-1.69 (m, 2H, H-2'), 1.461.24 (m, 26H, H-3'-H-15'), 0.90 (t, $\left.J_{15^{\prime}, 16^{\prime}}=6.6 \mathrm{~Hz}, 3 \mathrm{H}, \mathrm{H}-16^{\prime}\right) ;{ }^{13} \mathrm{C}$ NMR $(125$ $\left.\mathrm{MHz}, \mathrm{CD}_{3} \mathrm{OD}\right) \delta 71.4(\mathrm{C} 3), 71.2(\mathrm{C} 2), 64.7$ (C4), 63.3 (C1), 55.5 (C5), 56.6 (C1'), 40.2 (N-Me), 31.7, 29.4, 29.4, 29.3, 29.2, 29.1, 28.9, 26.3, 22.3 (C3'-C15'), $23.8\left(\mathrm{C}^{\prime}\right), 13.1$ (C16'); HRMS(ESI) $m / z$ calcd. for $\left[\mathrm{C}_{22} \mathrm{H}_{47} \mathrm{O}_{4} \mathrm{~N}+\mathrm{H}\right]^{+}: 390.3578$, obsd.: 390.3594 .<smiles>[Y4]C1([CH]NC[C@H](O)[C@@H](O)[C@H](O)CO)CC1</smiles>

hexadecylamino-D-lyxitol<smiles>[Y4]C(C)(C)CN(C[C@@H](O)[C@@H](O)[C@H](O)CO)C[C@@H](O)[C@@H](O)[C@H](O)CO</smiles>

5-deoxy-5-

hexadecylamino-bis-D-lyxitol (210): To a solution of D-arabinose (197 mg, 1.3 mmol) in EtOH (16.8 mL), was added hexadecylamine (576 mg, $2.4 \mathrm{mmol}$ ), $\mathrm{NaCNBH}_{3}(124 \mathrm{mg}, 2.0 \mathrm{mmol})$, and $\mathrm{AcOH}(0.96 \mathrm{~mL})$. The reaction was stirred at $50{ }^{\circ} \mathrm{C}$ for $18 \mathrm{~h}$ then the solvent was removed under reduced pressure. The crude reaction mixture was co-evaporated with $2 \times 25 \mathrm{~mL}$ of $5 \% \mathrm{HCl}$ in distilled methanol (w/v), then purified by gradient flash silica chromatography (DCM/EtOH/MeOH/35\% $\mathrm{NH}_{3 \text { (aq.), }}, 105 / 2 / 2 / 1$ to $15 / 2 / 2 / 1, \mathrm{v} / \mathrm{v} / \mathrm{v} / \mathrm{v}$ ) to give 208 as a white solid (168.6 $\mathrm{mg}, 0.45 \mathrm{mmol}, 34 \%$ ) and 210, also a white solid, as a byproduct (14 mg, $0.03 \mathrm{mmol}$, 4\%). Amine 208 was subsequently acidified and concentrated to give the $\mathrm{HCl}$ salt for characterisation.

5-deoxy-5-hexadecylamino-bis-D-lyxitol $\quad \mathbf{( 2 1 0 ) :} \quad \mathrm{R}_{f}=0.17$ (DCM/EtOH/MeOH/35\% NH $\left.\mathrm{NH}_{3 \text { (aq.) }}, 5 / 2 / 2 / 1, \mathrm{v} / \mathrm{v} / \mathrm{v} / \mathrm{v}\right) ;[\alpha]_{\mathrm{D}}{ }^{26}=+9.0$ (c = 1.0, pyridine); IR (film) 3357, 2954, 2922, 2853, 1466, 1203, 1135, $1080 \mathrm{~cm}^{-1} .{ }^{1} \mathrm{H}$ NMR (500 MHz, Pyridine-d 5 ) $\delta$ 4.98-4.89 (m, 1H, H-4), 4.59-4.54 (m, 1H, H-2), $4.52\left(\mathrm{dd}, J_{1 \mathrm{a}, 2}=3.8, J_{1 \mathrm{a}, 1 \mathrm{~b}}=10.7 \mathrm{~Hz}, 1 \mathrm{H}, \mathrm{H}-1 \mathrm{a}\right), 4.39\left(\mathrm{dd}, J_{1 \mathrm{~b}, 2}=5.6, J_{1 \mathrm{a}, 1 \mathrm{~b}}=10.7\right.$ $\mathrm{Hz}, 1 \mathrm{H}, \mathrm{H}-1 \mathrm{~b}), 4.32$ (d, $\left.J_{2,3}=8.0 \mathrm{~Hz}, 1 \mathrm{H}, \mathrm{H}-3\right), 3.27$ (dd, $J_{4,5 \mathrm{a}}=7.9, J_{5 \mathrm{a}, 5 \mathrm{~b}}=12.9$ $\mathrm{Hz}, 1 \mathrm{H}, \mathrm{H}-5 \mathrm{a}), 3.12\left(\mathrm{dd}, J_{4,5 \mathrm{~b}}=5.4, J_{5 \mathrm{a}, 5 \mathrm{~b}}=12.9 \mathrm{~Hz}, 1 \mathrm{H}, \mathrm{H}-5 \mathrm{~b}\right), 2.78-2.65(\mathrm{~m}, 2 \mathrm{H}$, H-1'), 1.63-1.54 (m, 2H, H-2'), 1.32-1.15 (m, 26H, H-3'-H-15'), 0.88 (t, $J_{15^{\prime}, 16^{\prime}}=$ 
$\left.6.9 \mathrm{~Hz}, 3 \mathrm{H}, \mathrm{H}-16^{\prime}\right) ;{ }^{13} \mathrm{C}$ NMR (125 MHz, Pyridine-d $\left.\mathrm{d}_{5}\right) \delta 73.9$ (C3), 73.5 (C2), 68.2 (C4), 65.5 (C1), 59.4 (C5), 56.5 (C1'), 32.5, 30.4, 30.3, 30.1, 30.0, 27.9, 23.3 (C3' $\left.-\mathrm{C} 15^{\prime}\right), 26.6\left(\mathrm{C}^{\prime}\right), 14.6\left(\mathrm{C} 16^{\prime}\right)$; HRMS(ESI) $m / z$ calcd. for $\left[\mathrm{C}_{26} \mathrm{H}_{55} \mathrm{O}_{8} \mathrm{~N}+\mathrm{H}\right]^{+}$: 510.4000, obsd.: 510.4004 .<smiles>[Y4]C1CCC(Cl)C1NC[C@H](O)[C@@H](O)[C@H](O)CO</smiles>

Optimised synthesis of 5-deoxy-5-hexadecylaminoD-lyxitol hydrochloride (208): To a solution of D-arabinose (100 mg, 0.67 $\mathrm{mmol}$ ) in EtOH (46.6 mL), was added hexadecylamine (1.66 g, $6.9 \mathrm{mmol})$, $\mathrm{NaCNBH}_{3}(62.1 \mathrm{mg}, 1.0 \mathrm{mmol})$, and AcOH $(2.6 \mathrm{~mL})$. The reaction was stirred at $50{ }^{\circ} \mathrm{C}$ for $4 \mathrm{~h}$ then the solvent was removed under reduced pressure. The crude reaction mixture was co-evaporated with $2 \times 25 \mathrm{~mL}$ of $5 \% \mathrm{HCl}$ in distilled methanol (w/v), then purified by gradient flash silica chromatography (DCM/EtOH/MeOH/35\% $\mathrm{NH}_{3 \text { (aq.) }}, 105 / 2 / 2 / 1$ to $15 / 2 / 2 / 1, \mathrm{v} / \mathrm{v} / \mathrm{v} / \mathrm{v}$ ) to give 208 as a white solid (195 mg, $0.52 \mathrm{mmol}, 78 \%$ ).<smiles>[Y4]C1CC1C(Cl)N(C)C[C@H](O)[C@@H](O)[C@H](O)CO</smiles>

\section{Optimised synthesis of 5-deoxy-5-} hexadecylmethylamino-D-lyxitol hydrochloride (209): To a solution of Darabinose (101.5 mg, $0.67 \mathrm{mmol})$ in $\mathrm{MeOH}(46.6 \mathrm{~mL})$, was added hexadecylamine (1.65 g, $6.8 \mathrm{mmol}), \mathrm{NaCNBH}_{3}(64.8 \mathrm{mg}, 1 \mathrm{mmol})$, and $\mathrm{AcOH}$ $(2.6 \mathrm{~mL})$. The reaction was stirred at $45^{\circ} \mathrm{C}$ for $4 \mathrm{~h}$ before $1 \mathrm{~mL}$ of $37 \%$ aqueous formaldehyde $(13.3 \mathrm{mmol})$ was added. After a further $3 \mathrm{~h}$, additional $\mathrm{NaCNBH}_{3}$ (840 mg, $13.3 \mathrm{mmol}$ ) was added and the reaction was left to stir overnight (16 h), then the solvent was removed under reduced pressure. The crude reaction mixture was co-evaporated with $2 \times 25 \mathrm{~mL}$ of $5 \% \mathrm{HCl}$ in distilled methanol (w/v), then the residue was purified by gradient flash silica chromatography

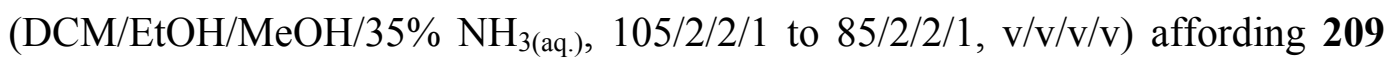
as a white solid that was converted into the $\mathrm{HCl}$ salt by addition of $\mathrm{HCl}(1.2 \mathrm{M}$, aq.) and concentration (236 mg, $0.61 \mathrm{mmol}, 90 \%)$. 


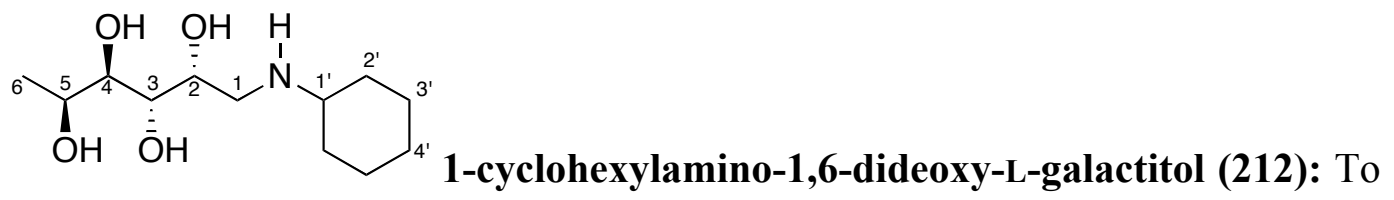
a solution of L-fucose $(100 \mathrm{mg}, 0.63 \mathrm{mmol})$ in EtOH $(3 \mathrm{~mL})$, was added cyclohexylamine (54 mg, $0.55 \mathrm{mmol}), \mathrm{NaCNBH}_{3}(113 \mathrm{mg}, 1.8 \mathrm{mmol})$, water $(0.3$ $\mathrm{mL})$, and $\mathrm{AcOH}(0.04 \mathrm{~mL})$. The reaction was stirred at room temperature for $3 \mathrm{~d}$. The solvent was then removed under reduced pressure, and the residue loaded onto Dowex- $\mathrm{H}^{+}$cation exchange resin and eluted with $5-35 \% \mathrm{NH}_{3}$ in $\mathrm{H}_{2} \mathrm{O}$.

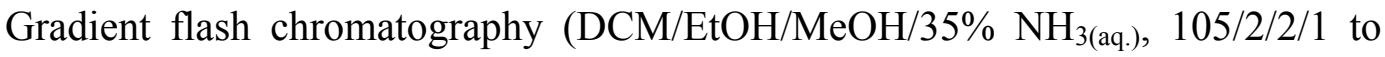
15/2/2/1, v/v/v/v) afforded 1-cyclohexylamino-1,6-dideoxy-L-galactitol (212) (41 $\mathrm{mg}, 0.17 \mathrm{mmol}, 30 \%) . \mathrm{R}_{f}=0.40$ (DCM/EtOH/MeOH/30\% $\mathrm{NH}_{3 \text { (aq.) }}, 15 / 2 / 2 / 1$, $\mathrm{v} / \mathrm{v} / \mathrm{v} / \mathrm{v}) ;[\alpha]_{\mathrm{D}}^{25}=+10.6(\mathrm{c}=0.86, \mathrm{EtOH}) ; \mathrm{IR}($ film) 3351, 2948, 2836, 1651, 1450, 1410, 1114, $1017 \mathrm{~cm}^{-1}$. ${ }^{1} \mathrm{H}$ NMR (500 MHz, $\left.\mathrm{D}_{2} \mathrm{O}\right) \delta 4.14$ (ddd, $J_{2,3}=1.6$, $\left.J_{1 \mathrm{~b}, 2}=4.5, J_{1 \mathrm{a}, 2}=8.5 \mathrm{~Hz}, 1 \mathrm{H}, \mathrm{H}-2\right), 4.10\left(\mathrm{qd}, J_{4,5}=1.7, J_{5,6}=6.7 \mathrm{~Hz}, 1 \mathrm{H}, \mathrm{H}-5\right)$, $3.58\left(\mathrm{dd}, J_{2,3}=1.6, J_{3,4}=9.3 \mathrm{~Hz}, 1 \mathrm{H}, \mathrm{H}-3\right), 3.47\left(\mathrm{dd}, J_{4,5}=1.7, J_{3,4}=9.3 \mathrm{~Hz}, 1 \mathrm{H}\right.$, $\mathrm{H}-4), 3.11\left(\mathrm{dd}, J_{1 \mathrm{a}, 2}=8.5, J_{1 \mathrm{a}, 1 \mathrm{~b}}=13.0 \mathrm{~Hz}, 1 \mathrm{H}, \mathrm{H}-1 \mathrm{a}\right), 3.09\left(\mathrm{dd}, J_{1 \mathrm{~b}, 2}=4.5, J_{1 \mathrm{a}, 1 \mathrm{~b}}=\right.$ 13.0 Hz, 1H, H-1b), 3.00-2.94 (m, 1H, H-1' '), 2.07-2.01 (m, 2H, H-2'a), 1.84-1.77 (m, 2H, H-3'a), 1.69-1.64 (m, 1H, H-4'a), 1.34-1.28 (m, 4H, H-2'b, H-3'b), 1.25 $\left(\mathrm{d}, J_{5,6}=6.7 \mathrm{~Hz}, 3 \mathrm{H}, \mathrm{H}-6\right), 1.23-1.12\left(\mathrm{~m}, 1 \mathrm{H}, \mathrm{H}-4{ }^{\prime} \mathrm{b}\right) ;{ }^{13} \mathrm{C} \mathrm{NMR}\left(125 \mathrm{MHz}, \mathrm{D}_{2} \mathrm{O}\right)$ ठ 72.7 (C4), 70.9 (C3), 67.1 (C2), 65.8 (C5), 57.0 (C1'), 47.7 (C1), 29.9, 29.6 (C2'), 24.8 (C4'), 24.1, 24.1 (C3'), 18.6 (C6); HRMS(ESI) $m / z$ calcd. for $\left[\mathrm{C}_{12} \mathrm{H}_{25} \mathrm{O}_{4} \mathrm{~N}+\mathrm{H}\right]^{+}:$248.1856, obsd.: 248.1866.

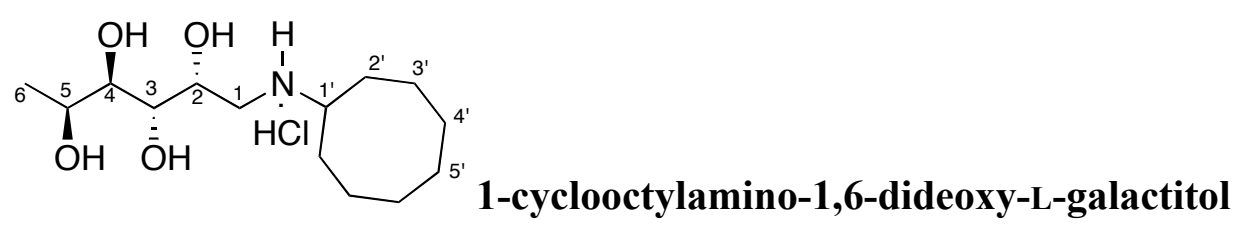

hydrochloride (213): To a solution of L-fucose (100 mg, $0.63 \mathrm{mmol})$ in EtOH (3 $\mathrm{mL}$ ), was added cyclooctylamine (84 mg, $0.66 \mathrm{mmol}), \mathrm{NaCNBH}_{3}(113 \mathrm{mg}, 1.8$ mmol), water $(0.3 \mathrm{~mL})$, and $\mathrm{AcOH}(0.04 \mathrm{~mL})$. The reaction was stirred at room temperature for $22 \mathrm{~h}$. The solvent was then removed under reduced pressure, and the residue loaded onto Dowex- $\mathrm{H}^{+}$cation exchange resin and eluted with 5-35\% $\mathrm{NH}_{3}$ in $\mathrm{H}_{2} \mathrm{O}$. Gradient flash chromatography (DCM/EtOH/MeOH/35\% $\mathrm{NH}_{3 \text { (aq.), }}$, 
$105 / 2 / 2 / 1$ to $55 / 2 / 2 / 1, \mathrm{v} / \mathrm{v} / \mathrm{v} / \mathrm{v}$ ), followed by acidification with $1 \mathrm{M} \mathrm{HCl}$ and concentration afforded 1-cyclooctylamino-1,6-dideoxy-L-galactitol hydrochloride (213) as a white solid (19 $\mathrm{mg}, 0.07$ mmol, $12 \%) . \quad \mathrm{R}_{f}=0.16$ (DCM/EtOH/MeOH/30\% $\left.\mathrm{NH}_{3 \text { (aq.) }}, 15 / 2 / 2 / 1, \mathrm{v} / \mathrm{v} / \mathrm{v} / \mathrm{v}\right) ;[\alpha]_{\mathrm{D}}{ }^{25}=+10.5$ (c = 1.0, EtOH); IR (film) 3355, 2928, 2858, 1642, 1450, 1285, 1052, $1023 \mathrm{~cm}^{-1}$. ${ }^{1} \mathrm{H}$ NMR $\left(500 \mathrm{MHz}, \mathrm{D}_{2} \mathrm{O}\right) \delta 4.13\left(\mathrm{ddd}, J_{2,3}=1.6, J_{1 \mathrm{~b}, 2}=4.4, J_{1 \mathrm{a}, 2}=9.1 \mathrm{~Hz}, 1 \mathrm{H}, \mathrm{H}-2\right), 4.01$ $\left(\mathrm{qd}, J_{4,5}=1.7, J_{5,6}=6.6 \mathrm{~Hz}, 1 \mathrm{H}, \mathrm{H}-5\right), 3.51\left(\mathrm{dd}, J_{2,3}=1.6, J_{3,4}=9.4 \mathrm{~Hz}, 1 \mathrm{H}, \mathrm{H}-3\right)$, $3.39\left(\mathrm{dd}, J_{4,5}=1.7, J_{3,4}=9.4 \mathrm{~Hz}, 1 \mathrm{H}, \mathrm{H}-4\right), 3.35\left(\mathrm{tt}, J_{1^{\prime}, 2^{\prime} \mathrm{a}}=3.5, J_{1^{\prime}, 2^{\prime} \mathrm{b}}=9.3 \mathrm{~Hz}\right.$, $\left.1 \mathrm{H}, \mathrm{H}-1^{\prime}\right), 3.18\left(\mathrm{dd}, J_{1 \mathrm{a}, 2}=9.1, J_{1 \mathrm{a}, 1 \mathrm{~b}}=13.2 \mathrm{~Hz}, 1 \mathrm{H}, \mathrm{H}-1 \mathrm{a}\right), 3.14\left(\mathrm{dd}, J_{1 \mathrm{~b}, 2}=4.4\right.$, $\left.J_{1 \mathrm{a}, 1 \mathrm{~b}}=13.2 \mathrm{~Hz}, 1 \mathrm{H}, \mathrm{H}-1 \mathrm{~b}\right), 1.92-1.85$ (m, 2H, H-2'a), 1.73-1.65 (m, 4H, H-2’b, H-3'a), 1.60-1.40 (m, 7H, H-3'b-5'a), 1.37-1.30 (m, 1H, H-5'b), 1.17 (d, J5,6 $=6.6$ $\mathrm{Hz}, 3 \mathrm{H}, \mathrm{H}-6) ;{ }^{13} \mathrm{C}$ NMR (125 MHz, D $\left.2 \mathrm{O}\right) \delta 72.6$ (C4), 70.7 (C3), 66.2 (C2), 65.6 (C5), 59.0 (C1'), 47.8 (C1), 29.2, 28.7 (C2'), 25.6, 25.6 (C4'), 25.2 (C5'), 23.3 (C3'), 18.6 (C6); HRMS(ESI) $m / z$ calcd. for $\left[\mathrm{C}_{14} \mathrm{H}_{29} \mathrm{O}_{4} \mathrm{~N}+\mathrm{H}\right]^{+}: 276.2169$, obsd.: 276.2170 .

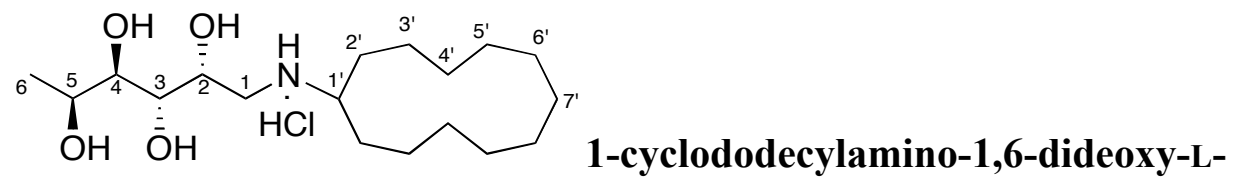

galactitol hydrochloride (214): To a solution of L-fucose (165 mg, $1.0 \mathrm{mmol})$ in EtOH (20 mL), was added cyclododecylamine (294 mg, $1.5 \mathrm{mmol}), \mathrm{NaCNBH}_{3}$ (189 $\mathrm{mg}, 3.0 \mathrm{mmol})$, water $(0.5 \mathrm{~mL})$, and $\mathrm{AcOH}(0.07 \mathrm{~mL})$. The reaction was stirred at room temperature for $7 \mathrm{~d}$. The solvent was then removed under reduced pressure, and the residue loaded onto Dowex $-\mathrm{H}^{+}$cation exchange resin and eluted with $5-35 \% \mathrm{NH}_{3}$ in EtOH/ $\mathrm{H}_{2} \mathrm{O}$. Reverse phase chromatography with HP20 beads (eluting in $10 \%$ to $100 \% \mathrm{MeOH}$ ), afforded a white solid $(59.8 \mathrm{mg}, 0.18 \mathrm{mmol}$, $18 \%$ ) that was subsequently acidified with $1 \mathrm{M} \mathrm{HCl}$ and concentrated to provide 1-cyclododecylamino-1,6-dideoxy-L-galactitol hydrochloride (214) for characterisation. $\mathrm{R}_{f}=0.29\left(\mathrm{DCM} / \mathrm{EtOH} / \mathrm{MeOH} / 30 \% \mathrm{NH}_{3(\text { aq. })}, 5 / 2 / 2 / 1, \mathrm{v} / \mathrm{v} / \mathrm{v} / \mathrm{v}\right)$; $[\alpha]_{\mathrm{D}}^{25}=+6.0(\mathrm{c}=0.29, \mathrm{EtOH})$; IR (film) 3366, 2928, 2859, 1637, 1471, 1448, 1414, 1052, $996 \mathrm{~cm}^{-1} .{ }^{1} \mathrm{H}$ NMR $\left(500 \mathrm{MHz}, \mathrm{D}_{2} \mathrm{O}\right) \delta 4.21\left(\mathrm{t}, J_{1,2}=6.3 \mathrm{~Hz}, 1 \mathrm{H}, \mathrm{H}-\right.$ 2), 4.07 (q, $\left.J_{5,6}=6.6 \mathrm{~Hz}, 1 \mathrm{H}, \mathrm{H}-5\right), 3.56\left(\mathrm{~d}, J_{3,4}=9.5 \mathrm{~Hz}, 1 \mathrm{H}, \mathrm{H}-3\right), 3.44\left(\mathrm{~d}, J_{3,4}=\right.$ 
$9.5 \mathrm{~Hz}, 1 \mathrm{H}, \mathrm{H}-4), 3.32-3.38$ (m, 1H, H-1'), 3.24 (d, $\left.J_{1,2}=6.3 \mathrm{~Hz}, 2 \mathrm{H}, \mathrm{H}-1\right), 1.74-$ 1.84 (m, 2H, H-2'a), 1.63-1.73 (m, 2H, H-2’b), 1.32-1.51 (m, 18H, H-3' - H-7'), $1.22\left(\mathrm{~d}, J_{5,6}=6.6 \mathrm{~Hz}, 3 \mathrm{H}, \mathrm{H}-6\right) ;{ }^{13} \mathrm{C}$ NMR $\left(125 \mathrm{MHz}, \mathrm{D}_{2} \mathrm{O}\right) \delta 72.5$ (C4), 70.7 (C3), 66.0 (C2), 65.6 (C5), 56.9 (C1'), 48.0 (C1), 25.7, 25.3, 24.0, 24.0, 23.9, 22.5, 22.3, 22.3, 22.2, 19.9, 19.7 (C2'-C7'), 18.5 (C6); HRMS(ESI) $m / z$ calcd. for $\left[\mathrm{C}_{18} \mathrm{H}_{37} \mathrm{O}_{4} \mathrm{~N}+\mathrm{H}\right]^{+}: 332.2795$, obsd.: 332.2802 .

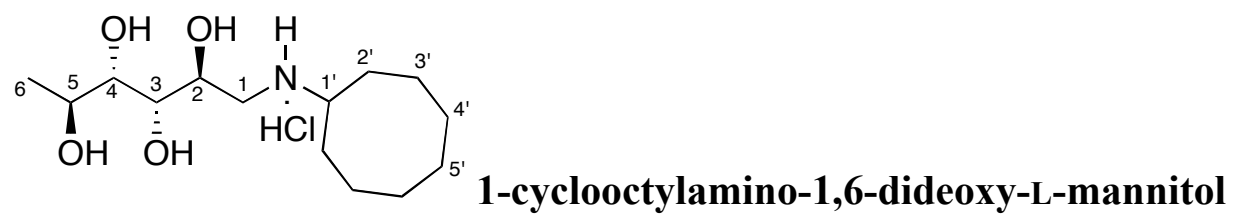

hydrochloride (216): To a solution of L-rhamnose (100 $\mathrm{mg}, 0.63 \mathrm{mmol})$ in $\mathrm{EtOH}$ $(5.5 \mathrm{~mL})$, was added cyclooctylamine (62 mg, $0.49 \mathrm{mmol}), \mathrm{NaCNBH}_{3}(104 \mathrm{mg}$, $1.7 \mathrm{mmol})$, water $(0.3 \mathrm{~mL})$, and $\mathrm{AcOH}(0.15 \mathrm{~mL})$. The reaction was stirred at room temperature for $19 \mathrm{~h}$. The solvent was then removed under reduced pressure, and the residue loaded onto Dowex $-\mathrm{H}^{+}$cation exchange resin and eluted with $5-35 \% \quad \mathrm{NH}_{3}$ in $\mathrm{EtOH} / \mathrm{H}_{2} \mathrm{O}$. Gradient flash chromatography

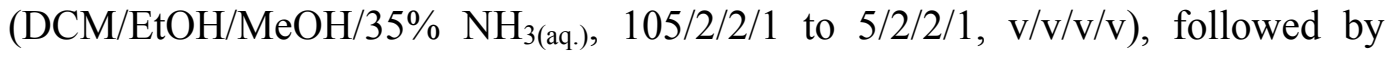
acidification with $1 \mathrm{M} \mathrm{HCl}$ and concentration afforded 1-cyclooctylamino-1,6dideoxy-L-mannitol hydrochloride (216) as a white solid (16 $\mathrm{mg}, 0.05 \mathrm{mmol}$, $10 \%) . \mathrm{R}_{f}=0.36\left(\mathrm{DCM} / \mathrm{EtOH} / \mathrm{MeOH} / 30 \% \mathrm{NH}_{3(\text { aq. })}, 5 / 2 / 2 / 1, \mathrm{v} / \mathrm{v} / \mathrm{v} / \mathrm{v}\right) ;[\alpha]_{\mathrm{D}}{ }^{25}=$ +1.3 (c = 0.38, EtOH); IR (film) 2930, 2851, 1641, 1450, 1306, 1071, $1019 \mathrm{~cm}^{-1}$. ${ }^{1} \mathrm{H}$ NMR $\left(500 \mathrm{MHz}, \mathrm{D}_{2} \mathrm{O}\right) \delta 3.94\left(\mathrm{ddd}, J_{1 \mathrm{a}, 2}=3.0, J_{2,3}=8.2, J_{1 \mathrm{~b}, 2}=9.5 \mathrm{~Hz}, 1 \mathrm{H}, \mathrm{H}-\right.$ 2), $3.82\left(\mathrm{dq}, J_{5,6}=6.3, J_{4,5}=8.1 \mathrm{~Hz}, 1 \mathrm{H}, \mathrm{H}-5\right), 3.78\left(\mathrm{dd}, J_{3,4}=1.5, J_{2,3}=8.2 \mathrm{~Hz}\right.$, $1 \mathrm{H}, \mathrm{H}-3), 3.51\left(\mathrm{dd}, J_{3,4}=1.5, J_{4,5}=8.1 \mathrm{~Hz}, 1 \mathrm{H}, \mathrm{H}-4\right), 3.46-3.40\left(\mathrm{~m}, 1 \mathrm{H}, \mathrm{H}-1^{\prime}\right)$, $3.41\left(\mathrm{dd}, J_{1 \mathrm{a}, 2}=3.0, J_{1 \mathrm{a}, 1 \mathrm{~b}}=13.0 \mathrm{~Hz}, 1 \mathrm{H}, \mathrm{H}-1 \mathrm{a}\right), 3.11\left(\mathrm{dd}, J_{1 \mathrm{~b}, 2}=9.5, J_{1 \mathrm{a}, 1 \mathrm{~b}}=13.0\right.$ Hz, 1H, H-1b), 1.98-1.90 (m, 2H, H-2'a), 1.81-1.70 (m, 4H, H-2'b, H-3'a), 1.671.45 (m, 7H, H-3'b-5'a), 1.42-1.35 (m, 1H, H-5'b), 1.25 (d, J5,6 $=6.3 \mathrm{~Hz}, 3 \mathrm{H}, \mathrm{H}-$ 6); ${ }^{13} \mathrm{C}$ NMR (125 MHz, $\left.\mathrm{D}_{2} \mathrm{O}\right) \delta 72.9$ (C4), 70.9 (C3), 66.9 (C2), 66.8 (C5), 59.0 (C1'), 47.5 (C1), 29.3, 28.6 (C2'), 25.6, 25.6 (C4'), 25.1 (C5'), 23.3, 23.3 (C3'), 18.9 (C6); HRMS(ESI) $\mathrm{m} / z$ calcd. for $\left[\mathrm{C}_{14} \mathrm{H}_{29} \mathrm{O}_{4} \mathrm{~N}+\mathrm{H}\right]^{+}: 276.2169$, obsd.: 276.2175 . 


\section{General Procedure for the synthesis of alkenylamines}

To a solution of methyl 5-deoxy-5-iodo- $\alpha / \beta$-D-arabinoside $(1 \mathrm{mmol})$ in EtOH (20 $\mathrm{mL})$, was added amine $(1.1-1.2 \mathrm{mmol})$, activated $\mathrm{Zn}(5 \mathrm{mmol}), \mathrm{NaCNBH}_{3}(3$ $\mathrm{mmol})$, water $(0.6 \mathrm{~mL})$, and $\mathrm{AcOH}(0.3 \mathrm{~mL})$. The reaction was stirred under reflux overnight $(18 \mathrm{~h})$, then cooled, filtered and the solvent removed under reduced pressure. The product was dry loaded on silica and purified by repeated gradient flash chromatography (DCM/EtOH/MeOH/35\% $\mathrm{NH}_{3 \text { (aq.) }}$, 305/2/2/1 to $5 / 2 / 2 / 1, \mathrm{v} / \mathrm{v} / \mathrm{v} / \mathrm{v})$.

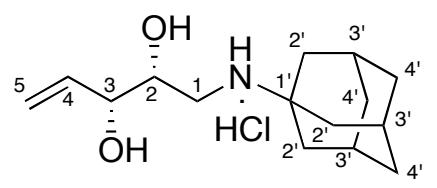

(2R, 3R)-1-adamantylamino-pent-4-ene-2,3-diol

hydrochloride (218): Methyl 5-deoxy-5-iodo- $\alpha / \beta$-D-arabinoside (134 mg, 0.49 $\mathrm{mmol}$ ) and 1-adamantanamine (96 $\mathrm{mg}, 0.64 \mathrm{mmol}$ ) was subjected to the general procedure for the synthesis of alkenylamines. Further purification by $\mathrm{C}_{8}$ reverse phase chromatography $\left(\mathrm{H}_{2} \mathrm{O}\right.$ to $\left.\mathrm{H}_{2} \mathrm{O} / \mathrm{MeOH}, 1 / 4, \mathrm{v} / \mathrm{v}\right)$ followed by acidification with $1 \mathrm{M} \mathrm{HCl}$ and concentration gave $(2 R, 3 R)$-1-adamantylamino-pent-4-ene-2,3diol hydrochloride (218) as a white solid (70 mg, $0.24 \mathrm{mmol}, 49 \%$ ). $\mathrm{R}_{f}=0.42$ (DCM/EtOH/MeOH/30\% NH 3 (aq.), 15/2/2/1, v/v/v/v); $[\alpha]_{\mathrm{D}}{ }^{25}=+24.9$ (c = 1.0, EtOH); IR (film) 3364, 2915, 2855, 1644, 1454, 1365, 1310, 1071, 1022, $938 \mathrm{~cm}^{-}$ 1. ${ }^{1} \mathrm{H}$ NMR $\left(500 \mathrm{MHz}, \mathrm{D}_{2} \mathrm{O}\right) \delta 5.90\left(\mathrm{ddd}, J_{3,4}=5.9, J_{4,5 \text {-cis }}=10.6, J_{4,5 \text {-trans }}=17.2\right.$ $\mathrm{Hz}, 1 \mathrm{H}, \mathrm{H}-4), 5.39$ (d, $J_{4,5-\text { trans }}=17.2 \mathrm{~Hz}, 1 \mathrm{H}, \mathrm{H}-5$-trans), 5.33 (d, $J_{4,5 \text {-cis }}=10.6$ $\mathrm{Hz}, 1 \mathrm{H}, \mathrm{H}-5-c i s), 4.14\left(\mathrm{dd}, J_{2,3}=5.1, J_{3,4}=5.9 \mathrm{~Hz}, 1 \mathrm{H}, \mathrm{H}-3\right), 3.84\left(\mathrm{ddd}, J_{1 \mathrm{a}, 2}=\right.$ $\left.2.6, J_{2,3}=5.1, J_{1 \mathrm{~b}, 2}=10.2 \mathrm{~Hz}, 1 \mathrm{H}, \mathrm{H}-2\right), 3.18\left(\mathrm{dd}, J_{1 \mathrm{a}, 2}=2.6, J_{1 \mathrm{a}, 1 \mathrm{~b}}=12.7 \mathrm{~Hz}, 1 \mathrm{H}\right.$, $\mathrm{H}-1 \mathrm{a}), 3.04\left(\mathrm{dd}, J_{1 \mathrm{~b} .2}=10.2, J_{1 \mathrm{a}, 1 \mathrm{~b}}=12.7 \mathrm{~Hz}, 1 \mathrm{H}, \mathrm{H}-1 \mathrm{~b}\right), 2.22-2.17$ (m, 3H, H-3'), 1.95-1.85 (m, 6H, H-2'), $1.75\left(\mathrm{~d}, J_{4^{\prime} \mathrm{a}, 4^{\prime} \mathrm{b}}=12.5 \mathrm{~Hz}, 3 \mathrm{H}, \mathrm{H}-4^{\prime} \mathrm{a}\right), 1.66\left(\mathrm{~d}, J_{4^{\prime} \mathrm{a}, 4^{\prime} \mathrm{b}}=\right.$ $\left.12.5 \mathrm{~Hz}, 3 \mathrm{H}, \mathrm{H}-4{ }^{\prime} \mathrm{b}\right) ;{ }^{13} \mathrm{C} \mathrm{NMR}\left(125 \mathrm{MHz}, \mathrm{D}_{2} \mathrm{O}\right) \delta 135.4$ (C4), 118.4 (C5), 73.9 (C3), 69.6 (C2), 57.9 (C1'), 41.7 (C1), 37.8 (C2'), 34.8 (C4'), 28.8 (C3'); HRMS(ESI) $m / z$ calcd. for $\left[\mathrm{C}_{15} \mathrm{H}_{25} \mathrm{O}_{2} \mathrm{~N}+\mathrm{H}\right]^{+}: 252.1958$, obsd.: 252.1961 . 


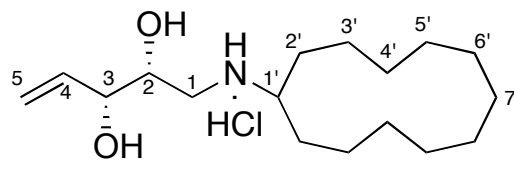

$(2 R, 3 R)$-1-cyclododecylamino-pent-4-ene-2,3-

diol hydrochloride (219): By subjecting methyl 5-deoxy-5-iodo- $\alpha / \beta$-Darabinoside ( $89.1 \mathrm{mg}, 0.33 \mathrm{mmol})$ and cyclododecylamine $(65.5 \mathrm{mg}, 0.36 \mathrm{mmol})$ to the general procedure for the synthesis of alkenylamines, the $(2 R, 3 R)-1$ cyclododecylamino-pent-4-ene-2,3-diol (219) was obtained as the $\mathrm{HCl}$ salt, a white solid (38 mg, $0.12 \mathrm{mmol}, 37 \%) . \mathrm{R}_{f}=0.69(\mathrm{DCM} / \mathrm{EtOH} / \mathrm{MeOH} / 30 \%$ $\left.\mathrm{NH}_{3 \text { (aq.) }}, 35 / 2 / 2 / 1, \mathrm{v} / \mathrm{v} / \mathrm{v} / \mathrm{v}\right) ;[\alpha]_{\mathrm{D}}{ }^{21}=-0.7$ (c =1.0, EtOH); IR (film) 3335, 2932, 2863, 1642, 1471, 1446, 1096, 1025, 926, $719 \mathrm{~cm}^{-1} .{ }^{1} \mathrm{H}$ NMR (500 MHz, $\left.\mathrm{CD}_{3} \mathrm{OD}\right)$ $\delta 5.98$ (ddd, $\left.J_{3,4}=5.6, J_{4,5-c i s}=10.7, J_{4,5-\text { trans }}=17.1 \mathrm{~Hz}, 1 \mathrm{H}, \mathrm{H}-4\right), 5.40\left(\mathrm{~d}, J_{4,5-\text { trans }}\right.$ $=17.1 \mathrm{~Hz}, 1 \mathrm{H}, \mathrm{H}-5$-trans $), 5.26\left(\mathrm{~d}, J_{4,5-c i s}=10.5 \mathrm{~Hz}, 1 \mathrm{H}, \mathrm{H}-5\right.$-cis $), 4.16-4.11(\mathrm{~m}$, 1H, H-3), 3.93-3.86 (m, 1H, H-2), 3.34-3.28 (m, 1H, H-1'), 3.18 (d, $J_{1 \mathrm{a}, 1 \mathrm{~b}}=12.7$ $\mathrm{Hz}, 1 \mathrm{H}, \mathrm{H}-1 \mathrm{a}), 3.05$ (dd, $\left.J_{1 \mathrm{a}, 2}=9.7, J_{1 \mathrm{a}, 1 \mathrm{~b}}=12.7 \mathrm{~Hz}, 1 \mathrm{H}, \mathrm{H}-1 \mathrm{~b}\right), 1.80$ (ddd, $J=7.3$ $\left.\mathrm{Hz}, J=14.3 \mathrm{~Hz}, J=22.0 \mathrm{~Hz}, 2 \mathrm{H}, \mathrm{H}-2^{\prime} \mathrm{a}\right), 1.75-1.64$ (m, 2H, H-2'b), 1.58-1.34 (m, 18H, H-3' - H-7'); ${ }^{13} \mathrm{C}$ NMR (125 MHz, CD 3 OD) $\delta 138.1$ (C4), 117.3 (C5), 75.1 (C3), 70.5 (C2), 57.9 (C1'), 49.3 (C1), 27.3, 26.7, 25.7, 25.6, 25.4, 24.0, 24.0, 23.9, 23.9, 21.6, $21.3\left(\mathrm{C}^{\prime}{ }^{\prime}-\mathrm{C}^{\prime}\right)$ HRMS(ESI) $\mathrm{m} / \mathrm{z}$ calcd. for $\left[\mathrm{C}_{17} \mathrm{H}_{33} \mathrm{O}_{2} \mathrm{~N}+\mathrm{H}\right]^{+}$: 284.2584, obsd.: 284.2584 .

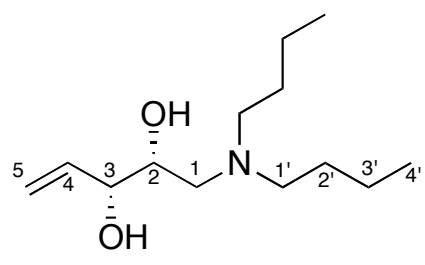

(2R, 3R)-1-di-n-butylamino-pent-4-ene-2,3-diol (221): By subjecting methyl 5-deoxy-5-iodo- $\alpha / \beta$-D-arabinoside $(100.2 \mathrm{mg}, 0.37 \mathrm{mmol})$ and di- $n$-butylamine $(74 \mu \mathrm{L}, 0.44 \mathrm{mmol})$ to the general procedure for the synthesis of alkenylamines, the $(2 R, 3 R)$-1-di- $n$-butylamino-pent-4-ene-2,3-diol (221) was obtained as a white solid (19 mg, $0.08 \mathrm{mmol}, 22 \%) . \mathrm{R}_{f}=0.90$ (DCM/EtOH/MeOH/30\% NH 3 (aq.), $35 / 2 / 2 / 1, \mathrm{v} / \mathrm{v} / \mathrm{v} / \mathrm{v}) ;[\alpha]_{\mathrm{D}}{ }^{20}=+48.3(\mathrm{c}=0.82$, $\mathrm{CHCl}_{3}$ ); IR (film) 3370, 3086, 2957, 2931, 2872, 2863, 2821, 1644, 1467, 1378, 1305, 1267, 1163, 1069, 994, 921, $735 \mathrm{~cm}^{-1} .{ }^{1} \mathrm{H}$ NMR (500 MHz, $\left.\mathrm{CDCl}_{3}\right) \delta 5.92$ $\left(\mathrm{ddd}, J_{3,4}=5.8, J_{4,5-\text {-cis }}=10.5, J_{4,5 \text {-trans }}=17.3 \mathrm{~Hz}, 1 \mathrm{H}, \mathrm{H}-4\right), 5.38\left(\mathrm{ddd}, J_{3.5-\text { trans }}=\right.$ 
$1.5, J_{5-\text { cis }, 5 \text {-trans }}=1.5, J_{4.5 \text {-trans }}=17.3 \mathrm{~Hz}, 1 \mathrm{H}, \mathrm{H}-5$-trans $), 5.24\left(\mathrm{ddd}, J_{3.5 \text {-cis }}=1.4\right.$, $J_{5 \text {-cis,5-trans }}=1.5, J_{4,5-c i s}=10.5 \mathrm{~Hz}, 1 \mathrm{H}, \mathrm{H}-5$-cis $), 3.99\left(\mathrm{ddd}, J_{3,5}=1.4, J_{2,3}=4.2\right.$, $\left.J_{3,4}=5.8 \mathrm{~Hz}, 1 \mathrm{H}, \mathrm{H}-3\right), 3.65\left(\mathrm{ddd}, J_{2,3}=4.2, J_{1 \mathrm{~b}, 2}=4.3, J_{1 \mathrm{a}, 2}=8.6 \mathrm{~Hz}, 1 \mathrm{H}, \mathrm{H}-2\right)$, $2.62\left(\mathrm{ddd}, J=8.7, J=11.7, J_{1^{\prime} \mathrm{a}, 1^{\prime} \mathrm{b}}=15.9 \mathrm{~Hz}, 2 \mathrm{H}, \mathrm{H}-1^{\prime} \mathrm{a}\right), 2.59\left(\mathrm{dd}, J_{1 \mathrm{a}, 2}=8.6\right.$, $\left.J_{1 \mathrm{a}, 1 \mathrm{~b}}=12.9 \mathrm{~Hz}, 1 \mathrm{H}, \mathrm{H}-1 \mathrm{a}\right), 2.54\left(\mathrm{dd}, J_{1 \mathrm{~b}, 2}=4.3, J_{1 \mathrm{a}, 1 \mathrm{~b}}=12.9 \mathrm{~Hz}, 1 \mathrm{H}, \mathrm{H}-1 \mathrm{~b}\right), 2.47$ (ddd, $\left.J=5.2, J=8.6, J_{1^{\prime} \mathrm{a}, 1^{\prime} \mathrm{b}}=15.9 \mathrm{~Hz}, 2 \mathrm{H}, \mathrm{H}-1^{\prime} \mathrm{b}\right), 1.53-1.40$ (m, 4H, H-2'), 1.38-1.25 (m, 4H, H-3'), 0.92 (t, $\left.J_{3^{\prime}, 4^{\prime}}=7.3 \mathrm{~Hz}, 6 \mathrm{H}, \mathrm{H}-4^{\prime}\right) ;{ }^{13} \mathrm{C}$ NMR $(125 \mathrm{MHz}$, $\left.\mathrm{CDCl}_{3}\right) \delta 137.5(\mathrm{C} 4), 116.5(\mathrm{C} 5), 74.4(\mathrm{C} 3), 69.2$ (C2), 57.0 (C1), 54.2 (C1'), $28.8\left(\mathrm{C}^{\prime}\right), 20.5\left(\mathrm{C}^{\prime}\right), 14.0\left(\mathrm{C}^{\prime}\right)$; HRMS(ESI) $m / z$ calcd. for $\left[\mathrm{C}_{13} \mathrm{H}_{27} \mathrm{O}_{2} \mathrm{~N}+\mathrm{H}\right]^{+}$: 230.2115, obsd.: 230.2122 .

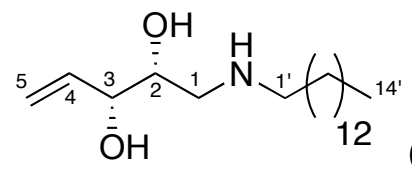

(2R, 3R)-1-tetradecylamino-pent-4-ene-2,3-diol (223): By subjecting methyl 5-deoxy-5-iodo- $\alpha / \beta$-D-arabinoside (146 mg, $0.53 \mathrm{mmol}$ ) and tetradecylamine $(136 \mathrm{mg}, 0.64 \mathrm{mmol})$ to the general procedure for the synthesis of alkenylamines, the white solid $(2 R, 3 R)$-1-tetradecylamino-pent-4ene-2,3-diol (223) was obtained (74 mg, 0.24mmol, 44\%). $\mathrm{R}_{f}=0.65$ (DCM/EtOH/MeOH/30\% $\left.\mathrm{NH}_{3(\text { aq. })}, 35 / 2 / 2 / 1, \mathrm{v} / \mathrm{v} / \mathrm{v} / \mathrm{v}\right) ;[\alpha]_{\mathrm{D}}{ }^{21}=+0.3$ (c=0.66, EtOH); IR (film) 3380, 3275, 2954, 2916, 2847, 1646, 1468, 1420, 1326, 1252 , $1162,1119,1095,1053,1030,987,926,859 \mathrm{~cm}^{-1} .{ }^{1} \mathrm{H}$ NMR (500 MHz, CD 3 OD) $\delta 5.93\left(\mathrm{ddd}, J_{3,4}=6.3, J_{4,5-\text { cis }}=10.6, J_{4,5 \text {-trans }}=17.2 \mathrm{~Hz}, 1 \mathrm{H}, \mathrm{H}-4\right), 5.32$ (ddd, $J_{3,5-}$ ${ }_{\text {trans }}=1.5, J_{5 \text {-cis,5-trans }}=1.6, J_{4,5-\text { trans }}=17.2 \mathrm{~Hz}, 1 \mathrm{H}, \mathrm{H}-5$-trans $), 5.19\left(\mathrm{ddd}, J_{3,5-\text {-is }}=\right.$ $1.5, J_{5-c i s, 5-\text { trans }}=1.6, J_{4,5-c i s}=10.6 \mathrm{~Hz}, 1 \mathrm{H}, \mathrm{H}-5$-cis $), 3.99\left(\mathrm{ddd}, J_{3,5}=1.5, J_{2,3}=\right.$ $\left.5.2, J_{3,4}=6.3 \mathrm{~Hz}, 1 \mathrm{H}, \mathrm{H}-3\right), 3.65\left(\mathrm{ddd}, J_{1 \mathrm{a}, 2}=3.7 \mathrm{~Hz}, J_{2,3}=5.2, J_{1 \mathrm{~b}, 2}=8.8 \mathrm{~Hz}, 1 \mathrm{H}\right.$, $\mathrm{H}-2), 2.72\left(\mathrm{dd}, J_{1 \mathrm{a}, 2}=3.7, J_{1 \mathrm{a}, 1 \mathrm{~b}}=12.2 \mathrm{~Hz}, 1 \mathrm{H}, \mathrm{H}-1 \mathrm{a}\right), 2.63\left(\mathrm{dt}, J_{1^{\prime} \mathrm{a}, 2^{\prime}}=7.6, J_{1^{\prime} \mathrm{a}, 1^{\prime} \mathrm{b}}\right.$ $\left.=11.7 \mathrm{~Hz}, 1 \mathrm{H}, \mathrm{H}-1^{\prime} \mathrm{a}\right), 2.61\left(\mathrm{dd}, J_{1 \mathrm{~b}, 2}=8.8, J_{1 \mathrm{a}, 1 \mathrm{~b}}=12.2 \mathrm{~Hz}, 1 \mathrm{H}, \mathrm{H}-1 \mathrm{~b}\right), 2.58(\mathrm{dt}$, $\left.J_{1^{\prime} \mathrm{b}, 2^{\prime}}=7.6, J_{1^{\prime} \mathrm{a}, 1^{\prime} \mathrm{b}}=11.7 \mathrm{~Hz}, 1 \mathrm{H}, \mathrm{H}-1^{\prime} \mathrm{b}\right), 1.56-1.49\left(\mathrm{~m}, 2 \mathrm{H}, \mathrm{H}-2^{\prime}\right), 1.36-1.27$ (m, $\left.22 \mathrm{H}, \mathrm{H}-3^{\prime}-\mathrm{H}-13^{\prime}\right), 0.91$ (t, $\left.J_{13^{\prime}, 14^{\prime}}=7.0 \mathrm{~Hz}, 3 \mathrm{H}, \mathrm{H}-14^{\prime}\right) ;{ }^{13} \mathrm{C}$ NMR $(125 \mathrm{MHz}$, $\left.\mathrm{CD}_{3} \mathrm{OD}\right) \delta 139.0(\mathrm{C} 4), 116.7$ (C5), 76.1 (C3), 73.5 (C2), $52.6(\mathrm{C} 1), 50.6\left(\mathrm{C}^{\prime}\right)$, 33.0, 30.7, 30.7, 30.6, 30.6. 30.6, 30.4, 29.5, 28.3, 28.2, 27.9, 23.7 (C2'-C13'), 
14.3 (C14'); HRMS(ESI) $m / z$ calcd. for $\left[\mathrm{C}_{19} \mathrm{H}_{39} \mathrm{O}_{2} \mathrm{~N}+\mathrm{H}\right]^{+}:$314.3054, obsd.: 314.3058.

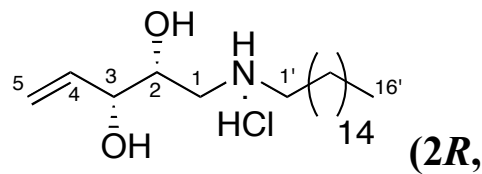

\section{R)-1-hexadecylamino-pent-4-ene-2,3-diol}

hydrochloride (224): By subjecting methyl 5-deoxy-5-iodo- $\alpha / \beta$-D-arabinoside (102 $\mathrm{mg}, 0.37 \mathrm{mmol})$ and hexadecylamine $(110 \mathrm{mg}, 0.44 \mathrm{mmol})$ to the general procedure for the synthesis of alkenylamines, $(2 R, 3 R)$-1-hexadecylamino-pent-4ene-2,3-diol (224) was obtained as a white solid as the $\mathrm{HCl}$ salt $(96 \mathrm{mg}, 0.25$ mmol, 69\%). $\mathrm{R}_{f}=0.19$ (DCM/EtOH/MeOH/30\% $\left.\mathrm{NH}_{3 \text { (aq.) }}, 35 / 2 / 2 / 1, \mathrm{v} / \mathrm{v} / \mathrm{v} / \mathrm{v}\right)$; $[\alpha]_{\mathrm{D}}^{22}=+28.4(\mathrm{c}=1.0, \mathrm{EtOH})$; IR (film) 3352, 2955, 2919, 2850, 1739, 1650, $1470,1373,1146,1016 \mathrm{~cm}^{-1} .{ }^{1} \mathrm{H}$ NMR $\left(500 \mathrm{MHz}, \mathrm{CD}_{3} \mathrm{OD}\right) \delta 5.96$ (ddd, $J_{3,4}=$ $\left.5.2, J_{4,5-c i s}=10.7, J_{4,5-t r a n s}=16.9 \mathrm{~Hz}, 1 \mathrm{H}, \mathrm{H}-4\right), 5.38\left(\mathrm{~d}, J_{4,5-\text { trans }}=16.9 \mathrm{~Hz}, 1 \mathrm{H}, \mathrm{H}-\right.$ 5-trans), $5.25\left(\mathrm{dd}, J_{5-c i s, 5-t r a n s}=0.9, J_{4,5-c i s}=10.7 \mathrm{~Hz}, 1 \mathrm{H}, \mathrm{H}-5\right.$-cis), 4.09 (dd, $J_{2,3}=$ $\left.4.4, J_{3,4}=5.2 \mathrm{~Hz}, 1 \mathrm{H}, \mathrm{H}-3\right), 3.87\left(\mathrm{dd}, J_{1,2}=1.7, J_{2,3}=4.4 \mathrm{~Hz}, 1 \mathrm{H}, \mathrm{H}-2\right), 3.12(\mathrm{dd}$, $\left.J_{1 \mathrm{a}, 2}=2.5 \mathrm{~Hz}, J_{1 \mathrm{a}, 1 \mathrm{~b}}=12.6 \mathrm{~Hz}, 1 \mathrm{H}, \mathrm{H}-1 \mathrm{a}\right), 3.06-2.95\left(\mathrm{~m}, 3 \mathrm{H}, \mathrm{H}-1 \mathrm{~b}, \mathrm{H}-1^{\prime}\right), 1.75-$ $1.66\left(\mathrm{~m}, 2 \mathrm{H}, \mathrm{H}-2^{\prime}\right), 1.42-1.24\left(\mathrm{~m}, 26 \mathrm{H}, \mathrm{H}-3^{\prime}-\mathrm{H}-15^{\prime}\right), 0.90$ (t, $J_{15^{\prime}, 16^{\prime}}=6.7 \mathrm{~Hz}$, $\left.3 \mathrm{H}, \mathrm{H}-166^{\prime}\right) ;{ }^{13} \mathrm{C}$ NMR (125 MHz, $\left.\mathrm{CD}_{3} \mathrm{OD}\right) \delta 138.1$ (C4), 117.3 (C5), 75.0 (C3), 70.5 (C2), 50.8 (C1), 48.5 (C1'), 33.1, 30.8, 30.8, 30.8, 30.7, 30.6, 30.5, 30.2, 27.6, 27.0, 23.7 (C2'-C15'), 14.5 (C16'); HRMS(ESI) $m / z$ calcd. for $\left[\mathrm{C}_{21} \mathrm{H}_{43} \mathrm{O}_{2} \mathrm{~N}+\mathrm{H}\right]^{+}: 342.3367$, obsd.: 342.3371 .

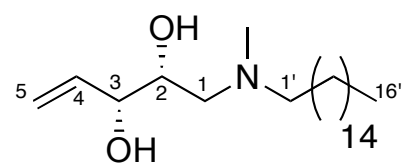

$(2 R, 3 R)$-1-hexadecylmethylamino-pent-4-ene-2,3-diol

(225): To a solution of hexadecylalkenylamine $224(15.8 \mathrm{mg}, 0.04 \mathrm{mmol})$ in $\mathrm{MeOH}(1 \mathrm{~mL})$ and $\mathrm{AcOH}(0.05 \mathrm{~mL})$, was added 37\% aqueous formaldehyde (60 $\mu \mathrm{L}, 0.8 \mathrm{mmol})$, and $\mathrm{NaCNBH}_{3}(75.6 \mathrm{mg}, 1.2 \mathrm{mmol})$. This was stirred under reflux for $24 \mathrm{~h}$ with additional formaldehyde $(100 \mu \mathrm{L})$ and $\mathrm{NaCNBH}_{3}(100 \mathrm{mg})$ added after $15 \mathrm{~h}$ and $21 \mathrm{~h}$, respectively. For workup, an additional $1 \mathrm{~mL}$ of formaldehyde was added to remove the excess reducing agent, and the reaction mixture was concentrated in vacuo. Purification by reverse phase column chromatography 
(octadecyl bonded endcapped silica prepacked column), eluting in $\mathrm{MeOH}$ gave methylated alkenylamine 225 as a white solid (11 mg, $0.03 \mathrm{mmol}, 73 \%$ ). $\mathrm{R}_{f}=$ $0.69\left(\mathrm{DCM} / \mathrm{EtOH} / \mathrm{MeOH} / 30 \% \mathrm{NH}_{3(\mathrm{aq} .)}, 35 / 2 / 2 / 1, \mathrm{v} / \mathrm{v} / \mathrm{v} / \mathrm{v}\right) ;[\alpha]_{\mathrm{D}}{ }^{22}=+28.0(\mathrm{c}=$ 0.5, MeOH); IR (film) 3373, 3156, 2923, 2853, 1658, 1643, 1466, 1379, 1266, 1072, 994, $921 \mathrm{~cm}^{-1} .{ }^{1} \mathrm{H}$ NMR (500 MHz, $\left.\mathrm{CD}_{3} \mathrm{OD}\right) \delta 5.97$ (ddd, $J_{3,4}=5.0, J_{4,5 \text {-cis }}=$ $\left.10.5, J_{4,5-\text { trans }}=17.5 \mathrm{~Hz}, 1 \mathrm{H}, \mathrm{H}-4\right), 5.33\left(\mathrm{~d}, J_{4,5-\text { trans }}=17.5 \mathrm{~Hz}, 1 \mathrm{H}, \mathrm{H}-5\right.$-trans $)$, $5.20\left(\mathrm{~d}, J_{4,5-c i s}=10.5 \mathrm{~Hz}, 1 \mathrm{H}, \mathrm{H}-5\right.$-cis $), 4.04\left(\mathrm{dd}, J_{2,3}=4.4, J_{3,4}=5.0 \mathrm{~Hz}, 1 \mathrm{H}, \mathrm{H}-\right.$ 3), $3.72\left(\mathrm{ddd}, J_{2,3}=4.4, J=7.5, J=9.5 \mathrm{~Hz}, 1 \mathrm{H}, \mathrm{H}-2\right), 2.53(\mathrm{dd}, J=4.6, J=13.0$ Hz, 1H, H-1a), 2.45-2.40 (m, 3H, H-1b, H-1'), 2.28 (s, 3H, N- $\underline{\text { Me) }), ~ 1.52-1.48 ~(m, ~}$ $\left.2 \mathrm{H}, \mathrm{H}-2^{\prime}\right), 1.37-1.22$ (m, 26H, H-3' - H-15'), 0.90 (t, $\left.J_{15^{\prime}}, 16^{\prime}=7.0 \mathrm{~Hz}, 3 \mathrm{H}, \mathrm{H}-16^{\prime}\right)$;

${ }^{13} \mathrm{C}$ NMR (125 MHz, CD $\left.3 \mathrm{OD}\right) \delta 139.1$ (C4), 116.4 (C5), 76.1 (C3), 71.7 (C2), 61.1 (C1), 59.5 (C1'), 43.0 (N-Me), 33.1, 30.8, 30.8, 30.8, 30.7, 30.7, 30.5, 28.5, 28.0, 23.7 (C2'-C15'), $14.4\left(\mathrm{C} 16^{\prime}\right)$; $\mathrm{HRMS}(\mathrm{ESI}) \mathrm{m} / z$ calcd. for $\left[\mathrm{C}_{22} \mathrm{H}_{45} \mathrm{O}_{2} \mathrm{~N}+\mathrm{H}\right]^{+}$: 356.3523, obsd.: 356.3523 .

\subsubsection{BCG Alamar Blue ${ }^{\circledR}$ Growth Inhibition Assay Protocol}

Bacteria: Stock solutions of BCG $\left(1.5 \times 10^{7}\right.$ bugs per $\left.\mathrm{mL}\right)$ were stored at $-80{ }^{\circ} \mathrm{C}$. These were defrosted with repeated cycles of 10 seconds sonication, followed by 10 seconds on ice. A stock sample of BCG was diluted to a concentration of $8 \mathrm{x}$ $10^{4}$ bugs per $\mathrm{mL}$ using sterile Tween albumin broth [Dubos broth base/OADC] to suspend.

Compounds: Compounds were dissolved in one of two ways, depending on solubility:

1) For compounds soluble in phosphate buffered saline (PBS) with up to 5\% DMSO, a solution was prepared with sterile PBS and sterile DMSO at double the desired concentration and these were filter sterilised using Acrodisc $13 \mathrm{~mm}$ syringe filters, with $0.22 \mu \mathrm{m}$ pore size into sterile eppendorf tubes. 
2) Compounds soluble only in DMSO were prepared at forty times the desired starting concentration, in sterile eppendorf tubes. Sterility filtering was not necessary because DMSO is toxic to bacteria, but if required, the compounds were sterility tested separately, by incubating compounds at a concentration of $2.5 \%$ DMSO in PBS on blood agar, and observing bacterial growth after 3 days.

Plate Set-up: Optical bottom black 96 well plates were used to screen 4 compounds at one time, each in triplicate, and tested over three serial dilutions (Figure 4.6). For the compounds dissolved in PBS, $200 \mu \mathrm{L}$ of the compound solutions were added to each of three wells before serial dilutions. For the compounds dissolved in DMSO, $190 \mu \mathrm{L}$ of PBS was added to the three initial wells, followed by $10 \mu \mathrm{L}$ of compound solution. Subsequent two-fold serial dilutions of the compounds were carried out, by removing $100 \mu \mathrm{L}$ of compound from the first wells and diluting with $100 \mu \mathrm{L}$ PBS, then repeating this procedure. As a control, $200 \mu \mathrm{L}$ EMB at a concentration of $64 \mu \mathrm{g} / \mathrm{mL}$ was added to the plate in duplicate. EMB titrations, by serial two-fold dilutions, gave concentrations of 32 to $1 \mu \mathrm{g} / \mathrm{mL}$ EMB after addition of the bacteria. To determine if the compounds had any inherent redox potential, $200 \mu \mathrm{L}$ solutions of compounds and PBS were added to individual control wells (i.e. no bacteria were added to these wells). Control wells of bacteria only, and PBS medium only were also prepared. $100 \mu \mathrm{L}$ of BCG solution was added to all wells except the PBS only, and compound only wells, and the plate was incubated at $37{ }^{\circ} \mathrm{C}$ and $5 \% \mathrm{CO}_{2}$ for 7 days. The outer wells were left free of compound and filled with water throughout the course of the incubation to avoid uneven evaporation of compounds. $20 \mu \mathrm{L}$ of Alamar Blue ${ }^{\circledR}$ dye was added to all test wells on day 7 , and the plate was incubated for another 24 hours before fluorescence was measured (excitation at $544 \mathrm{~nm}$, emission at $590 \mathrm{~nm}$ ) using a FLUOstar OPTIMA plate reader. The results were graphed to determine the MICs. Any compounds with significant antimycobacterial activity were retested at the necessary lower concentrations over 6 titrations of two-fold dilutions to more accurately determine the MIC. The lowest drug concentration effecting $100 \%$ growth inhibition is considered the MIC. 
A:

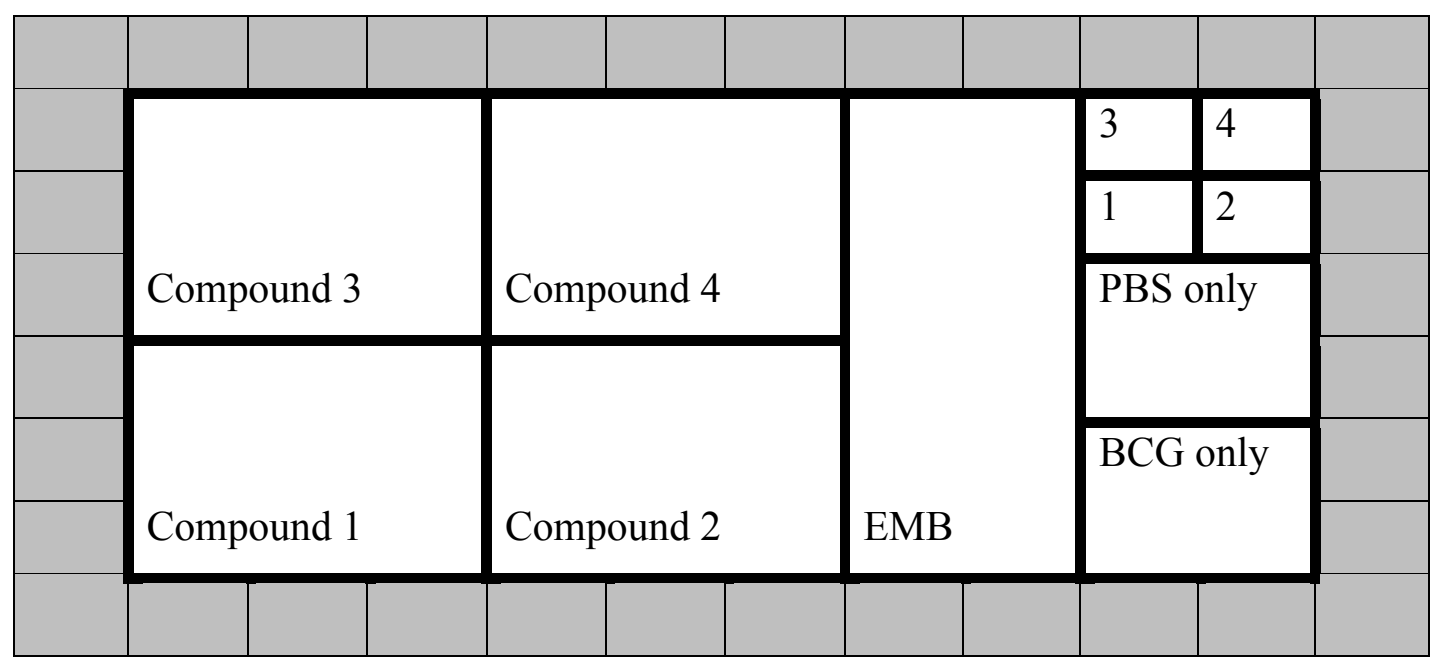

B:

\begin{tabular}{|c|c|c|c|c|}
\hline & & & $\begin{array}{l}\text { Cpd } \\
2 \\
\text { Only }\end{array}$ & $\begin{array}{l}\text { PBS } \\
\text { only }\end{array}$ \\
\hline Compound 1 & Compound 2 & EMB & $\begin{array}{l}\text { Cpd } \\
1 \\
\text { only }\end{array}$ & $\begin{array}{l}\text { BCG } \\
\text { only }\end{array}$ \\
\hline & & & & \\
\hline
\end{tabular}




\section{C:}

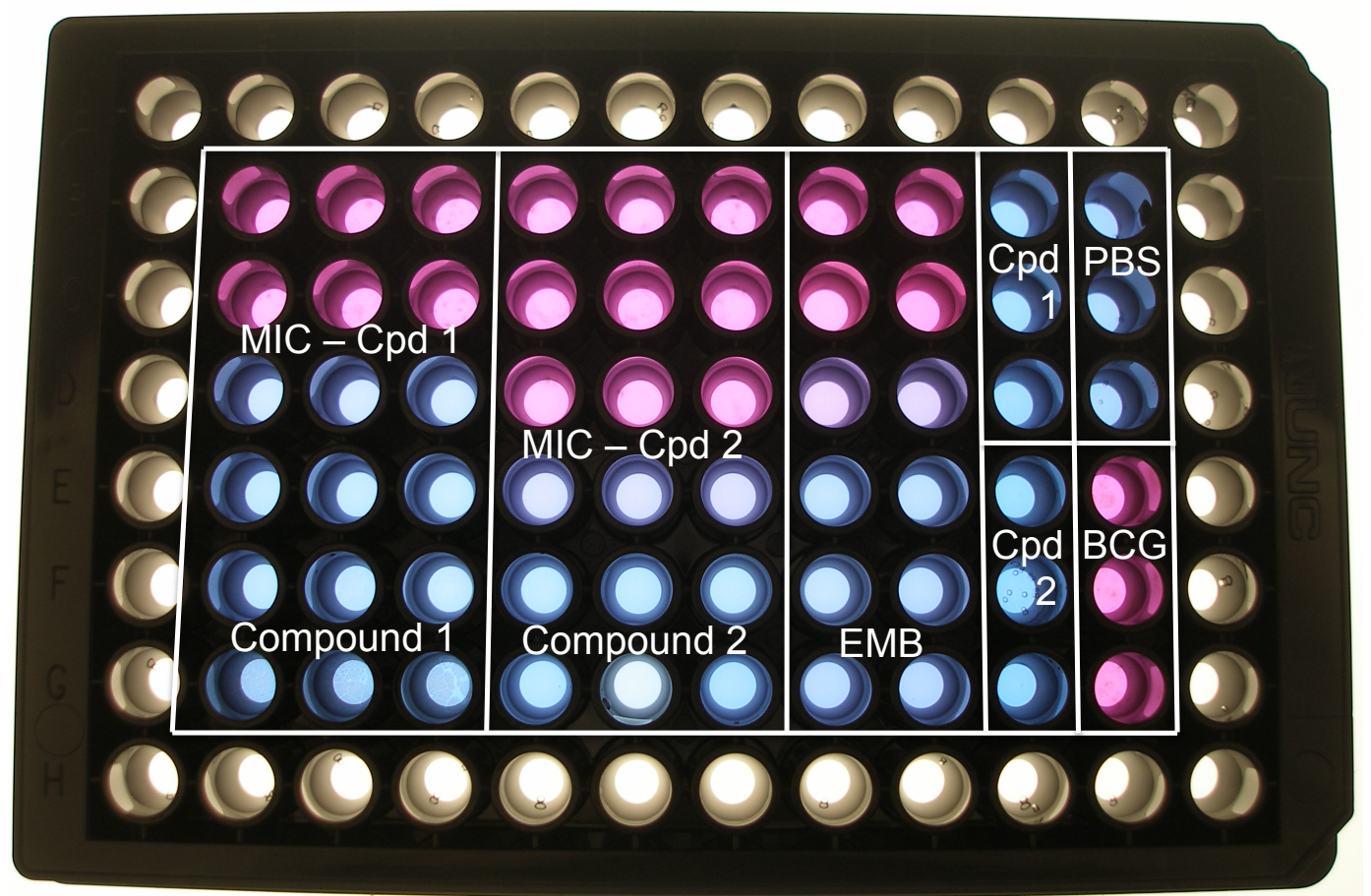

Figure 4.6: 96 well plate layout for BCG Alamar Blue ${ }^{\circledR}$ growth inhibition assay: A. 96 well plate layout for 4 compounds per plate screening. B. Plate layout for 2 compounds per plate MIC calculations. C. Photograph of an example plate with the MIC noted for compounds 1 and 2.

\subsubsection{Anti-proliferative HL60 and T cell MTT Assays}

James Baty (MIMR) carried out cytotoxicity testing on HL60 (cancer) cells, and human T cells in an anti-proliferative MTT assay. ${ }^{53}$ The experimental procedure is briefly summarised here. HL60 or T cells were plated into a 96 well plate in the presence of different concentrations of compounds (final cell concentration $=0.2$ x $10^{6}$ cells $/ \mathrm{mL}$ in complete RPMI), and incubated for $48 \mathrm{~h}\left(37{ }^{\circ} \mathrm{C}, 5 \% \mathrm{CO}_{2}\right) .20$ $\mu \mathrm{L}$ of MTT (3-(4,5-dimethylthiazol-2-yl)-2,5-diphenyltetrazolium bromide, 2.5 $\mathrm{mg} / \mathrm{mL}$ in HBSS) was added before incubating for a further $2 \mathrm{~h}$, then adding 100 $\mu \mathrm{L}$ SDS lysing buffer and incubating overnight. The absorbance at $570 \mathrm{~nm}$ was read with a FLUOstar OPTIMA plate reader. ${ }^{22}$ 


\subsection{References:}

1. World Health Organization (WHO) Global Tuberculosis Report 2013;

WHO: Geneva; 23 Oct 2013. Available from:

http://apps.who.int/iris/bitstream/10665/91355/1/9789241564656_eng.pdf (accessed January 18, 2014).

2. Tiemersma, E. W.; van der Werf, M. J.; Borgdorff, M. W.; Williams, B. G.; Nagelkerke, N. J. D. PLoS ONE 2011, 6, e17601.

3. Working Group on New TB Drugs. Drug Pipeline; http://www.newtbdrugs.org/pipeline.php (Accessed March 10, 2014).

4. Zumla, A.; Nahid, P.; Cole, S. T. Nat. Rev. Drug Discov. 2013, 12, 388404.

5. Tahlan, K.; Wilson, R.; Kastrinsky, D. B.; Arora, K.; Nair, V.; Fischer, E.; Barnes, S. W.; Walker, J. R.; Alland, D.; Barry 3rd, C. E.; Boshoff, H. I. Antimicrob. Agents Chemother. 2012, 56, 1797-809.

6. $\quad$ Stocker, B. L.; Timmer, M. S. M.; Dangerfield, E. M.; Plunkett, C. H.; Haslett, G. W. Unpublished Work; School of Chemical and Physical Sciences, Victoria University of Wellington and Malaghan Institute of Medical Resarch: Wellington, 2009.

7. Yajko, D. M.; Madej, J. J.; Lancaster, M. V.; Sanders, C. A.; Cawthon, V. L.; Gee, B.; Babst, A.; Hadley, W. K. J. Clin. Microbiol. 1995, 33, 2324-7.

8. Taneja, N. K.; Tyagi, J. S. J. Antimicrob. Chemother. 2007, 60, 288-293.

9. Skaanderup, P. R.; Poulsen, C. S.; Hyldtoft, L.; Jørgensen, M. R.; Madsen, R. Synthesis 2002, 1721-1727.

10. Chatterjee, D. Curr. Opin. Chem. Biol. 1997, 1, 579-588.

11. Erickson, J. G. J. Am. Chem. Soc. 1955, 77, 2839-2843.

12. Pestman, J. M.; Kevelam, J.; Blandamer, M. J.; van Doren, H. A.; Kellogg, R. M.; Engberts, J. B. F. N. Langmuir 1999, 15, 2009-2014.

13. Song, X.; Xia, B.; Stowell, S. R.; Lasanajak, Y.; Smith, D. F.; Cummings, R. D. Chem. Biol. 2009, 16, 36-47.

14. Sanchez-Ruiz, A.; Serna, S.; Ruiz, N.; Martin-Lomas, M.; Reichardt, N.C. Angew. Chem. Int. Ed. 2011, 50, 1801-1804. 
15. Dalpathado, D. S.; Jiang, H.; Kater, M. A.; Desaire, H. Anal. Bioanal. Chem. 2005, 381, 1130-1137.

16. a) Latge, P.; Rico, I.; Garelli, R.; Lattes, A. J. Disp. Sci. Technol. 1991, 12, 227-237; b) Garelli-Calvet, R.; Latge, P.; Rico, I.; Lattes, A.; Puget, A. Biochim. Biophys. Acta. 1992, 1109, 55-58; c) Laska, U.; Wilk, K. A.; Maliszewska, I.; Syper, L. J. Surfact. Deterg. 2006, 9, 115-124.

17. Abdel-Raouf, M. E.-S.; Abdul-Raheim, A.-R. M.; Abdel-Azim, A.-A. A. J. Surfact. Deterg. 2011, 14, 113-121.

18. Klein, J.; Kunz, M.; Guderjahn, L. Can. J. Chem. 1995, 73, 1941-1947.

19. Senuma, M.; Fujii, T.; Seto, M.; Okamura, K.; Date, T.; Kinumaki, A. Chem. Pharm. Bull. 1990, 38, 882-887.

20. Andersen, P.; Doherty, T. M. Nature Rev. Microbiol. 2005, 3, 656-662.

21. Altaf, M.; Miller, C. H.; Bellows, D. S.; O'Toole, R. Tuberculosis 2010, 90, 333-337.

22. Mulchin, B. J.; Newton, C. G.; Baty, J. W.; Grasso, C. H.; Martin, W. J.; Walton, M. C.; Dangerfield, E. M.; Plunkett, C. H.; Berridge, M. V.; Harper, J. L.; Timmer, M. S. M.; Stocker, B. L. Bioorg. Med. Chem. 2010, $18,3238-3251$.

23. Dangerfield, E. M. The Synthesis of Carbohydrates for the Treatment of Disease. Ph.D. Thesis, Victoria University of Wellington, Wellington, 2011.

24. Davison, H. C.; Woolhouse, M. E. J.; Low, J. C. Trends Microbiol. 2000, $8,554-559$.

25. Brennan, P. J.; Young, D. B. Tuberculosis 2008, 88, 102-5.

26. Shawar, R. M.; Humble, D. J.; Van Dalfsen, J. M.; Stover, C. K.; Hickey, M. J.; Steele, S.; Mitscher, L. A.; Baker, W. Antimicrob. Agents Chemother. 1997, 41, 570-4.

27. Miller, C. H.; Dasyam, N.; O'Toole, R. Unpublished work, School of Biological Sciences, Victoria University of Wellington: Wellington, 2011.

28. a) Rico-Lattes, I.; Lattes, A. Colloids Surf., A 1997, 123-124, 37-48; b) Townsley, C.; Sköld, R.; Surfactant Compositions with Anti-microbial Effect. International Patent WO 96/28458, September 19, 1996.

29. Ebert, A. D.; Svendsen, C. N. Nat. Rev. Drug Discov. 2010, 9, 367-372. 
30. Zang, R.; Li, D.; Tang, I.-C.; Wang, J.; Yang, S.-T. Int. J. Biotechnol. Wellness Ind. 2012, 1, 31-51.

31. Huang, P. S.; Oliff, A. Curr. Opin. Genetics Dev. 2001, 11, 104-110.

32. Lipinski, C. A.; Lombardo, F.; Dominy, B. W.; Feeney, P. J. Adv. Drug Delivery Rev. 1997, 23, 3-25.

33. van de Waterbeemd, H.; Smith, D. A.; Beaumont, K.; Walker, D. K. J. Med. Chem. 2001, 44, 1313-1333.

34. Moriguchi, I.; Hirono, S.; Nakagome, I.; Hirano, H. Chem. Pharm. Bull. 1994, 42, 976-978.

35. Leo, A. J. Chem. Pharm. Bull. 1995, 43, 512-513.

36. Langer, R.; Peppas, N. A. AIChE J. 2003, 49, 2990-3006.

37. Caner Research UK, Doxorubicin;

http://www.cancerresearchuk.org/cancer-help/aboutcancer/treatment/cancer-drugs/doxorubicin (accessed 27/03/2014).

38. Moore, S. L.; Denyer, S. P.; Hanlon, G. W.; Olliff, C. J.; Lansley, A. B.; Rabone, K.; Jones, M. Int. J. Antimicrob. Agents 2006, 28, 503-513.

39. Muegge, I. Med. Res. Rev. 2003, 23, 302-321.

40. Kelder, J.; Grootenhuis, P. D. J.; Bayada, D. M.; Delbressine, L. P. C.; Ploemen, J.-P. Pharm. Res. 1999, 16, 1514-1519.

41. Ghose, A. K.; Viswanadhan, V. N.; Wendoloski, J. J. J. Comb. Chem. 1999, $1,55-68$.

42. Oprea, T. I. J. Comput.-Aided Mol. Des. 2000, 14, 251-264.

43. Veber, D. F.; Johnson, S. R.; Cheng, H.-Y.; Smith, B. R.; Ward, K. W.; Kopple, K. D. J. Med. Chem. 2002, 45, 2615-2623.

44. Ertl, P.; Rohde, B.; Selzer, P.; Fast Calculation of Molecular Polar Surface Area Directly from SMILES:

http://www.daylight.com/meetings/emug00/Ertl/ (accessed 16/11/2014).

45. Shi, W.; Zhang, X.; Jiang, X.; Yuan, H.; Lee, J. S.; Barry 3rd, C. E.; Wang, H.; Zhang, W.; Zhang, Y. Science 2011, 333, 1630-1632.

46. Xin, Z.; Yan, S.; Ding, J.; Yang, Z.; Du, B.; Du, S. Appl. Surf. Sci. 2014, $300,8-15$. 
47. Bevinakatti, H. S.; Reekmans, S. I. J.; Scovell, E. G.; Blease, T. G.;

Davies, S. J.; Polyhydroxy hydrocarbyl and amine containing surfactants for herbicidal and pesticidal compositions. International Patent WO 01/05224A1, January 25, 2001.

48. Brycki, B.; Szulc, A. PLoS One 2014, 9, e84936.

49. Brycki, B. Pol. J. Microbiol. 2010, 59, 227-231.

50. Ikekawa, T.; Matsuda, H.; Ohtsuka, M.; Eto, H.; Katori, T.; Ohkawa, M. Chem. Pharm. Bull. 1986, 34, 4879-82.

51. Dasyam, N.; Munkacsi, A. B.; Fadzilah, N. H.; Senanayake, D. S.; O'Toole, R. F.; Keyzers, R. A. J. Nat. Prod. 2014, 77, 1519-1523.

52. a) Clark, R. J.; Garson, M. J.; Hooper, J. N. A. J. Nat. Prod. 2001, 64, 1568-1571; b) Garrido, L.; Zubia, E.; Ortega, M. J.; Naranjo, S.; Salva, J. Tetrahedron 2001, 57, 4579-4588.

53. Baty, J. W.; Berridge, M. V. Unpublished work, Malaghan Institute of Medical Research: Wellington, 2012. 


\section{Chapter 5: Global Conclusion and Future Prospects}

In this thesis the use of PGF synthetic methodology for drug discovery has been explored and this chapter highlights the main conclusions of the research and discusses possible future directions for these projects. With that in mind, some of the future prospects discussed in this chapter involve the use of PGs to either aid in mechanistic understanding, or to allow for the synthesis of a desired synthetic target. Although the use of PGs is not generally in the interest of the green chemist, the understanding of chemoselective mechanisms and the development of the most efficient synthetic route is in everybody's best interest.

\subsection{The PGF Synthesis of Azasugars}

In Chapter 2 the PGF azasugar methodology was applied to 2-deoxy-D-glucose (105) with the anticipation of selectively forming 5-epi-fagomine 108. Instead, the $\mathrm{I}_{2}$-mediated carbamate annulation of the gluco alkenylamine $\mathbf{1 1 0}$ resulted in the formation of four products (Scheme 5.1). Cis and trans piperidines 112a and 112b, pyrrolidine 111, and linear iodohydrin 113 were identified using a variety of spectroscopic and synthetic techniques. Hydrolysis of the three cyclic carbamates provided 5-epi-fagomine $\mathbf{1 0 8}$ and fagomine $\mathbf{7 8}$ as minor products, and the trihydroxylated pyrrolidine $\mathbf{1 1 5}$ as the major product in $15 \%$ yield. 
<smiles>C=C[C@H](O)C(O)CCNCC(C)C</smiles><smiles>C1CCCCC1</smiles><smiles>OC[C@H]1NCCC(O)[C@@H]1O</smiles>

108

78<smiles>OCC(O)[C@]1(O)CCN1</smiles>

115

Scheme 5.1: Carbamate annulation of 2-deoxy-D-glucose derived alkenylamine 110 and the subsequent hydrolysis of the cyclic carbamates.

Insight into the carbamate annulation mechanism for the 2-deoxy-D-glucose derived alkenylamine $\mathbf{1 1 0}$ was also provided in this chapter. Analysis of the sixmembered iodocyclisation transition state models indicated no obvious low energy TS in the gluco cyclisation, which could explain why a variety of products were formed. The preferred mechanisms to explain the formation of the four carbamates were then proposed in Scheme 2.10. An extension of the iodocyclisation model that was originally proposed by Chamberlin ${ }^{1}$ was used to explain the formation of the cis and trans piperidines 112a and 112b, while the formation of pyrrolidine 111 could be explained via an iodo-epoxide intermediate. The formation of the iodohydrin $\mathbf{1 1 3}$ was suggested to form through the direct attack of water on the $I_{2}$-alkene complex, with carbamate formation at the 3position. Future experiments and calculations to confirm these proposed mechanisms would also be useful.

The $\mathrm{I}_{2}$-mediated carbamate annulation for piperidines was then discussed in relation to other cyclisations. It was observed that, in addition to the stereodirecting effect of the allylic hydroxyl, factors such as the position of ringsubstituents, across-ring trans directing effects, and the reaction conditions could 
also influence the selectivity of annulations. Accordingly, to aid in understanding of the 2-deoxy-D-glucose derived alkenylamine annulation mechanism, and to favour the formation of a specific product, a variety of selective protection strategies are proposed (Scheme 5.2). Herein it should be noted that the selective protection of one hydroxyl group may require multiple protecting group manipulation steps and thereby reduce the overall efficiency of the process.

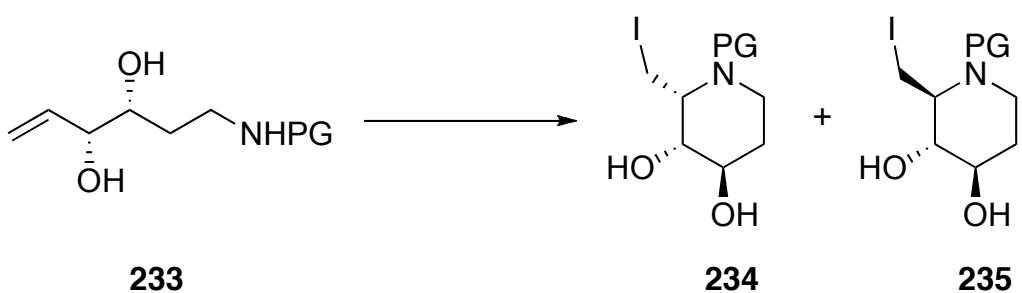

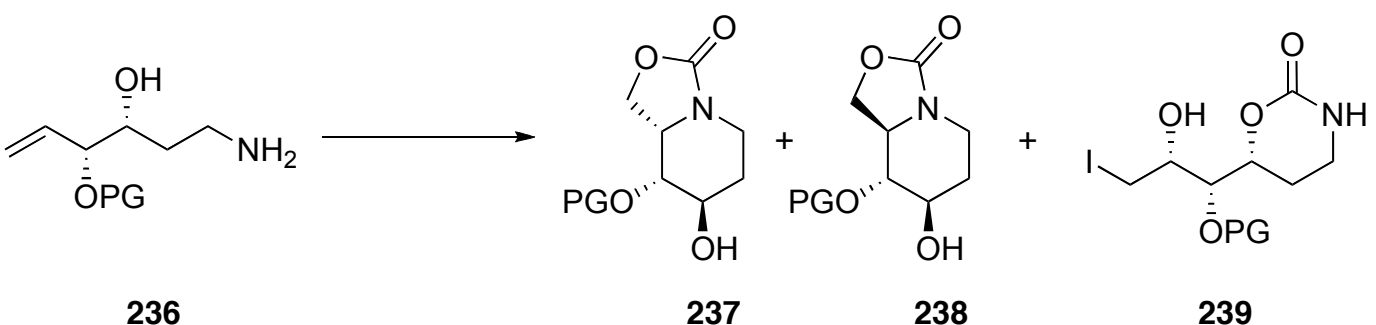<smiles>C=C[C@H](O)C(O[Na])O[Na]</smiles><smiles>O=C1OC[C@H]2[C@H](O)[C@H](O)CCN12</smiles>

240 241 242 243<smiles>C=CC(O[Na])C(CCN)OPOC(=O)O</smiles>

244

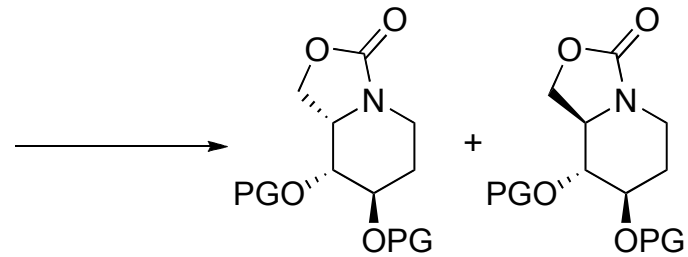

245
246

Scheme 5.2: Selective protection strategies favouring particular products.

Of the strategies proposed to probe the reaction mechanism and explore the conditions required to favour certain gluco annulation products, the first involves the use of an electron donating amine PG, such as a benzyl group in amine $\mathbf{2 2 6}$. 
This would make the amine more nucleophilic, hence more reactive, and therefore more likely to rapidly react via a six-membered transition state to form the corresponding piperidine iodides, 227 and 228. Another strategy involves the selective protection of the 4-OH (as in 229), which would prevent the formation of the iodo-epoxide intermediate and therefore pyrrolidine 111. The selective protection of the 3-OH (as in 240) may prevent the formation of an iodohydrin and, by doing so, increase the yields of piperidines 241 and 242, and pyrroldine 243. This $3-\mathrm{OH}$ protection strategy could provide insight into the mechanism of formation of iodide 113. As discussed in Chapter 2, the formation of iodide 113 may occur through initial water attack on the $\mathrm{I}_{2}$-alkene complex, or through initial carbamate formation at $\mathrm{C} 3$. Therefore, prevention of the carbamate formation at the 3-OH may encourage the amine attack on the $\mathrm{I}_{2}$-alkene complex, suggesting that the initial carbamate formation in iodide $\mathbf{1 1 3}$ precedes the iodohydrin formation. Similarly, the protection of both hydroxyls in alkenylamine 244 could lead to the selective formation of piperidines $\mathbf{2 4 5}$ and $\mathbf{2 4 6}$.

As described in Scheme 2.15 the presence of a group $\alpha$ to the amine has a trans directing effect across the ring. To exploit this effect, a 2-deoxy-D-glucose alkenylamine analogue with a bulky group at $\mathrm{C} 1$ could be prepared. To this end, the development of a new PGF $\mathrm{C}-\mathrm{C}$ bond forming addition to the Vasella reductive amination methodology (similar to that developed in the synthesis of conduramines in Chapter 3) could potentially be utilised to prepare an $\alpha$ substituted alkenylamine that could then be submitted to the carbamate annulation conditions. This will be discussed in Section 5.2.

As the selective formation of pyrrolidine $\mathbf{1 1 1}$ is difficult to favour through PG manipulations, an alternative synthetic route for its formation, which would support the predicted iodoepoxide intermediate, is suggested (Scheme 5.3). Retrosynthetically, pyrrolidine 111 can be envisaged to be prepared via the deprotection and carbamate annulation of protected iodoepoxide $\mathbf{2 4 7}$. The iodide 247 can be prepared via a Sharpless asymmetric epoxidation ${ }^{2}$ of the protected amine 248, which should itself be available from the cross metathesis of protected 
alkenylamine 249 and allyliodide (250). ${ }^{3}$ The protected alkenylamine 249 can be made by the Vasella-reductive amination of 2-deoxy-D-xylose (251) and an appropriate primary amine. In addition to supporting the proposed mechanism for the carbamate annulation step, this synthetic route could be used to prepare pyrrolidine $\mathbf{1 1 1}$ in better yield, and also be a means to provide access to diastereomers of $\mathbf{1 1 1}$ and its hydrolysis product, pyrrolidine $\mathbf{1 1 5}$.

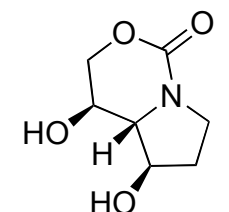

111

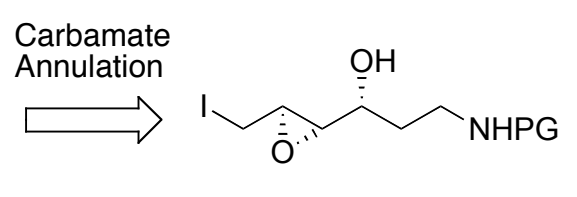

247

Vasella-reductive

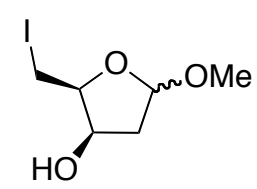

251 amination

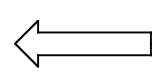

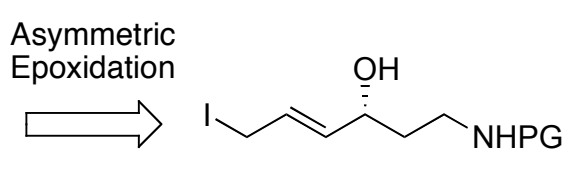

248

Cross

Metathesis

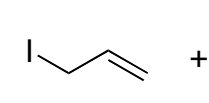

250

249

Scheme 5.3: Retrosynthetic plan for alternative route to pyrrolidine carbamate 111. 


\subsection{The PGF Synthesis of Conduramines}

The development of a PGF methodology for the synthesis of conduramines was described in Chapter 3. 4-Deoxy-3-conduramine 171 was prepared from Dxylose in a $27 \%$ yield over four steps, with the critical step being the C-C bond forming adaptation of the Vasella-reductive amination reaction (Scheme 5.4). To this end, a stereoselective PGF Vasella-Barbier amination provided 4,5-anti amino diene 172 in $35 \%$ yield. Key to the success of this reaction was the use of $\mathrm{NH}_{4} \mathrm{OAc}$ as the amine source, and indium as the metal. To complete the synthesis, a RCM provided conduramine $\mathbf{1 7 1}$ quantitatively in the presence of free hydroxyl groups and an in situ protected amine.<smiles>OCC1OC(O)C(O)C1O</smiles>

174

i) $0.3 \% \mathrm{AcCl}, \mathrm{MeOH}$

ii) Imid. $\mathrm{PPh}_{3}, \mathrm{I}_{2}$

THF, reflux, $1.5 \mathrm{~h}$

$78 \%$ (2 steps)

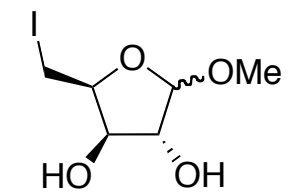

173

In, $\mathrm{NH}_{4} \mathrm{OAc}$

Allyl bromide

$\mathrm{MeOH}$, reflux

$20 \mathrm{~h}, \quad 35 \%$<smiles>N[C@H]1CC=C[C@@H](O)[C@@H]1O</smiles>

171 i) $\mathrm{TfOH}, \mathrm{H}_{2} \mathrm{O}$

ii) Hoveyda-Grubbs II THF, rt, $1 \mathrm{~h}$

quant.

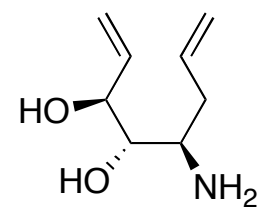

172

Scheme 5.4: The PGF synthesis of 4-deoxy-3-conduramine 171.

In addition to the PGF Vasella-Barbier reaction developed in Chapter 3, there is also potential for the development of other $\mathrm{C}-\mathrm{C}$ bond forming variations of the PGF Vasella-reductive amination. The use of different carbon nucleophiles in a similar reaction would provide access to differently functionalised alkenylamines, and hence, different products. One example, as alluded to earlier, is the 
preparation of a hexenylamine $\mathbf{2 5 2}$ with an across-the-ring trans-directing cyano group $\alpha$ to the amine, whereby hexenylamine $\mathbf{2 5 2}$ is prepared through the use of $\mathrm{Zn}, \mathrm{NH}_{4} \mathrm{OAc}$, and TMSCN in a modified PGF Vasella-Strecker reaction (Scheme 5.5). ${ }^{4}$ After the key $\mathrm{C}-\mathrm{C}$ bond forming step, an adaptation of the synthesis of fivemembered amino-iminosugars ${ }^{4}$ via an $\mathrm{I}_{2}$-mediated carbamate annulation to give 253, followed by hydrolysis $(\rightarrow \mathbf{2 5 4})$ and then hydrogenation is envisioned to provide the 2,6-trans-5,6-cis-amino-imino-heptitol 255 in a PGF manner.

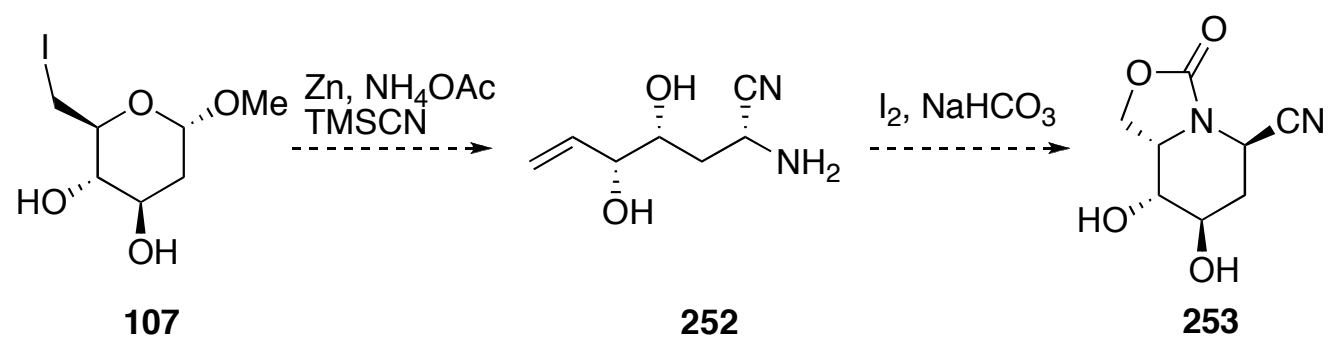<smiles>CC(C)(C)[C@@H]1C[C@@H](CN)N[C@@H](CO)[C@@H]1O</smiles>

Scheme 5.5: Proposed development of a PGF Vasella-Strecker reaction for the PGF synthesis of amino-imino-heptitol 255.

Due to the interesting biological properties of aminocyclitols, ${ }^{5}$ their preparation would be a useful extension to the PGF methodology for the synthesis of conduramines. To this end, a dihydroxylation of 4-deoxy-3-conduramine $\mathbf{1 7 1}$ is expected to provide deoxyaminocyclitol 256. An initial dihydroxylation of conduramine 171 was attempted using Upjohn conditions ${ }^{6}$ but this was unsuccessful (conditions A, Scheme 5.6). Instead, the use of a Sharpless asymmetric dihydroxylation ${ }^{7}$ (conditions B) may prove more effective. It is unclear which asymmetric dihydroxylation mix (AD mix- $\alpha$ or $-\beta$ ) would produce the desired anti selectivity, therefore reactions using either catalyst may need to 
be explored. Furthermore the application of the aminocyclitol synthesis methodology to several different furanose scaffolds, and the use of both $\mathrm{AD}$ mixes ( $\alpha$ and $\beta$ ) in the dihydroxylation, would provide access to a variety of 2deoxyaminocyclitols, which could then be screened for glycosidase activity.<smiles>N[C@H]1CC=C[C@@H](O)[C@H]1O</smiles>

171

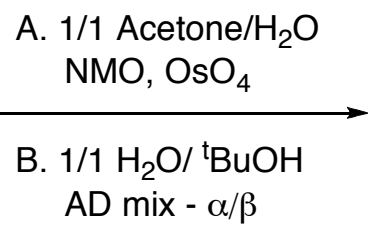

AD mix $-\alpha / \beta$<smiles>N[C@H]1C[C@H](O)[C@H](O)[C@H](O)[C@H]1O</smiles>

256

Scheme 5.6: A. Upjohn conditions for dihydroxylation of conduramine 171. B. Sharpless dihydroxylation of conduramine 171.

A variety of other molecules can also be prepared from the conduramine scaffold. For example, subjecting conduramine 171 to (-)-diethyl tartrate and $\mathrm{Ti}\left(\mathrm{O}^{i} \mathrm{Pr}\right)_{4}$ in a Sharpless asymmetric epoxidation ${ }^{2}$ would provide syn epoxide 257 (Scheme 5.7), however, the amine group in conduramine $\mathbf{1 7 1}$ may need to be protected to achieve the desired transformation. From epoxide 257, nucleophilic attack with different nucleophiles would then provide a range of products including aziridines, ethers, and diamines. ${ }^{8}$ This could also provide an alternative route to deoxyaminocyclitols with an anti relationship between the newly formed hydroxyls, compared with the syn dihydroxylation described above. 


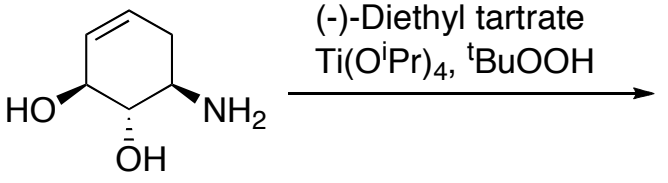

171<smiles>N#CCCCC12C[C@H](N)[C@@H](O)[C@H](O)[C@H]1O2</smiles>

257<smiles>N[C@H]1CC2OC2[C@@H](O)[C@@H]1O</smiles>

257<smiles>[R]C1C[C@H](N)[C@H](O)[C@H](O)[C@H]1O[13CH3]</smiles>

258: $\mathrm{R}=\mathrm{OH}$

259: $\mathrm{R}=\mathrm{H}$

260: $\mathrm{R}=\mathrm{NH}_{2}$

261: $\mathrm{R}=\mathrm{OEt}$

262: $\mathrm{R}=\mathrm{N}_{3}$

Scheme 5.7: Sharpless asymmetric epoxidation of conduramine 171. 


\subsection{The Synthesis and Testing of Lipophilic Amines as Anti-TB Drugs}

The development of a potential amine anti-tuberculosis drug was described in Chapter 4. To this end, a 20-member amine library was prepared using reductive amination and Vasella-reductive amination reactions. Variation in the stereochemistry of the sugar, and the use of several different lipophilic amines provided a wide range of amines and alkenylamines for anti-mycobacterial testing. The BCG Alamar Blue growth inhibition assay was used to test for potential anti-TB activity. The trends in BCG growth inhibition for the amine library revealed that the arabinose configuration was the favoured stereochemistry for the sugar group, and that larger, linear amines conferred more potent antimycobacterial activity compared to the shorter chain alkylamines or the cyclic amines. It was proposed that the lipophilicity and flexibility of the amine affected the ability of a molecule to pass through the cell wall and inhibit cell growth. Additional biological testing of the more active amines revealed that with increasing anti-mycobacterial activity, an increase in anti-proliferative activity was also observed for both human $\mathrm{T}$ cells and the human leukaemia cell line HL60. The in vitro trend in general cytotoxicity for the amines was disappointing, however, as in vivo data provides a better prediction of anti-TB activity and cytotoxicity, two promising alkylamines, arabinohexadecylamine 208 and arabinohexadecylmethylamine 209 (Figure 5.1), both prepared in a single step, were sent to the group of Assoc. Prof. Anne Lenaerts at Colorado State University for further biological testing in a mouse model of TB. The results of these studies will be reported in due course. 
<smiles>[Y4]C(C)(C)CNC[C@H](O)[C@@H](O)[C@H](O)CO</smiles>

208<smiles></smiles>

209<smiles>[Y4]C(C)(C)CN(C[C@H](O)[C@@H](O)[C@H](O)CO)C[C@H](O)[C@@H](O)[C@H](O)CO</smiles>

210

Figure 5.1: Lead amines 208 and 209 with promising anti-TB activity that have been submitted for in vivo testing, and potential anti-cancer lead 210.

Future work on the anti-TB drug discovery project includes the preparation of a third generation amine library, with the aim of further improving antimycobacterial activity while also reducing the cytotoxicity of the compounds. Although the stereochemistry of the sugar group was studied to some extent in the first and second generation amine libraries, a more structured approach to the design of future inhibitors would be useful. To this end, a series of inhibitors with the active hexadecylamine lipid but with different pentose, hexose, and ketose sugars could be prepared to better understand how the stereochemistry of the sugar affects activity. As arabinohexadecylamine $\mathbf{2 1 0}$ was poorly soluble in most solvents, it is anticipated that the proposed sugar series in the third generation amine library may also be poorly soluble, hence $N$-methylation of the corresponding amines could also be carried out. It has been shown in this thesis that $\mathrm{N}$-methylated amines retained anti-mycobacterial activity, and in some cases improved solubility, hence a series of $N$-alkylated amines would also be of interest from a SAR perspective.

In addition to the potential anti-TB drugs 208 and 209, diarabino hexadecylamine 210 was notably more active towards the cancer cell line, HL60, compared with the human T cell line (Figure 5.1). This selectivity suggests potential for diarabino hexadecylamine $\mathbf{2 1 0}$ to act as an anti-cancer drug and further investigations into the biological testing of this compound would be valuable. The optimisation of the synthesis of amine $\mathbf{2 1 0}$ is anticipated through the use of excess arabinose, and 
one equivalent of hexadecylamine as the limiting reagent. Moreover, an anticancer amine library based on amine $\mathbf{2 1 0}$ with varied sugar groups and lipophilic tails could be used to assess the SAR of these compounds, with the idea that this would lead to the identification of a more selective and more potent anticancer drug. 


\subsection{References}

1. Chamberlin, A. R.; Mulholland Jr., R. L.; Kahn, S. D.; Hehre, W. J. J. Am. Chem. Soc. 1987, 109, 672-677.

2. Katsuki, T.; Sharpless, K. B. J. Am. Chem. Soc. 1980, 102, 5974-5976.

3. Jacobs, T.; Rybak, A.; Meier, M. A. R. Appl. Catal., A 2009, 353, 32-35.

4. a) Win-Mason, A. L.; Dangerfield, E. M.; Tyler, P. C.; Stocker, B. L.; Timmer, M. S. M. Eur. J. Org. Chem. 2011, 4008-4014; b) Win-Mason, A. L.; Jongkees, S. A. K.; Withers, S. G.; Tyler, P. C.; Timmer, M. S. M.; Stocker, B. L. J. Org. Chem. 2011, 76, 9611-9621.

5. Delgado, A. Eur. J. Org. Chem. 2008, 3893-3906.

6. VanRheenen, V.; Kelly, R. C.; Cha, D. Y. Tetrahedron Lett. 1976, 17, 1973-1976.

7. Jacobsen, E. N.; Marko, I.; Mungall, W. S.; Schroeder, G.; Sharpless, K. B. J. Am. Chem. Soc. 1988, 110, 1968-1970.

8. Schneider, C. Synthesis 2006, 3919-3944. 


\section{Appendix}

Chapter 2: NMR Spectra 


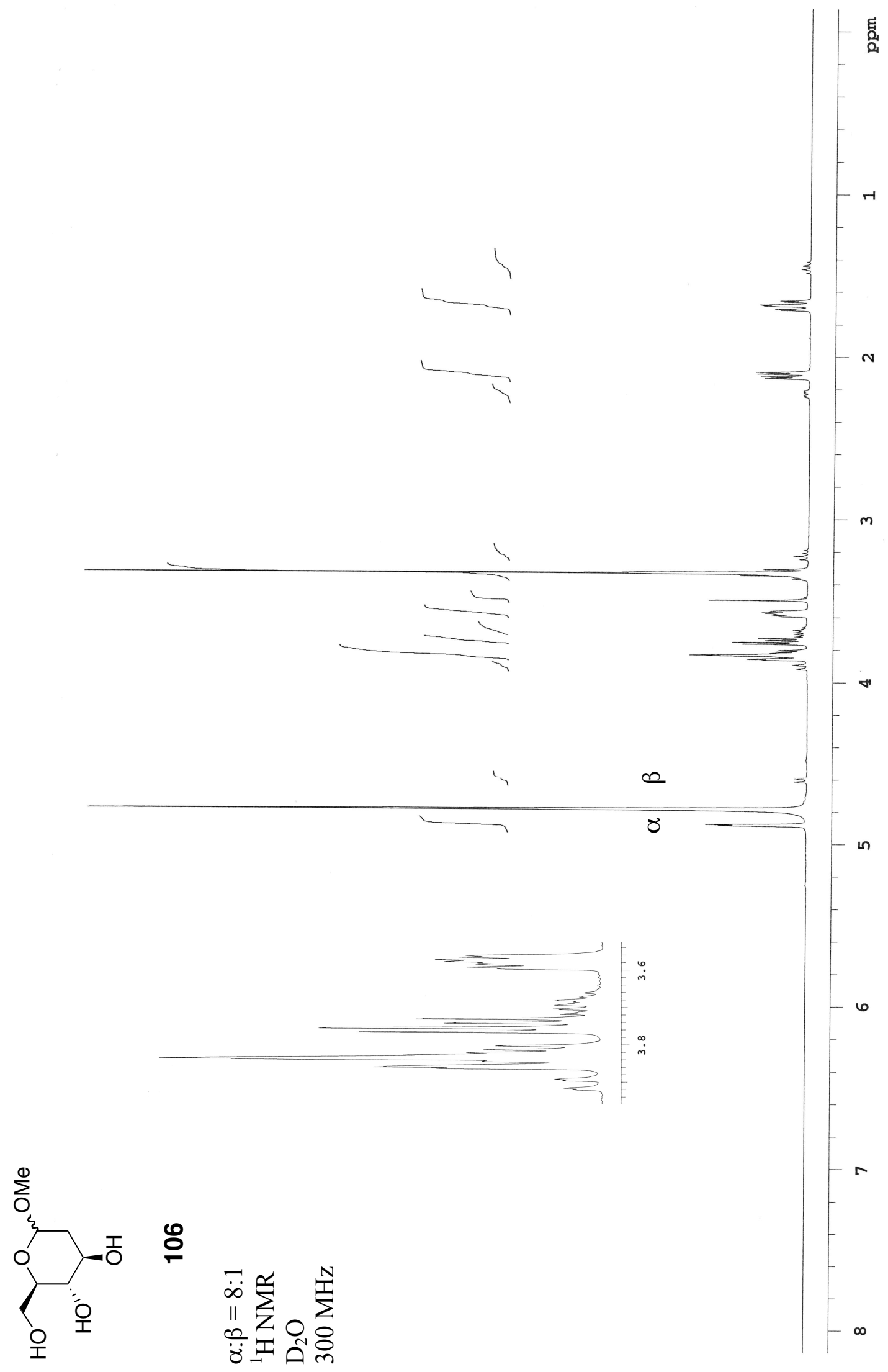




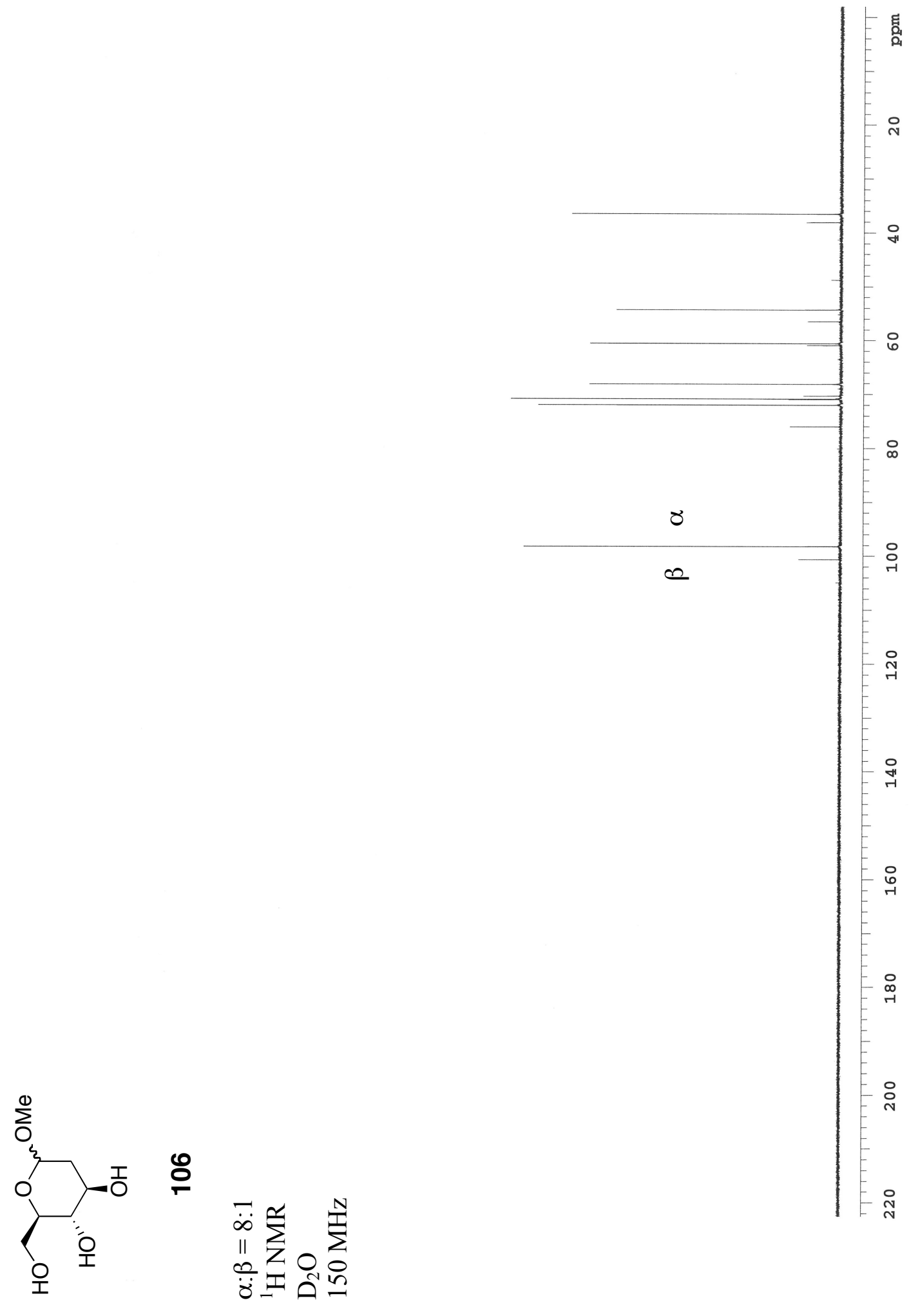

$$
\text { : }
$$




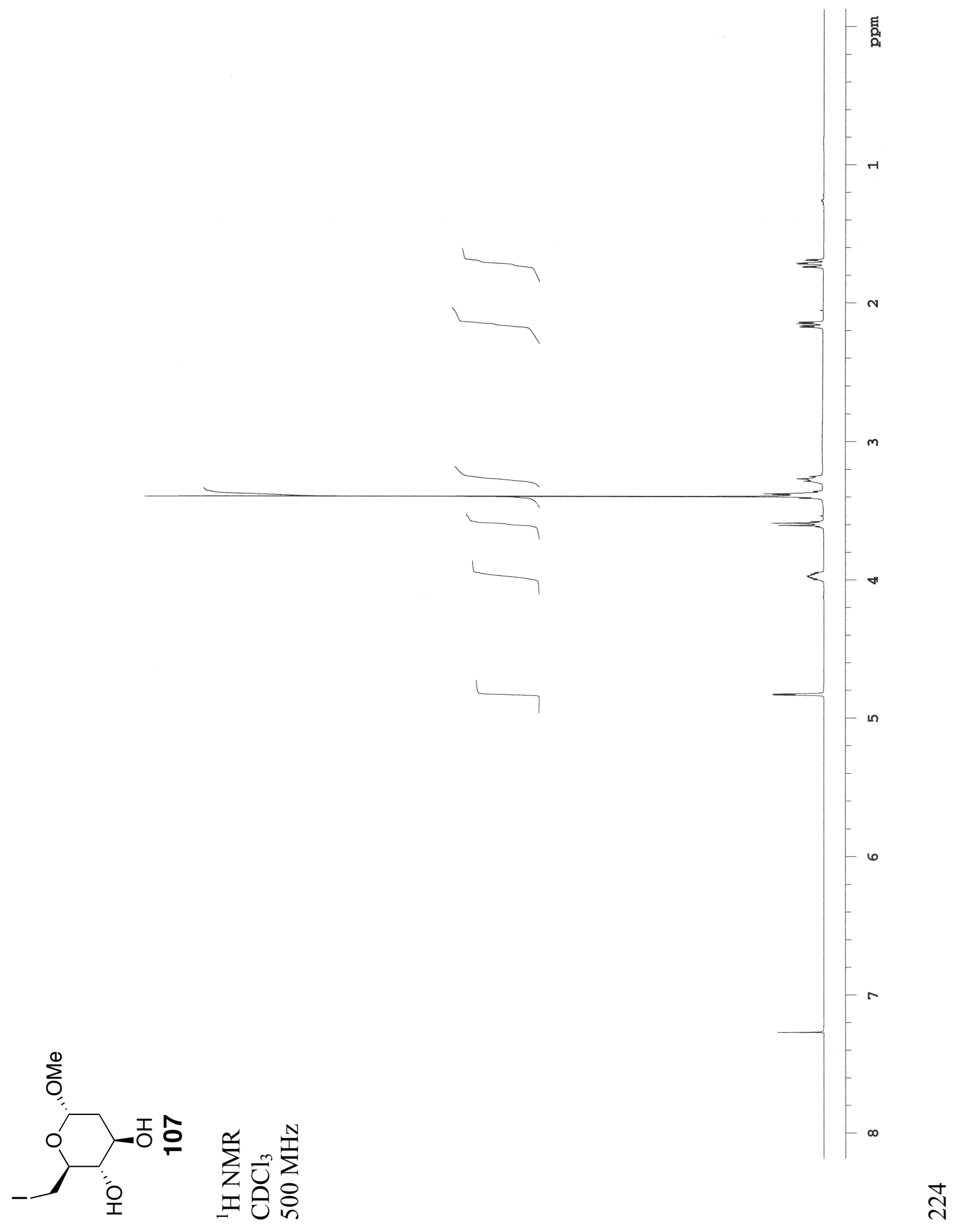




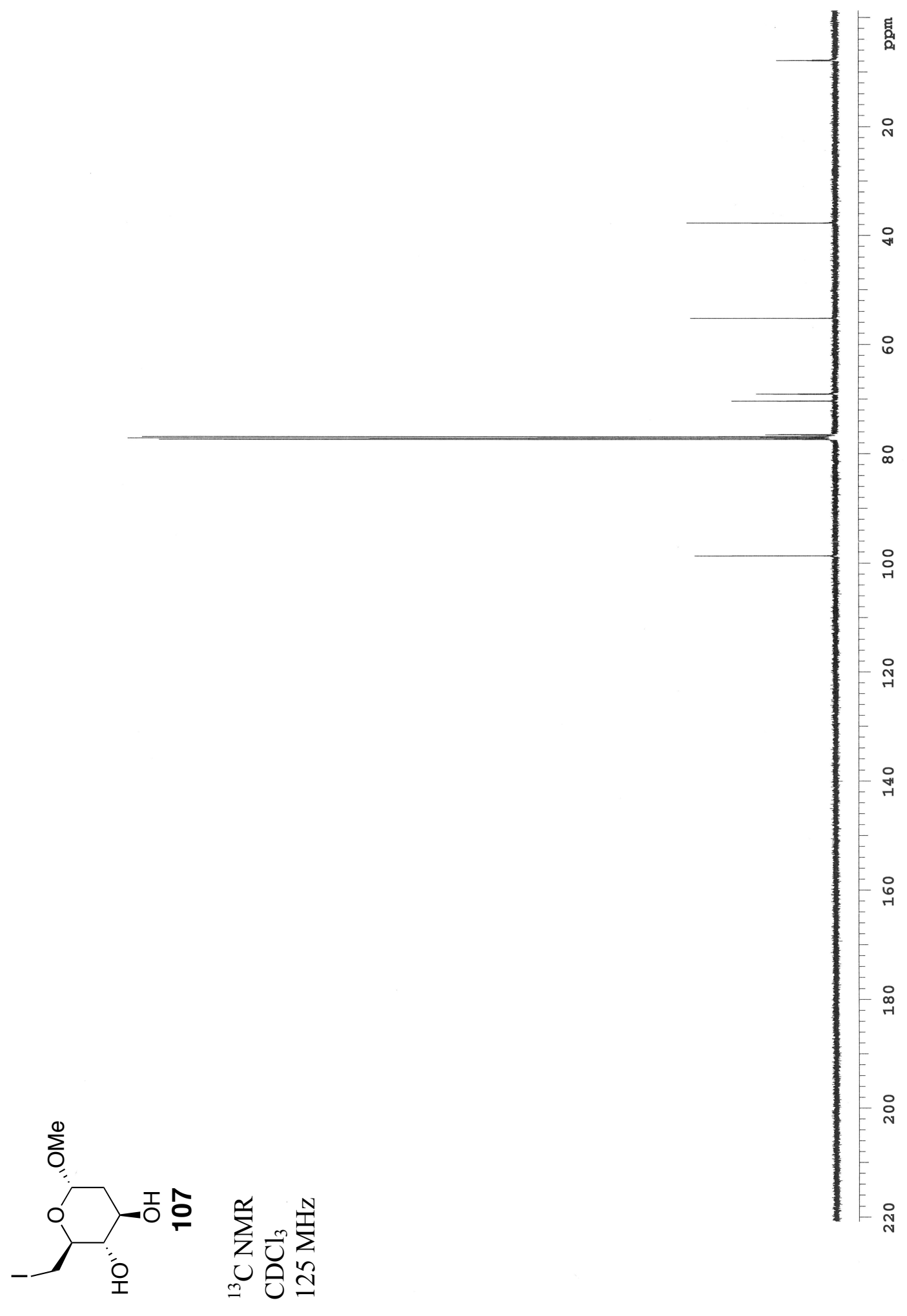




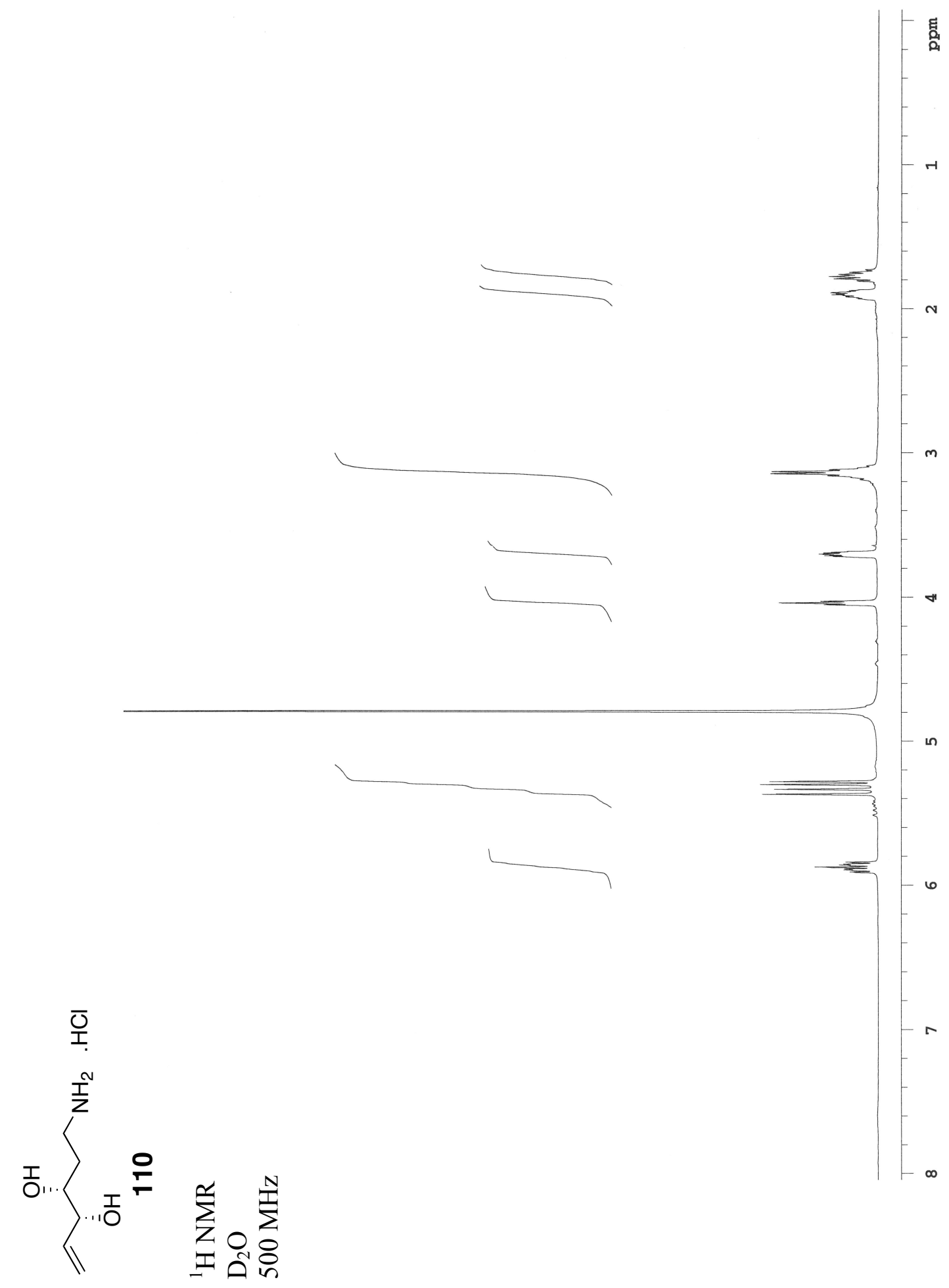

สั 

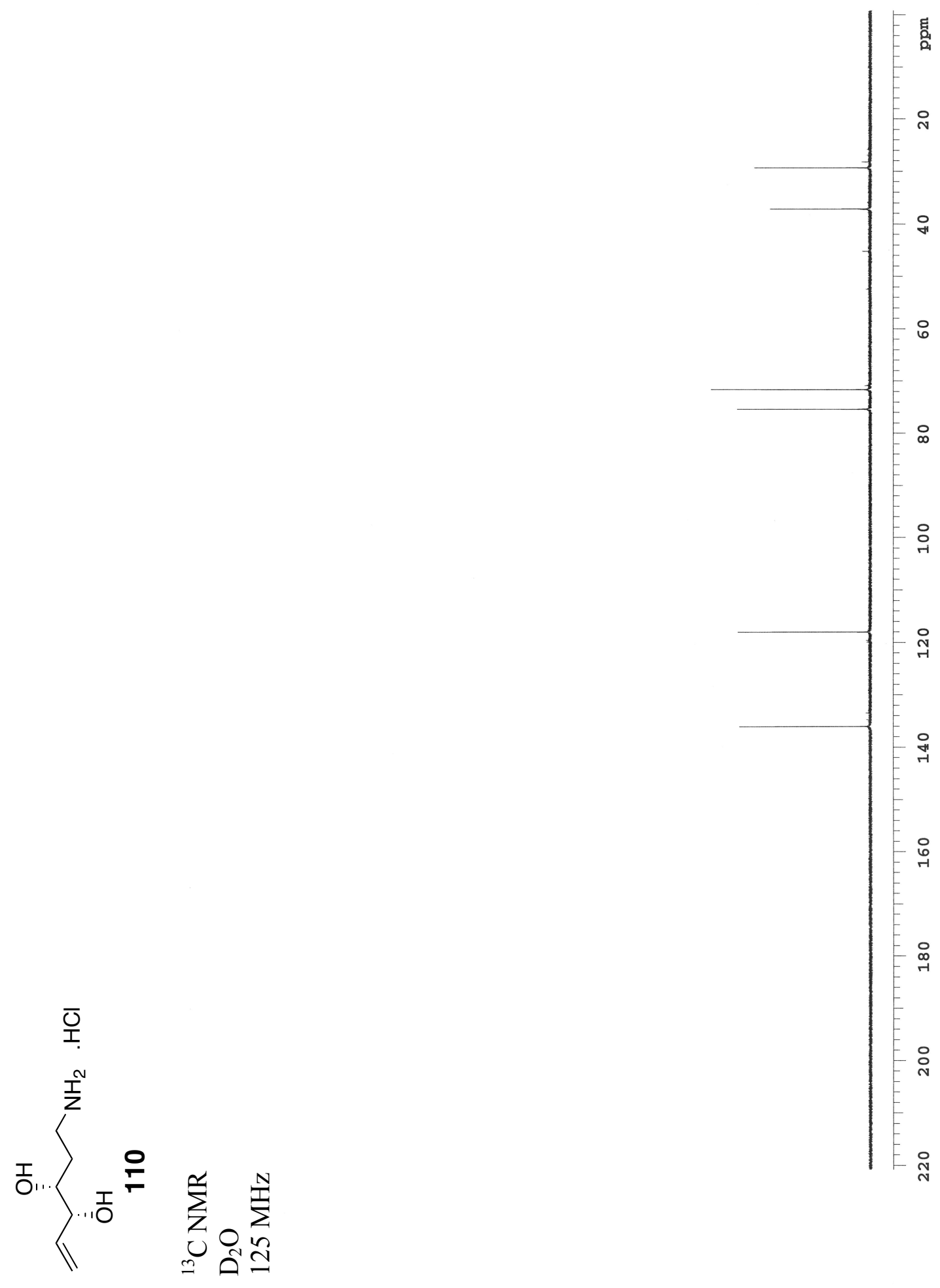


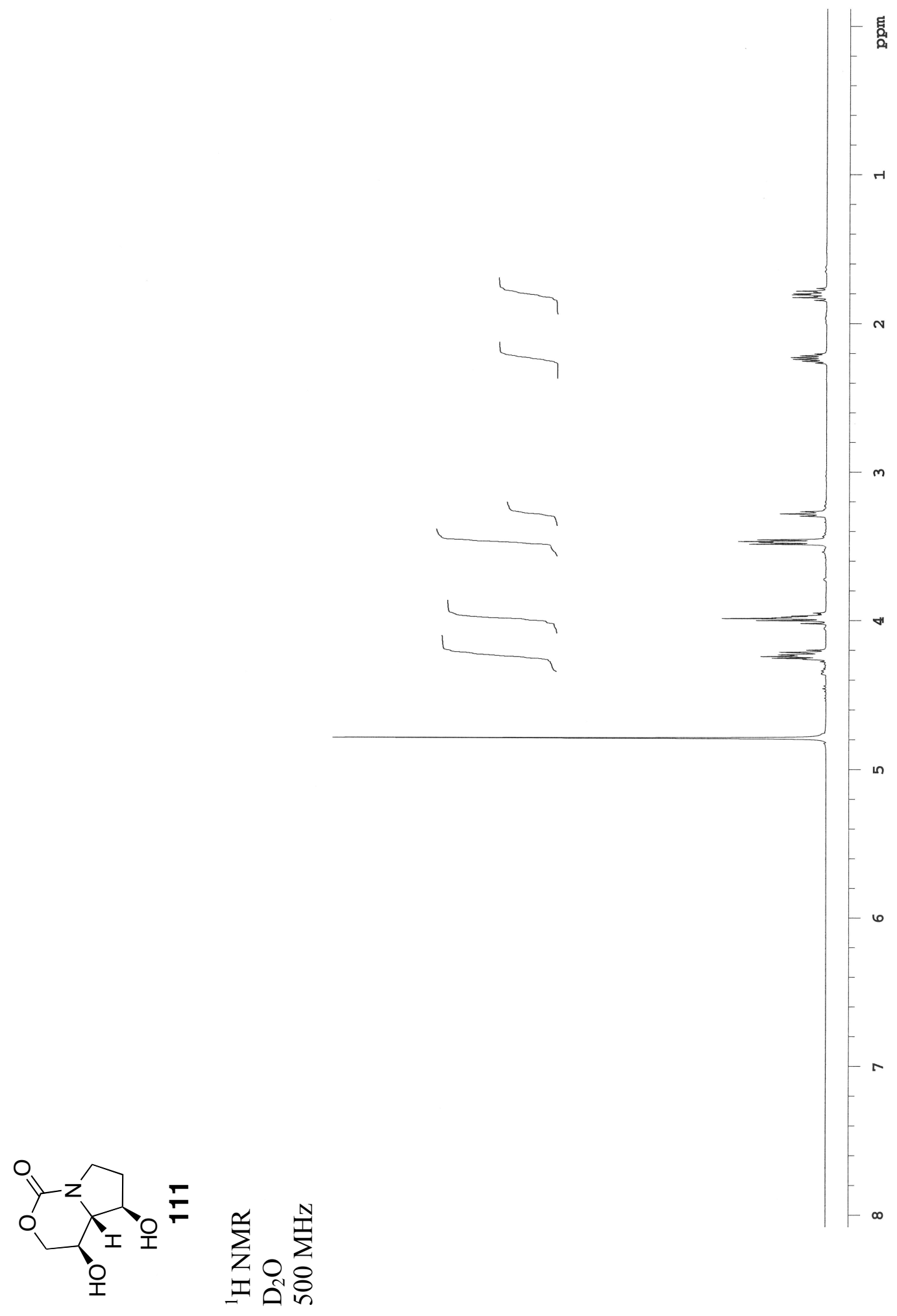




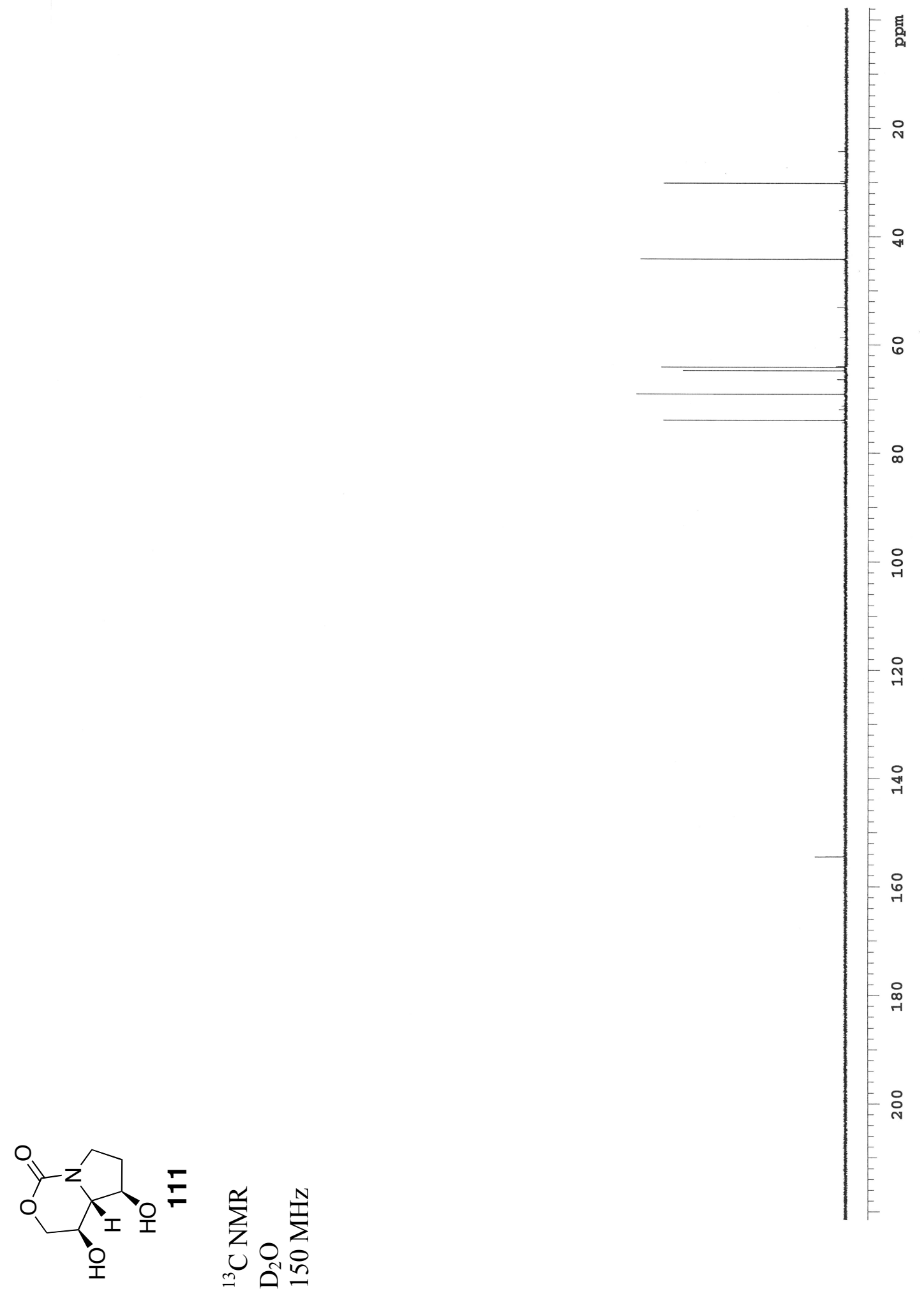

สิ 


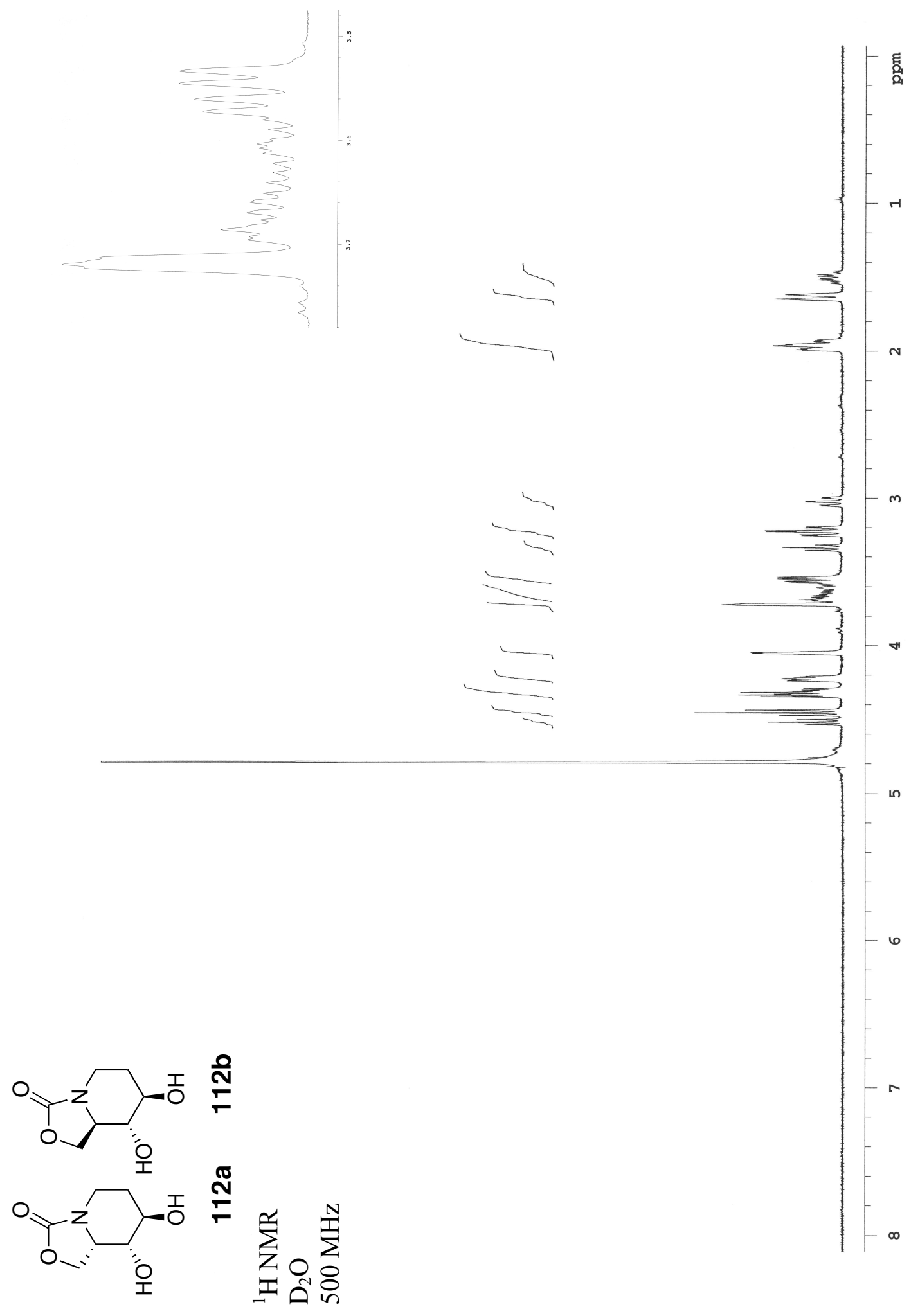




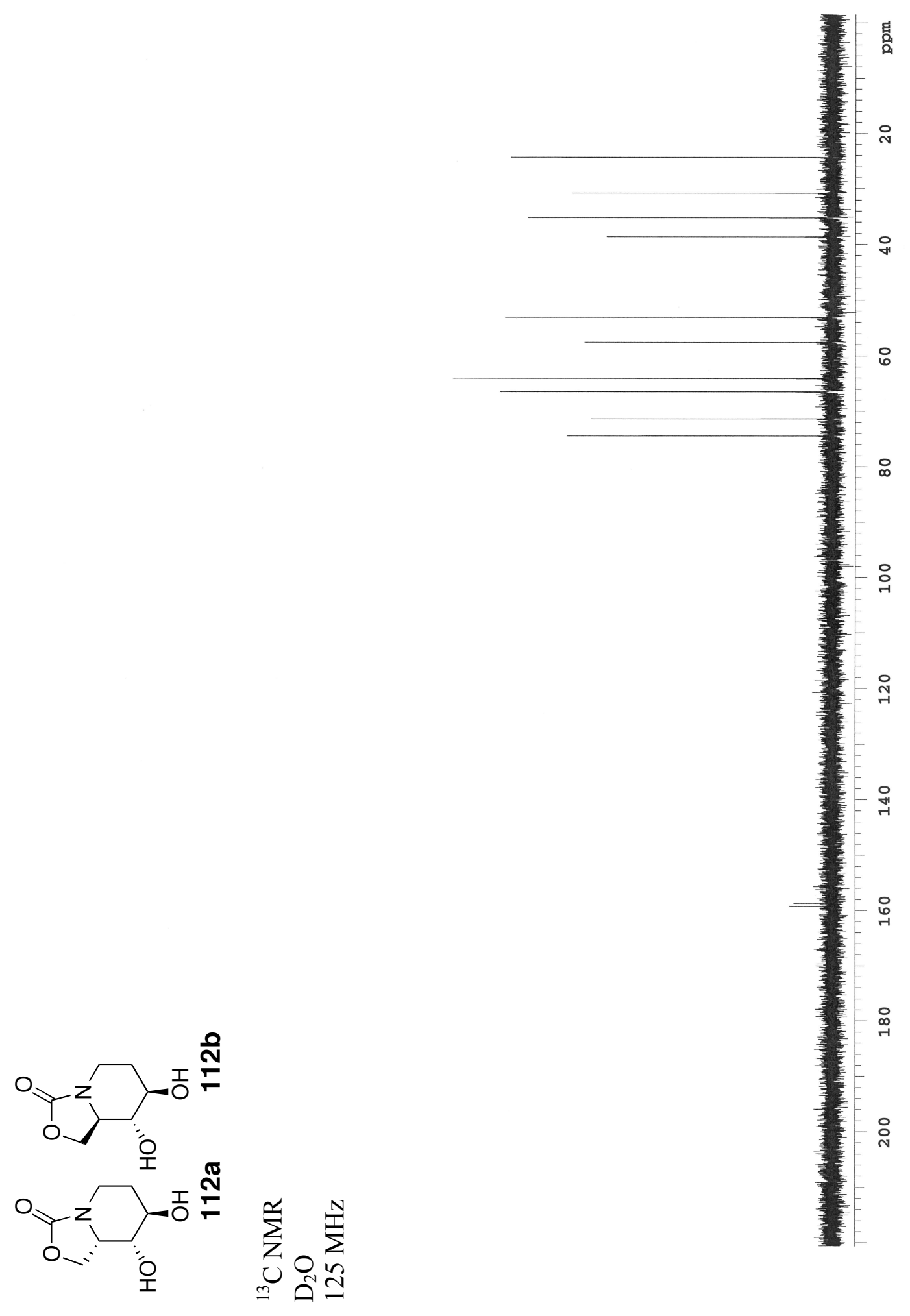

$\overrightarrow{3}$ 


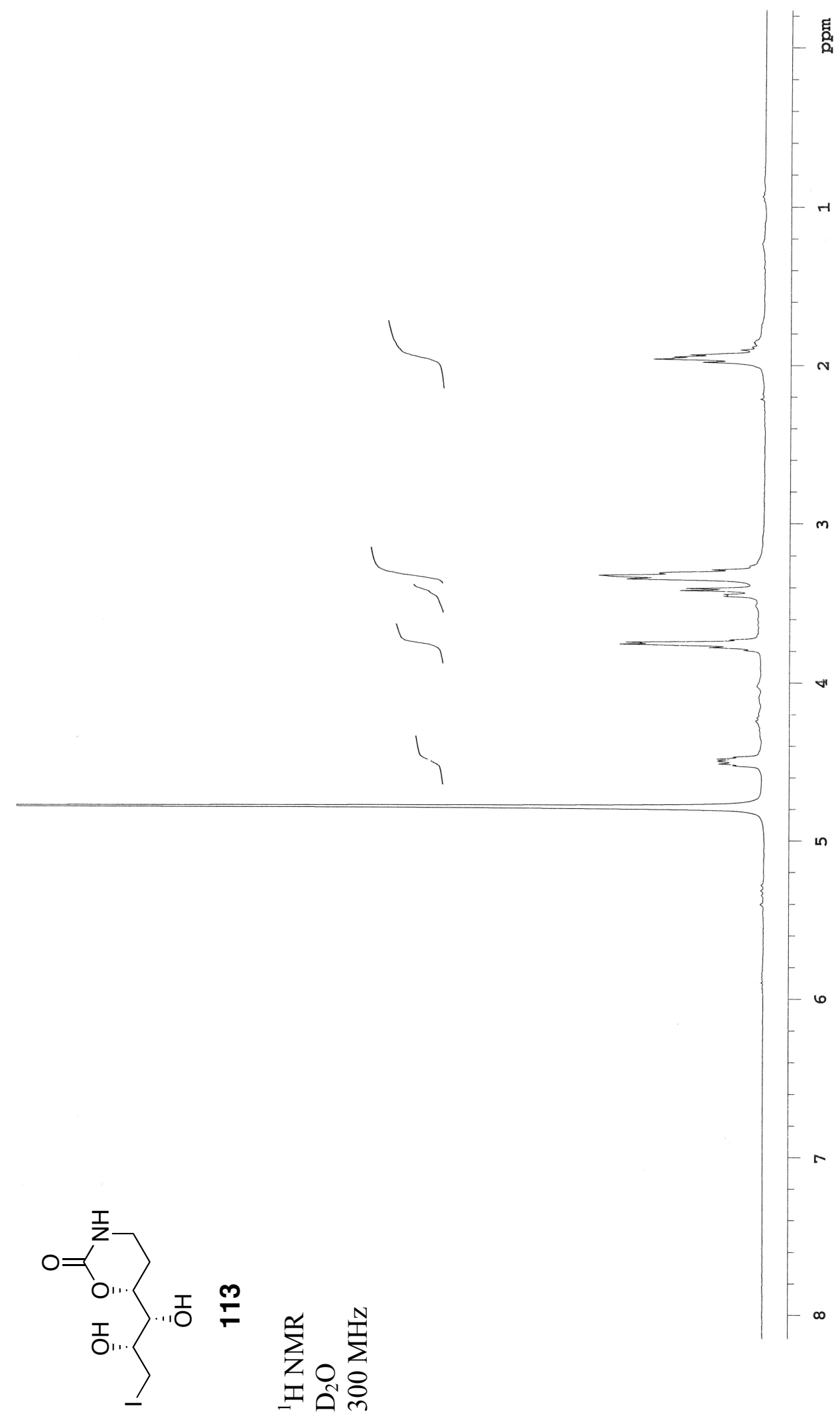



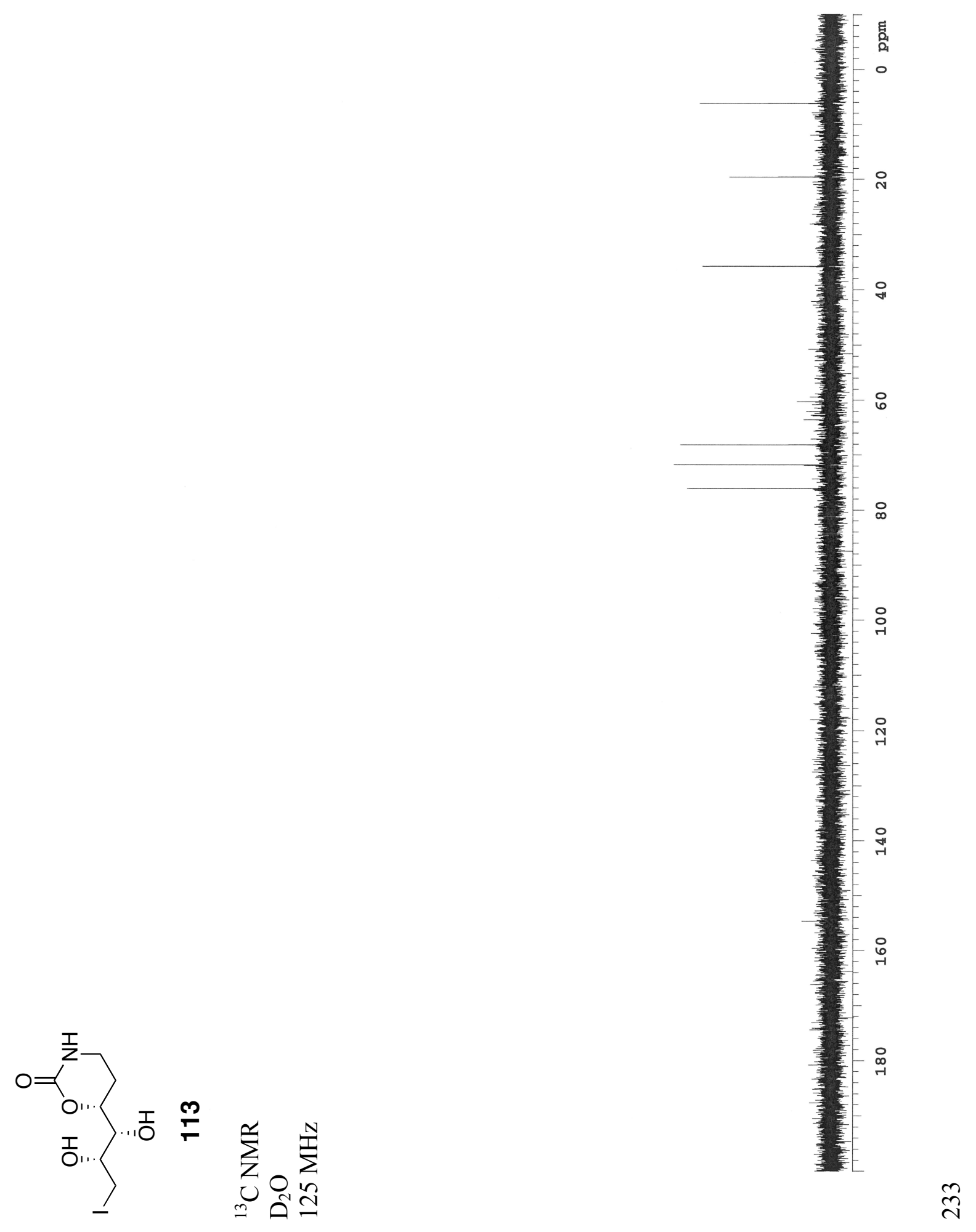


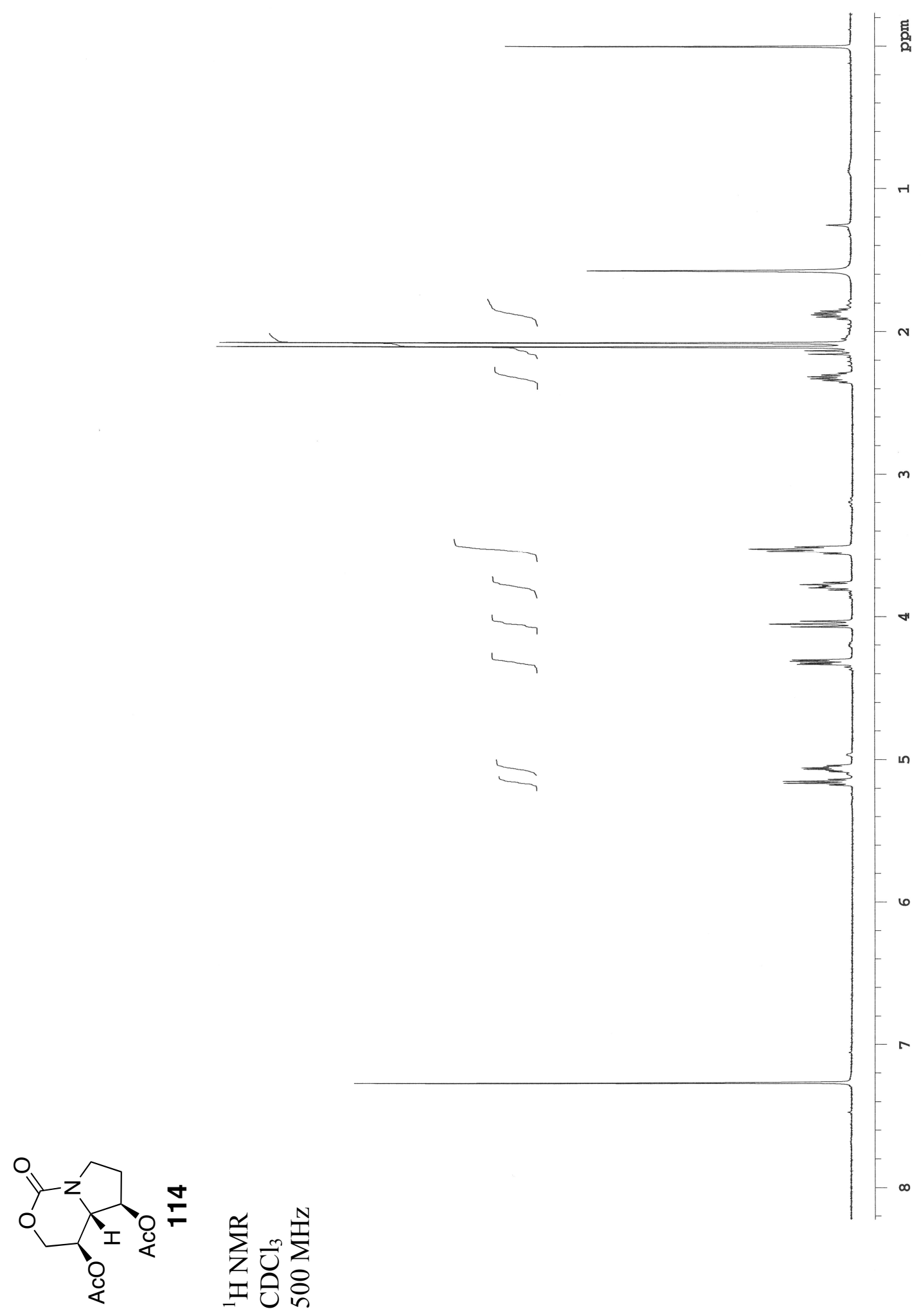

J 


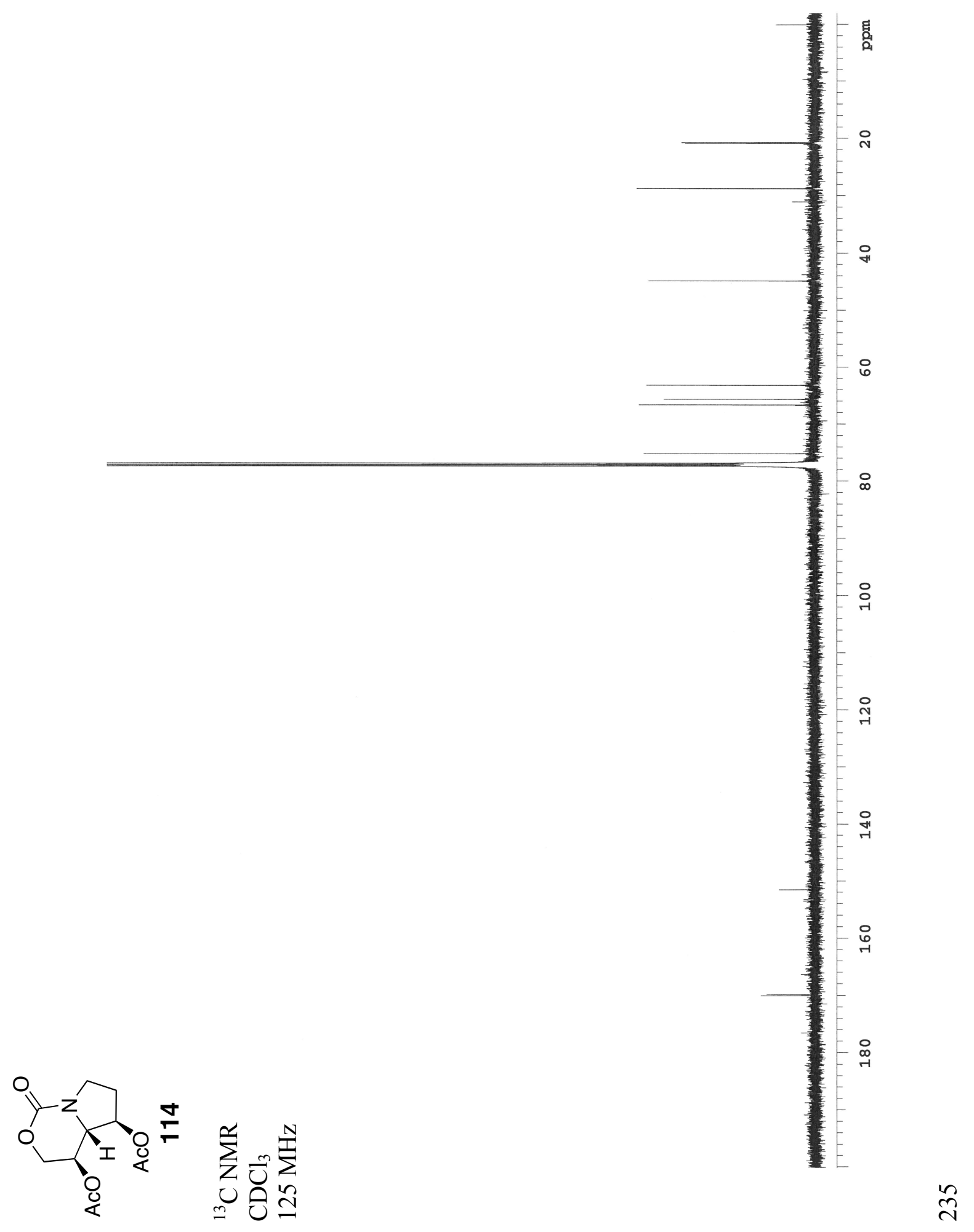




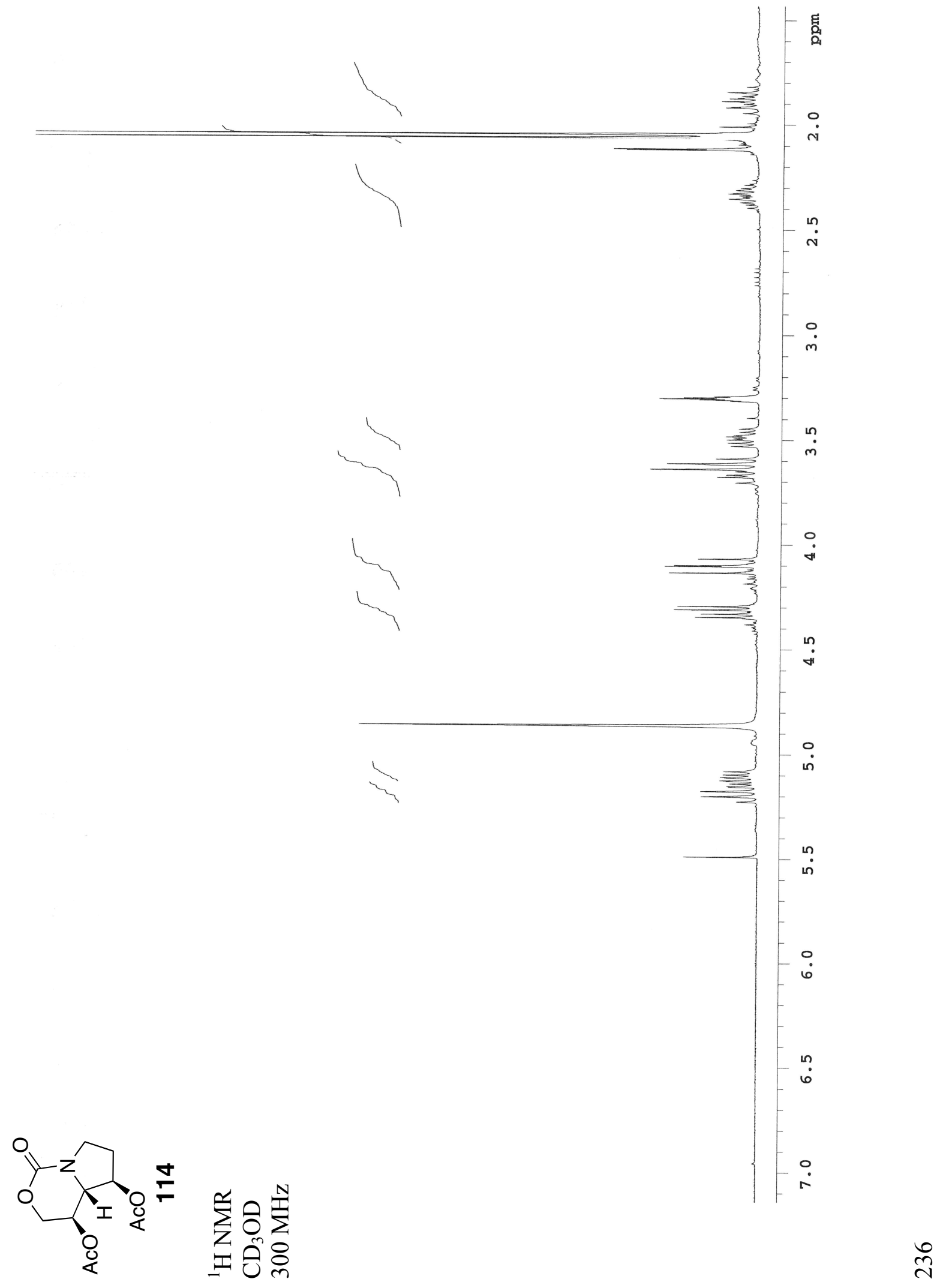



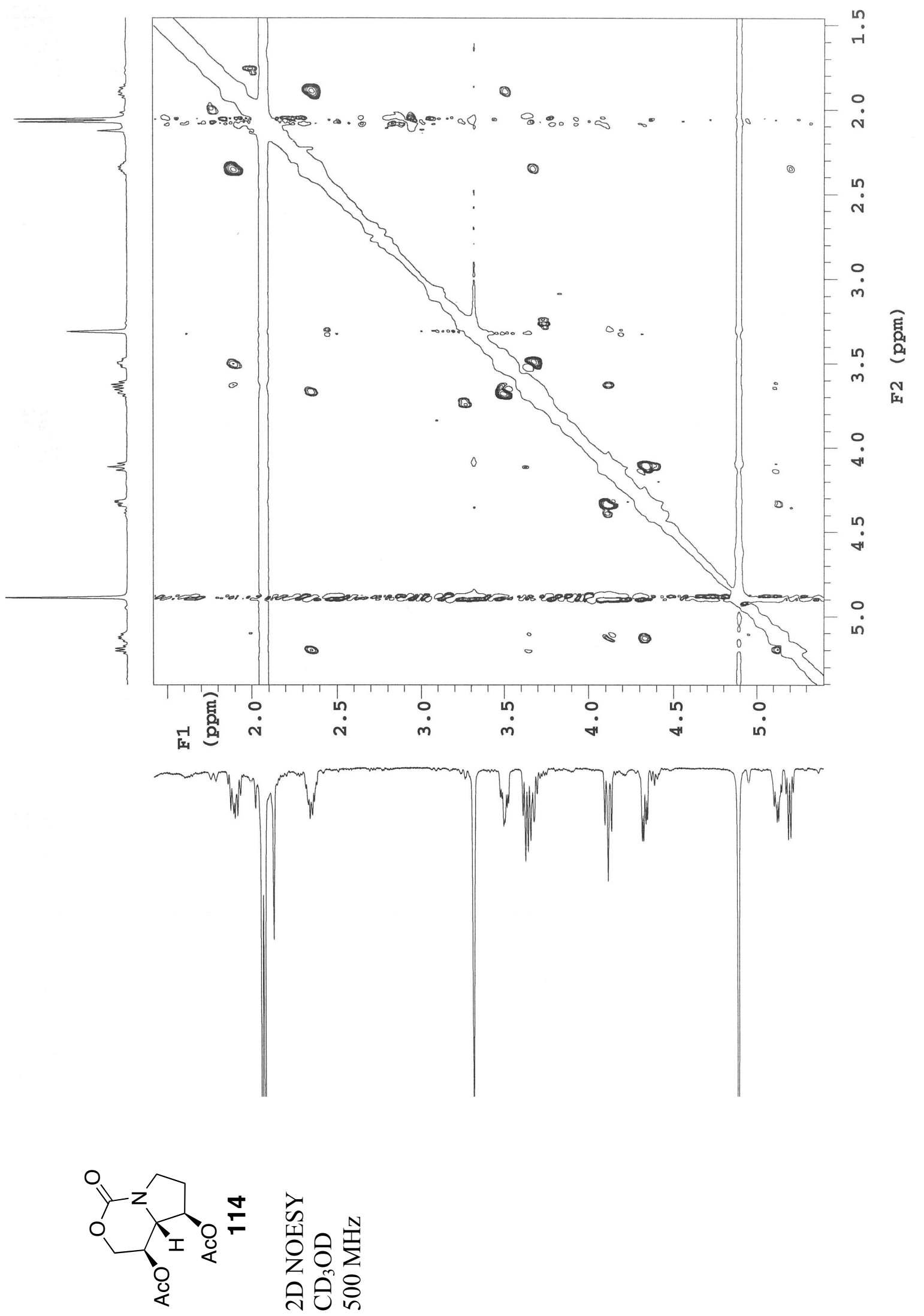


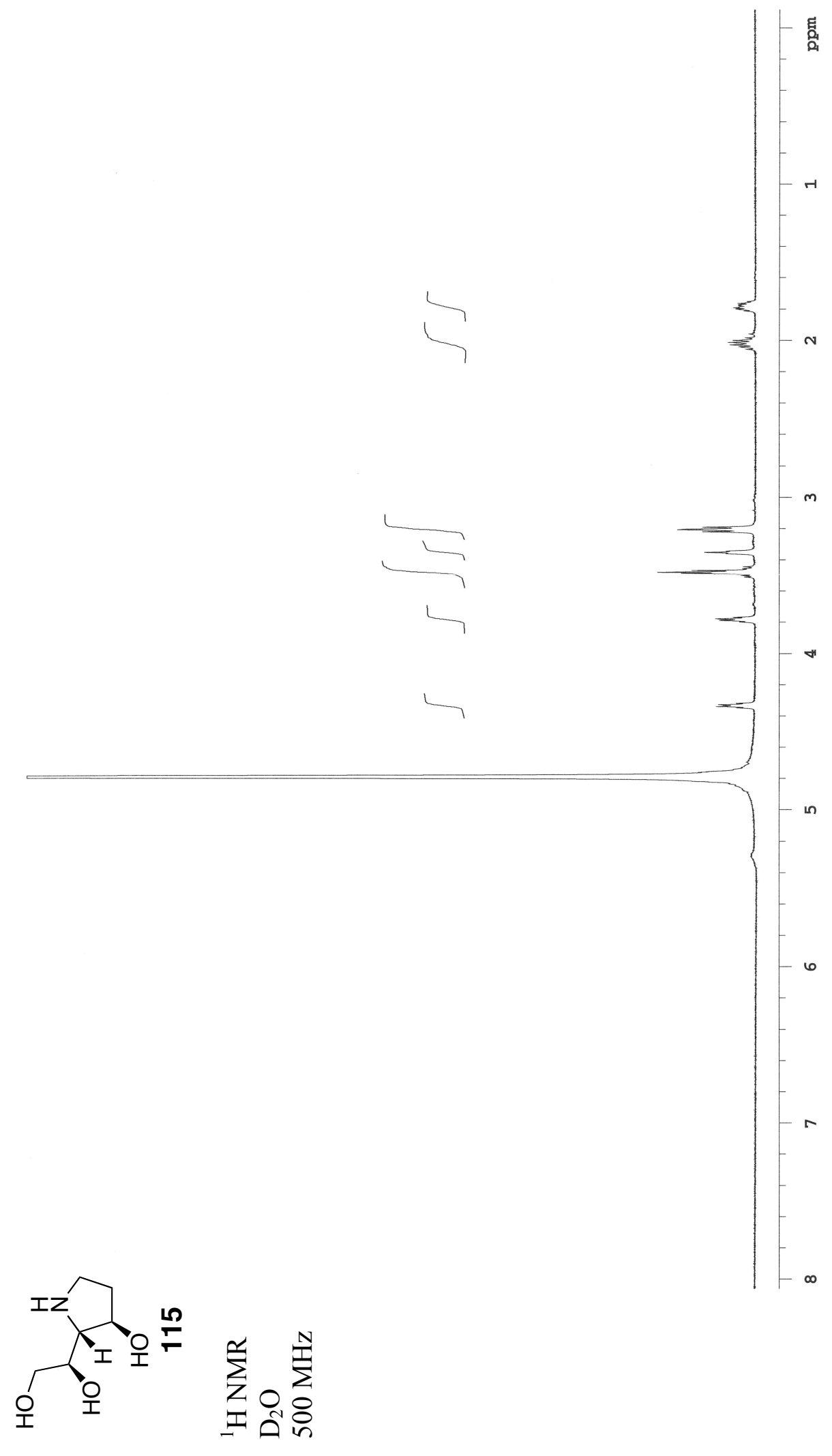




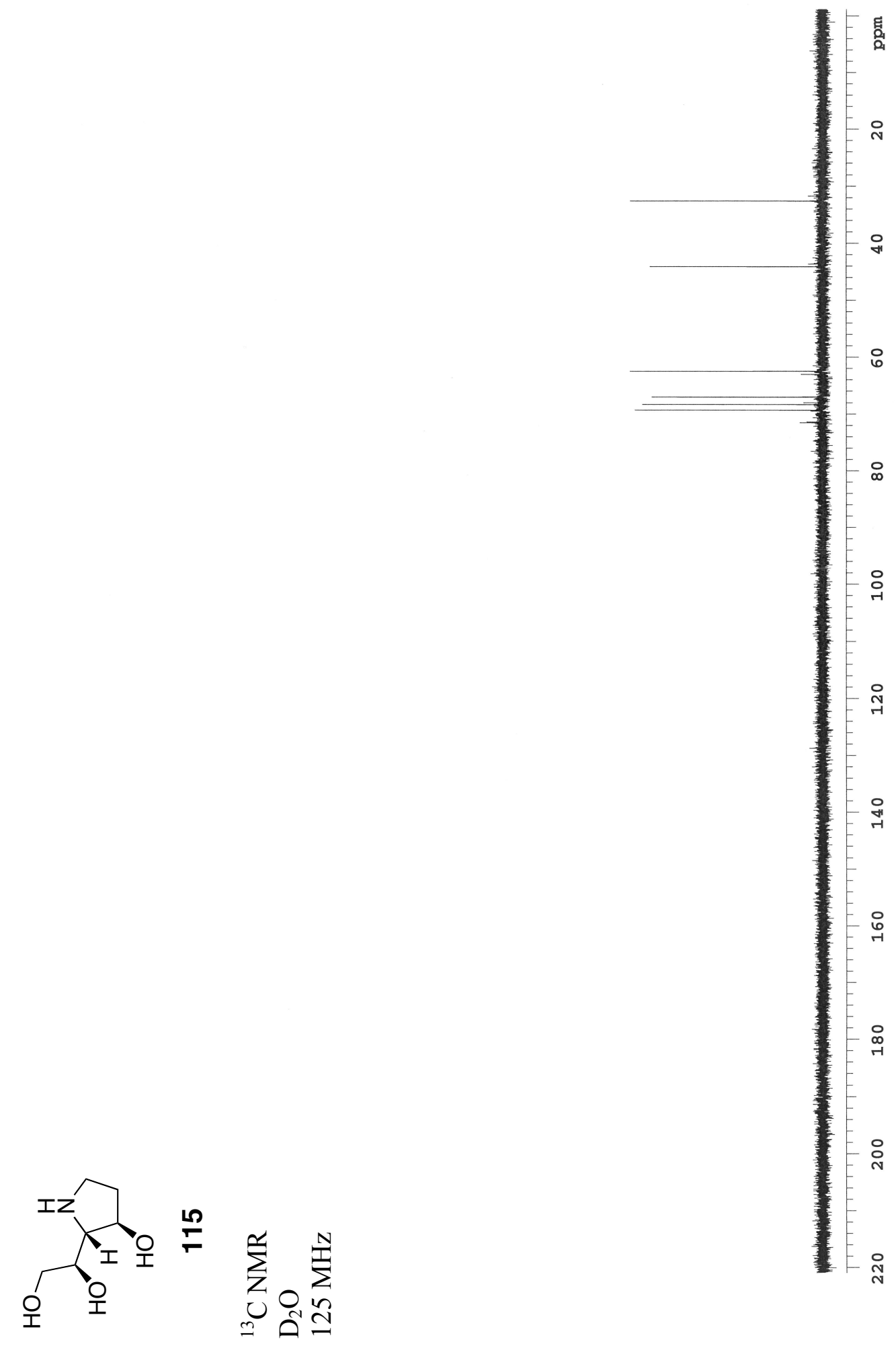

సे 


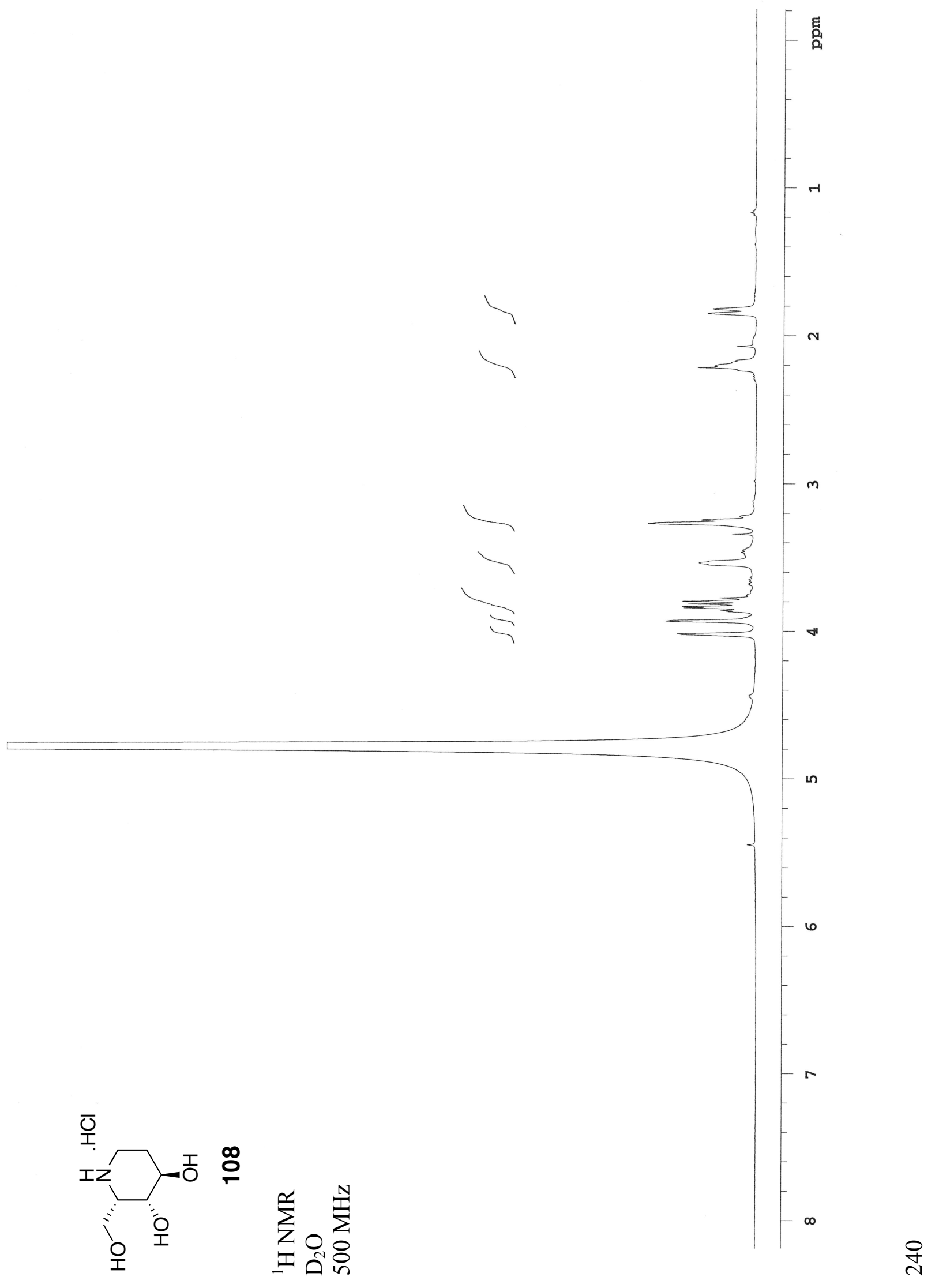




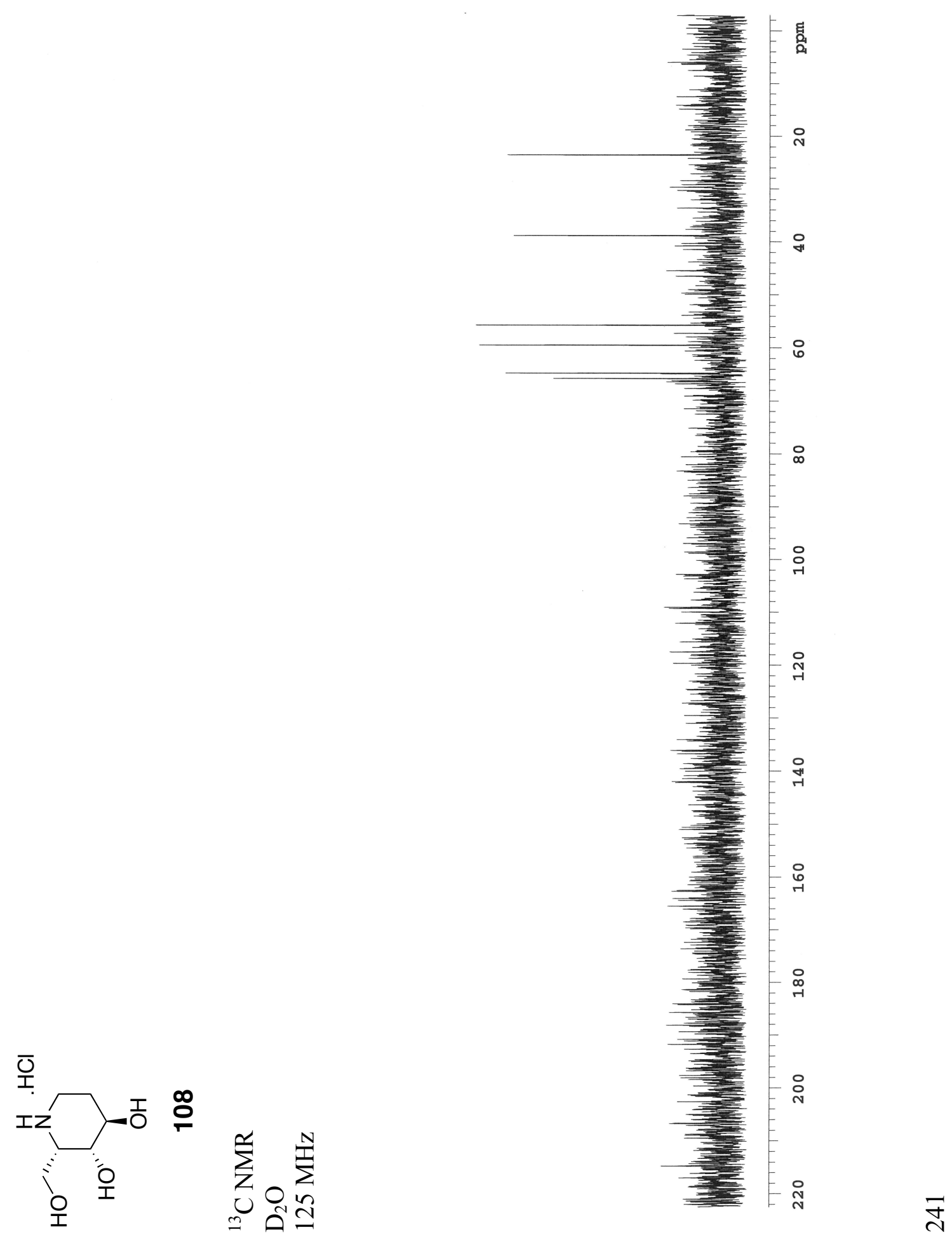




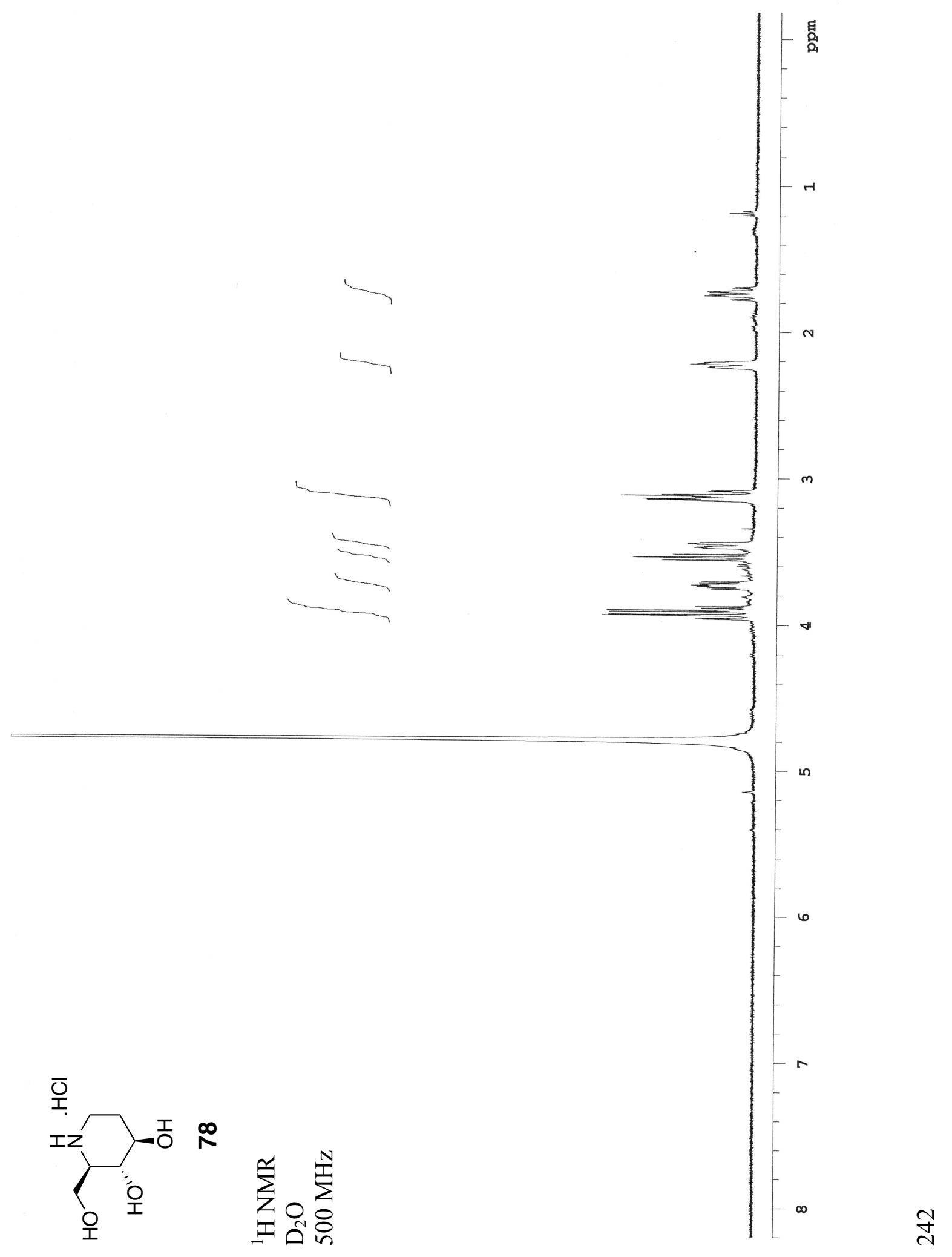




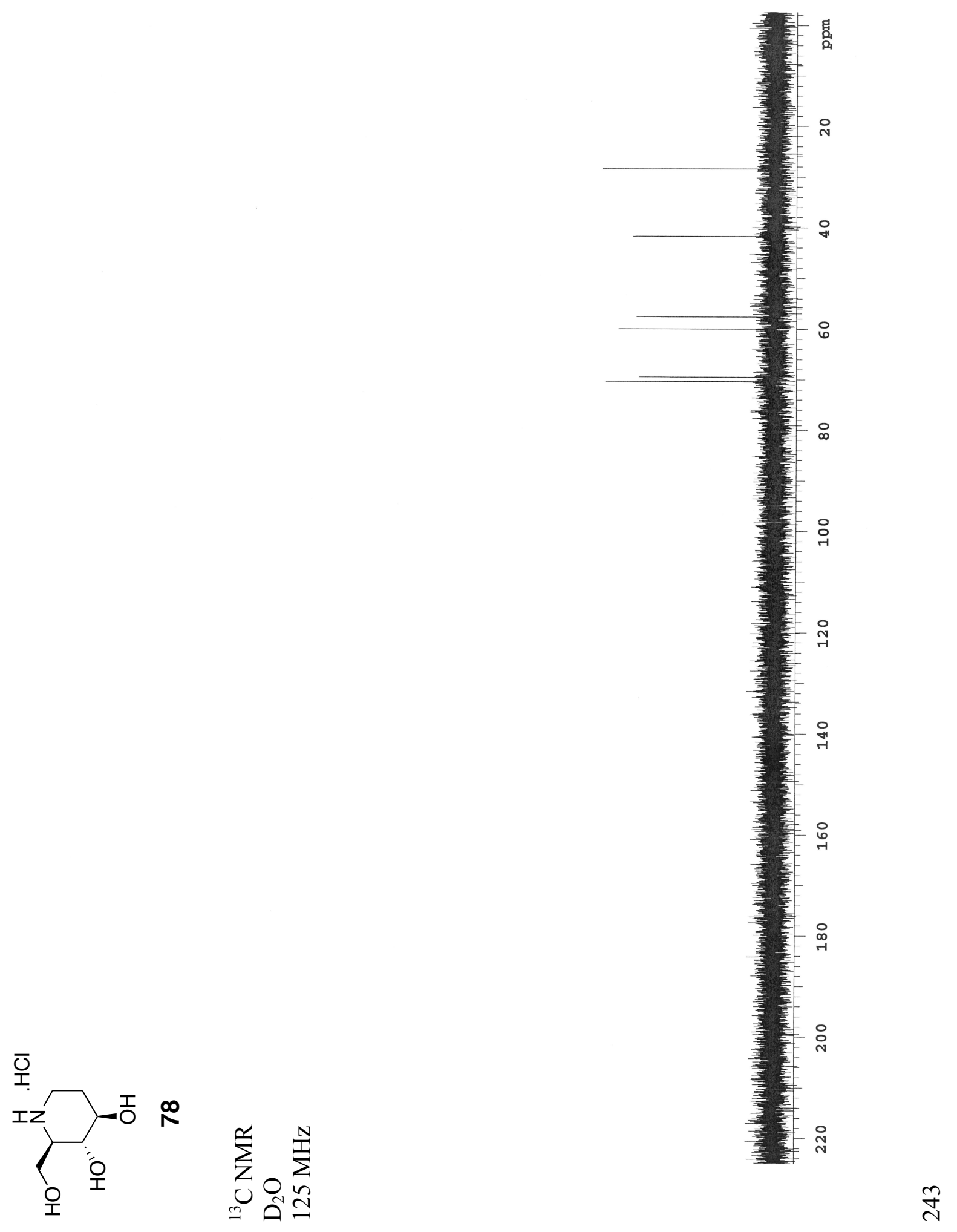




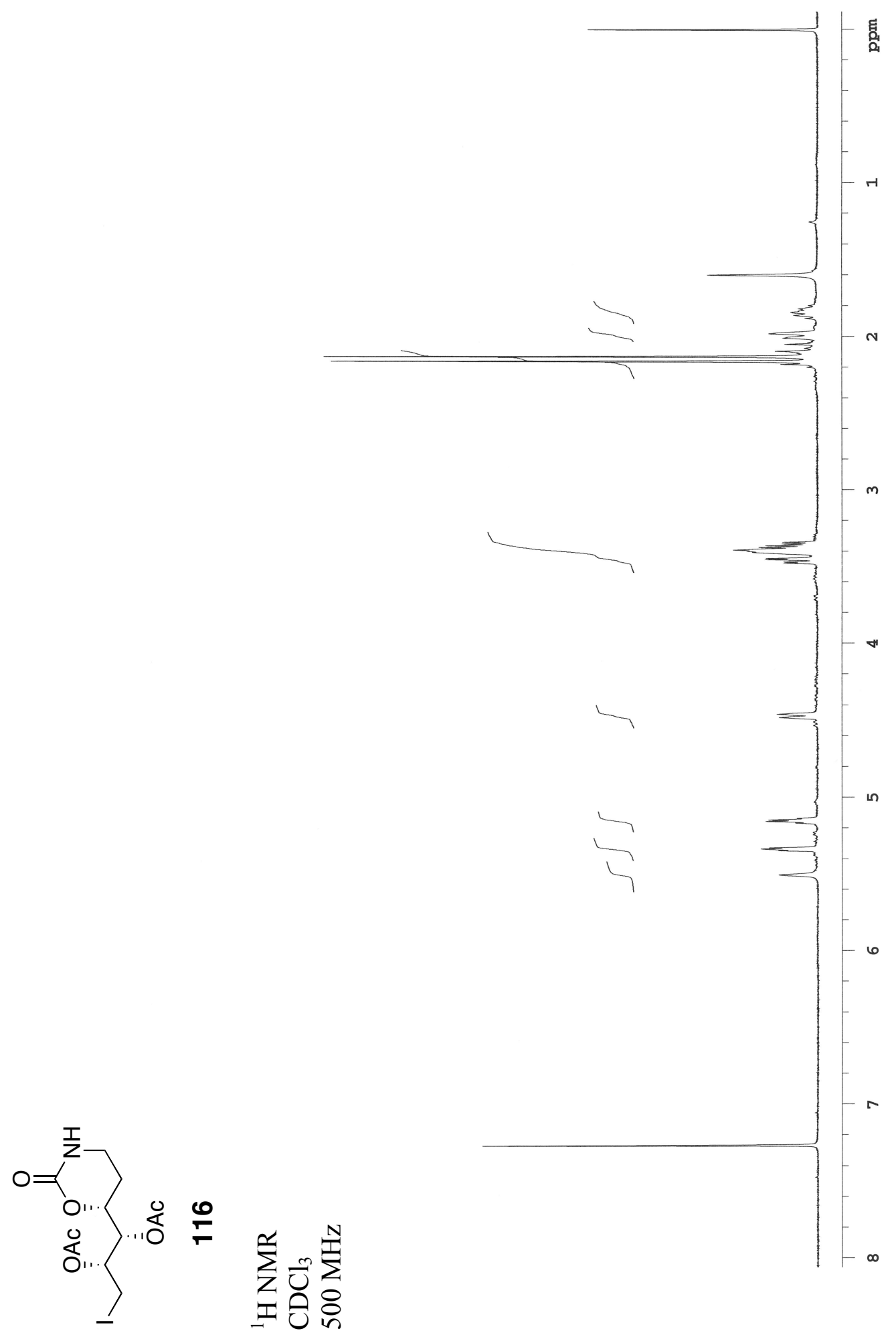




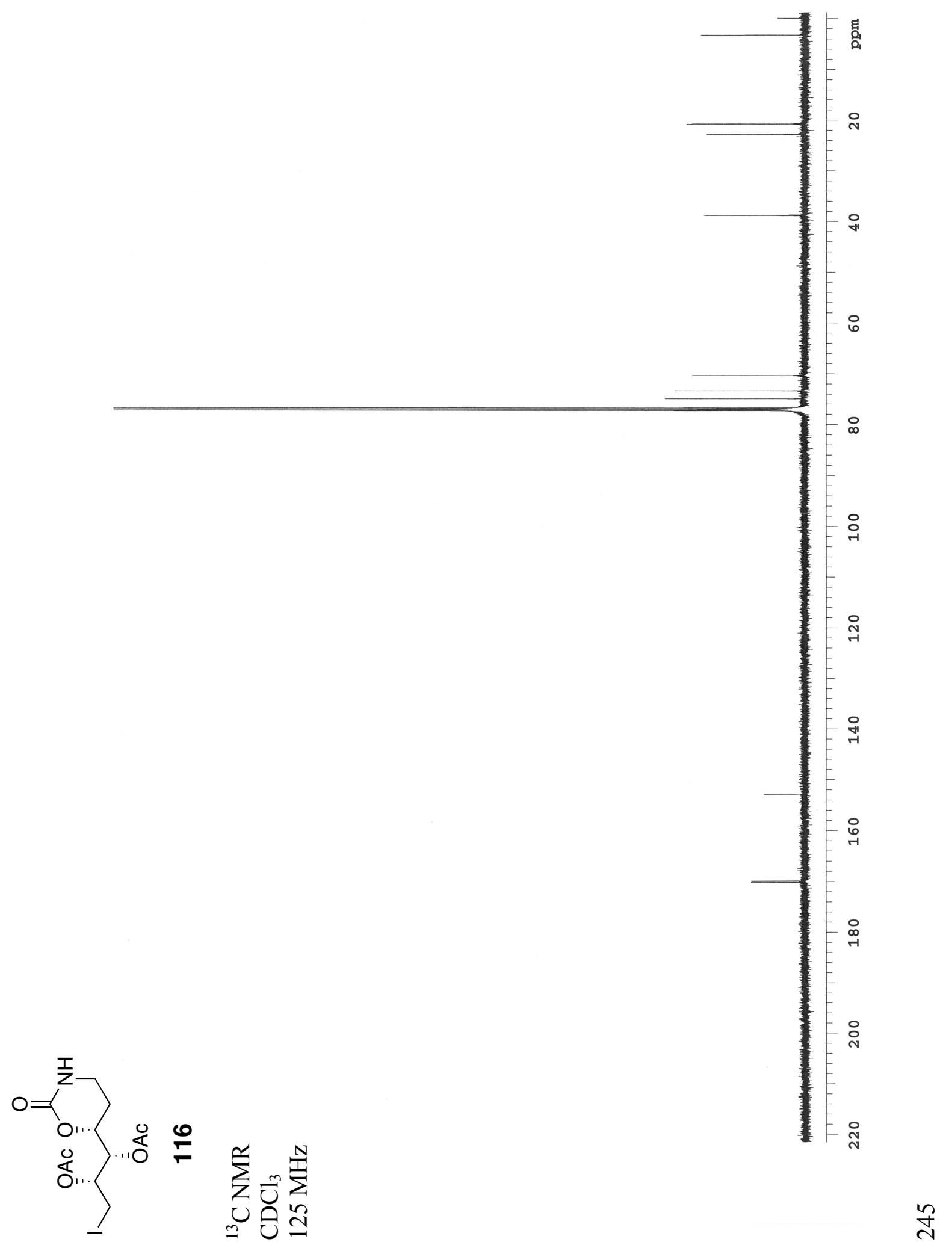




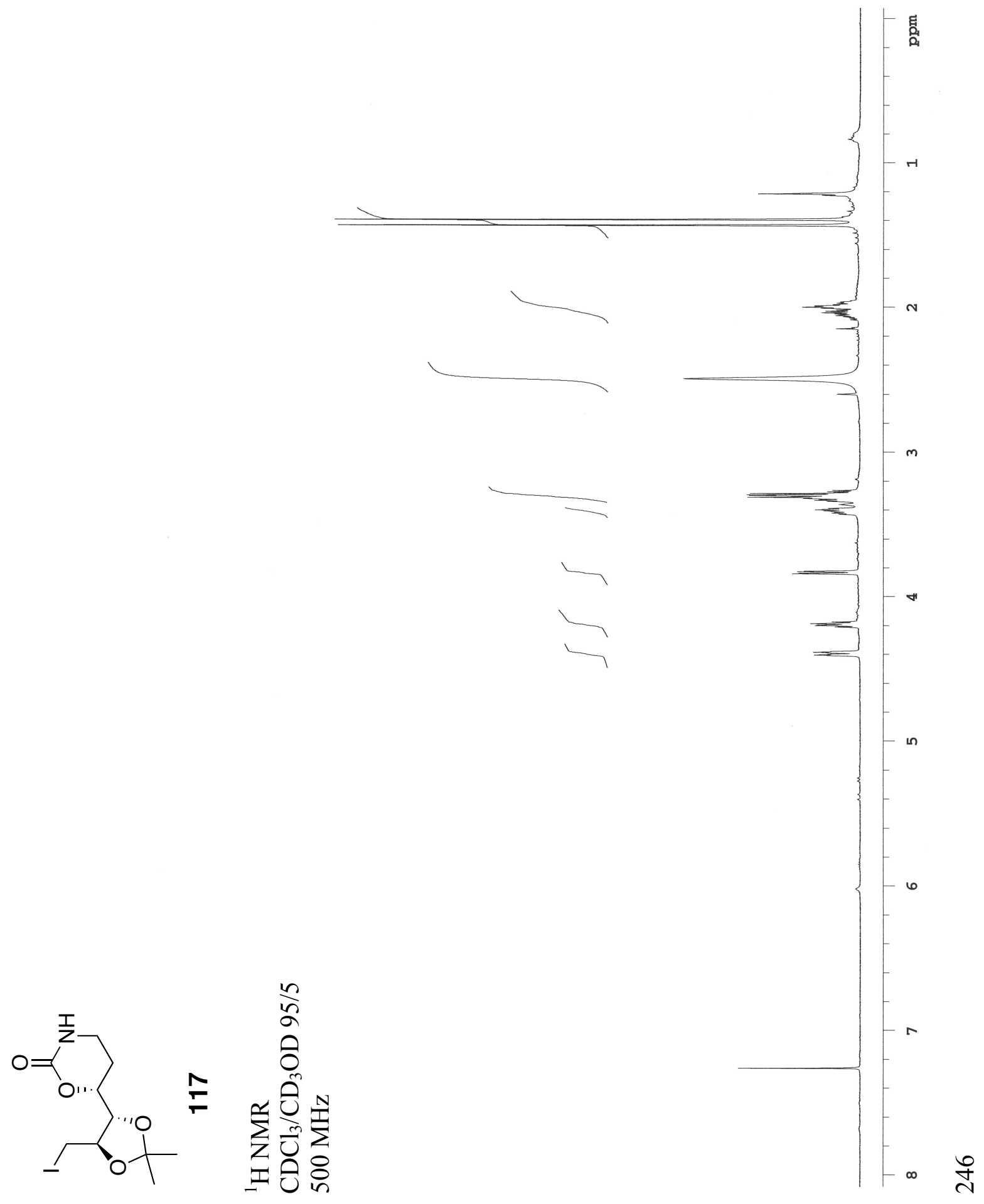




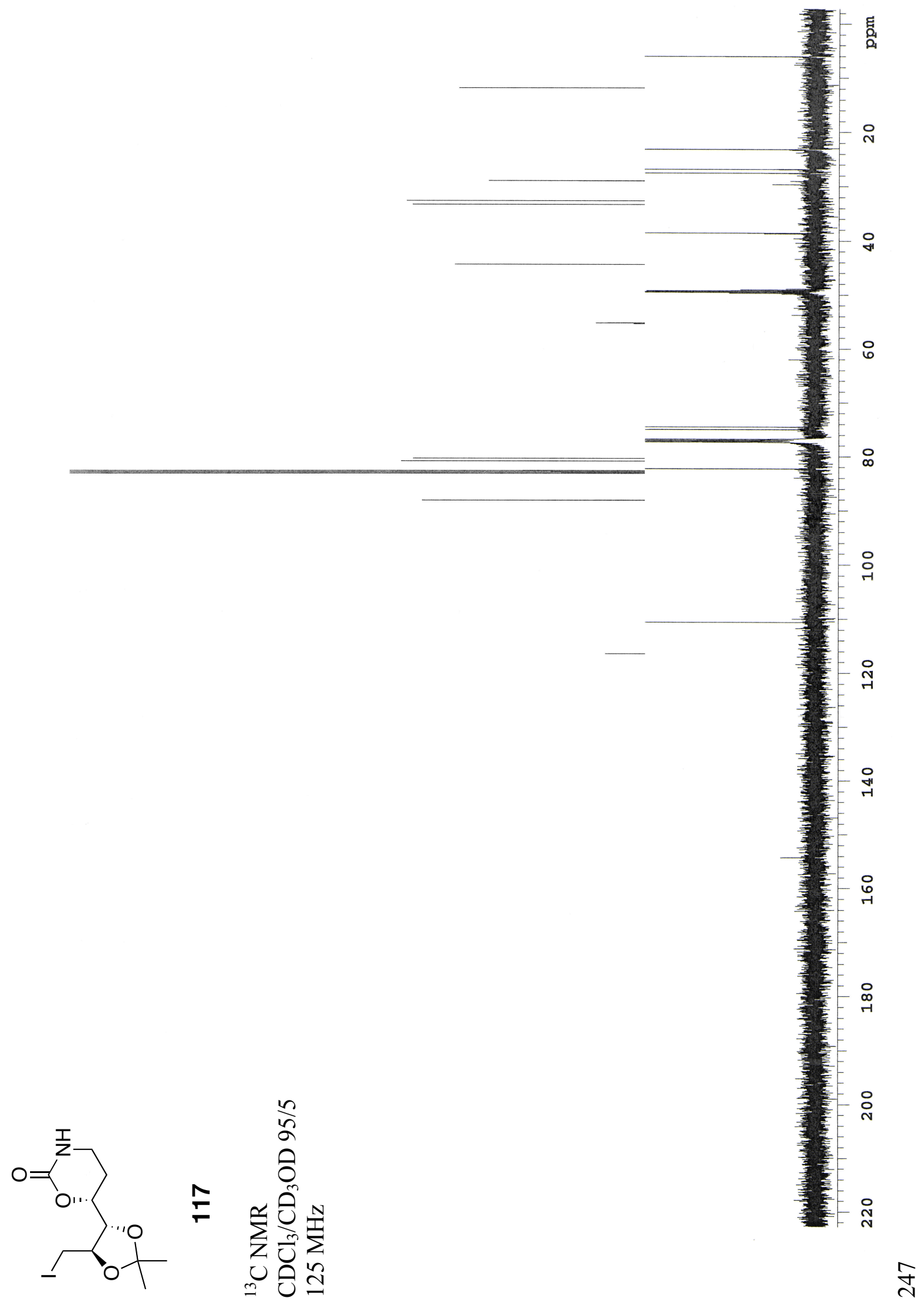




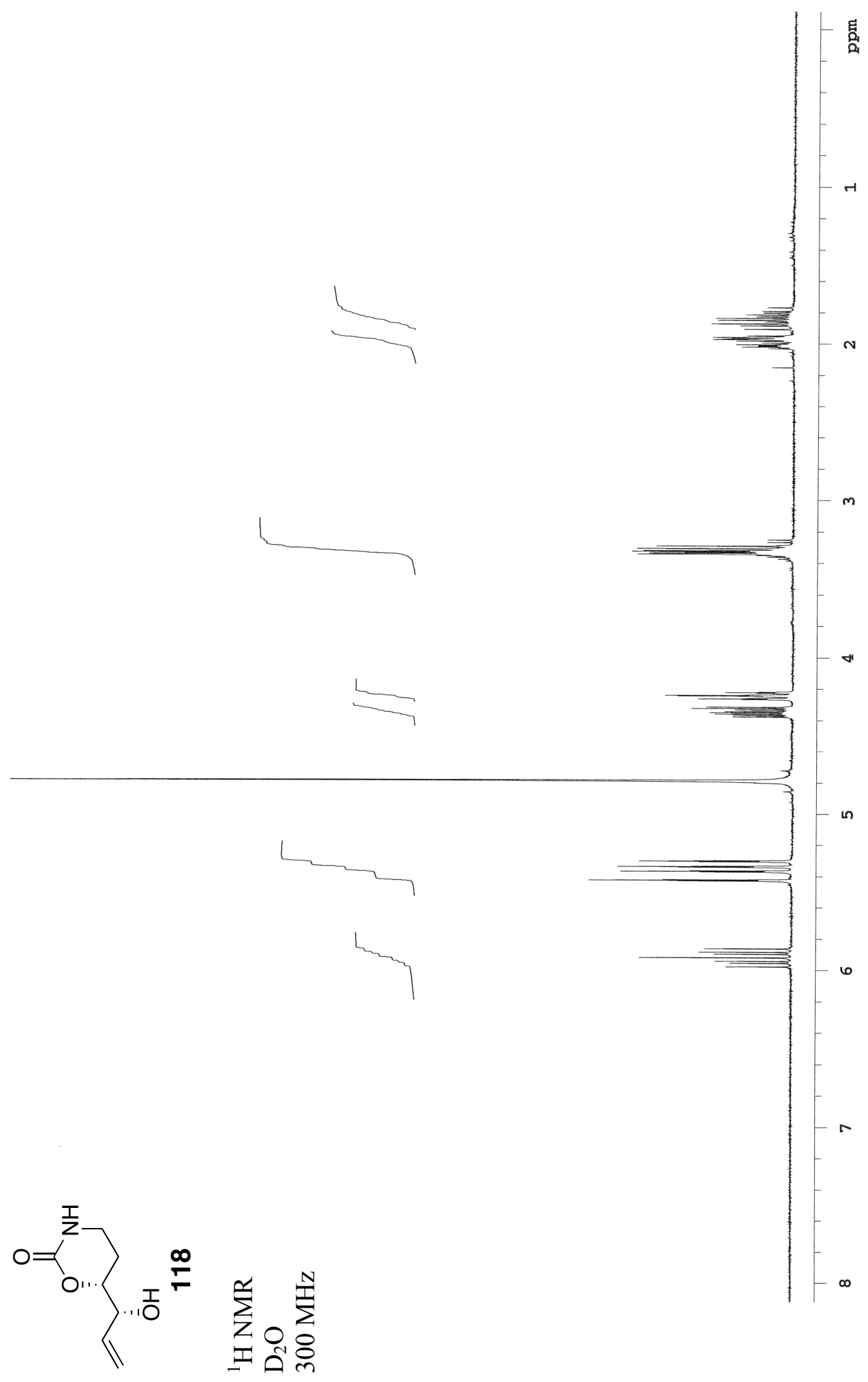




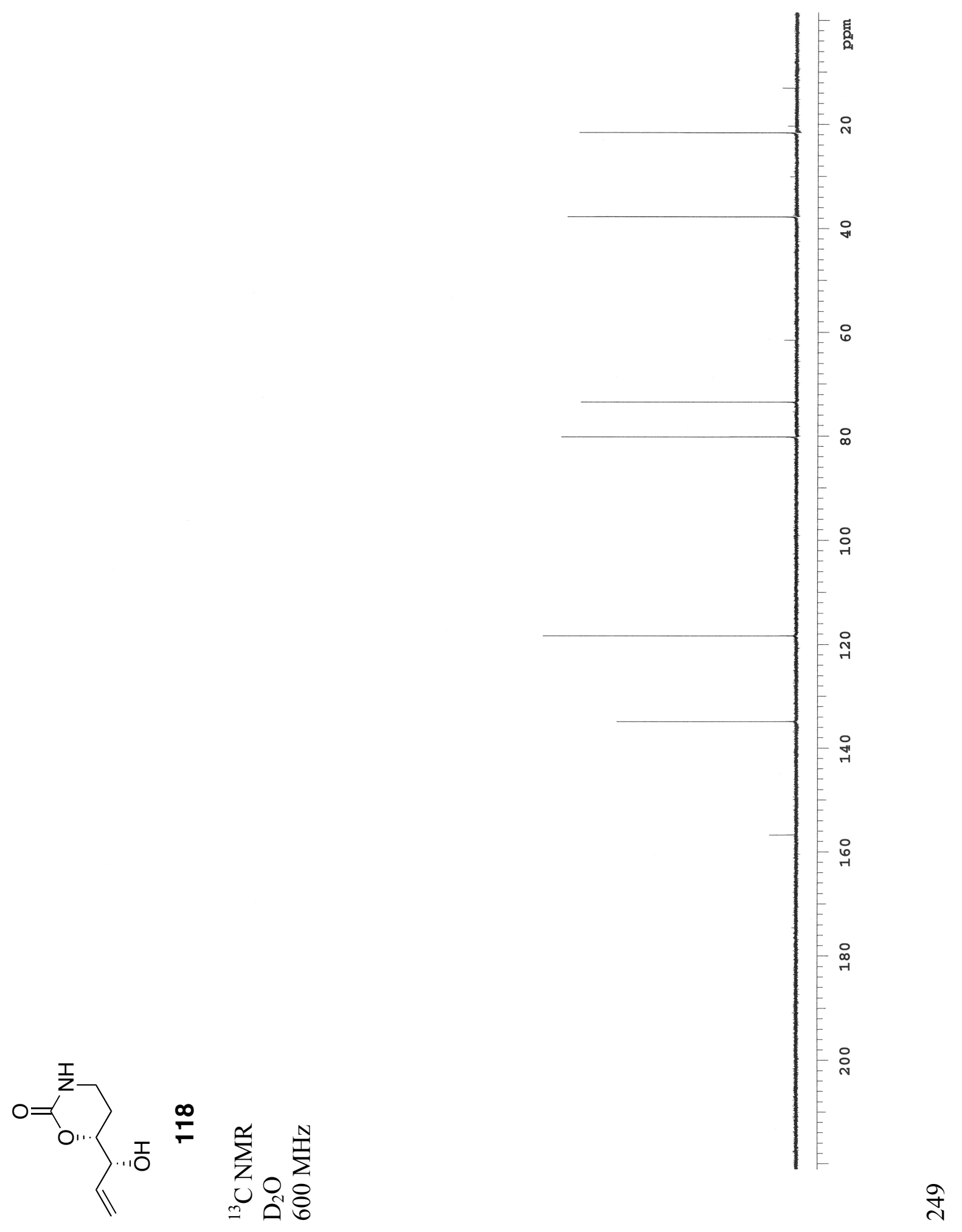




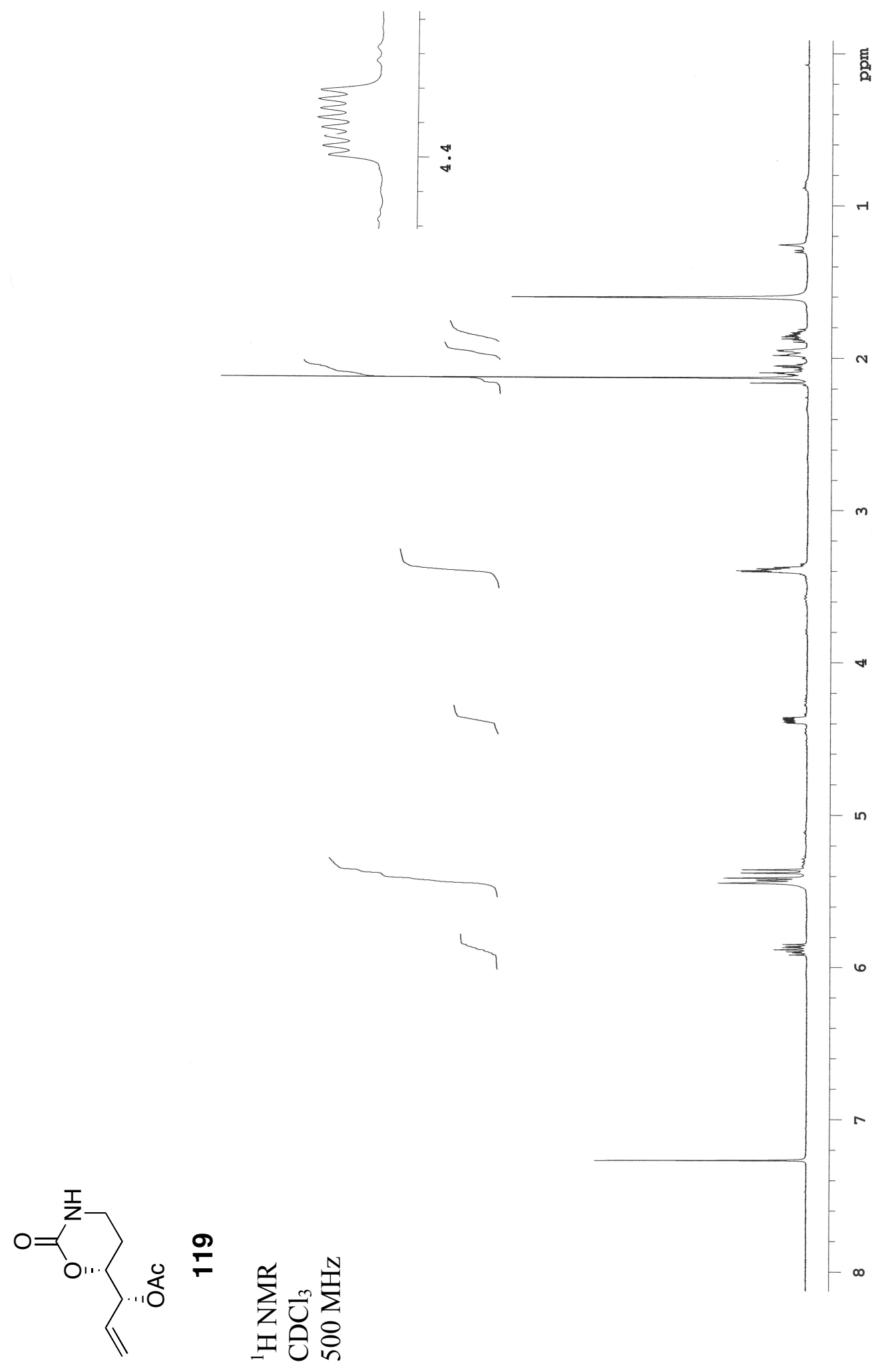




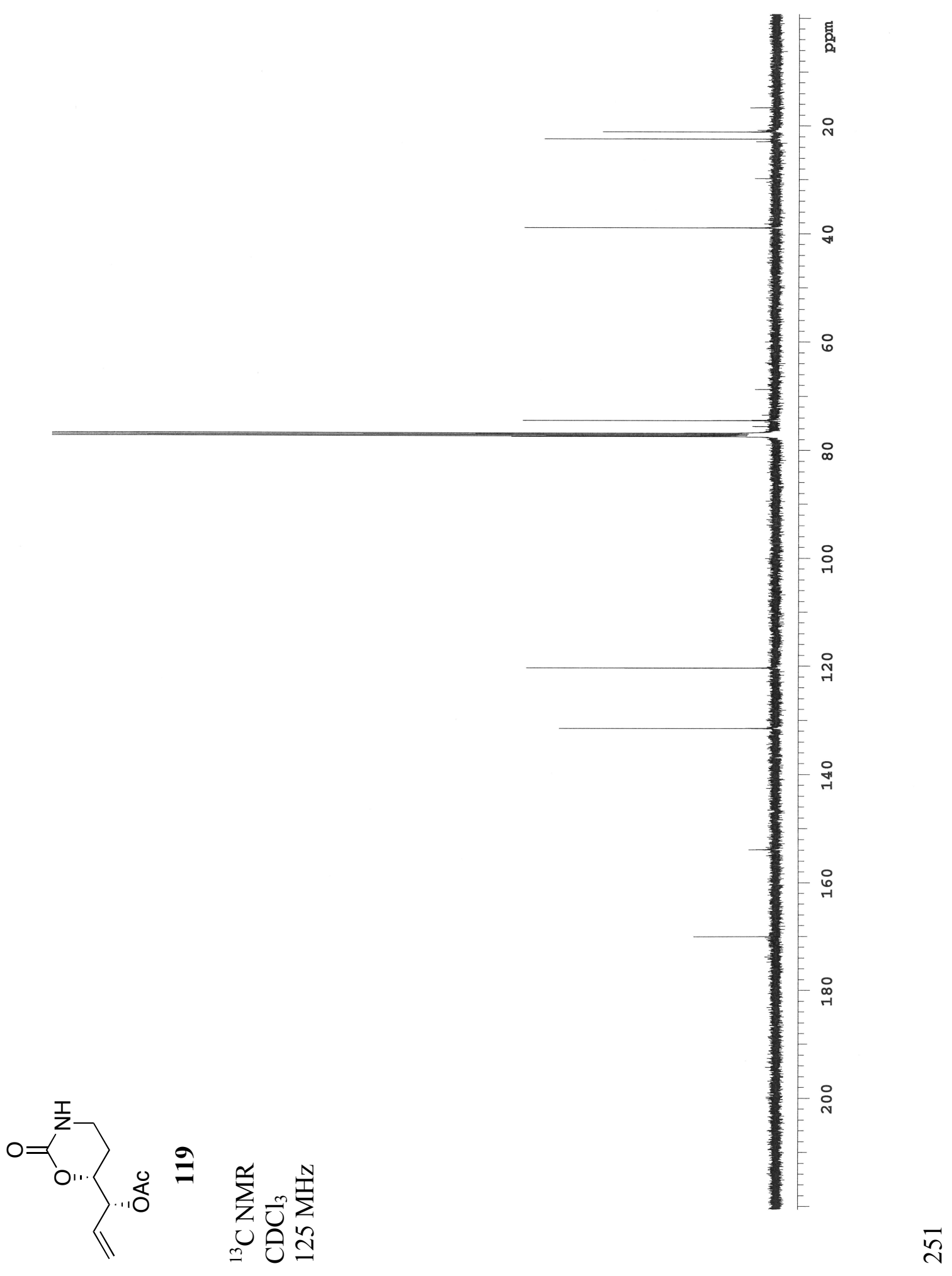


Chapter 3: NMR Spectra 


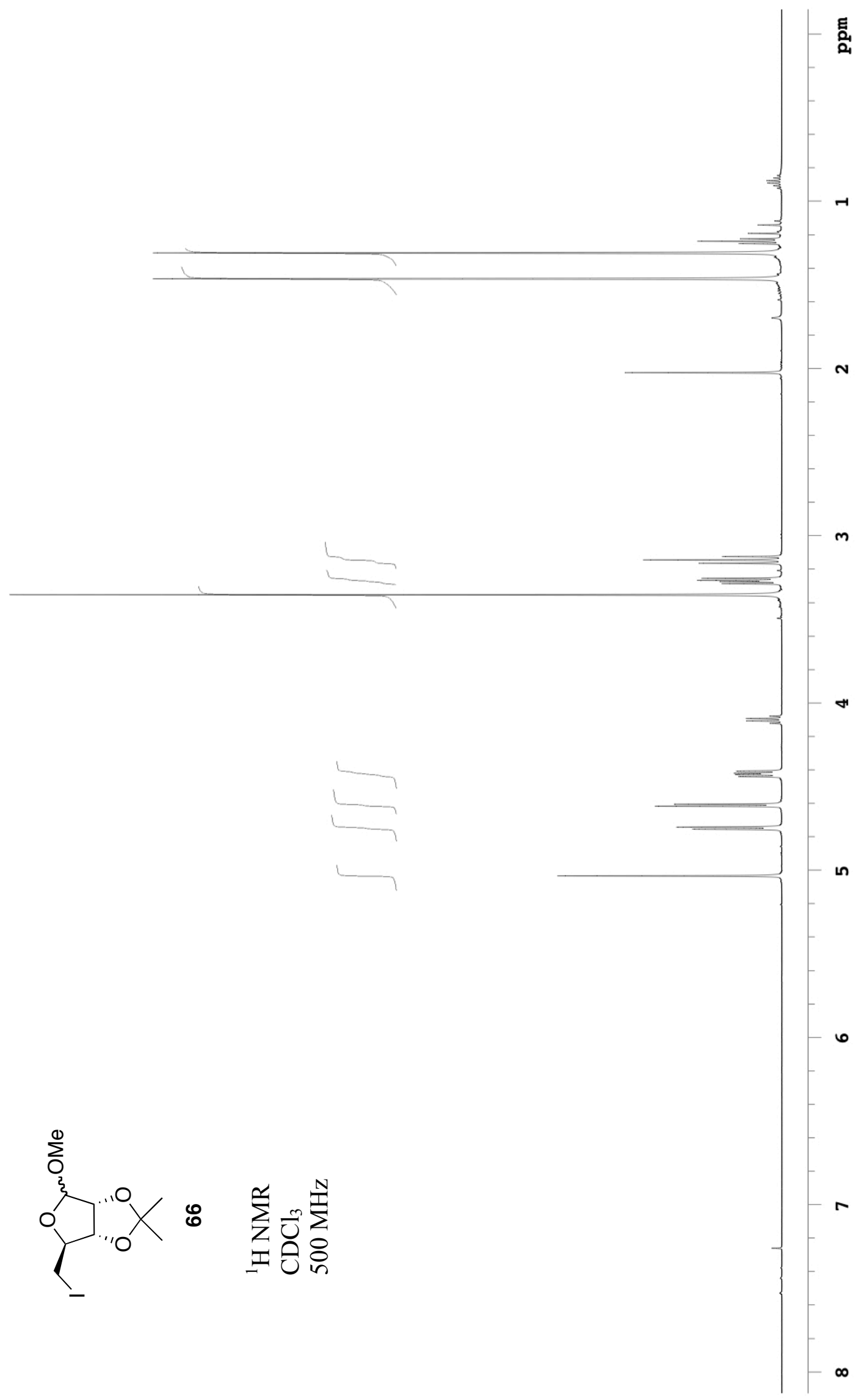




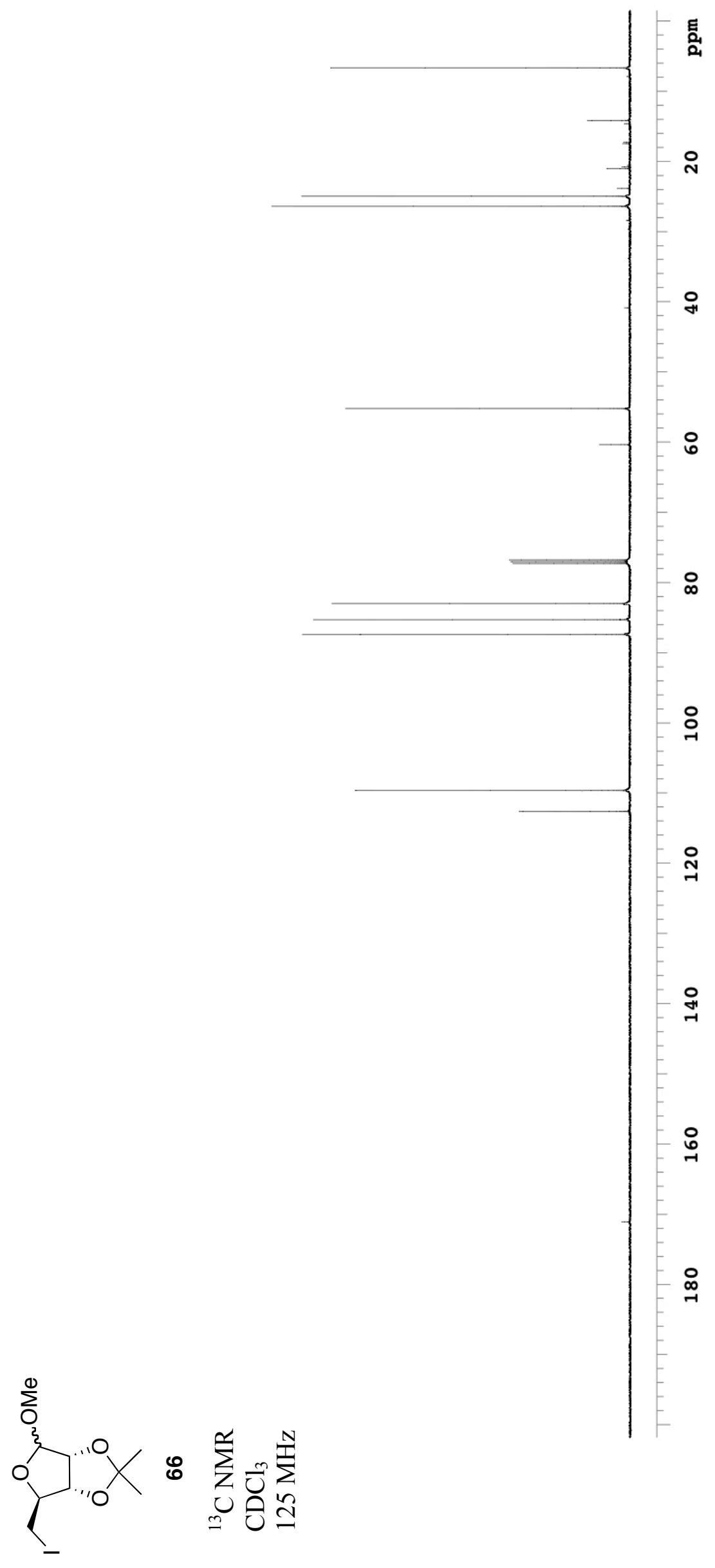




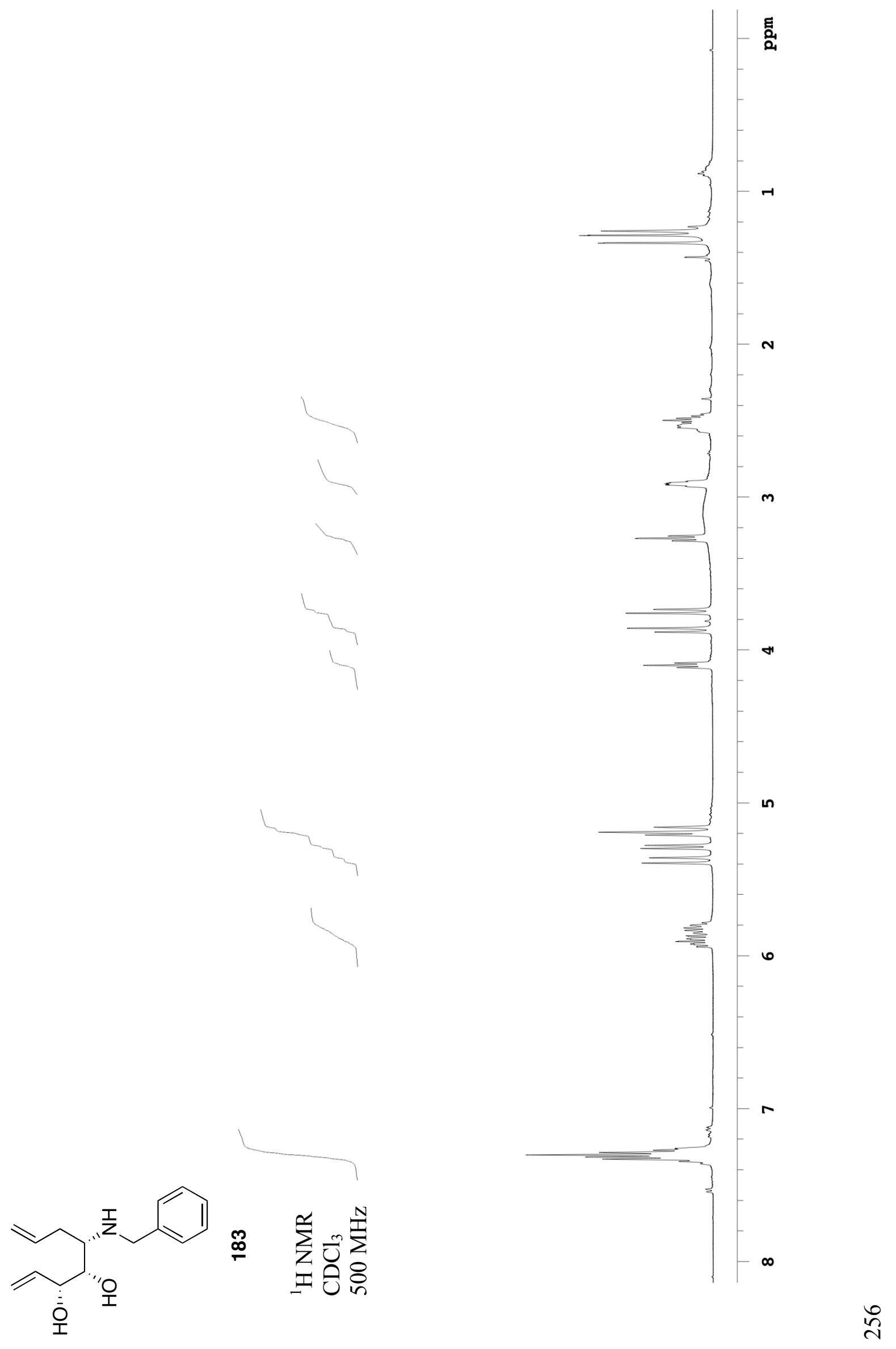




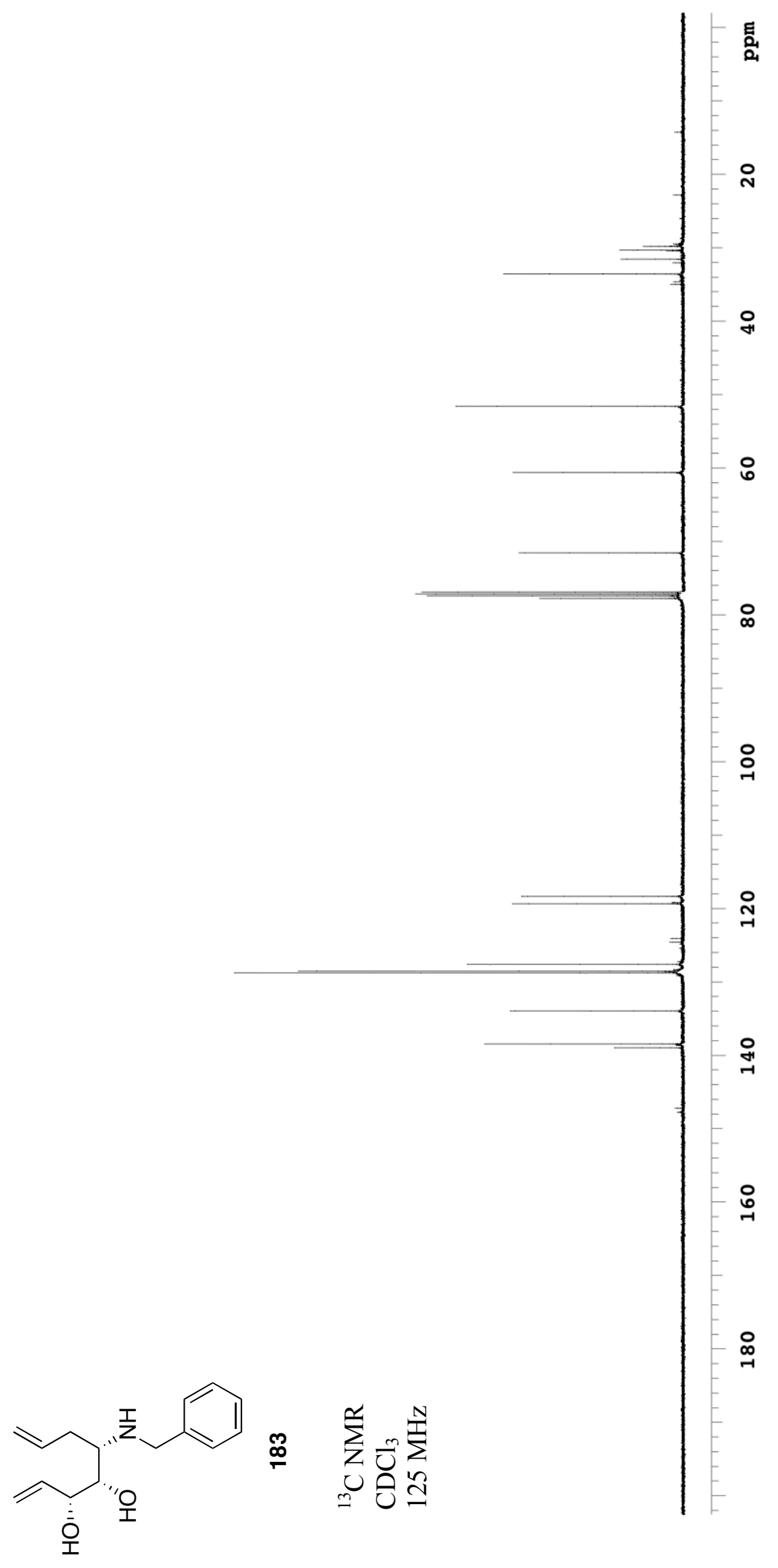




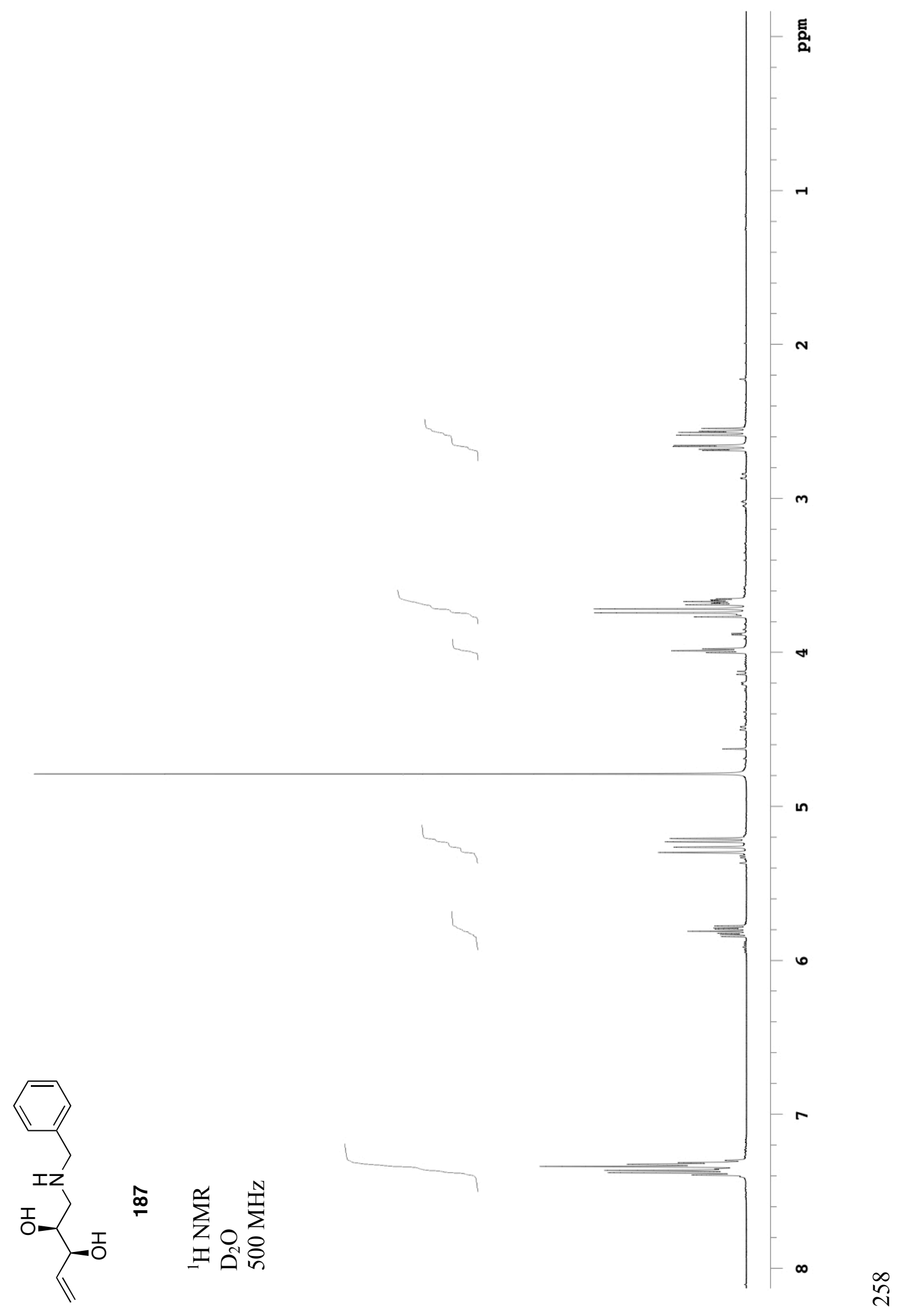




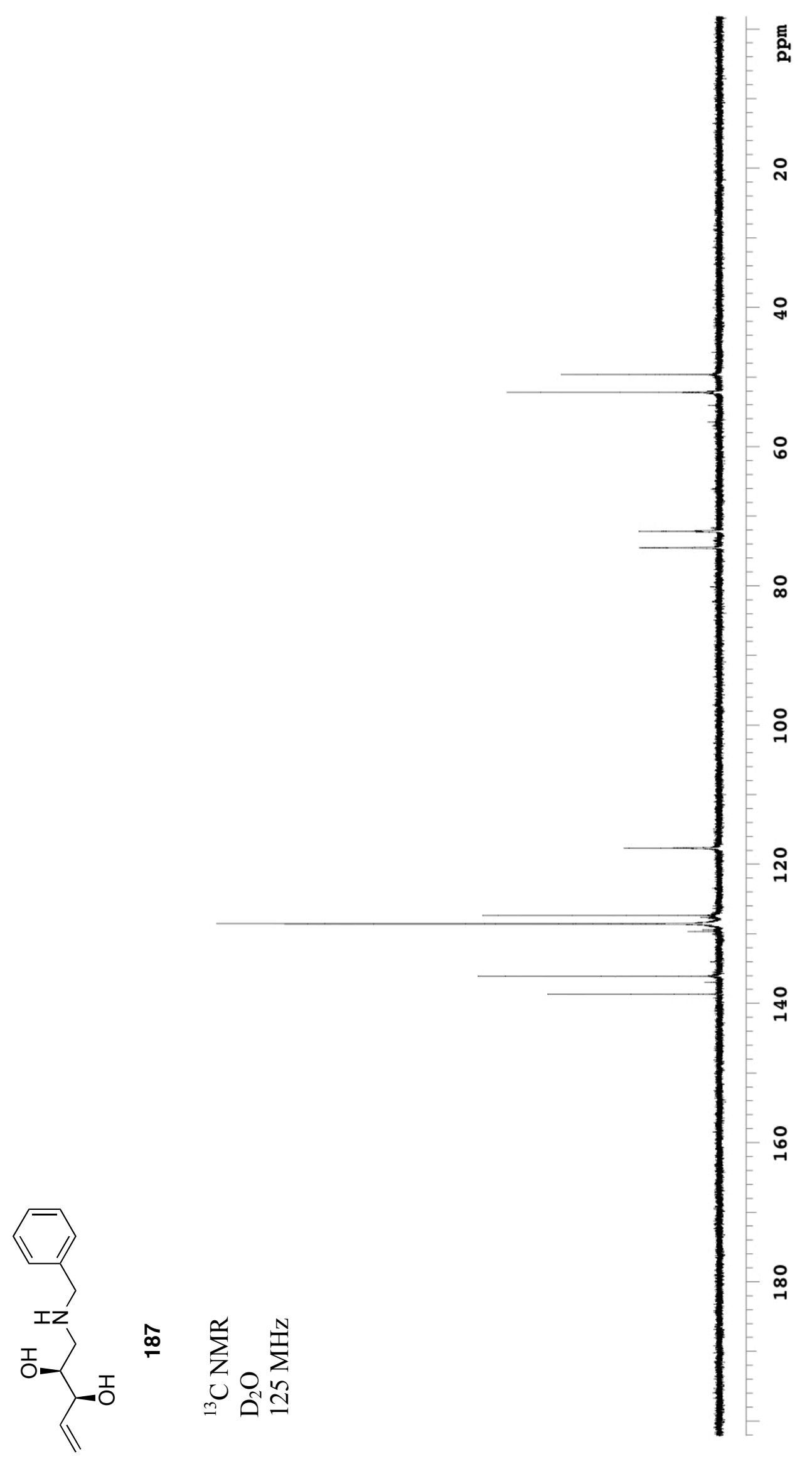

ลิ 


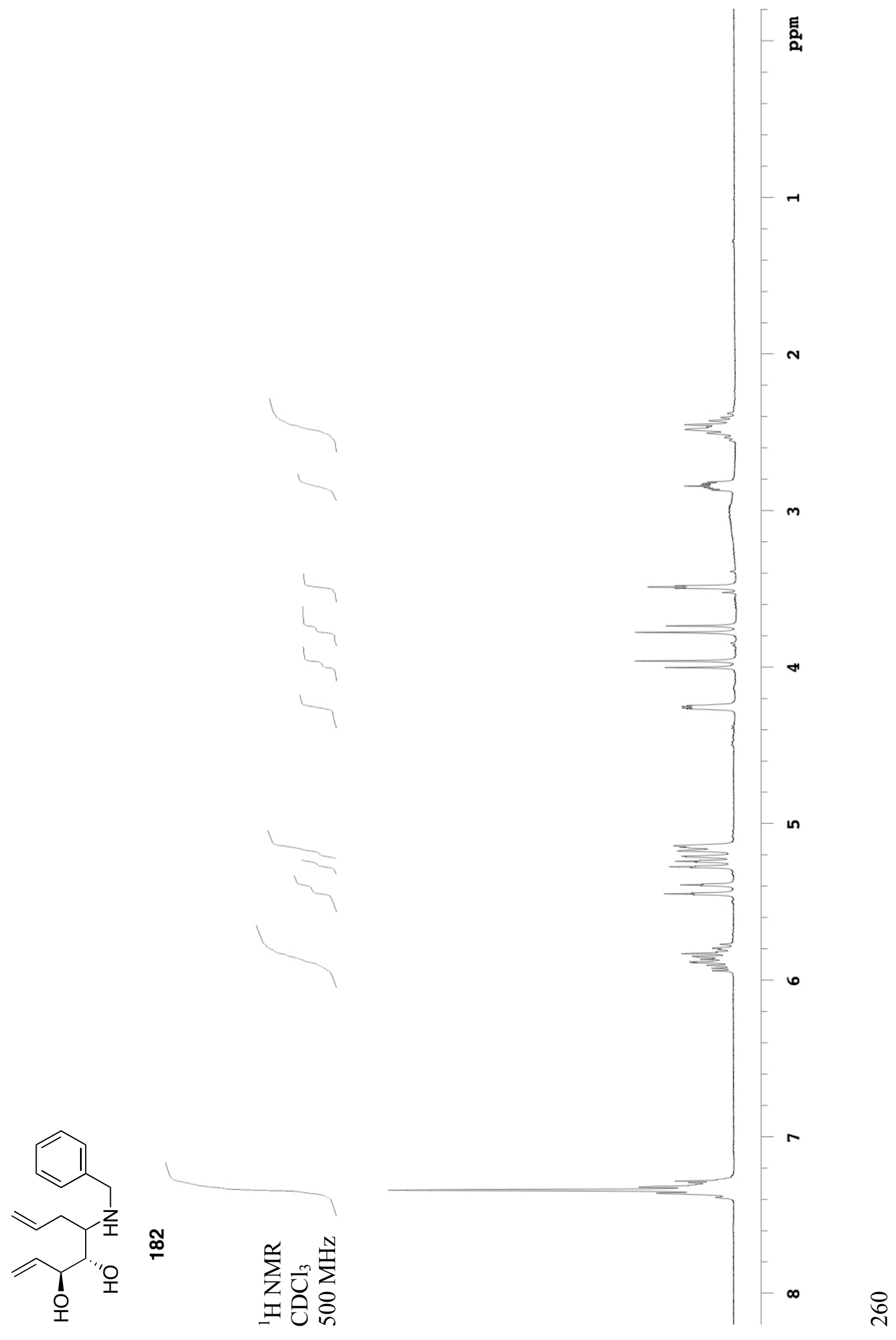




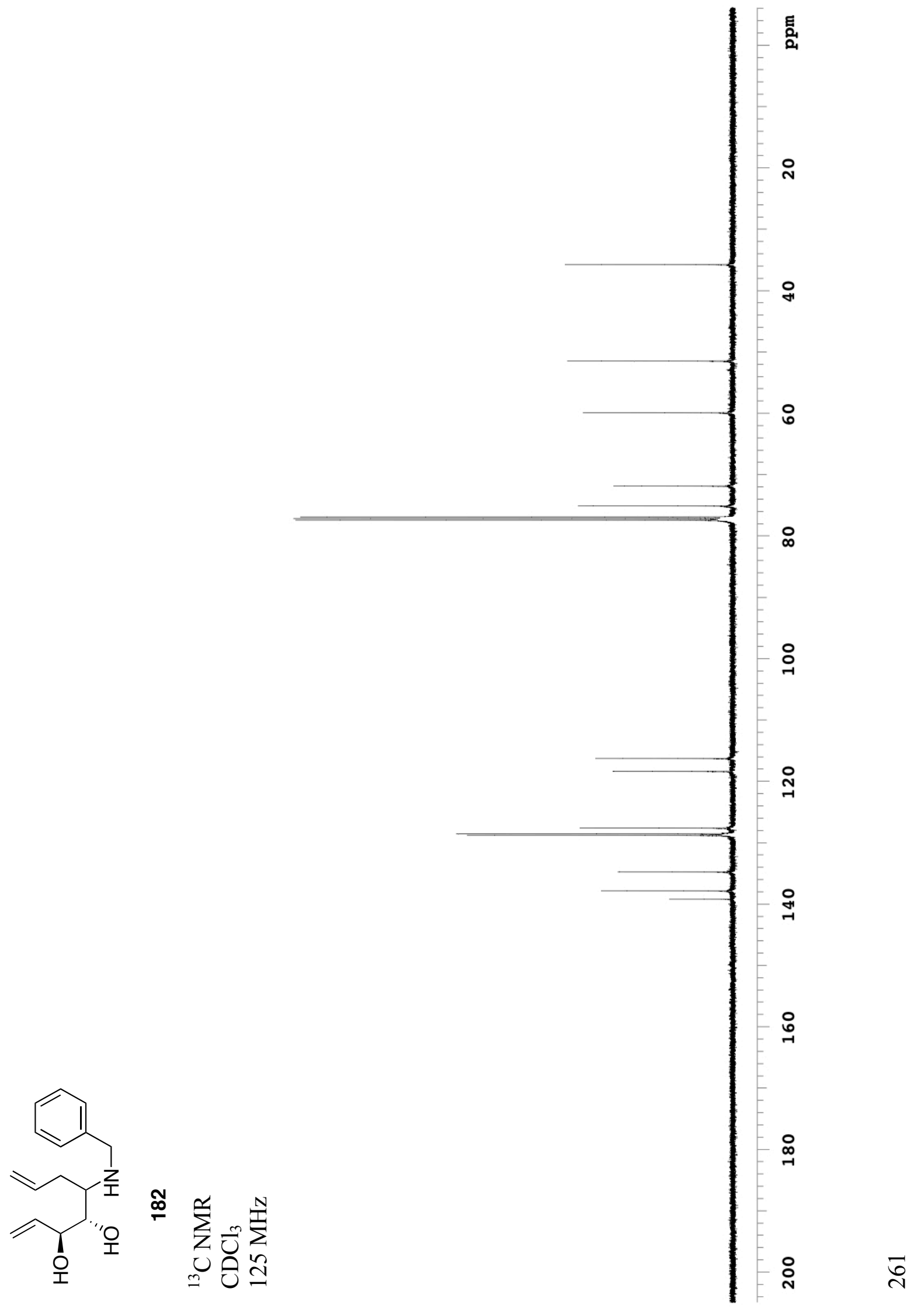




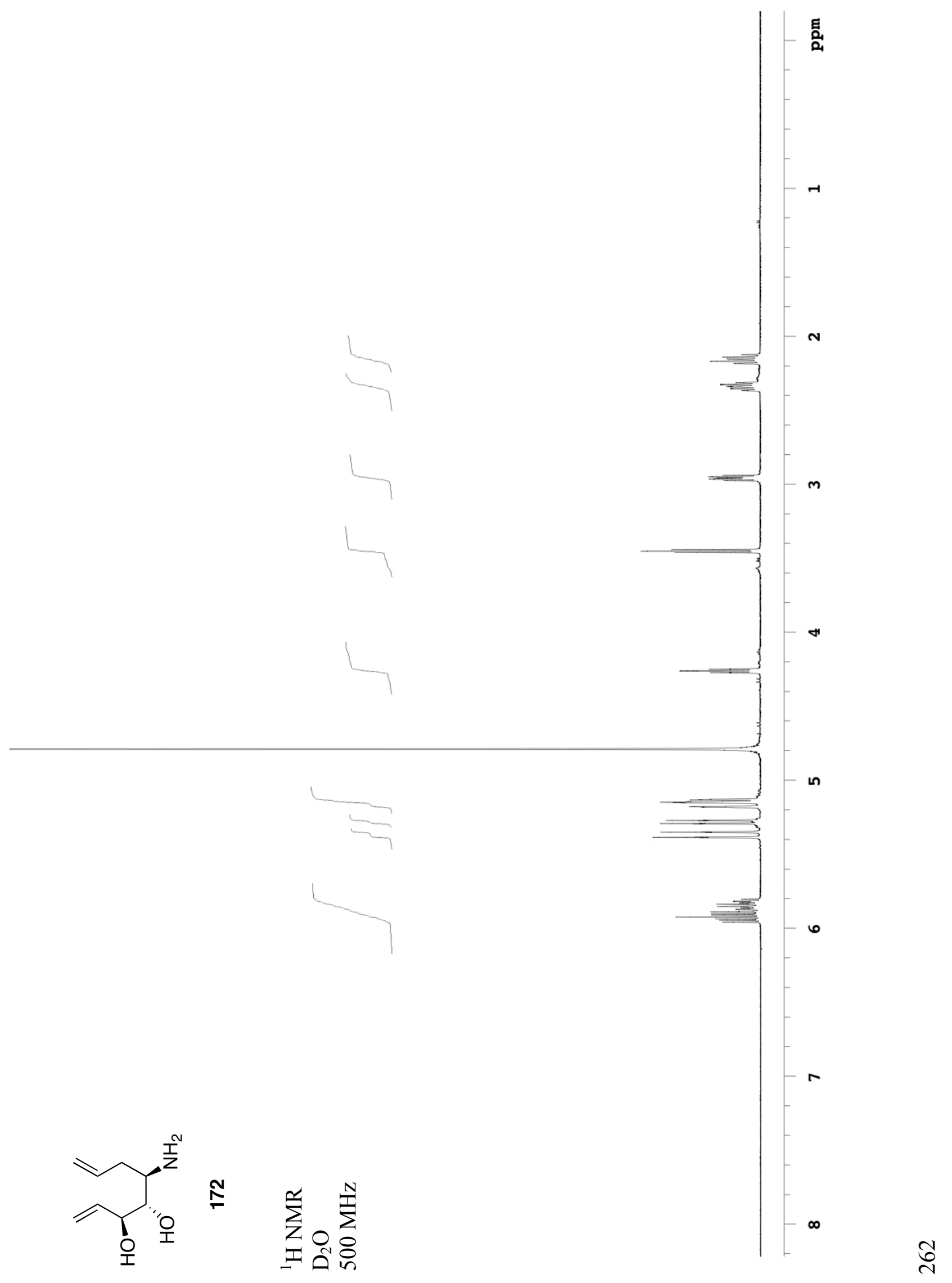




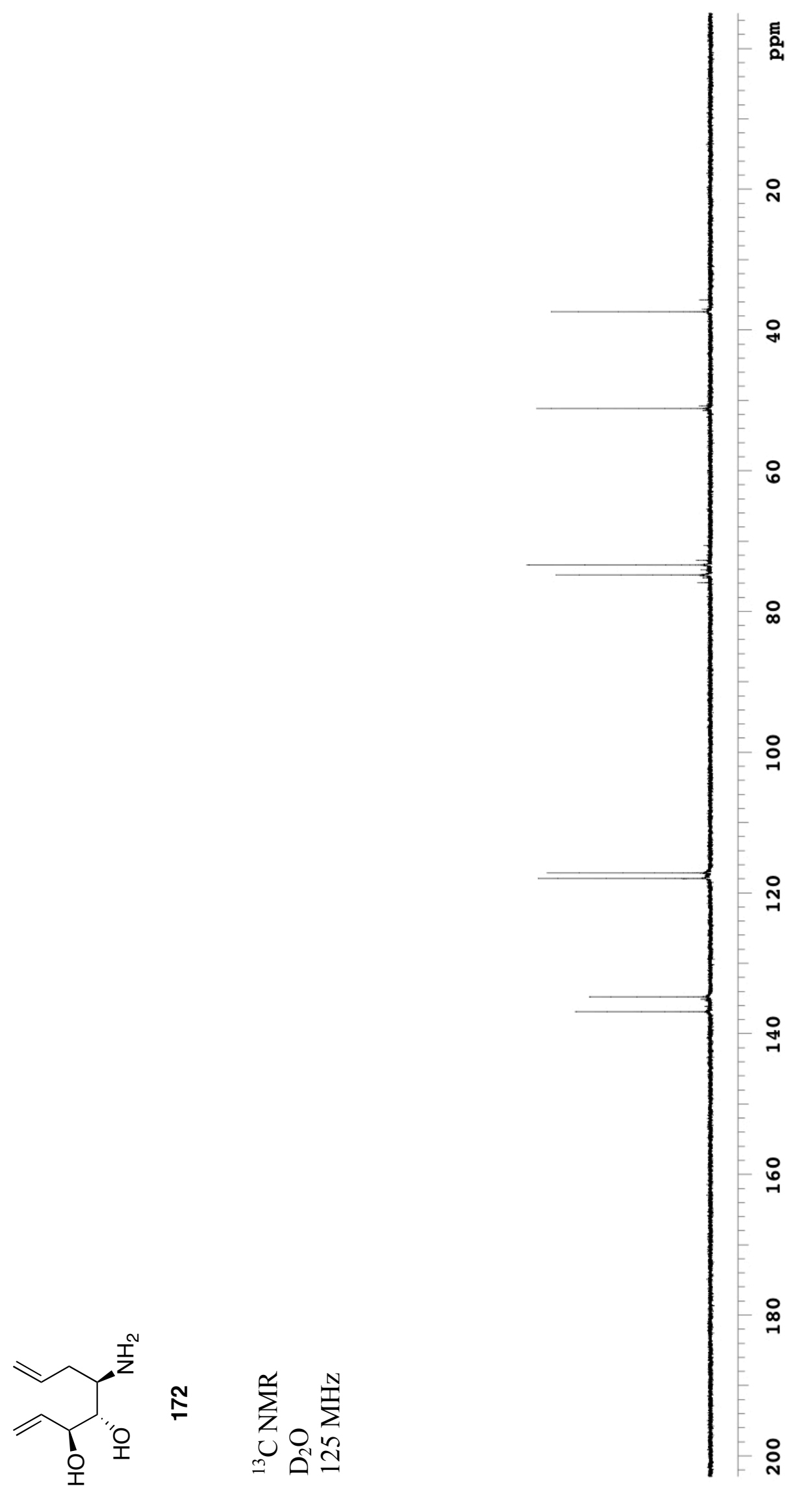

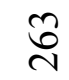




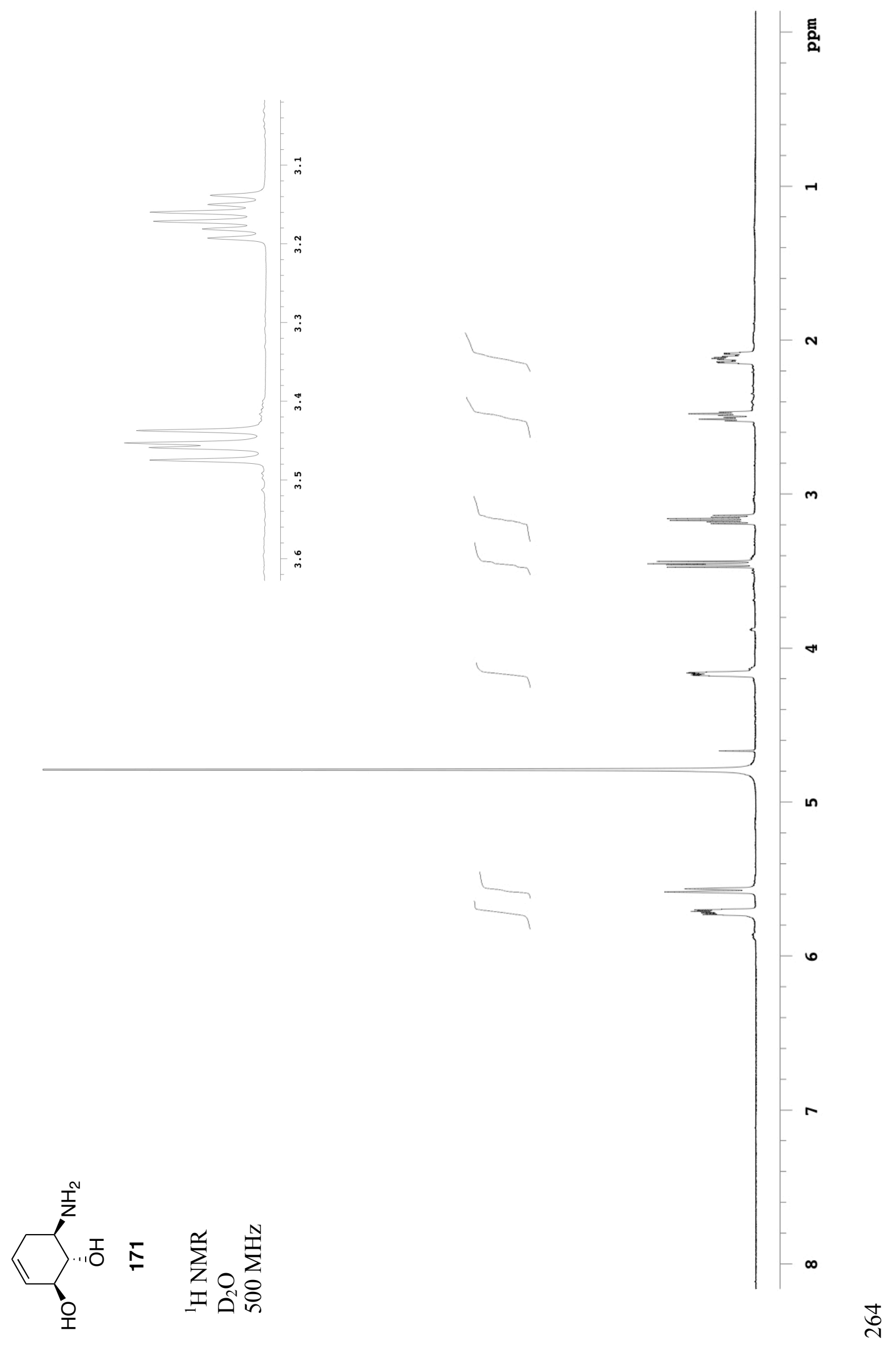




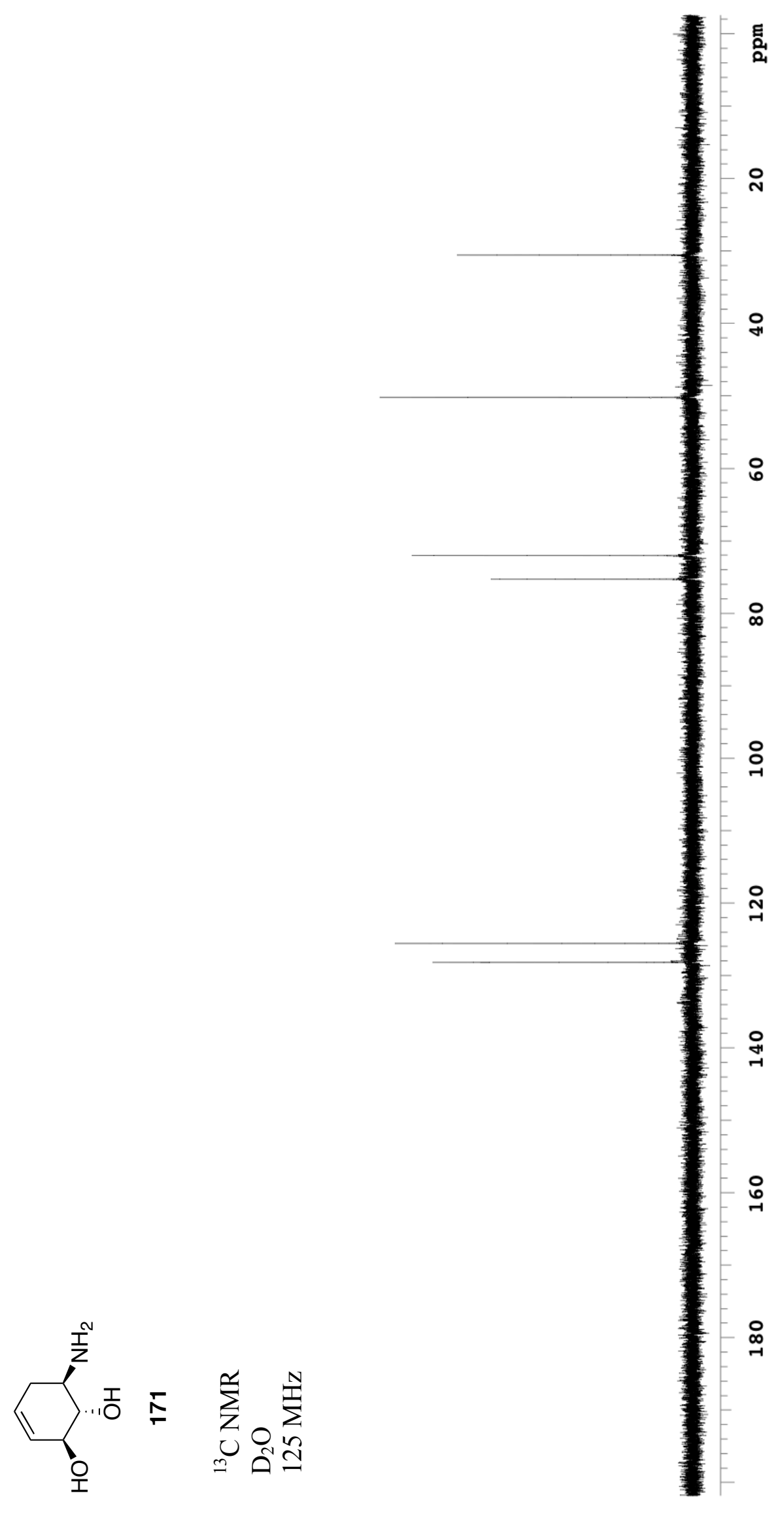


Chapter 4: NMR Spectra 


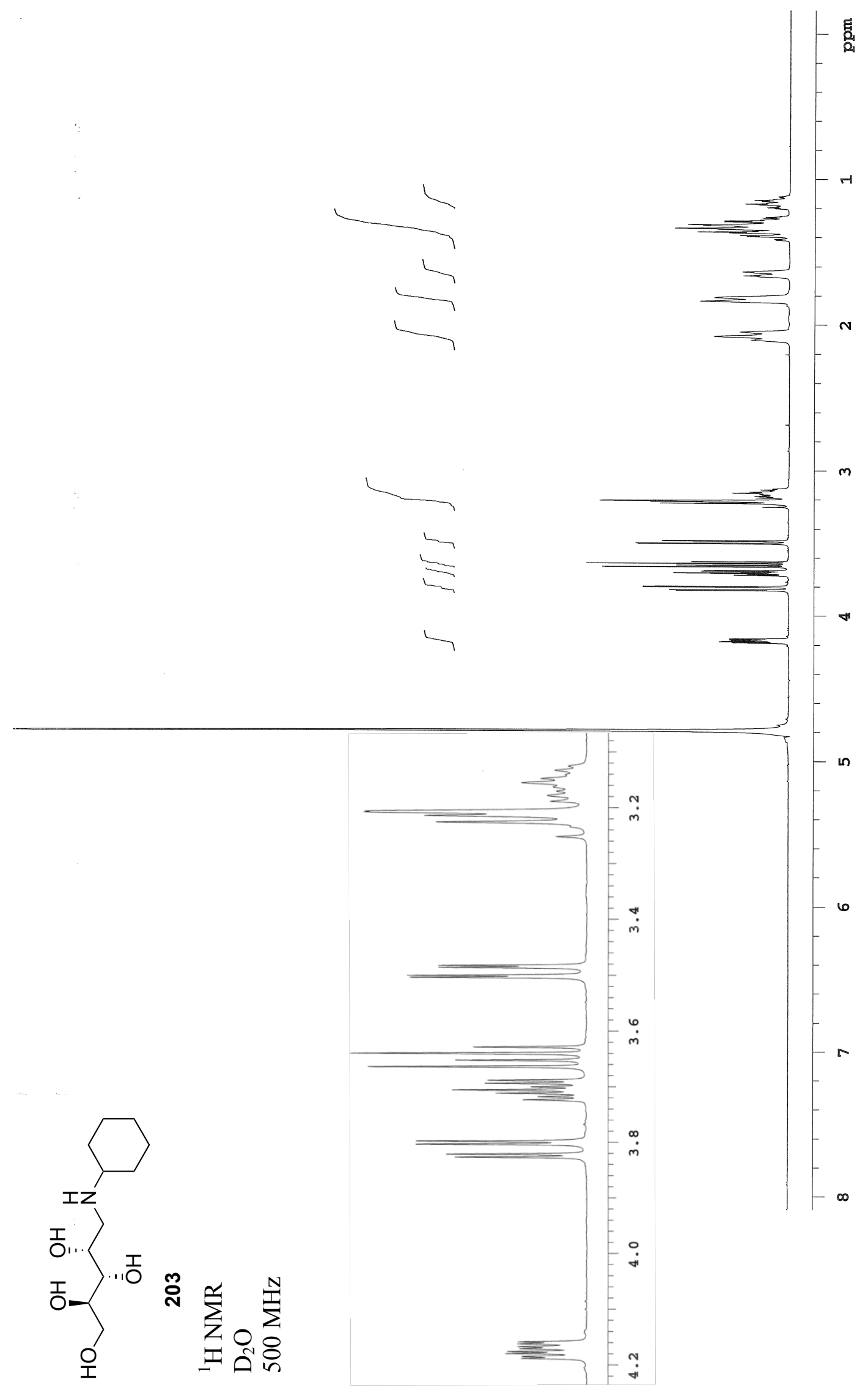



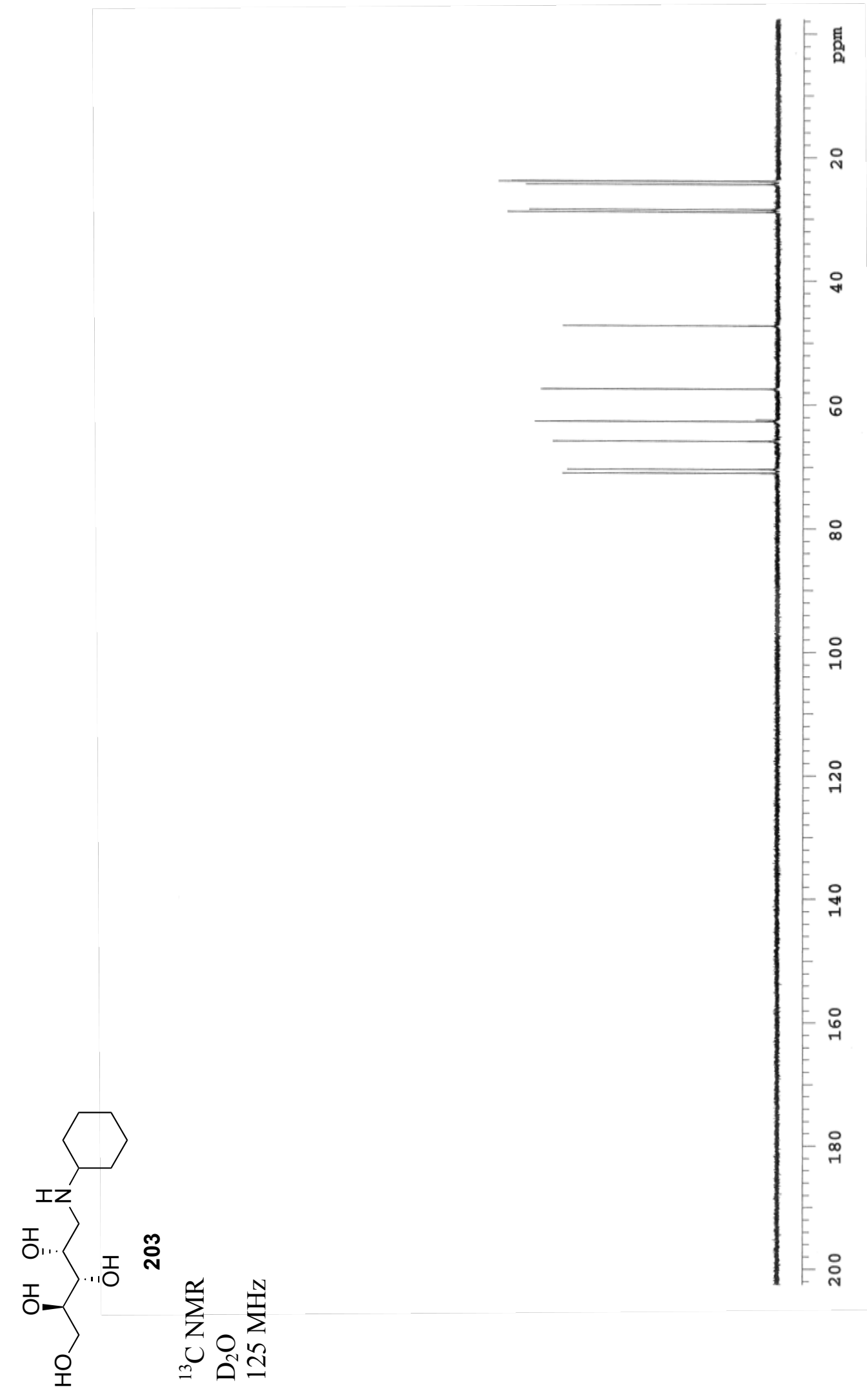

인 


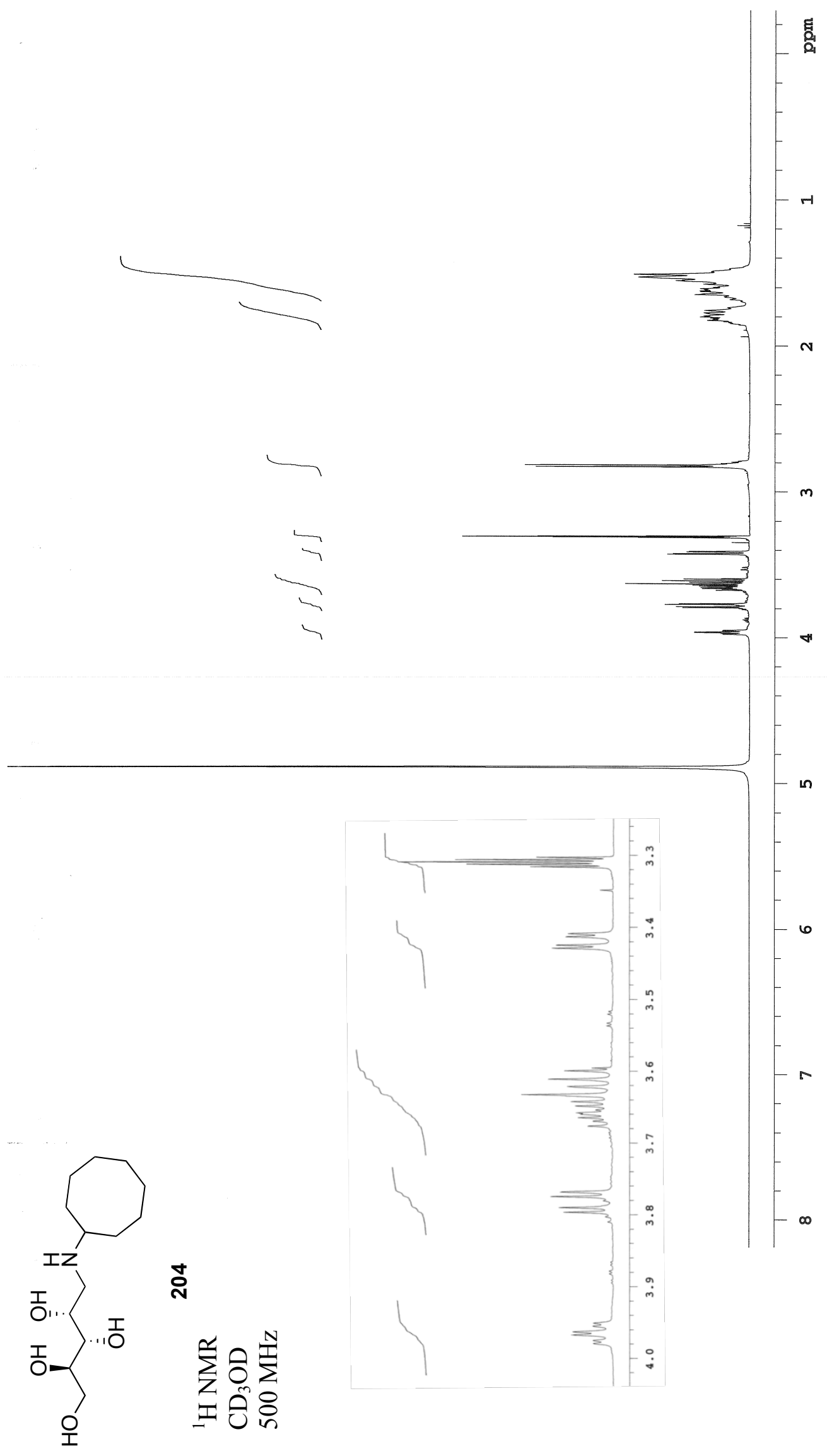




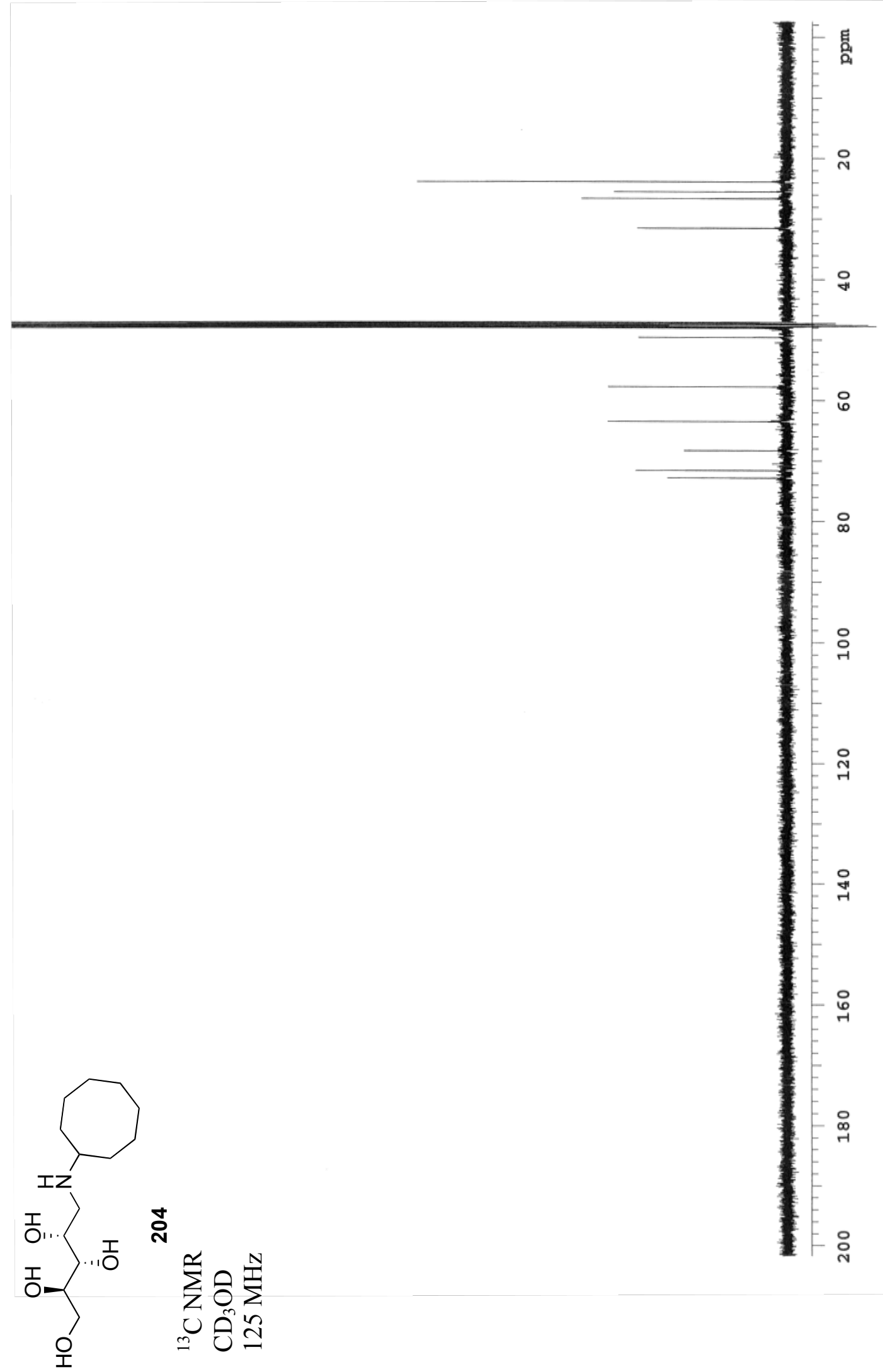




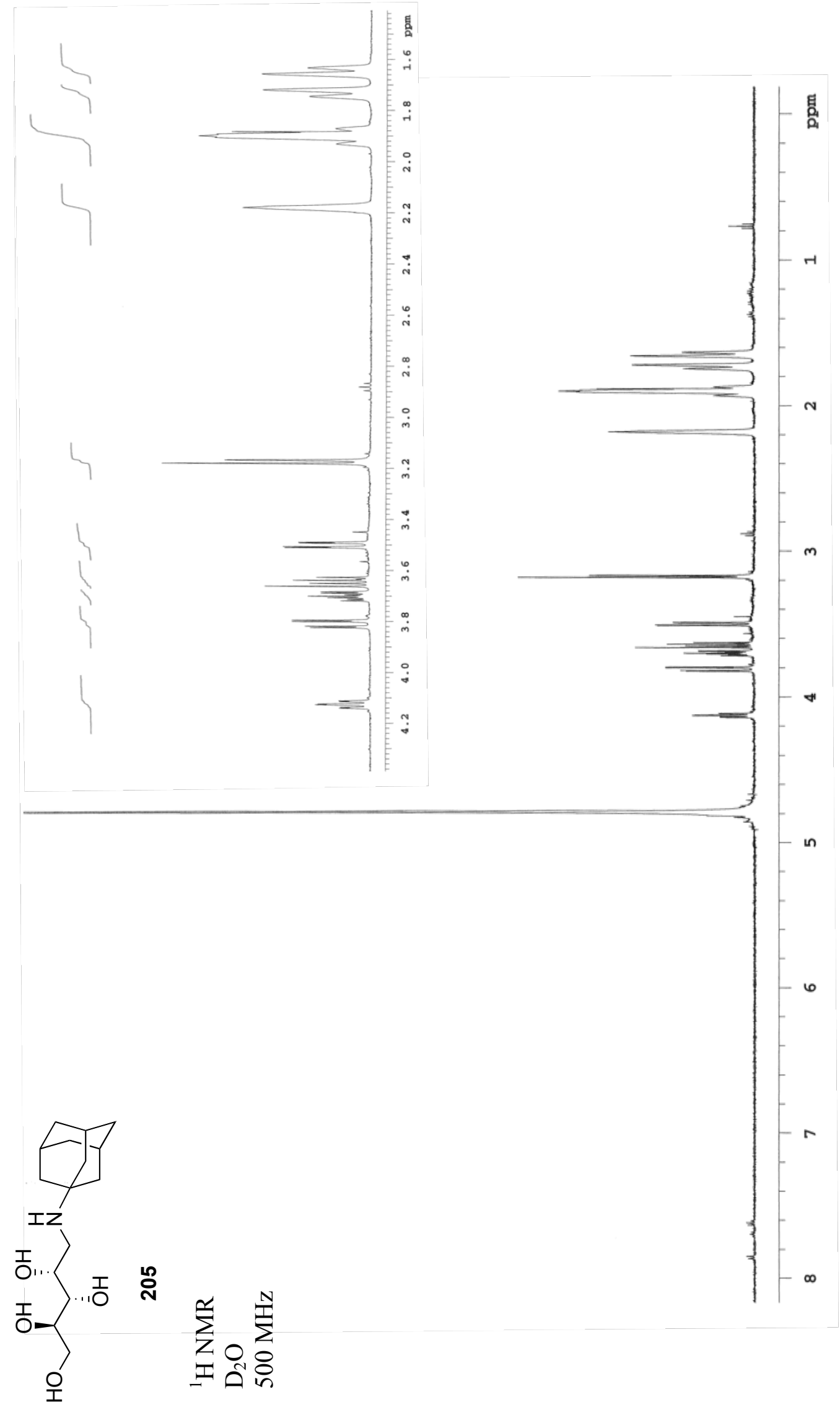




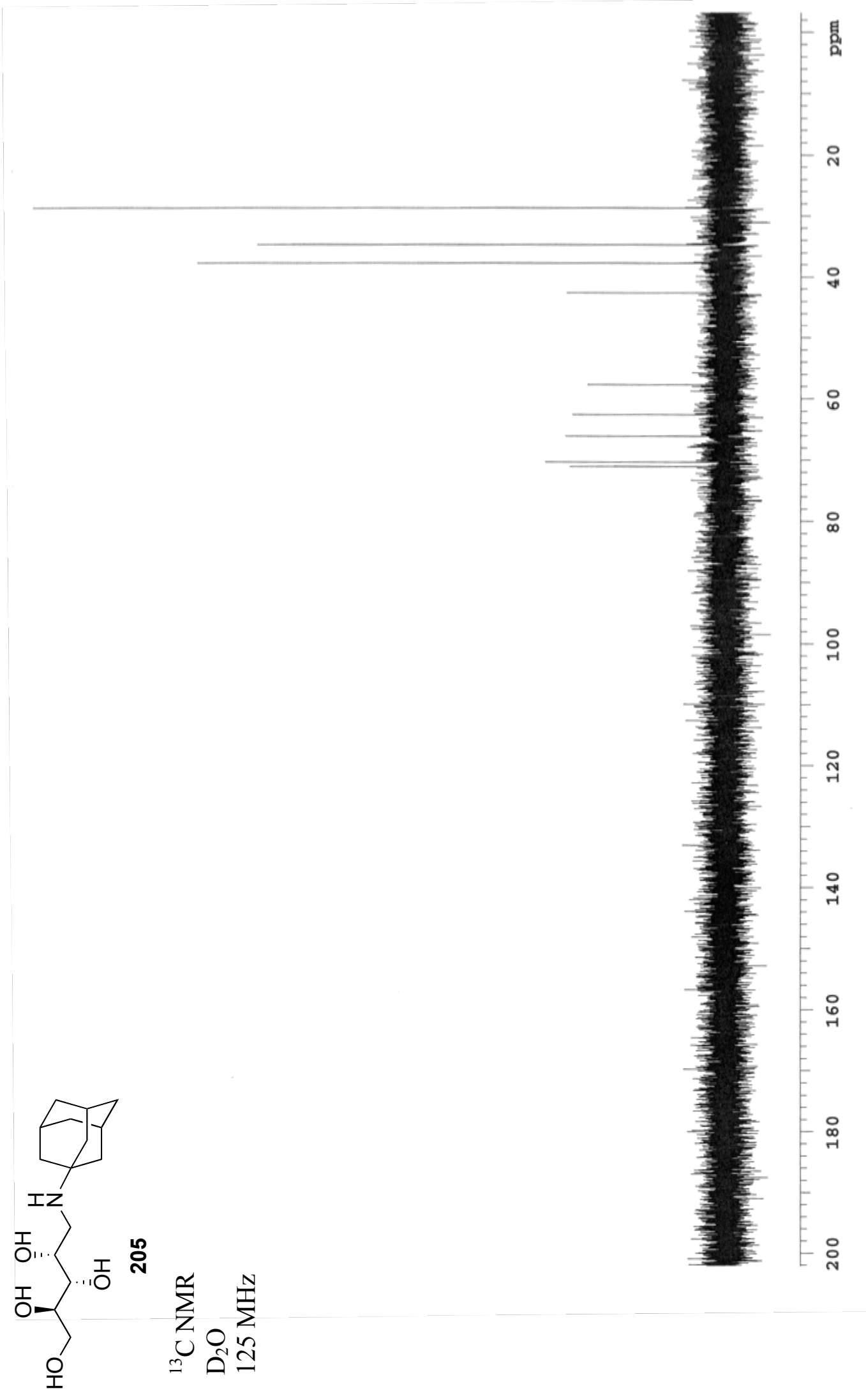

$\stackrel{n}{N}$ 


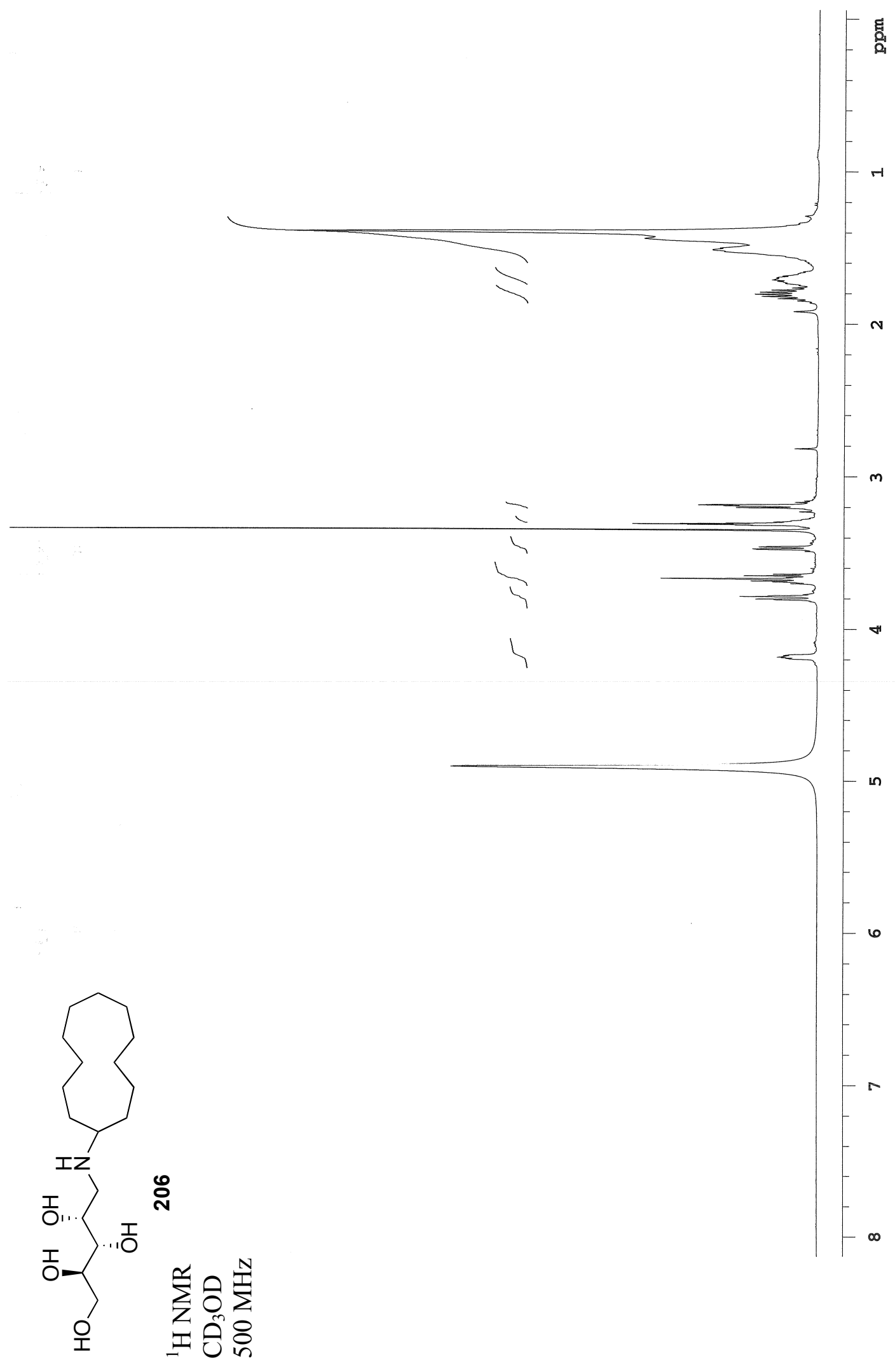




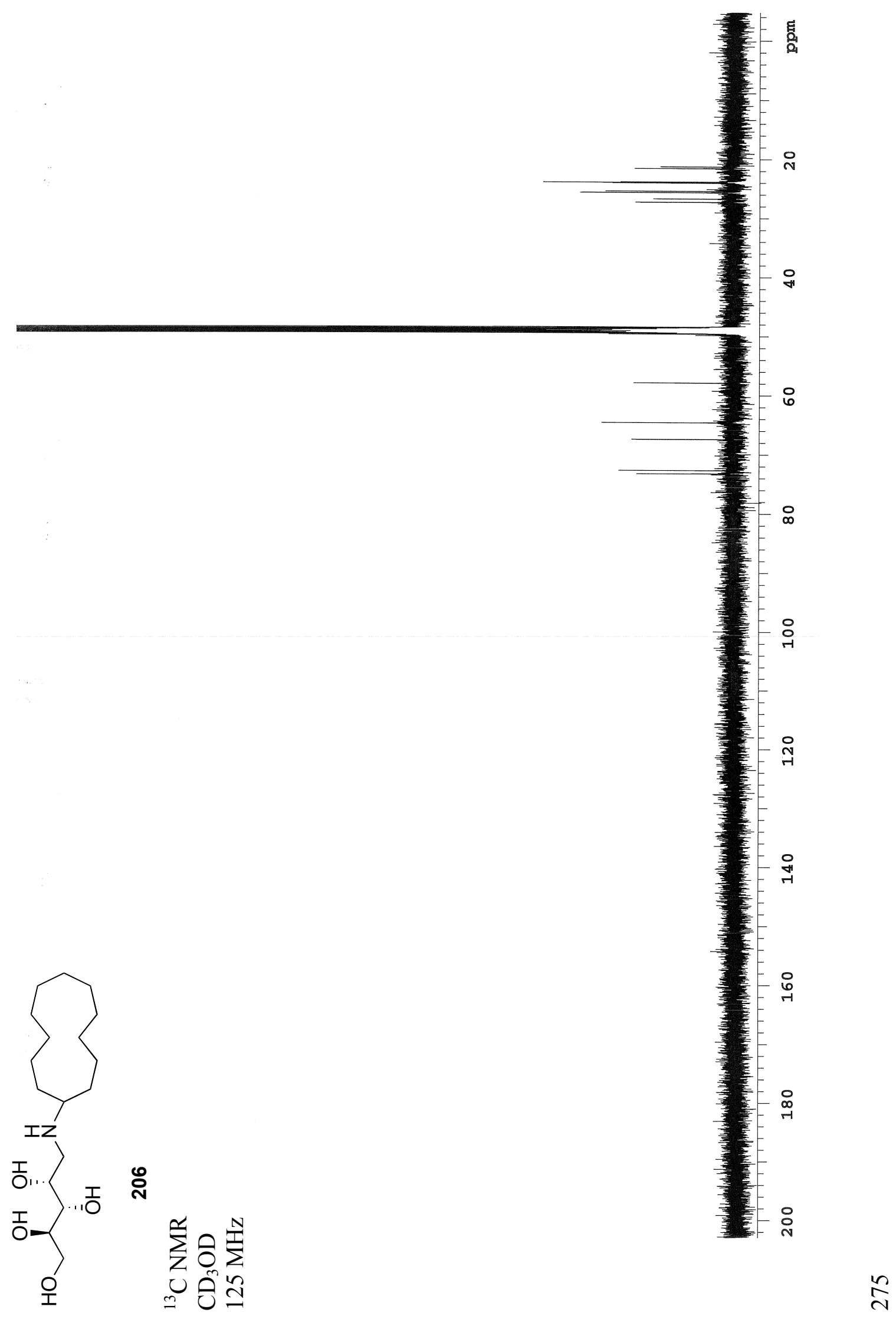




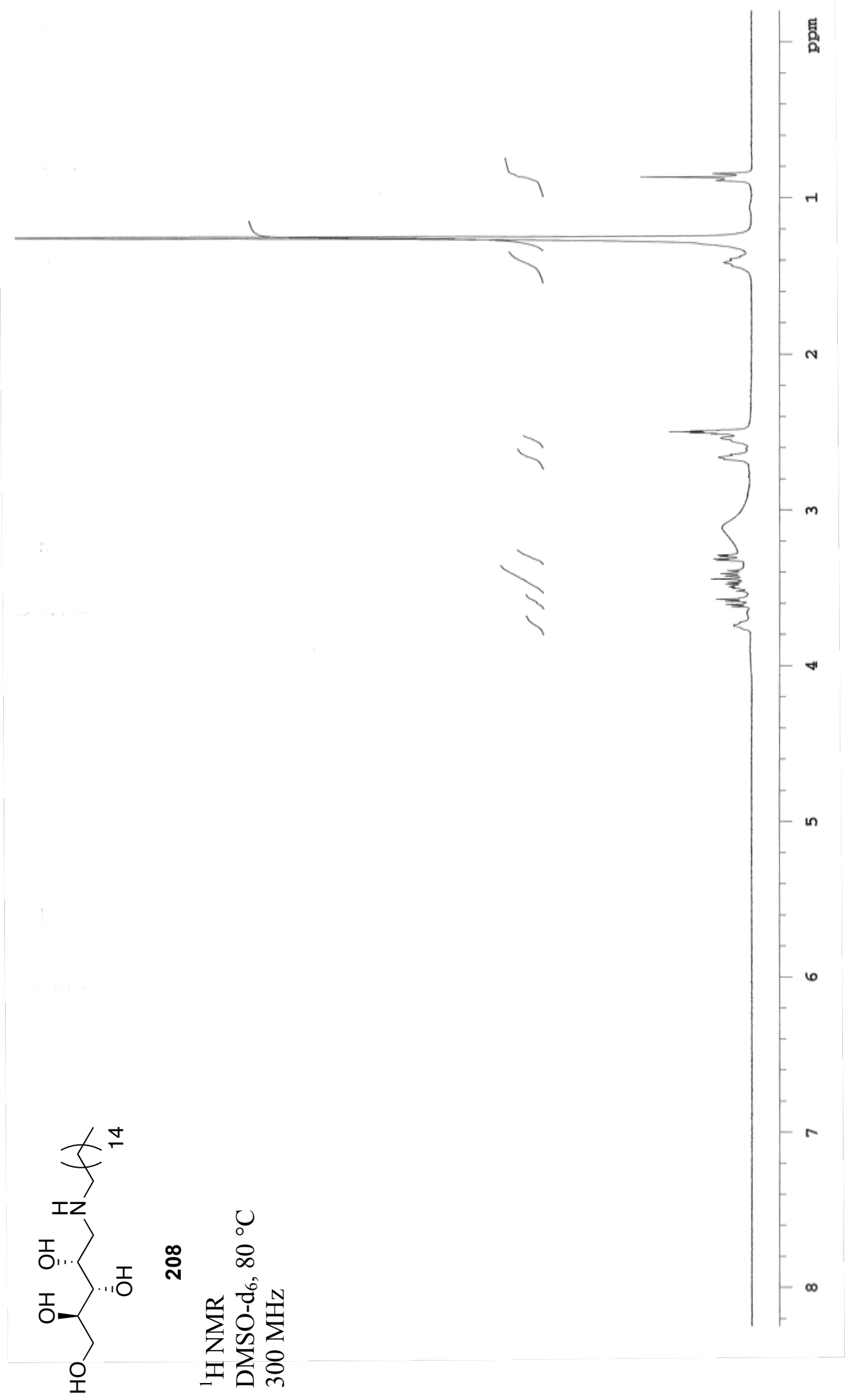




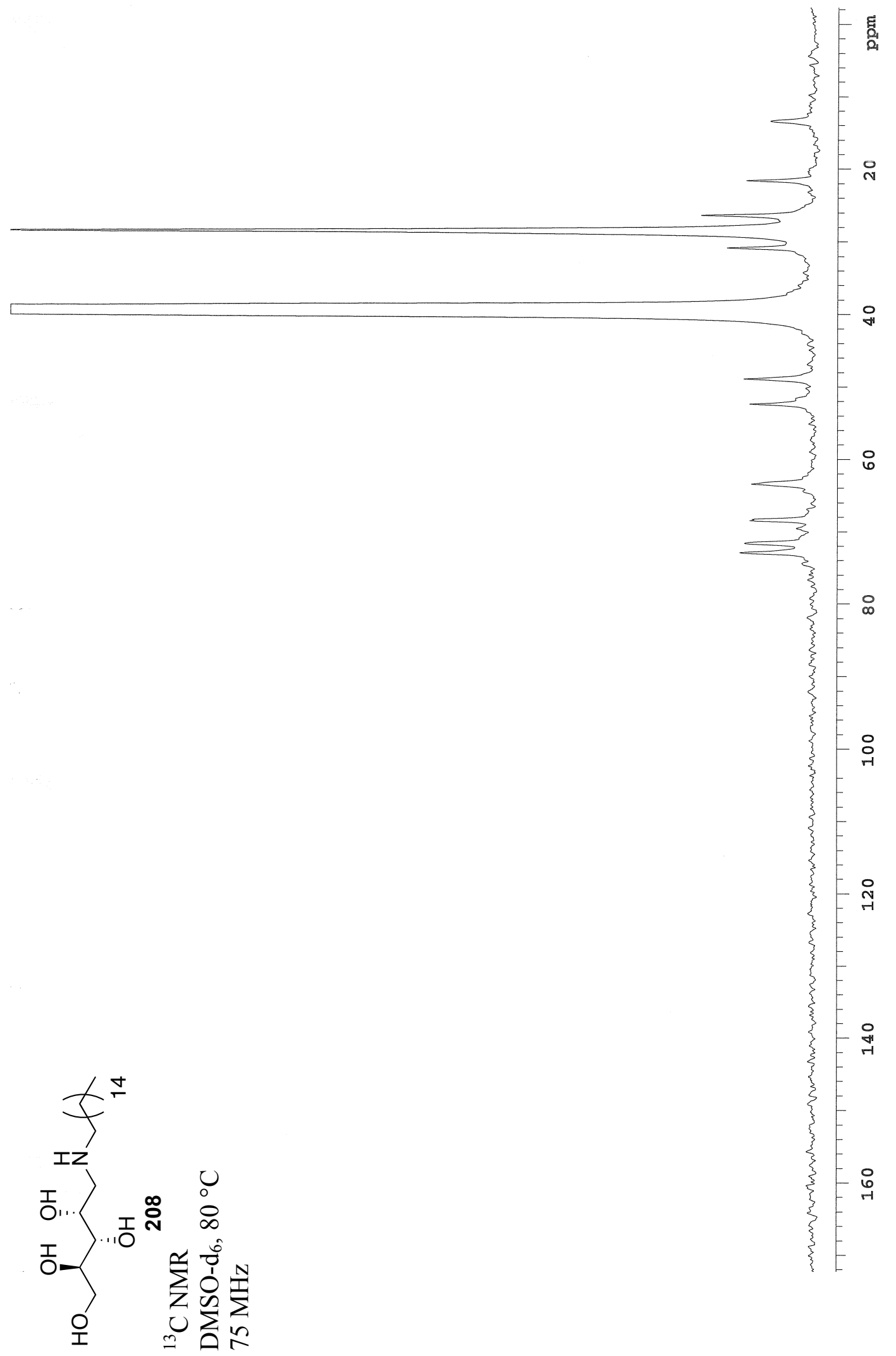

E 


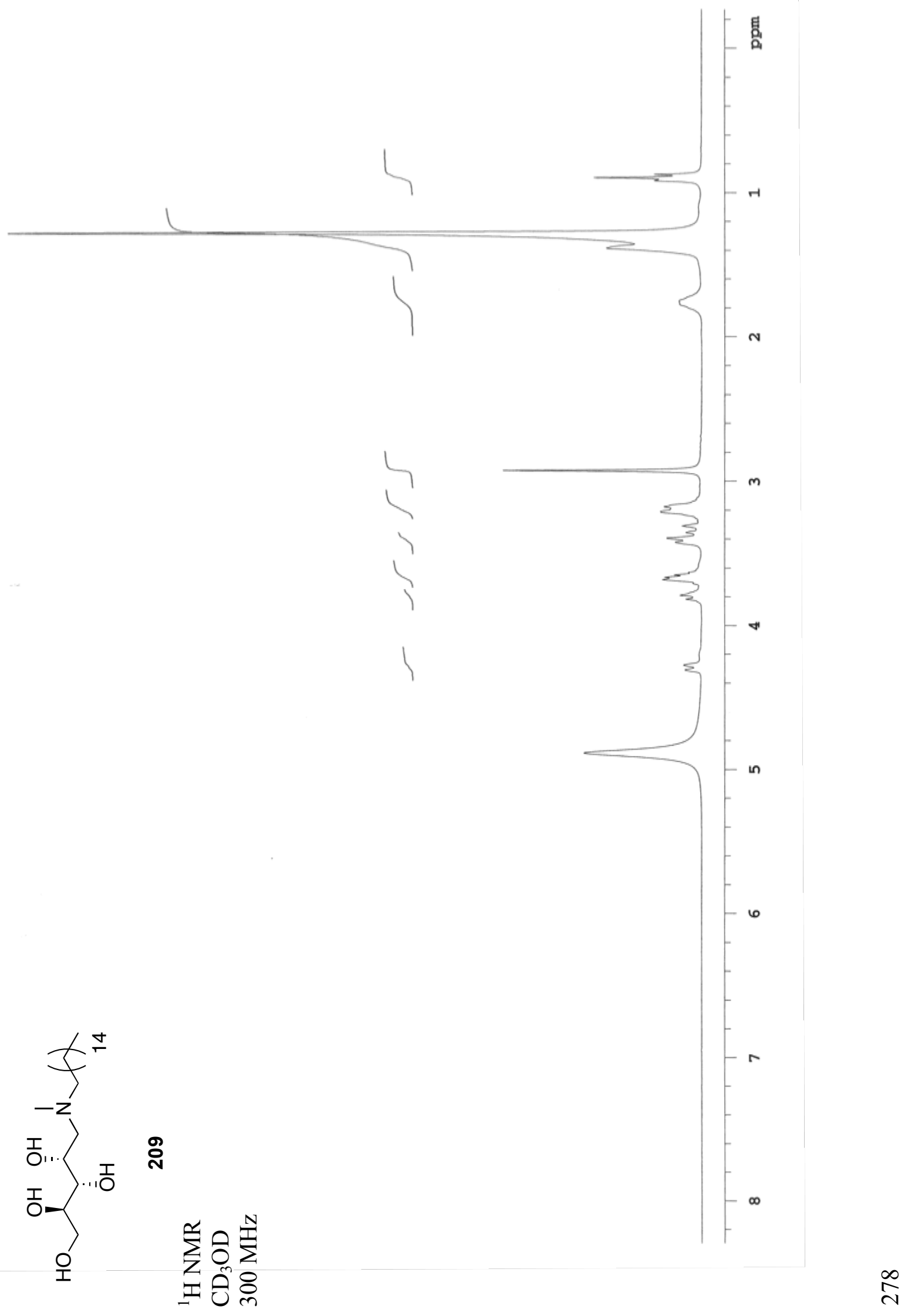




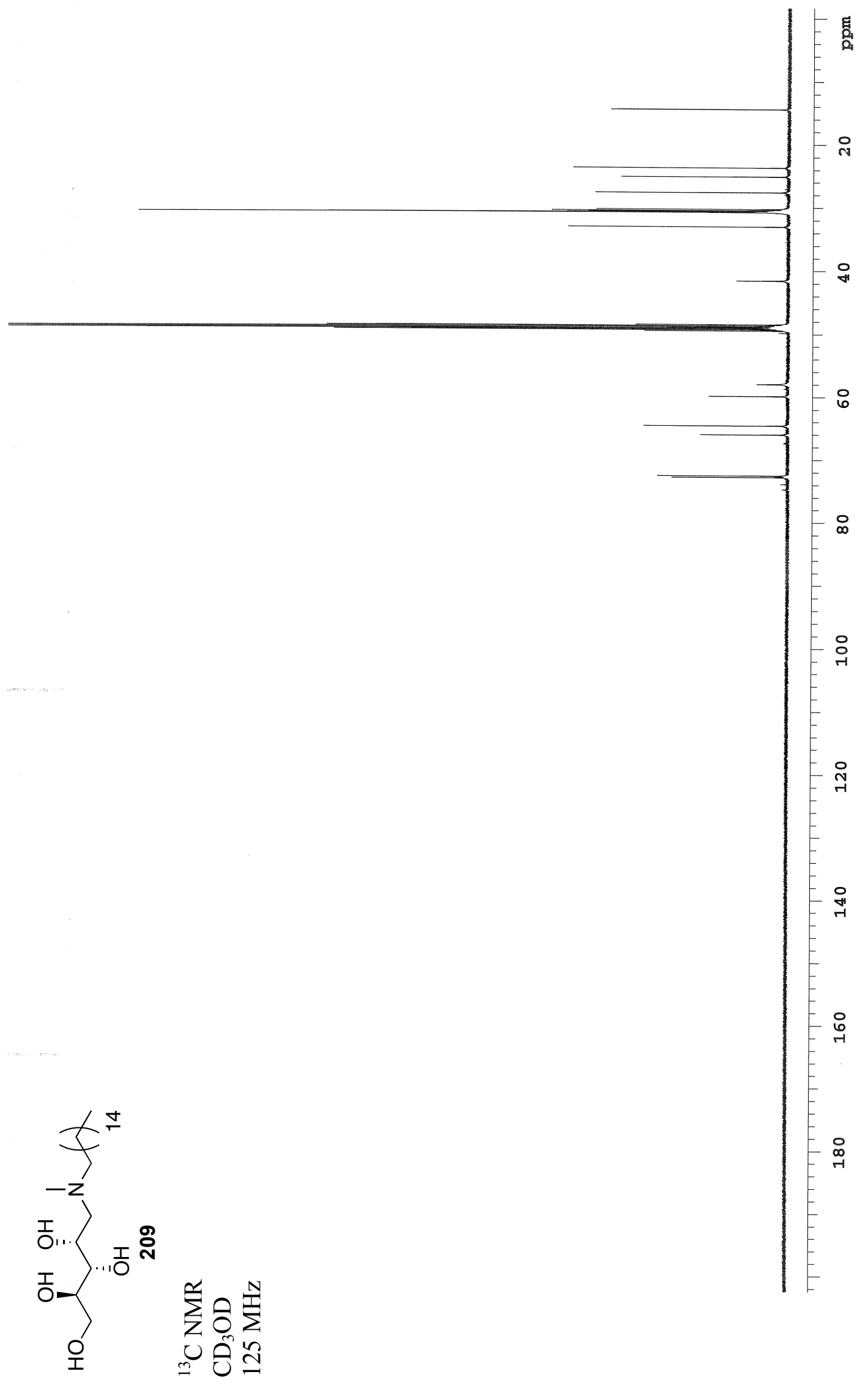

$\frac{2}{2}$ 


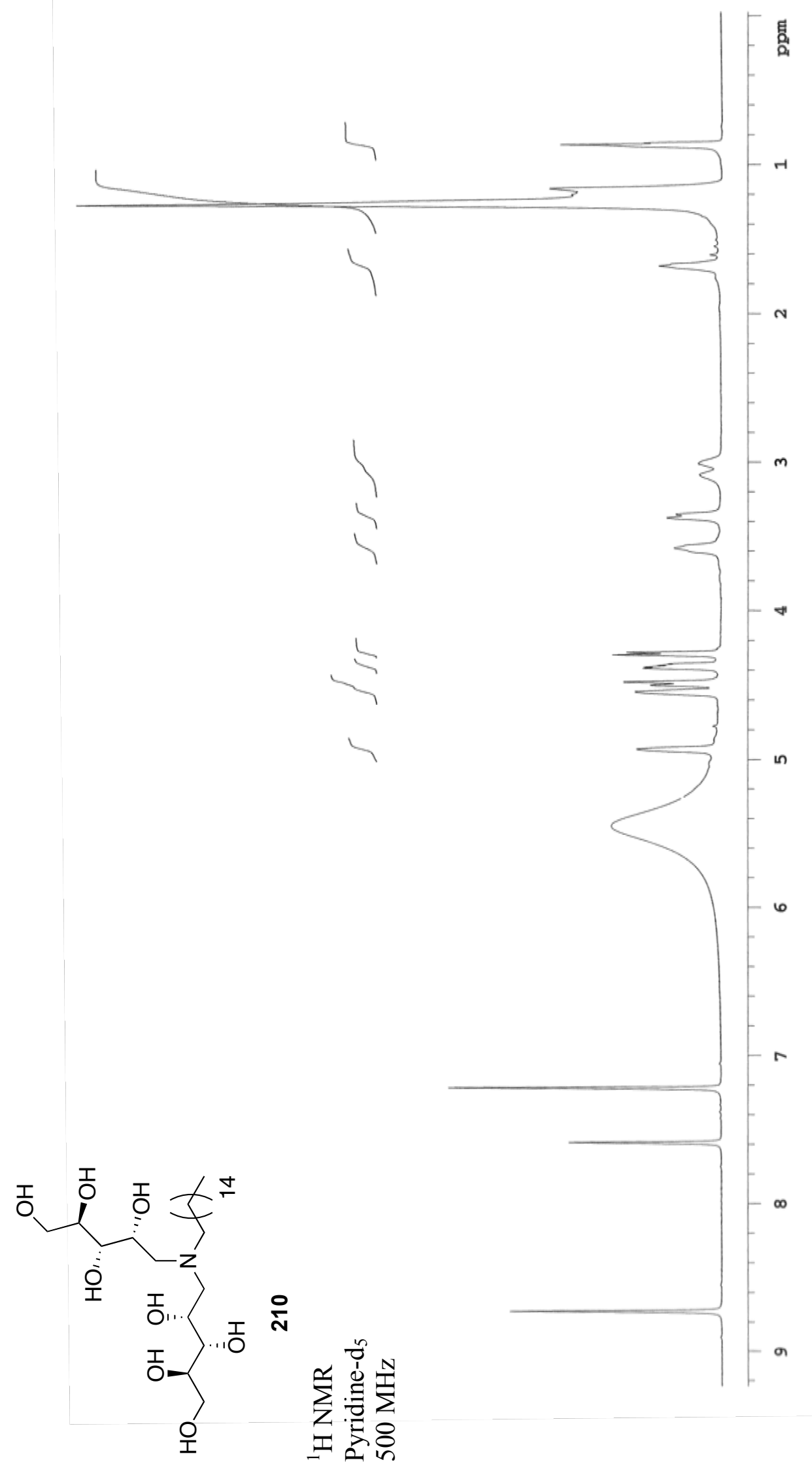

$\stackrel{\infty}{\sim}$ 


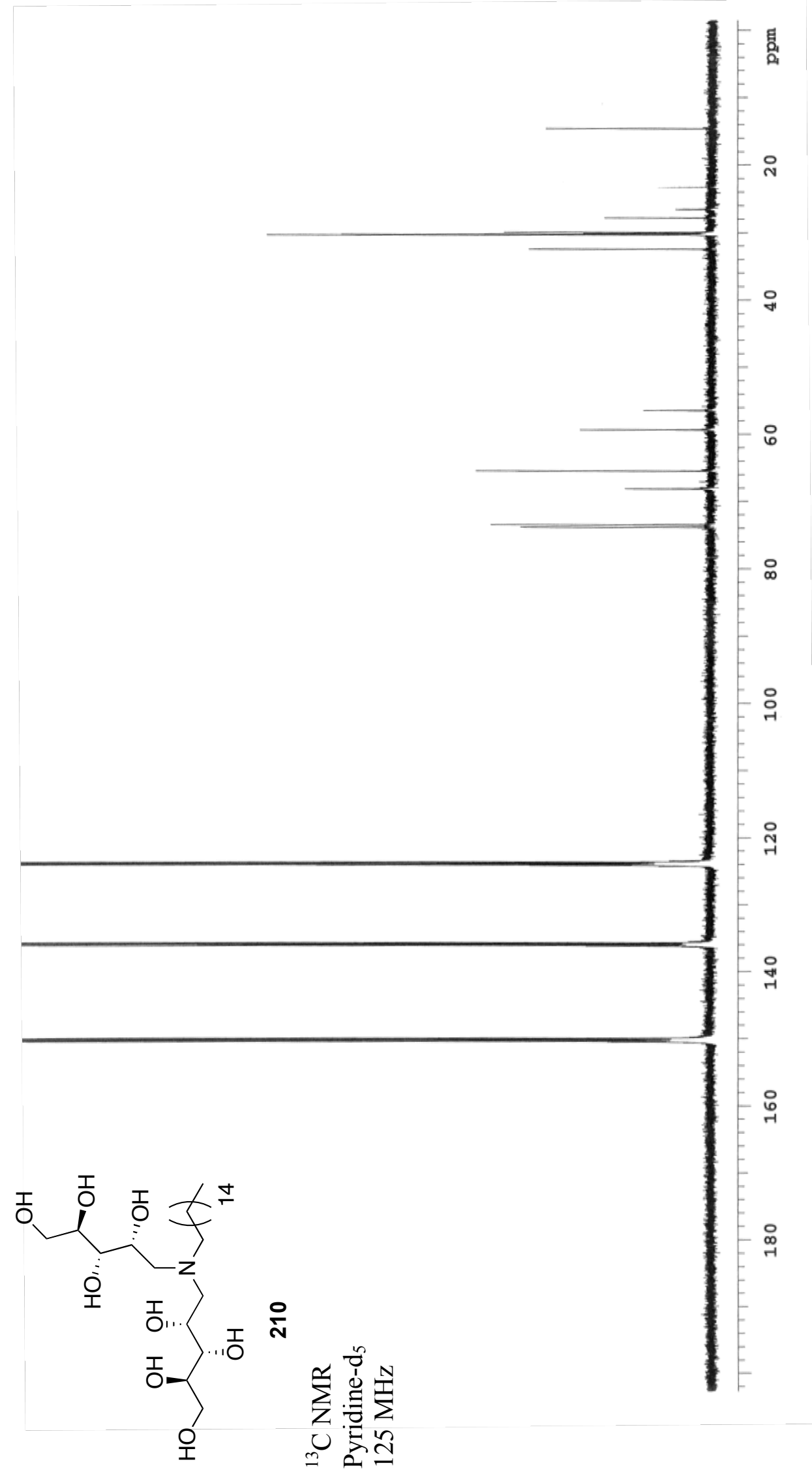




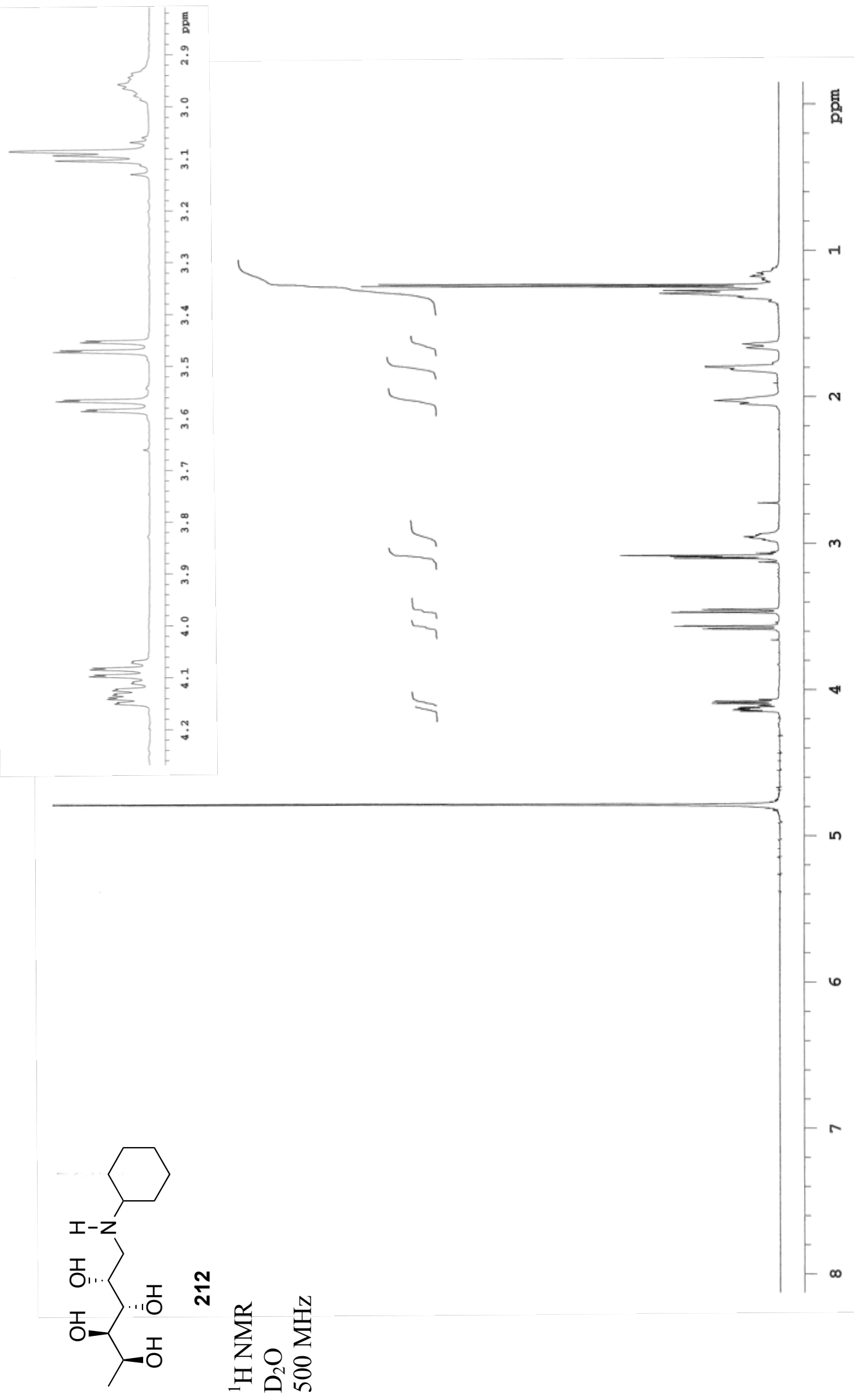




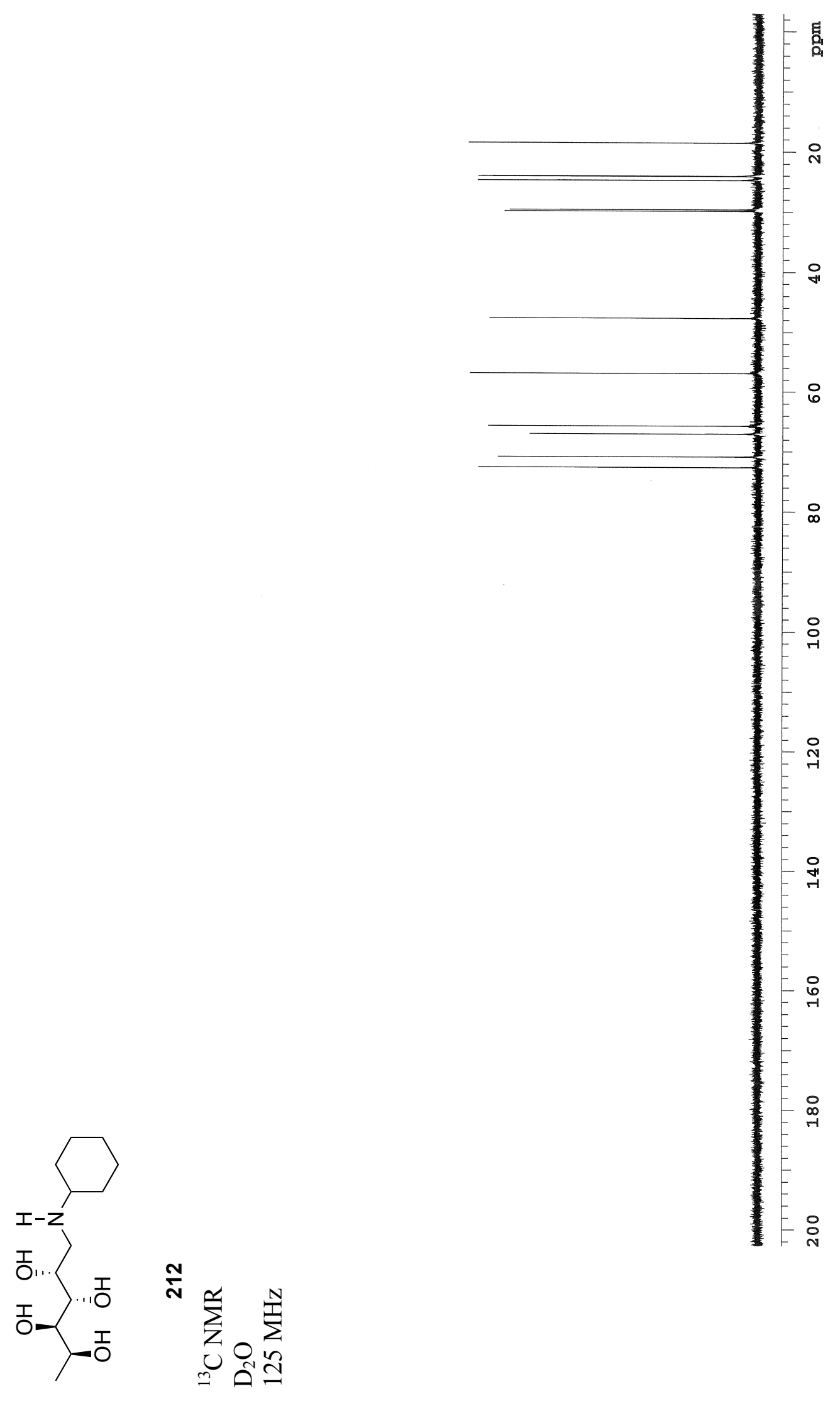




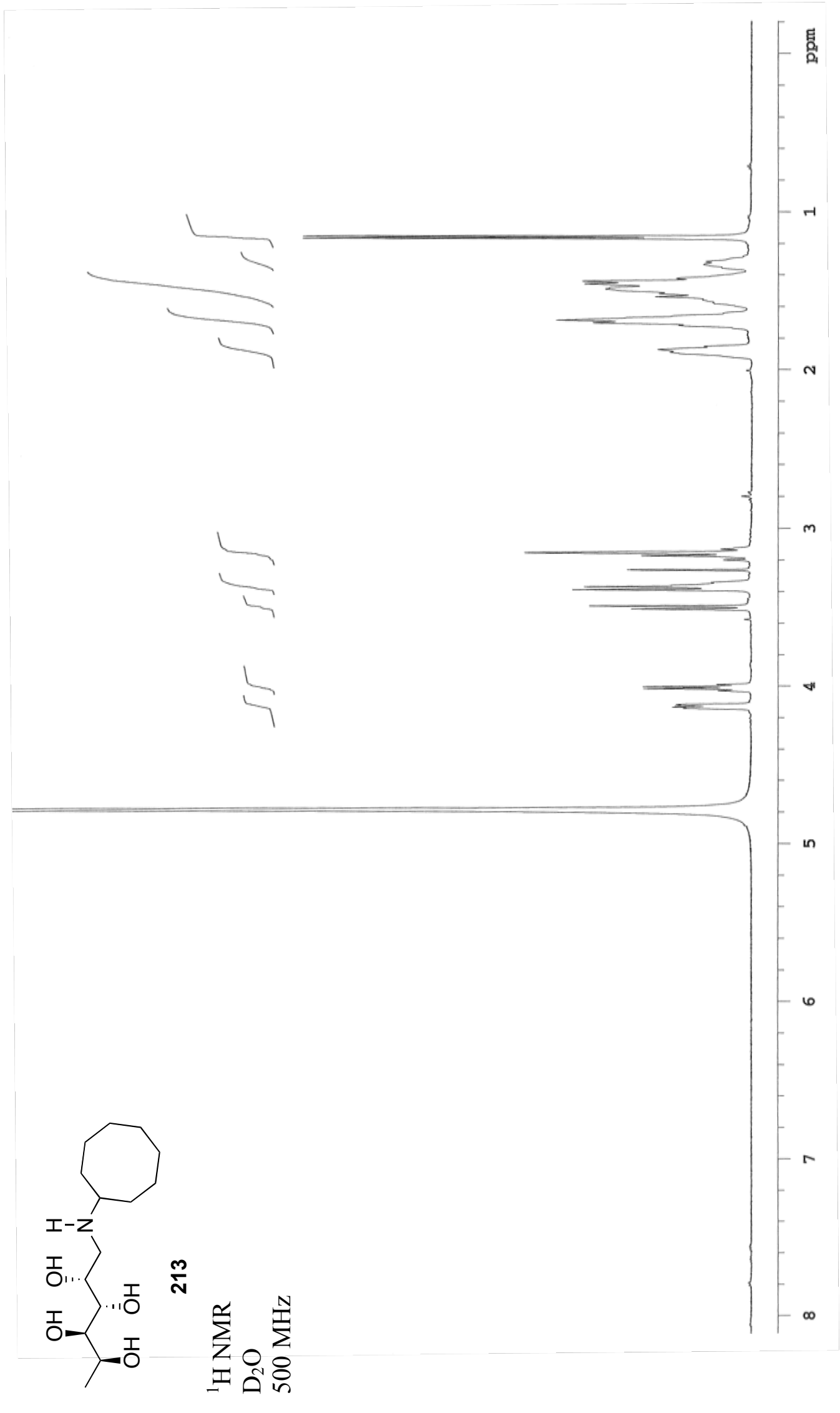




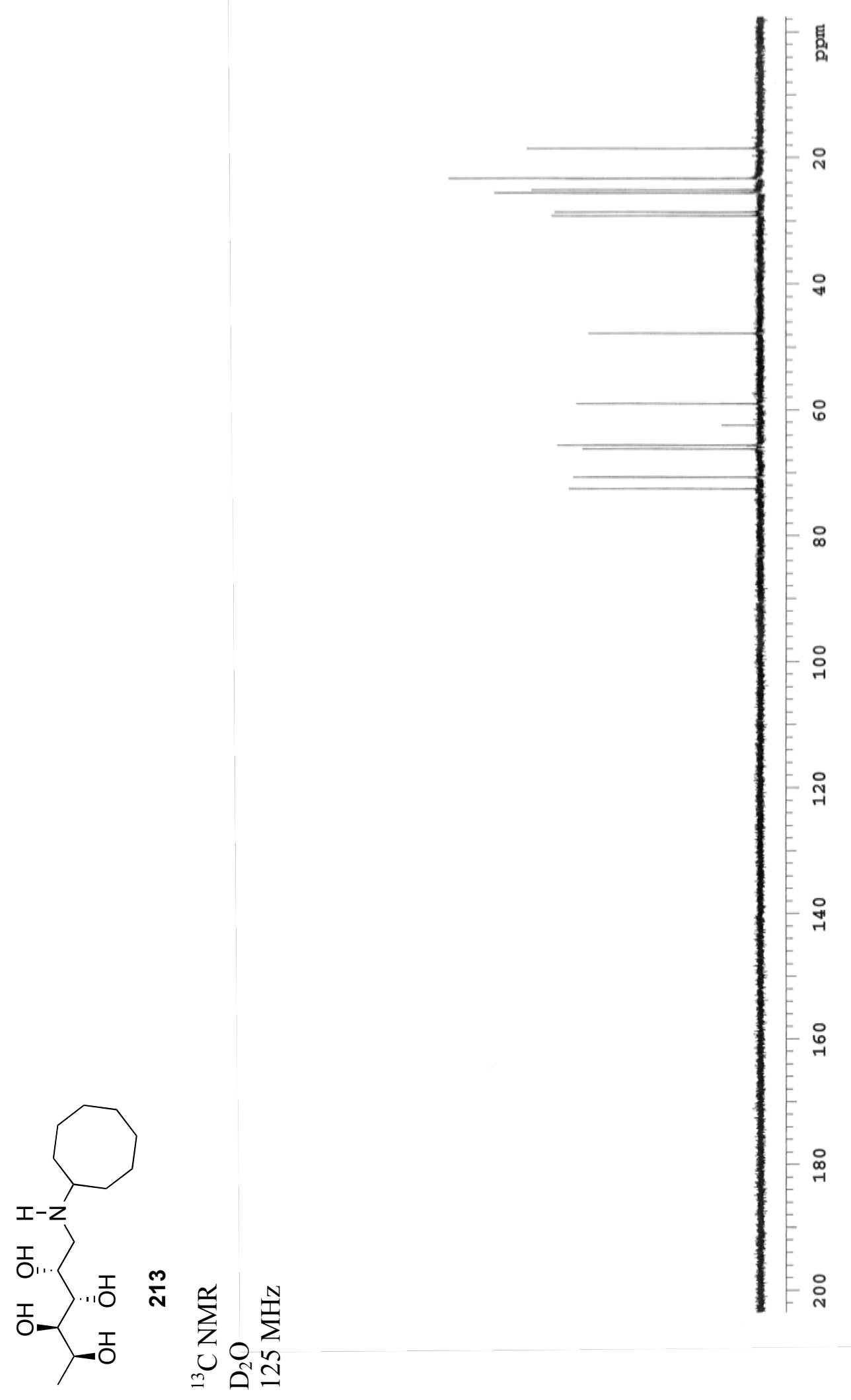




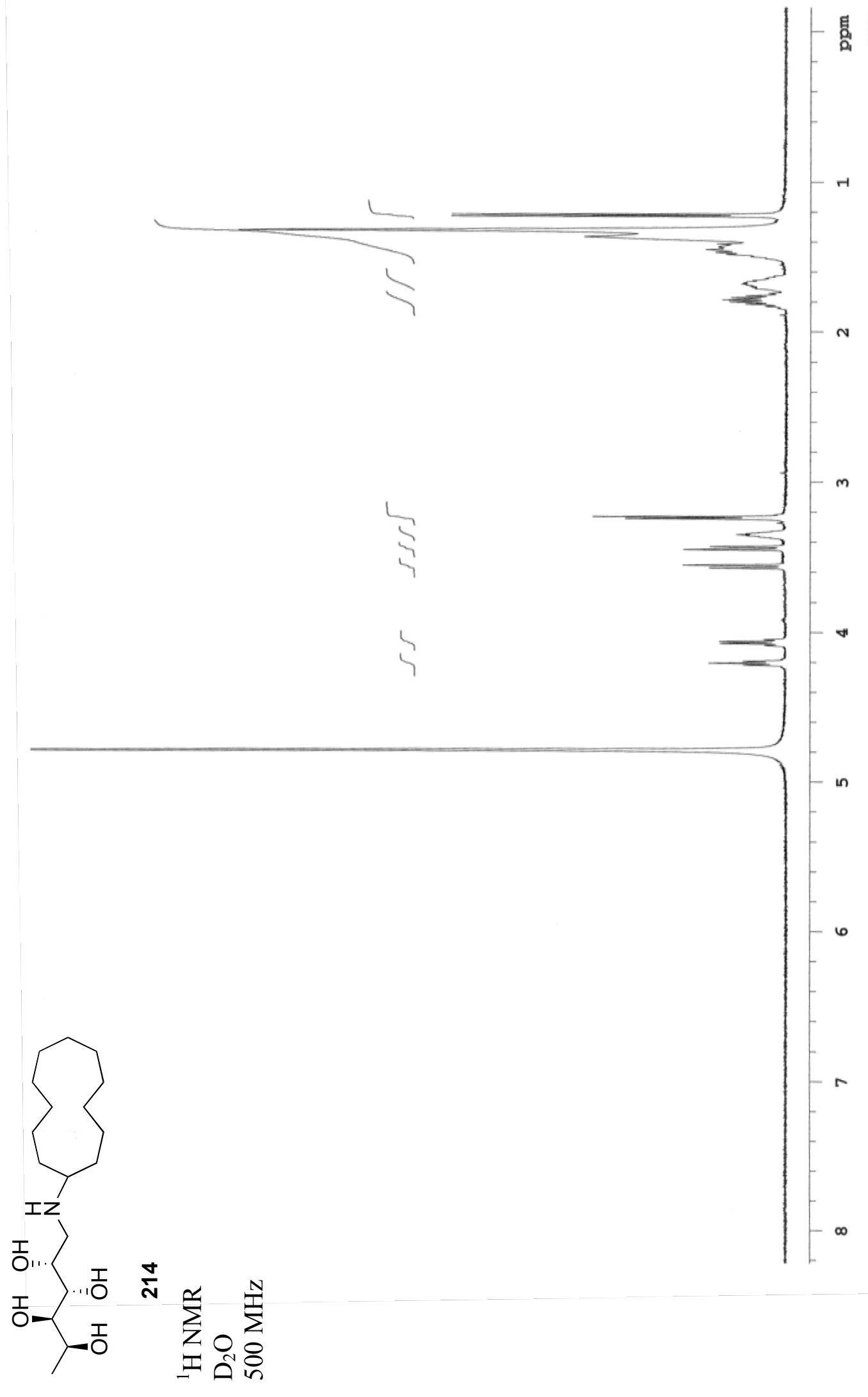

品 

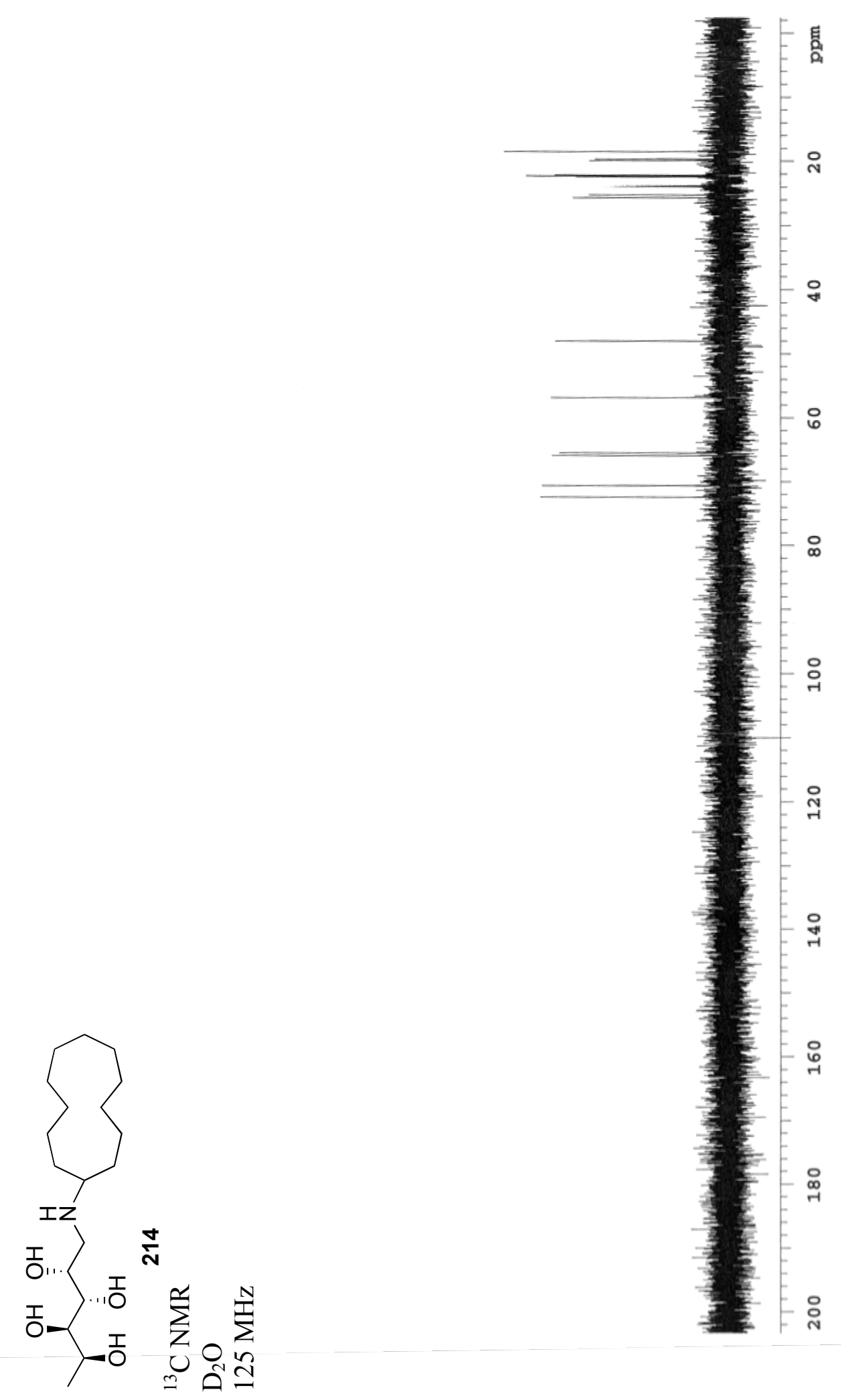


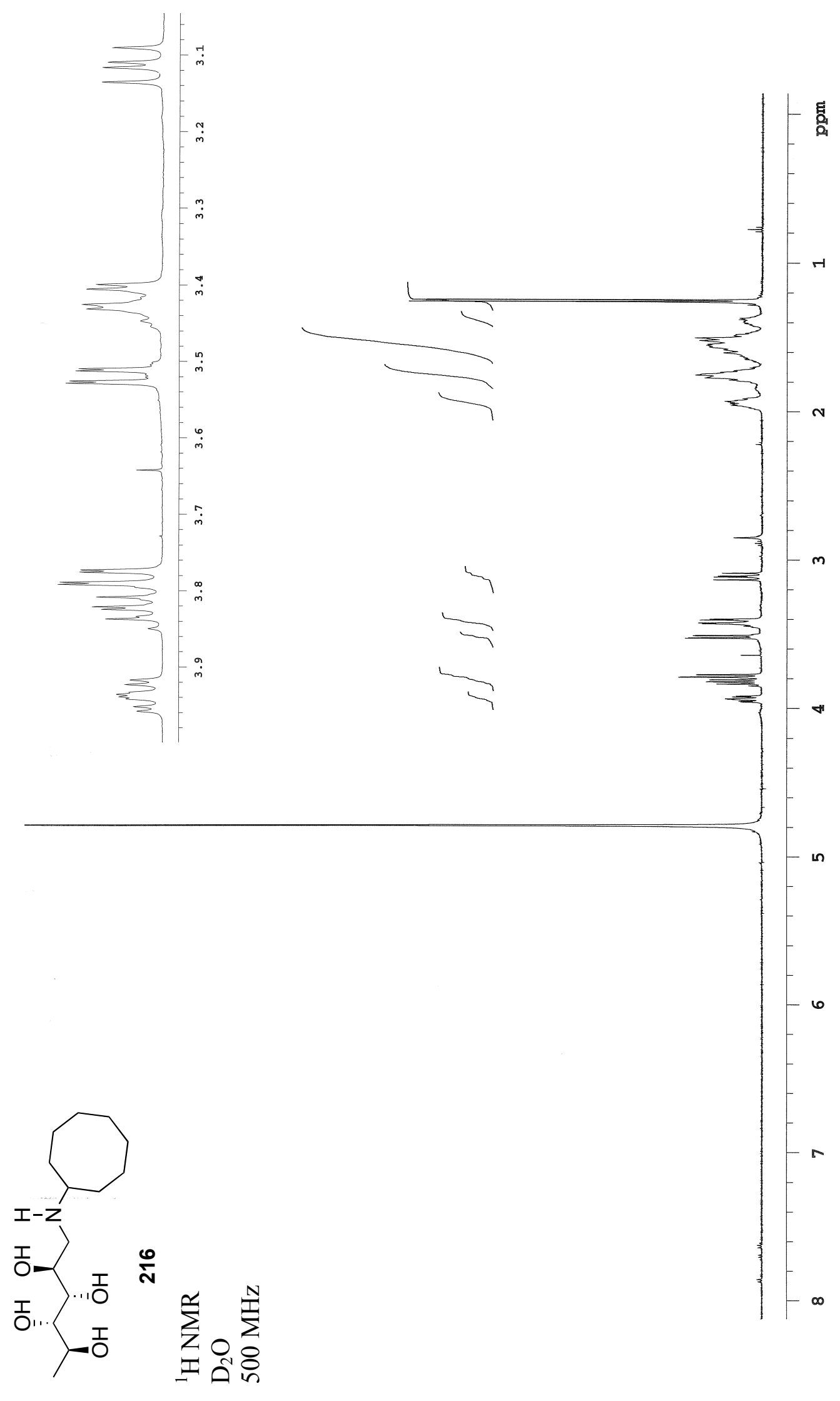

$\underset{\sim}{\infty}$ 

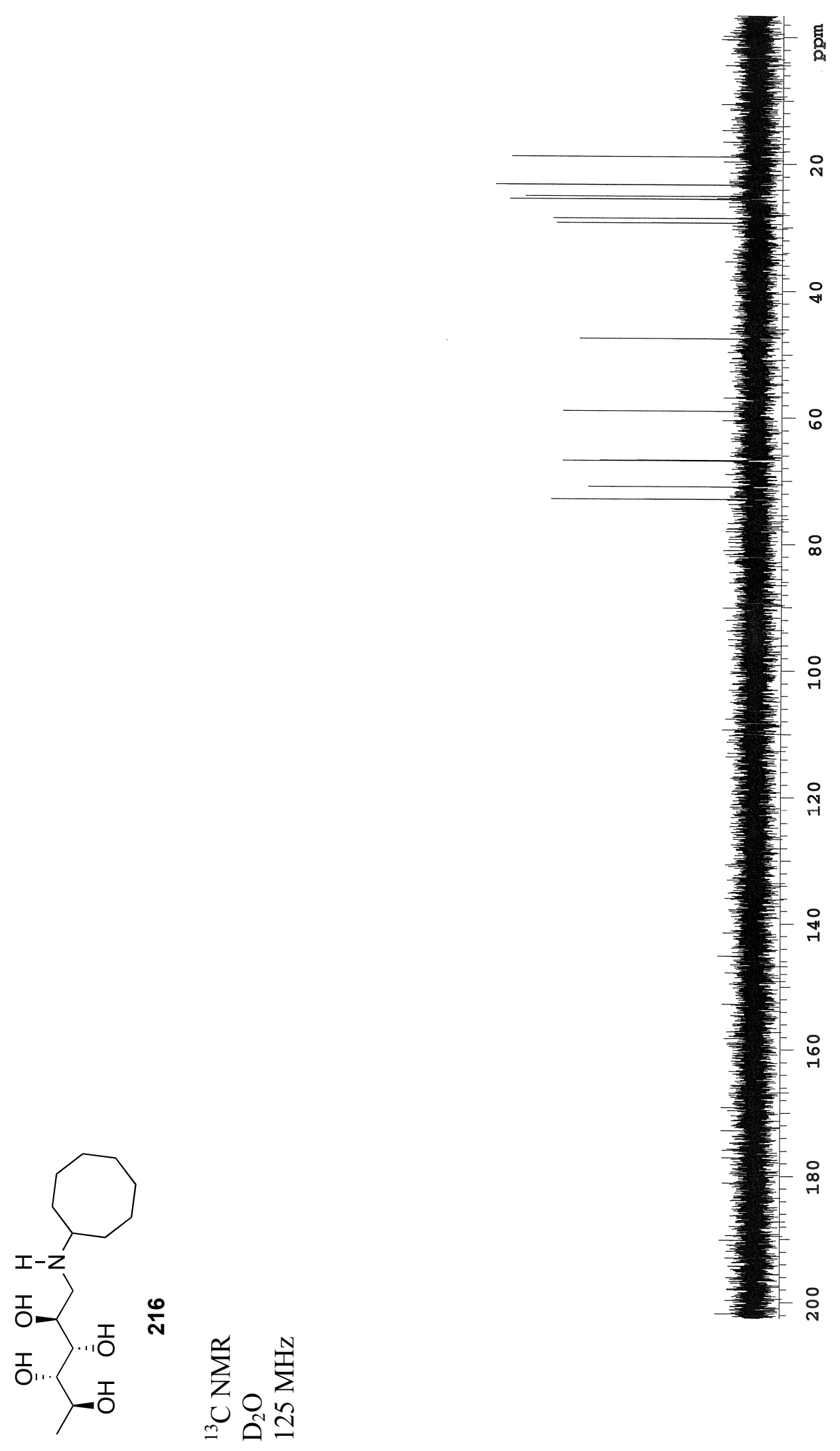


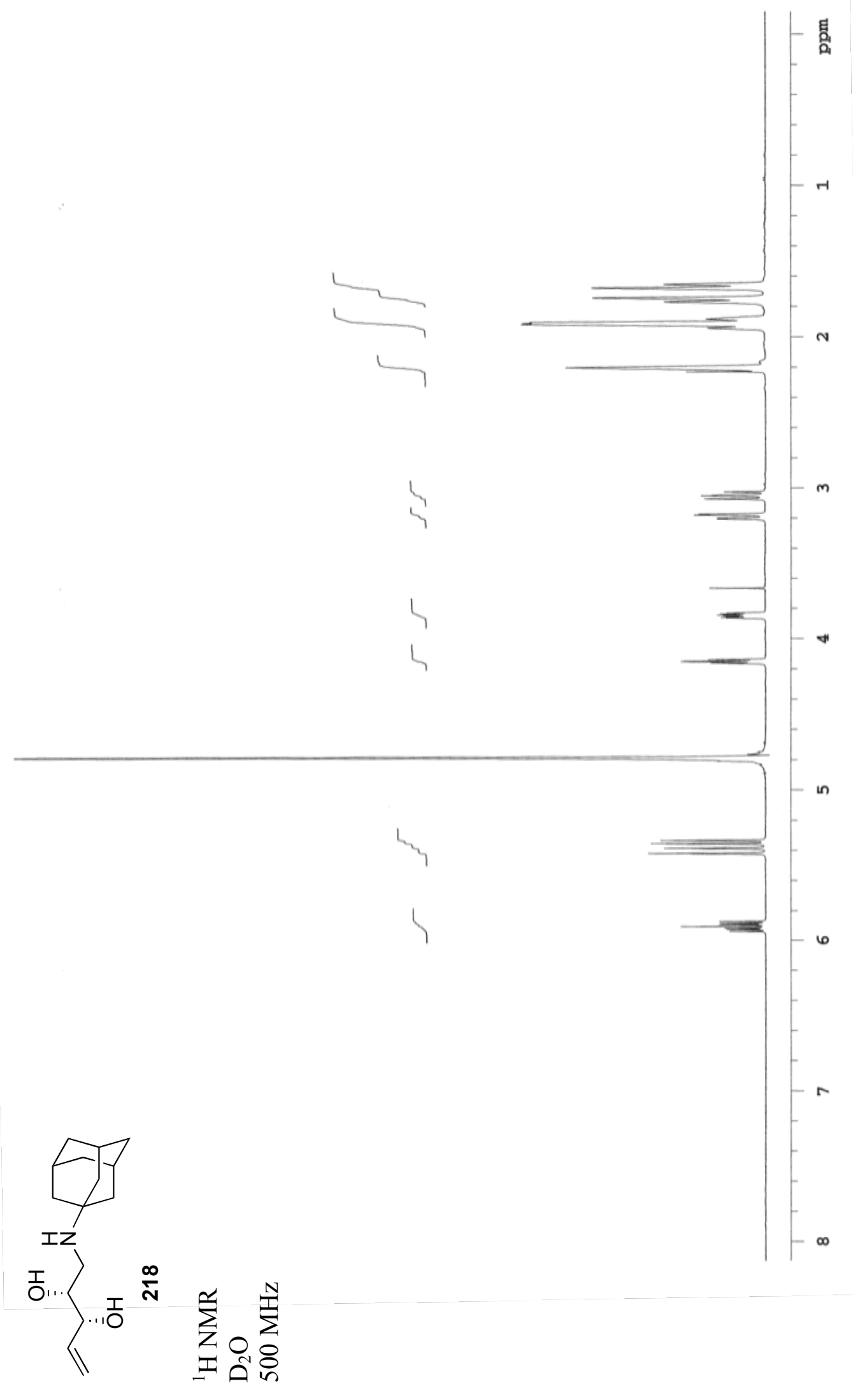

ন 


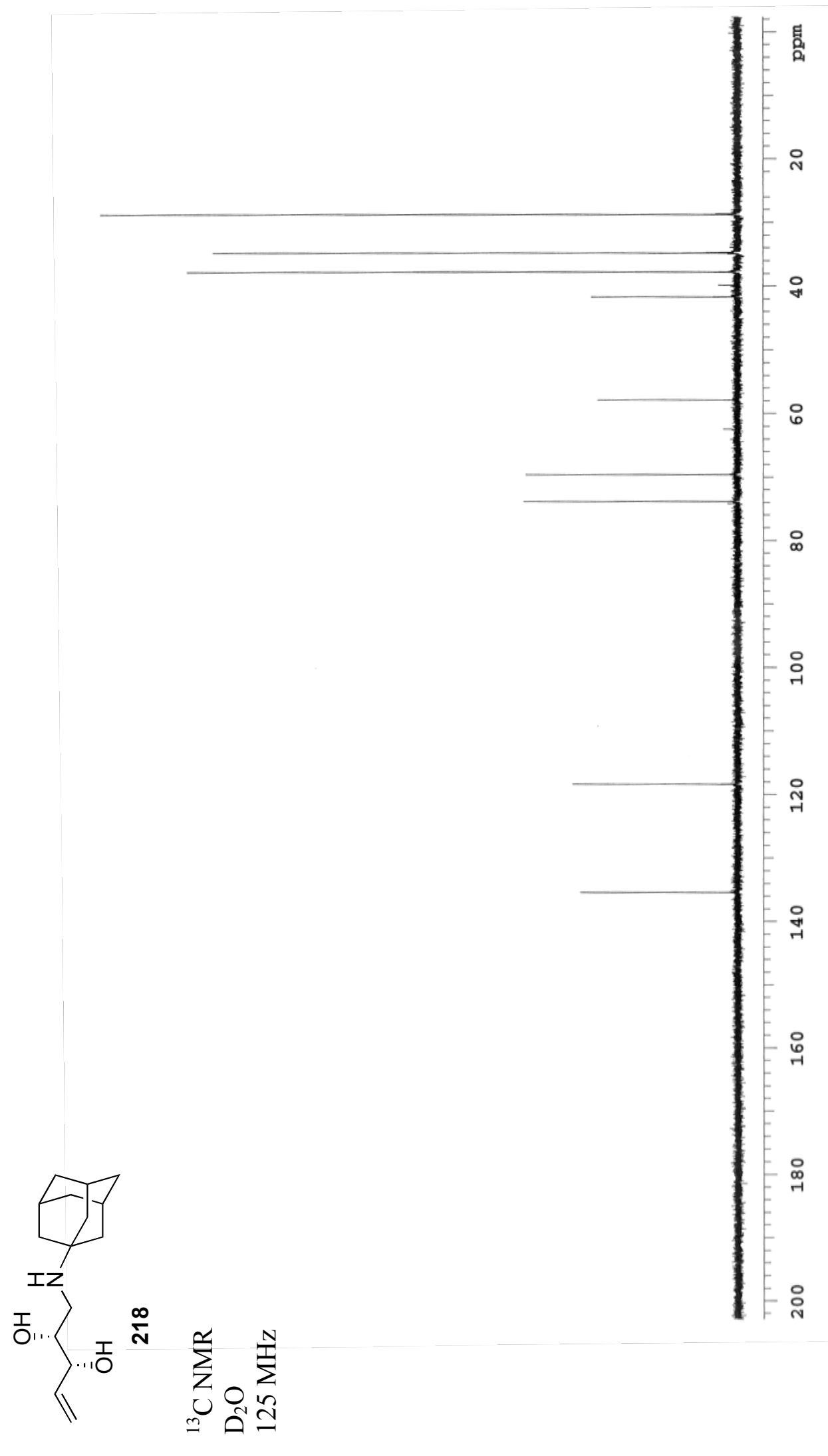

ন্ 


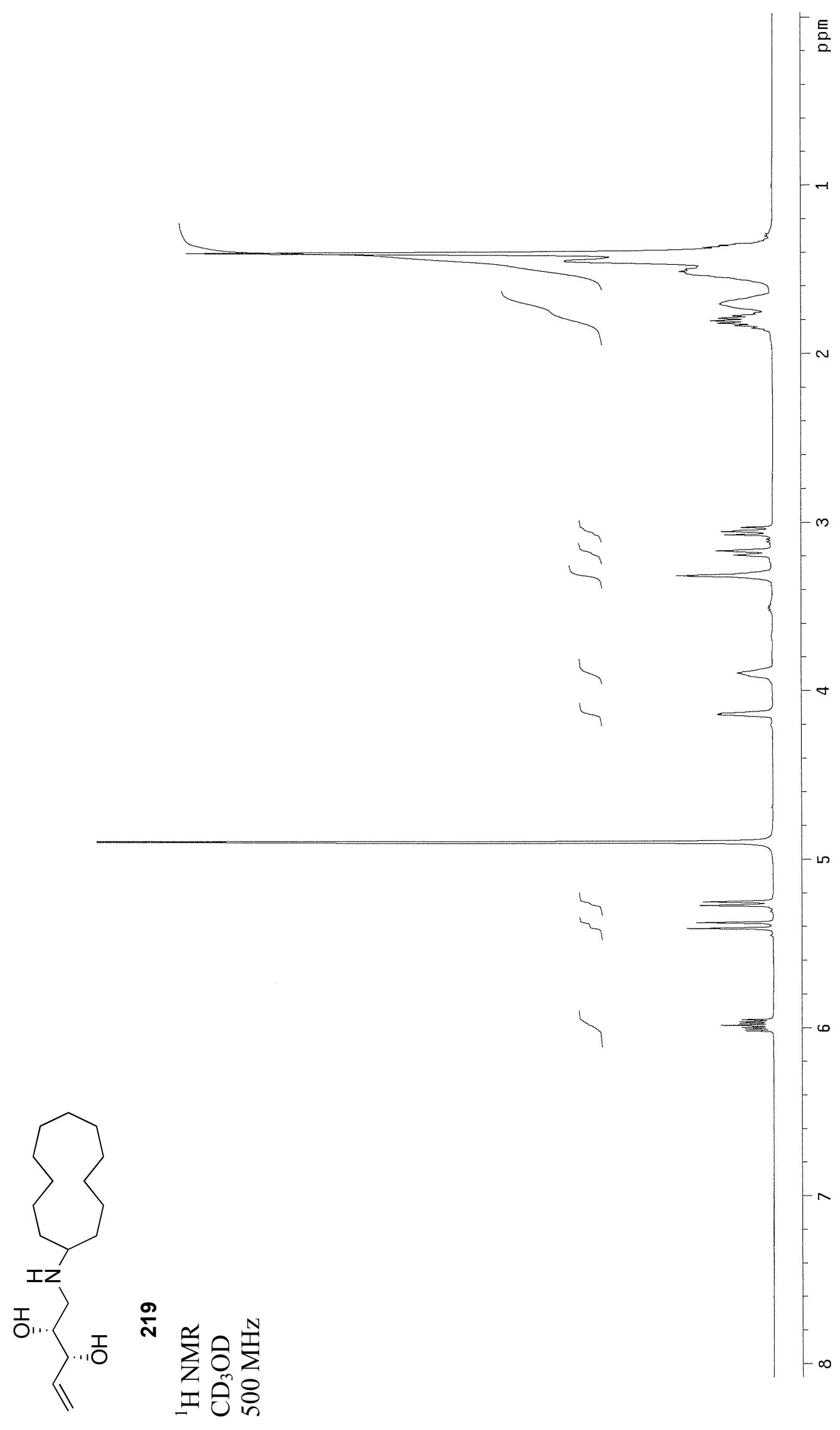




$$
\text { t }
$$




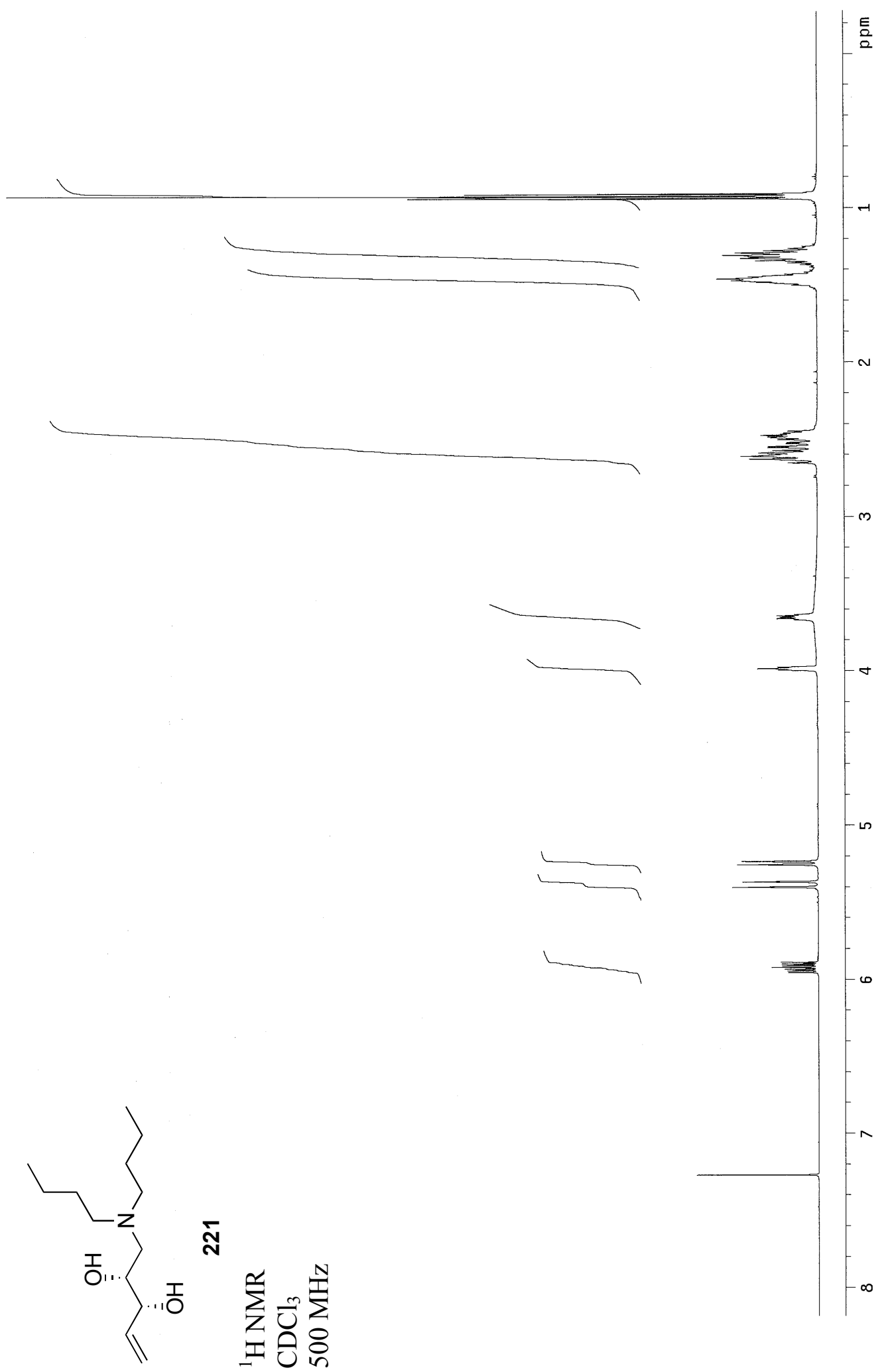




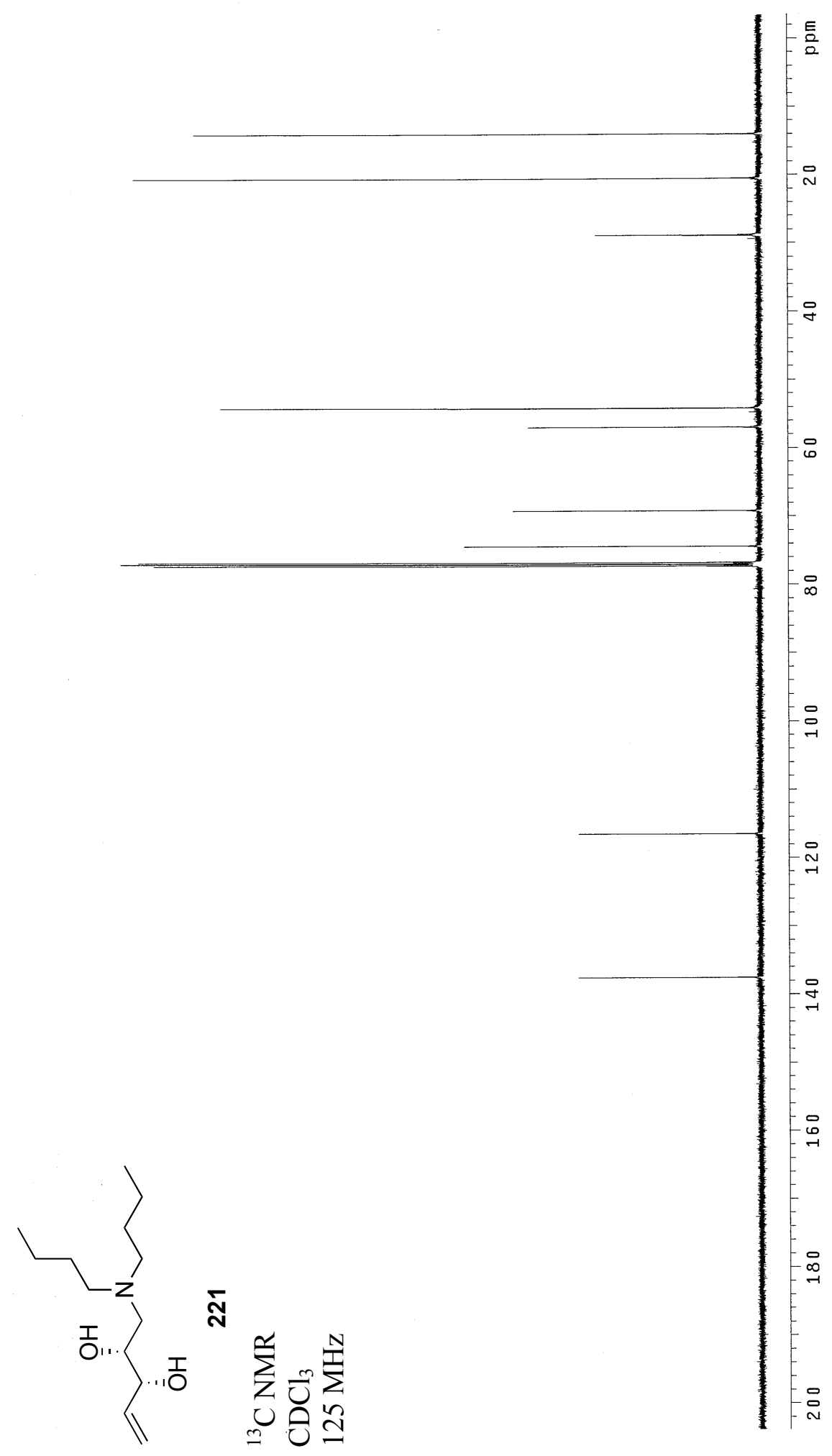




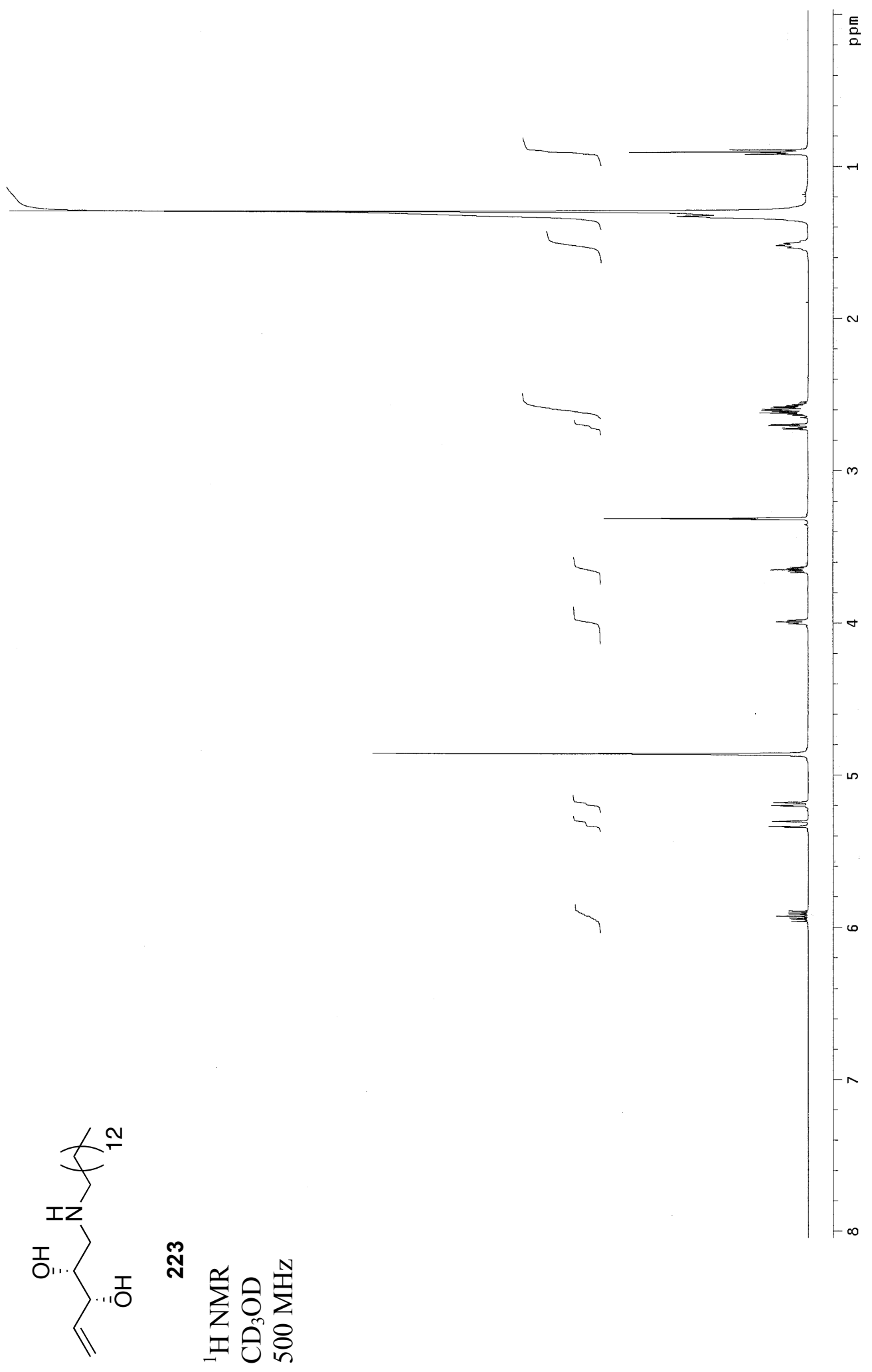




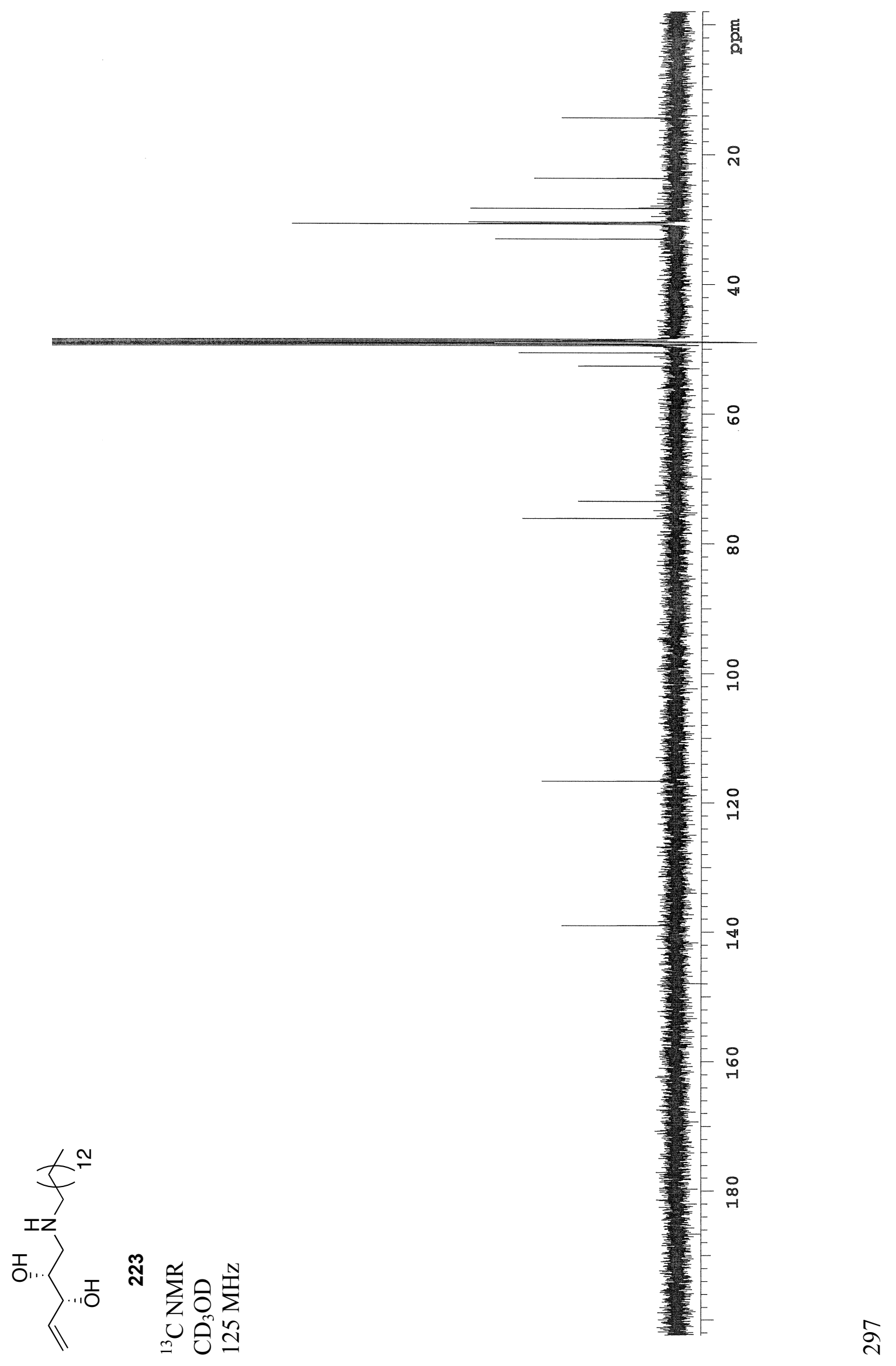




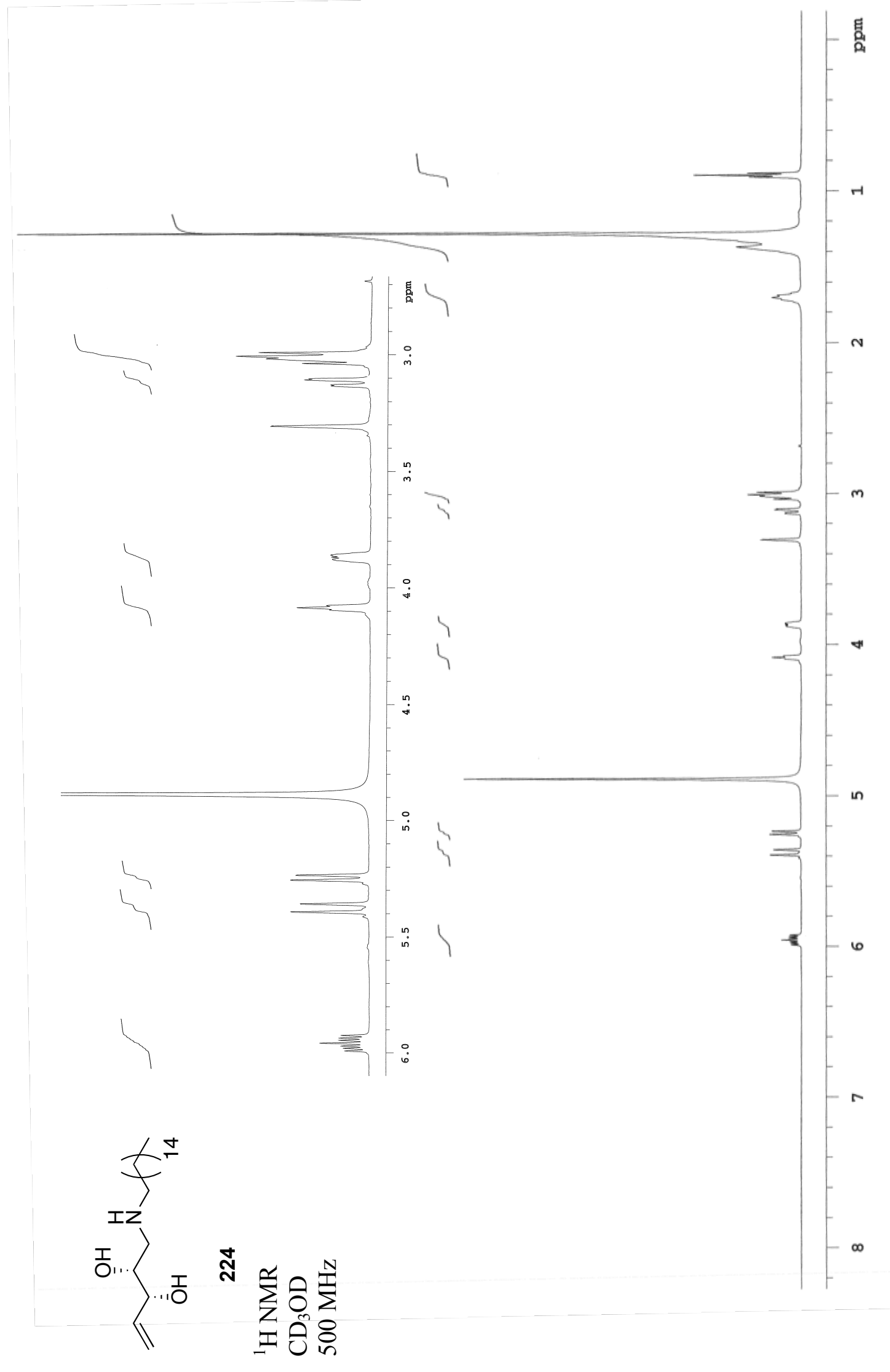




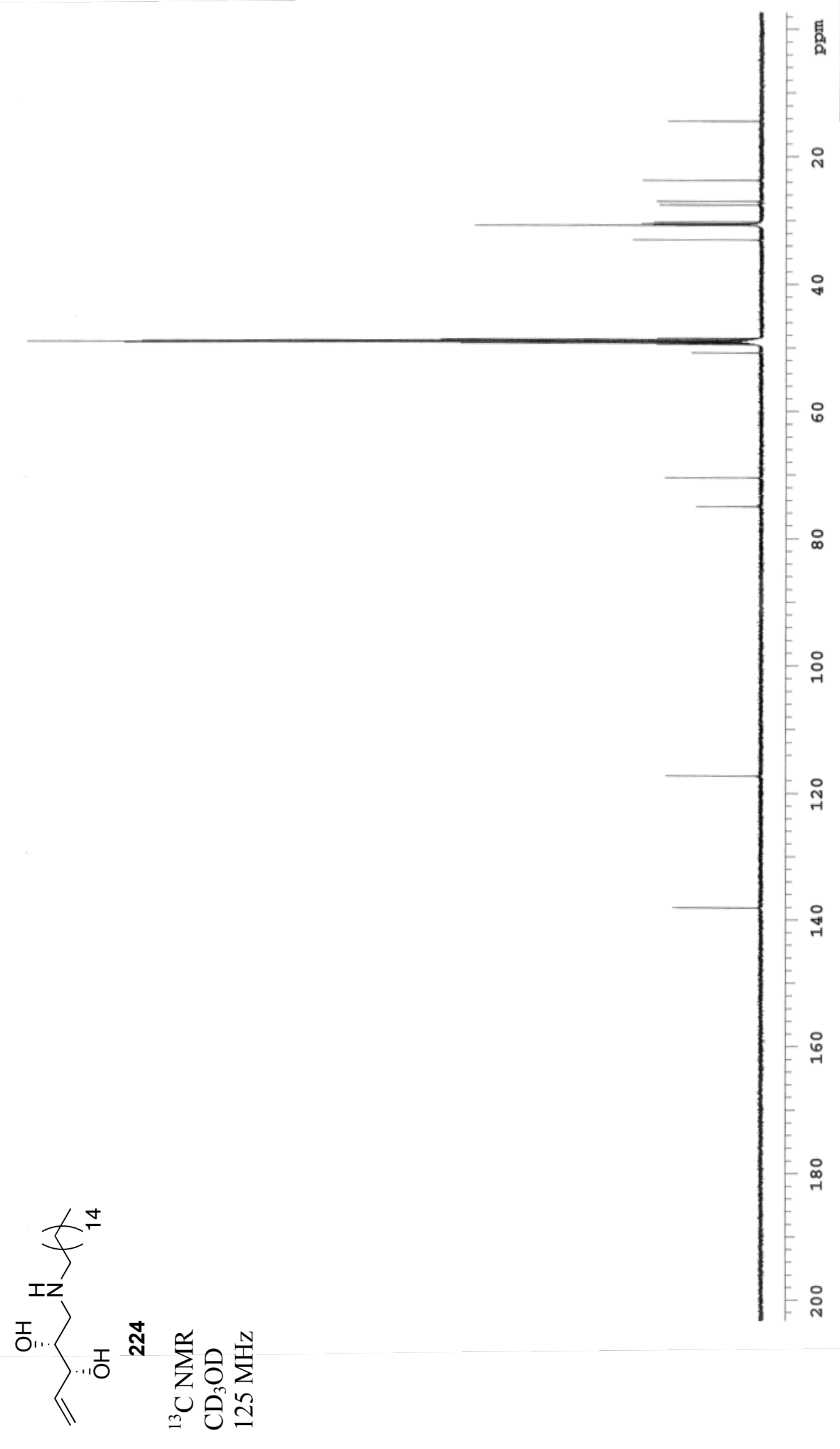




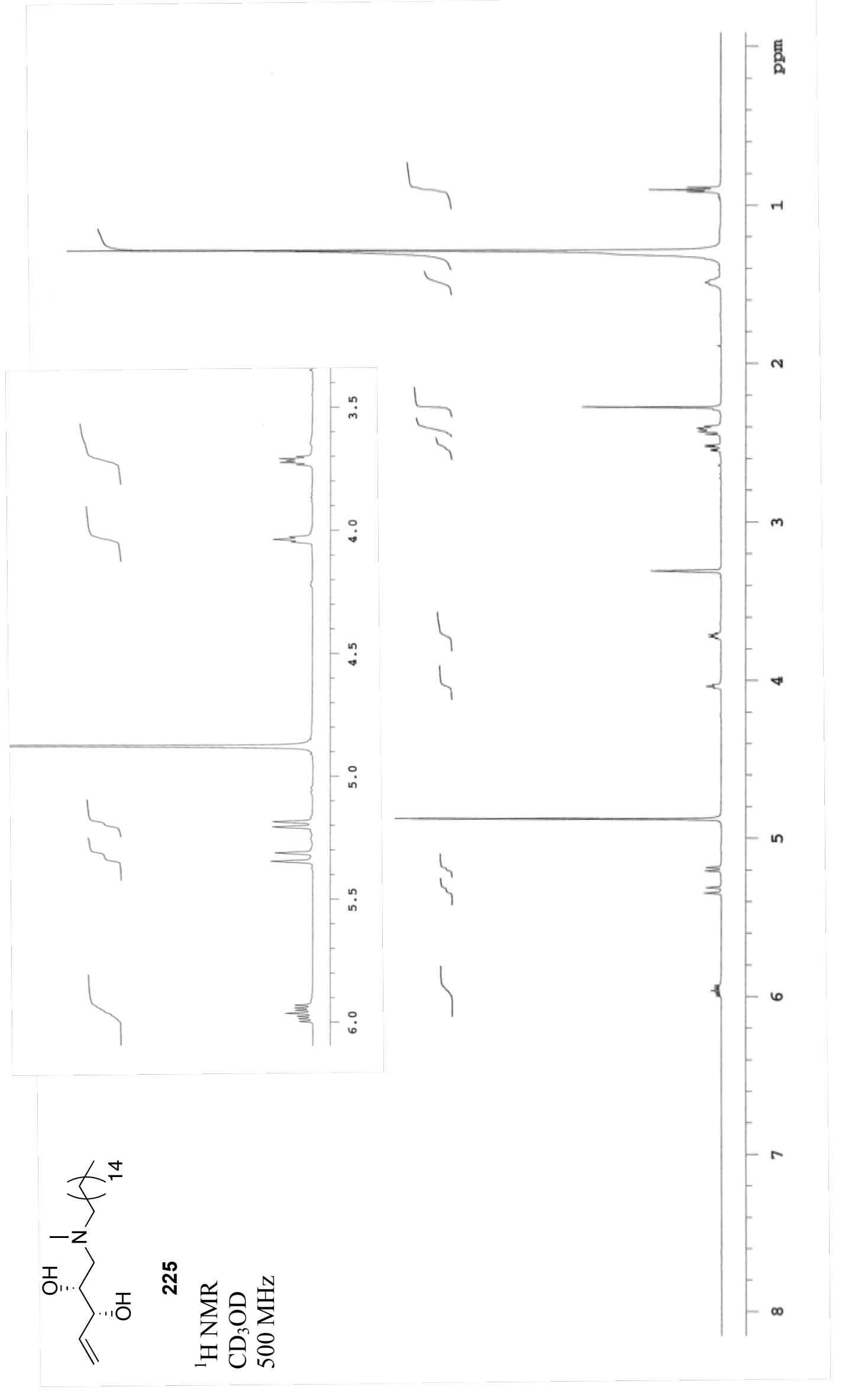

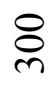




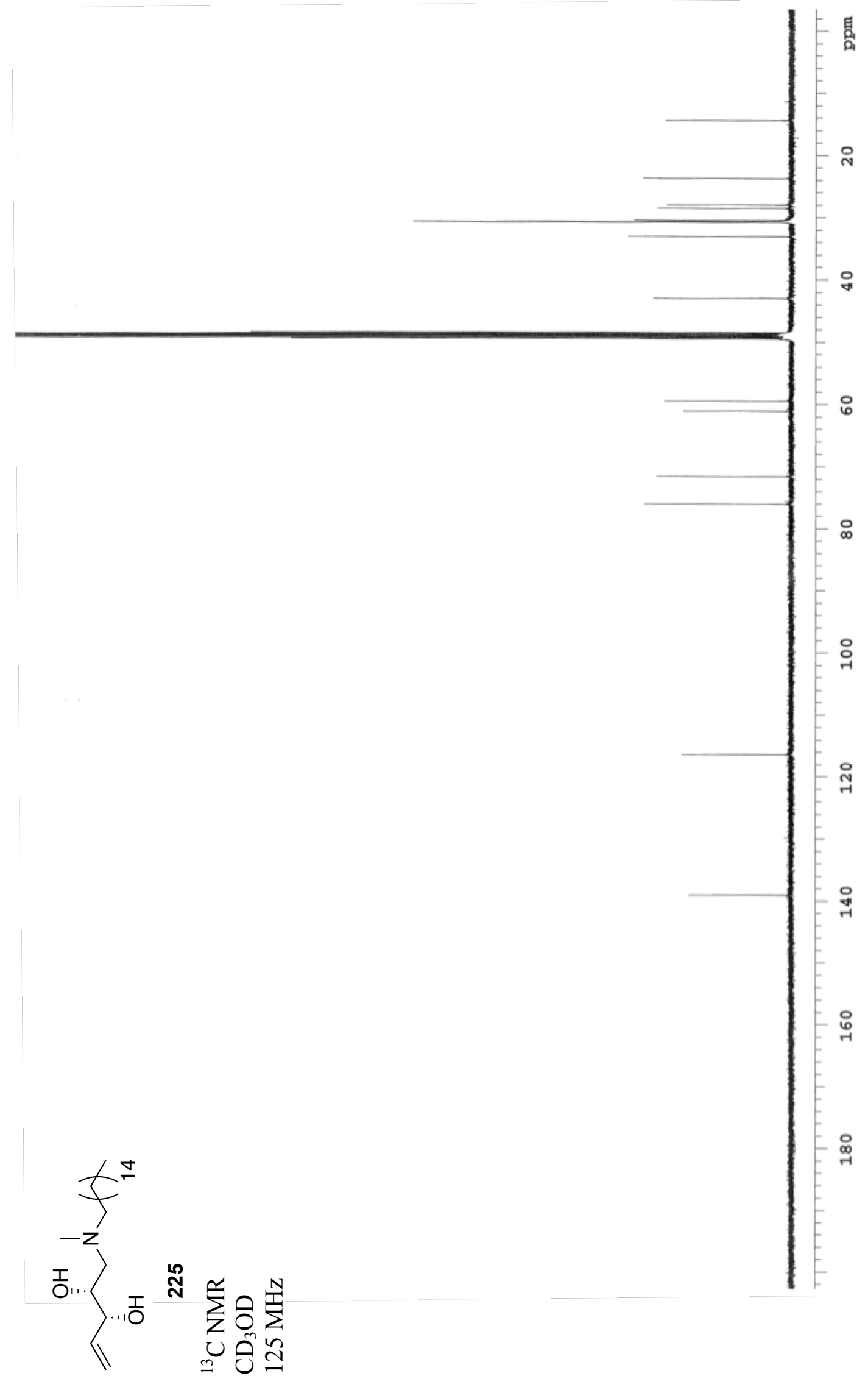

$\overline{\mathrm{c}}$ 
రి 


\section{Previously published paper:}

Corkran, H. M.; Munneke, S.; Dangerfield, E. M.; Timmer, M. S. M.; Stocker, B. L. J. Org. Chem., 2013, 78, 9791-9802. 


\title{
Applications and Limitations of the $\mathrm{I}_{2}$-Mediated Carbamate Annulation for the Synthesis of Piperidines: Five- versus Six- Membered Ring Formation
}

\author{
Hilary M. Corkran, ${ }^{\dagger \dagger}$ Stefan Munneke, ${ }^{\dagger}$ Emma M. Dangerfield, ${ }^{\dagger, \ddagger}$ Bridget L. Stocker, ${ }^{*}, \dagger, \ddagger$ \\ and Mattie S. M. Timmer* ${ }^{\dagger}$ \\ ${ }^{\dagger}$ School of Chemical and Physical Sciences, Victoria University of Wellington, P.O. Box 600, Wellington, New Zealand \\ ${ }^{\ddagger}$ Malaghan Institute of Medical Research, P.O. Box 7060, Wellington, New Zealand \\ Supporting Information
}

ABSTRACT: A protecting-group-free synthetic strategy for the synthesis of piperidines has been explored. Key in the synthesis is an $\mathrm{I}_{2}$-mediated carbamate annulation, which allows for the cyclization of hydroxy-substituted alkenylamines into piperidines, pyrrolidines, and furans. In this work, four chiral

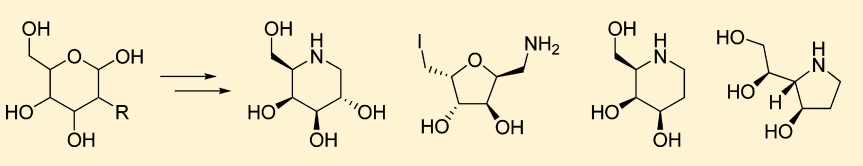
scaffolds were compared and contrasted, and it was observed

that with both D-galactose and 2-deoxy-D-galactose as starting materials, the transformations into the piperidines 1deoxygalactonorjirimycin (DGJ) and 4-epi-fagomine, respectively, could be achieved in few steps and good overall yields. When D-glucose was used as a starting material, only the furan product was formed, whereas the use of 2-deoxy-D-glucose resulted in reduced chemo- and stereoselectivity and the formation of four products. A mechanistic explanation for the formation of each annulation product could be provided, which has improved our understanding of the scope and limitations of the carbamate annulation for piperidine synthesis.

\section{INTRODUCTION}

Iminosugars have enormous therapeutic potential in the treatment of a number of diseases, such as cancer, diabetes, and lysosomal storage disorders. ${ }^{1}$ Notable members of the piperidine iminosuguar family include $N$-hydroxyethyl-DNJ (Miglitol, 1), which has been approved for the treatment of non-insulin-dependent diabetes, ${ }^{2}$ and 1-deoxygalactonojirimycin (DGJ, 2), recently used in a phase- 2 clinical trial for the treatment of Fabry's disease (Figure 1). ${ }^{3}$ The corresponding 2deoxypiperidines, fagomine $(3)^{4,5}$ and the unnatural 4-epiisomer 4, also exhibit promising biological activities. Fagomine was found to have activity against mammalian gut $\alpha$ glucosidases and $\beta$-galactosidase ${ }^{6}$ and a potent antihyperglyce-<smiles>OCCN1CC(O)C(O)C(O)C1O</smiles>

1<smiles>OCC1NCCC(O)C1O</smiles>

3<smiles>OCC1NCC(O)C(O)C1O</smiles>

2<smiles>OCC1NCCC(O)C1O</smiles>

4

Figure 1. Piperidines.

mic effect in streptozotocin-induced diabetic mice, ${ }^{7}$ while fagomine isomer 4 inhibits lysosomal $\alpha$-galactosidase A activity in Fabry lymphoblasts. ${ }^{8}$

Given the interesting biological activity of piperidines, we became interested in extending our previously reported protecting-group-free strategy for the synthesis of pyrrolidines $^{9-11}$ to the synthesis of piperidines. ${ }^{12}$ To this end, we proposed that the target piperidines I could be attained following the hydrolysis of the intermediate cyclic carbamate II, itself prepared via the $\mathrm{I}_{2}$-mediated cyclization of alkenylamine precursor III (Scheme 1). Alkenylamine III would in turn be prepared from methyl iodoglycoside IV via our recently reported protecting-group-free Vasella reductive amination methodology. ${ }^{13}$ Key in this approach was the provision that when $\mathrm{R}^{1}=\mathrm{OH}$, alkenylamine III should cyclize to form the desired piperidine ( $\mathrm{N}$-cyclization) rather than undergoing $\mathrm{O}$ cyclization, which would lead to the undesired aminomethylfuran.

To explore the potential of our annulation methodology for the synthesis of piperidines, we first set out to prepare 1deoxygalactonojirimycin (DGJ, 2). As previously described, ${ }^{14}$ alkenylamine 5, itself available in three steps from D-galactose, was subjected to an $\mathrm{I}_{2}$-mediated carbamate annulation to give, under optimized conditions, piperidine isomers $\mathbf{6 a}$ and $\mathbf{6 b}$ and furan $6 \mathrm{c}$ in a 3:1:1 ratio, respectively (Scheme 2). Whereas our previously reported pyrrolidine annulation methodology

Received: July 12, 2013

Published: August 29, 2013 
Scheme 1. Retrosynthetic Analysis for the Synthesis of Piperidines

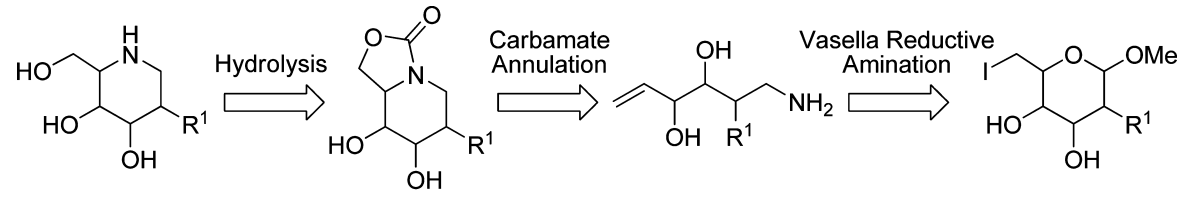

I

II

III

IV

Scheme 2. Synthesis of DGJ (2)
$\overbrace{\mathrm{OH}}^{\mathrm{C}_{\mathrm{H}} \mathrm{OH}} \underset{\mathrm{H}_{2} \mathrm{O}, \mathrm{rt}, 3 \mathrm{~d}}{\stackrel{\mathrm{I}_{2}, \mathrm{NaHCO}_{3}}{\longrightarrow}}$

5<smiles>O=C1OC[C@H]2[C@@H](O)[C@H](O)[C@@H](O)CN12</smiles>

$6 a$

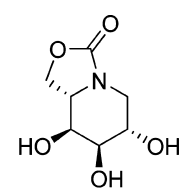

6b (3: $1: 1)$

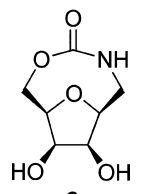

$6 c$

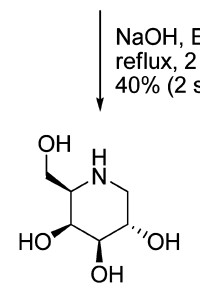

2

proceeded in $18 \mathrm{~h}$ at room temperature and with $>95: 5$ diastereoselectivity in favor of the cis product, ${ }^{9-11}$ cyclization to the piperidine framework was much slower and resulted in lower stereoselectivity. Hydrolysis of the carbamate and purification by silica gel flash column chromatography, however, allowed 2 to be prepared in a respectable $40 \%$ yield (from 5) and in five steps in total. Given this, we were keen to explore whether a similar methodology could be used for the preparation of other piperidines. The results of our studies in this area are reported herein.

\section{RESULTS AND DISCUSSION}

Following our successful synthesis of DGJ, we then explored the potential of our $\mathrm{I}_{2}$-mediated annulation strategy for the synthesis of 1,5-dideoxy-1,5-imino-L-iditol (7) (Scheme 3). To this end, methyl glucopyranoside $\mathbf{8}$ was subjected to triphenylphosphine, imidazole, and iodine to give the corresponding iodosugar 9 in $98 \%$ yield. ${ }^{13}$ Subsequent Vasella reductive amination led to the smooth formation of alkenyl-

amine 10, again in excellent yield (93\%) with only minor traces of the secondary amine $(<5 \%) .{ }^{15}$ Alkenylamine 10 was then treated with $\mathrm{I}_{2}$ and $\mathrm{NaHCO}_{3}$ in anticipation that carbamate 11 would be formed. Though TLC analysis revealed the smooth transformation into a higher-running product $\left(R_{\mathrm{f}}=0.23\right.$, $\mathrm{DCM} / \mathrm{EtOH} / \mathrm{MeOH} / 30 \%$ aq. $\left.\mathrm{NH}_{3}, 5 / 2 / 2 / 1 \mathrm{v} / \mathrm{v} / \mathrm{v} / \mathrm{v}\right),{ }^{13} \mathrm{C}$ NMR analysis of the crude reaction mixture revealed the presence of an iodomethylene carbon $\left(-0.3 \mathrm{ppm},-\mathrm{CH}_{2} \mathrm{I}\right)$, thus indicating that the desired carbamate had not been formed. Furthermore, an aminomethylene signal at $39.4 \mathrm{ppm}$ and four oxymethine signals (82-76 ppm) were observed, which indicated the presence of aminomethylfuran 13 rather than piperidine 12, both of which satisfy the HRMS result ([M $\left.+\mathrm{H}]^{+}=273.9938\right)$. Attempts to purify the material to allow for further characterization proved futile, as Dowex $-\mathrm{H}^{+}$or silica gel chromatography led to degradation of the product. Full characterization was therefore achieved after acetylation of the crude product with acetic anhydride and pyridine. The ${ }^{1} \mathrm{H}$ NMR spectral data clearly revealed an NH proton at $5.84 \mathrm{ppm}$ with a COSY correlation to both $\mathrm{Hla}$ and $\mathrm{H} 1 \mathrm{~b}$ and no correlation to $\mathrm{H} 5$. In addition, the HMBC correlations between both $\mathrm{H} 1$ protons and the NHAc carbonyl were also present. As acetylation of pyran $\mathbf{1 2}$ would protect the amine, leaving no observable $\mathrm{NH}$ proton, these observations allowed the product of the acetylation reaction to be determined as furan 14 . Following on from this, the product of the $\mathrm{I}_{2}$-mediated annulation reaction could then be assigned as furan $\mathbf{1 3}$.

In an attempt to encourage attack of the nitrogen atom and formation of the desired carbamate $\mathbf{1 1}$ during the annulation reaction, alkenylamine $\mathbf{1 0}$ was treated with a stronger base, $\mathrm{Na}_{2} \mathrm{CO}_{3}$, to favor formation of the free amine. After the reaction mixture was stirred at room temperature overnight, no starting material remained; concentration and NMR analysis of the crude reaction mixture, however, revealed that the carbamic acid derivative of furan 13 , formed via $\mathrm{CO}_{2}$ absorption onto the amine, ${ }^{16,17}$ had been prepared. Numerous other changes were

Scheme 3. Formation of an Undesired Iodofuranoside by $\mathrm{I}_{2}$-Mediated Annulation

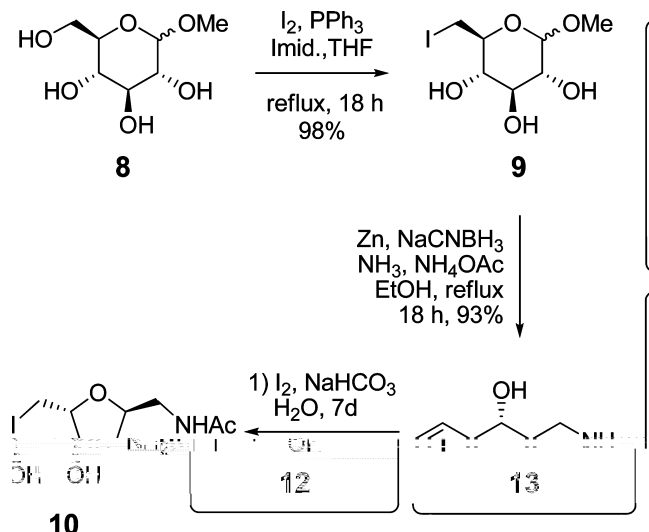

10
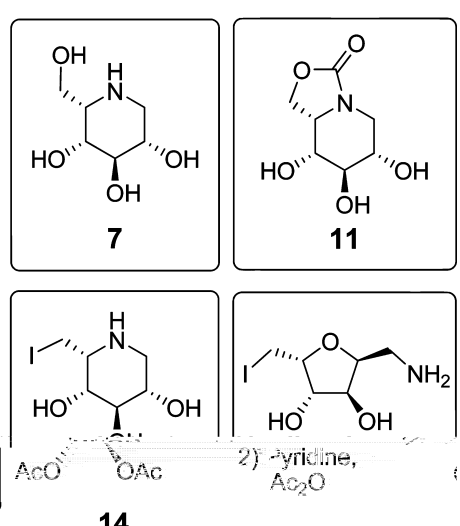

14

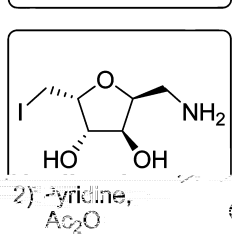


Scheme 4. Formation of Linear Alkenylamine 24<smiles></smiles>

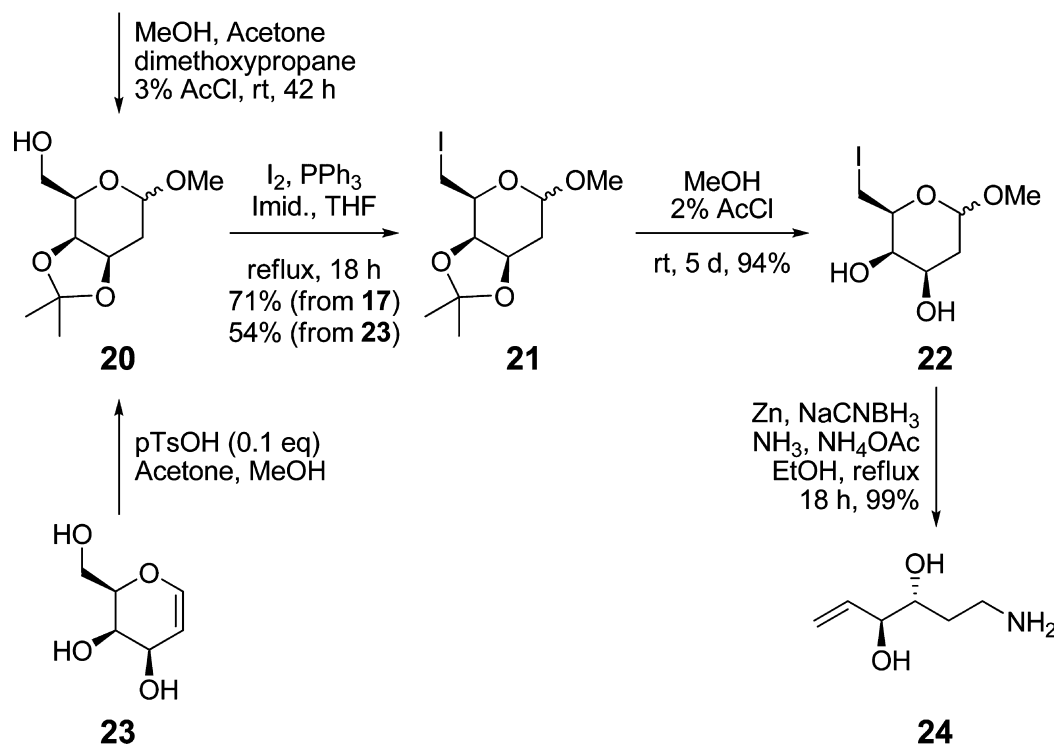

then made to the reaction conditions, including changes to the temperature $\left(0{ }^{\circ} \mathrm{C}\right.$ to reflux $)$ and the reagent concentrations. However, under all of the conditions attempted, there was no observable formation of the desired carbamate $\mathbf{1 1}$ as determined by ${ }^{1} \mathrm{H}$ NMR analysis of the crude reaction mixture, and furan products always appeared to dominate. Though this result was disappointing, the inherent problem of controlling the chemoselectivity during protecting-group-free syntheses is well-known and thus explains why the development of protecting groups, though undesirable in terms of atom economy, still remains an important objective for the synthetic chemist. ${ }^{18}$

Having observed competing O-cyclization in an attempt to prepare 1,5-dideoxy-1,5-imino-L-iditol (7) and to a lesser extent DGJ (2), we thus proposed the synthesis of members of the fagomine family. Fagomine analogues retain interesting biological properties but are devoid of the hydroxyl functionality at $\mathrm{C} 2\left(\mathrm{R}^{1}=\mathrm{H}\right.$; Scheme 1$)$, and hence, the synthesis would be more readily accomplished. Accordingly, we first set out to synthesize 4-epi-fagomine (4) (Scheme 4). To this end, 2deoxy-D-galactose (17) was first subjected to a Fischer glycosylation using $\mathrm{AcCl}$ and $\mathrm{MeOH}$ to give the corresponding methyl glycoside 18 in modest (40\%) yield, with a second major product being the kinetically favored furan. Methyl glycoside 18 was then treated with $I_{2}$, triphenylphosphine, and imidazole in THF. Under these conditions, however, only bicyclic pyranoside 19 was observed, ${ }^{19}$ a consequence of intramolecular substitution of the activated phosphonium group at $\mathrm{C} 6$ by the hydroxyl at the 3-position. Indeed, a similar observation was seen en route to the synthesis of DGJ, ${ }^{14}$ and given the tendency for this intramolecular cyclization in iodination of methyl glycosides of the galacto configuration, we resorted to the installation of an isopropylidine protecting group at the 3- and 4-positions via the treatment of 2-deoxy-D- galactose (17) with $\mathrm{MeOH}$, acetone, dimethoxypropane, and $\mathrm{AcCl}$. Conveniently, these conditions led to the concomitant installation of the methyl group at the anomeric position to give galactoside $\mathbf{2 0}$ in one step. Galactoside $\mathbf{2 0}$ was then subjected to the standard iodination conditions to give the required primary iodide $\mathbf{2 1}$ in $71 \%$ yield (from 17), and the isopropylidine group was then removed to give the desired methyl iodoglycoside $\mathbf{2 2}$ in $94 \%$ yield. Here it is also interesting to note that 20 can be prepared from D-galactal (23) by protonation of the alkene with $\mathrm{TsOH}$ followed by nucleophilic attack of methanol. ${ }^{20}$ Under these conditions, pyranose $\mathbf{2 0}$ was formed in $\sim 78 \%$ yield with small amounts (ca. 10\%) of methyl 5,6-O-isopropylidene-D-galactofuranoside, which was more readily separable following conversion of $\mathbf{2 0}$ into iodide $\mathbf{2 1}$.

With primary iodide $\mathbf{2 2}$ in hand, we then applied the Vasella reductive amination conditions and obtained alkenylamine $\mathbf{2 4}$ in excellent yield (99\%). Alkenylamine 24 was then subjected to a solution of $\mathrm{I}_{2}$ and $\mathrm{NaHCO}_{3}$ in $\mathrm{H}_{2} \mathrm{O}$ to affect the desired carbamate annulation reaction (Table 1 ). Again, cyclization to the desired six-membered ring proved to be sluggish, and no appreciable reaction was observed after alkenylamine 24 was stirred in $\mathrm{NaHCO}_{3}$ (sat. aq.) in the presence of excess $\mathrm{I}_{2}(10$ equiv) at room temperature (ca. $20{ }^{\circ} \mathrm{C}$ ) for 7 days (entry 1 ). When the solution was heated to $50{ }^{\circ} \mathrm{C}$, however, complete conversion of the starting material was observed after 3 days (entry 2), and following filtration, carbamates $25 \mathrm{a}$ and $\mathbf{2 5 b}$ were observed in a 3:1 ratio, as determined by ${ }^{1} \mathrm{H}$ NMR analysis of the crude reaction mixture. Lowering the reaction temperature to $40{ }^{\circ} \mathrm{C}$ resulted in an increased reaction time (5 days) but led to improved diastereoselectivity in favor of the cis isomer 25a (25a:25b = 9:1; entry 3). Remarkably, a diastereoselectivity of $>95: 5$ was achieved when the reaction was performed at $35{ }^{\circ} \mathrm{C}$ with a reaction time of 5 days (entry 4). Indeed, using the latter conditions, carbamate 25a was 
Table 1. Diastereoselectivity of Carbamate Annulation

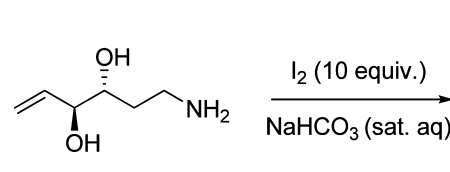

24

\begin{tabular}{cccl} 
entry & $T\left({ }^{\circ} \mathrm{C}\right)$ & $t$ (days) & \multicolumn{1}{|c|}{$\mathbf{2 5 a : 2 5 \mathbf { b } ^ { a }}$} \\
1 & 20 & $>7$ & no reaction \\
2 & 50 & 3 & $3: 1$ \\
3 & 40 & 5 & $9: 1$ \\
4 & 35 & 5 & $>95: 5^{b}$
\end{tabular}

${ }^{a}$ As determined by ${ }^{1} \mathrm{H}$ NMR analysis of the crude reaction mixture. ${ }^{b} \mathbf{2 5}$ a was isolated in $86 \%$ yield.

isolated in $86 \%$ yield following silica gel column chromatography.

To complete the synthesis, carbamate 25 a was then hydrolyzed via treatment with $\mathrm{NaOH}$ in $\mathrm{EtOH}$ at reflux (Scheme 5). This resulted in the smooth formation of 4-epi-

Scheme 5. Hydrolysis of cis-Carbamate 25a<smiles>CC(O)C(O)C1COC(=O)N1</smiles>

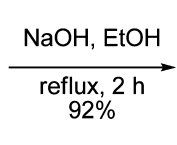<smiles>OCC1NCCC(O)C1O</smiles>

fagomine (4) in $92 \%$ yield, thus completing this remarkably efficient six-step synthesis with an overall yield of 52\%. 4-epiFagomine has been prepared on several other occasions. ${ }^{21-24}$ The first synthesis required 10 steps from $3^{21}$ using the method of Heiker and Schueller ${ }^{22}$ (no yield reported), and the synthesis with the best reported yield (28\%) proceeded via an asymmetric route from a benzyl-protected galactal. ${ }^{25}$ Although the need for a protecting group here was unavoidable because of the inherent reactivity of the galacto configuration, protecting group manipulation added just one step to the synthesis, and an expedient synthesis of $\mathbf{4}$ was achieved with the best yield to date.

To further demonstrate the potential of our strategy for the synthesis of fagomine diastereomers, we then set about to synthesize 5-epi-fagomine (26) (Scheme 6). 2-Deoxy-D-glucose

Scheme 6. Synthesis of Alkenylamine 29 Derived from 2Deoxy-D-glucose

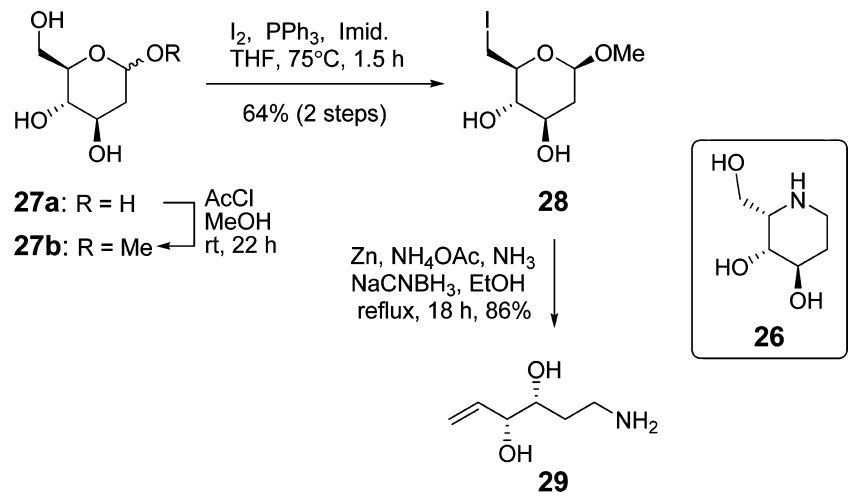

(27a) was converted to the methyl glycoside (27b) under Fischer glycosylation conditions, and subsequent treatment with iodine, triphenylphosphine, and imidazole at $75{ }^{\circ} \mathrm{C}$ for 1.5 h gave primary iodide $\mathbf{2 8}$ in good overall yield (64\% for two steps). ${ }^{26,27}$ The reaction times and temperatures were critical to avoid overiodination or incomplete consumption of starting material. Iodide 28 was then treated with $\mathrm{Zn}, \mathrm{NaCNBH}_{3}, \mathrm{NH}_{3}$, and $\mathrm{NH}_{4} \mathrm{OAc}$ according to the standard Vasella reductive amination protocol to effect its smooth transformation into alkenylamine 29 in good yield (86\%).

Alkenylamine 29 was then subjected to a variety of annulation conditions (Table 2). As previously highlighted, slightly warmer temperatures were required for the annulation of alkenylamine 24, and because of this, alkenylamine 29 was first treated with $\mathrm{I}_{2}$ and $\mathrm{NaHCO}_{3}$ (sat. aq.) at $40{ }^{\circ} \mathrm{C}$ (entry 1). These conditions led to a complex mixture of four carbamate products later identified as pyrrolidine 30 , the two piperidine diastereomers $\mathbf{3 1 a}$ and $\mathbf{3 1 b}$, and iodide 32 (vide infra), with iodide 32 being the major product in this instance. In an attempt to limit the formation of so many carbamate products, the reaction temperature was then lowered and the number of equivalents of $\mathrm{NaHCO}_{3}$ was reduced (entry 2). After the reaction mixture was stirred at room temperature for 9 days, however, no product formation was observed. Next, iodine was added in portions over the course of the reaction while the reaction mixture was stirred at room temperature until all of the starting material was consumed, as gauged by TLC analysis (entry 3 ). While these conditions invoked annulation reactions and a slight improvement in the ratio of the piperidine carbamate 31a was observed, iodide 32 was once again the major product and all four carbamates were still formed. The reaction was then attempted at room temperature, again using a saturated solution of $\mathrm{NaHCO}_{3}$ and $\mathrm{I}_{2}$ ( 5 equiv) added in one portion at the start of the reaction (entry 4). Under these conditions, the formation of iodide 32 was reduced and pyrrolidine 30 was formed with modest selectivity in a 30:31a:31b:32 ratio of $4: 2: 2: 3$. The role of the halide in influencing the ratio of products was then investigated through the use of $\mathrm{Br}_{2}$ (entry 5); however, this proved futile, with degradation being observed. Further changes were then made to the number of equivalents of reagents and the temperature at which the reaction was performed, but in all instances complex mixtures of products were observed, and the best yield of any single product apart from iodide $\mathbf{3 2}$ was still found to be that of pyrrolidine 30 (as highlighted in entry 4). Although the yield was disappointing (10-30\%), pyrrolidine 30 could nevertheless be isolated as a pure compound following repeated flash silica gel column chromatography (eluting in $2 \% \mathrm{MeOH}$ in EtOAc) and reversed-phase column chromatography $\left(\mathrm{C} 8, \mathrm{H}_{2} \mathrm{O}\right)$. Here the range of yields reflects the difficulty of this chromatographic separation. Piperidines 31a and 31b, however, could not be separated from one another and were isolated in a poor combined yield (ca. 20\%). Attempts to separate the products at a later stage in the synthesis (i.e., following hydrolysis) also did not lead to any overall improvement in the isolated yields.

To confirm the structures of pyrrolidine $\mathbf{3 0}$ and alkyl iodide 32, extensive $1 \mathrm{D}$ and $2 \mathrm{D}$ NMR spectral analysis was undertaken. For pyrrolidine 30, an HMBC correlation was observed between $\mathrm{H} 4$ and $\mathrm{C} 1$, thus enabling the 5,6-bicyclic ring system of $\mathbf{3 0}$ to be established. Unfortunately, overlapping signals in the proton spectra meant that the configurations of the stereocenters could not be determined unequivocally. However, NMR analysis of the acetylated derivative 33 proved 
Table 2. Carbamate Annulation Reaction for Alkenylamine 29

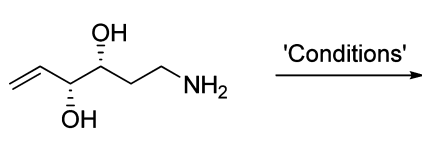

29

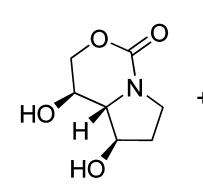

30<smiles>O=C1OC[C@@H]2[C@H](O)C(O)CCN12</smiles>
$31 \mathrm{a}$<smiles>O=C1NCC[C@H]([C@H](O)[C@H](O)CI)O1</smiles>

31b
32

ent
1
2
3
4

$\mathrm{I}_{2}$ (5 equiv), $\mathrm{NaHCO}_{3}$ (sat.), $40{ }^{\circ} \mathrm{C}, 18 \mathrm{~h}$

$\mathrm{I}_{2}$ (5 equiv), $\mathrm{NaHCO}_{3}$ ( 1.5 equiv), rt, 9 days

$\mathrm{I}_{2}(3 \times 1.5$ equiv added over 22 days $), \mathrm{NaHCO}_{3}$ (sat.), rt

$3: 2: 2: 8$

starting material

$3: 2: 1: 7$

$\mathrm{I}_{2}$ (5 equiv), $\mathrm{NaHCO}_{3}$ (sat.), rt, 5 days

$4^{b}: 2: 2: 3$

$\mathrm{Br}_{2}$ (5 equiv), $\mathrm{NaHCO}_{3}$ (sat.), rt, 3 days

decomposition

${ }^{a}$ As determined by ${ }^{1} \mathrm{H}$ NMR analysis of the crude reaction mixture ${ }^{b} \mathbf{3 0}$ was isolated as a pure compound in $10-30 \%$ yield following column chromatography

to be more beneficial. The relative configurations of $\mathrm{H} 5, \mathrm{H} 4$, and $\mathrm{H} 6 \mathrm{~b}$ were apparent through two large trans-diaxial couplings $\left(J_{4,5}=J_{5,6 \mathrm{~b}}=9 \mathrm{~Hz}\right)$, and the coupling constant between $\mathrm{H} 5$ and H6a $\left(J_{5,6 \mathrm{a}}=4.9 \mathrm{~Hz}\right)$ indicated an axial/ equatorial relationship between these two protons. As the stereochemistry at $\mathrm{C} 3$ is known, NOEs were then used to determine the stereochemistries of the remaining centers. NOEs were observed between $\mathrm{H} 5$ and $\mathrm{H} 3, \mathrm{H} 3$ and $\mathrm{H} 2 \mathrm{a}, \mathrm{H} 2 \mathrm{a}$ and $\mathrm{Hla}$, and H6a and $\mathrm{H} 5$ (Scheme 7), indicating these

Scheme 7. Synthesis of Previously Undisclosed Trihydroxylated Pyrrolidine 34 and NOE Correlations for Acetylated Carbamate 33
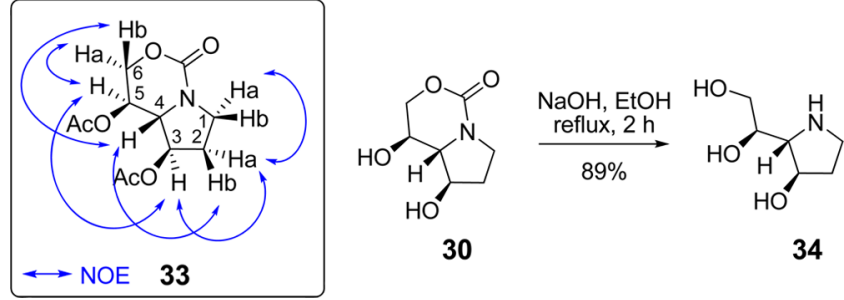

protons to be on the bottom face of the molecule, while NOEs between $\mathrm{H} 2 \mathrm{~b}$ and $\mathrm{H} 4$ and between $\mathrm{H} 4$ and $\mathrm{H} 6 \mathrm{~b}$ identified these protons to be on the opposite face, thereby allowing for the assignment of the L-allo stereochemistry. Pyrrolidine $\mathbf{3 0}$ was then treated with $\mathrm{NaOH}$ in $\mathrm{EtOH}$, which resulted in the smooth hydrolysis of the carbamate and allowed for the synthesis of the previously undisclosed trihydroxylated pyrrolidine 34 in 5-15\% yield over five steps. The enantiomer of 34 has been prepared once previously. ${ }^{28}$ Comparison of NMR data showed minor differences in the chemical shifts, which can be explained by the use of a different solvent and differences in $\mathrm{pH}$ (34 was treated with conc. $\mathrm{DCl}$ to ensure that the amine was fully protonated). The optical rotation of $\mathbf{3 4}$ was measured as $[\alpha]_{\mathrm{D}}^{26}=-1.8(c=0.41, \mathrm{MeOH})$, while that of the enantiomer was of the opposite sign and slightly larger in magnitude, reported as $[\alpha]_{\mathrm{D}}^{22}=+4.7(c=4.0, \mathrm{MeOH})$, which can be explained by the differences in concentration and protonation state of the two compounds. At this stage, the piperidine carbamates $31 \mathrm{a}$ and $\mathbf{3 1} \mathbf{b}$ were also hydrolyzed to give 5-epi-fagomine (26) and fagomine (3), which were separated following flash silica gel column chromatography (Scheme 8). The spectral data were similar to those previously reported, $^{24,29}$ once again with some variation due to slight differences in $\mathrm{pH}^{30}$

Scheme 8. Hydrolysis of Piperidine Carbamates To Give Fagomine (3) and 5-epi-Fagomine (26)<smiles>O=C1OC[C@@H]2[C@H](O)[C@H](O)CCN12</smiles><smiles>O=C1OC[C@@H]2[C@H](O)C(O)CCN12</smiles><smiles>O=C(O)COc1ccccc1</smiles><smiles>OC[C@H]1NCC[C@@H](O)[C@@H]1O</smiles>

Confirmation of the structure of iodide 32 proved to be more difficult. No HMBC correlation was observed between the carbonyl and $\mathrm{H} 3$, and accordingly, the acetylated adduct 35 (Scheme 9) was prepared to aid with structural elucidation. Indeed, upon acetylation, downfield shifts of the resonances for protons $\mathrm{H} 4$ (5.34 ppm) and H5 (5.14 ppm), which were previously at ca. $3.76 \mathrm{ppm}$ in the starting material, were observed. Proton H3, which was already at a relatively high chemical shift, did not move significantly upon acetylation. An $\mathrm{HMBC}$ correlation between $\mathrm{H} 1$ and the carbonyl was observed, though unfortunately, again no HMBC correlation was observed between the carbamate carbonyl and $\mathrm{H} 3$. As the stereochemistry of compound $\mathbf{3 2}$ also needed to be confirmed, we proposed that the synthesis of the corresponding alkenylamine (Scheme 9) would allow for confirmation of the structure of 32 , including the chirality of all stereogenic centers. To this end, iodide $\mathbf{3 2}$ was first converted to the corresponding acetonide 36, and on the basis of a slightly smaller $\Delta \delta$ of the acetonide methyl group proton signals $\left(\Delta \delta^{1}{ }_{\mathrm{H}}\right.$ $=0.039 \mathrm{ppm})^{31}$ and diagnostic $\delta^{13} \mathrm{C} \approx 27 \mathrm{ppm}$ for both methyl groups $\left(\delta^{13} \mathrm{C}=27.0 \mathrm{ppm}\right.$ and $\left.\delta^{13} \mathrm{C}=27.6 \mathrm{ppm}\right),{ }^{32,33}$ this allowed for the relative stereochemistries of the 4- and 5-substituents to be determined as trans in the acetonide five-membered ring, indicating a syn relationship in iodide 32. Opening of the acetonide via oxidative addition of zinc and subsequent reductive ring opening then provided the truncated carbamate 37 in good yield. Finally, hydrolysis of the carbamate in $\mathbf{3 7}$ via treatment with $\mathrm{NaOH}$ under reflux for $4 \mathrm{~h}$ gave the desired alkenylamine 29. Comparison of the ${ }^{1} \mathrm{H}$ NMR and ${ }^{13} \mathrm{C} N M R$ spectra of the synthesized alkenylamine with those of (+)-29 revealed them to be identical, and the optical rotations were of the same sign and comparable magnitude $\left\{[\alpha]_{\mathrm{D}}^{27}=+37.5(c=\right.$ $1.0, \mathrm{MeOH})$ and $\left.[\alpha]_{\mathrm{D}}^{27}=+31.8(c=0.2, \mathrm{MeOH})\right\}$, thus 
Scheme 9. Determination of the Structure of Iodocarbamate 32 via Transformation into Alkenylamine (+)-29
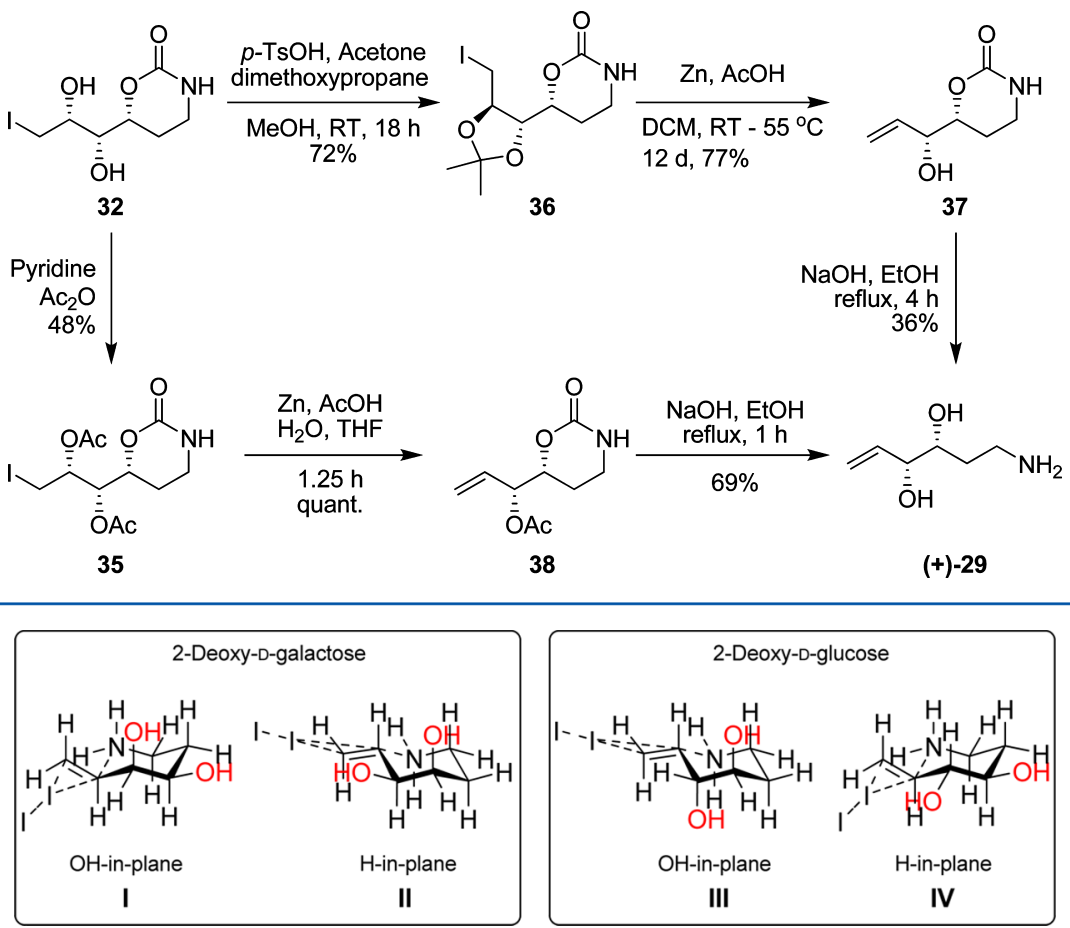

Figure 2. Six-membered iodocyclization transition states for 2-deoxy sugar series.

establishing the structure of the synthesized alkenylamine to be that of the starting material, (+)-29. From this information and the previously deduced trans relationship in acetonide 36 , the starting iodocarbamate 32 was thus determined to be $(3 R, 4 R, 5 R)$, as depicted. To confirm our methodology, alkenylamine (+)-29 was also synthesized from the acetylated adduct 35 by way of reductive elimination of 5-OAc $(\rightarrow 38)$ and subsequent carbamate hydrolysis.

Taken as a whole, the range of products formed en route to the synthesis of the target piperidines highlights the inherent problems of chemoselectivity in protecting-group-free chemistry. While we have previously illustrated that the protectinggroup-free synthesis of pyrrolidines proceeds relatively smoothly with good to excellent cis selectivity for the carbamate annulation, ${ }^{34}$ the present results illustrate that this methodology does not always translate readily to the synthesis of piperidines. The first factor to be considered when applying the carbamate annulation methodology to the synthesis of piperidines is $\mathrm{O}$ - versus $\mathrm{N}$-cyclization. As illustrated when Dgalactose was used as the starting material en route to the synthesis of DGJ, ${ }^{14}$ it is possible to favor formation of the desired pyran. This observation is remarkable in its own right given the general preference for five- versus six-membered ring formation. Indeed, when D-glucose was used as the starting material, only the furan was observed.

To eliminate formation of the furan as a competing reaction, the synthesis of piperidines devoid of the hydroxyl functionality at $\mathrm{C} 2$ can then be attempted using the corresponding 2-deoxy sugars as starting materials. Here, the chirality of the alkenylamine is crucial in determining the number of products formed during the annulation reaction. While the alkenylamine derived from 2-deoxy-D-galactose was transformed into the 4epi-fagomine carbamate scaffold with excellent chemo- and diastereoselectivity (cis:trans > 95:5), subjection of the corresponding alkenylamine derived from 2-deoxy-D-glucose to the annulation conditions resulted in poor selectivity and the formation of four products despite much effort to optimize this reaction to favor piperidine formation. The difference in selectivity for the two annulation reactions can be explained by considering the corresponding six-membered iodocyclization transition states, wherein, according to the seminal work of Chamberlin and co-workers, ${ }^{35}$ the allylic hydroxyl has a stereodirecting effect in the formation of both five- and sixmembered rings. Here, Chamberlin proposed that the unfavorable $\mathrm{C}-\mathrm{O} \sigma^{*}$ to $\mathrm{C}=\mathrm{C} \pi$ orbital overlap can be minimized by an $\mathrm{OH}$-in-plane (with the double bond) transition state. In the case of our $\mathrm{I}_{2}$-mediated carbamate annulations, this is illustrated in Figure 2, wherein transition state I for the 2-deoxy-D-galactose series depicts the major $\mathrm{OH}$ in-plane conformer while II depicts the unfavorable $\mathrm{H}$-in-plane conformer. Similarly, the OH-in-plane transition state III and the $\mathrm{H}$-in-plane transition state IV are also given for the 2deoxy-D-glucose series.

In addition to the conformation of the allylic hydroxyl, for six-membered rings the relative axial or equatorial orientation of the hydroxyl substituents needs to be considered. For the 2deoxy-D-galactose series, both the $\mathrm{OH}$-in-plane transition state I and the $\mathrm{H}$-in-plane transition state II have one axial and one equatorial hydroxyl group, and as a consequence, the $\mathrm{OH}$-inplane transition state is lower in energy because there is no unfavorable $\mathrm{C}-\mathrm{O} \sigma^{*}$ to $\mathrm{C}=\mathrm{C} \pi$ orbital overlap. For the 2deoxy-D-glucose series however, the $\mathrm{OH}$-in-plane transition state III has the two hydroxyl substituents placed in an unfavorable axial orientation, thereby increasing the overall energy of this transition state and making it closer in energy to transition state IV, which, while having the unfavorable $\mathrm{H}$-inplane conformation, has the hydroxyl substituents in a more favorable equatorial orientation. In summary, the 2-deoxy-Dgalactose series thus leads to the preferential formation of the cis-piperidine carbamate, while the 2-deoxy-D-glucose series, 
Scheme 10. Proposed Mechanism for the Formation of Pyrrolidine 30, Piperidines 31a and 31b, and Iodide 32

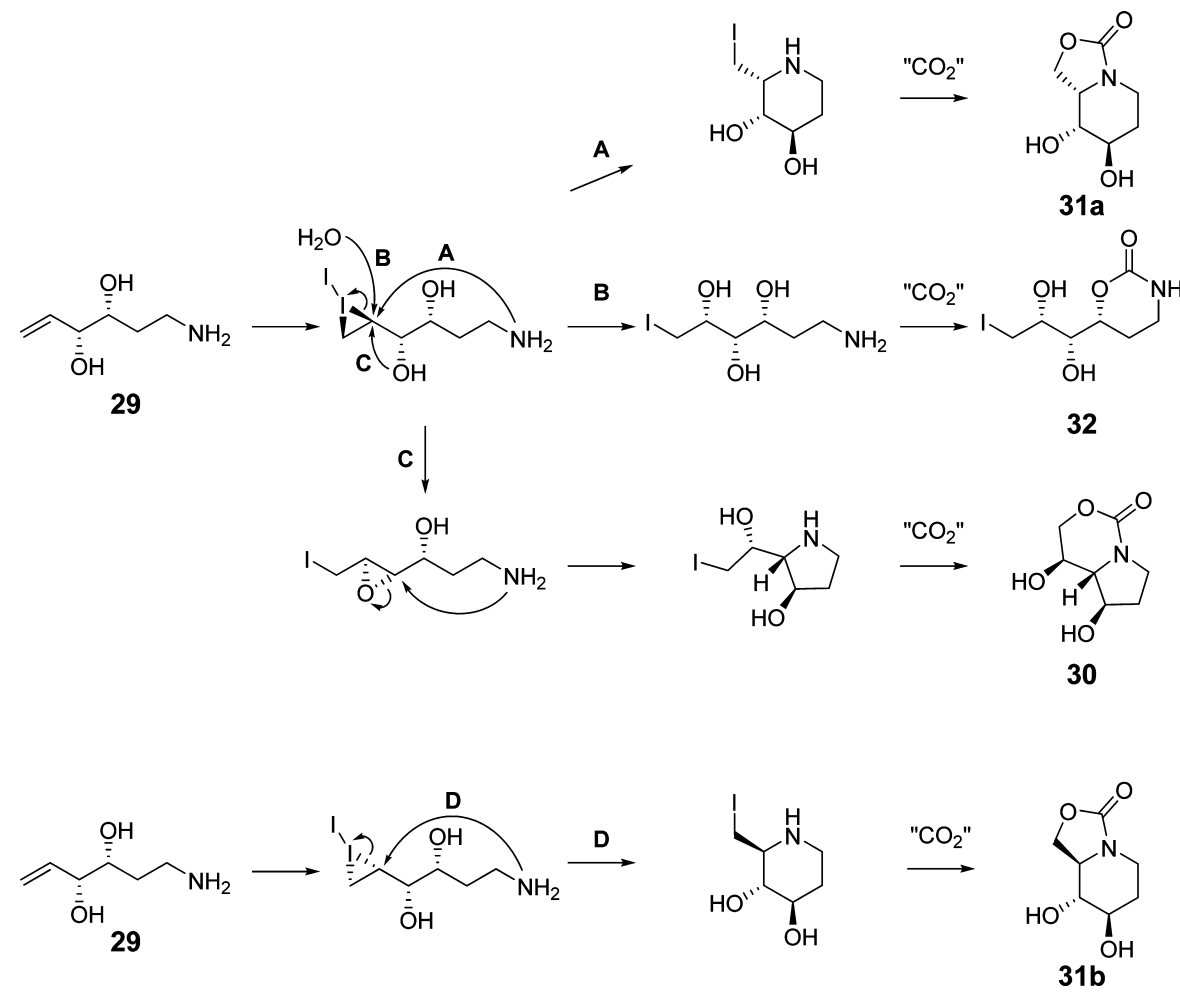

with iodocyclization transition states of similar energy, leads to a variety of products.

To gain further insight into how to better design starting materials to favor the formation of the desired piperidine or pyrrolidine, reaction mechanisms have been proposed to explain the formation of the four products following the subjection of alkenylamine 29 to the carbamate annulation conditions (Scheme 10). First, attack of iodine from the top face of alkenylamine 29 (via transition state III in Figure 2) leads to an intermediate that can be transformed into piperidine 31a, iodide 32, and pyrrolidine 30. Here, pathway A involves amine attack on the iodine complex at C5 followed by the addition of $\mathrm{CO}_{2}$ to give cis-carbamate 31a in accordance with our previously published annulation methodology. ${ }^{34}$ The synthesis of iodocarbamate 32, which contains a chiral backbone with a C5 stereocenter that differs from the parent alkenylamine 29 , is proposed to occur via $S_{N} 2$ attack of water on the iodine complex (pathway B) followed by the addition of $\mathrm{CO}_{2}$ to the linear iodoamine, which itself can be formed via the dissociation of carbonic acid. While there is no literature precedent for the reaction of terminal unsubstituted allylic alcohols with iodine, a number of halohydrin reactions have been performed on similar substrates with both the substitution pattern and the accessibility of the halonium ion effecting regio- ${ }^{36-38}$ and stereochemical ${ }^{39,40}$ outcomes. In the most closely related system involving hydrobromination, a variety of products were observed. ${ }^{41,42}$ In our case, however, ${ }^{1} \mathrm{H}$ NMR analysis revealed no product that could have arisen from opening of the iodine complex by water at the terminal carbon or from attack on the diastereomeric iodine complex. The observed regioselectivity can be explained by Markovnikov's rule, while the stereoselectivity is more difficult to rationalize but is correlated to the relative reaction rates for formation of the intermediate iodine complex and the subsequent intra- molecular or intermolecular nucleophilic ring opening. It is also conceivable that formation of a cyclic carbamate at the 3position takes place prior to halohydrin formation ${ }^{43}$ and that this provides an alternative route to 32 . The possibility that $\mathbf{3 2}$ is formed via a Payne rearrangement ${ }^{44}$ of the intermediate epoxide is unlikely, as this reaction would require strongly basic conditions. ${ }^{45}$ Such a cyclic carbamate intermediate, however, does not add to a conceivable mechanism for the formation of either 31 a or 30.

To explain the formation of pyrrolidine 30, a mechanism that supports the inversion of the C4 and C5 chiral centers is required, and thus an iodoepoxide (pathway $\mathrm{C}$ ) is proposed as a key intermediate. ${ }^{42,46}$ Nucleophilic 5-exo-tet ring opening of the epoxide followed by the addition of $\mathrm{CO}_{2}$ then allows for the formation of 30. ${ }^{47}$ Finally, the formation of trans-piperidine $31 \mathrm{~b}$ can be envisioned to occur via $\mathrm{S}_{\mathrm{N}} 2$ attack of the diastereomeric iodine complex (pathway $\mathrm{D}$ ), with the iodine complex itself arising from transition state IV (Figure 2). Subsequent addition of $\mathrm{CO}_{2}$ to the intermediate cyclic iodoamine then gives the piperidine. Here it should also be noted that attack at the 5-position of the intermediate epoxide

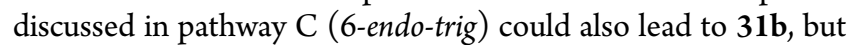
this is less favored than the corresponding 5-exo-trig cyclization $(\rightarrow \mathbf{3 1 b}),{ }^{47}$ especially in the absence of a bulky group $\alpha$ to the nitrogen. ${ }^{48}$

Taken together, a number of factors should thus be considered before using the carbamate annulation reaction as a key step in the synthesis of piperidines containing multiple reactive sites. First, the orientations of the ring substituents affect the relative energies of the $\mathrm{OH}$-in-plane or $\mathrm{H}$-in-plane transition states, and where there is no obvious low-energy conformer, this can lead to a variety of products. One could thus envisage the use of judiciously placed bulky substituents to favor one conformer over the other, while the positioning of a 
protecting group at the 4-position of the alkenylamine could be used to inhibit formation of the intermediate epoxide and hence the associated pyrrolidine products (e.g., 30). We have previously shown that the carbamate annulation can occur in the presence of protecting groups, ${ }^{49,50}$ which supports the validity of installing one or more protecting groups to control the chemoselectivity of the annulation when required.

\section{CONCLUSION}

We have presented two highly efficient syntheses of the biologically important piperidines DGJ (2) and 4-epi-fagomine (4) in good overall yields. Key in these reactions is the use of an $\mathrm{I}_{2}$-mediated carbamate annulation. The use of the carbamate annulation for the synthesis of other piperidines, however, was less successful, as either O-cyclization or a series of competing intramolecular reactions occurred. To this end, trihydroxypyrrolidine 34 was prepared in five steps and modest overall yield (up to 15\%). These studies highlight the limitations of using the carbamate annulation for the preparation of piperidines in protecting-group-free syntheses, although the work also points to the potential of this methodology for the synthesis of interesting chiral scaffolds when either protected or suitably functionalized alkenylamines are used as starting materials.

\section{EXPERIMENTAL SECTION}

General Procedures. Unless otherwise stated, all reactions were performed under atmospheric air. THF was distilled from $\mathrm{LiAlH}_{4}$ prior to use. Pyridine was distilled over $\mathrm{KOH}$ prior to use. All chemicals obtained from commercial suppliers were used without further purification. $\mathrm{Zn}$ dust was activated by the careful addition of concentrated $\mathrm{H}_{2} \mathrm{SO}_{4}$ followed by decantation, washing with EtOH $(3 \times)$ and hexanes $(3 \times)$, and storage under dry hexanes. All solvents were removed by evaporation under reduced pressure. Reactions were monitored by TLC analysis on silica gel-coated plastic sheets with detection by coating with $20 \% \mathrm{H}_{2} \mathrm{SO}_{4}$ in $\mathrm{EtOH}$ followed by charring at ca. $150{ }^{\circ} \mathrm{C}$, by coating with a solution of ninhydrin in $\mathrm{EtOH}$ followed by charring at ca. $150{ }^{\circ} \mathrm{C}$, or by coating with a solution of $5 \% \mathrm{KMnO}_{4}$ and $1 \% \mathrm{NaIO}_{4}$ in $\mathrm{H}_{2} \mathrm{O}$ followed by heating. ${ }^{1} \mathrm{H}$ and ${ }^{13} \mathrm{C}$ chemical shifts $(\delta)$ were internally referenced to the residual solvent peak. NMR peak assignments are based on 2D NMR experiments (COSY, HSQC, and HMBC). High-resolution electrospray ionization mass spectrometry [HRMS(ESI)] was performed on a Q-TOF instrument.

1-Amino-2,5-anhydro-1,6-dideoxy-6-iodo-L-iditol (13). To a solution of alkenylamine $10^{13}(310 \mathrm{mg}, 1.69 \mathrm{mmol})$ in sat. aq. $\mathrm{NaHCO}_{3}(7 \mathrm{~mL})$ was added $\mathrm{I}_{2}(645 \mathrm{mg}, 2.54 \mathrm{mmol})$, and the solution was stirred for 7 days. The reaction mixture, a crude oil, was concentrated and used without further purification. $R_{\mathrm{f}}=0.23$ (DCM/ $\mathrm{EtOH} / \mathrm{MeOH} / 30 \%$ aq. $\left.\mathrm{NH}_{3}, 5 / 2 / 2 / 1 \mathrm{v} / \mathrm{v} / \mathrm{v} / \mathrm{v}\right) ;{ }^{1} \mathrm{H}$ NMR $(500 \mathrm{MHz}$, $\left.\mathrm{D}_{2} \mathrm{O}\right) \delta 4.45\left(\mathrm{dt}, J_{4,5}=3.1, J_{5,6 \mathrm{a}}=J_{5,6 \mathrm{~b}}=7.3 \mathrm{~Hz}, 1 \mathrm{H}, \mathrm{H} 5\right), 4.40$ (ddd, $\left.J_{2,3}=3.8, J_{1 \mathrm{a}, 2}=4.4, J_{1 \mathrm{~b}, 2}=5.6 \mathrm{~Hz}, 1 \mathrm{H}, \mathrm{H} 2\right), 4.38\left(\mathrm{dd}, J_{3,4}=1.3, J_{2,3}=\right.$ $3.8 \mathrm{~Hz}, 1 \mathrm{H}, \mathrm{H} 3$ ), 4.28 (dd, $\left.J_{3,4}=1.3, J_{4,5}=3.1 \mathrm{~Hz}, 1 \mathrm{H}, \mathrm{H} 4\right), 3.27(\mathrm{dd}$, $\left.J_{5,6 \mathrm{a}}=7.3, J_{6 \mathrm{a}, 6 \mathrm{~b}}=9.8 \mathrm{~Hz}, 1 \mathrm{H}, \mathrm{H6a}\right), 3.26\left(\mathrm{dd}, J_{5,6 \mathrm{~b}}=7.3, J_{6 \mathrm{a}, 6 \mathrm{~b}}=9.8 \mathrm{~Hz}\right.$, $1 \mathrm{H}, \mathrm{H} 6 \mathrm{~b}), 3.258\left(\mathrm{dd}, J_{1 \mathrm{a}, 2}=4.4, J_{1 \mathrm{a}, 1 \mathrm{~b}}=13.6 \mathrm{~Hz}, 1 \mathrm{H}, \mathrm{Hla}\right), 3.23(\mathrm{dd}$, $\left.J_{1 \mathrm{~b}, 2}=5.6, J_{\mathrm{a} a, 1 \mathrm{~b}}=13.6 \mathrm{~Hz}, 1 \mathrm{H}, \mathrm{Hlb}\right) ;{ }^{13} \mathrm{C} \mathrm{NMR}\left(125 \mathrm{MHz}, \mathrm{D}_{2} \mathrm{O}\right) \delta$ 81.7 (C5), 77.5 (C3), 76.52, 76.50 (C2 and C4), 39.4 (C1), 0.6 (C6); HRMS(ESI) $\mathrm{m} / z$ calcd for $\left[\mathrm{C}_{6} \mathrm{H}_{12} \mathrm{O}_{3} \mathrm{NI}+\mathrm{H}\right]^{+} 273.9935$, found 273.9938.

1-Acetamido-3,4-di-O-acetyl-2,5-anhydro-1,6-dideoxy-6iodo-L-iditol (14). A solution of iditol 13 was stirred overnight at $\mathrm{rt}$ in a solution of acetic anhydride $(4 \mathrm{~mL})$ and pyridine $(4 \mathrm{~mL})$. The reaction mixture was concentrated, dissolved in EtOAc, washed with sat. aq. $\mathrm{NaHCO}_{3}$ and brine, dried over $\mathrm{MgSO}_{4}$, filtered, and concentrated in vacuo to give acetylated iditol 14 as a colorless oil. $R_{\mathrm{f}}=0.12(\mathrm{EtOAc}) ;{ }^{1} \mathrm{H}$ NMR $\left(500 \mathrm{MHz}, \mathrm{CDCl}_{3}\right) \delta 5.84\left(\mathrm{t}, J_{1 \mathrm{a}, \mathrm{NH}}=\right.$ $\left.J_{1 \mathrm{~b}, \mathrm{NH}}=6.2 \mathrm{~Hz}, 1 \mathrm{H}, \mathrm{NH}\right), 5.38\left(\mathrm{dd}, J_{3,4}=1.4, J_{4,5}=4.0 \mathrm{~Hz}, 1 \mathrm{H}, \mathrm{H} 4\right)$, $5.27\left(\mathrm{dd}, J_{3,4}=1.4, J_{2,3}=3.4 \mathrm{~Hz}, 1 \mathrm{H}, \mathrm{H} 3\right), 4.52\left(\mathrm{ddd}, J_{4,5}=4.0, J_{5,6 \mathrm{a}}=\right.$ 6.3, $\left.J_{5,6 \mathrm{~b}}=8.8 \mathrm{~Hz}, 1 \mathrm{H}, \mathrm{H} 5\right), 4.30\left(\mathrm{ddd}, J_{2,3}=3.4, J_{1 \mathrm{~b}, 2}=6.2, J_{1 \mathrm{a}, 2}=7.3\right.$
$\mathrm{Hz}, 1 \mathrm{H}, \mathrm{H} 2), 3.47\left(\mathrm{ddd}, J_{1 \mathrm{a}, \mathrm{NH}}=6.2, J_{1 \mathrm{a}, 2}=7.3, J_{1 \mathrm{a}, \mathrm{b}}=14.0 \mathrm{~Hz}, 1 \mathrm{H}\right.$, $\mathrm{H1a}), 3.27\left(\mathrm{td}, J_{1 \mathrm{~b}, \mathrm{NH}}=J_{1 \mathrm{~b}, 2}=6.2, J_{1 \mathrm{a}, 1 \mathrm{~b}}=14.0 \mathrm{~Hz}, 1 \mathrm{H}, \mathrm{H1b}\right), 3.21(\mathrm{dd}$, $\left.J_{5,6 \mathrm{a}}=6.3, J_{6 \mathrm{a}, 6 \mathrm{~b}}=9.7 \mathrm{~Hz}, 1 \mathrm{H}, \mathrm{H6a}\right), 3.17\left(\mathrm{dd}, J_{5,6 \mathrm{~b}}=8.8, J_{6 \mathrm{a}, 6 \mathrm{~b}}=9.7 \mathrm{~Hz}\right.$, $1 \mathrm{H}, \mathrm{H} 6 \mathrm{~b}), 2.16$ (s, 3H, Ac), 2.15 (s, 3H, Ac), 2.00 (s, 3H, NHAc); ${ }^{13} \mathrm{C}$ NMR $\left(125 \mathrm{MHz}, \mathrm{CDCl}_{3}\right) \delta 170.5(\mathrm{C}=\mathrm{O}, \mathrm{NHAc}), 170.1(\mathrm{C}=\mathrm{O}$, Ac), 169.4 ( $\mathrm{C}=\mathrm{O}, \mathrm{Ac}), 79.6$ (C5), 78.9 (C2), 76.4 (C3), 76.1 (C4), 38.1 (C1), $23.5\left(\mathrm{CH}_{3}, \mathrm{NHAc}\right), 20.9\left(\mathrm{CH}_{3}, \mathrm{Ac}\right), 20.8\left(\mathrm{CH}_{3}, \mathrm{Ac}\right),-0.6$ (C6); HRMS(ESI) $\mathrm{m} / z$ calcd for $\left[\mathrm{C}_{12} \mathrm{H}_{18} \mathrm{O}_{6} \mathrm{NI}+\mathrm{Na}\right]^{+} 422.0076$, found 422.0076.

Methyl 3,6-Anhydro-2-deoxy- $\alpha$-D-galactopyranoside (19). To a solution of methyl glycoside $18(28 \mathrm{mg}, 0.16 \mathrm{mmol})$ in dry THF $(3 \mathrm{~mL})$ were added $\mathrm{PPh}_{3}(83 \mathrm{mg}, 0.32 \mathrm{mmol})$, imidazole (43 $\mathrm{mg}, 0.63 \mathrm{mmol})$, and $\mathrm{I}_{2}(80 \mathrm{mg}, 0.32 \mathrm{mmol})$. The mixture was refluxed overnight $(18 \mathrm{~h})$ and then cooled and concentrated. The resulting oil was purified by flash column chromatography (petroleum ether/ EtOAc, $5 / 1$ to $1 / 1 \mathrm{v} / \mathrm{v})$ to give bicyclic galactoside $19 . R_{\mathrm{f}}=0.3$ $(\mathrm{EtOAc} / \mathrm{MeOH}, 98 / 2 \mathrm{v} / \mathrm{v}) ;{ }^{1} \mathrm{H}$ NMR $\left(500 \mathrm{MHz}, \mathrm{D}_{2} \mathrm{O}\right) \delta 4.69\left(\mathrm{~d}, J_{1,2 \mathrm{~b}}\right.$ $=6.2 \mathrm{~Hz}, 1 \mathrm{H}, \mathrm{H} 1), 4.31-4.32(\mathrm{~m}, 2 \mathrm{H}, \mathrm{H} 3$ and $\mathrm{H} 6 \mathrm{a}), 4.27-4.28(\mathrm{~m}$, $1 \mathrm{H}, \mathrm{H} 5), 4.02\left(\mathrm{~d}, J_{3,4}=1.8 \mathrm{~Hz}, 1 \mathrm{H}, \mathrm{H} 4\right), 3.98\left(\mathrm{dd}, J_{5,6 \mathrm{~b}}=3.4, J_{6 \mathrm{a}, 6 \mathrm{~b}}=\right.$ $9.9 \mathrm{~Hz}, 1 \mathrm{H}, \mathrm{H} 6 \mathrm{~b}), 3.40$ (s, 3H, OMe), 2.19 (dd, $J_{2 \mathrm{a}, 3}=4.6, J_{2 \mathrm{a}, 2 \mathrm{~b}}=14.5$ $\mathrm{Hz}, 1 \mathrm{H}, \mathrm{H} 2 \mathrm{a}$ ), 2.02 (ddd, $J_{2 \mathrm{~b}, 3}=1.6, J_{1,2 \mathrm{~b}}=6.2, J_{2 \mathrm{a}, 2 \mathrm{~b}}=14.5 \mathrm{~Hz}, 1 \mathrm{H}$, $\mathrm{H} 2 \mathrm{~b}) ;{ }^{13} \mathrm{C}$ NMR (125 MHz, $\left.\mathrm{D}_{2} \mathrm{O}\right) \delta 97.2$ (C1), 77.8 (C3), 77.3 (C5), 74.8 (C4), 70.2 (C6), 55.7 (OMe), 37.6 (C2); HRMS(ESI) $m / z$ calcd for $\left[\mathrm{C}_{7} \mathrm{H}_{12} \mathrm{O}_{4}+\mathrm{Na}\right]^{+}$183.0633, found 183.0631.

Methyl 2-Deoxy-3,4-O-isopropylidene- $\alpha / \beta$-D-galactopyranoside (20). From 17. AcCl $(180 \mu \mathrm{L})$ was added to a solution of 2deoxy-D-galactose (17) (200 mg, $0.61 \mathrm{mmol})$ in $\mathrm{MeOH} /$ acetone/ dimethoxypropane $(6 \mathrm{~mL}, 2 / 2 / 2 \mathrm{v} / \mathrm{v} / \mathrm{v})$, and the solution was stirred for $18 \mathrm{~h}$ at room temperature. The reaction was quenched with Dowex $-\mathrm{OH}^{-}$, and the mixture was filtered and concentrated. The resulting oil, 20, was used without purification.

From 23. To a solution of D-galactal $23(200 \mathrm{mg}, 1.36 \mathrm{mmol})$ in $\mathrm{MeOH}(8 \mathrm{~mL})$ and acetone $(8 \mathrm{~mL})$ was added $\mathrm{pTsOH} \cdot \mathrm{H}_{2} \mathrm{O}(24 \mathrm{mg}$, $0.14 \mathrm{mmol}$ ), and the reaction was stirred at room temperature for $18 \mathrm{~h}$. The reaction mixture was then neutralized by the addition of Dowex$\mathrm{OH}^{-}$, filtered, and concentrated in vacuo. The crude reaction product, 20, was used in the iodination reaction without further purification.

$R_{\mathrm{f}}=0.13$ (petroleum ether/EtOAc, $\left.1 / 1 \mathrm{v} / \mathrm{v}\right) ;{ }^{1} \mathrm{H}$ NMR $(500 \mathrm{MHz}$, $\left.\mathrm{CDCl}_{3}\right) \delta 4.86\left(\mathrm{dd}, J_{1,2 \mathrm{a}}=5.1, J_{1,2 \mathrm{~b}}=6.0 \mathrm{~Hz}, 1 \mathrm{H}, \mathrm{H1}\right), 4.47$ (ddd, $J_{2 \mathrm{~b}, 3}$ $\left.=4.1, J_{2 a, 3}=5.1, J_{3,4}=6.9 \mathrm{~Hz}, 1 \mathrm{H}, \mathrm{H} 3\right), 4.16\left(\mathrm{dd}, J_{4,5}=1.7, J_{3,4}=6.9\right.$ $\mathrm{Hz}, 1 \mathrm{H}, \mathrm{H} 4), 3.89$ (dd, $\left.J_{5,6 \mathrm{a}}=5.6, J_{6 \mathrm{a}, 6 \mathrm{~b}}=10.6 \mathrm{~Hz}, 1 \mathrm{H}, \mathrm{H6a}\right), 3.80$ (ddd, $\left.J_{4,5}=1.7, J_{5,6 \mathrm{~b}}=4.3, J_{5,6 \mathrm{a}}=5.6 \mathrm{~Hz}, 1 \mathrm{H}, \mathrm{H} 5\right), 3.77\left(\mathrm{dd}, J_{5,6 \mathrm{~b}}=4.3\right.$, $\left.J_{6 \mathrm{a}, 6 \mathrm{~b}}=10.6 \mathrm{~Hz}, 1 \mathrm{H}, \mathrm{H} 6 \mathrm{~b}\right), 3.37$ (s, 3H, OMe), 2.17 (dt, $J_{2 \mathrm{a}, 2 \mathrm{~b}}=14.8$, $\left.J_{1,2 \mathrm{a}}=J_{2 \mathrm{a}, 3}=5.1 \mathrm{~Hz}, 1 \mathrm{H}, \mathrm{H} 2 \mathrm{a}\right), 1.73\left(\right.$ ddd, $J_{2 \mathrm{~b}, 3}=4.1, J_{1,2 \mathrm{~b}}=6.0, J_{2 \mathrm{a}, 2 \mathrm{~b}}=$ $14.8 \mathrm{~Hz}, 1 \mathrm{H}, \mathrm{H} 2 \mathrm{~b}), 1.47$ (s, iPr), 1.31 (s, iPr); ${ }^{13} \mathrm{C}$ NMR $(75 \mathrm{MHz}$, $\left.\mathrm{CDCl}_{3}\right)$ 109.2(iPr-C $\left.\left(\mathrm{CH}_{3}\right)_{2}\right)$ 97.4 (C1), 73.4 (C4), 70.5 (C3), 68.5 (C5), 62.8 (C6), $55.0(\mathrm{OMe}), 30.8(\mathrm{C} 2), 26.8,25.3\left(\mathrm{iPr}-\mathrm{C}\left(\mathrm{CH}_{3}\right)_{2}\right)$; HRMS(ESI) $m / z$ calcd for $\left[\mathrm{C}_{10} \mathrm{H}_{18} \mathrm{O}_{5}+\mathrm{Na}\right]^{+} 241.1052$, found 241.1046.

Methyl 2,6-Dideoxy-6-iodo-3,4-O-isopropylidene- $\alpha / \beta$-D-galactopyranoside (21). From 17. To a solution of $20(0.61 \mathrm{mmol})$ in dry THF $(7 \mathrm{~mL})$ were added $\mathrm{PPh}_{3}(456 \mathrm{mg}, 1.74 \mathrm{mmol})$, imidazole (180 mg, $2.62 \mathrm{mmol})$, and $\mathrm{I}_{2}(442 \mathrm{mg}, 174 \mathrm{mmol})$. The mixture was refluxed for $18 \mathrm{~h}$ and then cooled and concentrated. The syrup was redissolved in ethyl acetate $(20 \mathrm{~mL})$, washed with sat. aq. $\mathrm{Na}_{2} \mathrm{~S}_{2} \mathrm{O}_{3}(2$ $\times 15 \mathrm{~mL})$ and then brine $(20 \mathrm{~mL})$, dried over $\mathrm{MgSO}_{4}$, filtered, and concentrated. The resulting oil was purified by flash column chromatography (petroleum ether/EtOAc, 15/1 v/v) followed by crystallization from hexanes to give iodogalactoside $\mathbf{2 1}$ as white crystals (142 mg, $0.434 \mathrm{mmol}, 71 \%$ from 17 ).

From 23. Iodination of $\mathbf{2 0}$ performed as above yielded iodogalactoside 21 as white crystals $(241 \mathrm{mg}, 0.73 \mathrm{mmol}, 54 \%$ over two steps from 23).

$R_{\mathrm{f}}=0.77$ (petroleum ether/EtOAc, $1 / 1 \mathrm{v} / \mathrm{v}$ ); Mp 91-92 ${ }^{\circ} \mathrm{C} ;[\alpha]_{\mathrm{D}}^{21}$ $=+72.4\left(c=1.0, \mathrm{CHCl}_{3}\right)$; IR (film) 2982, 2936, 2912, 2833, 1439, $1373,1246,1214,1186,1088,1047,969,880,738 \mathrm{~cm}^{-1} ;{ }^{1} \mathrm{H}$ NMR $\left(500 \mathrm{MHz}, \mathrm{CDCl}_{3}\right) \delta 4.86\left(\mathrm{dd}, J_{1,2 \mathrm{a}}=5.4, J_{1,2 \mathrm{~b}}=6.6 \mathrm{~Hz}, 1 \mathrm{H}, \mathrm{H1}\right), 4.49$ (ddd, $\left.J_{2 \mathrm{~b}, 3}=3.7, J_{2 \mathrm{a}, 3}=4.6, J_{3,4}=7.3 \mathrm{~Hz}, 1 \mathrm{H}, \mathrm{H} 3\right), 4.26$ (dd, $J_{4,5}=2.0$, $\left.J_{3,4}=7.3 \mathrm{~Hz}, 1 \mathrm{H}, \mathrm{H} 4\right), 3.86$ (ddd, $J_{5,4}=2.0, J_{5,6 \mathrm{a}}=5.8, J_{5,6 \mathrm{~b}}=8.1 \mathrm{~Hz}$, $1 \mathrm{H}, \mathrm{H} 5), 3.47$ (s, 3H, OMe), 3.34 (dd, $J_{5,6 \mathrm{a}}=5.8, J_{6 \mathrm{a}, 6 \mathrm{~b}}=10.2 \mathrm{~Hz}, 1 \mathrm{H}$, 
$\mathrm{H} 6 \mathrm{a}), 3.28\left(\mathrm{dd}, J_{5,6 \mathrm{~b}}=8.1, J_{6 \mathrm{a}, 6 \mathrm{~b}}=10.2 \mathrm{~Hz}, 1 \mathrm{H}, \mathrm{H6b}\right), 2.24\left(\mathrm{ddd}, J_{2 \mathrm{a}, 3}=\right.$ 4.6, $\left.J_{1,2 \mathrm{a}}=5.4, J_{2 \mathrm{a}, 2 \mathrm{~b}}=15.1 \mathrm{~Hz}, 1 \mathrm{H}, \mathrm{H} 2 \mathrm{a}\right), 1.64$ (ddd, $J_{2 \mathrm{~b}, 3}=3.7, J_{1,2 \mathrm{~b}}=$ 6.6, $\left.J_{2 \mathrm{a}, 2 \mathrm{~b}}=15.1 \mathrm{~Hz}, 1 \mathrm{H}, \mathrm{H} 2 \mathrm{~b}\right), 1.48(\mathrm{~s}, 3 \mathrm{H}, \mathrm{iPr}), 1.34(\mathrm{~s}, 3 \mathrm{H}, \mathrm{iPr}) ;{ }^{13} \mathrm{C}$ NMR (75 MHz, $\left.\mathrm{CDCl}_{3}\right)$ 109.3 (iPr-C $\left.\left(\mathrm{CH}_{3}\right)_{2}\right) 97.6(\mathrm{C} 1), 73.4(\mathrm{C} 4)$, 70.9 (C3), 70.0 (C5), 55.2 (OMe), 30.2 (C2), 26.6, 25.2 (iPr$\left.\mathrm{C}\left(\mathrm{CH}_{3}\right)_{2}\right), 3.2(\mathrm{C} 6)$; HRMS(ESI) $\mathrm{m} / z$ calcd for $\left[\mathrm{C}_{10} \mathrm{H}_{17} \mathrm{O}_{4} \mathrm{I}+\mathrm{Na}\right]^{+}$ 351.0069 , found 351.0072.

Methyl 2,6-Dideoxy-6-iodo- $\alpha / \beta$-D-galactopyranoside (22). To a solution of iodogalactoside 21 (237 mg, $0.79 \mathrm{mmol})$ in $\mathrm{MeOH}$ $(10 \mathrm{~mL})$, at $0{ }^{\circ} \mathrm{C}$ was added $\mathrm{AcCl}(200 \mu \mathrm{L})$. The reaction mixture was stirred at room temperature for 5 days, after which the reaction was quenched with Dowex $-\mathrm{OH}^{-}$and the mixture was concentrated in vacuo. The product was purified via gradient flash column chromatography (petroleum ether/EtOAc, $3 / 1$ to $1 / 1 \mathrm{v} / \mathrm{v}$ ) to provide galactoside 22 as a colorless oil $(200 \mathrm{mg}, 0.69 \mathrm{mmol}, 94 \%) . R_{\mathrm{f}}=0.11$ (EtOAc); $[\alpha]_{\mathrm{D}}^{21}=+0.11(c=1.0, \mathrm{MeOH})$; IR (film) 3292, 2925, 2854, $1735,1457,1209,1130,1034,668 \mathrm{~cm}^{-1} ;{ }^{1} \mathrm{H}$ NMR $(500 \mathrm{MHz}$ $\left.\mathrm{CD}_{3} \mathrm{OD}\right) \delta 4.71\left(\mathrm{~d}, J_{1,2 \mathrm{a}}=3.6 \mathrm{~Hz}, 1 \mathrm{H}, \mathrm{H1}\right), 3.81$ (ddd, $J_{3,4}=3.2, J_{2 \mathrm{~b}, 3}=$ 4.1, $\left.J_{2 \mathrm{~b}, 3}=12.6 \mathrm{~Hz}, 1 \mathrm{H}, \mathrm{H} 3\right), 3.78-3.72(\mathrm{~m}, 2 \mathrm{H}, \mathrm{H} 4$ and $\mathrm{H} 5), 3.31$ (s, $3 \mathrm{H}, \mathrm{OMe}), 3.30-3.22\left(\mathrm{~m}, 2 \mathrm{H}, \mathrm{H} 6 \mathrm{a}\right.$ and H6b), $1.82\left(\mathrm{td}, J_{2 \mathrm{a}, 2 \mathrm{~b}}=J_{2 \mathrm{a}, 3}=\right.$ $\left.12.6, J_{1,2 \mathrm{a}}=3.6 \mathrm{~Hz}, 1 \mathrm{H}, \mathrm{H} 2 \mathrm{a}\right), 1.62\left(\mathrm{dd}, J_{2 \mathrm{~b}, 3}=5.1, J_{2 \mathrm{a}, 2 \mathrm{~b}}=12.6 \mathrm{~Hz}, 1 \mathrm{H}\right.$, $\mathrm{H} 2 \mathrm{~b}) ;{ }^{13} \mathrm{C}$ NMR (125 MHz, CD $\left.\mathrm{OD}\right) \delta 100.3$ (C1), 72.9 (C4), 70.5 (C5), 66.7 (C3), $55.5\left(\mathrm{OCH}_{3}\right), 33.1$ (C2), 4.5 (C6); HRMS(ESI) $\mathrm{m} / z$ calcd for $\left[\mathrm{C}_{7} \mathrm{H}_{13} \mathrm{O}_{4} \mathrm{I}+\mathrm{Na}\right]^{+} 310.9756$, found 310.9756 .

(3R,4S)-1-Aminohex-5-ene-3,4-diol (24). To a solution of iodogalactoside $22(58 \mathrm{mg}, 0.21 \mathrm{mmol})$ in a saturated solution of $\mathrm{NH}_{4} \mathrm{OAc}$ in $\mathrm{EtOH}(3 \mathrm{~mL})$ were added activated $\mathrm{Zn}(36 \mathrm{mg}, 0.55$ mmol), $\mathrm{NaCNBH}_{3}\left(21 \mathrm{mg}, 0.33 \mathrm{mmol}\right.$ ), and $30 \%$ aq. $\mathrm{NH}_{3}(1 \mathrm{~mL})$. The mixture was stirred at reflux for $18 \mathrm{~h}$, filtered, and concentrated in vacuo. The mixture was loaded on a Dowex- $\mathrm{H}^{+}$column, eluted in $15 \%$ aq. $\mathrm{NH}_{3}$, and concentrated in vacuo. Acidification with $1 \mathrm{M} \mathrm{HCl}$ yielded alkenylamine 24 , a white solid, as the $\mathrm{HCl}$ salt $(35 \mathrm{mg}, 0.21$ mmol, $99 \%) . R_{\mathrm{f}}=0.11$ (DCM/EtOH/MeOH/30\% aq. $\mathrm{NH}_{3}, 5 / 2 / 2 / 1$ $\mathrm{v} / \mathrm{v} / \mathrm{v} / \mathrm{v}) ;[\alpha]_{\mathrm{D}}^{25}=-114(c=0.1, \mathrm{EtOH}) ;$ IR (film) 3370, 3321, 2962, 2836, 1642, 1504, 1435, 1378, 1025, $652 \mathrm{~cm}^{-1}$; ${ }^{1} \mathrm{H}$ NMR $(500 \mathrm{MHz}$, $\left.\mathrm{D}_{2} \mathrm{O}\right) \delta 5.87$ (ddd, $J_{4,5}=6.2, J_{5,6 \text {-cis }}=10.3, J_{5,6 \text {-trans }}=17.1 \mathrm{~Hz}, 1 \mathrm{H}, \mathrm{H} 5$ ), $5.30\left(\mathrm{~d}, J_{5,6 \text {-trans }}=17.1 \mathrm{~Hz}, 1 \mathrm{H}, \mathrm{H6}-\mathrm{cis}\right), 5.27\left(\mathrm{~d}, J_{5,6-\text {-is }}=10.3 \mathrm{~Hz}, 1 \mathrm{H}\right.$, H6-trans), 4.03 (dd, $\left.J_{3,4}=4.6, J_{4,5}=6.2 \mathrm{~Hz}, 1 \mathrm{H}, \mathrm{H} 4\right), 3.69$ (ddd, $J_{2 \mathrm{a}, 3}=$ $\left.3.2, J_{3,4}=4.6, J_{2 \mathrm{~b}, 3}=9.6 \mathrm{~Hz}, 1 \mathrm{H}, \mathrm{H} 3\right), 2.85\left(\mathrm{ddd}, J_{1 \mathrm{a}, 2 \mathrm{~b}}=5.9, J_{\mathrm{la}, 2 \mathrm{a}}=8.5\right.$, $\left.J_{1 \mathrm{a}, 1 \mathrm{~b}}=12.8 \mathrm{~Hz}, 1 \mathrm{H}, \mathrm{H1a}\right), 2.77$ (ddd, $J_{1 \mathrm{~b}, 2 \mathrm{a}}=7.0, J_{1 \mathrm{~b}, 2 \mathrm{~b}}=8.0, J_{1 \mathrm{a}, 1 \mathrm{~b}}=$ $12.8 \mathrm{~Hz}, 1 \mathrm{H}, \mathrm{H} 1 \mathrm{~b}$ ), 1.72 (dddd, $J_{2 \mathrm{a}, 3}=3.2, J_{1 \mathrm{~b}, 2 \mathrm{a}}=7.0, J_{1 \mathrm{a}, 2 \mathrm{a}}=8.5, J_{2 \mathrm{a}, 2 \mathrm{~b}}$ $=17.5 \mathrm{~Hz}, 1 \mathrm{H}, \mathrm{H} 2 \mathrm{a}$ ), 1.55 (dddd, $J_{1 \mathrm{a}, 2 \mathrm{~b}}=5.9, J_{1 \mathrm{~b}, 2 \mathrm{~b}}=8.0, J_{2 \mathrm{~b}, 3}=9.6$, $\left.J_{2 \mathrm{a}, 2 \mathrm{~b}}=17.5 \mathrm{~Hz}, 1 \mathrm{H}, \mathrm{H} 2 \mathrm{~b}\right) ;{ }^{13} \mathrm{C}$ NMR $\left(75 \mathrm{MHz}, \mathrm{D}_{2} \mathrm{O}\right) \delta 135.5$ (C5), 118.0 (C6), 75.4 (C4), 71.6 (C3), 37.1 (C1), 28.9 (C2); HRMS(ESI) $m / z$ calcd for $\left[\mathrm{C}_{6} \mathrm{H}_{13} \mathrm{O}_{2} \mathrm{~N}+\mathrm{H}\right]^{+} 132.1025$, found 132.1022 .

1-N,6-O-Carbonyl-4-epi-fagomine (25a). To a solution of alkenylamine hydrochloride $24(17 \mathrm{mg}, 0.13 \mathrm{mmol})$ in saturated $\mathrm{NaHCO}_{3}$ (aq) $(0.6 \mathrm{~mL})$ was added $\mathrm{I}_{2}(32 \mathrm{mg}, 0.25 \mathrm{mmol})$. The solution was stirred for 5 days at $35{ }^{\circ} \mathrm{C}$ and then filtered and concentrated in vacuo. Purification by flash chromatography (EtOAc/ $\mathrm{MeOH}, 99 / 1 \mathrm{v} / \mathrm{v}$ ) yielded carbamate $25 \mathrm{a}$ as a white solid $(15.1 \mathrm{mg}$, $0.0873 \mathrm{mmol}, 86 \%)$. $[\alpha]_{\mathrm{D}}^{19}=+4.0(c=1, \mathrm{MeOH})$; IR (film) 3338, $2945,2833,2360,2342,1653,1449,1417,1114,1021 \mathrm{~cm}^{-1}$; ${ }^{1} \mathrm{H}$ NMR $\left(500 \mathrm{MHz}, \mathrm{D}_{2} \mathrm{O}\right) \delta 4.48\left(\mathrm{t}, J_{5,6}=J_{6 \mathrm{a}, 6 \mathrm{~b}}=9.0 \mathrm{~Hz}, 1 \mathrm{H}, \mathrm{H} 6 \mathrm{a}\right), 4.37(\mathrm{dd}$, $\left.J_{5,6}=5.5, J_{6 \mathrm{a}, 6 \mathrm{~b}}=9.0 \mathrm{~Hz}, 1 \mathrm{H}, \mathrm{H} 6 \mathrm{~b}\right), 4.03\left(\mathrm{ddd}, J_{4,5}=1.8, J_{5,6 \mathrm{~b}}=5.5, J_{5,6 \mathrm{a}}\right.$ $=9.0 \mathrm{~Hz}, 1 \mathrm{H}, \mathrm{H} 5), 3.89(\mathrm{~m}, 1 \mathrm{H}, \mathrm{H} 4), 3.86\left(\mathrm{dd}, J_{3,4}=2.5, J_{2,3}=5.5 \mathrm{~Hz}\right.$, $1 \mathrm{H}, \mathrm{H} 3), 3.76\left(\mathrm{ddd}, J_{1 \mathrm{a}, 2 \mathrm{a}}=1.8, J_{1 \mathrm{a}, 2 \mathrm{~b}}=5.5, J_{1 \mathrm{a}, 1 \mathrm{~b}}=13.5 \mathrm{~Hz}, 1 \mathrm{H}, \mathrm{H1a}\right)$, 3.06 (app dt, $\left.J_{1 \mathrm{~b}, 2 \mathrm{a}}=J_{1 \mathrm{~b}, 2 \mathrm{~b}}=4.5, J_{1 \mathrm{a}, 1 \mathrm{~b}}=13 \mathrm{~Hz}, 1 \mathrm{H}, \mathrm{H1b}\right), 1.70-1.80$ $(\mathrm{m}, 2 \mathrm{H}, \mathrm{H} 2 \mathrm{a}$ and $\mathrm{H} 2 \mathrm{~b}) ;{ }^{13} \mathrm{C}$ NMR $\left(125 \mathrm{MHz}, \mathrm{D}_{2} \mathrm{O}\right) \delta 159.2(\mathrm{C}=\mathrm{O})$ 68.6 (C3), 67.9 (C4), 64.1 (C6), 57.0 (C5), 38.5 (C1), 25.1 (C2); HRMS(ESI) $m / z$ calcd for $\left[\mathrm{C}_{7} \mathrm{H}_{11} \mathrm{NO}_{4}+\mathrm{Na}\right]^{+} 196.0586$, found 196.0590.

4-epi-Fagomine (4). To a solution of carbamate $25 \mathrm{a}(11 \mathrm{mg}, 0.06$ $\mathrm{mmol})$ in $\mathrm{EtOH}(2 \mathrm{~mL})$ was added $\mathrm{NaOH}(32 \mathrm{mg}, 0.80 \mathrm{mmol})$. The solution was stirred at reflux for $2 \mathrm{~h}$ and then cooled and purified directly using a Dowex $-\mathrm{H}^{+}$column. The product was eluted in 5 to $15 \%$ aq. $\mathrm{NH}_{3}$ and concentrated in vacuo. Purification by flash chromatography (DCM/EtOH/MeOH/30\% aq. $\mathrm{NH}_{3}, 25 / 2 / 2 / 1$ to $5 / 2 / 2 / 1 \mathrm{v} / \mathrm{v} / \mathrm{v} / \mathrm{v})$ yielded piperidine 4 as a white solid $(8.1 \mathrm{mg}, 0.055$ mmol, 92\%). $[\alpha]_{\mathrm{D}}^{19}=+11.8(c=0.1, \mathrm{MeOH})$; IR (film) 3286, 2923,
$1653,1398,1145,1100,1046,1022 \mathrm{~cm}^{-1} ;{ }^{1} \mathrm{H}$ NMR $\left(600 \mathrm{MHz}, \mathrm{D}_{2} \mathrm{O}\right)$ $\delta 3.92$ (bs, $1 \mathrm{H}, \mathrm{H} 4$ ), 3.76 (ddd, $J=2.8, J=8.4 \mathrm{~Hz}, J=10.5 \mathrm{~Hz}, 1 \mathrm{H}$, H3), 3.69 (dd, $J=5.8, J=11.7 \mathrm{~Hz}, 1 \mathrm{H}, \mathrm{H} 6 \mathrm{a}), 3.65$ (dd, $J=7.6, J=$ $11.6 \mathrm{~Hz}, 1 \mathrm{H}, \mathrm{H6b}$ ), 3.17 (dt, $J=3.6, J=12.7 \mathrm{~Hz}, 1 \mathrm{H}, \mathrm{H1a}$ ), 2.92 (app $\mathrm{t}, J=7.1 \mathrm{~Hz}, 1 \mathrm{H}, \mathrm{H} 5), 2.73(\mathrm{~m}, 1 \mathrm{H}, \mathrm{H} 1 \mathrm{~b}), 1.74-1.79(\mathrm{~m}, 2 \mathrm{H}, \mathrm{H} 2 \mathrm{a}$ and $\mathrm{H} 2 \mathrm{~b}) ;{ }^{13} \mathrm{C}$ NMR $\left(150 \mathrm{MHz}, \mathrm{D}_{2} \mathrm{O}\right) \delta 67.4(\mathrm{C} 3), 65.8(\mathrm{C} 4), 60.0$ (C6), 59.4 (C5), 42.1 (C1), 24.0 (C2); HRMS(ESI) $\mathrm{m} / z$ calcd for $\left[\mathrm{C}_{6} \mathrm{H}_{13} \mathrm{NO}_{3}+\mathrm{H}\right]^{+} 148.0974$, found 148.0974.

Methyl 2-Deoxy- $\alpha / \beta$-D-glucopyranoside (27b). To a solution of $\mathrm{AcCl}(240 \mu \mathrm{L})$ in $\mathrm{MeOH}(240 \mathrm{~mL})$ was added 2-deoxy-D-glucose (27a) (1200 mg, $7.3 \mathrm{mmol}$ ), and the mixture was stirred at room temperature for $18 \mathrm{~h}$. The reaction mixture was then neutralized by the addition of Dowex $-\mathrm{OH}^{-}$, filtered, and concentrated. The resulting oil was used without further purification. Methyl 2-deoxy- $\alpha / \beta$-Dglucopyranoside $(\mathbf{2 7 b})$ was obtained as a colorless oil in an 8:1 $\alpha: \beta$ ratio.

Data for the $\alpha$ isomer: $R_{\mathrm{f}}=0.27\left(10 \% \mathrm{MeOH}\right.$ in EtOAc); ${ }^{1} \mathrm{H}$ NMR $\left(600 \mathrm{MHz}, \mathrm{D}_{2} \mathrm{O}\right) \delta 4.86\left(\mathrm{~d}, J_{1,2 \mathrm{~b}}=3.5 \mathrm{~Hz}, 1 \mathrm{H}, \mathrm{H1}\right), 3.83\left(\mathrm{dd}, J_{5,6 \mathrm{a}}=\right.$ 2.1, $\left.J_{6 a, 6 \mathrm{~b}}=12.0 \mathrm{~Hz}, 1 \mathrm{H}, \mathrm{H6a}\right), 3.79-3.87(\mathrm{~m}, 1 \mathrm{H}, \mathrm{H} 3), 3.73$ (dd, $J_{5,6 \mathrm{~b}}$ $\left.=5.5, J_{6 \mathrm{a}, 6 \mathrm{~b}}=12.0 \mathrm{~Hz}, 1 \mathrm{H}, \mathrm{H} 6 \mathrm{~b}\right), 3.56\left(\mathrm{ddd}, J_{5,6 \mathrm{a}}=2.1, J_{5,6 \mathrm{~b}}=5.5, J_{4,5}=\right.$ $9.6 \mathrm{~Hz}, 1 \mathrm{H}, \mathrm{H} 5), 3.32$ (s, 3H, OMe), $3.31(\mathrm{~m}, 1 \mathrm{H}, \mathrm{H} 4), 2.10$ (dd, $J_{2 \mathrm{a}, 3}$ $\left.=5.3, J_{2 \mathrm{a}, 2 \mathrm{~b}}=13.5 \mathrm{~Hz}, 1 \mathrm{H}, \mathrm{H} 2 \mathrm{a}\right), 1.67\left(\mathrm{ddd}, J_{1,2 \mathrm{~b}}=3.5, J_{2 \mathrm{~b}, 3}=12.0, J_{2 \mathrm{a}, 2 \mathrm{~b}}\right.$ $=13.5 \mathrm{~Hz}, 1 \mathrm{H}, \mathrm{H} 2 \mathrm{~b}) ;{ }^{13} \mathrm{C}$ NMR $\left(150 \mathrm{MHz}, \mathrm{D}_{2} \mathrm{O}\right) \delta 98.1(\mathrm{C} 1), 71.9$ (C5), 70.8 (C4), 68.0 (C3), 60.5 (C6), 54.2 (OMe), 36.4 (C2); HRMS(ESI) $m / z$ calcd for $\left[\mathrm{C}_{7} \mathrm{H}_{14} \mathrm{O}_{5}+\mathrm{Na}\right]^{+}$201.0733, found 201.0735

Data for the $\beta$ isomer: $R_{\mathrm{f}}=0.27\left(10 \% \mathrm{MeOH}\right.$ in EtOAc); ${ }^{1} \mathrm{H}$ NMR $\left(600 \mathrm{MHz}, \mathrm{D}_{2} \mathrm{O}\right) \delta 4.59\left(\mathrm{dd}, J_{1,2 \mathrm{a}}=1.8, J_{1,2 \mathrm{~b}}=9.9 \mathrm{~Hz}, 1 \mathrm{H}, \mathrm{H1}\right), 3.89$ (dd, $\left.J_{5,6 \mathrm{a}}=2.0, J_{6 \mathrm{a}, 6 \mathrm{~b}}=12.0 \mathrm{~Hz}, 1 \mathrm{H}, \mathrm{H} 6 \mathrm{a}\right), 3.65-3.72(\mathrm{~m}, 2 \mathrm{H}, \mathrm{H} 3$ and H6b), 3.48 (s, 3H, OMe), $3.32(\mathrm{~m}, 1 \mathrm{H}, \mathrm{H} 5), 3.21\left(\mathrm{t}, J_{3,4}=J_{4.5}=9.6\right.$ $\mathrm{Hz}, 1 \mathrm{H}, \mathrm{H} 4), 2.21$ (ddd, $J_{1,2 \mathrm{a}}=1.8, J_{2 \mathrm{a}, 3}=5.1, J_{2 \mathrm{a}, 2 \mathrm{~b}}=12.9 \mathrm{~Hz}, 1 \mathrm{H}$, $\mathrm{H} 2 \mathrm{a}$ ), 1.43 (ddd, $J_{1,2 \mathrm{~b}}=9.9, J_{2 \mathrm{~b}, 3}=12.0, J_{2 \mathrm{a}, 2 \mathrm{~b}}=12.9 \mathrm{~Hz}, 1 \mathrm{H}, \mathrm{H} 2 \mathrm{~b}$ ); ${ }^{13} \mathrm{C}$ NMR (150 MHz, $\left.\mathrm{D}_{2} \mathrm{O}\right) \delta 100.6$ (C1), 75.9 (C5), 70.9 (C4), 70.2 (C3), 60.8 (C6), 56.4 (OMe), 38.0 (C2); HRMS(ESI) $\mathrm{m} / z$ calcd for $\left[\mathrm{C}_{7} \mathrm{H}_{14} \mathrm{O}_{5}+\mathrm{Na}\right]^{+}$201.0739, found 201.0735.

Methyl 2,6-Dideoxy-6-iodo- $\alpha$-D-glucoside (28). To a solution of methyl 2-deoxy-D-glucoside $(70.1 \mathrm{mg}, 0.4 \mathrm{mmol})$ in dry THF (4 $\mathrm{mL})$ under an atmosphere of argon were added imidazole $(81.6 \mathrm{mg}$, $1.2 \mathrm{mmol}), \mathrm{PPh}_{3}(157 \mathrm{mg}, 0.6 \mathrm{mmol})$, and $\mathrm{I}_{2}(152 \mathrm{mg}, 0.6 \mathrm{mmol})$. The reaction mixture was heated to $75{ }^{\circ} \mathrm{C}$ for $1.5 \mathrm{~h}$ and then cooled and concentrated. The product was purified by silica gradient flash column chromatography (petroleum ether/EtOAc, $2 / 1 \mathrm{v} / \mathrm{v}$ ) and then reversed-phase HP20 chromatography $(\mathrm{MeOH} /$ water, $1 / 5 \mathrm{v} / \mathrm{v})$ to give methyl 2,6-dideoxy-6-iodo- $\alpha$-D-glucopyranoside (28) as a colorless oil ( $74.1 \mathrm{mg}, 0.26 \mathrm{mmol}, 64 \%$ over two steps from 2-deoxyglucose 27). $R_{\mathrm{f}}=0.42(1 \% \mathrm{MeOH}$ in EtOAc $)$; $[\alpha]_{\mathrm{D}}^{23}=+84.0\left(c=1.0, \mathrm{CHCl}_{3}\right)$ (lit $[\alpha]_{\mathrm{D}}^{27}=+97, c=0.9$ in chloroform ${ }^{51}$ ); IR (film) 3387, 2934, 1442, 1377, 1211, 1128, 1044, 966, $938 \mathrm{~cm}^{-1}$; ${ }^{1} \mathrm{H}$ NMR $\left(500 \mathrm{MHz}, \mathrm{CDCl}_{3}\right)$ $\delta 4.83\left(\mathrm{~d}, J_{1,2 \mathrm{~b}}=3.4 \mathrm{~Hz}, 1 \mathrm{H}, \mathrm{H1}\right.$ ), 3.97 (ddd, $J_{2 \mathrm{a}, 3}=5.1, J_{3,4}=8.7, J_{2 \mathrm{~b}, 3}$ $=11.7 \mathrm{~Hz}, 1 \mathrm{H}, \mathrm{H} 3), 3.57-3.62(\mathrm{~m}, 1 \mathrm{H}, \mathrm{H} 6 \mathrm{a}), 3.40(\mathrm{~s}, 3 \mathrm{H}, \mathrm{OMe})$, 3.35-3.41 (m, 2H, H5 and H6b), 3.24-3.30 (m, 1H, H4), 2.16 (ddd, $\left.J_{1,2 \mathrm{a}}=1.0, J_{2 \mathrm{a}, 3}=5.1, J_{2 \mathrm{a}, 2 \mathrm{~b}}=12.9 \mathrm{~Hz}, 1 \mathrm{H}, \mathrm{H} 2 \mathrm{a}\right), 1.71$ (ddd, $J_{1,2 \mathrm{~b}}=3.2$, $\left.J_{2 \mathrm{~b}, 3}=11.7, J_{2 \mathrm{a}, 2 \mathrm{~b}}=12.9 \mathrm{~Hz}, 1 \mathrm{H}, \mathrm{H} 2 \mathrm{~b}\right) ;{ }^{13} \mathrm{C} \mathrm{NMR}\left(125 \mathrm{MHz}, \mathrm{CDCl}_{3}\right)$ $\delta 98.7(\mathrm{C} 1), 77.6$ (C4), 70.4 (C5), 69.1 (C3), 55.3 (OMe), 37.8 (C2), 7.9 (C6); HRMS(ESI) $\mathrm{m} / z$ calcd for $\left[\mathrm{C}_{7} \mathrm{H}_{13} \mathrm{O}_{4} \mathrm{I}+\mathrm{Na}\right]^{+} 310.9756$, found 310.9751 .

(3R,4R)-1-Amino-hex-5-ene-3,4-diol Hydrochloride (29). To a solution of methyl 2,6-dideoxy-6-iodo- $\alpha$-D-glucoside (28) (111 mg, $0.39 \mathrm{mmol})$ in a saturated solution of $\mathrm{NH}_{4} \mathrm{OAc}$ in $\mathrm{EtOH}(7.3 \mathrm{~mL})$ were added activated $\mathrm{Zn}(450 \mathrm{mg}, 6.9 \mathrm{mmol}), \mathrm{NaCNBH}_{3}(85 \mathrm{mg}, 1.3$ $\mathrm{mmol})$, and $30 \%$ aq. $\mathrm{NH}_{3}(2.9 \mathrm{~mL})$. The mixture was stirred at reflux for $4.5 \mathrm{~h}$, cooled to room temperature, filtered through Celite, and concentrated under reduced pressure. $\mathrm{HCl}(30 \mathrm{~mL}, 2 \mathrm{M})$ was added, and $\mathrm{AcOH}$ was removed by evaporation. Coevaporation with water/ $\mathrm{EtOH}$ was performed to remove traces of $\mathrm{AcOH}$, after which an aqueous solution of $\mathrm{NaOH}(40 \mathrm{~mL}, 1.25 \mathrm{M})$ was added and the $\mathrm{NH}_{3}$ was evaporated. The resulting solid was filtered and washed with $\mathrm{EtOH}$ to remove the bulk of the insoluble $\mathrm{NaCl}$ salt, and the filtrate and combined washings were concentrated and then dry-loaded on silica for column chromatography (DCM/EtOH/MeOH/35\% aq. 
$\mathrm{NH}_{3}, 55 / 2 / 2 / 1$ to $5 / 2 / 2 / 1 \mathrm{v} / \mathrm{v} / \mathrm{v} / \mathrm{v}$ ). Alkenylamine 29 was obtained as the $\mathrm{HCl}$ salt after the addition of aq. $\mathrm{HCl}(1.2 \mathrm{M})$ and concentration to obtain a white solid $(55.5 \mathrm{mg}, 0.33 \mathrm{mmol}, 86 \%)$. $R_{\mathrm{f}}=0.16\left(\mathrm{DCM} / \mathrm{EtOH} / \mathrm{MeOH} / 35 \%\right.$ aq. $\left.\mathrm{NH}_{3}, 5 / 2 / 2 / 1 \mathrm{v} / \mathrm{v} / \mathrm{v} / \mathrm{v}\right) ;$ $[\alpha]_{\mathrm{D}}^{27}=+37.5(c=1.0, \mathrm{MeOH})$; IR (film) 3336, 2924, 1621, 1505, $1468,1396,1312,1255,1122,1020,997,931,854 \mathrm{~cm}^{-1} ;{ }^{1} \mathrm{H}$ NMR $\left(500 \mathrm{MHz}, \mathrm{D}_{2} \mathrm{O}\right) \delta 5.87\left(\mathrm{ddd}, J_{4,5}=6.7, J_{5,6 \text {-iis }}=10.5, J_{5,6 \text {-trans }}=17.3\right.$ $\mathrm{Hz}, 1 \mathrm{H}, \mathrm{H} 5), 5.34$ (d, $J_{5,6-\text { trans }}=17.3 \mathrm{~Hz}, 1 \mathrm{H}, \mathrm{H} 6$-trans), 5.28 (d, $J_{5,6-c i s}$ $=10.5 \mathrm{~Hz}, 1 \mathrm{H}, \mathrm{H6}$-cis), 4.03 (dd, $J_{4,5}=6.7, J_{3,4}=6.8 \mathrm{~Hz}, 1 \mathrm{H}, \mathrm{H} 4$ ), 3.70 (ddd, $\left.J_{2 \mathrm{a}, 3}=2.9, J_{2 \mathrm{~b}, 3}=5.4, J_{3,4}=6.8 \mathrm{~Hz}, 1 \mathrm{H}, \mathrm{H} 3\right), 3.13(\mathrm{~m}, 2 \mathrm{H}, \mathrm{H} 1)$, $1.89(\mathrm{~m}, 1 \mathrm{H}, \mathrm{H} 2 \mathrm{a}), 1.77(\mathrm{~m}, 1 \mathrm{H}, \mathrm{H} 2 \mathrm{~b}) ;{ }^{13} \mathrm{C}$ NMR $\left(125 \mathrm{MHz}, \mathrm{D}_{2} \mathrm{O}\right) \delta$ 136.1 (C5), 118.1 (C6), 75.4 (C4), 71.7 (C3), 37.2 (C1), 29.4 (C2); HRMS(ESI) $m / z$ calcd for $\left[\mathrm{C}_{6} \mathrm{H}_{13} \mathrm{O}_{2} \mathrm{~N}+\mathrm{H}\right]^{+} 132.1025$, found 132.1031.

Iodocyclization/Carbamate Annulation. To a solution of alkenylamine hydrochloride $29(240 \mathrm{mg}, 1.4 \mathrm{mmol})$ in saturated aq. $\mathrm{NaHCO}_{3}(7.2 \mathrm{~mL})$ (made fresh immediately prior to use) were added $\mathrm{I}_{2}(1900 \mathrm{mg}, 7.5 \mathrm{mmol})$ and $\mathrm{NaHCO}_{3}(1400 \mathrm{mg}, 17 \mathrm{mmol})$. The solution was stirred at room temperature for 5 days, filtered, and concentrated under reduced pressure. The products, all as white solids, were separated by repeated use of silica plug $(\mathrm{MeOH}$ in EtOAc, 0$10 \% \mathrm{v} / \mathrm{v}$ ) and reversed-phase columns (octyl-bonded end-capped silica beads) eluting in $\mathrm{H}_{2} \mathrm{O}$ (for carbamates 30, 31a, and 31b) and $\mathrm{MeOH}$ (for iodide 32). Yield of $\mathbf{3 0}=10-30 \%$.

1-N,6-O-Carbonyl-1,2,4-trideoxy-1,4-imino-L-allitol (30). $[\alpha]_{\mathrm{D}}^{25}=$ $-0.5(c=0.4, \mathrm{MeOH})$; IR (film) 3390, 3331, 2965, 2914, 1719, 1634, $1517,1477,1455,1133,1110,1070 \mathrm{~cm}^{-1} ;{ }^{1} \mathrm{H}$ NMR $\left(500 \mathrm{MHz}, \mathrm{D}_{2} \mathrm{O}\right)$ $\delta 4.19-4.27$ (m, 2H, H3 and H6a), 3.94-4.03 (m, 2H, H5 and H6b), $3.47\left(\mathrm{dd}, J_{1,2 \mathrm{a}}=6.1, J_{1,2 \mathrm{~b}}=9.0 \mathrm{~Hz}, 2 \mathrm{H}, \mathrm{H1}\right), 3.28\left(\mathrm{t}, J_{4,5}=J_{3,4}=7.7 \mathrm{~Hz}\right.$, $1 \mathrm{H}, \mathrm{H} 4), 2.24\left(\mathrm{dq}, J_{1,2 \mathrm{a}}=J_{2 \mathrm{a}, 3}=6.1, J_{2 \mathrm{a}, 2 \mathrm{~b}}=12.6 \mathrm{~Hz}, 1 \mathrm{H}, \mathrm{H} 2 \mathrm{a}\right), 1.80$ $\left(\mathrm{dq}, J_{1,2 \mathrm{~b}}=J_{2 \mathrm{~b}, 3}=9.0, J_{2 \mathrm{a}, 2 \mathrm{~b}}=12.6 \mathrm{~Hz}, 1 \mathrm{H}, \mathrm{H} 2 \mathrm{~b}\right) ;{ }^{13} \mathrm{C}$ NMR $(150 \mathrm{MHz}$, $\left.\mathrm{D}_{2} \mathrm{O}\right) \delta 154.4(\mathrm{C}=\mathrm{O}), 74.0(\mathrm{C} 3), 69.2(\mathrm{C} 6), 64.8(\mathrm{C} 4), 64.2(\mathrm{C} 5)$, 44.2 (C1), $30.2(\mathrm{C} 2)$; HRMS (ESI) $\mathrm{m} / z$ calcd for $\left[\mathrm{C}_{7} \mathrm{H}_{11} \mathrm{O}_{4} \mathrm{~N}+\mathrm{Na}\right]^{+}$ 196.0586, found 196.0579 .

1-N,6-O-Carbonyl-5-epi-fagomine (31a) and 1-N,6-O-Carbonylfagomine (31b). IR (film) 3409, 2948, 2840, 1632, 1462, 1403, $1092,1010 \mathrm{~cm}^{-1}$.

Data for the major isomer (31a): ${ }^{1} \mathrm{H}$ NMR $\left(500 \mathrm{MHz}, \mathrm{D}_{2} \mathrm{O}\right) \delta 4.53$ $\left(\mathrm{t}, J_{5,6 \mathrm{a}}=J_{6 \mathrm{a}, 6 \mathrm{~b}}=9.0 \mathrm{~Hz}, 1 \mathrm{H}, \mathrm{H} 6 \mathrm{a}\right), 4.34\left(\mathrm{dd}, J_{5,6 \mathrm{~b}}=6.0, J_{6 \mathrm{a}, 6 \mathrm{~b}}=9.0 \mathrm{~Hz}\right.$, $1 \mathrm{H}, \mathrm{H} 6 \mathrm{~b}$ ), 4.23 (ddd, $J_{4,5}=2.5, J_{5,6 \mathrm{~b}}=6.0, J_{5,6 \mathrm{a}}=9.0 \mathrm{~Hz}, 1 \mathrm{H}, \mathrm{H} 5$ ), 4.06 $\left(\mathrm{dd}, J_{3,4}=3.2, J_{2 \mathrm{a}, 3}=6.3 \mathrm{~Hz}, 1 \mathrm{H}, \mathrm{H} 3\right), 3.73(\mathrm{~m}, 1 \mathrm{H}, \mathrm{H} 4), 3.56(\mathrm{dd}$, $\left.J_{1 \mathrm{a}, 2 \mathrm{a}}=6.3, J_{1 \mathrm{a}, 1 \mathrm{~b}}=13.5 \mathrm{~Hz}, 1 \mathrm{H}, \mathrm{Hla}\right), 3.23\left(\mathrm{td}, J_{1 \mathrm{~b}, 2 \mathrm{a}}=3.7, J_{1 \mathrm{a}, 1 \mathrm{~b}}=J_{1 \mathrm{~b}, 2 \mathrm{~b}}\right.$ $=13.5 \mathrm{~Hz}, 1 \mathrm{H}, \mathrm{H} 1 \mathrm{~b}), 1.95-2.02(\mathrm{~m}, 1 \mathrm{H}, \mathrm{H} 2 \mathrm{a}), 1.64\left(\mathrm{~d}, J_{2 \mathrm{a}, 2 \mathrm{~b}}=15.0\right.$ $\mathrm{Hz}, 1 \mathrm{H}, \mathrm{H} 2 \mathrm{~b}) ;{ }^{13} \mathrm{C}$ NMR $\left(125 \mathrm{MHz}, \mathrm{D}_{2} \mathrm{O}\right) \delta 159.2(\mathrm{C}=\mathrm{O}), 66.5$ (C3), 66.5 (C4), 64.1 (C6), 53.2 (C5), 35.2 (C1), 24.4 (C2); HRMS(ESI) $\mathrm{m} / z$ calcd for $\left[\mathrm{C}_{7} \mathrm{H}_{11} \mathrm{O}_{4} \mathrm{~N}+\mathrm{Na}\right]^{+} 196.0586$, found 196.0587.

Data for the minor isomer (31b): ${ }^{1} \mathrm{H}$ NMR $\left(500 \mathrm{MHz}, \mathrm{D}_{2} \mathrm{O}\right) \delta$ $4.53\left(\mathrm{t}, J_{5,6 \mathrm{a}}=J_{6 \mathrm{a}, 6 \mathrm{~b}}=9.0 \mathrm{~Hz}, 1 \mathrm{H}, \mathrm{H6a}\right), 4.31\left(\mathrm{dd}, J_{5,6 \mathrm{~b}}=5.0, J_{6 \mathrm{a}, 6 \mathrm{~b}}=9.0\right.$ $\mathrm{Hz}, 1 \mathrm{H}, \mathrm{H} 6 \mathrm{~b}$ ), $3.68-3.71$ (m, 1H, H1a), 3.67 (ddd, $J_{5,6 \mathrm{~b}}=5.0, J_{5,6 \mathrm{a}}=$ 9.0, $\left.J_{4,5}=9.5 \mathrm{~Hz}, 1 \mathrm{H}, \mathrm{H} 5\right), 3.62\left(\mathrm{ddd}, J_{2 \mathrm{~b}, 3}=5.0, J_{3,4}=9.5, J_{2 \mathrm{a}, 3}=11.5\right.$ $\mathrm{Hz}, 1 \mathrm{H}, \mathrm{H} 3), 3.34\left(\mathrm{t}, J_{3,4}=J_{4,5}=9.4 \mathrm{~Hz}, 1 \mathrm{H}, \mathrm{H} 4\right), 3.03\left(\mathrm{td}, J_{1 \mathrm{~b}, 2 \mathrm{a}}=3.2\right.$, $\left.J_{1 \mathrm{a}, 1 \mathrm{~b}}=J_{1 \mathrm{~b}, 2 \mathrm{~b}}=13.0 \mathrm{~Hz}, 1 \mathrm{H}, \mathrm{H} 1 \mathrm{~b}\right), 1.92-1.98(\mathrm{~m}, 1 \mathrm{H}, \mathrm{H} 2 \mathrm{a}), 1.51$ (ddt, $\left.J_{2 \mathrm{~b}, 3}=5.0, J_{1 \mathrm{a}, 2 \mathrm{~b}}=11.7, J_{1 \mathrm{~b}, 2 \mathrm{~b}}=J_{2 \mathrm{a}, 2 \mathrm{~b}}=13.0 \mathrm{~Hz}, 1 \mathrm{H}, \mathrm{H} 2 \mathrm{~b}\right) ;{ }^{13} \mathrm{C} \mathrm{NMR}$ $\left(125 \mathrm{MHz}, \mathrm{D}_{2} \mathrm{O}\right) \delta 158.7(\mathrm{C}=\mathrm{O}), 74.5(\mathrm{C} 4), 71.4(\mathrm{C} 3), 66.5$ (C6), 57.6 (C5), 38.7 (C1), 30.8 (C2); HRMS(ESI) $\mathrm{m} / z$ calcd for $\left[\mathrm{C}_{7} \mathrm{H}_{11} \mathrm{O}_{4} \mathrm{~N}+\mathrm{Na}\right]^{+} 196.0586$, found 196.0587 .

1-Amino-1-N,3-O-carbonyl-1,2,6-trideoxy-6-iodo-L-gulitol (32). $R_{\mathrm{f}}$ $=0.26\left(10 \% \mathrm{MeOH}\right.$ in EtOAc); $[\alpha]_{\mathrm{D}}^{26}=-8.9(c=0.67, \mathrm{MeOH})$; IR (film) 3367, 2928, 1680,1488, 1457, 1300, 1223, 1108, 1021, 523 $\mathrm{cm}^{-1}$; ${ }^{1} \mathrm{H}$ NMR $\left(500 \mathrm{MHz}, \mathrm{D}_{2} \mathrm{O}\right) \delta 4.50(\mathrm{dt}, J=3.3, J=9.9 \mathrm{~Hz}, 1 \mathrm{H}$, $\mathrm{H} 3$ ), 3.72-3.81 (m, $2 \mathrm{H}, \mathrm{H} 4$ and $\mathrm{H} 5), 3.44(\mathrm{dd}, J=3.9, J=10.5 \mathrm{~Hz}$, $1 \mathrm{H}, \mathrm{H} 6 \mathrm{a}), 3.29-3.37$ (m, 3H, H1a,b and H6b), 1.90-2.01 (m, $2 \mathrm{H}$, $\mathrm{H} 2 \mathrm{a}, \mathrm{b}) ;{ }^{13} \mathrm{C}$ NMR $\left(125 \mathrm{MHz}, \mathrm{D}_{2} \mathrm{O}\right) \delta 154.7(\mathrm{C}=\mathrm{O}), 76.1(\mathrm{C} 3), 71.8$, 68.1 (C4 and C5), 35.8 (C1), 19.6 (C2), 6.2 (C6); HRMS(ESI) $m / z$ calcd for $\left[\mathrm{C}_{7} \mathrm{H}_{12} \mathrm{O}_{4} \mathrm{NI}+\mathrm{H}\right]^{+} 301.9889$, found 301.9888 .

3,5-Di-O-acetyl-1-N,6-O-carbonyl-1,2,4-trideoxy-1,4-imino-Lallitol (33). Carbamate (30) $(124.7 \mathrm{mg}, 0.7 \mathrm{mmol})$ was subjected to dry pyridine $(1.0 \mathrm{~mL})$ and acetic anhydride $(1.0 \mathrm{~mL})$ at $\mathrm{rt}$ under an argon atmosphere overnight $(14 \mathrm{~h})$. After concentration, the crude compound was dry-loaded on silica before gradient column chromatography (petroleum ether to petroleum ether/EtOAc, 1/1 $\mathrm{v} / \mathrm{v})$. Acetylated carbamate 33 was recovered as a white solid. $R_{\mathrm{f}}=0.44$ $\left(5 \% \mathrm{MeOH}\right.$ in EtOAc); $[\alpha]_{\mathrm{D}}^{27}=+19.9(c=0.1, \mathrm{MeOH})$; IR (film) 2957, 2925, 1741, 1711, 1430, 1367, 1238, 1070, $754 \mathrm{~cm}^{-1}$; ${ }^{1} \mathrm{H}$ NMR $\left(500 \mathrm{MHz}, \mathrm{CDCl}_{3}\right) \delta 5.16\left(\mathrm{dt}, J_{3,4}=6.5, J_{2 \mathrm{a}, 3}=J_{2 \mathrm{~b}, 3}=7.5 \mathrm{~Hz}, 1 \mathrm{H}, \mathrm{H} 3\right)$, $5.06\left(\mathrm{td}, J_{5,6 \mathrm{a}}=4.9, J_{4,5}=J_{5,6 \mathrm{~b}}=9.0 \mathrm{~Hz}, 1 \mathrm{H}, \mathrm{H} 5\right), 4.32\left(\mathrm{dd}, J_{5,6 \mathrm{a}}=4.9\right.$, $\left.J_{6 \mathrm{a}, 6 \mathrm{~b}}=11.0 \mathrm{~Hz}, 1 \mathrm{H}, \mathrm{H6a}\right), 4.05\left(\mathrm{dd}, J_{5,6 \mathrm{~b}}=9.0, J_{6 \mathrm{a}, 6 \mathrm{~b}}=11.0 \mathrm{~Hz}, 1 \mathrm{H}\right.$, H6b), $3.79\left(\mathrm{dt}, J_{1 \mathrm{a}, 2 \mathrm{a}}=J_{1 \mathrm{a}, 2 \mathrm{~b}}=7.5, J_{1 \mathrm{a}, 1 \mathrm{~b}}=11.0 \mathrm{~Hz}, 1 \mathrm{H}, \mathrm{H1a}\right), 3.50-$ $3.57(\mathrm{~m}, 2 \mathrm{H}, \mathrm{H} 1 \mathrm{~b}$ and $\mathrm{H} 4), 2.32\left(\mathrm{dt}, J_{1 \mathrm{a}, 2 \mathrm{a}}=J_{1 \mathrm{~b}, 2 \mathrm{a}}=J_{2 \mathrm{a}, 3}=7.5, J_{2 \mathrm{a}, 2 \mathrm{~b}}=\right.$ $14.5 \mathrm{~Hz}, 1 \mathrm{H}, \mathrm{H} 2 \mathrm{a}), 2.11$ (s, 3H, Me), 2.08 (s, 3H, Me), 1.88 (dt, $J_{1 \mathrm{a}, 2 \mathrm{~b}}$ $\left.=J_{1 \mathrm{~b}, 2 \mathrm{~b}}=J_{2 \mathrm{~b}, 3}=7.5, J_{2 \mathrm{a}, 2 \mathrm{~b}}=14.5 \mathrm{~Hz}, 1 \mathrm{H}, \mathrm{H} 2 \mathrm{~b}\right) ;{ }^{1} \mathrm{H}$ NMR $(300 \mathrm{MHz}$, $\left.\mathrm{CD}_{3} \mathrm{OD}\right) \delta 5.19\left(\mathrm{dd}, J_{3,4}=7.2, J_{2 \mathrm{~b}, 3}=7.9 \mathrm{~Hz}, 1 \mathrm{H}, \mathrm{H} 3\right), 5.12\left(\mathrm{dd}, J_{5,6 \mathrm{a}}=\right.$ 4.7, $\left.J_{4,5}=J_{5,6 \mathrm{~b}}=8.7 \mathrm{~Hz}, 1 \mathrm{H}, \mathrm{H} 5\right), 4.32\left(\mathrm{dd}, J_{5,6 \mathrm{a}}=4.7, J_{6 \mathrm{a}, 6 \mathrm{~b}}=10.8 \mathrm{~Hz}\right.$, $1 \mathrm{H}, \mathrm{H} 6 \mathrm{a}), 4.11$ (dd, $\left.J_{5,6 \mathrm{~b}}=8.7, J_{6 \mathrm{a}, 6 \mathrm{~b}}=10.8 \mathrm{~Hz}, 1 \mathrm{H}, \mathrm{H} 6 \mathrm{~b}\right), 3.66(\mathrm{dt}$, $\left.J_{1 \mathrm{a}, 2 \mathrm{a}}=J_{1 \mathrm{a}, 2 \mathrm{~b}}=8.0, J_{1 \mathrm{a}, 1 \mathrm{~b}}=11.1 \mathrm{~Hz}, 1 \mathrm{H}, \mathrm{H1a}\right), 3.62\left(\mathrm{dd}, J_{3,4}=7.2, J_{4,5}=\right.$ $8.7 \mathrm{~Hz}, 1 \mathrm{H}, \mathrm{H} 4), 3.49$ (ddd, $J_{1 \mathrm{~b}, 2 \mathrm{~b}}=4.7, J_{1 \mathrm{~b}, 2 \mathrm{a}}=9.1, J_{1 \mathrm{a}, 1 \mathrm{~b}}=11.1 \mathrm{~Hz}$, $1 \mathrm{H}, \mathrm{H} 1 \mathrm{~b}$ ), 2.34 (dddd, $J_{1 \mathrm{~b}, 2 \mathrm{~b}}=4.7, J_{2 \mathrm{~b}, 3}=7.9, J_{1 \mathrm{a}, 2 \mathrm{~b}}=8.0, J_{2 \mathrm{a}, 2 \mathrm{~b}}=12.9$ $\mathrm{Hz}, 1 \mathrm{H}, \mathrm{H} 2 \mathrm{a}), 2.07(\mathrm{~s}, 3 \mathrm{H}, \mathrm{Me}), 2.05(\mathrm{~s}, 3 \mathrm{H}, \mathrm{Me}), 1.88$ (ddt, $J_{\mathrm{la}, 2 \mathrm{~b}}=$ $\left.J_{2 \mathrm{~b}, 3}=7.9, J_{1 \mathrm{~b}, 2 \mathrm{~b}}=9.1, J_{2 \mathrm{a}, 2 \mathrm{~b}}=12.9 \mathrm{~Hz}, 1 \mathrm{H}, \mathrm{H} 2 \mathrm{~b}\right) ;{ }^{13} \mathrm{C} \mathrm{NMR}(125$ $\left.\mathrm{MHz}_{\mathrm{CDCl}}\right) \delta 170.1(\mathrm{C}=\mathrm{O}, \mathrm{Ac}), 169.9(\mathrm{C}=\mathrm{O}, \mathrm{Ac}), 151.6(\mathrm{C}=$ O), 75.2 (C3), 66.7 (C6), 65.7 (C5), 63.2 (C4), 44.9 (C1), 28.8 (C2), $20.9\left(\mathrm{CH}_{3}, \mathrm{Ac}\right), 20.8\left(\mathrm{CH}_{3}, \mathrm{Ac}\right) ; \mathrm{HRMS}(\mathrm{ESI}) \mathrm{m} / z$ calcd for $\left[\mathrm{C}_{11} \mathrm{H}_{15} \mathrm{O}_{6} \mathrm{~N}+\mathrm{Na}\right]^{+}$280.0797, found 280.0791 .

1,2,4-Trideoxy-1,4-imino-L-allitol (34). Carbamate (30) (10.6 $\mathrm{mg}, 0.061 \mathrm{mmol})$ was dissolved in $\mathrm{EtOH}(1 \mathrm{~mL})$, and $\mathrm{NaOH}(26 \mathrm{mg}$, $0.6 \mathrm{mmol}$ ) was added. The solution was refluxed for $2 \mathrm{~h}$, neutralized with aq. $\mathrm{HCl}(1 \mathrm{M})$, and loaded on silica for chromatography (DCM/ $\mathrm{EtOH} / \mathrm{MeOH} / 35 \%$ aq. $\mathrm{NH}_{3}, 55 / 2 / 2 / 1$ to $15 / 2 / 2 / 1$ v/v/v/v). Product 34 was obtained as a white solid $(8.0 \mathrm{mg}, 0.054 \mathrm{mmol}$, $89 \%) . R_{\mathrm{f}}=0.19\left(\mathrm{DCM} / \mathrm{EtOH} / \mathrm{MeOH} / 35 \%\right.$ aq. $\mathrm{NH}_{3}, 5 / 2 / 2 / 1 \mathrm{v} / \mathrm{v} / \mathrm{v} /$ $\mathrm{v}) ;[\alpha]_{\mathrm{D}}^{26}=-1.8(c=0.41, \mathrm{MeOH})$; IR (film) 3309, 2956, 2927, 1629, 1420, 1089, $1041 \mathrm{~cm}^{-1}$; ${ }^{1} \mathrm{H}$ NMR $\left(500 \mathrm{MHz}, \mathrm{D}_{2} \mathrm{O}\right) \delta 4.33\left(\mathrm{dt}, J_{2 \mathrm{~b}, 3}=\right.$ $\left.J_{3,4}=4.3, J_{2 \mathrm{a}, 3}=6.2 \mathrm{~Hz}, 1 \mathrm{H}, \mathrm{H} 3\right), 3.78\left(\mathrm{dd}, J_{4,5}=4.3, J_{5,6}=10.3 \mathrm{~Hz}\right.$, $1 \mathrm{H}, \mathrm{H} 5), 3.44-3.52(\mathrm{~m}, 2 \mathrm{H}, \mathrm{H} 6), 3.35\left(\mathrm{t}, J_{3,4}=J_{4,5}=4.3 \mathrm{~Hz}, 1 \mathrm{H}, \mathrm{H} 4\right)$, $3.21\left(\mathrm{dd}, J_{1,2 \mathrm{~b}}=6.3, J_{1,2 \mathrm{a}}=8.1 \mathrm{~Hz}, 2 \mathrm{H}, \mathrm{H1}\right), 2.02\left(\mathrm{ddd}, J_{2 \mathrm{a}, 3}=6.2, J_{1,2 \mathrm{a}}\right.$ $\left.=8.1, J_{2 \mathrm{a}, 2 \mathrm{~b}}=14.2 \mathrm{~Hz}, 1 \mathrm{H}, \mathrm{H} 2 \mathrm{a}\right), 1.78\left(\mathrm{ddd}, J_{2 \mathrm{~b}, 3}=4.3, J_{1,2 \mathrm{~b}}=6.3, J_{2 \mathrm{a}, 2 \mathrm{~b}}\right.$ $=14.2 \mathrm{~Hz}, 1 \mathrm{H}, \mathrm{H} 2 \mathrm{~b}) ;{ }^{13} \mathrm{C} \mathrm{NMR}\left(125 \mathrm{MHz}, \mathrm{D}_{2} \mathrm{O}\right) \delta 69.4(\mathrm{C} 3), 68.4$ (C5), 67.1 (C4), 62.5 (C6), 44.1 (C1), 32.6 (C2); HRMS(ESI) $\mathrm{m} / z$ calcd for $\left[\mathrm{C}_{6} \mathrm{H}_{13} \mathrm{O}_{3} \mathrm{~N}+\mathrm{H}\right]^{+}$148.0974, found 148.0978 .

5-epi-Fagomine (26) and Fagomine (3). Carbamates 31a and $31 \mathrm{~b}(11.7 \mathrm{mg}, 0.07 \mathrm{mmol})$ were dissolved in $\mathrm{EtOH}(1 \mathrm{~mL})$, and $\mathrm{NaOH}(80 \mathrm{mg}, 2 \mathrm{mmol}$ ) was added. The solution was refluxed for $2 \mathrm{~h}$, neutralized with aq. $\mathrm{HCl}(1 \mathrm{M})$, and concentrated in vacuo. Purification by gradient silica column chromatography (DCM/ $\mathrm{EtOH} / \mathrm{MeOH} / 35 \%$ aq. $\mathrm{NH}_{3}, 45 / 2 / 2 / 1$ to $15 / 2 / 2 / 1 \mathrm{v} / \mathrm{v} / \mathrm{v} / \mathrm{v}$ ) gave the products 3 and $\mathbf{2 6}$ as a white solid and a mixture of diastereomers (12.4 mg, $0.07 \mathrm{mmol}$, quant.).

Data for 5-epi-fagomine (26): $R_{\mathrm{f}}=0.24(\mathrm{DCM} / \mathrm{EtOH} / \mathrm{MeOH} / 35 \%$ aq. $\left.\mathrm{NH}_{3}, 5 / 2 / 2 / 1 \mathrm{v} / \mathrm{v} / \mathrm{v} / \mathrm{v}\right) ;[\alpha]_{\mathrm{D}}^{29}=-8.9(c=0.63, \mathrm{MeOH}) ; \mathrm{IR}$ (film) $3364,2970,1425,1366,1217,1079 \mathrm{~cm}^{-1}$; ${ }^{1} \mathrm{H}$ NMR $(500 \mathrm{MHz}$, $\left.\mathrm{D}_{2} \mathrm{O}\right) \delta 4.02(\mathrm{~m}, 1 \mathrm{H}, \mathrm{H} 3), 3.93(\mathrm{~m}, 1 \mathrm{H}, \mathrm{H} 4), 3.85\left(\mathrm{dd}, J_{5,6 \mathrm{a}}=4.9, J_{6 \mathrm{a}, 6 \mathrm{~b}}\right.$ $=12.0 \mathrm{~Hz}, 1 \mathrm{H}, \mathrm{H6a}), 3.80\left(\mathrm{dd}, J_{5,6 \mathrm{~b}}=8.5, J_{6 \mathrm{a}, 6 \mathrm{~b}}=12.0 \mathrm{~Hz}, 1 \mathrm{H}, \mathrm{H} 6 \mathrm{~b}\right)$, $3.54\left(\mathrm{dd}, J_{5,6 \mathrm{a}}=4.9, J_{5,6 \mathrm{~b}}=8.5 \mathrm{~Hz}, 1 \mathrm{H}, \mathrm{H} 5\right), 3.20-3.31(\mathrm{~m}, 2 \mathrm{H}$, $\mathrm{H} 1 \mathrm{a}, \mathrm{b}), 2.16-2.24(\mathrm{~m}, 1 \mathrm{H}, \mathrm{H} 2 \mathrm{a}), 1.84\left(\mathrm{~d}, J_{2 \mathrm{a}, 2 \mathrm{~b}}=14.5 \mathrm{~Hz}, 1 \mathrm{H}, \mathrm{H} 2 \mathrm{~b}\right)$; ${ }^{13} \mathrm{C}$ NMR (125 MHz, $\mathrm{D}_{2} \mathrm{O}$ ) $\delta 65.8$ (C4), 64.8 (C3), 59.5 (C6), 55.8 (C5), 38.9 (C1), 23.6 (C2); HRMS(ESI) $m / z$ calcd for $\left[\mathrm{C}_{6} \mathrm{H}_{13} \mathrm{O}_{3} \mathrm{~N}+\right.$ $\mathrm{H}]^{+}$148.0974, found 148.0968 .

Data for fagomine (3): $R_{\mathrm{f}}=0.33(\mathrm{DCM} / \mathrm{EtOH} / \mathrm{MeOH} / 35 \%$ aq $\left.\mathrm{NH}_{3}, 5 / 2 / 2 / 1 \mathrm{v} / \mathrm{v} / \mathrm{v} / \mathrm{v}\right) ;[\alpha]_{\mathrm{D}}^{29}=+8.4(c=0.27, \mathrm{MeOH}) ; \mathrm{IR}($ film $)$ $3367,2930,1461,1271,1073 \mathrm{~cm}^{-1} ;{ }^{1} \mathrm{H}$ NMR $\left(500 \mathrm{MHz}, \mathrm{D}_{2} \mathrm{O}\right) \delta 3.93$ $\left(\mathrm{dd}, J_{5,6 \mathrm{a}}=3.2, J_{6 \mathrm{a}, 6 \mathrm{~b}}=12.5 \mathrm{~Hz}, 1 \mathrm{H}, \mathrm{H6a}\right), 3.88\left(\mathrm{dd}, J_{5,6 \mathrm{~b}}=5.5, J_{6 \mathrm{a}, 6 \mathrm{~b}}=\right.$ $12.5 \mathrm{~Hz}, 1 \mathrm{H}, \mathrm{H} 6 \mathrm{~b}$ ), 3.71 (ddd, $J_{2 \mathrm{a}, 3}=4.9, J_{3,4}=9.0, J_{2 \mathrm{~b}, 3}=11.7 \mathrm{~Hz}, 1 \mathrm{H}$, $\mathrm{H} 3), 3.52\left(\mathrm{t}, J_{3,4}=J_{4,5}=9.0 \mathrm{~Hz}, 1 \mathrm{H}, \mathrm{H} 4\right), 3.44\left(\mathrm{ddd}, J_{\mathrm{aa}, 2 \mathrm{a}}=2.5, J_{\mathrm{la}, 2 \mathrm{~b}}=\right.$ 4.1, $\left.J_{1 \mathrm{a}, 1 \mathrm{~b}}=13.5 \mathrm{~Hz}, 1 \mathrm{H}, \mathrm{H1a}\right), 3.12-3.16(\mathrm{~m}, 1 \mathrm{H}, \mathrm{H} 5), 3.10$ (dd, $J_{1 \mathrm{~b}, 2 \mathrm{a}}$ $\left.=2.5, J_{1 \mathrm{~b}, 2 \mathrm{~b}}=J_{1 \mathrm{a}, 1 \mathrm{~b}}=13.5 \mathrm{~Hz}, 1 \mathrm{H}, \mathrm{H} 1 \mathrm{~b}\right), 2.21$ (ddd $J=2.5, J_{2 \mathrm{a}, 3}=4.9$, $\left.J_{2 \mathrm{a}, 2 \mathrm{~b}}=13.5 \mathrm{~Hz}, 1 \mathrm{H}, \mathrm{H} 2 \mathrm{a}\right), 1.72\left(\mathrm{ddt}, J_{1 \mathrm{a}, 2 \mathrm{~b}}=4.1, J_{2 \mathrm{~b}, 3}=11.7, J_{1 \mathrm{a}, 2 \mathrm{~b}}=\right.$ $\left.J_{2 \mathrm{a}, 2 \mathrm{~b}}=13.5 \mathrm{~Hz}, 1 \mathrm{H}, \mathrm{H} 2 \mathrm{~b}\right) ;{ }^{13} \mathrm{C}$ NMR $\left(125 \mathrm{MHz}, \mathrm{D}_{2} \mathrm{O}\right) \delta 70.4(\mathrm{C} 3)$ 69.5 (C4), 60.0 (C5), 57.6 (C6), 41.8 (C1), 28.5 (C2); HRMS(ESI) $m / z$ calcd for $\left[\mathrm{C}_{6} \mathrm{H}_{13} \mathrm{O}_{3} \mathrm{~N}+\mathrm{H}\right]^{+} 148.0974$, found 148.0968 . 
4,5-Di-O-acetyl-1-amino-1-N,3-O-carbonyl-1,2,6-trideoxy-6iodo-L-gulitol (35). Iodide $32(20.4 \mathrm{mg}, 0.07 \mathrm{mmol})$ was subjected to dry pyridine $(0.5 \mathrm{~mL})$ and acetic anhydride $(0.5 \mathrm{~mL})$ at room temperature under an argon atmosphere overnight $(9 \mathrm{~h})$. After concentration and repeated coevaporation with toluene to remove pyridine, the crude compound was dry-loaded on silica before gradient column chromatography (petroleum ether to petroleum ether/EtOAc, $1 / 1 \mathrm{v} / \mathrm{v})$. Acetylated iodide 35 was recovered as a white solid in $48 \%$ yield $(12.5 \mathrm{mg}, 0.03 \mathrm{mmol}) . R_{\mathrm{f}}=0.44\left(10 \% \mathrm{MeOH}\right.$ in EtOAc); $[\alpha]_{\mathrm{D}}^{25}$ $=+6.6\left(c=0.23, \mathrm{CHCl}_{3}\right)$; IR (film) 3266, 3056, 2927, 1742, 1716, 1373, 1266, 1219, 1117, 1059, 1024, $598.7 \mathrm{~cm}^{-1}$; ${ }^{1} \mathrm{H}$ NMR $(500 \mathrm{MHz}$, $\left.\mathrm{CDCl}_{3}\right) \delta 5.51($ br s, $1 \mathrm{H}, \mathrm{NH}), 5.34\left(\mathrm{dd}, J_{3,4}=3.7, J_{4,5}=5.5 \mathrm{~Hz}, 1 \mathrm{H}\right.$, $\mathrm{H} 4), 5.14\left(\mathrm{dd}, J_{5,6 \mathrm{a}}=4.5, J_{4,5}=J_{5,6 \mathrm{~b}}=5.5 \mathrm{~Hz}, 1 \mathrm{H}, \mathrm{H} 5\right), 4.47\left(\mathrm{~d}, J_{2 \mathrm{~b}, 3}=\right.$ $10.8 \mathrm{~Hz}, 1 \mathrm{H}, \mathrm{H} 3$ ), 3.46 (dd, $\left.J_{5,6 \mathrm{a}}=4.5, J_{6 \mathrm{a}, 6 \mathrm{~b}}=11.4 \mathrm{~Hz}, 1 \mathrm{H}, \mathrm{H6a}\right)$, $3.37-4.43(\mathrm{~m}, 2 \mathrm{H}, \mathrm{Hla}, \mathrm{b}), 3.36\left(\mathrm{dd}, J_{5,6 \mathrm{~b}}=5.5, J_{6 \mathrm{a}, 6 \mathrm{~b}}=11.4 \mathrm{~Hz}, 1 \mathrm{H}\right.$, H6b), 2.16 (s, 3H, 4-OAc), 2.13 (s, 3H, 5-OAc), 2.00 (d, $J_{2 \mathrm{a}, 2 \mathrm{~b}}=14.2$ $\mathrm{Hz}, 1 \mathrm{H}, \mathrm{H} 2 \mathrm{a}), 1.79-1.89(\mathrm{~m}, 1 \mathrm{H}, \mathrm{H} 2 \mathrm{~b}) ;{ }^{13} \mathrm{C}$ NMR $(125 \mathrm{MHz}$, $\left.\mathrm{CDCl}_{3}\right) \delta 170.2(\mathrm{C}=\mathrm{O}, 4-\mathrm{Ac}), 169.9(\mathrm{C}=\mathrm{O}, 5-\mathrm{Ac}), 152.9(\mathrm{C}=\mathrm{O})$, 75.0 (C3), 73.4 (C4), 70.4 (C5), 38.9 (C1), 22.8 (C2), $20.9\left(\mathrm{CH}_{3}\right.$, Ac), $20.6\left(\mathrm{CH}_{3}, \mathrm{Ac}\right), 3.3$ (C6); HRMS(ESI) $\mathrm{m} / \mathrm{z}$ calcd for $\left[\mathrm{C}_{11} \mathrm{H}_{16} \mathrm{O}_{6} \mathrm{NI}+\mathrm{H}\right]^{+}$386.0101, found 386.0094 .

1-Amino-1- $\mathrm{N}, 3-\mathrm{O}$-carbonyl-1,2,6-trideoxy-6-iodo-4,5-O-isopropylidene-L-gulitol (36). Iodide $32(8.8 \mathrm{mg}, 0.3 \mathrm{mmol})$ was dissolved in acetone $(0.45 \mathrm{~mL})$, dimethoxypropane $(0.45 \mathrm{~mL})$, and $\mathrm{MeOH}(0.25 \mathrm{~mL})$. A $100 \mu \mathrm{L}$ aliquot of $\mathrm{pTsOH} \cdot \mathrm{H}_{2} \mathrm{O}$ in acetone $(2.85$ $\mathrm{mg} / \mathrm{mL}$ ) was added, and the reaction mixture was stirred at room temperature overnight $(17 \mathrm{~h})$. The mixture was then neutralized with Dowex $-\mathrm{OH}^{-}$, filtered, and concentrated to give a white solid 36 (7.2 $\mathrm{mg}, 0.02 \mathrm{mmol}, 72 \%)$ that was used without further purification. $R_{\mathrm{f}}=$ $0.49\left(10 \% \mathrm{MeOH}\right.$ in EtOAc); $[\alpha]_{\mathrm{D}}^{23}=-23.0\left(c=0.48, \mathrm{CHCl}_{3}\right)$; IR (film) 3282, 2985, 2930, 1700, 1487, 1456, 1421, 1372, 1294, 1239, 1214, 1107, 1069, $554 \mathrm{~cm}^{-1}$; ${ }^{1} \mathrm{H}$ NMR $\left(500 \mathrm{MHz}, \mathrm{CDCl}_{3} / \mathrm{CD}_{3} \mathrm{OD}\right.$ $95 / 5) \delta 4.40\left(\right.$ app dt, $\left.J_{3,4}=2.2, J_{2 \mathrm{a}, 3}=10.0 \mathrm{~Hz}, 1 \mathrm{H}, \mathrm{H} 3\right), 4.20\left(\mathrm{dt}, J_{5,6 \mathrm{a}}\right.$ $\left.=J_{5,6 \mathrm{~b}}=4.7, J_{4,5}=7.5 \mathrm{~Hz}, 1 \mathrm{H}, \mathrm{H5}\right), 3.83\left(\mathrm{dd}, J_{3,4}=2.2, J_{4,5}=7.5 \mathrm{~Hz}\right.$, $1 \mathrm{H}, \mathrm{H} 4), 3.41$ (ddd, $\left.J_{1 \mathrm{a}, 2 \mathrm{~b}}=3.7, J_{1 \mathrm{a}, 2 \mathrm{a}}=5.8, J_{1 \mathrm{a}, 1 \mathrm{~b}}=11.0 \mathrm{~Hz}, 1 \mathrm{H}, \mathrm{H1a}\right)$, $3.36(\mathrm{~m}, 1 \mathrm{H}, \mathrm{NH}), 3.31-3.35(\mathrm{~m}, 1 \mathrm{H}, \mathrm{H} 1 \mathrm{~b}), 3.31\left(\mathrm{dd}, J_{5,6 \mathrm{a}}=4.7, J_{6 \mathrm{a}, 6 \mathrm{~b}}\right.$ $=10.8 \mathrm{~Hz}, 1 \mathrm{H}, \mathrm{H} 6 \mathrm{a}), 3.28\left(\mathrm{dd}, J_{5,6 \mathrm{~b}}=4.7, J_{6 \mathrm{a}, 6 \mathrm{~b}}=10.8 \mathrm{~Hz}, 1 \mathrm{H}, \mathrm{H} 6 \mathrm{~b}\right)$, $2.06\left(\mathrm{dtd}, J_{1 \mathrm{a}, 2 \mathrm{a}}=5.8, J_{1 \mathrm{~b}, 2 \mathrm{a}}=J_{2 \mathrm{a}, 3}=10.0, J_{2 \mathrm{a}, 2 \mathrm{~b}}=14.0 \mathrm{~Hz}, 1 \mathrm{H}, \mathrm{H} 2 \mathrm{a}\right)$, 1.98 (m, 1H, H2b), 1.43 (s, 3H, Me), 1.40 (s, 3H, Me); ${ }^{13} \mathrm{C}$ NMR $\left(125 \mathrm{MHz}, \mathrm{CDCl}_{3} / \mathrm{CD}_{3} \mathrm{OD} 95 / 5\right) \delta 154.4(\mathrm{C}=\mathrm{O}), 110.7(\mathrm{iPr}-$ $\left.\mathrm{C}\left(\mathrm{CH}_{3}\right)_{2}\right), 82.4(\mathrm{C} 4), 75.1$ (C3), 74.6 (C5), 38.7 (C1), 27.6, 27.0 (iPr-C $\left.\left(\mathrm{CH}_{3}\right)_{2}\right), 23.3$ (C2), 6.1 (C6); HRMS(ESI) $\mathrm{m} / \mathrm{z}$ calcd for $\left[\mathrm{C}_{10} \mathrm{H}_{16} \mathrm{O}_{4} \mathrm{NI}+\mathrm{H}\right]^{+}$342.0202, found 342.0201.

D-threo-1-Amino-1-O,3-N-carbonyl-1,2,5,6-tetradeoxyhex-5enose (37). Iodoacetonide $36(6.8 \mathrm{mg}, 0.02 \mathrm{mmol})$ was subjected to DCM $(0.3 \mathrm{~mL}), \mathrm{AcOH}(0.1 \mathrm{~mL})$, and zinc $(27.6 \mathrm{mg}, 0.2 \mathrm{mmol})$ and stirred at $40-55{ }^{\circ} \mathrm{C}$ for 12 days. The reaction mixture was filtered through silica and concentrated to remove zinc. The crude product was purified by silica column chromatography (petroleum ether to petroleum ether/EtOAc, $1 / 3 \mathrm{v} / \mathrm{v})$, yielding 37 as a white solid (2.4 $\mathrm{mg}, 0.015 \mathrm{mmol}, 77 \%) . R_{\mathrm{f}}=0.22\left(10 \% \mathrm{MeOH}\right.$ in EtOAc); $[\alpha]_{\mathrm{D}}^{29}=$ $-12.8(c=0.16, \mathrm{MeOH})$; IR (film) 3373, 2926, 2856, 1682, 1489, 1459, 1294, 1108, 1071, 1028, $946 \mathrm{~cm}^{-1} ;{ }^{1} \mathrm{H}$ NMR (500 MHz, $\left.\mathrm{D}_{2} \mathrm{O}\right) \delta$ $5.92\left(\mathrm{ddd}, J_{4,5}=6.6, J_{5,6 \text {-cis }}=10.5, J_{5,6 \text {-trans }}=17.3 \mathrm{~Hz}, 1 \mathrm{H}, \mathrm{H} 5\right), 5.40$ (app dt, $J_{4,6 \text {-trans }}=1.2, J_{5,6 \text {-trans }}=17.3 \mathrm{~Hz}, 1 \mathrm{H}, \mathrm{H6}$-trans), $5.32(\mathrm{app} \mathrm{dt}$, $J_{4,6-c i s}=1.2, J_{5,6-c i s}=10.5 \mathrm{~Hz}, 1 \mathrm{H}, \mathrm{H6}$-cis), 4.35 (ddd, $J_{2 \mathrm{a}, 3}=3.0, J_{3,4}=$ $\left.5.7, J_{2 \mathrm{~b}, 3}=10.5 \mathrm{~Hz}, 1 \mathrm{H}, \mathrm{H3}\right), 4.24\left(\mathrm{ddt}, J_{4,6 \text {-trans }}=J_{4,6 \text {-cis }}=1.2, J_{3,4}=5.7\right.$, $\left.J_{4,5}=6.6 \mathrm{~Hz}, 1 \mathrm{H}, \mathrm{H} 4\right), 3.33\left(\mathrm{ddd}, J_{1 \mathrm{a}, 2 \mathrm{a}}=3.0, J_{1 \mathrm{a}, 2 \mathrm{~b}}=6.9, J_{1 \mathrm{a}, 1 \mathrm{~b}}=12.0\right.$ $\mathrm{Hz}, 1 \mathrm{H}, \mathrm{H1a}$ ), 3.32 (ddd, $J_{1 \mathrm{~b}, 2 \mathrm{a}}=4.5, J_{1 \mathrm{~b}, 2 \mathrm{~b}}=10.5, J_{1 \mathrm{a}, 1 \mathrm{~b}}=12.0 \mathrm{~Hz}, 1 \mathrm{H}$, H1b), 1.99 (ddt, $J_{2 a, 3}=J_{1 a, 2 a}=3.0, J_{1 b, 2 a}=4.5, J_{2 a, 2 b}=14.1 \mathrm{~Hz}, 1 \mathrm{H}$, $\mathrm{H} 2 \mathrm{a}), 1.84\left(\mathrm{dtd}, J_{1 \mathrm{a}, 2 \mathrm{~b}}=6.9, J_{1 \mathrm{~b}, 2 \mathrm{~b}}=J_{2 \mathrm{~b}, 3}=10.5, J_{2 \mathrm{a}, 2 \mathrm{~b}}=14.1 \mathrm{~Hz}, 1 \mathrm{H}\right.$, $\mathrm{H} 2 \mathrm{~b}) ;{ }^{13} \mathrm{C}$ NMR $\left(150 \mathrm{MHz}, \mathrm{D}_{2} \mathrm{O}\right) \delta 156.8(\mathrm{C}=\mathrm{O}), 134.9$ (C5), 118.4 (C6), 80.2 (C3), 73.5 (C4), 37.8 (C1), 21.7 (C2); HRMS(ESI) $m / z$ calcd for $\left[\mathrm{C}_{7} \mathrm{H}_{11} \mathrm{O}_{3} \mathrm{~N}+\mathrm{H}\right]^{+} 158.0817$, found 158.0805 .

D-threo-4-O-Acetyl-1-amino-1-O,3-N-carbonyl-1,2,5,6-tetradeoxyhex-5-enose (38). Iodide $35(10.7 \mathrm{mg}, 0.03 \mathrm{mmol})$ was dissolved in THF $(0.3 \mathrm{~mL})$, and $\mathrm{H}_{2} \mathrm{O}(0.06 \mathrm{~mL}), \mathrm{AcOH}(0.06 \mathrm{~mL})$, and zinc $(62 \mathrm{mg}, 0.6 \mathrm{mmol})$ were added. The resulting mixture was then stirred at room temperature for $1 \mathrm{~h}$. The reaction mixture was filtered through Celite, washed with DCM and EtOH, and concentrated before coevaporation with $\mathrm{H}_{2} \mathrm{O}$ and toluene to remove traces of $\mathrm{AcOH}$. The crude product was purified by silica column chromatography (petroleum ether to petroleum ether/EtOAc, $1 / 3 \mathrm{v} /$ $\mathrm{v})$ to give 38 as a white solid ( $5.5 \mathrm{mg}, 0.03 \mathrm{mmol}$, quant.). $R_{\mathrm{f}}=0.38$ $\left(10 \% \mathrm{MeOH}\right.$ in EtOAc); $[\alpha]_{\mathrm{D}}^{25}=-11.0\left(c=0.13, \mathrm{CHCl}_{3}\right)$; IR (film) $3278,2925,2854,1703,1489,1459,1424,1372,1294,1227,1104$, $1023,950,763 \mathrm{~cm}^{-1}$; ${ }^{1} \mathrm{H}$ NMR $\left(500 \mathrm{MHz}, \mathrm{CDCl}_{3}\right) \delta 5.88\left(\mathrm{ddd}, J_{4,5}=\right.$ 6.5, $\left.J_{5,6 \text {-cis }}=10.5, J_{5,6 \text {-trans }}=17.0 \mathrm{~Hz}, 1 \mathrm{H}, \mathrm{H} 5\right), 5.51(\mathrm{br} \mathrm{s}, 1 \mathrm{H}, \mathrm{NH}), 5.44$ (d, $\left.J_{4,5}=6.5 \mathrm{~Hz}, 1 \mathrm{H}, \mathrm{H} 4\right), 5.43$ (d, $J_{5,6 \text {-trans }}=17.0 \mathrm{~Hz}, 1 \mathrm{H}, \mathrm{H} 6$-trans), 5.37 (d, $\left.J_{5,6-c i s}=10.5 \mathrm{~Hz}, 1 \mathrm{H}, \mathrm{H} 6-c i s\right), 4.39$ (ddd, $J=2.5, J=5.5, J_{2 \mathrm{~b}, 3}=$ $10.5 \mathrm{~Hz}, 1 \mathrm{H}, \mathrm{H} 3), 3.35-3.45$ (m, 2H, H1a,b), 2.13 (s, 3H, Me), 1.94$2.01(\mathrm{~m}, 1 \mathrm{H}, \mathrm{H} 2 \mathrm{a}), 1.86\left(\mathrm{dtd}, J=6.5, J=J_{2 \mathrm{~b}, 3}=10.5, J_{2 \mathrm{a}, 2 \mathrm{~b}}=14.0 \mathrm{~Hz}\right.$, $1 \mathrm{H}, \mathrm{H} 2 \mathrm{~b}) ;{ }^{13} \mathrm{C}$ NMR (125 MHz, $\left.\mathrm{CDCl}_{3}\right) \delta 170.0$ (C=O, Ac), 153.8 (C=O), 131.5 (C5), 120.4 (C6), 77.5 (C3), 74.5 (C4), 39.0 (C1), 22.5 (C2), $21.2\left(\mathrm{CH}_{3}, \mathrm{Ac}\right)$; HRMS(ESI) $m / z$ calcd for $\left[\mathrm{C}_{9} \mathrm{H}_{13} \mathrm{O}_{4} \mathrm{~N}+\right.$ $\mathrm{H}]^{+} 200.0923$, found 200.0918 .

(3R,4R)-6-Aminohex-1-ene-3,4-diol Hydrochloride (29). Acetylated alkene carbamate $38(5.7 \mathrm{mg}, 0.03 \mathrm{mmol})$ was dissolved in EtOH $(1 \mathrm{~mL})$, and $\mathrm{NaOH}(80 \mathrm{mg}, 2 \mathrm{mmol})$ was added. The solution was refluxed for $1 \mathrm{~h}$, neutralized with aq. $\mathrm{HCl}(1.2 \mathrm{M})$, and then concentrated in vacuo. Purification by gradient silica column chromatography (DCM/EtOH/MeOH/35\% aq. $\mathrm{NH}_{3}, 65 / 2 / 2 / 1$ to $5 / 2 / 2 / 1 \mathrm{v} / \mathrm{v} / \mathrm{v} / \mathrm{v}$ ) gave the alkenylamine, which was converted into the $\mathrm{HCl}$ salt 29 as a white solid $(3.3 \mathrm{mg}, 0.02 \mathrm{mmol}, 69 \%)$ by the addition of $\mathrm{HCl}(1.2 \mathrm{M}$, aq. $)$ and concentration. $R_{\mathrm{f}}=0.16(\mathrm{DCM} /$ $\mathrm{EtOH} / \mathrm{MeOH} / 35 \%$ aq. $\left.\mathrm{NH}_{3}, 5 / 2 / 2 / 1 \mathrm{v} / \mathrm{v} / \mathrm{v} / \mathrm{v}\right) ;[\alpha]_{\mathrm{D}}^{27}=+31.8(c=$ $0.2, \mathrm{MeOH})$.

\section{ASSOCIATED CONTENT}

\section{Supporting Information}

NMR spectra $\left({ }^{1} \mathrm{H}\right.$ and $\left.{ }^{13} \mathrm{C}\right)$ for all new compounds. This material is available free of charge via the Internet at http:// pubs.acs.org.

\section{AUTHOR INFORMATION}

\section{Corresponding Authors}

*E-mail: bridget.stocker@vuw.ac.nz.

*E-mail: mattie.timmer@vuw.ac.nz. Telephone: + 644463 6529. Fax: + 6444635237.

\section{Notes}

The authors declare no competing financial interest.

\section{ACKNOWLEDGMENTS}

The authors acknowledge the financial contributions of Victoria University of Wellington (Postgraduate Scholarship and CurtisGordon Research Scholarship, H.M.C.) and the Royal Society of New Zealand Marsden Fund (M.S.M.T.).

\section{REFERENCES}

(1) For some recent reviews outlining the biological activity of azasugars, see: (a) Asano, N.; Nash, R. J.; Molyneux, R. J.; Fleet, G. W. J. Tetrahedron: Asymmetry 2000, 11, 1645-1680. (b) Butters, T. D.; Dwek, R. A.; Platt, F. M. Curr. Top. Med. Chem. 2003, 3, 561-574. (c) Greimel, P.; Spreitz, J.; Stütz, A. E.; Wrodnigg, T. M. Curr. Top. Med. Chem. 2003, 3, 513-523. (d) Borges de Melo, E.; da Silveira Gomes, A.; Carvalho, I. Tetrahedron 2006, 62, 10277-10302. (e) Merino, P.; Delso, I.; Marca, E.; Tejero, T.; Matute, R. Curr. Chem. Biol. 2009, 3, 253-271. (f) Nash, R. J.; Kato, A.; Yu, C.-Y.; Fleet, G. W. J. Future Med. Chem 2011, 3, 1513-1521. (g) Lopez, O.; Merino-Montiel, P.; Martos, S.; Gonzalez-Benjumea, A. Carbohydr. Chem. 2012, 38, 215-262. (h) Alonzi, D. S.; Butters, T. D. Chimia 2011, 65, 35-39. (i) Iminosugars: From Synthesis to Therapeutic Applications; Compain, P., Martin, O. R., Eds.; Wiley: Chichester, U.K., 2007.

(2) Segal, P.; Feig, P. U.; Schernthaner, G.; Ratzmann, K. P.; Rybka, J.; Petzinna, D.; Berlin, C. Diabetes Care 1997, 20, 687-691. 
(3) See: A Study of AT1001 in Patients with Fabry Disease. http:// www.clinicaltrials.gov/ct/gui/show/NCT00231036 (accessed July 7, 2013).

(4) Lillelund, V. H.; Jensen, H. H.; Liang, X.; Bols, M. Chem. Rev. 2002, 102, 515-554.

(5) Meyers, A. I.; Andres, C. J.; Resek, J. E.; Woodall, C. C.; McLaughlin, M. A.; Lee, P. H.; Price, D. A. Tetrahedron 1999, 55, 8931-8952.

(6) Kato, A.; Asano, N.; Kizu, H.; Matsui, K.; Watson, A. A.; Nash, R. J. J. Nat. Prod. 1997, 60, 312-314.

(7) Nojima, H.; Kimura, I.; Chen, F.-J.; Sugihara, Y.; Haruno, M.; Kato, A.; Asano, N. J. Nat. Prod. 1998, 61, 397-400.

(8) Fan, J.-Q.; Ishii, S.; Asano, N.; Suzuki, Y. Nat. Med. 1999, 5, $112-$ 115.

(9) Dangerfield, E. M.; Timmer, M. S. M.; Stocker, B. L. Org. Lett. 2009, 11, 535-538.

(10) Dangerfield, E. M.; Gulab, S. A.; Plunkett, C. H.; Timmer, M. S. M.; Stocker, B. L. Carbohydr. Res. 2010, 345, 1360-1365.

(11) Dangerfield, E. M.; Plunkett, C. H.; Stocker, B. L.; Timmer, M. S. M. Molecules 2009, 14, 5298-5307.

(12) For recent reviews concerning the synthesis of azasugars, see: (a) Pearson, M. S. M.; Mathé-Allainmat, M.; Fargeas, V.; Lebreton, J. Eur. J. Org. Chem. 2005, 2159-2191. (b) Afarinkia, K.; Bahar, A. Tetrahedron: Asymmetry 2005, 16, 1239-1287. (c) Davis, B. G. Tetrahedron: Asymmetry 2009, 20, 652-671. (d) Stocker, B. L.; Dangerfield, E. M.; Win-Mason, A. L.; Haslett, G. W.; Timmer, M. S. M. Eur. J. Org. Chem. 2010, 1615-1637. (e) Wijdeven, M. A.; Willemsen, J.; Rutjes, F. P. J. T. Eur. J. Org. Chem. 2010, 2831-2844.

(13) Dangerfield, E. M.; Plunkett, C. H.; Win-Mason, A. L.; Stocker,

B. L.; Timmer, M. S. M. J. Org. Chem. 2010, 75, 5470-5477.

(14) Timmer, M. S. M.; Dangerfield, E. M.; Cheng, J. M. H.; Gulab,

S. A.; Stocker, B. L. Tetrahedron Lett. 2011, 52, 4803-4805.

(15) For a full discussion of the factors influencing the protectinggroup-free reductive amination methodology, see: (a) Miriyala, B.; Bhattacharyya, S.; Williamson, J. S. Tetrahedron 2004, 60, 1463-1471. (b) Pelter, A.; Rosser, R. M.; Mills, S. J. Chem. Soc., Perkin Trans. 1 1984, 717-720. (c) Borch, R. F.; Bernstein, M. D.; Durst, H. D. J. Am. Chem. Soc. 1971, 93, 2897-2904. (d) Gomez, S.; Peters, J. A.; van der Waal, J. C.; van den Brink, P. J.; Maschmeyer, T. Appl. Catal., A 2004, 261, 119-125. (e) Gomez, S.; Peters, J. A.; Maschmeyer, T. Adv. Synth. Catal. 2002, 344, 1037-1057. (f) Baxter, E.; Reitz, A. Org. React. 2002, 59, 1-714.

(16) McGhee, W.; Riley, D.; Christ, K.; Pan, Y.; Parnas, B. J. Org. Chem. 1995, 60, 2820-2830.

(17) Hampe, E. M.; Rudkevich, D. M. Tetrahedron 2003, 59, 96199625.

(18) For some examples of recently developed protecting groups, see: (a) Chmielewski, M. K. Tetrahedron Lett. 2012, 53, 666-669.

(b) Li, Y.; Roy, B.; Liu, X. Chem. Commun. 2011, 47, 8952-8954.

(c) Codée, J. D. C.; Ali, A.; Overkleeft, H. S.; van der Marel, G. A. C. R. Chim. 2011, 14, 178-193. (d) Hagen, V.; Kilic, F.; Schaal, J.; Dekowski, B.; Schmidt, R.; Kotzur, N. J. Org. Chem. 2010, 75, 27902797. (e) Ali, A.; Van den Berg, R. J. B. H. N.; Overkleeft, H. S.; Filippov, D. V.; van der Marel, G. A.; Codée, J. D. C. Tetrahedron Lett. 2009, 50, 2185-2188. (f) Timmer, M. S. M.; Stocker, B. L.; Northcote, P. T.; Burkett, B. A. Tetrahedron Lett. 2009, 50, 71997204.

(19) Foster, A. B.; Overend, W. G.; Stacey, M.; Vaughan, G. J. Chem. Soc. 1954, 3367-3377.

(20) Toyokuni, T.; Cai, S.; Dean, B. Synthesis 1992, 1236-1238.

(21) Asano, N.; Oseki, K.; Kizu, H.; Matsui, K. J. Med. Chem. 1994, 37, 3701-3706.

(22) Heiker, F.-R.; Schueller, A. M. Carbohydr. Res. 1990, 203, 314318.

(23) Takahata, H.; Banba, Y.; Ouchi, H.; Nemoto, H.; Kato, A.; Adachi, I. J. Org. Chem. 2003, 68, 3603-3607.

(24) van den Berg, R. J. B. H. N.; Wennekes, T.; Ghisaidoobe, A.; Donker-Koopman, W. E.; Strijland, A.; Boot, R. G.; van der Marel, G.
A.; Aerts, J. M. F. G.; Overkleeft, H. S. ACS Med. Chem. Lett. 2011, 2, 519-522.

(25) Kumari, N.; Reddy, B. G.; Vankar, Y. D. Eur. J. Org. Chem. 2009, 160-169.

(26) Yorimitsu, H.; Murakami, Y.; Takamatsu, H.; Nishimura, S.; Nakamura, E. Chem.-Asian J. 2007, 2, 57-65.

(27) Skaanderup, P. R.; Poulsen, C. S.; Hyldtoft, L.; Jorgensen, M. R.; Madsen, R. Synthesis 2002, 1721-1727.

(28) Swamy, N. K.; Pyne, S. G. Synth. Commun. 2011, 41, 24352445.

(29) Bates, R. W.; Ng, P. S. Tetrahedron Lett. 2011, 52, 2969-2971.

(30) Jiangseubchatveera, N.; Bouillon, M. E.; Liawruangrath, B.; Liawruangrath, S.; Nash, R. J.; Pyne, S. G. Org. Biomol. Chem. 2013, 11, $3826-3833$.

(31) Lombardo, M.; Morganti, S.; Trombini, C. J. Org. Chem. 2003, 68, 997-1006.

(32) Dana, G.; Danechpajouh, H. Bull. Soc. Chim. Fr. 1980, 395-399.

(33) Bock, M.; Buntin, K.; Müller, R.; Kirschning, A. Angew. Chem., Int. Ed. 2008, 47, 2308-2311.

(34) Stocker, B. L.; Win-Mason, A. L.; Timmer, M. S. M. Carbohydr. Res. 2012, 356, 163-171.

(35) Chamberlin, A. R.; Mulholland, R. L., Jr.; Kahn, S. D.; Hehre, W. J. J. Am. Chem. Soc. 1987, 109, 672-677.

(36) Song, W.-J.; Suh, D.-Y.; Kang, Y.-H.; No, K.; Han, B. H. Bull. Korean Chem. Soc. 1998, 19, 593-595.

(37) Ohta, H.; Sakata, Y.; Takeuchi, T.; Ishii, Y. Chem. Lett. 1990, 733-736.

(38) Masuda, H.; Takase, K.; Nishio, M.; Hasegawa, A.; Nishiyama, Y.; Ishii, Y. J. Org. Chem. 1994, 59, 5550-5555.

(39) Giese, B.; Bartmann, D. Tetrahedron Lett. 1985, 26, 1197-1200.

(40) Chamberlin, A. R.; Dezube, M.; Dussault, P.; McMills, M. C. J. Am. Chem. Soc. 1983, 105, 5819-5825.

(41) Chamberlin, A. R.; Mulholland, R. L., Jr. Tetrahedron 1984, 40, 2297-2302.

(42) Midland, M. M.; Halterman, R. L. J. Org. Chem. 1981, 46, 1227-1229.

(43) Peeters, A.; Ameloot, R.; De Vos, D. E. Green Chem. 2013, 15, $1550-1557$.

(44) Payne, G. B. J. Org. Chem. 1962, 27, 3819-3822.

(45) Hanson, R. M. Org. React. 2002, 60, 1-156.

(46) For literature precedent for the formation of iodoexpoxides; see: (a) Winstein, S.; Goodman, L. J. Am. Chem. Soc. 1954, 76, 4373-4378. (b) Lindgren, B. O.; Svahn, C. M. Acta Chem. Scand. 1970, 24, 26992704. (c) Ganem, B. J. Am. Chem. Soc. 1976, 98, 858-859. (d) Santelli, M.; Viala, J. Tetrahedron Lett. 1977, 18, 4397-4400. (e) Evans, R. D.; Magee, J. W.; Schauble, J. H. Synthesis 1988, 862-868. (f) Brunel, Y.; Roussseau, G. Synlett 1995, 323-324.

(47) Baldwin, J. E. J. Chem. Soc., Chem. Commun. 1976, 734-736.

(48) Wipf, P.; Stephenson, C. R. J.; Walczak, M. A. A. Org. Lett. 2004, 6, 3009-3012.

(49) Win-Mason, A. L.; Dangerfield, E. M.; Tyler, P. C.; Stocker, B. L.; Timmer, M. S. M. Eur. J. Org. Chem. 2011, 4008-4014.

(50) Win-Mason, A. L.; Jongkees, S. A. K.; Withers, S. G.; Tyler, P. C.; Timmer, M. S. M.; Stocker, B. L. J. Org. Chem. 2011, 76, 96119621.

(51) Durette, P. L. Synthesis 1980, 1037-1038. 
